The Philosophy of the Imagination

in Vico and Malebranche

PAOLO FABLANI 
STRUMENTI

PER LA DIDATTICA E LA RICERCA

$-86-$ 

Paolo Fabiani

\title{
The Philosophy of the Imagination in Vico and Malebranche
}

\author{
Translated and Edited \\ by \\ Giorgio Pinton
}

Firenze University Press

2009 
The Philosophy of the Imagination in Vico and Malebranche / Paolo Fabiani. - Firenze : Firenze University Press, 2009.

(Strumenti per la didattica e la ricerca ; 86)

http://digital.casalini.it/97864530680

ISBN 978-88-6453-066-6 (print)

ISBN 978-88-6453-068-0 (online)

Immagine di copertina:

(c) Elenaray I Dreamstime.com

Progetto grafico di Alberto Pizarro Fernández

(C) 2009 Firenze University Press

Università degli Studi di Firenze

Firenze University Press

Borgo Albizi, 28, 50122 Firenze, Italy

http://www.fupress.com/

Printed in Italy 


\section{"In memory of my mother \\ ... to honor the courage of my father"}

\section{Paolo Fabiani}

"This is more than my book, it also represents Giorgio Pinton's interpretation of the imagination in early modern philosophy. In several places of my work he felt obliged to simplify the arguments to easy the reading; he did it in agreement with me. In a few others, he substituted, with intelligence and without forcing, the structure of the original academic version in a different narrative organization of the contents. He has done a great job.

It is an honor for me that the most important translator of Vico's Latin Works into English translated and edited my first philosophical essay.

I heartly thank. Giorgio Pinton, a true master of philosophy;

Alexander Bertland, a very good scholar in Vico studies; and the editorial staff of FUP, expecially Patrizia Cotoneschi and Fulvio Guatelli"

\section{Paolo Fabiani}





\section{CONTENTS}

TRANSLATOR'S PREFACE by Giorgio Pinton 9

INTRODUCTION by Alexander Bertland 13

GLOSSARY 22

PROEMIUM 23

PART ONE

THE FIRST KIND OF IMAGINATION:

FROM ERROR TO THE BIRTH OF THOUGHT

ONE The Rules for the Avoidance of Errors 31

TWO The Third Primitive Notion and the Human Fall 37

THREE The Human Fall and the Pagan Mentality 43

FOUR Aristotelianism: The Logical Sublimation

of the Pagan Mentality 47

$\begin{array}{ll}\text { The Scientific Foundations } & 51 \\ \text { of Vico's Psychology } & \end{array}$

SIX The Most Dangerous Error of the Ancients 67

SEVEN The Birth of Thought 83

EIGHT The Metaphorical Nature of Thought 111

\section{PART TWO \\ THE FIRST AND SECOND KIND OF IMAGINATION \\ THE SENSES AND THE INTELLECT}

NINE The Intelligible Extension: The Idea of Death and of Idolatry 129

$\begin{array}{lll}\text { TEN } & \text { The Origin of Idolatry } & 137\end{array}$

ELEVEN Psychology and Psycho-Linguistics of Paganity 161

TWELVE Sensitivity and Intellect 193

THIRTEEN The Familiar Ideas and Mentality 207

FOURTEEN Verisimilarity and Imagination 215 


\section{PART THREE}

\section{THE SOCIAL FUNCTIONS OF THE IMAGINATION}

FIFTEEN The Function of the Imagination and of Imitation in Society

SIXTEEN The Organicistic Conception of Society 245

SEVENTEEN The Nature of Social Interrelations 253

EIGHTEEN The Communicative Power of the Strong Images 271

NINETEEN The Heroic Mentality 283

TWENTY The Heroes of the Imagination 293

TWENTY-ONE The Power of Imagination and Superstition 305

TWENTY-TWO The Conceit of the Learned and The Problem of Knowledge

TWENTY-THREE Passions and Imagination: The Power of Wonder

TWENTY-FOUR The Universals of the Imagination

NOTES 


\section{TRANSLATOR'S PREFACE}

In 1501, Giovanni Pico della Mirandola wrote about imagination. In 1898, Luigi Ambrosini published a history of philosophy focusing on what through the ages philosophers said about the imagination and its psychological functions. In the same year, the American Journal of Psychology published G. V. Dearborn's study of imagination. Jean Paul Sartre's works on l'imagination appeared in 1936 and on l'imaginaire in 1940. In 1951, Wallace Stevens called the imagination "the necessary angel." Jean Piaget analysed mental imagery in children, in 1966. Jacob Bronoski narrated the origin of knowledge and imagination in 1978. Donald Phillip Verene, during the 1981, spoke of imagination as a science in Vico, while Ned Block edited essays on imagery, and Dietmar Kamper offered a history of Einbildungkraft. In 2001, Manuela Sanna wrote La fantasia, ch'e l'occhio dell'ingegno (Fantasy, the eye of the Intellect), and since then she and Monica Riccio have been giving seminars on "perception between sensation and imagination" at the Institute for the History of Modern Philosophical and Scientific Thought (ISPF). In the last two decades of the twenty century, indeed, Centers and Institutes of Learning have studied imagery and mental representations, under a variety of perspectives and in several different fields of research. Already before 1914, Alexander F. Chamberlain said that the twentieth century was the age of the idea and the intellect, while the twenty-first century was going to be the age of images and sensations. All learning and discovery has become representative, graphically expressible, and instantaneously communicable.

Though both Malebranche (1638-1715) and Vico (1668-1744) died by the first half of the Eighteenth century, they came to be better known by the end of the Twentieth one. They spoke about imagination in their most important works: La recherche de la vérité $(1674,1675)$ and La Scienza Nuova (1730, 1744). Fabiani shows how the ventennio of Vico's studies of human nature and the discovery of the master key of the new science had a constant point of reference in the psychology and anthropology of the Cartesian perspectives of Malebranche. But, while Malebranche tells modern human beings to find in the Eternally Divine and Human Being the One Who proclaims "I am the Truth," freedom from erroneousness, Vico instead tells them to embrace the poetic wisdom that sees beyond the historical paganist event the primitiveness of a recourse and the surprise of a coming rebirth of cultures. While one speaks of the mystifying power of religious 
images, the other claims the sole historicizing poetical force of our human creative action.

With this work, Fabiani has established several principles that regulate images and imagination and has indicated the passage from the modern to the postmodern era in our conceptions of these two notions. The book deals with human nature per se and assumes that in human beings human nature suffers paganity, which is the natural propensity for error. Pagan mentality is the manifestation of an erroneous conscience in human beings. The hidden message of the work of Fabiani is that the Post-modern world is a pagan world. Pagan, as he suggests, means irrational. The Post-modern Irrationalism originated from the triumph of the corporeal over the mental reality. The supremacy of the visible, the oppressiveness of the audible, the attractiveness of the tasteful, and the fascination of scent and corporeity are the contemporary jailers of Post-modern human beings. This book speaks of the true Post-modern Irrationality, Irreligiousness, Violence, Solipsism, and destructive Voluntarism, all based on contemporary Instinctiveness and Immediateness. It shows that the present digital generations have truly disregarded the civilizing principles taught during the early modern courses of Western Civilization. Emanuel L. Paparella said, "There are two dangerous extremes in modern Western philosophy: that of mythos without logos leading to a false transcendence and ushering in the Nietzschean charismatic Man; and that of logos without mythos leading to pure rationalism and ushering in technocratic Man. In between those dangerous extremes there is Vico's poetic philosophy, humanistic, holistic and able to harmonize the two extreme." An abundant meaningness exists in the fascinating narration of Fabiani, who in the descriptions of the origin through imagination of language and thought lets it known that there is a condition that comes before we have proper language, and let it possible a multiplicity of representations, as Giorgio Colli affirmed. In Poetics of Imagining: Modern to Postmodern, Richard Kearney describes our evolving perception of imagination from the twentieth to the twenty-first century, from phenomenological (Husserl), ontological (Heidegger), existential (Sartre), poetical (Bachelard), dialectical (MerleauPonty), hermeneutical (Ricoeur), to post-modern imagination (Lacan, Althusser, Foucault as in a labyrinth of mirrors, and Vattimo, Kristeva, Lyotard as hermeneuticians). At last, Richard speaks of a narrative imagination with an ethical function, within which cathegory I place Fabiani. His narration detailed the theories of imagination of two Mercurial philosophers, Malebranche and Vico, and combine them to prepare unexpectedly the foreground for all the perspectives on imagination analyzed by Kearney. The unsuspected symbolic triumph of pagan imagination and mentality in our times as it has even been exemplified in the literary "infinite jest" of David Foster Wallace makes us hopeful for a recourse of a more benevolent imagination equally sponsored by sensation and reason. In its original language, the book has been reviewed by New Vico Studies 22 (2004), Quadernos Sobre Vico 15-16 (2003), and Bollettino del Centro di Studi Vicbiani XXXIV 
(2004). The Centre d'Études en Rhétorique, Philosophie et Histoire des Idées (CERPHI) has also published abstracts of the book in English and Italian. By adding an Index, building a Bibliography of sources available in English, breaking long chapters into sections, and placing the Notes at the end of the book, we hope to have made it handier and suitable to research. For the purpose of clarity, we have compiled a Glossary.

Giorgio Pinton, University of Hartford 



\section{INTRODUCTION}

Despite the fact that Giambattista Vico (1668-1744) published the first edition of his New Science in 1725, eighty-four years after the publication of Descartes' Meditations on First Philosophy, many who are unfamiliar with Vico do not think of him as a modern philosopher. This prejudice, as it exists among philosophers, is due in part to the fact that the canonical history of modern philosophy, which stretches from Descartes into the Nineteenth Century-tends to ignore the work done on the Italian peninsula. Further, this history does not recognize a distinct Baroque period of philosophy that had its own particular character. This leaves Vico without a home in the history of modern philosophy. Despite the fact that Vico was chronologically as much of a modern philosopher as Nicolas Malebranche (1638-1715) who was only thirty years Vico's senior, Vico is viewed as an outsider looking in at the modern period from an ancient or renaissance perspective.

Vico perpetuates the portrayal of himself as outside of the mainstream of modern philosophy. Certainly the structure of the New Science is unlike the canonical texts of modern philosophy. Further, he writes, "So, for purposes of this inquiry, we must reckon as if there were no books in the world." 1 Further, Vico describes in his Autobiography how horrified he was at the way Naples had been taken over by modern Cartesian thinkers. He writes, "Vico lived in his native city not only a stranger but quite unknown." 2 This led to the creation of an image of Vico as an isolated figure that Paolo Rossi dates back as far as Vincenzo Cuoco (1770-1823). ${ }^{3}$ Isaiah Berlin maintained this image by describing Vico's neglect and isolation as, "perhaps the best of all known examples of what is too often dismissed as romantic fiction."4 While Vico is isolated in the sense of being an original thinker staking out his own territory, this romantic view of Vico being in an intellectual bubble is largely hyperbole that has greatly privileged Vico's ancient and renaissance influences over his modern ones.

Vico does take issue with many other modern philosophers. He directly attacks Descartes' attempt to refute skepticism through cogito ergo sum. Vico argues, in On the Most Ancient Wisdom of the Italians, that people are not skeptical about their existence but their ability to know truth. The verum-factum principle addresses this skepticism because it shows that one can indeed know the truth about what one makes.

Vico also opposes much of the social contract theory of the modern era. He accuses social contract thinkers such as John Locke of the conceit of scholars. 
This is the false prejudice contemporary scholars have for assuming that people always thought the same as they did. ${ }^{6}$ The social contract thinkers assume that the first people could have reached some sort of rational agreement early in history. Vico argues that such rational agreement must have happened much later after rational thought developed out of poetic thought. Vico suggests an alternative understanding of the origin of humanity that is based on the first humans thinking poetically rather than rationally. This gives Vico a political philosophy radically different from the modern social contract theorists.

So Vico had significant disagreements with specific modern philosophers and with larger schools of modern philosophy. This does not remove Vico entirely, however, from many intellectual projects of modern philosophy. Indeed, Vico places himself in the context of these modern ideas in many ways. Despite his claim to ignore the other books of the world, he identifies four authors as his major influences: Plato, Tacitus, Grotius, and Bacon. ${ }^{7}$ The fact that he includes in this list Grotius (1583-1645), who was a social contract theorist, and Bacon (15611626), who was one of the developers of the scientific method, indicates that Vico did see himself as engaged in the project of modern philosophy. The fact that he calls his major work the New Science indicates that he is placing his ideas alongside other modern attempts to develop new structures for science.

In the New Science, Vico does not spend a great deal of time responding to his contemporaries. As Paolo Rossi points out, some scholars had said that Vico was believed not to be conversant with French, English or German and that, if that were true, he would have been limited in his ability to respond to the philosophy of the day. ${ }^{8}$ Nevertheless, there are other important reasons why Vico remained silent and why we should think of Vico as seriously considering the modern philosophy of his time. Fabiani, in fact, shows the anthropology inspired by the major work of Malebranche, then well-known in Naples. In the Proemium and throughout the book, Fabiani relies, at least for the French language, on the contemporary acquired scholarly certainty that Vico knew French language and culture as much, if no better, than his contemporaries.

Before Vico published the 1725 edition of the New Science he claims to have written a now lost version of the New Science in negative form that attacked the other views of the day. Vico claims he did not have enough money to publish that edition and so wrote the shorter 1725 edition in positive form. ${ }^{9}$ Presumably, in that lost work Vico demonstrated how his work responded to the philosophy of his day. Vico may have also not wanted to respond to the philosophy of the day because of the threat of the inquisition. Gustavo Costa argues that Vico may not have wanted to refer to texts, including those of Malebranche, who were on the index. ${ }^{10}$ While the lost edition and the Inquisition may not help prove Vico read these texts, it does open the door for philosophical speculation on how Vico fits into the project of modern philosophy. 
Fabiani's work on Vico and Malebranche is important because it takes Vico's philosophical ideas, most notably the imaginative universal, and shows how they answer some of the same problems that other moderns, and specifically Cartesians, confronted. Specifically, he shows how the imaginative universal may be understood as an answer to Malebranche's general question concerning the source of error. This creates a new context in which to reveal the depth of Vico's ideas.

In approaching Fabiani's work, it is helpful to place it in the variety of ways in which Vico was influenced by the modern philosophy of his day. I want to explore some recent work done on the Enlightenment in Naples to illustrate some of the ways in which Vico's ideas are a response to issues that were contemporary to him. Then, I will examine some recent work done that examines how Vico's project fits into some of the larger trends of modern philosophy. This account will not be exhaustive of all the work being done to show how Vico's ideas were a response to the intellectual problems of his day. For the reader who is new to Vico or new to Vico scholarship, however, it will show some of the ways in which Vico's often obscure philosophy may be revealed by focusing on Vico as a modern philosopher rather than as an anachronistic representative of ancient or renaissance traditions.

Eighteenth-century Naples had its own explosion of ideas that are substantial enough to suggest that it had its own Enlightenment. These ideas were generated initially out of the import of Cartesian philosophy in the areas of medicine and biology. These ideas were generated through the creation of the Accademia degli Investiganti in 1650 by Tommaso Cornelio (1614-1686) and Leonardo Di Capua (1617-1693). The purpose of this group was, in large measure, to meet and discuss the influence of Cartesian biology on medicine. As Max Harold Fisch points out, the Academy intended to promote modern methods of medicine against the traditional Aristotelian methods. ${ }^{11}$ While the Academy stopped meeting around 1670, its members stayed active long after its closing. As Vico laments, these ideas were quite prevalent while he was working.

Vico, particularly in his early writings, responded to particular debates being held amongst the Neapolitain Cartesians. Antonio Borrelli discusses, for example, how Vico's doctrine of metaphysical points in the Ancient Wisdom is a response to the atomists working in Naples. Borrelli argues that whereas in most of Europe, atomistic theory was already having a large impact on physics, in Naples there was still a large ideological debate over the implications of atomism for the possibility of knowledge. ${ }^{12}$ Vico argues that knowledge in general cannot be reduced to knowledge of the realm of matter because what makes matter move is motion or conatus which emanates from God which is unmoving. Vico writes, "Between God and extended things, there is a mediating thing, unextended certainty, but capable of extension; and this mediation is the metaphysical point." 13 This, Vico suggests, allows for the possibility of extending the capacity for knowledge from the material realm to the universal realm of the divine. Vico's arguments 
about conatus seem unusual for people coming to Vico's works outside of their context. In the context of the debate with the atomists that Borrelli describes, however, it is possible to understand how it fits into the greater debate of the day.

In Vico's work on education, On the Study Methods of Our Time, Vico strongly defends the merits of ancient methods of study against the novelty of Cartesian methods. However, Vico's goal is not to simply dismiss the Cartesians in their entirety. Instead, Vico's goal is to uncover the ways in which the modern Cartesian system of education is both superior and inferior to the educational system of the ancients. ${ }^{14}$ The bulk of Vico's text is to defend the importance of teaching rhetoric and ethics. Nevertheless, Vico does defend the practical value of Cartesian science. ${ }^{15}$ By defending the ancients, Vico was not a lone rebel fighting off an overwhelming mass of modern thinkers. In fact, by defending the ancients, Vico was actually participating in a lively debate amongst the intellectuals in Naples over the relative merits of ancient and modern philosophy. Vico was not rejecting his contemporaries but joining with them as one voice among many in one of the major debates of the day in Naples. On the Study Methods of Our Time may have been the best work to be produced by this debate, but it was far from the only one.

Joseph Levine describes how the battle between the Ancients and the Moderns ranged in Naples on two major fronts that had a direct influence on Vico. On the one hand, there was a ranging debate over whether Homer should be regarded as a pillar of wisdom or as outdated by the developments of Descartes. Vico's response to this debate is his discovery of the true Homer in the New Science. On the other hand, Cartesian scientists, under pressure from the Inquisition, wanted to defend their new science against the claims of the Church. This involved both attempts to refute ancient science and to discover ways of positively incorporating ancient ideas into modern science. ${ }^{16}$ Some of the debates over the relative merits of ancient versus modern methods occurred in a new academy founded by the patron of the arts and sciences, Medina Coeli, who became the Viceroy of Naples in 1696. As Harold Stone relates, this academy, that lasted from 1698 to 1702 and was called Accademia Medina Coeli or Accademia Palatina, "was devoted to eloquence, learning and the restoration of letters."17 Vico became a member of this academy and gave a paper there entitled "On the Sumptuous Dinners of the Romans" in 1699.18 As Stone describes, many of the papers presented discussed history, religion and politics.

One of the most important members of this Academy was Giuseppe Valletta who was renowned for having one of the finest libraries in Italy. Valletta was a staunch defender of the rights of the Cartesians in Naples against the Inquisition. Valletta argued that the hidden purpose of the Inquisition was to silence the Cartesians and so protect the science of Aristotle. As Stone describes, in studying Aristotle to better defend Descartes, Valletta developed a respect for Aristotle's ideas. ${ }^{19}$ As a result, Valletta became a major advocate for appropriating the ideas 
of the ancients where possible. Levine claims that Valletta had a major influence on the intellectual development of Vico and the intellectual scene in Naples. ${ }^{20}$

Given the way in which the quarrel between the ancients and the moderns played out in Naples, it is not surprising that Vico would accept some of the ideas of the Cartesians as well as reject others. One place where Vico appears to accept the developments of modern Cartesian science is found in his depiction of the passions. Vico discusses the passions in the section of the 1744 New Science dedicated to the Poetic Physics. He makes a distinction between spirit, which he identifies as animus, and soul, which he identifies as anima. ${ }^{21} \mathrm{He}$ describes spirit as ethereal bodies running quickly through the nerves and soul as the blood. This is quite similar given to the depiction given by Descartes in $O n$ the Passions of the Soul.22 The only time Vico refers to Descartes specifically by name in the 1744 New Science is when he appears to praise Descartes for demonstrating that sight occurs because rays of light issue from the eyes to touch things. Vico uses this to confirm the wisdom of the ancients who claimed that sight possessed things. ${ }^{23}$

This is not to say, of course, that Vico accepted everything the Cartesians claimed about the passions. Silvia Contarini points out the level to which Vico's account of passion disagrees with the Cartesians of Naples. The Cartesians accepted Descartes' idea that it was possible to train the animal spirits that produce passions by exposing them to the proper images to restrain channel their motion. They emphasized the mechanical way in which this could be done. Vico, on the other hand, had a richer understanding of how the passions could be trained, relying on principles of rhetoric and good society to produce wisdom. ${ }^{24}$

It was the way in which Vico entered into debates cast by the generation of intellectuals in Naples that immediately preceded him. Vico had peers of his own who were working on ideas similar to his. Vico dedicated the Ancient Wisdom to his good friend, Paolo Mattia Doria (1661-1746). Doria actually developed his fame while a member of the Accademia Palatina. Doria, unlike Vico, spent much more time working with mathematics and geometry trying to understand it from the inside rather than just rejecting it. However, Doria had very broad interests. One of his most important works is La vita civile e l'educazione del principe. As John Robertson describes in his recent work comparing the Scottish and Neapolitan Enlighenment, this work responds to Machiavelli by trying to develop a philosophical justification of political virtue. Doria also gives an account of "the course of human social development." 25 While Doria's objective and results are much different from Vico's, it is easy to see how they would have shared their ideas in productive ways and faced similar philosophical problems.

Pietro Giannone (1676-1748) in 1723 published the influential Istoria civile del Regno di Napoli. This work represents a major historical project that attempts to document the entire history of Naples. Unfortunately, Giannone, who strongly opposed the church, was sentenced by the Inquisition and died in prison. His work bears a number of interesting parallels to Vico. The prime example of this is 
both authors base their histories on an investigation of Roman Law. Vico's Universal Law and New Science both attempt to find truth in history by tracing the authority of the Roman law as it adapted to changing institutions. Giannone's history of Naples attempts to show the extent to which the law of Naples was based in Roman law and the ways in which it was corrupted. ${ }^{26}$ While Vico's reliance on Roman law may seem strange to someone coming to his text for the first time, it does not appear to be an uncommon approach in intellectual circles in Naples.

Even after Vico, a long intellectual tradition continued in Naples and Italy that explored the realm of social science. Antonio Genovesi (1712-1769) was the first person to teach a university course in political economics. As Girolamo Imbruglia describes, Genovesi examined the economic structure of Naples in a realistic way to suggest the need for developing a middle class. ${ }^{27}$ As social theory came to focus on the conflicts between the classes, Vico's work was revived because of its discussion of the conflict between the heroes and the plebs in the New Science. ${ }^{28}$ Vico's influence was maintained in Naples and he had an influence on a number of thinkers in the formation of the Italian Risorgimento. The way in which Vico's political ideas lasted in Naples well after his passing bespeaks a powerful intellectual culture in which these ideas existed. It suggests that while Vico was an original thinker, his ideas did not develop in a vacuum. The intellectual life in Naples spurred some of Vico's ideas. It is, however, undeniable that Vico may be seen as engaged in some of the broader projects of modern philosophy that existed throughout Europe. One of the more obvious projects in which he engaged is the search for an understanding of the origin of language. Vico's discussion of language is often placed in contemporary contexts. For example, Marcel Danesi and Jürgen Trabant have placed Vico's theory of language in the contexts of cognitive science and sematology. ${ }^{29}$ Other authors try to examine Vico's analysis of language in the context of eighteenth-century investigations.

It is unclear what influence, if any, Vico had on other eighteenth-century thinkers working on language, particularly on Jean-Jaques Rousseau. Catherine L. Hobbs shows how Vico is in line with some major eighteenth century developments in the history of philosophy. She argues that Vico, by recognizing the importance of making and invention, was able to show how rhetoric was significant for the creation of citizens and the preservation of society. ${ }^{30}$ This insight depends on Vico's recognition of the importance of searching for the origin of society in poetic language and his recognition that systems of thought and language change as eras of history change. Hobbs argues that while thinkers that came after Vico, namely Condillac, may have had very different projects, they recognized a similar need to understand language by returning to an authentic understanding of the origins of humanity. ${ }^{31}$ This places Vico in line with Condillac's modernist attempts to give a schematic and logical account of the order of language.

Another modern project that Vico participated in was the attempt to organize knowledge into an encyclopedia. This is somewhat surprising to those who 
see Vico as entirely anti-modern since the notion of the possibility of creating a unifying order of knowledge is one of the cornerstones of Enlightenment thinking. Vico pre-dated the French encyclopedia, and his notion of unifying knowledge drew upon Renaissance notions of imaginatively organizing thought. Nevertheless, one of the foundations of his theory of education in On the Study Methods of Our Time is to suggest that one of the important reasons why the imagination needs to be cultivated is so that the different branches of human knowledge can be brought together. Vico writes, "I would suggest that our professors should co-ordinate all disciplines into a single system so as to harmonize them with our religion and with the spirit of the political form under which we live." 32 In another passage, Vico praises the ancients who unified all disciplines under philosophy and calls those who tore them apart tyrants. ${ }^{33}$

Giuseppe Mazzotta argues that while Vico is interested in the general project of encyclopedia, his notion of it is distinctly Baroque. By recognizing the fundamental nature of poetic thought, Vico posits a fundamental unity of knowledge based upon the metaphorical power of language. Mazzotta writes, "poetry is the knot of threads that reach out into all parts of Vico's intellectual and moral world. This insight into poetry makes possible his quest for the whole of knowledge (and for knowledge as a whole), which is his new discourse for the modern age." 34 Since poetry is at the root of all linguistic forms, poetry can hold together all human knowledge and institutions into a fundamental unity.

This insight into poetry allows Vico to create a distinctly Baroque structure for his New Science that traces and connects human ideas by following circuitous routes. This allows Vico to incorporate into his New Science accounts of both ancient wisdom and modern developments. For Mazzotta, "By pursuing oblique paths and serpentine lines of thought, Vico shows himself as possessing the authority and knowledge to grasp the reality both of the new sciences, with their elliptical paradigms, and of modern political science, with its arcane practices of power." 35 While this makes Vico anti-modern to the extent that he does not want to create a concise geometric scheme for documenting history, it actually fulfills the dream for the unity of knowledge in a way that goes beyond what other moderns can recognize. Vico's anti-modern insight, in this case, allows him to be more modern that other Enlightenment figures.

Perhaps Vico's most original discovery and the one that is most difficult to understand is the imaginative universal. This is a poetic concept that, Vico argues, humans generate at the origin of humanity. They greatly differ from the concepts generated through reflection in the modern era. The imaginative universals are extremely significant because they are the cornerstone piece of evidence for Vico's claim that human beings think differently in different historical eras. Without these universals, then it is hard to isolate a fundamental difference between contemporary ideas and the ideas of the past. If this were the case, Vico would fall into what he himself calls the conceit of scholars that holds all people 
of all ages think fundamentally the same. So the imaginative universals are the backbone of Vico's New Science.

Vico himself admits that these imaginative universals are extremely difficult to understand. Vico writes of them that "with our civilized natures we cannot at all imagine and can understand only by great toil the poetic nature of these first men." 36 Of course, this should not be that surprising. If these universals were easy to grasp, then it would be hard to fathom that they constitute an entirely different form of thinking. Vico identifies the different imaginative universals as the various gods of the Roman pantheon. Each imaginative universal represents a variety of human cultural institutions that were at the core of society during the ages of gods and heroes. Jove, for example, represents the institutions of the first priests ruling by reading the auspices from the sky, and Juno represents the institution of marriage. Vico's account of these universals appears quite strange to the reader. This is because in his attempt to maintain the unique nature of these universals, Vico presents them in a way radically unlike any other modern philosophy. This reinforces the notion that Vico's New Science is a work that was created in an isolated way and is thoroughly anti-modern.

Scholars have been arguing that while the imaginative universal is Vico's discovery, it is still partially the result of modern influences. One of the most important scholars attempting to place Vico in a modern context is Andrea Battistini. He recently argues that Vico's notion of the imaginative universal has part of its origin in the writings of Gerhard Johann Vossius (1577-1649). Vossius argued that myths were in fact instances of identifying someone according to a characteristic rather than an arbitrary name. This type of identification is part of the rhetorical trope identified as antonomasia. ${ }^{37}$ This represents one of the first times that a thinker attempted to use the tropes of rhetoric as a way of understanding mythical thought as a unique type of knowing. Vico followed this same basic tact by identifying mythical thought with the trope of metaphor. ${ }^{38}$ Through recognizing this insight of Vossius, Vico's notion of the imaginative universal can be placed into the context of an intellectual tradition.

Fabiani's book is important because it takes the imaginative universal, which is seemingly one of the most anti-Cartesian concepts in Vico because of its reliance on the imagination, and relates it to a distinctly Cartesian influence coming from Malebranche. There is a temptation to read Vico not only as representing the imaginative universal as an alternative form of thought but also defending its use in contemporary society as an alternative to the methods of modern science. This would make Vico an advocate of returning to a previous form of thought. This would turn Vico into a radical anti-modern.

By placing Vico in conversation with Malebranche, Fabiani presents a very different goal for Vico. Malebranche, as an occasionalist, holds that all causality actually stems from the eternal creator, God, who has created all events in time. What appear to be material causes to humans, for example, one ball hitting anoth- 
er, are actually illusions. Malebranche's concern was to understand why human beings are so prone to error, and, starting from original sin, Malebranche engages in a type of psychology to explain why humans are so confused about the true origin of cause. Fabiani argues that Vico actually has a similar project when it comes to the imaginative universals. Rather than trying to defend poetic wisdom as a practical alternative to modern science, Fabiani suggests that Vico is actually exploring the imaginative universal to reveal why humans are so confused about science and truth. The key difference is that whereas Malebranche looks for the origin of error in child psychology, Vico looks for it in the infancy of humanity as a whole. Through this historical analysis, Vico explains why it is so difficult for humans to recognize the true force of divine providence by revealing the effects of the fact that humans must start thinking in a way that is over burden with powerful passions and sensation. This depiction of poetic wisdom in Vico goes a long way to helping account for Vico's understanding of religion in his works. Any philosopher worthy of intense and careful study must have an air of timelessness. The insights of the philosopher must speak to future generations. Vico's philosophy of history, philosophy of myth and his account of political institutions brings him directly into conversation with a variety of important contemporary thinkers including Habermas, Gadamer and MacIntyre. Further, I do not want to underestimate the importance of Vico's ancient and Renaissance sources. After all, Vico also included Plato and Tacitus in his group of authors. Nevertheless, these conversations should not lead one to exaggerate his isolation and the extent of his attack on modernity. By understanding Vico in conversation with his contemporaries, his ideas become richer and more worthy of philosophical analysis. Fabiani's work places Vico in conversation with Malebranche in an important and insightful way.

Alexander U. Bertland, Niagara University 


\section{GLOSSARY}

Bestioni

Error

Fall (The):

Fantasy

Idolatry

Imagination

Mentality

Mode:

Pagan Mentality:

Pagan Mind:

Pagan Thought

Paganism

Primitive Notions:

First Notion:

Second Notion:

Third Notion:

Quality:

Soul:
The animal being not yet human, but becoming human at his encounter with Jupiter The erroneous conception of human sensitivity The human act of disobedience to God's command with its consequences (as narrated in the Bible)

The process of abstraction of the imagination from the representative contents presented to conscience by sensitivity

Worship of any image, idea, or object, as opposed to the worship of a God

The characteristic structure that makes the brain capable of vestiges and traces so extremely incisive and overpering that wear out the energy of the soul, which becomes unable to attend at any other things than those represented by these incisive and overpowering images

Mentality is the imitation of the manner of thinking difused among the peoples of one or more Countries

The thought thinking of a substance under modification or transformation

The effects of the mind subjugated by passions, sensitivity and imagination

The mind subjugated to passions, sensitivity, imagination

The philosophical sublimation of the Aristotelian theories Synonym of Irrationalism

The notions that are pure eternal truths for human beings and that have no need of propositions that would explain them

The body: the notion of extension (figure and movement) The mind: the notion of thought (including the conception of the intellect and the inclinations of the will)

The notion of the union of mind and body (on which depends the interaction that causes sensations \& passions) The modification that designates a substance as such and such; (quality as a subset of the mode)

The true substantial form of the human being that includes mind, intellect, and will. 


\section{PROEMIUM}

Giambattista Vico was a receptive philosopher; he cared to list his own authors. Among them, however, he did not mention Malebranche. In Malebranche's The Search after Truth, we have identified many theoretical presuppositions of Vichian conceptions. Vico treated and developed these conceptual presuppositions in a manner truly autonomous and original. Conceding these two points, our concern is not that of placing the different conceptions of these two philosophers into a formal contrast in order to evince how and where they differ. The discussion on how they developed their theories, specifically those on anthropology, language, and myth, will be more proficuous.

One observation when reading Vico's New Science is that in it the complex theories of the Renaissance on imagination, as they appear in the treatises of mnemonics, are absent. In the Vichian work, there are no profound argumentations on the classic conceptions of phantasy. His conception of imagination is modern. Within the Schools, phantasma meant the "image" formed by the representative faculty that from the cumulative ensemble of the perceptions reconstructs in the human spirit the simulacrum of the external thing. This conceptual icon is the phantasma, which though immaterial preserves all the sensible characteristics of the physical external thing. In Thomas Aquinas, the intellect abstracts from the phantasma a purer concept, the species intelligibilis, through which it effectively knows the thing. The Aristotelians consider the described process as a real one, since through this process the mind reaches something true. The Platonists, on the contrary, though accepting the process of the abstraction of concepts from the phantasma, deny the validity of the mental operation. In the Neo-Platonic tradition, phantasy identifies with the deceptive fallibility of the senses, with error in the cognitive field and sin in the moral one. The Cartesians and Vico adhered to this current of thought.

Malebranche sees in Aristotelianism the philosophical sublimation of natural thinking, in which "natural" means the cognitive human power after the Fall, and consequently erroneous. He places his conception of human cognitive power between the points of the line that grows from the condition of a newly born child to that of an Aristotelian philosopher. The cognitive power of each human being moves between these two extremes, within which human individual thought must handle its psychological traits and abstractive capacity, react to the force of the 
prejudices and errors that have taken form and vigor, and choose between the different opinions and credences of human societies. In psychological terms, the fundamental difference between Aristotle and an analphabet idolater is due to the abstractive and conceptualizing capacity of the one in rapport to the other. The proven historical fortune of the Aristotelian physics is for Malebranche due to the recognition of the natural power of conceptualization that humankind possess. Relying on the common sense, Aristotelian theories and physics have commanded the sciences, but only as the sublimation of an erroneous mentality and of a poetic logic, that shaped thought according to sensation. The philosophy of Aristotle is an imaginative logic through which the highest human cognitive power develops and triumphs. At the lowest opposite extreme, we see the coarse thinking of simpletons, analphabets, fools, primitives, and other kinds of people described in The Search after Truth, in which the overabundance of an unregulated imagination overcomes the limited intellective powers. Malebranche's descriptions of these human beings and the theoretical deductions he derives from their dynamism come to resemble the work of the poetic theologian. In Malebranche and Vico, the dynamics of human conscience follow the same line of development and intentionality. The study of imagination compels the study of the human conscience. The human conscience, for Malebranche, possesses an ever-changing vitality and, therefore, a diachronic component: error and sin, they exist.

The essays of Bernard Lamy, Nouvelles reflexions sur l'art poetique and Entretiens sur les Sciences, make manifest the parallelism between the psychology of Malebranche and the anthropology of Vico. Lamy applied Malebranche's linguistics to the poetry and the mentality of the ancients. Vico opposes the allegorical conception of myth, sustaining that myth is born out of the phantastic, false interpretation of what has been naturally experienced. He denies every "real" link between the physical event and the myth that human beings create in order to interpret the event. Vico rejects any material bond between body (thing, event) and mythological thought; he refutes the simulacra and the phantasmata of Scholasticism; he dispels the possibility of the abstract associations introduced by the supporters of allegory and euhemerisms. From the beginning, Vico proceeds as an anthropologist, modern and Platonic. His anthropology is not that of Malebranche, but in its essential frame derives from that of Malebranche. Analyzing the conclusions of The Search after Truth, Vico adopted and modified them in a peculiar fashion of his own. Vico is modern as far as his view is subjectivist. Sensible ideas are subjective and myth originates from them: the first deity that the bestioni recognized was their own representation of nature as perceived through the senses. The first of their thought was a fully sensitive thought, by its nature subjective, because sensitivity for the Cartesians and Vico is of the soul, of human beings and of no other animal. According to The New Science, the first human being differentiates itself from the beasts because of its ability to sense. Animals and bestioni perceive but they do not sense. Physical perception alone is like the mechanical action reac- 
tion. Vico's position is similar to that of Descartes, for its mechanicistic conception of the interaction among bodies and for the subjectivity of the sensible ideas. The bestione is the opposite of the poetic theologian: the first perceives but does not sense; the second perceives and senses the perceived. The bestione is an animal, whereas the poetic theologian is a human being.

Three kinds of objections may challenge the assumptions presented. Some scholars have objected that Vico did not know sufficiently the theories of Malebranche. He possessed a limited knowledge of French, and in his own city, he lived a solitary life. How much could he absorb of the current vitality of the cultural life of Naples? Modern research, however, has already deflated the validity of this challenge. It is possible, others would say, that Vico derived conceptualizations that seems of Malebranche from some other well-known philosopher, Spinoza, for instance. Who? No one in the seventeenth century has constructed a theory of imagination so complex and profound as Malebranche did. We will show how the fundamental principles of the Vichian anthropology existed already in Malebranche and how Vico often followed on the path of Malebranche's refined and acute analysis. Finally, a third party affirmed that the notion of imagination in the two philosophers stands in a contradiction: it is esteemed in $\mathrm{Vi}$ co as much as it is defiled in Malebranche. They are right in appearance alone, whereas truly both authors highly appreciate imagination, when associated with a strong critical sense and with clarity of intellect. Malebranche lamented the power of imagination whenever the will was feeble and the intellect idle. For Malebranche, the power of imagination consisted essentially in the possession of strong sensations, vivacious images, and a proven ability of representing many different things. His study of the imagination intended to defeat the errors that a high voltage imagination would generate in a human being of little mental capacity. Knowing how much Vico valued memory, the disciples of this last group have pointed out the adversary critical Cartesian attitude of Malebranche toward the sciences or techniques of memory. In Traité de morale (bk. 2, ch. 10, sect. 14), Malebranche, in a self-defensive way, explains that his opposition is to those who lack generous intellect, while making a show of a memorized treasure of erudition:

I do not affirm that in our studies we must disregard history, for example, and study only those solid sciences that make the spirit perfect and the heart unwavering. We must study the sciences according to their rank. We may study history after we have acquired knowledge of our identity, religion, and obligations. When our spirit will be fully and firmly formed, then we will have the preparation needed to discern at least in part the truth of history from the imaginations of the historians. We must study languages when we have become philosophical enough to be able to know what a language is, when we know well the language of our own country, and when the desire of knowing how the ancients felt inspires the desire of 
knowing their language. We will learn, with these desires, in one year what we will not be able to learn in ten years without them.

Vico, no doubt, agreed with all these statements. Malebranche's words suggested that philology and history are sciences since true philology and true history are rooted in an adequate knowledge of oneself, in the truth of religion, and in the validity of some moral principles. In Malebranche, history and philology are not the copies of true things in a mathematical and geometrical scale. They achieve the factual purpose of penetrating the sentiments of the ancients.

Critics have said that Malebranche took a Cartesian negative conception of imagination and letters. On the contrary, Malebranche was a man of letters and of science. Like Vico, he did not like erudition or memory for their own sake, but for what with them any student may be able to achieve. The criticism accumulated against a study of Malebranche and Vico states that little of what interested Malebranche could interest Vico and vice versa. We may reply by saying that if Malebranche's The Search after Truth is essentially an analysis of the pagan mind through its imagination, superstitions, society, idolatry, and heresies, then it is a psychological study that parallels the Vichian intuitions of the primitive mind. The concept of pagan mind freed psychology from theology and allowed psychology to challenge some metaphysical conceptions without falling into a contradiction. The pivot of the pagan mind is sensitivity, not reason. The pagan mind also develops diachronically: it is not always identical, like the Cartesian intellect, to itself; it proceeds from sensitivity toward imagination and from imagination toward reason. In the Cartesian mind, clear and distinct ideas are always and everywhere true; in the pagan mind, prejudices, credences, and superstitions change in time according to identifiable lines of development. The pagan mind proceeds theoretically from sin toward salvation in a process that cannot be defined historically, but that certainly begins as moral and ends as eschatological, as a movement of conscience that troubles the senses.

Our aim is not that of identifying the Vichian anthropology with that of Malebranche, but of showing that Malebranche's The Search after Truth has been the constant point of reference, the motive of reflection, and the reliable theoretical platform of support for Vico in his reconstruction of the pagan mind in The New Science. The point of departure will be that of isolating the nucleus of the pagan mind that we have indicated to be found in the theory of error of Descartes, which Malebranche and Vico adopted and adapted to their own interests. The pagan mind is nothing more than an erroneous mental power. In Riforma cattolica e filosofia moderna, A. Del Noce stated that Vico began where Malebranche ended. Del Noce gave no other explanation. M. Agrimi, in Vico e Malebranche (p. 10), historically reconstructed the diffusion of the philosophies of Descartes and Malebranche in Vico's Naples and has established that the comparison between 
the French philosopher and the Italian one must begin from the European Descartes:

The presence and incidence of Malebranche's thought in Naples should be linked to the more general problem of Naples' Cartesianism, in regard to which once and for all we must state that it is a matter not only of a direct and often critical confrontation with the work of Descartes, but of a colloquy profoundly threaded weaved with the Post-Cartesian, French and European debate which was known also in Naples. Of the large number of minor or major thinkers involved, we like to mention only four: Henricus Regius, Malebranche, Nicole and Antoine Arnaud, because their works widely circulated in Naples and because they are explicitly mentioned by Vico. Let us remark that the oscillating adhesions and attentions paid by Vico to the theses of the philosopher of the Oratoire should somewhat be connected with the polemic (vivaciously opposed by Vico) of Arnauld against Malebranche. Furthermore, the analysis of the rapport Vico-Malebranche must be necessarily and constantly referring to that of Vico-Descartes, the reason for this being that Naples's Cartesianism was often practiced as a unique Cartesian-Malebranchean experience.

Agrimi added that the work of Malebranche constituted a precious treasure house, widely used, of proposals, solutions, and themes especially in the field of anthropology, pragmatic-ethic, without exclusion of the great metaphysical theological problems of the time. He presents a whole series of elements that prove irrefutably that Vico had a deep knowledge of The Search after Truth, for the wide diffusion of the work in Naples and for those Vichian argumentations and observations on Malebranche that without such knowledge of the original source he would hardly have been able to express. Francesco Botturi in La sapienza della storia (p. 241) showed the influence of Malebranche on Vico's political philosophy, jurisprudence, and conception of society:

The metaphysical character of Vico's philosophy of law manifests conceptualizations that manifest the power of the Malebranchean influence. We may say that at this phase of the Vichian thought, Vico found in the Cartesianism of Malebranche the most suitable formulas for deducing the strict connection between philosophy and law, and in this connection the implication of an absolute in the regulation of social rapports. The defense of the natural law against the skeptic doubt exalts in Vico the search for the ultimate condition of the possibility of law itself, possibility that is identified in the transcendental relationship of the human mind with God. Law in the eyes of Vico becomes practiced metaphysics, expression of the nature of the human mind. The metaphysical structure of law is analyzed 
by Vico with a terminology and some references that echo in profundity the Malebranchean meditations. This is verifiable at the analytical or systematic level and indeed we may say that Malebranche represents the magnetic orientation of Vico's thought.

By way of conclusion, we may definitely affirm that Malebranche has been the guiding star throughout the many and new mental areas, through which the young Vico dared to cross, explore, and map. 


$$
\text { PART ONE }
$$

THE FIRST KIND OF IMAGINATION:

FROM ERROR TO THE BIRTH OF THOUGHT 



\section{ONE}

\section{THE RULES FOR THE AVOIDANCE OF ERRORS}

The Cartesian principles found in The Search after Truth are systematically utilized in order to dismantle from its own foundations the castle of fantasies that the Aristotelian physics constructed. In book six, dedicated to method, the criterion of rational evidence constitutes the axis around which an advanced criticism runs. ${ }^{1}$ More than being a refusal of the specific scientific theories of the Stagirite, Malebranche's argumentations are centered on a petitio principii: Aristotle and his disciples are merely reasoning with ideas that are confused, for which reason they reach false conclusions. ${ }^{2}$

The main error of the scholars who understand science in the Peripatetic manner is that of relying on ideas derived from sensation, and it must be on this ground that such conception and philosophy must be faced and defeated. The principal argument of The Search after Truth deals with errors as the erroneous perceptions of human sensitivity. It is pertinent to observe that modern science and Cartesian philosophy had primarily challenged Scholastic science with the analysis of the status of sensitivity in the scientific field. Malebranche, with the intention of expressing the focal point of the question and of the terms involved, introduced his argumentation in this way: "Almost all the works of Aristotle, but principally the eight books of Physics, of which there are as many commentators as there are practitioners of philosophy, are nothing else than pure logic." 3 The criticism changes and no longer will center on the theme of sensitivity, but on the philosophical and scientific principles that Aristotle deduced by way of abstraction from the sensible data. The implicit logic of the Aristotelian physics is for Malebranche a different logic than the one found in the Organon, it is the conceptual sublimation of the common sense. In order to understand how this happens at least in its general lines, we must be aware that Aristotelianism with Descartes becomes the philosophical correlative term of the prejudicial, though natural, attitude with which all human beings tackle reality. After Descartes, this way of considering Aristotelianism will become the constant view in the philosophical and scientific context. ${ }^{4}$ Malebranche adopted this view when he sustained that the sensitivity and the other preconceived conceptions in the practical life, if they have 
no moral or scientific implications, they have at least the scope of facilitating our lives.

Modern rationalists, especially Descartes, Leibniz, Spinoza, and Malebranche, sustain that the Aristotelian philosophy forms the inner root of the human natural mentality that comfortably manifests itself in what we call "common sense." This kind of criticism of Aristotelianism and of the assimilation of its principles in the natural mentality of the majority of humankind was truly new, in these terms unthinkable before the arrival and diffusion of modern physics and Cartesianism. The consideration of the Aristotelian science as the philosophical representation of the forma mentis of common sense finds its first coherent formulation in two famous letter that Descartes sent to Princess Elizabeth of Bohemia on the 21 May and 28 June 1643,5 in which he theorized on the conception of "some primitive notions or ideas."

Primitive ideas are a particular variety of innate ideas; they are ideas that help the mind in its effort to organize knowledge; 6 they are categories that in their complex comprehend all kinds of knowledge and that at their own turn are not subsumed under more general categories. The absolute irreducibility of these notions goes with the absolute otherness of the nature of the real things that constitute the object of our knowing. Error consists in not distinguishing adequately the principles that we use when we judge bodily objects from the principles we use when judging matters of our soul. Descartes says that this is primarily a scientific question. ${ }^{7}$ The first rule to follow is that of organizing ideas in reference to the primitive ideas that are in us, ideas that are at the source of all our thought. Descartes explains:

The reason for this is that when we wish to explain some difficulty by means of a notion that is not related to such a difficulty, we cannot fall otherwise than into error. Equally, when we want to explain one of these notion by way of another of these notions, we fall into error, because these notions, being primitive, each one of them cannot be understood otherwise than through itself. ${ }^{8}$

The human mind can know reality in a general manner under three different aspects corresponding to the three primitive notions. In this way, a science or a group of sciences with proper rules, principles, and objects of research corresponds to every level of reality. In the sciences of nature, all errors have at their origin judgments formulated on inappropriate principles. ${ }^{9}$ It is because of the violence exercised by the sensations on the soul that we often are tempted to explain how a substance can act on another substance through the modalities with which two entities of the same substance interact between them: in this we find the origin of all our prejudices on nature, of all our false sciences that intend to explain the world. Descartes explains again: 
I believe that here we have confused the notion of the force with which the soul acts within the body with the force with which a body acts within another body. Thus, I believe, that we have attributed both kinds of force to the different qualities of the bodies like weight, heat, and others that we have imagined to be real, that is, capable of having an existence distinct from that of the body. We consequentially considers them substances, though we had previously called them qualities. ${ }^{10}$

The passage from the error made by the majority of human beings to the philosophical error perpetrated by the Aristotelians clearly shows up in the direct reference to "qualities." The impulse of motion of a body on another body is an event that we can know adequately in mathematics and mechanics, disciplines that have their "archetype" in the primitive notion of extension. The fall of a stone cannot be compared to the personal experience of the force necessary to move an $\mathrm{arm}$. The concept of force, as it is commonly understood as a willing impulse, is relative to the reality that it assumes in us in relation to the third primitive notion. Corporeal motions, on the contrary, must be explained within a mechanicistic conception.

The necessary work of clarification of this concept, according to Descartes, has often ended in the belief of the animation of pure corporeity: human beings arrived at the extreme of attributing a willing force to the reciprocal interaction between bodies; inanimate objects have been thought as possessing intentionality; the temptation succeeded in calling "real" the qualities that actually are subjective. All this happened within the theoretical frame of Aristotelianism, which considered what is primary in an idea to pertain objectively to the things represented by the idea. Aristotelianism was the philosophy that sublimated the common sense rooted on sensitivity, without effacing it. Listening to Descartes, the spirit would free itself from all the small images that spin in the air, the socalled "intentional species," which have been greatly troubling the philosophers. ${ }^{11}$ If we could follow the precepts of correct philosophizing and separate the events to be analyzed from the inappropriate argumentative contexts within which students introduced them, then all the fictitious entities that Aristotelian philosophy formulated in order to comprehend what would otherwise have remained unknown would disappear. In conclusion, Descartes with his theory of error established also the criteria for the understanding of the psychological genesis of anthropo-morphism and anthropo-latria.

The mentality derived from "common sense" claims that weight, color, and all other qualities are realities of the bodies, whereas they are entities merely in relation to our manner of sensing. In the cited letters, Descartes clearly stated that the human error is found in attributing the power of the soul over the body and the power of a body over another body to the diverse qualities of the bodies, while 
they were to be assigned to the soul. ${ }^{12}$ The ignorance of interpreting the subjective qualities as objective attributes of physical entities is not merely ignorance of the material world, but also and basically it is ignorance or confused knowledge of our soul. If we were to have a clear knowledge of our soul, we could also comprehend that which pertains to the soul and that instead we erroneously attributed to something else.

At the source of error we always meet with an insufficient consciousness of oneself; this insufficiency brings us to judge with criteria that spring mainly from our nature through the third primitive notion. ${ }^{13}$ This miscalculation is a methodological error in the scientific context in the same way that it is an error in the psychological one because of the natural disposition of our mind. In other words, error claims that our particular way of sensing and perceiving things is the same way in which things are made. From a sensation a quality is born; from a fear, a substance; and, from this illusion, a world. It is not a real world, but a world reconstructed by the imagination and the sensitivity of the human beings. If we are searching for an adequate knowledge of the physical world, we must conceptually remove from it (cleanse) all qualities, faculties, forces, and intentionality. Erring is denying this distinction and its consequential implications.

The criteria for this work of cleansing will be developed by Malebranche, who did not accept the theory of the primitive notions and in his system maintained instead a classification of the ideas in relation to the subdivision of substances:

We have only two kinds of ideas: those of the spirits and those of the bodies. Because we can speak only about what we conceive, we should reason only by utilizing these two kinds of ideas.... The spirit and the body, the substance that thinks and that which possesses extension, are two kinds of being totally different and even opposed.... The actual situation is that human beings in the majority have not paid attention to the properties of thought, and being always in touch with their bodies, have come to regard the soul and the body like one and the same thing. They have fancied a resemblance between two so different things. ${ }^{14}$

The extended thing and the thinking thing (res extensa et res cogitans) constitute two levels of reality; in order for us to examine them correctly it is necessary to use different principles and methods. ${ }^{15}$ Human beings are not easily convinced to adopt this mental attitude because of the feebleness of the souls (the Fall) and the overarching power of the bodies over them. If we were Occasionalist and wanted to proceed correctly by reasoning, we would introduce arguments of the following kind. If we sustain that a body or finite entity cannot move by itself, then we may also say that no created spirit that is a finite entity can give motion to a body because the spirit by being limited and finite cannot be the true cause of something 
that happens in another dimension of reality. The spirit would have to be able to give something to an object that cannot receive anything from it; or it would have to regulate the universe, modifying its own nature and that of the object in motion. This is impossible, but nonetheless movement appears as a reality. ${ }^{16}$

We must agree that if the idea we have of bodies does not comprehend the concept of voluntary action or of the ability of acting, then action or acting is not a propriety or faculty of bodies. Should we then say that the spirit and the mind are the movers of the bodies? Malebranche observes that if we would examine carefully our finite minds, we will not find anything that would allow us to state with some reliability that a necessary link exists between the act of will in the mind and the motion in the body. Considering the human situation in this perspective, we can neither affirm that the human being is the true cause of the displacement of bodies nor that it is the true mover of its own body. This argument is coherent because if we were to assume the hypothesis that minds can move bodies, then we would combine into one two opposed substances (in the Cartesian system). ${ }^{17}$ If this were true, then we would reintroduce the substantial forms of the Aristotelian tradition and easily fall into idolatry and superstition. The danger would be that of assigning a spirit (anima) to nature. Mind and matter are two distinct entities that must remain separate.

Only one cause operating by general means can justify reality. This cause, without any particular involvement in the nature of mind and matter, would still allocate thought, sensations, and passions to the mind and displacement or movement to the matter. Aristotelian thinkers and pagans in general have not comprehended this cause. Malebranche answered the question by identifying the cause with the divine will. The divine will alone can operate by general means and warrant that to specific corporeal motions would correspond definite sensations in the soul. In Malebranche, the theological aspect of this question that in Descartes remained in obscurity became prominent. For Malebranche, the divine will would explicate itself according to the laws of unity between mind and body; laws established after the Fall. Because of the Fall, we are darkness to ourselves, inclined to error, and become conscious of our being with difficulty.

The unclean glass of the imagination became opaque through the error in the Fall and would hardly help in the goal of achieving the knowledge of ourselves, as much as psychologically possible. Superstitious and pagan people had no knowledge of this, and the Aristotelians did not recognize it. The comparison between pagan and erroneous mind constitute a theoretical recurrent element in all modern rationalists, but it is only in Malebranche that it finds a complete formulation in both the theological and metaphysical fields. We err metaphysically because we confuse the dimensions of reality and the notions that are not suitable to its comprehension. We err theologically because the consequences of the Fall determine in us the overbearing action of the senses over the intellect, determining our pagan inclination, which constitutes our erroneous and idolizing mentality. 
The relation that links imagination and sensitivity on one side and Fall and error on the other is truly important, because it facilitates the comprehension of how from an argumentation in a scientific context, Descartes-Malebranche, it is possible to move to a theological one in Malebranche, and to a psychoanthropological other in Malebranche and Vico. Convenience brings us to the deepening of the relationship between the third primitive notion and the pagan mentality. 


\section{$T W O$}

\section{THE THIRD PRIMITIVE NOTION AND THE HUMAN FALL}

Cartesianism intended to reform philosophy and science by changing the perspective that we have of Aristotelianism and the conception of what common sense is. The mutation in the perspective would have the goal of correcting the error and clarifying the equivocation that accompanies what Descartes and Malebranche called pagan thought, whose philosophical sublimation is what we know as Aristotelianism.

Before explaining the correspondence between paganism and Aristotelian philosophy, we must introduce and interpret the third primitive notion and thereafter reach some definite conclusions. First, the third notion is not the proof of the union of the soul with the body. In his definition of the notion, Descartes did not present the argument that demonstrates what this union of soul and body is. Elizabeth was asking Descartes for an explanation, a demonstration, but he offered only an experience. Obviously, this did not satisfy Elizabeth. Not even the disciples of Descartes formulated an explanation in their own reconstruction of Descartes's philosophy. Could anyone tell Descartes that people needed an explanation because the experience itself of the union of mind and body constitutes the life of all human beings? Is it not true that once people understood the ontological distinction between res cogitans and res extensa, they asked for a comparable understanding of the union of mind and matter, soul and body?

The evidence of the primary notions is not like the intellectual evidence by which we can conceive extension and thought; it is the psychological evidence, a sensible certainty, which forced Descartes to embrace psychology, leaving metaphysics aside. ${ }^{1}$ This evidence of the third primary notion is totally different from the evidence of reason. The peculiarities of the experience that make us conscious of such evidence are at the origin of the equivocation made by Scholasticism and paganism. The error of the Scholastics is recognizable in their having built physics as a bemused science. Their physics was a description of nature rooted on psychophysiology instead that on mathematics and some evident principles. Their physics was the methodological and metaphysical by-product of a personal experience; it 
began from sensation but was afterward channeled toward inappropriate goals, whose result was a castle of impressive abstractions. Aristotle and Thomas Aquinas remodeled, beautified, and reinforced the castle that nonetheless maintained the original empirical-pagan structure and evinced the erroneous logic used in its creation.

The third primitive notion provides an explanation of the origin of error in the human mind. If the Aristotelians and the pagans were to have known the third primitive notions, they would have automatically become Cartesian scientists. Descartes speaks of the prejudice that human beings have including the philosophers who have constructed their metaphysics on the common sense of humanity. Abstracting from the common sense qualities and faculties that could not correct the fundamental error that the senses carry, the human beings simply conceptualized qualities and faculties. ${ }^{2}$ At the root of the error of the Aristotelians and of common people stood the unawareness of the third primitive notion and the ignorance of the zone of reality to which it applies. The ignorance of oneself is the cause of the prejudices that human beings construct in relation to the physical reality that surround them. Not knowing itself, the human being becomes the cause of the prejudices about physical phenomena.

In the psychological field and in the psycho-physical sciences, Descartes does not attribute to consciousness the cognitive power of a clear and distinct intellectual knowledge. Under the best conditions, ${ }^{3}$ consciousness gives us a sensible certainty that confirms that the human being is as we actually experience it. We may object to Descartes that this is exactly the point of origin of the problem, not the solution. The experience supported by our conscience is an experience that does not demonstrate how soul and body form a unity. We may say that this experience is an experiment that at the psychological level shows that the consciousness of oneself is not identifiable with the knowledge of oneself. The intellectual evidence of the Cogito at the metaphysical level transforms itself at the psycho-physical level into the sensible certainty. This certainty, because sensible, makes us aware of the substantial union of soul and body, but, again because sensible, will not provide us with the knowledge, the modes in which the union is made possible.

Descartes's third primitive notion and Malebranche's interior sentiment provide us consciousness, not knowledge. ${ }^{4}$ The third notion gives us the consciousness of the union of soul and body, without which all our practical life would be impossible. Without this awareness, we would not be able to coordinate our goals with our actions, shy away from danger, act and react promptly to the unforeseen happenings with which life continuously challenges us, and for which in practice the intellect's operation is mostly useless. The third notion performs the same function than the sentiment of Malebranche. The value of the interior sentiment is not metaphysical; it does not produce an ontological knowledge; it is valid only at the psycho-physical level. Malebranche repudiates the theory of the 
primitive notions as a metaphysical proof of the union of soul and body but values them, their assumptions and consequences at the psychological level. ${ }^{5}$ Life continuously requires sudden decisions; impending urgencies undermine the ability of responding with a pure mind through clear and distinct ideas to challenges of all kinds. When time pressures us, we cannot esteem material advantages or disadvantages by using either the science of bodies or that of the mind, metaphysics. If in the desert I were thirsty and encountered an oasis, I would have no way of analyzing scientifically its water: I would drink. Life goes on within the domain to which the third notion applies. ${ }^{6}$ This domain pertains to the psycho-physical science, but assumes also a theological tone.

During the seventeenth century, a gnoseological and theological controversy aroused about sensitivity. After the Fall, corruption began to plague human nature. God had removed its continuous sustaining action, abandoning the two first human beings to themselves. The inquiry centered on the evaluation of the damage to human nature that was caused by the Fall. The notions or conceptions of sensitivity became the ground on which theoretically the battle was fought, because the quality and the nature of sensitivity determined the nature of the union of soul and body. ${ }^{7}$ For Malebranche, the senses are suitably proportioned to the functions for which they were intended: survival. For Descartes, no teleological interest is assigned to the senses; Descartes has no scientific or metaphysical use for them. ${ }^{8}$ Malebranche's perspective differs from that of Descartes, but only at first sight, because he takes an ethico-religious path that Descartes had actually indicated but not taken. In Malebranche, the soul is united to the body and to God. The effect of the Fall was a greater predilection of the mind for the body than for God. Malebranche's ethico-religious perspective on the union of soul and body is justified by the motive that the biological explanation of the union does not explain the errors of the senses or the prejudices of sensations about reality, and gives an erroneous conception of the union itself. If the finality of the sensitivity is survival, then the union of soul and body favors the body, and the soul is metaphysically subordinate. ${ }^{9}$ For Malebranche and those who accept the Cartesian philosophy as the only Christian philosophy, the biological explanation of the union of soul and body is not acceptable. The conception of sensitivity must be approached at a gnoseological level, but also at a moral, and, eminently, at a religious one. In this way, sensitivity would become a path toward God. The human being's condition is that of an intermediate being and the possibility of nonreflective action (automatic?) for survival frees it from the permanent attention to be given to all that happens to be around, obliging it to analyze even what is banal. Thus, the human being is free to turns its reason to the search after truth and God.

The freedom from the continuous application of the mind to problems of practical order and matters that common sense could adequately resolve allows the mind the possibility of exploring itself, reinforcing its union with God. ${ }^{10}$ Accord- 
ing to Alquier, it was Malebranche who extended the application of the third primitive notion to all the practical and religious human sphere, though Descartes had already implied the idea in the famous letters to Princess Elizabeth. ${ }^{11}$ Though the third notion frees us from many worries, it does not explain how and why soul and body are connected and how and why the union is as it is. Malebranche gave an explicit theological color to a problematic that hitherto had been considered merely gnoseological, and that Descartes had already in different ways suggested. Alquier wrote,

These observations assume that the union is already made, and do not explain it. How can we then explain this union? Malebranche appears at times to think that God has united the spirits to the bodies through the body in order to unite them to what are their neighbors or environment. In this way, God perhaps wanted to unite the spirits among themselves by way of the bodies, and form some particular communities or societies. In this case, as M. Gueroult remarked, the final reason for the union is moral and religious. Practically, the union may serve for our achievement of holiness, acquisition of those merits that would give us the right to heavenly happiness. We have to crucify our bodies as Christ did. The soul is united to the body in order to sacrifice it, not to preserve it. The body, however, cannot obtain the saving sufferings unless it is preserved. Suicide or sacrificing our body is far from uniting us to God, because it will be contrary to God's design. To kill oneself or to let us die by fasting or other ways, means to destroy with our body the opportunity of suffering and offering our pains in sacrifice to God. We must care for our body; this care justifies the biological function of sensitivity, whose finality, by preserving our organic health would be by necessity subject to a higher one. If God the Father has united minds and bodies is because He wanted to give us a victim that like His Son we could offer to Him. With the sacrifice and the annihilation of ourselves, we could merit the possession of the heavenly beatitude. Sure enough, this seemed right and corresponding to the universal order. Presently, it is as if we were within our bodies to be tested. Do we have to add that, understood in this way, the finality of our affections is not as the one formulated by Descartes? Taken outside the context, the doctrine of Malebranche may appear similar to that of Descartes; but, once considered within its context, it takes a new significance. ${ }^{12}$

Malebranche, trying to answer some questions raised by Descartes, answered them by placing himself outside the Cartesian perspective. To ask why God has united the spirits to the bodies in a certain manner that we know by way of the third notion is to ask a general question about the nature of humankind. The problematic 
of the Fall, of the most determinant motive of the actual human condition, is the problematic of the third notion, as the lines of Alquiér have shown.

The laws of God that govern the union of mind and body, whether or not they were modified after the Fall, are born from the theological ground of the narration of the consequences of the Fall. The two questions that the Cartesian theory of the primitive notions left unanswered (why the soul is united to the body and how) found in the position of Malebranche an answer in his theory of the Fall and its consequences (the original sin). We know our nature, the soul as mind united to a body, through sensitivity; sensitivity is the witness within ourselves and to ourselves of what we are. The error, the logical form of any error, is due to our application of the criterion valid only for our own consciousness to the knowledge of the world and the physical reality. The cause of this error, at the anthropological level for Descartes and at the psychological and metaphysical levels for Malebranche, is the ignorance of our soul, ignorance or confused consciousness. ${ }^{13}$ The theory of the third notion presents the logical possibility of error. Without this "third dimension of the real," human beings could not attribute to physical entities the qualities proper to spiritual beings. In itself and without prejudices, sensitivity is the proper dimension of the third primitive notion. Without this dimension of what can be thought (pensabile, thoughtable), the human being would not err, or would err in a manner unknown to us. If we could think of an error different from the one that Descartes and Malebranche hypothesized, but still within the theoretical frame suggested in the letters of Princess Elizabeth, we could imagine the type of error made by the person who applies its pure intellect to the knowledge of the nature of bodies. This would not be an error; on the contrary, it would be the only way for not erring. ${ }^{14}$ The third primitive notion proposes a criterion of knowledge different from the one of the other two notions. The cognitive canon relative to the first two notions is self-evident, whereas the criterion of the third notion is a criterion of consciousness; it is not a criterion of knowledge. The disparity between the human condition (the unity of mind and body) and the other two realities (thought and corporeity) makes error possible as it made the Fall possible in Eden. If we would ask with Malebranche why there is error, we would have inevitably to touch within the theoretical frame of the philosophy of the eighteen century the problem of the Fall and its consequences. The third notion makes us conscious of the nature of our being, its eternal truth stands at the center of our being. Neither the res cogitans nor the res extensa are at fault. The problem of the human nature after the Fall is intrinsic to the relationship mind-body. The problem of the Fall and its consequences as much as it remained latent in Descartes, so much it became important and centrally noticeable in Malebranche. 



\section{THREE}

\section{THE HUMAN FALL AND THE PAGAN MENTALITY}

The Fall of humankind and the human fault are tied together with a double knot. The Fall of humanity from the Garden of Eden followed the transgression that the first human couple perpetrated. Their single error called for their expulsion and that of their progeny. ${ }^{1}$ In this view, The Search after Truth should be read at two levels, whose the most evident consists in the criticism of Aristotelianism through the analysis of the nature of error, and the second consists in the anthropological and logical analysis of the pagan mentality, of the manner of thinking proper to all human beings, from the time of the Fall. The logical-ontological possibility of error comes from the confusion between what is proper of the soul and what is of nature and from the lack of self-awareness. This is what Descartes asserted in formulating the theory of the primitive notions and what Malebranche applies in The Search after Truth.

At the origin of error, we find the obscure consciousness of oneself in the same way than at the origin of the fault in the Garden of Eden we find the union of the soul with the body and the dependence of the soul from it, with the obvious consequences of the fault and the Fall. The problem of the relationship between soul and body is the axis around which our reflections on error and transgression run. ${ }^{2}$ The original fault of humankind in the person of Adam and Eve constitutes the vector and the ground on which the relationships between the two substances that make the human being display themselves. The relationships between soul and body, which God decreed, are actually determined and combined within the frame of the Fall, after which the soul in its union with the body assumed dependency. Nevertheless, God did not change the human nature, says Malebranche, because God cannot be sorry for what He did. The dependency of the soul means that the body and the sensible goods have a major impact on sensitivity. We must be aware that this new condition of the soul is not the effect of an arbitrary and unmotivated decree of God, but one of the consequences of the Fall on Adam and Eve. In a way, God distanced Himself from Adam, but only because the first parents with their conduct decided so. ${ }^{3}$

The original transgression of our first parents was the first moral error that launched the psycho-physical equilibrium of the human being. ${ }^{4}$ The tendency to 
transgress determined by concupiscence is parallel to the tendency to err determined by the unawareness of our being. ${ }^{5}$ We have a parallelism between two pairs of contrary concepts. First, the evident consciousness of what is of the body and what of the soul gives us truth; the confusion of the modes of the res extensa with those of the res cogitans gives us error. Second, the Christian Mentality is reception of the divine light and comes to conceive clearly and distinctly what is proper of bodies and what of minds. The Pagan Mentality, on the contrary, is the product of concupiscence and of a union with a dependent soul. This parallelism of an erroneous mentality with paganism is merely hinted in Descartes, but finds its full development in Malebranche, ${ }^{6}$ as Ferdinand Alquiér and Michel Gueroult have justly observed.

The question of the transgression or moral error arises only when the other question, why the union of soul and body is such as it is, is asked. Malebranche in The Search after Truth has identified the erroneous consciousness with the pagan mentality, but to this fact modern criticism, in our opinion, has not given the due attention. Students of Malebranche have not recognized, as they should have done at the anthropological level, that erroneous conscience and pagan mentality are the same thing and that human nature is "pagan" in all human beings. The theological argument is simple: if human nature were not pagan in all human beings, including Christians, why did we need a savior in Christ? Malebranche has never sustained that the laws that set up the mode in which soul and body are united and ordered have undergone a modification in respect to the laws that govern the psychophysical rapports among pagans, unbelievers, and savages. The atheist, the Muslim, the savage, and the Christian possess the same human nature. On the contrary, Malebranche has stated that without God's protection the Roman Church would have suffered the contamination of heresies. ${ }^{7}$ All human beings share the same pagan human nature, which means that the soul is in the condition of subordination to the body. This subordination, however, is not absolute, if it were salvation would be impossible. ${ }^{8}$

The Jewish people represent a case that is simultaneously unique and emblematic. They represent a population that in relation to religion must all be with a pagan mentality or a Christian mentality, though obviously they are not like the ones or the others. In Conversations Chrétiennes, Malebranche distinguished Carnal Jews from Christian Jews. ${ }^{9}$ Carnal Jews believe in the letter of the Scriptures, see salvation in terms of this world and the gathering of transitory goods. Christian Jews know that the promise land, the true salvation is not to be found in this world but in the heavenly kingdom that Jesus Christ came to announce. The difference between the pagan and the Christian is not due to their human nature, but to the mentality of each, to the grade of the awareness each has achieved, awareness that is self-consciousness and right comprehension of the physical reality. The difference between the Christian and the pagan, the carnal Jew and the Christian Jew is not the mark of nature, but the result of the process of liberation and emancipation 
from the yoke of the body. ${ }^{10}$ The anthropology of The Search after Truth is structured as an analysis of the carnal human being, ${ }^{11}$ of human nature as it was determined after the original fault and Fall from Eden. ${ }^{12}$ The relationship soul-body is the same in all human beings; human nature is unique, but different are the many rapports of force between the soul and the body. In the pagan and in the Christian, the ability of comprehending abstract truths, of clarifying our inner consciousness, and of considering religion is different. In addition, there are Christians professing themselves Christian, who are in practice true pagans because they have an idolatric idea and cult of the divinity.

The human being described in The Search after Truth is not the true Christian, who knows its defects, faults, and finds in its faith, in a pure thought, in a moral conduct the weapons to fight evil, but the Pagan. People born in a Christian society, even if they have received the sacraments, have observed the external requirements of their religion, and behaved superficially but rightly, may remain pagan in spirit. Individual Christianity or Paganism is not an anagraphic or social caracteristic but moral. When at the bottom of our conscience we feel confused, we are pagan. Even when we believe that the tomato is truly red, we show one of the effects from having a pagan mind. From the time of Aristotle on to his most ingenious disciples and interpreters, to the superstitious, the idolaters, the analphabets, and the savages the pagan mind has been forming the minimum common denominator of human nature. In general, human beings have the pagan mentality and they reason by way of the natural causality, which attributes subjective qualities to things. The pagan mind is subject to the body, but it is not subject in same way, in the same measure, in the same proportions and with the same modalities in every human being. Malebranche obviously knows what the differences between Aristotle and the ignorant shepherd (a personage present in The Search after Truth, introduced for a narrative purpose) are. It is not convenient for Malebranche to stop at the consideration of individual differences that at times are truly enormous. In order to define the pagan mentality, he must analyze and define the elements that characterize it and that all pagan of conscience share..$^{13}$ In The Search after Truth, he said,

All these insignificant pagan divinities and all these particular causes of the philosophers are merely chimeras that the wicked mind tries to establish to undermine worship of the true God in order to occupy the minds and hearts that the Creator has made only for Himself. It is not the philosophy received from Adam that teaches these things, it is that received from the serpent; for since Original Sin, the mind of man is quite pagan. It is this philosophy that, together with the errors of the senses, made man adore the sun, and that today is still the universal cause of the disorder of men's minds and the corruption of men's hearts. It is true that the true faith rein- 
forces us, but we may very well say, that in this matter if the heart is Christian, the spirit deeply down is pagan. ${ }^{14}$

Many more quotes from Malebranche's work could be added, but let us insert this one15: "I grant that men nowadays are sufficiently enlightened not to fall into the gross errors of the pagans and idolaters; but I have no fear in saying that often our mind is turned, or rather that our heart is disposed as was the pagans', and that there will always be a kind of idolatry in the world." The comparison between the mentality of pagan people and the mentality of Christian people concludes with the affirmation that in general the two mentalities are identical. Considering specific points, we may say that the mind submitted to the body is pagan and would produce a corporeal (carnal) mentality. The fault in Eden and the transgressions in us have greatly enfeebled the human union with God and strengthened that with the body in such a way that the human being has become like an animal-machine, a biological agent. Malebranche's description of the soul under the power of the body is always similar to the description of physical entities, as if the passions and the sensible inclinations were mechanical and unavoidable. ${ }^{16}$ Because of the original transgression, the human being has become the slave of matter and its spirit succumbs easily to sensations. The subjection of the human being to matter is the cause of human transgressions and errors. Speaking in anthropological and psychological terms, the pagan mentality is the effect of the original transgression in Eden. Until the day when the Mediator would end the work started in Palestine, God will neither reveal its judgment on human conduct nor terminate human history, and the human mind will remain prisoner within the sensible boundaries of the pagan mentality. All humankind, at the exception of the exiguous minority of the Christians in spirit, has a mind inclined to irrationality and a will subservient to idleness. Culture, acquired knowledge, reflective individual abilities, with the help of Grace, could reduce the coarseness and the number of human errors. In substance, and in this frame, both the unlearned shepherd and the philosopher by profession or with ingenuity like Aristotle are sharing the same mentality, fruit of the fault in Eden. 


\section{FOUR}

\section{ARISTOTELIANISM: THE LOGICAL SUBLIMATION OF THE PAGAN MENTALITY}

Malebranche stated that the Cartesian philosophy is the true Christian philosophy because Descartes has defined the clear boundaries between the physical and the spiritual realities, between mind and body. The Cartesian metaphysics has perfectly clarified that the interaction between bodies cannot be comprehended through the analogy of the force that we experience in ourselves. Pagan philosophers understood that the physical forces that govern the world were similar to the psychophysical forces they sensed in themselves. The effects of this point of view were deleterious. This position produced the misunderstanding of the concept of force, the improbable notion of cause, the introduction of the power of action of some particular entities within a reality merely physical, and the mistaken notions of matter, quality, and substance.

Constructing science on these mistaken principles, Aristotelianism shared with idolatry and pagan religions a comprehensive vision of the world. The fundamental facts of the Aristotelian physics, according to Malebranche, are identical to those of idolatry. Identical are the idea of substance, the concept of force, and the conception of causality. Aristotelian physics is based on an erroneous logic. Without knowing it, the common human being is an Aristotelian: a multitude of prejudices has conditioned its mind. Aristotelianism is a strong philosophy because its foundations are rooted in principles that agree with the common sense, which is the pagan sense opposed to the Cartesian common sense. Aristotelianism is the abstract philosophical expression of the pagan mentality; indirectly, it is a metaphysical consequence of the Fall:

Since the sin of the first man, the mind constantly spreads itself freely externally; it forgets itself and Him who enlightens and penetrates it, and it lets itself be so seduced by its body and by those surrounding it that it imagines finding in them its perfection and happiness. God, who alone is capable of acting on us, is now hidden to our eyes; His operations contain nothing sensible, and although He produces and conserves all beings, the mind, which so arduously seeks the cause of all things, has difficulty in re- 
cognizing Him, although it encounters Him at every moment. Some philosophers prefer to imagine a nature and certain faculties as the cause of the effects we call natural, than to render to God all the honor that is due His power; and although they have neither a proof nor even a clear idea of this nature or these faculties, as I hope to show, they prefer to speak without knowing what they say and to respect a purely imaginary power, than to make any effort of mind to recognize the hand of Him who does everything in all things. ${ }^{1}$

Aristotelianism and all the philosophies previous to the advent of Cartesianism, with the exception of the Augustinian Platonism, are seen as the philosophical crystallizations of the thought of a conscience inclined to the exteriorization of itself, of a conscience subject to the effects of the Fall. ${ }^{2}$ In The Search after Truth, we find the recurrent juxtaposition of the Christian religion to the Stoic and Epicurean philosophies. ${ }^{3}$ It can be justly said that this work of Malebranche constitutes an attempt at the destruction of the pre-Cartesian philosophies. It is as a battle engaged on the moral front against Stoics and Epicureans; on the religious front against idolatry, heresies, and the pagan religions; and on the metaphysical front against Aristotelianism. ${ }^{4}$ Malebranche's criticism is focused particularly on the concepts of "substantial form" and "natural causality."

Malebranche refused to consider the soul as the form of the body, going beyond the position of his teacher. Descartes admitted that the soul was the only acceptable substantial form, but considered the "substantial union" in a manner different from that of Scholasticism. Both Descartes and Malebranche intended to eliminate from physical reality all substantial forms. To conceive of nature in light of the principles of Aristotelian physics means to attribute to bodies properties that are only of the soul and to confuse the modalities in which the soul becomes conscious of things, with the essence of things. This discourse runs again around the sensible qualities. Because of the Fall and the obfuscation of the mind due to many prejudices, pagan philosophers have not realized that the only certainty that human beings have is the attribution of extension to bodies. The idea of extension is an objective idea that receives its objectivity for being an idea intellectually evident, and not from the reality of the existence of bodies. Malebranche observed that the human bizarre views of the sensible qualities are due to the strict union of the soul with the body since the Fall, and to the predominance of the flesh. The soul, becoming unable to concentrate, ascribes to bodies what are its own properties. In this fashion, the soul does not distinguish itself from bodies. Bodies are believed to possess sensations, the force of imagination, and at times the faculty of reasoning. A great number of foolish and gross philosophers have thought of the soul as the thinnest and most agile part of the body. ${ }^{5}$ The mental confusion of these philosophers is equivalent to that of idolaters: they melt together in a chaotic fashion all the dimensions of reality and identified inert matter as the source of action and 
will. ${ }^{6}$ The refusal of substantial forms is strictly correlated to the Occasionalist conception of causality. Malebranche, in clear terms, juxtaposes his theory of Occasionalism to that of the natural or real causality. In this theory, the fundamental question is that, because of the original transgression and our ignorance about the sphere of application of the third primitive notion, human beings are inclined to think that our sensations are in the objects and that the objects really act the ones on the others. ${ }^{7}$ If we accept that to explain a phenomenon we may use natural causes, than we have to accept that nature and the objects that in nature are included act deliberately and voluntarily. To explain a phenomenon through natural causes signifies to understand it with human imagination but not with human intellect.

In the position of Malebranche, the rationalist thinker adopts Occasionalism as the logical-gnoseological principle for the understanding of the cause-effect relationship. On the contrary, the pagan thinker would be naturally inclined to think in terms of natural causes. ${ }^{8}$ Through a criticism of natural causality we can arrive to deny the possibility of substantial forms. ${ }^{9}$ To infer by way of natural causality means that a particular being as, for example, the fire has the capacity of provoking the heat that I sense by walking close to it. ${ }^{10}$ However, the fire is only the occasional cause of my sensation, not the real cause. The fire cannot pass from the res extensa to the res cogitans; it has, in other terms, no faculty of making itself felt. Common people and all pagan philosophers reason by way of natural causes. Idolaters also think through natural causes and from this logic all idolatric religions were and are born. 



\section{FIVE}

\section{THE SCIENTIFIC FOUNDATIONS OF VICO'S PSYCHOLOGY}

Malebranche, more than Leibniz and Spinoza, dedicated himself to the critical analysis of Aristotelian physics, especially to the Aristotelian way of inferring the relation cause-effect, and to the consequences in the field of anthropology. When Vico assumed Malebranche's positions in this area, nobody recognized the importance of their impact in the anthropological vision that Vico came to formulate with them. ${ }^{1}$ To analyze topics such as "mentality" and "common sense" means to do anthropology, and to view them as products of the pagan-Aristotelian forma mentis is to consider human nature as the Cartesians do. This does not make Vico an unwitting Cartesian, but only a new kind of anthropologist as he enjoys to profess at the beginning of The First New Science (1725).

The theological poets are the senses of humankind in the same way that Aristotle represents its intellect. The theological poets are Aristotelian for their use of the common sense, whereas the Philosopher represents the conceptual distillation and the intellectual synthesis of natural thought, the pagan thought. ${ }^{2}$ The parallelism is Cartesian, and we should not marvel that about this specific argument Vico is assuming a position similar to the Cartesian one. ${ }^{3}$

\section{Conatus: The Corporeal and the Spiritual Sphere}

Vico referred to the advantages of making a distinction between what is of the corporeal sphere and what of the spiritual one, as Descartes and Malebranche did in relation to movement. This convergence of view is noticeable in many points of Vico's De Antiquissima Italorum Sapientia (On the Most Ancient Wisdom of the Italians, 1710) which is his only metaphysical work: "It is an error to study physics with the mentality of metaphysicians, and vice versa" (Erroneo sia il meditare sulle cose fisiche con l' aspetto di metafisici, sia l'inverso). ${ }^{4}$

Explaining that there is no conatus (force, effort) in bodies, Vico shows to be close to modern mechanicism in physics: 
It is not really a conatus if I break a wall with the power of my arm. In fact, it is a true motion of the nerves that changed from being relaxed to being very tense. No different is the motion of the fish swimming toward the river bank and opposing a certain resistance to the current. For a flow of animal spirits follows upon this tension of nerves, and hence, there is true motion until, with fresh spirits arriving, the nerves grow weak and relax..$^{5}$

The principle, which avers that there are ideas of bodies and ideas of spirits and that they should not be applied outside their proper sphere of reality, is not acceptable to all scholars, though it is evident. Thus, modern Empiricists did not accept it because for them all ideas are of the same nature. Renaissance NeoPlatonists disregarded it because they lived within a universe more animated than the Aristotelian one. The Skeptics enjoyed dismantling it with doubt as they tackled the pre-constructed classification that Descartes proposed to Princess Elizabeth. In other words, those who have a conception of matter and of the nature of the ideas differing from the Cartesian view, or deny the possibility of demonstrable knowledge, cannot accept a classification of ideas that is parallel to the distinction among substances. The acceptance of a classification of this kind would entail the acceptance not only of a specific constitution of the universe or of the nature of substance, but also and in a more direct way the subjectivism of Cartesian inheritance. Spinoza, Leibniz, and Malebranche thought differently from Descartes in relation to the concepts of substance and divine action, but could accept, though with an eventual distinction (distinguo), the classification of ideas that he proposed.

To find in Vico a conception that steps towards the reconstruction of the nature of ideas as delineated in the works of Descartes is remarkable. Vico's first pace in that direction was that of denying the possibility of conatus in extended entities and of dissolving the vitalism that the Aristotelian theories inspired by a qualitative conception of reality often evoked. To deny the possibility of conatus in bodies is equivalent to denying any intentionality in them, any extra ingredient like intelligence. No need exists for analyzing the metaphysical questions in $O n$ the Most Ancient Wisdom of the Italians to find out how Vico stands on the qualitative conception of nature. His rejection of the theories that speak of the qualities of matter and of the forces acting in nature equals that of Descartes and Malebranche and it means the rebuttal of the form of thought that in Aristotelianism was philosophically sublimated:

Consequently, the phenomena of an already existing natural order cannot be explained by appeal to powers and forces. Thanks to the better physicists, the language of "natural sympathies and antipathies" and of "nature's secret designs," called "hidden qualities," has already been expelled from 
the schools of physics. The word conatus survives as a holdover from metaphysical language. So in order for the language of physics to be perfected, conatus should be taken out of the schools of physics and restored to the metaphysicians. ${ }^{6}$

For Vico, it is irrational to think of a corporeal reality with the conceptual categories proper to Scholasticism. In the sciences, authority must give way to reason, and reason must avoid nature's secret designs founded on hidden qualities. The use of the word conatus, a cardinal concept of the Vichian metaphysics and anthropology, should be limited to metaphysicians; erroneous is its use in matters of physics. ${ }^{7}$ It is a concept valid only in a specific context, outside of which conatus looses its meaning and acquires a different one. The dichotomy in Vico is between physics and metaphysics, two kinds of knowledge that has two kinds of objects. In each of the two fields of science, what is valid in one is excluded from the other; the principles of one are not transferable to the other; the realities to which they refer are different. To explain the movement of two physical objects, the action of one in correspondence with the action of the other, by way of intentionality and willingness means to confuse physics with metaphysics, to classify together what should rationally remain separate.

With the explanation of the concept of conatus, Vico formulates a theory of error that emerges from all his physics and, as it is applied to the concept of force, it would remind us of the doctrines enunciated by Descartes in the letters to Princess Elizabeth. The concept of a force that caused by an act of will produces a physical motion presupposes a concept of substance, causality, and reality that Descartes, Malebranche, and Vico, at least under particular aspects, rejected. The implications of psychological order that Vico's position implies are multiple and hereherto insufficiently analyzed. Vico wrote:

The opinion that motion can be communicated from one body to another seems no less objectionable than the common Scholastic doctrine that explains attractions and motions by appealing to the abhorrence of a vacuum. For, to my mind, the view that a projectile carries with it the full force of the throwing hand appears similar to the opinion that air sucked up out of pumps draws up the water after itself. For through most illuminating experiments on the basis of the new improved physics, these attractions have now been discovered to be truly the pressure of the surrounding air. And it is now steadily maintained that all motion is born of impulses (impetus). 8

There is no need for more examples, since this one is emblematic of the traits we intend to underline. We do not wish to show some parallelisms between the Cartesian mechanicism and Vico, but rather to point out that Vico maintains a 
conception of error compatible with the one of Descartes and how he takes a critical standing as Malebranche did in regard to natural causality. Vico explicitly denies the conception of motion of the Aristotelians and we may say that the citation given above could have been extracted from any of the writings of Malebranche. Profound are indeed the differences between anthropology and the physical science, in as much as the realities to which they refer and are applied are different. It is erroneous to judge the things that concern our practical life according to scientific criteria because human beings in the quotidianness of life in general do not act on the basis of rational principles. It is an error to use criteria based on sensitivity rather than on the geometric method. ${ }^{9}$ It is a recurring theme. The opposition between the universal principles that rule over reason and the particular motives born out of our sensations that push us to action mingle with the dichotomy of true-false, and with the impossibility of conciliation. What Malebranche was used to sustain in regard of the contrast between ordinary living situations and the clear and distinct thought returns in Vico. Responsive action cannot spring from the consideration of clear and distinct ideas. The speed of actions toward quotidian solutions is incompatible with the intellectual speed toward the truth.

\section{Error and Methods}

Error is the interpretation, with methodologies used for the comprehension of rational truths, of verisimilarities provoked by active passions. The different levels of the argument follows the changing of the contexts, and a difference in the realities within which certain facts happen requires the choice between the sciences suitable to the justification of those facts..$^{10}$ In this, we find the origin of the incapability for a finite mind of taking in the whole of infinity. On the contrary, the pagan mind would adopt the same spectrum of principles for studying the one and the many, the conceptual and the material, God and the bodies, with the effect that the theologian poets would imagine divinities like big animated bodies. The human being as a limited being studies the different levels in which reality represents itself to its limited mind through different sciences. The narrowness of human intelligence obliges human beings to fragment all knowledge into as many sciences as the aspects in which the real shines. We have metaphysics studying being; arithmetic, the one and its multiplication; geometry, the figure and its measure; mechanics, motion from the periphery; physics, the motion from the center; medicine, the human body; logic, the reasonableness of arguments; and morality, the will. ${ }^{11}$ If the human being wants to achieve some kinds of knowledge, it must consult this classification of the sciences in relation to its objects of interest. In God and for God, all knowledge is one because God is infinite and immutable. God has an objective view of the whole reality, while the human being comprehends 
things only from one point of view, one perspective that is definite and limited. Human beings are not God; they cannot consider all things with a unique criterion of judgment independently from the aspects with which things veil themselves. The risk of confusion is always impending on the human beings. Vico as Malebranche before him would insist on the limitations of the human intelligence and on the tension of the human spirit in their effort to grasp the infinite with finite means, using the imagination, and falling into error.

It is necessary to assert that, though some fundamental assumptions of Vico may be different from those of Malebranche, the position at which Malebranche and Vico arrive is identical; and this position is that of Malebranche. For both Malebranche and Vico, the physical and moral spheres are two different realities or two differing aspects of reality. These realities "respond" to diverse principles and it is an error to judge the facts of one reality with the principles suitable for the comprehension of another one: "For, just as it is impossible to have a certain science of physical things, i.e. of the movement of bodies, without the guidance of the abstract truths of mathematics, so it is impossible to have a science of morality without the guidance of metaphysics and, therefore, without a demonstration of God." 12 This citation can be read as an argument against Bayle or Grotius. For our purpose, it accentuates the fact that every science deals with a precise zone of reality, and that it is an error to apply to physics the principles appropriate to the moral sciences as much as to apply to the moral sciences the principles pertaining to the physical sciences. This, truly, is not an error among the many that can be made, but it represents the logical form of all the errors that consists of interpreting something without possessing the suitable means. The question raised by Vico is under some aspects one of method. The inappropriate use of some interpreting framework may be solicited by multiple factors, though it can be challenged with one only tool in hand: univocity. If I could arrive at the necessary consequences after starting from exact premises, it will be evident whether I used the right strategy, if the method was appropriate, and if my hypotheses were correct. In this area, the conciseness of speech of geometers, without ornaments and with unequivocal terms, would eliminate the possibility of confusion and misunderstanding.

The task of the philosopher, as well as of the geometer, is that of distinguishing the competencies of the various sciences. The mathematical language has the function of suppressing the human disposition for confusing notions otherwise unrelated. In relation to formality, the modern method of the scientists is that of following a criterion of evidence in each one of the logical passages from an idea to another. Evidence here becomes the obliging path that reasoning must take in its stepping from one concept to another. From one idea, we can move to only another distinct idea. Error originates when a method is adopted that foresees the possibility of a logical passage from one idea to two ideas in two successive moments: 
The geometrical method enables us to set forth matters in a purely geometrical, apodeictic form, and gives us the possibility of teaching them in a plain, unadorned way, devoid of any aesthetic charm. All of the modern physicists affect a style of exposition which is as severe as it is limited. Our theory of physics, in the process of learning as well as when mastered, moves forward by a constant and gradual series of small, closely concatenated steps. Consequently, it is apt to smother the student's specifically philosophic faculty, i.e., his capacity to perceive the analogies existing between matters lying far apart and, apparently, most dissimilar. It is this capacity which constitutes the source and principle of all ingenious, acute, and brilliant forms of expression. ${ }^{13}$

In this text, the vigorous debates of the Naples of the sixteenth century transpire, and under their influences it is no wonder that Vico absorbed some theses on the rapport of natural and scientific language of The Search after Truth. Vico completes the above text differentiating the concept of subtlety from that of acuity. ${ }^{14}$ Subtlety is represented by the single line on which the argumentation develops; thoughts take successive positions on a line and from one thought, we can move to only another successive one. Acuity is represented by two lines on both of which thought can move; acuity opens itself to the danger of giving a double meaning, the desired one in metaphors, the unwanted other in error. Eloquence and science travel on different tracks; the first, on acuteness; and the second, on subtleness.

The stylistic-pedagogical opposition between the geometric mathematical method and oratory performs the function of tutelage for both of them. Presenting the various uses of the various kinds of language, Vico intends to maintain solidly the differentiation among disciplines and the dimensions of reality to which they refer. This contrast is functional in the sense that it revalues rhetoric, which the new philosophy undermined at the root, and it protects the stylistic conquests like the precision of mathematical language that the science of the last centuries has achieved. From the citations given, we see how Vico maintains a discourse in dualistic terms: there are questions in which the geometric method is appropriate and there are other in which it is more consonant to use techniques and principles that govern eloquence. The acquisition of the true knowledge of the laws that regulate nature goes also through a language that regarding the questions is innocent of misinterpretations, decisively capable of discerning between similarities and differences, exact in the choice of various criteria suitable to one or the other of the various initial questions. In On the Most Ancient Wisdom of the Italians, Vico underlines the linguistic aspect of this conception of error when taking position against the Aristotelian theory of the definition. All errors come from homonymy. The homonym is a word attributed to two different things, in both cases spelled and pronounced in the same way. We think of this as an extension of the principles 
expressed by Vico and cited in the passage of The First New Science, where error is said to consist of applying to a series of phenomena the same criterion that is appropriate to the judgment of a different series. This error creates the equivocation of including an object in a group, in a series, of other objects that are substantially different: "All philosophical errors arise from homonyms, which are commonly called equivocations. Yet equivocations are nothing but words that signify more than one thing" (Omnes in philosophia errores ab homonymis, vulgo aequivocis, nascuntur: aequivoca autem aliud non sunt, nisi voces pluribus rebus communes). ${ }^{15}$ The philosophical language combine what in order to be understood must remain separate. In philosophy, the cause of all errors, though it must be found in an erroneous logic, manifests itself in the particular formulation of the language, an unwise formulation of terms that could mean things much far removed from each other. What stands behind the philosophical equivocations? Which categories of thought, which principles would produce erroneous homonyms? Vico had one answer, simple but to the point: the Aristotelian genera. "Hence, it happens that the more the arts and the sciences are founded upon Aristotelian instead of Platonic genera, the more they confuse the forms; and the more magnificent they turn out, the less useful they become. That is why Aristotelian physics has a bad reputation nowadays for its extreme generality." 16 The genera are the cause of equivocations, because in them things are collected like in some containers.

\section{The Aristotelian Genera}

The defect of the genera, let us insist on this point, is that they are too broad, too generic; they are capable of holding (and defining in the same way) things very dissimilar, whose differentiation can trespass their specificity. Aristotle's definition requires the closer genus and the specific differentiating character. The mentioned error is one made by the learned and not by the practical man of business who does not deal with abstract problems. The application and use of the wrong criterion in philosophy is, for Vico, as dangerous as the superstitions of the common people. The reason is that both the superstition and the philosophical error use the same modalities for the explanation of the phenomena: "So I do not know whether the genera lead the philosophers into errors more than the senses lead the vulgar into false conviction or prejudices. For in our way of speaking, genera confuse the forms, or, as they say, produce confuse ideas, and prejudices as well produce obscure ones." ${ }^{17}$ In this text, Vico adopts the modern perspective that we have previously described taking it from the Discourse on Metaphysics of Leibniz. The confusion created by the deduction of scientific principles from the data of the senses becomes in modern philosophy the object of gnoseological analysis and critical philosophy. This confusion, in its etymologic sense, assembles things that should be kept apart. Vico in The Second New Science (1730) speaks on this issue at 
paragraph 182. It makes explicit that the criticism of the prejudices of the common sense is comprehensive of the mentality that nourishes Aristotelian philosophy. This is not the place to discuss how much of the Cartesian dualism has been filtering into the Vichian philosophy, but we may affirm that in general terms the history of the error that Vico has constructed is present in Descartes and Malebranche, but not in Skeptics and Empiricists. Leibniz, if we wish to continue in the same line of thought, compared the Empiricists to the Aristotelians. ${ }^{18}$ The theory of error was constructed with anti-Aristotelian intentions and as a preamble to the construction of a theory of idolatry, which will constitute the first point of distinction between Vico and Malebranche. By way of this conception of error, Vico criticized the utilization of genera in philosophy and Malebranche likewise the "natural causality" championed by Aristotelianism.

Vico, having underlined the contradictions into which philosophers fall with the utilization, as meter of judgment, of the genera, extrapolated from this analysis the logic that they followed in their equivocal ratiocinations. Having then again noticed that all error came from a unique structure, Vico established the criterion for the identification of error, from which, afterward, he established the criterion of truth by way of an inversion. Physical facts are judged with the principles proper to the mathematics and the geometry of the new sciences; moral acts, with the principles proper to metaphysics and ethics.

The flexibility of language is an indication of the confusion of thought. ${ }^{19}$ When the ideas are clear, words have a confined but exact meaning. When the ideas are not conforming to truth and are twisted toward particular goals, words assume equivocal meanings. Then, the words will create contrasts that will not cease until we turn to the search after true knowledge removing all sectarian and class interests. The criterion of truth is the doorway to the understanding of what and how a thing is. The genera are a fallacious criterion that cannot define univocally the terms that are at the root of the sciences, of philosophy, and of jurisprudence. The genera are a criterion extrinsic to the various disciplines, and it is applied in a mechanical manner. The genera are a criterion reputed uniquely adapt, but not properly adaptable to the differences of the sciences, and through them, to the contrasting aspects of reality. Each dimension of reality requires its science, its proper principles, for whose formulation, the appropriate criteria of truth specifically oriented to each dimension of reality are used.

Every discipline must find within itself the principles on which to stand firmly. We must avoid the external imposition of principles and methods that, as in the case of the genera, will give to words and principles feeble and oscillating meanings. Vico, with the aid of Bacon, was implacable on this and moved fiercely and cleverly in the direct attack upon the Aristotelian genera. In On the Most Ancient Wisdom of the Italians, Vico stated that with the use of genera we cannot face innovations and inventiveness: "Indeed, all these new, extraordinary, unexpected wonders cannot be explained with the universal genera" (Atqui nova, mira, inopinata 
universalibus illis generibus non providentur). ${ }^{20}$ For being extrinsic to reality, the criterion of the genera is of no help in the progress of the sciences. Relying on the genera, we can build a fantasy world, castles of verisimilarities, theories ingeniously connected, but no scientific construction.

On this issue, the criticism of Aristotelianism becomes more radical. Aristotelianism makes impossible the comprehension of everything it has not categorized within its schemes, and it discards all the new forms of knowledge and logic at variance with its own: "Thus, Aristotle's Category and Topics are completely useless if one wants to find something new in them. One turns out to be a Lull or a Kircher and becomes like a man who knows the alphabet, but cannot arrange the letters to read the great book of nature" (Itaque Praedicamenta Aristotelis, et Topica, si quis in iis quid novi invenire velit, inutilissima sunt; et Lullianus aut Kirkerianus evadat, et similis eius fiat, qui scit quidem literas, sed eas non colligit, ut magnum librum naturae legat). ${ }^{21}$ The method or criterion of studying that does not reflect the nature of the matter studied but only label it creates inevitably an obstacle that cannot be removed unless we compulsorily renounced to the method or criterion itself. Vico concedes the use of genera in metaphysics because in the metaphysical form of knowledge we reason through generic universalities, but his concession has an intended goal: the achievement of a disposition to Platonic forms. ${ }^{22}$ Vico makes a clear distinction in the application of theories in relation to the clarity and simplicity that they can contribute to a philosophical system. In this page of the $O n$ the Most Ancient Wisdom of the Italians, so full of Platonic and Aristotelian hints, even when he appears not to oppose directly the Aristotelianism, the discriminating criterion, being that of clarity and simplicity of application, ends inevitably with the refusal of the Aristotelian perspective. This refusal goes through the tunnel of the univocity of the scientific logic and of the error of applying to science, but also to metaphysics, the imperfection of particular forms or inappropriate genera. Physics and metaphysics should accurately be kept distinct. ${ }^{23}$

We have analyzed some Vichian significant theoretical elements of the process of "purification" of matter from those hidden qualities that obstruct its comprehension. The first step in that direction has been that of removing the conception of conatus from the bodies. It is a step of an enormous importance toward the conception of modern science and philosophy. In the inaugural orations, Vico affirmed:

We consider among natural things those which have been already fully accepted by man, namely geometric figures and numbers from which mathematics constructs its own demonstrations, and also causes which are most frequently debated among the learned doctors and are investigated by physics. Under physics I include anatomy, which is the study of the fabric of the human body, and that part of medicine which inquires into the 
causes of illness and which is nothing else than the physics of the diseased human body. ${ }^{24}$

\section{Cartesian Psychology}

Vico praises the Cartesian psychology: "Listen to Descartes, how he has investigated the motion of bodies, the passions of the spirit, and the means of perfecting vision." 25 A complete acceptance of Malebranche's perspectives on mind, language, body, passions, theological problem of sin, becomes transparent throughout the words and thoughts of Vico, almost as if these words and thoughts were a duplicate of the words and thoughts of Malebranche:

And if I say that each of you must search within himself in order to consider carefully his human nature, he will in truth see himself to be nothing but mind, spirit, and capacity for language. Indeed, when he analyzes his body and its functions he will judge it to be either that of a brute or in common with the brutish. From this he will note that man is thoroughly corrupted, first by the inadequacy of language, then by a mind cluttered with opinions, and finally a spirit polluted by vice. He will observe that these are the divine punishments by which the Supreme Will punished the sin of the first parent so that humankind who descended from him will become separated, scattered, and dispersed. ${ }^{26}$

This passage offers many interesting aspects. Vico describes the human being in a dualistic terminology and in the between of body and mind, places language and passions, connecting these elements to the question of the original sin. At last, he inserts the physics's mechanicism. In this light, the consideration on anatomy is significant; for anatomy among the various scientific disciplines was at the center of the debate between traditionalists and Cartesians. Nothing is more Cartesian than the consideration of the body as inert matter. In Italy, Cartesianism was accepted for its critical potentialities in respect to the Peripatetic science. As Marcello Malpighi observed, the introduction of Cartesianism in Italy had a polemic origin rather than constructive; it represented the refusal of the tradition rather than a theoretical position. The first people showing a scientific interest for Descartes were professionals in the field of medicine and the naturalists were the first to accept his precepts. Vico grew up in a cultural milieu favorable to Cartesianism, permeated with the new philosophy. The Cartesian positions of Vico originated in a terrain well cultivated by personages like Costantino Grimaldi. The fact that Vico made his own the typically Cartesian conceptions at the time when the cultural milieu was formulating them implies that he necessarily was taking position in the pervasive omnipresent polemic between innovators and 
traditionalists. Vico's positions on the subjectivity of the sensible qualities, on the absence of conatus in bodies, on anatomy considered as a branch of physics, on the science of Galileo, on the human body seen as inert matter, on the admiration for the admirable studies of Descartes concerning the motion of bodies, pressed on him the obligation of taking a place in one or the other side of the blockade. In that ambiance, one person could kindly criticize a theory without renouncing to its standpoint.

In Vico's Autobiography there is a criticism of Descartes, Malebranche, Arnauld, Nicole for having been unable to work out a system of Christian morality. Vico did not state that the Cartesian and Malebranchean systems are alien to Christianity, but that Descartes and Malebranche from their science that he approves have not been capable of deducing an adequate system of morality. He instead did. In mentioning Descartes, The Passions of the Soul (1649), Vico affirmed that it is scientifically "more useful to medicine than to ethics," and in the inaugural orations he generously praised it.

With Vico, we can deduce that the Cartesian and Malebranchean psychology founded on the critique of Aristotelianism and on the distinction between soul and body is valid. On this psychology, who would build a philosophy that is also a genuine Christian morality? In our opinion, the question is not whether Vico was a Cartesian philosopher, but if as a thinker he accepted the most general principles of modern psycho-physiology and physics. With his own eyes, Vico saw the battles between the Galenic and Spagyric schools, the representatives of Cartesianism and of Aristotelianism, the like of Leonardo Di Capua, Costantino Grimaldi, Benedetto Aleatino, Giacomo Lavagna, Gaetano Tremigozzi, Carlo Celano, Carlo Musitano, Pietro Antonio De Martino, Carlo Majello, and Agnello di Napoli. The real question for Vico was that of being a modern philosopher. To share positions held by Descartes and Malebranche meant essentially to be modern. Cartesian and Malebranchean psychology appeared to Vico as a true and proper science that became modern science in the hands of the innovative philosophers.

With his basic acceptance of mechanicism in physics, Vico embraced more fully the triumphing Cartesianism while at the same time moving away from the scientific conceptions of nature that characterized the traditional physics and medicine. Because of the new scientific methodology, Vico removed conatus from bodies together with the Aristotelian genera. His argumentation in favor of the thesis that conatus is not possible in extended bodies centered on motion and its interpretation. If there were conatus in the bodies, the bodies could be said to be like "agents," entities capable of acting or avoiding acting. If they were capable of acting, how would their activity manifests itself in any other way than with motion? All philosophical sects preceding Cartesianism, implicitly or explicitly, reputed bodies as capable of action, Malebranche included. On this controversial subject, Vico sustained that motion is a unique physical fact that does not point to the presence of hidden faculties or qualities in matter. Motion is nothing else than 
the body itself: "Motion is nothing but a body in motion; in more accurate metaphysical language, it is not so much a "what" as an "of what." For the mode of a body is that which cannot be distinguished — not even mentally-from the thing of which it is a mode. Communication of motion is exactly the same as penetration of bodies." 27 According to what Malebranche says, the Aristotelian philosophers, and in general all Pre-Cartesian philosophers, in the questions of scientific order, argue by means of natural causes. Natural causes, they stated, act intentionally among themselves. In this view, if an object falls on the ground, it tends to reach its original place; the hand that throws a rock, gives impetus to the rock. ${ }^{28}$ Giving the last example, Vico joins Malebranche in the criticism of natural causality and shows how his position is not sporadic but due to exact philosophical choices and theories elaborated and presented in On the Most Ancient Wisdom of the Italians. ${ }^{29}$ Vico reclassifies motion within pure mechanicism. Motion is an event that concerns only corporeity. We should not meditate on physical things with the mentality of the metaphysician and should abandon the criterion of the natural causes, fruit of the mentality subject to sensitivity, which has never made a step toward the true knowledge of nature. Coherently, Vico gives at this point an explanation, typically mechanicistic, of heat: "And what is heat but motion?"30 This rhetorical question is important because, after having declared that movement is corporeity, Vico interpret with it a sensation. In synthesis, Vico operates in a manner opposite to that of the Aristotelians and, in general, of pagans and the major part of humankind: they interpreted the bodies beginning from the sensations; Vico analyzes sensations by referring solely to the modifications of the body.

\section{The Human Faculties}

From the beginning of this chapter, we saw that the debate between the Scholastics and the Cartesians ran exactly around the status to be assigned to sensitivity. The pivotal question is whether in the process that determines knowledge the objects conform to thought or, on the contrary, thought conforms to the objects. Vico believed that this classic problem was already in the mind of the ancient philosophers because we can find some marks of it in their language: "For if the senses are faculties, we make the colors of things by seeing, flavor by tasting, sound by hearing, and heat and cold by touching. An undistorted trace of this tenet of Italy's ancient philosophers survives in the words olere and olfacere. For a thing is said to have a smell and the animate sense is said to perceive a smell because the sense makes the scent by smelling the smell." 31 Odor, is it of the object from which it emanates or is it of the subject that senses it? The two verbs olere and olfacere do not truly furnish an etymological solution, but represent faithfully the ambiguity of the question. Vico gives his own exact answer, leaving no doubts on his position, on the theme of sensitivity between Scholastics and Cartesians: 
"The Scholastics speak quite elegantly when they call sensation, imagination, memory, and intellect the faculties of the soul. But they spoil that elegance when they declare that colors, flavors, sounds, and touch are in things." 32 On the contrary, sounds, flavors, and odors are operations of the sensing subject: "As appendixes to these discussions, the faculties of the soul are treated. Since a faculty is an aptitude to work, I infer that our soul creates its own subject matter with each of its faculties as colors with sight, odors with smell, sound with hearing, and so on." 33 Sensible qualities are for Vico subjective qualities, without any fundamental value for the sciences. To rely on qualities as the criterion of judgment it is of a coarse mind. Many pagan philosophers were slaves of this illusion, which made them no different than the multitude of idolaters and simpletons:

In fact, there was no sect of gentile philosophy that recognized that the human mind was free from all corporeity. Hence, they thought every work of the mind was sense; that is, whatever the mind does or undergoes derives from contact with bodies. But our religion teaches that the mind is quite incorporeal, and our metaphysicians confirm that when the bodily organ of sense are moved by bodies this is an occasion for the mind to be moved by God. ${ }^{34}$

This important text signals the union between the criticism of the sensible qualities and the analysis of the primitive pagan mentality in The New Science. The gentiles made the error of considering real the sensible qualities. They made the error of interpreting a fact proper to a particular sphere of reality like that of sensitivity and res cogitans (mind), as if it were a fact of another dimension of reality, as if, for example, colors were really of the bodies that the subject perceived as colored and res extensa (body). We could say that the gentile philosophy is essentially an objectification of sensations or, with Vico, a homonymy and an equivocation, as when we avoid the distinction between olere and olfacere. Vico mentions the correct interpretation that must be adopted, the Christian one, and that of "our" metaphysicians. Who are the metaphysicians whom Vico calls "his" at this time? Evidently, Malebranche is among the mentioned metaphysicians. Vico appears, therefore, to accept the presupposition, which he characterized as "Christian" more than as "Cartesian" of the complete immateriality of thought and the consequent real distinction between the mental and the corporeal. Furthermore, he opposes the Malebranchean occasionalism to the fatalism of the gentile philosophers.

\section{Analysis of Primitive Mind}

What does it mean to analyze the primitive pagan mentality? This point is extremely delicate. To analyze the pagan mentality means first of all to study a form 
of thought that is immerse in corporeity, that does not distinguish in a clear manner what is of the body and what is of the spirit, or, we may also say, that misinterprets as real the sensible qualities. In order to understand, as Vico does, that the pagan mentality commits this kind of error, we necessarily must place ourselves in a perspective that firmly and stoutly hold on the differentiation between what is proper of bodies and what is characteristic of minds. Only after having differentiated between corporeal reality and thought, we can state that the subjective qualities are qualities of the sensing subject, and then recognize this error in the thought of other thinkers. An Aristotelian will never be able to criticize the conception of sensitivity of another pagan philosopher, because by sharing the same basic tenets, it is impossible for the Aristotelian to move outside of the habitual perspectives and critically judge the pagan conception.

If we wish to judge, to analyze, and to study the pagan mind, we must adopt the viewpoint of the Christian mind with the principles of the Christian religion. These principles say that nothing corporeal exists in thought; that our body like all the other bodies is an automaton; and that the sensations that our soul experiences have their real cause in the divine will, which provokes specific sensations in the soul at the occasion of specific movements in the body. We have to be Christians if we are to judge the error of the idolatric religions of the pagans, because only faith and Scriptures can give us the true light for the comprehension of the darkness of superstition. We have to be Cartesians in the debate on sensible qualities, if we are to identify the philosophical errors of the Scholastics and Aristotelians. We have to be adults, if we are to analyze the mentality of an infant because the infant lacks the terms of the comparison. Thus, Vico spoke. We have seen the usefulness of the forms; let us now analyze the damage produced by the universals. "To speak with universal words is proper to babies and savages" ( $V i$ dimus utilitates formarum; nunc universalium damna exequamur. Loqui universalibus verbis infantium est aut barbarorum). ${ }^{35}$ The achievement of a philosophical maturity will warrant for the ability of judging scientifically the pagan mind, in the same way that the achievement of adulthood warrant for the recognition of what is characteristic in the thought of children. Aristotle and all ancient philosophers did not think of themselves as having a pagan mentality. For the Greeks, savages and gentile were the non-Greeks. But not even the non-Greeks could think themselves as pagans since they did not exist in opposition to the Christians. For the Scholastics, the ratiocination on this topic is the same. If they could think that the principles of their physics and their scientific methodology were superstitious, if they could recognize that at its roots their philosophy was pagan, they would certainly have refuted it. Vico moves closer to the Malebranchean perspective in all his criticism of the pagan thought. 


\section{Conclusion}

Going back to the question of the Aristotelian genera, we can conclude that the philosophers who assume a pre-constituted criterion for judgment end with an absolutism of interpretation in all things, through that criterion. This absolute criterion would become a screen through which all things are seen in the same color, so that at the end it becomes impossible to distinguish what things are and what instead depends from the manner of looking at them. The genera are a criterion extrinsic to the matter to which they are applied, so that at the end the concern is greater for the integrity and coherence of the philosophical system than for the comprehension of the things.

On the whole, in jurisprudence errors arise frequently under the influence of positive law or under the authority of rules. In medicine, those who carefully follow the book work harder at keeping their medical systems intact than at healing the ill. How often human beings sin in the business of living because they arranged their life according to their general maxims! Just for them we have brought into our vernacular a Greek word, themati$\cos$, so that we can call them "dreaming theorists, and idealists". 36

The efforts to fit into rigid rules the real life actions and situations are barren and leave unresolved the implicit anthropological and scientific problem. People who challenged reality with their credences and prejudices deceive themselves. Students who interpret natural phenomena by reconstructing them in their preconceived categories deceive themselves. As Descartes in the letters admonished Princess Elizabeth, we should select among the things we know and pay careful attention in applying to each of them always and only the methods and procedures naturally suitable to them. Vico, too, advised us: "This is what I reiterate in many places: that those who want to employ formed things as the standard of the formless ones are on the wrong track." 37 



\section{SIX}

\section{THE MOST DANGEROUS ERROR OF THE ANCIENTS}

It is possible to indicate exact parallels functions between the poetic true of Vico and the Malebranchean thematics on the verisimilitudes. The verisimilar is the poetic truth of the "carnal human being" of Malebranche in the same way that the poetic truth of the Vichian theologian poets is a form of verisimilitude in the Malebranchean sense. Vico and Malebranche have affirmed that the pagan mentality attributes some particular beliefs to the verisimilitudes. While Vico proves it using what he calls a poetic logic, Malebranche, instead, uses a form of erroneous thought that shatters all the rules of the logic he formulated in the rules for the identification of error.

Malebranche sustains that all pagan thought interprets nature through an erroneous attribution of meanings. This work of distortion follows a definite logic that for Malebranche is identifiable with the Aristotelian logic. The Aristotelian logic used in this work of interpretation of nature is not that of the Prior or Posterior Analytics, of the syllogism and principle of non-contradiction (the first considered useless in science, the second obviously acceptable), but the logic of the Physics. ${ }^{1}$ Malebranche declared that the Aristotelian physics is a pure logic, not in the sense that it is an exact logic, but in the sense that it is a formal logic, a theory of deduction that constructs on manifest principles and canons of reasoning. In The Search after Truth, he said:

[Pre-Cartesian philosophers] pretend to explain nature with their general and abstract ideas, as if nature were an abstract entity. They also hold fixedly the idea that the physics of their master is a true physics that goes to the bottom of things. For them, this physics is not a simple logic, though it has nothing of substance except some vague definitions and some generic terms that make it applicable to any kind of philosophy. Furthermore, they are so obstinate about all these imaginary entities and vague and undetermined ideas that spring up in their spirit that they are 
incapable of relaxing and taking enough time for the purpose of considering the real ideas of things and acknowledging their solidity and evidence. ${ }^{2}$

The logic of the Aristotelian Physics is the philosophical sublimation of the logic of all humanity, considered as unlearned and pre-Cartesian. The logic that is included in the Aristotelian physics is the logic that Malebranche has fully rejected. It is an erroneous logic with its theory of deduction, its principles derived from the observation of the natural world, and its substantial forms. These are all structural deceptions perpetrated by the mind to itself. It is the same logic that can be found in the superstitious and idolatric mentality, a logic born from the senses and nurtured by the imagination.

Descartes alone, says Malebranche, has clarified that sensible qualities are not in the objects, but they are the modalities under which we perceive the objects. ${ }^{3}$ Descartes alone has given us a convincing theory of error, fruit of his metaphysical position, in as much as it distinguishes metaphysically between the ideas of the body and those of the mind. Only now we can distinguish, Malebranche affirms, between true philosophy and pagan philosophy, which, in the best of the hypotheses, is only verisimilar. The chapter in The Search after Truth titled "The most dangerous error of the philosophy of the ancients"4 deals with the same problems we are discussing in this chapter, though in a more summarizing form..$^{5}$

We may briefly state that error is the consideration of the possible existence within matter of some entities that are conceptually distinct from it, but nonetheless present and active within it. This is the psychological origin of the conception of the substantial forms; matter is viewed as alive, as something apt to having intentionality, a will capable of producing some effects. ${ }^{6}$ The principle derived from this rapport between what our senses tell us is the cause and what represents the effect, is the principle of natural causality. An object, in other words, according to the pagan viewpoint, would have the capability of directly acting on another object; it would have the force of modifying it. 7 The succeeding step of Malebranche is that of pointing at the correlation between the conception of a natural causality and of that of the divinity, pagan or not. We will limit ourselves to the consideration of the logical origin, anthropological and cultural, of this natural causality in relation to the conception of the substantial forms.

The questions of the original Fall, the pagan mentality, the error, and the criticism of substantial forms attained a new significance in Malebranche since the acquisition of the new Cartesian view. The particular attention for the original sin in Malebranche's metaphysics caused no opposition to Descartes, who kept himself aloof from this topic. The theory of the original sin in Malebranche is strongly related to and is descending from Descartes's efforts to cleanse matter of vitalism. It was with Descartes that it was decided what truly pertains to either body or mind, that we obtained an adequate criterion for the relation cause-effect, and that 
the foundations for the building of a valid theory of error were laid down. Descartes, especially in the moral and theological fields, would not deduce all the possible conclusions, but Malebranche for his own purpose stepped ahead in the direction traced by his teacher.

The theory of natural causality and the conception of the substantial forms include the principle of idolatry and sin as far as they constitute the structure of a mentality that produces a kind of contorted, inflexible, and inescapable thought. These elements incline the obtuse mind of the pagans to conform to an animistic vision of nature that sees in all physical events the effects of one or more voluntary powers present in the corporeal things. This is the consequence of the human Fall from Eden, though it cannot be said that those who possess a pagan mentality would automatically commit sin or show a wicked or corrupt individual nature. The pagan mentality is not the cause of the possible transgressions and misbehavior in those who have it, but the effect of the naturally sinful human nature after the apple's bite of the first parent. We all have a pagan mentality, but it must be corrected with the Christian religion and the Cartesian philosophy. Our life is not a full sequence of sins because of the continuous errors in our interpretation of nature. Our life remains whole and righteous, if we make good use of our intelligence, use occasionalism in reasoning, recognize nature following divine rules and God operating by the simplest and most general means, deny vitalism in matter, and read the Scriptures in order to find the spirit beyond the words of the Scriptural text. The theory of the original sin in the works of Malebranche is only comprehensible in the light of the Cartesian philosophy. Malebranche often repeats that it is in this light that his analysis of the idolatric conceptions has to be seen:

If we come thereafter to consider attentively the idea that we have of cause or of a power of action, we will not doubt that this idea represents something divine. In fact, the idea of a sovereign power is the idea of the sovereign divinity, and the idea of a subaltern power is the idea of an inferior divinity, but still of a true divinity, at least according to the thought of the Pagans, whether or not it is the idea of a true power or cause. ${ }^{8}$

In the passage above, like in a nutshell, we see the web of relationships between pagan deities, natural causality, and substantial forms. ${ }^{9}$ The logic of error rests on two principles intimately correlated: the inference through natural causes and the consideration of subjective qualities, qualities proper to the manner of perceiving of the subject, as real qualities. The logical error of both principles derives from the confusion between the proprieties of bodies and those of spirits and the attribution to bodies what is of spirits and vice versa. Princess Elizabeth learned this in the letters from Descartes, letters whose topics Descartes developed in the Principia philosophiae. To explain a phenomenon by way of natural causes means to admit 
in natural things deliberate powers capable of voluntarily act and modify other things. Pagan thought found its origin in the classic thought, especially in the Aristotelian one, which manifested its most abstract and complex aspects. We can find pagan thought also in forms of thought that are simpler and more elementary than the Aristotelian one because even in them the pre-Cartesian philosophical reflection with its basic colors is visible.

The unlearned and the Aristotelian philosopher agree that in the objects that surround us those qualities exist that we with our senses perceive and enjoy. The savage as much as the most refined pre-Cartesian scientist would speak of snow as truly white, heat as warm, and matter as ready for action. Malebranche affirms that the pagan thought is a thought constructing on sensitivity even the ideas that represent extreme abstraction, universality, and rationality, such as the ideas of God, cause, and infinity. They are ideas that in the pagans have no speculative substance and that are completely immersed in matter to which they give life and of which they are the forms. On the contrary, if the mind is immersed in sensitivity, then the natural world will shine with intelligence. Forms, faculties, powers acting in nature, entities that animate nature and reveal intentionality in every phenomenon will be thought. The link between natural causality and the idea of idol can be found in the power of action that things are thought to have. The intentionality in the natural events induces the pagans to assume that one or more deities manifest themselves in nature and through nature. The power of action is so sublime that can be considered as divine. When the pagan looks at nature as an animated body, at things as empowered with action, he is necessarily projecting his thoughts into a divine sphere, divine, and mythical. Malebranche notices that the pagan mind with the act of thinking evaluates the observable quantity of force that things possess and makes a classification of the different gods. To a feeble event in nature will correspond a lower god with an inferior force; to a physical extraordinary phenomenon will correspond the most powerful and superior god: "We admit therefore something divine in all the things that surround us, when we admit that some forms, faculties, qualities, virtues, or real beings are capable of producing certain effects given the power of their nature. In this way, we glide gradually within the sentiments of the pagans whose philosophy we respect."10 Malebranche's hypothesis makes another step forward because for him, the idea of idols is an idea connatural to the human mind and because it is, in the psychological sense, the first idea of divinity that the human been formulate, it is the idea of a pagan god. The criticism of natural causality turns into a criticism of idolatric religions and, specifically, also of the myth of Jupiter. For Malebranche as for Vico thereafter the idea of Jupiter is psychologically antecedent, in the pagan mind, to the idea of the true God and to the ideas of all other idols. ${ }^{11}$ We should think of it as of a logical and chronological derivation. 


\section{The Idea of Jupiter and the Idea of God}

The universality of the idea of God refers to rationality, while the universality of the idea of Jupiter refers to imagination. The universality of Jupiter is a universality felt and imagined. ${ }^{12}$ In the Malebranchean argumentations, the Cartesian conceptions of error are connected with the criticism of the substantial forms, and the substantial forms are linked to the criticism of natural causation. In the same argumentations, these theoretical elements are applied to the criticism of the pagan mentality. This entire ratiocination centers on the principle of causality as either true or false. A true cause is always the one of which we can conceive in an evident manner a necessary link with the produced effect. ${ }^{13}$ The pagan thinker imagines necessary bonds of causality where there are none; mistakes the infinite power of God for the impressive effects of nature; uses individual rudeness as the meter and principle for knowing and judging reality; ${ }^{14}$ and confuses the general idea of cause with the indefinite idea of effect. ${ }^{15}$ At the philosophical and anthropological levels, the ideas of natural causation and substantial forms are the interpretive norms of the pagan mind that fatally must conclude with the idolatric conception of divinity.

The criticism of substantial forms, natural causality, and anthropolatry originated in the modernity, and Spinoza on these themes has views similar to those of Malebranche so that it would be improbable to assert an exclusive approach of Vico to Malebranche. It is not Spinoza, but Malebranche who constructed a complex and complete theory of pagan mentality, provided a conception of imagination as no other contemporary philosopher did, and succeeded to systematize substantial forms, natural causation, pagan mentality, and imagination in a systematic critique of idolatry. In addition, Malebranche alone inserted into his system the myth of Jupiter as the fundamental and essential idea (as the fantastic universal) of the pagan mind, and showed the dependency of all other ideas from that of Jupiter.

For Vico, too, the notion of the pagan mind rests on the principles that Malebranche proved: natural causality and substantial forms. All the information about the world that the human soul receives comes from the senses. ${ }^{16}$ When the intellect is too weak and unable to order its perceptions, sensitivity takes free reins and disposes the intellect to miscalculate as animate, alive, willing the same reality that is only imagined. It is on this comprehensive fiction that the pagan mind builds its own metaphysics, in which the relation of cause and effect is a direct and real action and matter possesses in itself the principle of existence and determination. God alone has the power of self-determination and direct action, Vico suggests, fully conforming himself to the perspective of occasionalism. God alone can really arrange what the pagan mind imagines that nature can do.

The explanation of natural phenomena unknowingly proposed by the pagan mentality and, in a conscious manner, by Aristotelianism, is a vulgar 
metaphysics. This metaphysics is built on the mode of the common sensation, the prejudicial conception that of nature have the ignorant people, those who interpret reality in a superficial manner relying on imagination and sensitivity and do not ask themselves how and why they think the way they do. Vico wrote: "The natural science of the ignorant is a sort of popular metaphysics, which explains the unknown in terms of God's will without considering the means he uses." 17 The ignorance of the real modes with which God acts equals the un-acknowledgment of the limits of the human mind with the result of attributing to nature the power that only God possesses. In this case, the error is the belief that idolatry shaped itself and that human beings began to believe in false divinities simply because they are gullible or someone smarter among them took advantage of their gullibility through idolatry and profited from it. For Vico, as Malebranche suggested, the presence of the false divinity in the pagan mind is due to the precise needs of the human spirit. In The Search after Truth, idolatry exists only when the pagan mind makes the inference of natural causation and conceives nature with the interpretive scheme of the substantial forms. ${ }^{18}$ Malebranche provides exact philosophical coordinates so to attain the psychological genesis of superstitions and false religions.

To believe that the fire is hot and the snow white is an idolatric conception of reality: without this assumption, human beings would never have reached the point of seeing deities present in nature. Without the powerful predisposition to the consideration of subjective qualities as real, human beings would not be the credulous simpletons they are: "False religions were born of people's own credulity, rather than impostures of others."19 The deceit into which the pagan falls is self-imposed; there is no hidden puppet maker, who pulls the strings of the heart. Original sin is actually the orchestra director since it left its mark in the soul of humankind. Idolatry is not an easy moral disease that can be isolated within the human soul; it is not the joke of a clever fakir who will take advantage of people's gullibility. On the contrary, primitive human beings followed a logic based on the relations of sensible similarities; they identified and diversified things in the direct proportion that their imagination recognized similarities and dissimilarities in them, and combined what they believed concretely in things with the way of perceiving them. The deity took shape in the primitive mind starting from this logic perfectly congruent with sensitivity and the panes of imagination. ${ }^{20}$ The divine substance must be considered in this same way: all nature is made with divine essence; everything is divine because alive; Jupiter is everywhere because nature is manifestly alive everywhere. ${ }^{21}$

\section{The Idea of Divinity and Idolatry}

No priest, no sharp metaphysician could insinuate the conception of idolatry with these characteristics in the human mind. To do this, the priest or the metaphysi- 
cian should have had the ability to create a forma mentis (form of thought), but priest and metaphysician are themselves the product, as all believers, of this form of thought. The idea of divinity in the pagan mind is born through a process of thought totally opposite to the one we are inclined to expect. In order to think of divinity in an easier manner, we ask imagination for help and then represent divinity as painters do, in a symbolic form. Imagination symbolizes divinity, but we know very well that divinity has none of the limitations with which we represent it. For our use, we locked an absolute thought within the outline of a figure, even though thereafter we could abstract from such figure to grasp the pure thought. The primitive mind could not do this. In the primitive mind, idolatry is born simultaneously with the thought of reality. Idolatry is to think reality without the help of the intellect. 22

Idolatry and myths cannot be understood in the same way than the euhemerists or as the product of a symbolizing metaphysical mind. This method of understanding the deception of idolatry is for Vico an error of superficiality that an anthropologist should never make and that, unfortunately, every interpreter of myth up to Vico's time made. Idolatry is one of the errors and deceptions into which it is possible to fall, but it is also the vision of the entire reality that is rooted on a forma mentis. Idolatry is a comprehensive error into which the pagan necessarily falls, at the doorsteps of intelligence. It is through the idolatric illusion that the human being begins to think. Then, idolatry is the total vision of the world surrounding the primitive pagan mind, according to which the mind judges everything: "These people now believed that everything they saw, imagined, or even did themselves was Jupiter. And they endowed the universe and its parts with the being of an animate substance. This is the civil and historical meaning of the poetic tag 'all things are full of Jupiter', Jovis omnia plena." 23 Jupiter is everywhere because everything is thought through Jupiter. Idolatry is not juxtaposed to any other perspective or to an aseptic vision of reality that ends with contamination, but represents the unique propulsion of a thought in formation. Idolatry is the mind itself in its full vigor, the conception of the mind immersed in body, the inability of discerning what is corporeal and what is mental. Idolatry is to make credible the impossible. It is impossible for corporeal entities to have intelligence and will, but not so for the pagan mind that thinks nature animate and all marvels of nature manifestations and essence of the divinity. ${ }^{24}$ Vico's position is close to that of Malebranche who reproached the Aristotelians for constructing an impossible doctrine of substantial forms. Malebranche teaches that the two doctrines of natural causation and substantial forms on which Aristotelianism and idolatry are based do not reach conclusively an animistic conception of all creation, but the two doctrines derive from the vision of animism and vitalism in creation. The physical theories of Aristotelianism are not the cause of idolatry but one of idolatry's various effects. Aristotle built the physics according to his own pagan mind; his theories are the effect and not the cause of his error. Like any other pagan, 
Aristotle changed the impossible, the vitalism of inert matter, into a credible doctrine in his scientific treatises.

In the Vichian bestione the form exists of a mentality that, in its basic traits, is perpetuated in the history of humanity up to our days. What modern mind possesses is the capacity of abstraction that the bestione could not have. Abstraction is an ability that humanity acquired at the price of continuous errors. The primitive had no abstractive faculty but a strong imagination. Vico speaks of a strong imagination when he refers to the theologian poets. He does not mean an imagination capable of imposing itself to the intellect because of its special strength. The imagination represents to the mind a reality invested by myths that are fantastic and multicolored as we can testify when we think of myth. The imagination of the theologian poets is not of the same kind that we need when we think of hell while reading the Divine Comedy of Dante. This imagination is extremely developed, pliable, symbolic, and calls up from the depth those mental capacities that are inexistent in the primitive pagan being.

The theological poets thought that through the divinity matter in things has the power of acting. ${ }^{25}$ The divinity of things consists in the faculty of things of having sense and passions, pain and pleasure, and a will as the human beings possess. The unaware human beings see themselves in things and nature as in a mirror, but they do not recognize themselves in the reflection. Thus, they take their own image in things and nature to be a different entity than they, indeed, a divinity. ${ }^{26}$ The poet looks at himself in nature, but is unaware that what he sees is only what he has depicted of himself. This incomprehension of the world invites the poetic theologian to construct an idolatric notion of reality. Vico's principle is that the more ignorant the human being, the more of verities it misses; it becomes more poetic and the creator of an explanation that would fill up the void of ignorance in its conscience. "Now, rational metaphysics teaches us that man becomes all things through understanding, homo intelligendo fit omnia. But with perhaps greater truth, this imaginative metaphysics shows that man becomes all things by not understanding, homo not intelligendo fit omnia. For when man understands, he extends his mind to comprehend things; but when he does not understand, he makes them out of himself and, by transforming himself, becomes them."27 Malebranche, too, reached this identical conclusion while analyzing the modes of proceeding of the pagan mind. The principle explains how the passage happened from a form of thought extremely simple and rude like the original monotheism of the cult of Jupiter to the more complex forms of idolatric thought. Imagination becomes the fabricator of thought using what it does not know. It is a shocking reversal. Knowledge is the effort of moving from the known to the unknown and making the unknown known; but the pagan mind moves from the unknown and immediately creates the known extracting it from what fully remains unknown and obscure. The Vichian principle makes it clear why the pagan mind chose the natural causality and the substantial forms as the explanatory basic elements of reality; 
why it was obliged to select such liable and obscure points of coordination that in the abstract re-elaborations of the Aristotelianism became more complex. The pagan mind with the help of imagination tries to bring light into its absolute mental darkness, but not comprehending reality uses theories that are even more incomprehensible. Man, the more ignorant he is of the surrounding world, the more he creates fantastic things in order to make sense. The more difficult becomes the material situation, the more the fantasy would fly higher, and the intellect would abandon its hold on the conscience that is affected by passions. If this is true for the modern man, how much more would it be for a primitive whose intellect is atrophied? Is it right to suggest that it would be more logical to react to the incomprehensibility simply with a utilitarian answer that would point to the satisfaction of primary needs? The consonant question, in the Vichian and Malebranchean perspective, is different. Why is it that the idolater experiencing an atmospheric phenomenon of particular intensity of which he has no explanation begins to picture the probable divinity that performed that natural show for the senses? Why is it that instead of imaginatively inventing a divinity, the idolater does not imaging a practical use of the phenomena for a utilitarian purpose? Malebranche reminds us that the pagans in the culturally evolved societies are still vexed by these and other similar questions. ${ }^{28}$ Malebranche's answers provide a psychological theory of the gnoseological principle of Vico (homo non intelligendo fit omnia), a theory that is also the interpretive canon of the pagan mind: "Oh, how much the things that are obscure and incomprehensible seem to be better connected to each other than obscure things to those that are clear and intelligible! The incomprehensible principles are more useful in every complex question than intelligible principles." 29 When the pagan mind interprets an incomprehensible phenomenon with an even more incomprehensible theory, it adds obscurity to obscurity. To move out of obscurity toward clarity is something that became possible only since Descartes. The pagan mind in its errors, immersed in sensitivity, goes from obscurity to obscurity, and moves from one incomprehensible effect to an imaginary cause, living in a fantasized reality. The human mind, because it is without the strength needed in order to find clarity within itself and thus see God in itself or itself in God, fabricates some deities made to measure, cuts them out of its imagination and with them lives in tremors and fears that produce the sensation of living.

The natural disposition for idolatry is possible only because of the easiness with which we enjoy our made up phantasies that, though they are more obscure than the things they supposedly meant to explain, come to mix up with passions and sentiments in order to satisfy the hunger for imaginative knowledge. What the imagination wants to know is greatly different from what the intellect must comprehend. The pagan mind inclined by its own ignorance takes refuge in the primordial and infantile needs of its own passions and fictions. ${ }^{30}$ The activity of the imagination is always a form of thought that like all the others has its own ef- 
fects that would produce usages, customs, and forced rapports among human beings. The pagan mind, even through an erroneous logic, even following infantile phantasms that all life long toss their shadows on the path of humankind, continues to produce a thought, but a thought that makes it a prisoner of corporeity. Following the stimulus of their passions that they support with their thought, the pagans in mind and heart get scared and prostrate before the divinities produced in their twisted and obtuse imagination. ${ }^{31}$

Because the pagans do not comprehend reality, they find themselves in the darkness of their conscience, in which they found no bottom, no point of orientation, and therefore imagine abysses, fearful precipices, terrible monsters that hide in the darkness of their mind and are ready to jump out to assault them. The unawareness of the limits of their mind is at the origin of all the tricks of the imagination that the idolaters suffer. To be ignorant of the phenomena of nature is human because our intellect is finite, limited, and lives by reflected light, while nature is the work of an infinite mind, which has no limits of comprehension or action. The true ignorance that makes us fallible is the ignorance of ourselves. Though it cannot justify itself and comprehend its nature, the human being has the gift of an intellect capable at least of defining its own fallibility. The idolaters, on the other hand, do not penetrate the darkness of conscience and realize their inability of comprehending it. They descend into that darkness with prideful arrogance and prostrate themselves before the ghosts they created, assuming a rigid and wicked behavior. ${ }^{32}$ The awareness of personal fallibility is the unique medicine against fallibility, but the fallibility of idolaters, hypocrites, and superstitious people is so overwhelming that they have not enough strength to face or control it. A profound and secret pride inflate their souls and in the fog of their false wisdom they become foul, fanatical, visionary, victims of their phantasies and at the same time prone to slaughtering any opponent. The unawareness of the gullibility of the individual spirit is the fundament of error and transgressions. Malebranche noticed that when the spirit is weak, it creates ghosts before which to kneel with idolatric devotion, but also fabricates a theology directly proportioned to the paucity of its mind:

The most dangerous result of ignorance, or rather of inadvertance to the weakness and limitations of the human mind, and consequently to its inability to understand what belongs to the infinite is heresy. More now than at any other time, it seems to me, there are many people who create their own theology, based on nothing but their own mind and the natural weakness of reason, because even in subjects not under the jurisdiction of reason, they wish to believe only what they can understand. ${ }^{33}$

Malebranche places in antithetical terms the finitude of our imagination and the infinite reality of God. The human being has always tried to find a shorten way to 
the union with its Principle, but not always has muddled itself falling in error or transgressions. The historical period in which we live determines the greater diffusion of a particular heresy rather than of a particular form of idolatry. The axiom says that "human beings want to believe only what they understand," and what they understand changes from one age to another. ${ }^{34}$ Human nature after the Fall from Eden is uniquely of one kind: it is a pagan nature that sees a phantastic world and believes in an idolatric deity. When this pagan nature steps on the philosophical path, it advances carrying a load of prejudices, on the way that instead of bringing to the peaks of truth stops in the absorbing marshes of heresy. "But heretics are not the only ones who lack attention in considering their mind's and who allow their mind too much freedom in judging things not under its jurisdiction. Practically all men have this fault, especially certain theologians in recent times." 35

\section{Idolatry}

Idolaters and heretics essentially share the same pride: the presumption of judging what in an absolute manner is superior to the ability of their weak intelligence, God. Theologians and common folks fall into the same errors. Not considering the weakness of their mind, they feel apt to comprehend the nature and intentions of the Divinity. They diminish their idea of divinity to please the unstable flow of their passions and inclinations, rather than raising themselves in faith toward the true God. The idolatrical religion they create becomes the instrument with which human beings form their mentality, structure their thought, assign a meaning to reality whose true significance they mistake, and confer a specific value to their actions. In this way, life still may assume a meaning, though with a false value, which fills up the void that anxiety, anguish, and even terror have generated.

The religion formulated in the passionate conditions of these human beings is a religion that conforms to their scarce intellectual capacities and that has the effect of reinforcing their mentality. ${ }^{36}$ This would create the vicious circle between idolatry and passions which reinforce each others and all together baffle the imagination. The pride of the false doctors and prophets of the pagans, giving free hand to all their secret ambitions of a corrupt heart and an obtuse and confused mind, produces the mentality that proudly grows in the fertile ground of thought about religious problems. Idolatry: is the point of departure of the pagan mentality, a form of religion that can be rude, coarse, and simple, but after having reinforced its principles, it may widely expand with complex and subtle ratiocinations. Time and the capacities of the single human beings would determine the nature and the path of this imaginative developmental expansion, and the complexity and refinement of the thought that within it is circulated. The imaginative process of the pagan mind is opposed to the one that allows us to contemplate the 
authentic God in the intelligible extension. In this second process, the human mind eliminates every residues of imagination from thought, denies every representation, and discovers in itself an unlimited extension. The human mind annihilates then itself in the intelligible extension, discards all thoughts concerning the union with the body, and think God directly through the light of divine intelligence. This human mind surrenders itself to an infinite mind that comprehends the human mind together with the whole universe; it does not transform or falsify the veritable idea of God reducing it to a static image. The human mind can contemplate the divine intelligence, but this contemplation is passive and does not add to or remove anything from the way God manifests Itself; it is active in deracinating the prejudices and in removing all the representations, passively receiving the light of the divine intelligence. When the human being acts and constructs a religion, we can be sure that this religion is a product of imagination, because only with the imagination the pagan mind can produce something. This new something is a false divinity. ${ }^{37}$

Idolatry is the product of a conscience that does not know its own limitations, of a mind that is fed in the unawareness or inadequate awareness of itself and the surrounding world. A pagan religion is the effect of the pagan who ignored the real extension of its own mind and judges about what is beyond its capacity for action. What this pagan would think would be determined by the boundaries of its mind, limited by and with them. Idolatry, considered as theory and practice of qualifying deities, gives the idolater the illusion of having reached the beyond. As the human pride stands like the judge of divinity and like any judge feels superior to what is judged, so the idolater unconsciously makes itself a divinity determining essence and existence of what is divine. Pride elevates the human being above nature, but in an illusion. The contents of these human credences will not go beyond the limits of the human mind and will dry up in the arid, infertile fields of the conscience that created them. For this reason, Vico sustained that the Jupiter of the theologian poets inhabited a place no higher than the mountains and the sky they used to see. ${ }^{38}$ Where at last the peak of the mountain and the line of the sky could still be perceived by the sensitivity of the theologian poets, there the perception of the theologians stopped, their imagination faded away, and their understanding vanished.

\section{Anthropolatry, Anthropology, and Humanization}

Retracing our steps, we are going to make some conclusive considerations. The pagan mind for both Malebranche and Vico is obscure and can formulate only obscure principles for the interpretation of the real. The system of knowledge that the pagan mind constructs originates from a total ignorance of the world and of itself, and the more the pagan mind ignores the more daringly it makes its judg- 
ments. As in the domino effect, the pagan mind creates thoughts after thoughts that are fantastic and unable to penetrate reality. The logical processes that this mind follows in building the palace of its memory derive from the two principles of the natural causality and substantial forms, on which it fabricates, in the absence of true thoughts, a fantastic thought. Both philosophers consider idolatry, before its cleansing from prejudices with the help of philosophy, as a natural disposition of the human spirit. The human being naturally believes in an idolatrical religion, deduces from natural causes, and thinks reality in substantial forms. These principles constitute the logic of the pagan mind. The knowledge they produce will reflect the nature of the human mind instead of the nature of the reflected objects. Vico shows the logical ties of a poetic logic that combine anthropolatry, natural causality, and substantial forms: "When people are ignorant of the natural causes that produce things, and cannot even explain them in terms of similar things, they attribute their own nature to them. For example, the masses say that a magnet 'loves' iron." ${ }^{39}$ This argument is the necessary premise to the note of the first axiom of the Vichian anthropology. The pagan mind creates itself when thinking of the other than itself, of what stands before it, the world. The post-diluvian conscience begins thinking by representing the world that sensitivity presents. How is this conscience thinking of the world? Conscience thinks of this world not as it is but as the representation of the totality of images which constitute the world, and into this fantastic wholeness conscience sinks: "By its nature, the human mind is indeterminate; hence, whenever man is sunk in ignorance, he makes himself the measure of the universe." 40 The world is interpreted through the domineering elements of the pagan psyche, that is, the sentiments and passions free from the control of the intellect. Imagination is the queen of interpretation of all representations and reality is totally and only represented. The universe is the universe of the imagination governed in its dynamism by the structures of the imagination. The universe becomes the mirror of the pagan mind and to study the pagan physics equals to studying the psyche that produced that physics. Vico asserts that the mind is essentially a producer of laws, because every form of thought, no matter how crude, has its logic, a complex of laws that rules over the course of thought. The laws that the pagan mind believes are running reality are instead the hypostasizing of the laws the pagan mind assumed for itself and which govern its own flowing thought.

The first Vichian axiom recalls to memory the criticism of anthropolatry done by Malebranche and all modern philosophers. What distinguishes the criticism of Malebranche from that of the others is that his criticism develops and grows within a complex theory of the imagination, which has no equal in the seventeenth century. Jupiter is for Vico the rule of the universe seen from the viewpoint of the theologian poets. Jupiter is the product of a legislative imagination and, in synthesis, a fantastic universal that causes all reality. Similar to that of Vico is Malebranche's position, whose idea of Jupiter is the humanization of the 
cause. For Malebranche, all pagan mythology stands as the proof that when the human mind goes sinking into ignorance, makes itself rule of the universe. In $\mathrm{Di}$ alogues on Death, Malebranche speaks to Ariste, that is, to Malebranche:

Dear Ariste, human beings humanize all things, even the divinity. They attribute to the divinity human thoughts, human conduct, and sometimes their own passions. Think of the examples: the adultery of Jupiter, the anger of Juno, and the larceny of Mercury. To judge according to what one feels is effortless, but for a serious meditation on the ideas we may have it takes effort, pain, attention, work before judging. This is why we honor our dog, attributing to it the knowledge and the gratitude itself, and the quantity of inclinations and projects similar to the ones we feel. We also feel firmly that the ants have foresight and wisdom and the bees have a marvelous political system. In one word, we attribute to all causes, whatever their nature may be, characteristics that are similar to our own. This is the most dangerous principle of errors. ${ }^{41}$

We humanize the final cause and mistakenly take it for the particular causes, and finally the notion of Being is for us the notion of beings, attributing divinity to the sky, which is only one being and not the Existence Itself. Passions and sentiments, which have a propulsive effect in the cognitive process, participate in this work of mystification. Forcing limitations upon the Infinity, trying to represent what by nature is unrepresentative, the pagan mind humanizes reality fusing into one single thought divinity, cause, physical objects, sentiments, and the idea of Being. In Dialogues on Metaphysics and on Religion, Malebranche addressing Theodore, the primary spokesman in the dialogue, says,

Oh my dear Theodore, how difficult it is to separate the notion of Being from the ideas of these or those beings! It is so difficult to avoid applying to God what we sense within ourselves! At every moment, we are humanizing the divinity: we by nature are confined to reducing the Infinity. The fact is that our spirit wants to comprehend what is incomprehensible: the human being wants to see the Invisible God. The human spirit searches for this God in the ideas of the creatures, but it stops at its own sentiments; they touch the human spirit and penetrate it. All this is too removed from being capable of representing the divinity! All those who judge divine perfections with the sentiments that they feel within themselves, make strange judgments about the attributes of God and Its adorable Providence. ${ }^{42}$

Though the idea of God is profoundly alive in our being, we conceive what happens within our vital space with the sensitivity we have, and interpret it through 
the motions that agitate our being. ${ }^{43}$ Our mood is the official painter that paints our representation of the world, with the colors of our passions we think nature and with strong colors we reduce to an icon the substance of the divinity. The divinity then becomes a being with human wishes and intentions, but with a greater faculty for their realization, a being gifted with the maximum power, a power that is limited only by the conception of force that the imagination may imagine. Again, in Dialogues on Metaphysics and on Religion, Malebranche explains, "All the human beings who judge of things relying on their experience or sensations instead than relying on the ideas that represent the things, transform the objects into something that is similar to human beings. Thus, the human beings make God act as the human beings act; attribute to beast what human beings feel about the beast; ascribe to fire and other natural elements the inclinations of which they have no other idea than the one in their conscience. In this way, the human being humanizes everything." 44 



\section{SEVEN}

\section{THE BIRTH OF THOUGHT}

According to Malebranche, it is with the imagination that the human being assigns value to things and all material objects. The individual person produces the logic of values modeled on fantasy. Each person constructs a range of values obtained from the sensible qualities, the verisimilar possibility of satisfaction of specific desires, and adaptable to definite personal inclinations. Each life runs like a river between the riversides determined by the range of this ladder of values. Fantasy depicts a world in the mind of every human being, a world presented every day in a new form and adapted to the new circumstances, an unreal world whose values are false and worthless.

\section{The Deceptions of Imagination and Fantasy}

Nature has provided us with imagination so to be able to represent the world to ourselves, but the human nature is provided also with reason and will, the faculties that amend the distortions of the imagination. The deceit of the imagination does not consist in the prospect of the acquisition of money, but in making belief that the goods we acquired with the money are true goods. They are only modifications of the res extensa like our body, which is good not because of what sensitivity and imagination suggest, but for the teaching, in our case, of Christ. The respect due to the body is a religious respect based on the doctrine of salvation for the soul, it is not the respect originated from selfishness or irreligious theories.

The cause of a corrupt morality is based on an erroneous conception of the world, on a distorted vision of reality, a vision falsified by the temptations, due to the Fall, of relying on the natural judgments of the senses. The same can be said for the goods obtained from the consideration we receive from other human beings: good name, fame, glory, respect, and power. At the origin of all these material and moral goods the original deceit is found. The criterion of the logic of values modeled on fantasy is pure illusion and deception. Malebranche's thesis is clear: we live in a world of imagination with our self-centeredness, blind to the fact that all wordly values have a false and falsifying meaning. 


\section{The Psychology of the Newborn and the Birth of Thought}

The ladder of the values of the imagination is like a pyramid at whose basis lays the infinite variety of the sensible qualities that are believed real, and at whose vertex are found sin and selfishness. The problem we face is that of determining the origin of this forma mentis, which is intrinsical to the origin and formation of thought itself and of each individual human life. The falsifying vision of the world that the imagination makes available to us was born when we were born and it accompanies us throughout life. We know that with reason we should try to correct the activities of the imagination. We know that the human thought forms itself in accordance with the strongest ideas present in our consciousness. The notion of sensible or imaginary similarity is the category with which we organize everything we come to know. Things become known when their ideas carry a certain degree of similarity with the ideas we already possess in our conscience. When there is a lack of similarity, then the imagination would supply what is missing and initiates the cognitive processes in the pagan mind. Some ideas within us can overcome the others and become familiar or predominant within our conscience. The possibility for an idea to become the cardinal idea of the human thought is decided by the sharpness of the sensible impact, the fear, or other fundamental sentiments. At the psychological level of consciousness, all present ideas went through their first moment of appearance in the human mind, when exactly their place within the cognitive structure of the subject was decreed. The first time a thing is known it assumes the character of novelty and the passion that comes with this new idea is wonderment. This passion is imperfect because it is not connected with the hope of a good, but the idea grows in strength in direct proportion with the shock we received for its newness. The greater wonderment would impress in the mind the idea, which would become a familiar idea, a fundamental idea, and a universal of the imagination. This, in brief, is the dynamism involved in the constitution and birth of thought in the pagan mind.

Thought in the pagan mind is rooted on a few pillars: the universals of the imagination. At first sight, Malebranche does not appear to concern itself about the birth of thought in the same manner than Vico. Malebranche is not interested in the infancy of humankind, Vico is. As a corollary to his greater philosophical concerns, Malebranche came to consider infancy in the individual human being with the definite goal of learning about the formation of prejudices. As Vico did, ${ }^{1}$ so Malebranche put together the metaphysics of the birth of thought, but through anthropological and psychological analyses. An enlightening paragraph in The Search after Truth narrates the first moments of a babe's birth, the first ideas that insinuate themselves in the babe's malleable mind, the first conditions of its emotions. ${ }^{2}$ It is important to remark that Malebranche's fixation is that of studying the "pagan nature" of thought, beginning from the very beginnings of life. Like Vico, Malebranche maintains that the study of children, who at the age of seven 
possess a vocabulary and a habit of credences already formed, is invalid for that purpose. If you want to understand how prejudices are born, you have to reconstruct their cognitive origin. Malebranche sustains that it is possible to observe in the newborn babe the formation of prejudices. Malebranche speaking about a newborn babe and not about children in The Search after Truth means something similar to what Vico meant when speaking about the youth of humankind in the New World instead of the youth in the advanced western civilizations. As Malebranche discovers the genesis of the pagan thought in the newborn babe, so Vico does in the brute (bestione):

When the babe abandons the darkness and sees for the first time the light and the cold of the external air makes it to shiver, then the woman who receives it protects the delicate limbs in her cuddling warm arms. All external objects surprise the newborn babe. They are all motive of fear, because the babe has no knowledge of them yet and he has no force to defend itself or run away. The tears and the cries with which the babe consoles itself are the infallible signs of its pains and fears. They are like prayers that nature addresses to its caretakers so that they would defend it from the evils it suffers and the objects it perceives. ${ }^{3}$

The birth of thought happens in a changing situation, and the first sentiments are fear and intense wonder. In the sudden passage from darkness to light, from the secure life in the womb to the open air of the universe, the babe experiences its first enemies. The newborn knows nothing of the world, but immediately perceives its precarious condition, and expresses fear. Because everything is new, great, and challenging, a bunch of perplexing sentiments fill up the babe's mind that until that moment had remained empty and inactive. Malebranche does not say that the first thing the babe thinks is its own self. The newborn babe has no consciousness of its own being, its attention is given to the stunning new surroundings that repel and at the same time invite. The first reaction at the view of the new world is the cry. The baby's cries however are not like the howling of animals. Malebranche sees the baby's crying as the instrument with which it consoles itself and indicates its sufferings and fears. Not having the soul, the animal does not experience fear, which is a passion, a sentiment of the soul. The baby's tears are the prayers of nature that wants in the baby's name to ask from the present persons help against pains and fear.

The passage from the instinctive to the cultural is, at the physical level, gradual. The screaming of the baby is on one hand instinctive because it is nature speaking for the baby; on the other hand, it is human because the message is for the parents or other caretakers in attendance, from whom the baby asks help and protection. From a metaphysical point of view, the baby's scream stands in juxtaposition between the instinct and the cultural, in which case the babe crying is not 
an instinctive expression but a prayer in order to receive protection from the surrounding shadows. Malebranche viewed the birth of thought as the dialogue between the newborn baby and the imposing surrounding shadows. Tears and screams are prayers, a natural language, almost onomatopoetic, with which the human nature in the baby speaks to the immediately present human beings. This dialogue truly happens only within the baby; the shadows around the baby are not what the baby believes they are and the people present will not understand the baby natural language in the sense in which the baby meant. If we identify the question of the birth of the pagan thought and separate it from the philosophical system in which it is enclosed, we may sustain that Malebranche was proposing Vico's identical perspective. In Vico, however, this viewpoint develops in an argumentation of historical nature, whereas in Malebranche the prevalent interest is basic for a genealogy of the prejudices. The conclusions they reach, if looked upon from their psychological content, are identical. The Vichian theory of onomatopoeia as the answer to the word of Jupiter is perfectly congruent with the affirmations of Malebranche. Vico will hypothesize that the brute (bestione) moves up to thought through a colloquy with the divinity (divination) deceptively present in the thunderstorm. Vico's discourse builds on two perspectives. First, conscience originates with the fantastic thought, but not as self-consciousness, because the human being is at this time conscious only of the world that the senses portray. Second, the human being creates thought as far as it deceives itself, because language is the instrument of passage from the feral stage to the stage of slavery, to its own illusions.

The first word spoken by the human being is onomatopoetic and is in response to the divine word manifesting itself in thunder and lightning. It is the expression of individual metaphysical solitude: thought is born from an illusion and a delusion. The Vichian brute (bestione) and the Malebranchean newborn baby are like genies deceiving themselves: they deceive their conscience proposing a world that does not exist outside the perceptible and perceived evidence of the senses. Malebranche and Vico applied to the pagan mind the wicked genie that Descartes hypothesized in the metaphysical meditations as capable of deceiving human beings about everything. Mythical thought and the first fleeting representations of the newborn constitute a fulsome deception. Jupiter does not exist, but it is the first animate thing about which the brute thinks. The monsters that the newborn baby described by Malebranche sees around are in reality its parents, who are there to help and not to harm, as the baby believes. It is in the newborn and in the brute that the malign genie of imagination is most active and there is no clear and distinct reflection powerful enough to awake them from their dream. The human being comes to the world of thought through a self-deception and the evident sign for it is onomatopoeia: the scream with which we react to our world, to our imagination. The human beings through the myth catapult themselves beyond the state of nature reaching a colloquy with an inexistent god and by so 
doing create a new dimension: thought. With onomatopoeia, with screams and tears as prayers, the baby and the brute hurl outside of themselves a cry that in reality returns upon itself in their interiority. The imagined nature that the newborn babe and the brute experienced with the imagination becomes the enormous alcove of resonance of their new conscience.

\section{The Dialogue between the Infant and the Brutish Primitive with the Divinity}

The experience of solitude, considered not as a psychological and individual problem but metaphysical, is an effect of the Cartesian subjectivism. Modern subjectivism excludes a possible bridge between the thinking subject and the world. Everything that exists is external to the subject and no matter how near, it is at an abysmal distance. The subject is alone; all reality is only a phenomenon. The subject sees the world with the imagination and can conceived it in its pure formality with the intellect, but as he tries to comprehend it with its thought it appears to escape and all objects vanish among the ideas. The human being consciously finds itself alone with its own thoughts in the same moment that it recognizes itself to be a thinking entity. The solitude is the sentiment that comes with the consciousness of being alone. With Descartes, this consciousness of solitude acquires a new profound significance: we are alone with our ideas. The body that we retain to be ours and that we sense is a stranger to us, not because of an ecstatic indifference like the one in the mystical rapture, but for an ontological difference. We are in such aloneness that we do not even know if we have a body.

Descartes proved the existence of the body and the advantages we can have from it in an argument that Malebranche invalidated. It is true that for Descartes and Malebranche the human being is not alone but in God's company, but the rational cognition of divinity in Descartes anchored to an innate idea and in Malebranche to the intelligible extension. These ideas have a formal value whose reality is the opposite of that of the bodies. This makes the human being more solitary and deserted: what the human being feels it is not real, the real remains estranged from its pagan life. For this reason, faith in Malebranche assumes a new religious and philosophical role. The sentiment of solitude may have an unconscious cause for unconscious is the inclination toward the good in the fallen human being. ${ }^{4}$ We may then assume the possibility of an intense and pervasive solitude that has no clear and manifest cause. Human beings can suffer their loneliness even without knowing what Descartes meditated in his meditations. As it is characteristic for the human beings, the reading of the Cartesian Meditations could bring the understanding of the factual experience. We are always alone, even with our faculty of reasoning, which consoles us and at the same time risks to deceive us. The Cartesian anthropologist will appeal to something that always has its mansion 
in our soul; he rationally would explain the universal dimensions of the soul. He would tell us that the feeling of solitude that is with us all through life since birth has an ontological matrix. Moving away from Descartes's views to those of Malebranche, we would add that the Fall from Eden has untied our bonds with God in favor of the connection with the apparent reality of the senses. Then our sentiment of abandonment, loneliness, and solitude would carry a theological validity. We must realize that these philosophies, keeping us in the metaphysical level, without the possibility of a religious consideration capable of consoling us with the omnipresence of the divinity, will leave us with our strong sense of emptiness. The rationalist philosopher comprehends in an evident manner what the pagan conscience experiences in a confused one. The horizon that the imagination presents to the human pagan conscience is vain and the reality that reason offers is empty because it is only a mathematical geometrical world.

If we could understand fully the Cartesian philosophy, we would be shocked for the pervasive sense of emptiness this philosophy exudes. It is for this reason that Malebranche decided to reform the Cartesian philosophy with a solid theological formula. We can wipe off our solitude with our reason, which would show directly the divine essence, and particularly with the faith, which makes us partaker of the Goodness and supports the vision of the ideas in God. Faith and reason are two goals we have to achieve; they are the salvation we have to work for; they are at the peak of the mountain we are climbing; they are not at the point of departure of our journey, but at its end. At the point of departure, our transgressions uproar, imagination lives in its illusory reality, and the sentiment of solitude demolishes our spirit. This sentiment of solitude has nothing of the existentialist nature; it is a real fear of absolute abandonment, a metaphysical bareness.

If a human being could be ontologically separate from its body, then it would be as if the body existed in another galaxy, millions of light-years away. In that hypothesis, if everything that concerns the body and the laws of the union of the soul with the body would appear to the human mind, it would present itself as an appalling estrangement. Because rooted on a distinct ontological feature, the original sentiment of solitude possesses a metaphysical characteristic of which all other sentiments are deprived. ${ }^{5}$ The sentiment of solitude is original because it is integral to our own existence. As thinking beings, the human beings are in the sea of aloneness; reality for them is the motive of their feeling of discreteness from everything and of aloneness for themselves. All this has meaning only for the rationally thinking subject, the philosopher, Vico and Malebranche, not for the infant or the brute. Only the student who has understood fully the isolation of a mind controlled by imagination will be able to analyze scientifically the fears that necessarily derived from the situation, the illusion created in order to find a remedy. The metaphysical awareness in our authors of this sentiment allows the analysis with other conceptual instruments, different from those of euhemerism and of all allegorical conceptions on the origin of mythological thought, of the sit- 
uation of the birth of thought in infants, both individually and historically. Their work helps us to understand how the first sentiments are born chaotically and humanly at the same time as the ideas. At the birth of the psyche, some mechanisms of defense are activated simultaneously concerning the contents of the first ideas. If the human being were alone, its first self-defense would be that of fabricating its own companionship: for instance, the fable of Jupiter, and the giants who took shape from the shadows perceived by the newborn baby who saw the world for the first time.

The overturning performance of fantasy brings up alive what is not alive and approaches what is ontologically unapproachable or out-of-the-way. The operation of the imagination continues within all rapports between knowing subject and known objects creating a dialogue between them as if they were two discrete entities. The human knower being alone in the world, being subject and object at the same time, would converse as a ventriloquist does, with some imaginary individual who apparently would fill up the surrounding void. This other individual is nothing but the result of the hypostasizing of the subject's solitude in the sensible contents of the imagination. Both the onomatopoeia of Vico's brute (bestione) as the human cry in answer to the thunder of Jupiter and of Malebranche's prayerscream of the babe, are the reactions toward the first beings that came to help the brute and the infant. We can discover some most original characters in the Vichian position: the human being does not begin to talk, and then think, to other human beings, but to the fabrications of its imagination. After this, the human being would talk to other human beings, but always through the mediation of Jupiter. Thought is born as an individual dialogue with the mediating intervention of a fictional entity. The first interlocutor of the first human beings, their first social expansion, is the divinity.

Human beings obtain the faculty of thinking by the mediation of the fiction in which the conversation between the human being and the divinity is construed, creating also a tension of wills in which the will of the make-believe (Jupiter) is the domineering one. The human will takes shape from the divine will, which is the product that imagination crafted with the raw albeit virgin mind of the infant child. If we imagine that we are going to paint a portrait, but that at the same time we must construct the canvas (mind) on which to paint, then the object to be painted becomes the subject of the action of painting; the will that moves the hand that paints the object is the imagination; the will from being a real cause is transformed into the believed effect of the will that, as a substitute reality, was a product that escaped from the control of the author. The dialogue between the infant and the divinity is a rapport between two living entities in which the truly living entity plays a secondary part and the living phantasm controls the dialogue.

The representation of Jupiter is the idea of space. The living primitive brute (bestione), the infant of humankind or of itself, does not possess within its visual faculty or in its representative sphere the idea of space. Myth is a language 
of corporeal images prevalently visual, a language in which the fundamental relationships between the signs are found in the idea (perception) of space, which is the newly formed idea. The idea and the awareness of time follow the process of the idea of space and for this reason in the first mythological signs time is implicit or not adequately explicit. The language of the origins is a language of visual images, and the conception of space is imaginative with the result that the soul is an outsider because the soul cannot represent itself in space. In order to be able to think the pagan mind should place itself outside of itself because it cannot represent itself to itself within itself. The soul must set itself in an image. The human will must associate itself to this image in order to determine and personalize itself in the image and become autonomous by simulating an external imposition in the eyes of the subject.

The dialogue with the divinity is likewise the construction of our own self, is a dialogue that we carry on with our own self. It cannot be in any other way. It is only through the formation of this world of imagination that human beings find a common ground, the fantasy, on which communication becomes possible, and civil society is formed. Only through the imagination, human beings can have an inter-subjective communication. The first communication is with our own selfhypostasized in nature (Jupiter); the second communication is by means of the fiction of Jupiter (religion) which begins the connection with the other human beings. The discovery of oneself is only a discovery; it is not a given fact; it is neither the first nor one among the first discoveries; the first experience that through imagination the primitive human being experiences is the discovery of the other being. Imagination always gives the image of what stands in front of us, of what faces us, not of us. The Platonism of Malebranche says that self-consciousness is sensible consciousness, not a conceptual consciousness. The sensible consciousness does not provide true knowledge. Vico appropriated this principle and, like Malebranche, applied it to the field of psychology. Self-consciousness is a terminal point; it follows the knowledge of what is external to the individual person, and only what is external is representative. This truth, according to Malebranche, is the cause of our prejudices, the origin of our erroneous mentality that manifests itself from the first living moments. Identical is the position of Vico: "Because of the senses, the human mind naturally tends to view itself externally to the body, and it is only with great difficulty that it can understand itself by means of reflection." 6 In another passage of The New Science (par. 331), Vico sustains, "Because it is buried deep within the body, the human mind naturally tends to notice what is corporeal, and must make a great and laborious effort to understand itself, just as the eye sees all external objects, but needs a mirror to see itself." This is a position in perfect agreement with Descartes. It is through the study of imagination that we arrive at the conclusion that the pagan mind can have some knowledge of itself by way of the body, the representation of bodies. The milieu into which the brute of Vico and the infant of Malebranche are thrown is a milieu of complete ignorance. 
Their minds are new, not yet contaminated by the prejudices, but on the verge of falling under their power. Everything can exercise a strong influence on these minds in the process of construction. Vico links the unconsciousness of oneself with poetry; their connection is made of sensations and sentiments that poetry demands from imagination. The Malebranchean Bernard Lamy said that poetry is conducive to the oblivion of oneself. ${ }^{7}$

\section{The Infant}

Given the extreme defenselessness of the infant, everything exercises on its brain and spirit a most stirring influence. The philosopher describes the infant in these terms: the infant is a fully new subject, ignorant about everything, without any awareness of what the surrounding world is, without any knowledge on which to rely, and without a certainty to which to appeal. The infant is a human being with a mind absolutely empty, without the most simple and accessible content. The classic description of this kind of mind is that it is like a tablet of wax: the mind of the newborn baby is a tablet of warm wax, unstable and impressionable, on which no mark has been made, but ready to receive any impression no matter how light. This impression will provoke a profound damage that marks the mind in an ineffaceable way. Fear alone, the first product of ignorance, is the first sentiment awakening in this new soul. This absolute ignorance will transform itself immediately into an extreme uncertainty that will arouse the sense of precariousness and will make reality an abyss into which in darkness the infant feels to be falling. Fear takes over the existence of an empty soul and fills it up with a terror that is a blurry but impelling sentiment, not yet a complex of well-structured representations:

To understand the trouble which the infant's spirit suffers in its conditions, we must remember how tender and delicate are the fibers of its brain and that consequently all the external objects make on them some very profound impressions. It is true that at times some small things are capable of wounding a feeble imagination, but a great number of objects all together overcoming the senses cannot but wound and burn those of an infant. ${ }^{8}$

Our discourse concentrates directly on the imagination as a faculty of the soul. The infant is not pure instinct; its fear is not the reaction of a machine. The infant is already a human being, has a conscience that is challenged, experiences fear, wonder, and prayer with its tears and screams. With its cries, the infant asks the monstrous surrounding shapes, who are its parents, relatives or assistants, for help and protection; the infant begs that they do not inflict harm. These hideous and huge shapes four or five time bigger than the babe, in the argumentation of Male- 
branche, become the giants who constitute the first representation appearing in the infantile imagination. The world for the newborn babe is the room where the birth happened and the first image impressing in the mind is that of a giant indistinct in its limits and form, but perceived as immense. ${ }^{9}$ The first perception of reality and the environment becomes the first idea, the first thought, vague but intense. The scene that Malebranche describes is identical to the one Vico narrates about the myth of Jupiter. Not only similarity is involved in their myth, but also the myth's purpose. A being that knows nothing, at its birth perceives itself as surrounded by an unusual phenomenon: giants exist who do not communicate their intentions and whose presence represents a looming offense.

Let us try to imagine more vividly the apprehensions and the pains that the newborn infants suffer at the time of their birth and the scars that their imagination must receive. Let ask ourselves, what a frightening experience would it be for adult human beings to see with their own eyes giants, four or five times taller than themselves, coming straight to them without giving any sign of their intentions? Would it not be a terrifying moment to have to face an unknown species of animals, which have no resemblance to those we know, like a flying horse or any other of the many chimeras that our poets invented, suddenly descending from the clouds upon you? Is it not true that these phenomena would impress themselves profoundly on our spirit and that some brains would remain distressed for having experienced these things once? ${ }^{10}$

Malebranche insists on explaining in the clearest possible way a concept that was innovative and hardly understandable for the people of his own time. He shows how this first thought could not be comprehended by analogy or by another relation to some other piece of knowledge because it was the first and unique thought present in the mind. In this, we find the origin of all forms of prejudices: the brain and the mind of the newborn infant are extremely malleable. With time, this malleability will decrease and the marks and the ideas suffered during the first moments of conscious life would weigh heavily on the life of successive thinking.

During these decisive moments, the newborn human being came at thought for the first time in an overpowering world full of enormous beings completely outside its control. Giants are approaching, but they could also be fantastic animals or bizarre beings produced in the mind of visionary poets; they speak a language the infant does not comprehend, but that soon it interprets by way of fear and haze. The new ideas will be fundamental for the succeeding course of thought; they will be the familiar ideas, the universals of the imagination, the fantastic universals. What would there exist more fantastic than a flying horse or chimeras fashioned by poets, descending from the clouds to earth? Malebranche insightfully links the poetry and the fantasies proper to adult human beings to the 
thought of the newborn baby. He compares the fantastic thought of adults to the thought of infants, with the explicit intention of explaining the characteristics of the human mind, not the mind of the adult or the infant, but of the mind and mentality of the natural human being as it is since the Fall from Eden. ${ }^{11}$ Fantasy is Her Ladyship of the pagan mind and takes ownership of it since the first instant after the infant is born. All passions bow before Her Ladyship in this fantastic representation; her idea of divinity charms the human will; she rules over the brute (bestione) and its thought; and she offers the babe as a victim to the surrounding giants.

The condition of the newborn infant is like the one of the person who for the first time thinks about a reality never experienced before and is intimately stunned at the first impressions that this new world presents. Poetry in this context is poetry in a form of language produced by a fantastic thought. "It happens that every day an unexpected event of something terrible may distress an adult person whose brain is not suitable enough to new strong impressions, but have some experience in dealing with the situation or can defend itself and find some solution to the problem. The infants, however, coming to this world will be hurt in some way by all the strange objects that affect their senses." 12 If the exceptionality of an event may discombobulate a mature person, what would be its effects in a newborn babe? The sensitivity is extremely powerful, while the will and the intellect are merely germinating. The new infant has no mirror in which to reflect and recognize itself. The mirror is the intellect, but in the infant's situation, the compelling sensations are overshadowing the intellect that remains latent. In the future, with an iron will and the cooperation of the events the human being will use the mirror of the intellect, which for this moment yields to the imagination and the sensations: "All the animals that they see are of different and new species for the infants because they have seen nothing of what they are seeing. The infants have neither power nor experience. The filaments of their brain are very delicate and impressionable. Is there anything that can be done to protect their imagination from remaining afflicted by so many different objects?" 13 It is certain that in time if the psyche of the infant would not find the equilibrium, then all human beings will grow in madness. We should admit that the mind is endowed with a mechanism of defense and control.

The familiar ideas, the rigidity of the pagan thought, the exorcising function of superstitions, the social validity of a controlled selfishness are the components of a movement toward the progressive and greater stability of the mind. What in the grown-up survives of the initial confusion of images that filled the mind of the infant is only a mark, the structure of that particular kind of thought, not the vivid and unending whirl of the sensations of those first moments. If this uproar of passions were to continue in the adult life, human beings could become prey of total madness, without possibility of escape or safety. 
It is true that the false impressions and wounds that the infants' imagination suffered at the view of so many horrifying objects may stop and heal with time. Time's healing generally is the preventive factor that saves almost all human beings from remaining fool from infancy. This, however, does not always assure us that some impressions and wounds that were so strong that could not be smoothed away, would continue to be felt all our life. ${ }^{14}$

The typical traits of our personality, as Malebranche affirmed in the same chapter, are developed during the first months of our life. All the sensations that the newborn infant experience are very strong, though they may not be particularly intense for an adult. The conscience of the infant is not accustomed to passions and sensations: everything the infant perceives is perceived as exceptional, stalwart, and intolerable. For the greatest part of humankind, this bombardment of perceptions at the early age has not been sufficient for producing folly or madness. Malebranche often defines madness as the excessive susceptibility of conscience toward the perceptions. If it is true that the confusion that is the characteristic of the first part of our life was unable to distort completely our mind, it is still true that, in some ways, we are fools because of our acquiescence to prejudices and neglect in amending the errors in our personality. In other words, Malebranche would say, we are fools because we are and remain pagans. "Here is the source most ordinary for the errors of humankind: the discombobulation of the human brain caused by the impression of the external objects at the time of birth. This cause, unfortunately, does not cease as early as we could imagine." 15 The first thoughts are the most important; they determine the structure of the mind and are the foundations of prejudices and errors. The pagan mind takes shape at birth and in the first moments of life finds its reason d'etre. The comparison between the birth of thought and poetry is fundamental for the understanding of the correlation of Malebranche's theory of the pagan mind with that constructed by Vico.

\section{The Theological Poet}

In an anthropological perspective, we may say that for both philosophers, thought is born as fantastic thought and that fantasy creates reality, that is, reality exists when it is thought. Without imagination, the primitive being would not be able to think reality. According to our point of view, the concept of reality that the pagan mind forms is fantastic. It is not so for the poetic theologian for whom there is no other way of thinking reality.

The fantastic universal is the idea on which stands the pagan mind; it is the all-comprehensive explanation of reality as the pagan mind sees it. The objectivity of the fantastic universal is other than the objectivity of the concept of 
reason. The universality of the fantastic universal is based on an illusory certainty of fantasy, seen not as a faculty among the faculties of the mind, but as the only available faculty of the mind. The logic of fantasy precedes the logic of the intellect, poetry comes before prose, the prejudice before the truth, natural causality before the occasional causality, and the pagan religion originates before the sciences. Fear, then, is the first motor of poetry and mythical thinking. Thus spoke Vico. Fear brings human beings to poetry. Poetry, in every age and place, roots itself in the cultivated field of fear, terror, and uncontrollable uncertainty. Poetry, however, is controllable in the verses of words. Within words, fear sublimates itself into thought, in which it solidifies and formalizes itself into a representative idea. The old saying that poetry is a speaking picture finds here its complete and deep explanation. Painting is the representation; the word is the brush with which the sentiments are painted in the human spirit. Every poet is a fearful human being because it feels the complete uncontrollability of the reality within which it resides or thinks of residing. The poet's fear transforms itself in words and the words into representations in uncontrollable concepts that are obscure, confused, and directed to the possession of the mind within which to instate its tyranny of sentiments. Of what are afraid these perturbed souls of the Vichian primitives? Of what are afraid all the poets? They fear death and annihilation. With this, the Malebranchean analysis of the fictitious thought of death returns and it is necessary for us to reconsider some thoughts and comparisons of this analysis with the position of Vico. If for Vico and Malebranche the poetic theologian (the newborn of all humanity) and the new born baby (the poetic theologian or single human being) have no conscience or awareness of themselves, how can they arrive to thought through the fear of death, that is, by losing something of which they have no knowledge of possessing? Is not the fear of dying bringing them progressively to a kind of self-knowledge? There is undoubtfully an instinctive component in self-preservation, but the fear that brings a person to poetry, to thought, is of a completely different nature than the fear of the animal. This new ontological fear is not a fear that dissolves itself in the instinctive physical reaction. This new fear burns in a different opposite world, in the reality of thought, in a dimension that is temporarily fictitious, in a paradoxical formula. It is an unreal reality, or a false reality, but that in relation to nothingness (thoughtlessness) constitutes a noticeable advantage. We may say that the poetic theologian, who depicts the myth of Jupiter, by depicting the idea of Jupiter, simultaneously gives a picture of his own soul.

\section{Vico and Bernard Lamy: On Poetry}

In the writings of Malebranche, we will find only a few passages on the topic of the poetic nature of the pagan thought. Thought in the newborn baby is born as a confuse representation of images: the idolatric value of the first ideas and the me- 
taphoric quality implicit in the fantastic thought of the newborn infant whose screams are like prayers and the obstetrician is like a divinity. Malebranche's analyses are brief and significant, but they do not constitute a complete theoretical corpus. Though aware of the poetical structure of the pagan mind, Malebranche has not dedicated a systematic study to poetry and particularly to poetry in relation to the imagination and the pagan mind as Vico did. What Malebranche did not, his friend Bernard Lamy did. ${ }^{16}$ For Lamy, poetry is a speaking picture: "Poetry is the speaking picture of what is most beautiful in nature" (La poesie est une peinture parlante de ce qu'ily a de plus beau dans les Creatures). ${ }^{17}$ Horace in Ars Poetica (vv. 361-365) said, "Ut pictura poesis" (Poetry is like a picture). Poetry is a series of visual and audible representations of what the poet is thinking. These affirmations made twenty years after the publication of the Méditations metaphysiques assume a new and definite significance. Poetry is an activity of the mind and it consists of speech and attributes a meaning to the motions of the soul that are its representations. The significance of poetry and its pictures are not to be found in their relation with the external reality, but uniquely with their own interior reality in the thinking poet.

Poetry is the expression of the essence of imaginative thinking. Poetry is thought and the pagan thought is poetic. ${ }^{18}$ Lamy introduces the criterion according to which the poetic thought should create the images. The representations or images must be powerfully perceptive and sensitive. Lamy amplified the affirmation that poetry is a speaking picture with the consideration that the picture to be able to speak must possess strong tones. A pale imagination does not germinate thought. Poetry, the greatest manifestation of the pagan thought, materializes as the effort of potent imaginations. The intensity and the emotivity of the pictures in the soul originate the poetical composition that is not considered poetical by the poet but a new reality. As vivid remembrance, desperation, and love would make the husband sees his dead wife as real in the portrait, ${ }^{19}$ so the poet can take as real the course of his own thoughts, judges as sounds of nature the music of his verses, essence of the universe the appearance of his own mental pictures. We will speak widely on the amazement for what is great and on the tendency of the human spirit for representing it. We will notice how this tendency of the imagination will cause a reversal of perspective in the perceptive sphere of the poet. The beginning point is not the reality on which the poet fantasizes, but the fantasy that creates new reality because of the potent imaginations that wish to represent the wonderful, the outstanding, and the extraordinary.

The process begun by these passions of wonderment or fear can substitute completely the perceived reality with fantasy. For the poet, the only reality is the imagined one. The poet is the painter who paints the world on the emptied canvas of his own mind. This turnaround is essentially the fruit of a process of interpretation based on passions and imagination instead of reason. Lamy's comparison of the portrait of the deceased wife can be used to explain that perception in the poet is not altered to the point of materializing fantasies. Truly, the 
poet has a normal perception of reality; he does not see monsters where there are only shadows. The poet sees the shadows, except that he takes them as monsters and ends with valuing those traits of the shadows that gave him the feeling that they were monsters. The pictorial faculty of the imagination, the amazement, and the other sentiments bring the poem to completion. The poet forges his thoughts within the limits of the poetic verse, which attributes rationality and reality to personal poetical fantasy. ${ }^{20}$ Lamy explains poetry using the concepts that he found in Descartes's The Passions of the Soul and Malebranche's The Search after Truth. He wants to re-interpret old conceptions of poetry like the ones previously mentioned (poetry is a speaking picture, the poet encapsulates his thought in the limits of the verse, and the poet chains reason to rhyme) in light of the new theories on passions and imagination. An evident attempt at applying the anthropological theories of Malebranche to poetry exists in Nowvelle Reflexions sur l'Art Poetique (New Reflections on the Art of Poetry). ${ }^{21}$ In this book, Lamy spends more time on psychological analyses of the poet and the pagan, which he identified as being the same, instead of on reflections on the poetic art. Lamy's Malebranchean conclusion is that the pagan thought would be at the image what reason is to the rhyme. This means that the mental representations will be modeled according to rhyme and the limits dictated by the verse. It is with poetry that the content of imagination is manifested. The form and the linguistic structure that the imagination produces determine the manner of thinking of the pagan poet, who in this case will submit his reason to poetry; he will model his thought with the tools he possesses, the poetic language, for manifestly rendering it. Poetry does not produce verses from a pitiable prime matter; poetry needs highly inflammable material, tinged with strong sensations, potent passions, and exceptional fantasies. For the Cartesians, as the imagination grows stronger so the reason grows weaker. Human thought is not born under the auspices of reason; human history evolved before reason developed. The Cartesian philosopher should consider the universal history of thought as it considers the birth and growth of the thought of the single human being. Descartes and Malebranche say that thought originates with a prejudice and the prejudice is greater in direct proportion to a weaker reason. For the Cartesian School, the birth of thought, in historical anthropological terms, happened in a situation in which imagination was powerful but the intellect inept. The study of a thought not intellectualized could form a corollary to a theory on the poetic-pagan mind. ${ }^{22} \mathrm{We}$ could ask why Malebranche did not move his theories from the psychologically subjective to the historically objective level; why he did not extend in an articulate way his conception of the imagination to poetry and to a critique of poetry in relation to the birth of thought in the primitive mind. Malebranche has not constructed a philosophical conception of history; it was beyond his concerns. Nevertheless, Malebranche's theory of the birth of thought, of the criticism of idolatry, and of the study of the pagan mind has a diachronic component: the historical progress of humanity from the Fall to Redemption, the genesis, growth, 
and transformation of prejudices in the conscience. The discussion on the imagination acquires inevitably a diachronic perspective. This would become more evident when considering the analysis of heroic morality in The Search after Truth.

\section{An Analysis of the Imagination}

Malebranche thinks that the development of imagination and the metamorphoses of fantasies are related to the emotional status of the subjects, to their social condition, and to the grade of corruption of their heart. In different periods of time, the same subject would have different imaginations, different representations of the same things, and different criteria. The Christian psychology that Malebranche intends to create is necessarily diachronic. He attempts to describe the growth of the pagan mentality or of the prejudices of all human beings, but also the transformations that with time mark the ambience in which the pagan lives. In the way that societies change with the mutation of time, in that same way the fantasies of humankind transform themselves. These transformations in usage and customs, in mentality and political institutions, are not happening in an arbitrary or casual way; they follow specific metaphysical and teleological laws. Malebranche structures the metaphysics of imagination that comprehends a diachronic element in so far as imagination is not a static entity, always equal to itself, but follows specific lines of development, and suffers transformations that cut deeply into the human psyche. The analyses of The Search after Truth show how the first representations are born in the conscience of the newborn baby, how credences develop and established themselves in the human mind, how prejudices modify in time and with the age of the individual human person. The Malebranchean anthropology describes and gives reason of the changes in beliefs, usage, and customs in the different nations and in the many different individual psychological types. He studies imagination in its historical becoming, in the historicity of the individual persons (newborn babies, children, youngsters, adults, and seniors) and of the nations (Ethiopians, Greeks, Romans; French, Italian and English people of the sixteenth century). His is a science of fantasy, without the deterministic and mechanicistic characteristics of physics. The scientific dimension of imagination and passions grow in a different ground than that of mathematics. Fantasy deals with truth and error, but also with goodness. Human reality is something more complex than geometry and, if it were possible to have the geometry of the human spirit, it would be only according to geometric general principles. Because of its rapport with goodness, anthropology is a diachronic science. The human spirit differs from physical objects, it is animate, it is mutable, and its principle of change is internal.

A comprehensive reconstruction of fantasy is based on the understanding that every human being is endowed with a particular kind of imagination: women, men, adults, children, elders, rich people, poor people, the learned, the analpha- 
bets, Frenchmen and Ethiopians, moderns and ancients, Stoics and Epicureans, Christians and pagans, soldiers and merchants. They have their type of imagination that will follow definite lines of growth. Malebranche thought of having individuated all of these forms of imagination in their general traits, given that the particular characteristics follow the personal and original sensitivity that makes fantasy different in each human being. The differences between imaginations have also a psycho-physical origin. Given that the imagination is the vision of the soul from the perspective of the body it is evident that every human being would have an imagination that differs from that of all other human beings. Even though accepting these undeniable differences, we must recognize that the succession of images in the pagan mind must follow determined rules that explain the functioning of the human cognitive activity and that the Christian psychologist must identify with precision in order to dismiss errors and transgressions. The path that goes from prejudice to truth is long, difficult, and tortuous. It is a cognitive change that cannot happen suddenly, as if we were with Paul on the way to Damascus. For the ordinary human beings change happens gradually according to the laws of the union of the soul with the body.

The analysis of the imagination is an indispensable study for those human beings who want to free themselves from the tragic inheritance of the Fall from Eden. The study has a theological and a psychological validity. The process that goes from the most vivid, confused, and obscure representations to an evident idea is both an individually psychological and collectively historical process. As a single human being spends a major part of its life for the understanding of truth and the acquisition of righteousness, so a nation necessitates centuries before achieving the triumph of the true religion. Malebranche does not formulate a conception of history as Vico will, but constructs an anthropology and a philosophy of the imagination that reveal a diachronic structure that is also present within his psychological analyses. The diachronic dimensions of Malebranche's views are more definite in the work of his friend, the Nouvelle Reflexions sur l'Art Poetique, in which Lamy applied the psychological principles, which will become public in The Search after Truth, to poetry and the mentality of the gentiles: "The most savage peoples have been sensitive to the pleasure of melodious verses. It is for this reason that when the human beings were dispersed throughout the Forests like wild beasts, those who wanted to assemble them and make them live under Laws in a Republic, used harmony in order to persuade them." 23 In this passage, Lamy points to poetry as the only possible form of thought among human beings at the stage of being brutes. Second, he speaks of the founders of nations as of theologian poets, who used poetry to bring the primitive human brutes into society and save them from their ferine roaming. Third, he mentions that the first nations governed themselves as republics. The reason given for these three events is not found in a contract, or in a conquest, but like in Vico in the illusionist power of poetry. This coming together was not due to an agreement on utilitarian advantag- 
es, but to the persuasive capability with verses of tempering the ferine bestiality. It is always with poetry that the human being stopped and succeeded in the dominion of nature. Is it not extraordinary that a Cartesian-Malebranchean, though describing a humanity reduced to the lowest stage, oppressed by primary needs, affirmed that poetry was responsible for the first human passage from being wild brutes to culture? Society was born through the work of poetical persuasion of the first poetic lawmakers: "This gave way to the Fable narrating that Orpheus, one of the first Poets and Legislators of the Greeks, tamed the lion and restrained the tiger with his chanting Verses on the Lyre. The poet Amphion also forced the rocks and the forest to move and organize themselves in the way of constructing a new city." 24 Vico, in the Inaugural Oration of 1707, touched this topic and explained it saying,

For no other reason, the very wise poets created their poetic fables of Orpheus with his lyre taming the wild animals and Amphion with his song able to move the stones, which arranged themselves of their own accord by his music, thus erecting the walls of Thebes. For their feats, the lyre of the one and the dolphin of the other have been urled into the heavens and are seen among the stars. Those rocks, those oaken planks, those wild animals are the fools among men. Orpheus and Amphion are the wise who have brought together by means of their eloquence the knowledge of things divine and human and have led isolated man into union, that is, from love of self to the fostering of human community, from sluggishness to purposeful activity, from unrestrained license to compliance with the law and by conferring equal rights united those unbridled in their strength with the weak. ${ }^{25}$

The human being, thanks to poetry, can control nature and transform it in function of the verses with their fantastic meaning. The poet is the legislator, the founder of nations who does not use force or pacts with other human beings, but convinces them with poetry, persuades them about an entire new vision of the world. The poetic capacity of moving stones and woods and dispose them for the building of new cities is the human industry that suppressing the ferine roaming decides to construct with wood and rocks the cities. The poetry that organizes trees and stones is the passionate activity of the new human beings. Poetry dictates the transformation from the wild brute to the human being; poetry changes the brute's exploits into human deeds. The first human being is both poet and legislator; the first law is poetic. Making poetry means ordering the environment. Lamy opposes the disorder of a savage soul dominated by brutish passions to the cultural order set up by the poetically animated soul that expresses itself in making civilization out of the wilderness (forests and stones). The poet creates mental and physical horizons. The horizons that the poetic art presents neither are simple de- 
scriptions of what exists nor abstract rhetorical artifices, but all-comprehensive illusions that easily take hold of the individual consciences.

\section{The Magic Power of Poetry and Poets}

Poetry, understood in this way, must have a magic character because it creates a new world, and having that power must necessarily be divine. The divine nature of the poet and of poetry is fantastic, imagined, and pagan. Lamy speaks of the gentiles as the kingdom of the instinct conquered by the kingdom of poetry. $\mathrm{He}$ viewed humanity as being completely savage and began his treatise noticing, "The most savage people have been sensitive to the sweetness of poetical verses" (Les peuples les plus sauvages ont eté sensibles à la douceur des vers). Poetry shapes minds and human passions in a manner that Lamy calls divine, though pagan: "Everyone agrees that the manner of speaking of the poets is marvelous and their language divine. They give a turn to what they say that is not ordinary and that enchants us in such a manner that we no longer sensing ourselves we begin pleasurably to feel the sentiments and all the passions that they decide to stimulate in our souls." 26 The legislator, the poet of the origin who dominates nature, with poetry creates a social dimension for all human beings, self-including. With poetry, he creates a world and he can do it because he previously has created himself. He is a visionary, an illusionist; he illudes and is illuded, both at the same time. Imagination is the first plasmator of thought. Imagination is the soul's ceramic art; imagination takes the mud of the senses, shapes and dries it into myth, then makes representative earthenware. Human beings, before thinking by way of myths and poetic verses, were only like animals, brutes roaming in the wasteland moved by instinct.

Lamy stated that the poet expands the mind through the fields of an extraordinary world, in an enchanting reality internal to our soul. We create a universe in which we do not recognize ourselves. Reverting deeply into the imagination, we come to forget ourselves, what we are, and objectify our fantasies in this illusory world created within us but believed to exist truly outside of us. The consciousness of the poetical pictures that dance in the mind triumphs over the individual conscience. With a gratifying pleasure, the poet becomes the architect of fantasy and poetry the workshop of illusion, where subjective passions and objective difficulties come together to make the human being a stranger in its own land, away from true goodness and near the precipice of madness. The poetical category that unites the illusion with the illuded person is that of the magnitude. If the hero is strong, his strength will be enormous; if the monster is terrible, the terror that it will excite will be extreme: "If they mention the storm, there will be nothing more frightful than perceiving that image in what they are saying." ${ }^{27}$ The imagination, with magnitude and magnification, makes substance out of appearances and compensation for passion out of the flimsy world of fantasy. Since the Fall from Eden, 
the human being has been searching for an internal equilibrium by means of the imagination, but the more stability the human being desires, the more deeply it falls in the abyss of concupiscence. The pictorial idea of magnitude is the cause that makes imagination the plasmator of the coarsest material that sensitivity submits to conscience. Only what hits forcefully the senses and keeps the subject awake with terror filters into poetry. The criterion of magnitude is based on a vision of the world worse than which, there is nothing else for a Christian thinker. ${ }^{28}$ As we will see, for Lamy, the poetry of the origins is linked to the idea of the representable magnitude.

Poetry is the art of illusion and illusory is the mentality that produces it. Poetry is the art of the debility of reason, of which the pagans were little endowed because rich in passions. With poetry, the human beings deny their imperfections construing a false image of themselves. ${ }^{29}$ The poet moves the attention away from his imperfections and acts with suitable fantasies so that the spirit would depict a satisfying reality that does not reflect the true one. The poet's conscience is so firmly attached to the fantasies that the pictorial art of the soul produces that there is no other way of thinking or seeing reality than through fantasy. For the poet no other reality exists than that created with poetry; the only true world is the poetic one; what we can perceive is what the poetic verses describe. ${ }^{30}$

The phenomena apperceived as great, immense, and fearful should be interpreted through the passions that they excited. They really are believed to be as the passions made us believe they are. This is the error of the poet: to interpret the phenomena and the reality that include them in function of the passions they generate. If the storm is frightful, it would be interpreted with fear and it will be a threat; but if it is a threat, who is the threatener? For Lamy, the threatener is god and for this reason he affirmed that poetry always contains some divine elements. From this point of view, poetry is reality's explanation derived from the emotions. ${ }^{31}$ Poetry profits from the weakness of a spirit that submits to the body by injecting into the conscience an illusion of an ethereal superiority, an improbable happiness, and a tendency to easy credibility that the false is true and the true is false. The philosopher always identifies the pagan mentality in epic poetry. In epic, the fantasies that the bard sings are the same ones that excite passions in the consciences, because "the ambitious find in these works the images of their ambition, the vengeance seekers see the picture of the effects of vengeance. We enjoy seeing and hearing people talking about what we love and do not associate with those who have contrary sentiments. We think of them as censors." 32 A poetic mind enjoys a poetic reality. Nature is such as the sentiments make us sense it, manifesting it to conscience with the false light of sensitivity. Poetry rules in a vortex of images and confused words in a confuse mind, and the thought it decreed is the law of nature. Human beings paint the walls of their conscience with poetic pictures and see in this psychological affresco the entire universe, forgetting themselves. "The poets cover all creatures with false splendor. With poetic verses, the poets satisfy 
the human spirits so that they will not reflect upon themselves and on the nullity of creatures." 33 The unconsciousness of oneself corresponds to the ignorance of the ambiance and the belief in the verisimilar. ${ }^{34}$

\section{The Verisimilar and the Verisimilarity}

Malebranche's psychology can be defined as the science of the verisimilar, and his anthropology as the science of the stratification of the beliefs rooted in the verisimilar. In The Search after Truth, Malebranche considers three kinds of truth: faith, rationality, and contingency. ${ }^{35}$ Faith and rationality reach eternal, universal, and necessary truths. Contingency is the source of ambiguous truths. That Caesar crossed the Rubicon is a contingent truth, though in the divine intelligence the contingent truths have a necessary explanation, for God has the science of vision with which he sees all the causal links that make the contingent events occur. Leibniz said that a contingent truth is a proposition whose proof is infinite. It is on the truth of the contingent events that the acceptance of the verisimilar is based. The reasoning with evidence, following the criterion of clarity and distinction, will form true knowledge, absolutely true. The reasoning with contingent insights into things we do not know according to criteria of clarity and distinction will form not veridical but verisimilar knowledge.

Vico has formulated the distinction between the truth of revealed religion and pagan religions on the above assumptions: the revealed religion is true; the pagan religions are verisimilar (truth like). Contingent truth as such is confutable because it is based on appearances and consequently all the pagan science and philosophy is confutable. Leibniz stated that the contingent truth is a proposition whose negation is not self-contradictory. It is possible for the poetic pagan mind to arrive at truth through error by deducing a contingent truth, which can be called also probable and verisimilar. If the error is a truth a little less true and the truth that derives from it is an error a little less erroneous, then we would be allowed to attribute a value to the study of history, the language of superstitions, idolatry, myths, and, in one word, to poetry. In the human sciences that study these phenomena, the highest level of possible truth is approximation. ${ }^{36}$ An approximation, indeed, is an inexact representation of something that is still close enough to be useful; it is a partial practical truth. Every step toward any inexact representation of truth is important because it prepares us for the next step that will be less approximated. Every progress in knowledge that begins from the verisimilar is not truth but allows further steps that bring us closer to the truth. At the cognitive level, every confused idea may gives way to one less confused.

Truth cannot be imposed suddenly in its fullness to a pagan mind. Truth is at the end of a process of clarification that found through the Cartesian method the most secure path. Malebranche, too, recognizes the usefulness of the verisimi- 
lar, though the rational end must illumine the research at every step: "We must not undervalue in any way the verisimilar, because it happened that ordinarily several verisimilars joined together had as much convincing force as the most evident demonstrations." 37 The power of the verisimilar on conscience is as strong as that of reason, and the opinions that the verisimilar lays down on conscience are as persistent as the evident ideas. In addition, if it is true that a probability carries a truth within, it is also true that the verisimilar is stronger in the emotive tension of the pagan mind. Poetry is the stage of similarities, not of verities. The truths of reason avoid emotions, with the exception of a genuine happiness, which deceive the spirit, whereas poetry uses all means to control sympathetic spirits and confused consciences. ${ }^{38}$ The conscience that lives among appearances loves apparent truths more than authentic ones. This is the way Lamy explains:

The will can love only goodness and what appears as goodness and so does the spirit. The spirit also cannot know but what seems true. For this reason, all the myths whose falseness is evident instead of seeming ridicule they please so long as the artistic ability of the poet enchants them and we imagine that they are verities. This is why the first rule of poetry is that of saying nothing else than the verisimilar. When the poets propose things that are surprising, they predispose their audiences: they do not cook up a plot that their readers would not be able to unravel in a natural manner, by way of some accident that would not be impossible, or by having divinities coming down from heaven. ${ }^{39}$

The verisimilar is the dominion of sensitivity. As the imagination relates to the verisimilar so does reason to the truth. The natural human condition after the Fall is that of living with a conscience at the level of sensitivity and drowning the intellect in the ocean of the imagination. For Vico, the study of poetry is theorizing about the verisimilar. Nothing is more verisimilar for a primitive than to identify the sky with Jupiter. Let us say that, almost by a historical necessity, the knowledge of the verisimilar is the prologue to the knowledge of truth. If the human beings were to have made a direct passage from the ferine stage to that of Truth, there would have been no cultures, as we understand them now, no languages, no uses and customs. These are the products of the credences of nations derived from prejudices of generations. If reason were to have been born with thought, there would have been no pagan history and no Fall from the Heavenly Eden. Though their original viewpoints are different, Lamy and Vico agreed that poetry is the art of the verisimilar.

\section{Instinct and Myth in Vico}

In Universal Right and The New Science, Vico separated the history of the Hebrews from the history of the pagan nations. ${ }^{40}$ Vico's interest in these works was to find 
out how thought can originate in the animal, not from the animal, that is, from the body of the animal. The idea of a "spontaneous creation" of the soul fascinated his genius and pervaded his uniquely anthropological interest. The birth of thought is the first step that the human being did from nature to culture, from the total absence of mind to the presence of a mind that was still in an embryonal and ephemeral form of thought. Nothing mental could have preceded the first form of thought. It is a gross error to explain the first thought or idea by way of an analogy with other ideas. Vico claimed that this error was made by all the philosophers who came before him. Within his perspective, the problem of the individuation of the origin of understanding the birth of thought excludes an explanation that rests on some form of symbolism. The first thought can be neither a symbol nor symbolized by any other thing than itself. If the first thought were a symbol, it could be necessarily only the symbol of itself; it would be simultaneously the sign and the signified. Another error, according to Vico, of the anthropologists has been of interpreting the first step from nature to culture in the same way than a passage from one cultural stage to a superior one. This error is connected with the next one, which consists in thinking that the accomplishment of the first step needed mental structures equal to those of an advanced mind in possession of specific faculties and noticeable suppleness.

Vico, in his effort of unearthing the origin of mythical thought, recognized these errors as the production of an imaginative mind. Before Vico, many scholars have reflected on fantastic thought or on the imagination as a faculty productive of thought. Scholastics and Neo-Platonists with their analyses and reflections, especially during the Renaissance, reached refined levels of intuitions and ideas as we can find in Giordano Bruno's writings on memory. Their world of symbols and complex abstractions and theories is not to be found in the pages of The New Science, in which instead we find a description of the primitive brute that will become human, and of his conquest of thought through the imagination. Vico's inspiration dealt with a different kind of classic questions relating to poetry as the humanizing power of the brutish beings in the state of nature. He imagined the human being in the state of nature as an enormous beast (bestione), a being with a deformed body that symbolized the force of the senses and the penury of the intellect, a being that as a ship without pilot is lost in the sea of a ferine life. The methodical fiction of the bestione was dictated in Vico neither uniquely by the religious conception of the human condition after the Fall, nor by the new knowledge accumulated in the sixteenth century in relation to the primitive peoples that inhabited the newly discovered continents. The conception and representation of the bestione came from some problems that the Vichian philosophy faced in an intensive original way. The first problem was the understanding of how the beast moved from the state of nature to that of culture, how thought was born in the brutish being and made it a human being. The second connected problem was the step to be made from the knowledge of the origins to the knowledge of the struc- 
ture of the novel being. The first thought, the first myth, the first universal that guides the physiology of thought is for Vico the myth of Jupiter. ${ }^{41}$ The greater part of this book will support the Vichian analyses of the myth. For Vico, the first theological poet, the brute who had the transforming vision of Jupiter, is the first thinking human being, the first to abandon totally the guidance of the instinct. ${ }^{42}$ The Vichian discourse is truly not about thought, but about the absence of thought in any form, and how could the passage from absence to presence of thought happen. The principle of the opposition of contrary allows either thought or instinct, not both. We can have either the "wandering beasts, scattered and dispersed throughout the earth's great forest" or the settling in a protective spot to contemplate Jupiter, but not both. Here, we should be careful of not falling into one of the errors previously mentioned. With the first thought, the novel being has not lost the ferine characteristics, it has not suddenly become civil, learned, and with a mind like ours. In reference to the concept of bestione, we may affirm that our culture kept it alive as an inheritance and a remembrance of what we have been and where we come from. If there is continuity in human evolution and thought, there exists an ontological opposition between the different phases that more or less dialectically follow each other. The first thought will be consequential to the bestial situation in which the human being was, it will reflect all the characteristics of coarseness, passion, and sensitivity in its reactions, but ontologically it will be different and counter opposed to instinctual responses to new situations. The novel being will acquire a gradual capacity of reflection and discernment. As The New Science logically begins with the description of the bestial condition of the gentiles, so conceptually it proceeds with the definition of the human nature as cultural. The first axiom says, "By its nature, the human mind is indeterminate; hence, when the human being is sunk in ignorance, it makes itself the measure of the universe." 43 Axiom sixty-three explains, "Because of the senses, the human mind naturally tends to view itself externally in the body, and it is only with great difficulty that it can understand itself by means of reflection." 44 Having to search for the birth of thought, we must consider how completely ignorant the human being was before the event of thinking, with a conscience that was not yet selfconsciousness.

A being with intellective capabilities reduced almost to zero, which makes itself the measure of the universe because of its intellective penury, interprets reality in the most personal manner possible, subjectively and passionately. The human being is the measure of the universe because it stands at the center of its own perceptive universe, is the axle around which all knowledge moves. The primitive being looks at the circumference from the center of its cognitive circle, unaware that the diameter of the senses and the imagination determine the motions of the mind. The primitive being ignores being one of the two extreme of this correlation; it ignores that its mind is the firm center that rotates the other extreme of the sentimental-passionate diameter designing the circumference of the world and of 
the universe of thought. The human mind, when for the first time it takes shape, is all taken in a fantastic conception of nature. The first thought develops and embraces everything at the level of imagination; the sensible qualities that forcefully capture the attention become the point of reference for judging the object. The spirit with an inactive intellect will judge the perceived world, all that it sees in the surrounding horizon, with the same criteria with which it senses and feels. Vico comments, "The first pagan people conceived ideas of things using imaginative archetypes of animate beings, or personifications." 45 The primitive is not able of comprehending the concept of existence or of the sensitive qualities. When the primitive thinks reality, it thinks it animate and objectifies its own sensations in what it sees. Thought for Vico is born as fantastic thought, myth. At its origins, myth is not a complex and articulate system of knowledge, is not a series of fantastic stories, it is the myth of Jupiter. Vico alleges that from this idea-myth the first societies took their beginnings, the pagan mind originated, and all human history evolved. The study of the historical origins of humanity coincides with the study of the psyche. Myth is the first sign of activity of the human mind, the point of origin of history. "We may truly say that in the world's first age people employed the primary function of the human mind." 46

In the state of the post-deluge nature, the human being is an animal like all other animals; at this time, in its bestiality, something happened that deranged the life of the beast and represented a point of no return. An unusual event, an extraordinary tempest hit the primordial forests where the bestioni lived wandering endlessly, as a ship without pilot in the marine vastness. When, because of the rumble of thunder and the flash of lightning, the beast looked for a shelter, to that shelter fear obliged it to return. Thus, "chained under the mountains by their frightful religion of thunderbolts, the giants checked their bestial habit of wandering wild through the earth's great forest." 47 As the bestioni fearful of the great natural events stopped roaming and found cover in the point of the forest where chance or providence wanted them to raise their heads at the surprising effects of the sky in tempest, there they laid down the corner stone of humanity. How was it possible that an act of nature (a natural phenomenon) could act on a being of nature (the bestioni) and produce an effect (thought) that is not from nature? The answer represents the core from which the larger part of Vico's masterpiece proceeds:

As was inevitable when such a violent phenomenon filled the sky for the first time, the heavens now produced the most frightening thunderclaps and lightning bolts. At this time, a few giants, who must have been the most robust, were living scattered through the forests of the mountain heights, which is where the most robust animals have their lairs. Suddenly they were frightened and thunderstruck by this inexplicable great phenomenon, and raised their eyes, and observed the heavens. In this state, such 
people by nature possessed only robust physical strength and expressed their violent passions by shouting and grunting. So they imagined the heavens as great living body, and in this manifestation, they called the sky Jupiter. The nature of the human mind in such cases leads it to attribute its own nature to an external phenomenon, as Axiom 32 states. And they thought that Jupiter, the first god of the so-called greater clans, was trying to speak to them through the whistling of his bolts and the crashing of his thunder. The giants now began to exercise that natural curiosity which is the daughter of ignorance and the mother of knowledge, and which is born when wonder arouses the human mind, as Axiom 39 states. This natural trait still persists tenaciously among the common people. When they see a comet, perihelion, or any unusual natural phenomenon, especially in the heavens, they grow curious and then quite anxious to learn its significance, as Axiom 39 states. ${ }^{48}$

Vico sees the history of humanity moving the first steps in the moment in which the subject, mentally still unshaped, the bestione, acts to step out of the state of nature and immerges in the reality that it has created creating also itself in that same act. In this case, action and creation are one thought: Jupiter. With myth, the animal moves inward, upturns its body in the soul that it has at that moment created, and then it is no longer an animal. The birth of thought is the birth of the world that is brought to the attention of conscience that assumes the characteristics of a pagan religiosity, an idolatrous religiosity. ${ }^{49}$ Vico does not focus on the critical illuminist question whether myth is illusion, error, or superstition, but on the point that, however false it may be, myth represents an event of ontological value, which brought thought into existence.

The human mind mirrors itself looking at the world and guesses a divinity because it senses itself in a condition of extreme danger, feebleness, and thinks about an unconditioned being, immensely strong, a god. The discourse seems paradoxical because it is based on a paradoxical situation that becomes the central point of the Vichian anthropological and philosophical reflection. Does anything exist more paradoxical than the condition of a primitive being continuously facing insidious and mortal dangers, in need of everything for the satisfaction of natural urgencies, who thinks of a divinity that speaks with thunderclaps and lightning bolts and through these signs is physically present? Thinking of Jupiter, as the wandering beast halts in the post-diluvian forests, astonished and shocked for the effects of the tempest, so the human being pauses because facing a wall on its path: the imagination. Thinking of Jupiter and fearing Him, the theological poet immediately denies the material existence made of necessities and real dangers, dominated by instinct. The first thought is a step conducive into the darkness where the pagan mind must create a new dimension at the same time than itself. The myth of Jupiter is the only idea existing in the mind, and because it is the idea 
that activated the mind, it must be simultaneously the idea that creates the mind and the mind that creates the idea. The poetry of the origin is not a creative act from nothing, but an awakening of the intellect from slumber. It is a spontaneous act without any instinctive spontaneity, to which it is opposed; it is an act contrary to nature and it begins from nature. It is a leaping act into the puddle of sensitivity, not into the clear waters of the intellect. The myth gives light to the mud of corporeity that does not reflect light but absorbs it. The thought generated is opaque, confused and dense, stagnant like sludge is in comparison with fresh water.

In the chapter on the origin of idolatry, the theses of Malebranche on this topic are summarized. The same theses, with some variations of perspective, exist in the Vichian conception of the myth of Jupiter. For Vico, too, the human being arrives at thought through the senses and the imagination and it is with these faculties, the only ones that the spirit from within the body can activate, that the human being assigns a value to the environment in which it finds itself. The bestione sees the sky for the first time and does not look at it as at a benevolent deity, but as at a pitiless entity that with the sensible impact of the thunder and the lightning demonstrates an annihilating force. In this dynamism of thought the obscure idea of death is also born. Fear of death does not overcome the intellect, but the imagination and the passions, that is, the spirit derived from the impact of the web of confused images fused together in a unique combination and fermentation of sentiments. Death is the prospect of a tremendous pain imposed by a potent and merciless god. The best and greatest of gods, having demonstrated its horrible authoritative power and shown that he is in the process of crashing the beast, lets the beast off. In this way the fear of death remained as the permanent hazard in the primitive mind. ${ }^{50}$ 



\section{EIGHT}

\section{THE METAPHORICAL NATURE OF THOUGHT}

Fantasy is the origin of human thought, and the first authors of the gentile nations, the founders of societies were poets. ${ }^{1}$ Poetry is the first form of thought, the pagan mind is a poetical mind. Poetry, the language of fantasy, is the avanguard of the army of the pagan mind, the plow that turns over the soil for the seeding of the intellect. As the plow descends into the clods, so fantasy penetrates the earthlier, carnal part of the soul. ${ }^{2}$ Poetry is the creation of meanings. The first human beings attributed to the bodies animate substances, as Vico said in the first Axiom that the human mind naturally tends to see itself externally in the body and ascribes its own nature to the effects (of its actions). Malebranche extended this tendency to all pagans. Poetry is made comprehensible when seen in light of the principles (including par. 236) of the first Axiom of The New Science:

All the primary figures of speech are corollaries of poetic logic. The most luminous figure, and hence the most basic and common, is metaphor. Metaphor is especially prized when, by the metaphysics just described, it confers sense and emotion on insensate objects. The first poets attributed to physical bodies the being of animate substances, endowed with limited power of sense and emotion like their own. In this way, they created myth about them; and such metaphor is a miniature myth. ${ }^{3}$

The metaphor, for Vico, is an instrument with which the human beings give meanings to things. Things can be thought because the human beings attribute sense and passions to the world that the mind represents to itself. The relation of similarity between the different elements of the metaphor originates from the transference of sentiments that, in the psychological field, is situated at the level of imagination. The supportive basis of the pagan thought, the myth, is an iconic analogy. The first thought, the myth of Jupiter, was formed in the primitive mind at the moment when the first theological poets gave sense and passion to the sky that they saw, transforming in this way an inanimate entity into what in the Aristotelian sense we call a living substance. The fable of Jupiter reveals what for the theological poet is the nature of the sky, the myth expresses the meaning of what 
the imagination represents, and the representation is believed erroneously equal to what truly exists. The representation is not a simple photography of what is perceived, it is what is perceived but with the addition of the distortions of the passions and through the opacity of the lens, the mind. The idea of sky, at the level purely of perception, would never be the matter for a myth. We know with Vico that the representation of the sky as an athmospheric entity is the point of arrival, not of departure.

A non-fantastic vision of the world is, in this point of view, a loss of the wealth of mythological meanings. Thought was born from an addition of meaning to objects, because objects, before being thought, have no meaning; objects possess no idea with which they can be represented to the mind. The attribution of meaning happens through the metaphor of Jupiter. The first rhetorical figure is however different from what we ordinarily call and understand as metaphor. The metaphors in articulate languages are possible only to a mind gifted with the ability of interrelating objects that have no effective and material similarity, but only an abstract and conceptual analogy, which we may call fantastic, but it is a conceptualizing fantasy that produced it. The rhetorical figures of articulate languages take the image from the concept. The first metaphor has a completely different structure. The primitive mind possesses no idea of things, but only one idea that it attributes to all things perceived: in everything, the primitive mind sees Jupiter. Jupiter is the metaphor representative of human sensations. The primitive mind is a decorating mind, whose decoration around the painting is the essence of the painting itself, the sensible representation. ${ }^{4}$

The first metaphor is the first idea with which the human being expresses its passions; the thundering and lightning sky is the metaphor of the human spirit. The first metaphor is not here recognized as a metaphor for the reason that the first thought is metaphorical by natural necessity. The human mind at this stage has no capability of thinking itself by itself, it must objectify itself in what the sensitivity offers; the mind must metaphorize itself. The primitive individual is not conscious of turning upside down the relation mind-object; it does not see itself in the sky, but another entity, Jupiter. The first metaphor is an imperfect figure because the orator, the theological poet, speaks about himself to himself, without knowing that he is both the subject and the object. The pagan does not know whether he is in the back or in front of the representation of divinity. Myth, then, is the reflected image of the human being.

In the mirror of a confused mind in expansion, the human being looks at itself but cannot acknowledge itself because he does not yet possess the concept of its own identity. Human is the image the human being sees, of this human being is the mind in which the image reflects, human are the eyes that see, but because of the lack of awareness of all the dynamics and nature of thought, in the image the human being sees nothing human but the divine expression in the fulmen and thunder. The storm is then the metaphor of the mind, a metaphor in 
which representation and represented are fused together and inseparable. The metaphor is a splitting of meaning; in this case, the human being is the meaning itself pulled apart as spectator and actor of thought. The human being is spectator as the animal that contemplates the sky, actor as Jupiter that makes himself known from the Olympian clouds, thunderbolts, and thunderclaps. The instinct in the animal represents a totality that supervises every action; in the human being, thought breaks this unity by virtually disconnecting the biological from the cultural being. Culture is the matter coming from the wound inflicted by thought on the instinct. With myth, the human being for the first time faces itself; imagination is the creator of thought, the producer of representations that place themselves between the human beings as spectators and as authors of thought. If the human mind were only a mirror, then there would be an ontological difference between the person who looks into the mirror, the reflected image, and the mirror. The truth is that the human mind is contemporaneously mirror, spectator, actor or subject, and the object of thought and representations. According to Malebranche, all these elements are rationally synthesized in the vision of the intelligible extension when in the mind there is no image that would create an obstacle to the infinite reflection in the self. The sensible representation imposes itself to conscience and upturns the dynamism of thought, providing an apparent or superficial structure that hides the real consistency of the mind.

The initial condition of the theological poet is that of the bestione, an animal controlled by instinct, with a reason made opaque because of the original transgression, followed by the loss of the light of reason. Sensitivity blunts the clear vision of the self and in its darkness the myth of Jupiter represents the first dissociation of the perceived that vivifies conscience. The metaphor is the fruit of this dissociation, ${ }^{5}$ a metaphor that, without abstract symbolism, is the imaginative content of the individual sensations. Jupiter as a body, in its own way, is the point of view of the soul. ${ }^{6}$ The structure of the myth is also metaphorical, and metaphorical is the pagan mind. Vico clearly explains how this metaphoricalness is not the intellectualized one:

And when we wish to express our understanding of intellectual notions, our imagination must assist us in explaining them and in giving them human form, as painters of allegories do. By contrast, the theological poets could not use their understanding and so performed the contrary operation, which is far more sublime. They attributed senses and emotions to physical bodies, even bodies as vast as the sky, earth and sea, as we have just seen. Later, as their vast imagination diminished and their power of abstraction increased, these deities shrank to diminutive symbols of themselves. Since the origins of these human institutions were buried in obscurity, metonymy dressed these symbols in the learned use of allegory. 
Jupiter grew so small and light that an eagle carries him in its flight. Neptune rides the sea in a dainty coach. And Cybele is seated on a lion. ${ }^{7}$

The intellectualized metaphoricalness derives from the disentangling of knowledge, from the abstraction performed in the mind by social life to the overturn of the terms of the question. The conceptualized metaphoricalness is the imagination that we used in our contemporary society and in its dynamics and structure is the reversal of the imagination of the theological poets. History has accomplished this dialectic turnaround. In the beginning, the primitive being did the opposite of what the modern human beings do. The first human beings attributed sense and passion to everything they came to know, looking at the world for the first time with human eyes they thought metaphorically themselves. In other terms, the theological poet is a metaphorical animal; thought is born as a metaphor of the thinking subject. In this, is found the barycenter of myth, idolatry, superstition, and fantastic thinking, which are all psychological phenomena.

Though myth is the metaphor of the perceiving subject, it is not a selfportrait signed by the perceiver-artist subject. The human being does not sign the picture of nature, imagined under the impulse of strong emotions, with its own name, but unconsciously with the pseudonym of Jupiter. Jupiter is the outcome of the conatus that restrained the bestial passions instead of letting them run their instinctive course. These passions were hypostasized and fixed in the fantastic representation of the pagan divinity. The fantastic representation appeased the passions and guided them through the channel of thought, and the instinctive wild bestial passions became fit to conveying the sensing of the thunderstorm as the image of divinity. ${ }^{8}$

The human being knows reality only through the imagination, an imagination that presents the knowledge of the world in its totality, by providing the world's photograph that the mind produced. This picture of the world is a religious representation and it defines the boundaries of primitive thought and of human thought. ${ }^{9}$ The most sublime reflections of philosophers like Aristotle begin from sensible certainty and on it by abstraction they build their metaphysics. For the theological poets the sensitive certainty is Jupiter whom they effectively believe to have seen. The theological poets possess the sensorial faculties, but not the intellective ones of the philosophers.

Thought has a divine origin, from a pagan deity that gives way to a superstitious idolatric religiosity. It is a thought that started with error, transgression, and the deception of our natural imagination. The veneration that materialized itself in the image of a divinity from our fears is the first human act. Anthropology becomes the way for the comprehension of poetical theology, the way for the comprehension of how from sin to sin, from error to error, the human being develops its intellectual capacities, its societies and the arts and how all these elements maintain the signs of their crude origins. ${ }^{10}$ 


\section{The Birth of Thought and Abstraction}

Human societies, which are the most evident effect of thought, originated from the progressive independence of thought from the palude of the sensations. It was a gradual detachment. The first thought represented the total break away from the previous situation, a complete change in perspective, or rather the creation of a perspective that did not exist before. ${ }^{11}$ This new thought was not a conceptualized thought, a clear vision of the real needs of the thinking subject, and the goals to be achieved. This thought was marked sensitively by the tracks of the mud from which it wanted to move away.

The great beast scared as it was by the enormous effects of the natural elements imagine the sky as Jupiter and not as a simple physical entity; it did not believe that lightning and claps were atmospheric agents but admonitions of the divinity. Only through the fiction of the divinity, the brute becomes aware of the existence of the sky that will not be recognized as such but as it is experienced, a divinity. In the successive phase of the cognitive development, the processes of abstraction desacralized the atmospheric phenomenon of the sky that began then to appear as what it actually was or as it appears to contemporary human beings, though the organs of the senses have perceived it always in the same manner.

The world of poetry and myth is the world of repressive passions, impulses, and strong sensations, confused images, battles against merciless nature, full of snares and adverse to the poor beast. The myths are the production of the creative human faculty, of fantasy; myths are poetic works. All techniques, all the actions performed with a precise aim are myths; the progressive dominion over nature, the clearing of forests, hunting, the cultivation of fields become myths. These are not actions in the same way we understand them; they are not done for an advantageous finality, though they may carry final usefulness. These are ritualized operations that an imperfect mind has produced and that through the myth tries to structure itself shaken as it is by violent passions and with an intellect lenient in imaginations.

Myth is language, and this term, too, should be interpreted in a new way. Language essentially is communication of experiences, fantasies, and sentiments. Language makes itself explicit in the communication of strong imaginations. Poetry is communication of forceful imaginations, speaking pictures that speak through the articulations of sound, but also through gestures, actions, natural signs, and the materials of these mental pictures, the hieroglyphs. Vico thinks myth and poetry as forms of thought or the first logically possible that the primitive minds could formulate. Thought is from its origin a representative thought, with a form of representativeness that is extremely raw and puzzled like the one of a child just born. Vico's' theological poets are beings who for the first time are born in the world of thought. 
Vico and Malebranche consider the psychological and the physical birth, but it is of the psychological birth that they study the lines of development. In The New Science, Vico narrates the birth of nations and particularly the birth of thought as a fantastic thought. In order to be able to immerge oneself into the vast imagination of the first human beings, we must assume that human beings could know the world only as much as they could think of it. Human beings always have to deal with their thought and their conception of the world would change in proportion to the changing of their thought. In Vico's perspective, in which knowledge is conformation of the object to thought, the mind dictates the transformation of the world. An analysis of the pagan mind from the point of view of Vico is possible within a subjectivist frame, and not only in a generic anti-Aristotelian attitude. The continuity between the bestioni and the theological poets is assured by nature's progressive and gradual continuity, without abrupt changes. It is not possible to move from the absence of thought to a well structured thought.

The first thought, the fantastic universal of Jupiter, is the depository of all instances of necessities, needs, and material conditions that made it possible. There is continuity between the animal and the human being because there is continuity between the physical world including the body of the animal and that of the theological poet. Our interest moves in a different direction. If for Vico thought were to have originated in the progressive specialization of human competencies, for instance, in the ability of building and using tools suitable for the modification of the environment, then we could assume an ontological continuity between the animal and the human being. The vegetative, sensible, and intellective soul could be disposed on the same line of development. From Vico's pages dealing with poetical logic, truly we cannot deduce this theory. No biological mutation happens, nothing new in the physical ambiance: the tempest that awakens the spirit of the brute is not the first storm in absolute, but only the first to be experienced and interpreted in a different way. On the contrary, the revolution exists inside the human spirit, so that the first thought is situated at a level superior to that of the pure instrumentality of the senses, to the vegetative life. The conceptual breach or ontological difference exists both in the material situation and in the interior motions of the brute and the perception of the theological poet. The theological poet perceives the world in the same way than the brute, but the theological poet interprets it, too. Briefly, the bestione does not become intelligent in one moment; there is no explosion of thought, intellective faculties, or a sudden and vertical increase of the intellectual power. The pulsations and the bio-chemical reactions are the same in the animal and in the human being and we may call them motions of animal spirits in the phraseology of the seventeenth century. The modality according to which the motions discharge themselves and where they discharge, are certainly different: in the brute, they relieve themselves in a physical reaction; in the human being, in the fantastic thought and myth. 
The first thought presents for the first time to the human mind a representation of reality, but this does not mean that if at the cognitive level a complete reversal happens, complete and immediate would be also the transformation of the material living conditions of the subject. With the first myth, the human being gives a ritualistic character to its existence by accomplishing a complete series of deeds that before it could not, because it could not think and plan them. At the dawn of civilization, the human being lives in a reality that is still savage and bestial. Thought is born in a mind that is awakening with the myth, a mind immersed in an instinctual sensitivity, a mind submissive to corporeity. Myth is the cause of the birth of nations; culture, which is the effect of nations, develops thereafter. When myth appears for the first time everything in the human beings and around them are nature, instinct, and bestiality. The advancement of humanness in nature both external, like the ambient, and internal, like the instinct, happens gradually and with effort.

The continuity of the physical ambient and the discontinuity of cognition between bestione and theological poet are simultaneously present in the myth. The myth of Jupiter, though it is sensible in its representative content, is a mental representation or idea, as Vico expressly says. This is the important point of the discussion, because the myth is something that the theological poet has and of which the bestione is deprived. The human beings have myth; the bestioni are randomly roaming throughout the enormous forests. The anthropologist Vico could not theorize that the first thought was the fantastic thought, the thought of a divinity (Jupiter), the thought that is all the reality there is, unless he presupposed a fracture between the mind and the physical reality. An Aristotelian anthropologist or an empiricist cannot interpret myth as Vico does, because the Aristotelian would interpret Jupiter as the abstraction of the sensible qualities of the lightning and the thunder, which is exactly the opposite of what Vico did. ${ }^{12}$ As Malebranche faces the newborn baby, so Vico faces the new gentes (gentiles) or bestioni who experienced the divinity of Jupiter. The midwife, the parents, and the obstetrician of the first case become the thunder and lightning of the second; the giants in the first instance become the Jupiter in the second. Fantastic thought presupposes a theory of representativeness that, though not fully Cartesian, is certainly antiAristotelian and subjectivist. The mentality of the theological poet is truly a rough form of subjectivist solipsism:

The first peoples of pagan antiquity were, by a demonstrable necessity of their nature poets who spoke by means of poetic symbols.... Their symbols were certain imaginative categories, or archetypes. These were largely images of animate beings, such as gods and heroes, which they formed in their imagination, and to which they assigned all the specifics and particulars comprised by each generic category.... We find then, that the divine and heroic symbols were true myths or true mythical speeches. ${ }^{13}$ 
For Malebranche and Vico, the imagination brings the human beings to the point of transferring the violent impulses of their soul to the phenomenal world. The state of the spirit of the first theological poet who contemplates Jupiter is conditioned by the passions, the natural inclinations, and the external factors that act forcefully on him. The world seen from imagination is radically modified in its reality, and the pagan mind will never know it as it really is, because even the perceptual data are modified. The imagination is not the objectification but the subjectification of the sensible data. The imagination transforms what is perceived, in the light of the passions that agitate the soul. ${ }^{14}$ The gentile or bestione of The New Science judges the sky according to its condition both physical, emotive, and cognitive. It is the condition of a being without orientation, with a conscience shaken by turbulent passions, searching justification for its sense of emptiness and that attributes meaning to everything in the surrounding nature. One of the innovative points in Vico's interpretation of myth is that the bestione recognizes Jupiter in the sky and that it recognizes only Jupiter. What we call sky and interpret as an atmospheric phenomenon, the primitive calls him Jupiter and does not see it as an atmospheric phenomenon. In the storming sky, the primitive does neither see the lightning nor hear the thunder.

The theological poet cannot say, "The storm is Jupiter." Such an affirmation requires at least three concepts in order to be formulated: tempest, divinityJupiter, and identity. In addition, two cognitive competencies are necessary: the faculty of representing ideas and the ability of abstracting from the representation of the physical event the abstract concept of divinity. Unfortunately, the first human being possessed in a vague format only one concept, the idea of Jupiter, and the limited ability of representing something. If we were to think of the sky as a god in the same way the primitive human did, we would not succeed because we have the intermediary idea of the physical phenomenon. In our case, the idea of the sky will be the first, and on the idea of sky that of god will be inserted. For the primitive human mind, the idea of Jupiter will be the first and from it in a successive growth of the mind parallel to that of the society of the "heroes," will be derived that of the sky. While our operation is one of abstraction (god from sky), the operation of the theological poet is one of concretization (Jupiter is a concrete entity and he manifests himself concretely and sensibly as the sky). For the theological poet, the sky did not exist before he began to think, and after he began to think the sky existed as Jupiter not as sky. We may also say that neither the sky nor the theological poet existed before the myth of Jupiter; the bestione or animal existed but not the human being. At this point, we will consider the operations of abstraction and non-abstraction in relation to the intelligible extension (esteso intelligibile) and the dynamics that control the functioning of the imagination. We may explain that the intelligible extension is like the condition of the mind that thinks in its purity without determining itself in representations, a mind with no ex- 
pressed particular ideas and identifying with the divine mind. An Aristotelian, a materialist, and an atheist will not comprehend the notion of the intelligible extension. They would think of the purity of thought as of an abstract goal that the mind wishes to obtain, as something that comes after the imagination, as something that is realized after the dissolution of the representative contents through the cleansing of the representative faculty by way of abstraction. The knowledge of the intelligible extension precedes the imagination; it is not an ideal abstraction but a concretization; it is a vision of the truth by way of intuition, free of what is composite. In the same way, an anthropologist accepting an Aristotelian optics will not comprehend Vico's concept of the myth of the origins.

Malebranche and Vico denied, each in his own way and with different theoretical perspectives, which the thinking of the divinity as of something that exists outside of the representation assumes a capability of abstracting that separates and at the same time binds symbolically together representation and concept. At the basis of these philosophers' analyses, which in some aspects are contrary, a commonly accepted principle exists: the imagination has no need of abstraction in its activity of representation. This does not mean that imagination in its normal functioning will not make use of abstractive capabilities. On the contrary, both the Oratorian and the Neapolitan philosophers believe that this is usually the case. The abstraction intervenes in the work of the imagination in a secondary position, but always within the totality of the time of the mind, at an individual and historical level. The discussion centers on the question whether the imagination could exist without the abstraction, and not whether the abstraction participates in the work of imagination.

Descartes with the primitive notions, Malebranche with the intelligible extension, and Vico with the anti-euhemerist and anti-symbolic conception of the myth of Jupiter affirm that it is possible and necessary that imagination could operate even without abstraction. This point of view underlines a more complex and articulate picture of the imagination and demands a more intricate conception of the human mind that must contextualize the imagination within the whole discourse on the topic of knowledge. In confirmation of this, we know that the first human beings of Vico found much more reality in the fiction of the divinity than in what they perceived without interpretation. Malebranche supports this point when he narrates that the pagan spirit, the victim of passions and sensation, enjoys greatly its condition of estrangement as if the life of fantasies were its natural optimal state. The human being enjoys so very much the fantasizing that of reality it only accepts what tallies with its fantasy. The imagination diverts from the consideration of reality as it is effectively, but facilitates the concentration on what it esteems as the object of its search. The illusion in which the Vichian bestione lives is a fully comprehensive fiction; it is not something extra alongside reality, it is all the reality there is. The false credence does not substitute or imposes itself on the true credence because there is no true credence. Before the illusion, nothing exists in 
the mind. The first form of thought is the trick that the human beings play to themselves. The first thought is a myth; the myth is the first word for convincing the human being of the veracity of the interpretation that the imagination has given to the hypostasizing of passions and sentiments in nature. The myth previously to being a story, is a form of thought and language that essentially speaks through images.

The language of myths is a mute language, made of images; it is the language of the imagination and essentially presents itself at the level of sentiments and sensitivity. The fable, the narration of what happened, the description of the successive events is not done through a verbal communication but the communication of vivid images. In this context, poetry is in effect a speaking picture, a picture colored with passions and sensations. For Vico, the ideas are images of essentially visual character; they are representations of bodies in the way the Cartesians and especially Malebranche understood them. The manifest effort in The New Science is that of penetrating the thought of the first human beings, who truly are not yet human, but are on the threshold of becoming human, of performing the passage from the instinctive to the humane, from the logic stimulusresponse to the universe imagined and experienced with the passions. The first ceremonies, the cults that these brutish beings will begin to celebrate will be also linguistic expressions, poetical and social products of the imagination. The whole reality is experienced with the imagination; it is thought through icons charged with emotivity and sensible connotations. For Malebranche, the representations in themselves have no abstractedness. Only if we consider the mental image concrete, that is, as directly intuited as it is in itself, and if we look at abstraction in the relations created by the mind among representations and ideas, we can obtain the conception of thought and of its configuration in the Vichian mode. For Vico, myth is a concrete idea, not abstract, conceivable only in itself and not in relation to other ideas. If we were to consider abstraction as the motor of the birth of thought, we would be obliged to assume on one side an ontological continuity between instinct and thought, between the brute and the theological poet, and on another side the formation of a mind that is already complex at its origin, capable of representations and abstractions.

\section{The Myth is the Reality}

For a clearer idea of what Vico means with myth in relation to imagination, a comment is needed on the expression "a great animate body." Jupiter is the storm, the lightning, the thunderclaps, all the phenomena that human beings have seen also before thinking of them through myths, which they did not interpret. With the intervention of the theological poet the phenomena are viewed as a great animate body as if it were the enormous body of a giant, whose words are thunders 
and whose power are the thunderbolts. We exemplify this by referring to some Chinese pictures in which a Dragon takes its form from the clouds of a tempestuous sky. On these pictures, an iconographic series exists of which certainly Vico was aware. The Dragon is not over imposed on the clouds, it is made of clouds, and its composition in the mind of the painter is not a mass of water, but the members alive and strong of the monster Dragon. The painter sees no clouds and sky, but a Dragon. ${ }^{15}$ Jupiter, which in our mythology corresponds to the Chinese Dragon, is the mass of stormy clouds. Jupiter has consistency and is animate. Jupiter is the being whose power is proportional to its (imagined) great body in contrast to the smallness of the human being. The clouds for the theological poet are not what they are for us. For us, the clouds may be aqueous vapor, but for the pagan mind they are living substance of the divinity; they are not vaporous but solid as a rock. Jupiter is a great animate body that imposes its will on human beings, with its thunderbolts and claps. In this way, thought is born and a society is formed. The imagination establishes values and norms, the conduct, and the rules of social living.

The whole represented world becomes a symbol, an instrument of communication, but a symbol coinciding with its signification because living in a coarse and obtuse mind that with difficulty lays itself on the level of imagination. Everything is imagined and only imagined, and it is all what reality is. The symbol cannot defer to another level of thought, which, at that exact moment, cannot exist. The relation between word and meaning is a natural relationship. Malebranche would say that the bond between traces and ideas is natural; neither abstraction nor intellectual distinction exists, but a fervent fantasy that refers everything to itself. Vico sees fantasy as the faculty that forms images, as the painter of the soul. In human beings, fantasy is stronger and more capable of creating icons of reality in indirect proportion to their power of ratiocination and use of articulate language.

Next, the necessity to express itself for communicating their ideas to others, at a time when, because of a lack of words, the spirit is wholly engaged in finding a way to express itself, makes such mute human beings naturally ingenious. Hence they express themselves by means of things and actions that have natural relation with the ideas they want to signify. Thus we find that the first words of the earliest nations were mute. ... Finally, when there is either little or no use of reasoning, the senses are robust; when the senses are robust the imagination is vivid; and a vivid imagination is the best painter of the images that objects imprint on the senses. ${ }^{16}$

Fantasy and imagination should be considered as the origin of the human mind; they are faculty of visual character, not abstract. The other senses are subordinates to that of vision, which is the best way of representing figures and things in the 
most vivid manner. We should judge geometry in the same way, because geometry asks prevalently for a visual imagination. Geometry demands the elimination of all other sensible components and this is possible only for an advanced mind, not for the pagan mind. Sight is the sense of vision, of picture, and in the pagan mind, of a picture with strong tints; it is not the picture of a geometric design. The geometric figure comes from mathematical reasoning, not from the fantasy, which is imagination and a chaotic succession of passions.

The human imagination looks at the external world, it does not provides knowledge of our conscience, but of the surrounding world's figures. The primitive human being of Vico thinks at the level of imagination, and this imagination offers the human being no criterion, no awareness of self, no understanding of the nature of the soul. The imagination pays attention only to representable experience and cannot form a representation of the soul, which therefore remains unknown. Myth is the first expressive formulation of humankind; it is the effect of imagination. In the beginnings, myth will not relate to the thinking subject; myth will relate to what in the sensible experience possesses characters strong enough to impose themselves on a robust and always agitated fantasy.

The first thought will be the first myth, but this myth will not coincide with self-consciousness. The first thought is a thought of otherness, of something else than ourselves. For Vico, our difficulty in penetrating the mind of the primitive human beings is due to our incapacity of identification with their emotive condition. Our mind is a keener mind, with abstractive faculties, used to distinctions, capable of thinking many different things at the same time. In addition, our society's customs and our ambiance constitute the impassable wall for us in our effort to see with primitive eyes the world the first human beings saw, the world of myth. This is the way Vico described his efforts, "As I sought to discover the manner in which this first human thought arose in the pagan world, I met with arduous difficulties which have cost me a full twenty years of research to overcome. For I had to descend from today civilized human nature to the savage and monstrous nature of these early people, which we can by no means imagine and can conceive only with great efforts."17

The beliefs that fantasy generated in the pagan mind were beliefs perfectly coherent with the perspective of the theological poets. The first thought was the first picture, the first fantastic representation of nature, which human beings made for themselves. ${ }^{18}$ The first myth is the first religion (pagan); it is absolutely the first thought; Jupiter is the first fantastic universal; it is the first picture, the first representation that took hold of a mind atrophied in sensitivity. The first thought is the idea of a superior being, imagined by a strong but limited fantasy. Frightened and thunderstruck by the exceptional atmospheric phenomenon, instead of reacting like any other animals, these first human beings stopped roaming and raising their eyes observed the heavens. The heavens, the great living body agitates itself, shows with thunderclaps and lightning bolts the force of which it is capable. The sky as- 
sumed the characters of an enormous ferocious beast that could annihilate the human beings if it so wanted, but saved and submitted them to its will. The first thought is also the first law. Thought, image, word, and law are the characters of the universale fantastico. The first thought is the idea of a living being that possesses the typical characters of exceptionality, novelty, and power: "And since these early people communicated by signs, they naturally believed that lightning bolds and thunderclaps were signs made to them by Jupiter. Later, from Latin nuo, to make a sign by nodding, they derived numen, divine will, by an idea which is utterly sublime and worthy to express divine majesty. They believed that Jupiter commanded by signs, that these signs were physical words, and that nature was Jupiter's language."19 Nature is the language of Jupiter; he speaks to human beings with the wind, the forests, and the rivers in which he exists as in everything else that the primitive eyes reach. Nature perceived through the filter of thought is not the same nature that the human beings knew with the instinct in the first conscious experience of the sky traversed by lightnings and thunderclaps. The bestioni reacted to all this first with fear. The answer to the atmospheric event is not a mechanical reaction; the sentiments of the bestioni joined with a representation. The atmospheric phenomenon transformed into an idea of fantastic character, into a divinity. From here on, the bestioni will never consider the sky anything else but a divinity. For the theological poet, the sky in itself does not exist; what exists is a great animate body, a divinity. The sky is not the sign that points to the divinity; it is the divinity. The first human being does not see the sky but a great animate body. What the human being sees is what exists, and what it sees is Jupiter. "Thus the first fable, the first principle of the divine poetry of the gentiles i.e. of the theological poets, was born. And it was born, as the supreme fable must be, wholly ideal, in that the idea of the poet gives things all the being that they lack. It is, as masters of the art of poetry say it should be, entirely imaginary, like the work of a painter of ideas, and not representational, like that of a painter of portraits. Hence, through this resemblance to God the creator, the poets were called 'divine'." 20 Thought is therefore born as a fantastic art, an art that does not convey meanings different from the signs used to represent them; there are no signs that recall arcane meanings, hidden and mysterious. Thought is the art of representing the world with the senses and the passions; it is the art of the perceived fixed with the gluing of fear, prostration, admiration, and obedience in the representation of a body. The way thought, myth, and poetry are born is through the attribution of life and will to a body, which in reality is lifeless and senseless, but which, under the pressure of fear, suppression, and the hope of being saved, is thought as a divinity, that is, as a superior corporeal being.

The imagined reality is the presence of an animate nature, alive in itself, having within itself the principle of its existence. The heavens are interpreted by the first authors of nations as an immense animate body, which speaks, threats, agitates, and wants to communicate with the human beings. In other words, nature 
is not the sign of Jupiter but Jupiter himself. No abstraction is performed from fantasy to concept; thought is all in the imagination; the fable is the description of what is imagined. Thought is born as the fiction of the fantasies of the primitive human clans that, through the power of the senses and the passions, painted in their minds Jupiter as a great animate body, a living substance that exhibited peculiar might. Reality is all in the imagination; the object is true in the way it is thought, experienced, and lived. The primitive mind is all gathered around the imagination, without abstractive faculties, without the ability of transferring meaning from sign to concept. The myth and the fable are not the means for the expression in fantastic terms of what is not fantastic and could be expressed with other more adequate modalities, better capable of rendering the idea. Allegorical interpretations of myth are here excluded. Myth and fable are the typical products of fantasy and convey thoughts that in their origin, in their nature are totally fantastic. Myth and fable are fantastically constituted and cannot adequately be presented, expressed, comprehended, and lived in any other way than fantastically: "For example, the theological poets understood Jupiter, Cybele or Berecynthia, and Neptune in this way. At first, pointing mutely, they interpreted them as the substance of the sky, earth, and sea, which they imagined to be animate deities; and, trusting the truth of their senses, they believed they were gods. In this way, they used these three deities to explain everything related to sky, earth, and sea, which is the function of poetic archetypes (universals)." 21 Truth for the theological poets is that of the senses and the imagination. The perception of the storm is equal to our own; what changes is the interpretation assigned to the experienced event, interpretation that at times may even influence the perception itself of the phenomenon. The principal interest of Vico centers on the interpretation of the representations that the subject produces in its mind. In the mind of the theological poet no distinction exists between reality and its representation; the only reality is the interpretation of the representation. The interpretation hides the reality, which remained beyond the ability of comprehension of the primitive intelligence.

Jupiter is the one who speaks to the beast, not the sky; Jupiter exists, not the sky. Cybele exists, not the earth. Neptune exists, not the sea. It is not redundant to insist on this point. The greatest difficulty in the understanding of Vico's theory of myth is to remember that the primitive mind begins with the sensations and ends with imagination. At this primitive stage, the intellect never acts as the faculty of abstraction as it does in our contemporary time. The first gentile thought could not have the comprehensible and intelligible structure like the one of the abstracting modern mind. Vico is adamant on this point and in the The New Science he is generous to remind the modern readers about such difficulty. ${ }^{22}$ The modern mind with a well developed abstracting faculty can distinguish between the physical phenomenon and the fantastic interpretation that eventually we may give. In such case, we will be fantasizing about a concept already cleared in our mind. It would be as if the fantasizing represented an ulterior abstraction to be 
added to the concept that performs the abstraction from the useless or barren components for the definition of the physical phenomenon. An operation of this kind is moving in the opposite direction of the one characterizing the mind of the Vichian theological poet. In the mind of the theological poet no concept of heavens exists, to which in a successive moment we had to add the belief of the divinity. In the theological poet's mind, the vision of the great animate body of Jupiter physically exists. We recognized the great animate body as the sky during a summer's storm.

In this manner, the earliest people of the pagan nations created things according to their own ideas: for they were the children of the nascent human race. Yet their act of creation was infinitely removed from the creation of God, who by his perfect understanding knows things and creates them in this knowledge. In their robust ignorance, the earliest people could create only by using their imagination, which was grossly physical. Yet this very physicality made their creation wonderfully sublime, and this sublimity was so great and powerful that it excited their imagination to ecstasy. By virtue of this imaginative creation, they were called poets, which in Greek means creators. ${ }^{23}$

In Cartesian terms, we are not free to interpret "two plus two" because from an evidence of reason we feel obliged to recognize a univocal solution. Mathematics and, in general, the truth of reason are discovered, they are not invented. On the contrary, because myth was not born under the dominion of rationality, it began from interpretation. If truth does not allow interpretation, then the mind was born as the erroneous thought of the faculty of imagination. The act of creation possible to human beings is that of error, falseness, and imagination. The poet thinks reality by creating it through the fantastic representation that his mind produces.

The world once created by the perfect mind of God is reproduced proportionally by the rough pagan mind at the usage and advantage of grossly intense and confused sentiments. We arrived at the decisive point: the pagan mind is the creator of meanings and things, and only a philosopher who considers in the modern manner the representations of the mind can theorize about it. These will be the ideas of the subject and will have nothing in common with reality. This thinker will be one who imputes to the pagan mind the error of considering as congruent, similar or even identical, both the representations of reality and the reality. Only with these two premises Vico can propose the thesis that we have presented in the previous citation: first, the ideas of bodies are representations of the subject and they are not truly similar to the bodies as they are; second, only the pagan mind that thinks through accidental and subjective similarities believes that reality is the way the mind represents it. It is by means of the most corporeal fantasy that things were created by imagining them. These premises were already 
present in the critical Cartesian construction, on whose axle Malebranche developed his attacks against the Scholastic philosophy. The reality of the myth is not to be found in the correspondence of thought to reality, but in the play acted on the stage of the conscience. The reality of the myth is its ability of existing in thought; it is the creation of a new dimension of the reality, thought. We will see how Malebranche analyzes the superstitions of the fool and how he, too, defines them real, not in their object, but as representations that are the content of thought. To us it appears obvious that a thought can be completely false relatively to the existence of what it affirms, but absolutely real in itself. In the field of philosophy, an affirmation of this kind presupposes an insurmountable wall between what happens in the soul and what happens outside the soul.

To ask whether a theory like the Vichian one that presents myth as the total and original fiction internal to conscience, detached from the external reality and even opposite to all external material necessity is possible, without admitting the existence of a previous movement of thought that theorized a total distinction of the mind from matter, it would be certainly a sophism. The mythical mind, like the monad of Leibniz, has no window; it creates in the interior of itself its own vision of the world; it sees the world from its own point; and proceeds progressively from a confused perception (with the myth) to a clear and distinct perception (with the concept of the intellect). The impulse toward thought comes from within the subject and not from the outside. Inside the primitive mind there is only sense and, according to Malebranche, the imagination is an aspect of sensitivity and not another faculty.

If the birth of thought is the awakening of the senses, it means that the senses belong to thought, not to the body. If the first thought is a myth, a representative fantastic character, then the senses belong to thought and instead of being a bridge with what is external to thought, they constitute an insurmountable barrier of the soul toward the body. We must distinguish between the perspective of the analyzing anthropologist and that of the subject analyzed, the theological poet or the idolater or anyone possessing a pagan mind. To the eyes of the $\mathrm{Vi-}$ chian anthropologist, the imagination is in itself a faculty that precedes the performance of the abstraction; it is a sense internal to the soul. If we will act contrary to the anthropologist's way, in a non analytical way, without that fundamental distinction, we would end looking at myth in the same way than those who created myths. Then, we could look at myths not as scientists, but as the primitives and the superstitious. The keystone for the comprehension of myth is that of penetrating into the imagination of the primitives, with a scientific study that considers the imagination as the gravitational point around which the pagan mentality orbits. 


$$
\text { PART TWO }
$$

THE FIRST AND SECOND KIND OF IMAGINATION THE SENSES AND THE INTELLECT 



\section{NINE}

\section{THE INTELLIGIBLE EXTENSION: THE IDEA OF DEATH AND OF IDOLATRY}

Malebranche's Dialogues on Metaphysics and on Religion are an analysis of idolatry understood as the product of an imaginative (pagan) thought. Idolatry is here considered in relation to the idea of death produced by fantasy and to the conception of the intelligible extension. For the defense of true faith and pure belief, people feel that they must criticize and fight all forms of religious falseness: superstitions. Idolatry and all forms of irrationality are born from the acceptance of presentiality as being the reality. ${ }^{1}$ Idolatry and irrationality are proper to a mind that attributes to things an importance proportional to the sensible intensity with which they are actually perceived. It is through the true idea of death that, according to Malebranche, we can arrive at a just and justified consideration of life and a veritable conception of God. In a moral set, death is what in the gnoseological plane the rational usage of criticism is. The thought of death is the instrument for the consideration of the real consistency of things, the nature of our wishes and inclinations, our thoughts, and the direction of our existence. The thought of death has such power as to be able to destroy the projects construed on false ideas of goodness. Only the thought dominated by the ghosts of our passions looks at death as the ending of life, whereas reason acknowledges in death the goal of life. For the Christian, the pure idea of death is the negation of all representations, but not of thought. Indeed, the idea of death is the solid affirmation of pure thought. For the carnal human being, reality is only what is actually experienced. Thought, existence, projects, world-view are turned upside down for the carnal human being. The carnal beings will sacrifice reality for its appearance; they will look for sensible goods because, having assumed that the only real is what is present, they are convinced that the sensible things at hand are the real goods. We could say that sensible (carnal) human beings are irrational because they lack a valid criterion for judging their own sensible thoughts and cannot give the correct sense and significance to what happens to them. Having established the senses as the fulcrum of their actions and as the barycenter of their thought, human beings have lost the measure of their sensitivity, the true significance of the body and the sensible pleasures, and the just consideration of corporeity. We may say that the sense of our 
senses, their significant orientation is toward a specific goal, which, for Malebranche, is the salvation of the individual soul.

Sensitivity has two sides: the pleasurable and, in a greater portion, the painful. The human beings enjoy pleasures in life, and death appears to them as the worst of all evils because death will remove the possibility of pleasures. Riches, honors, and powers are only dreams and like dreams they vanish as they become incubi. Then, each incubus is terrifying, and the carnal human being is awakened from its torpor by the phantasm of death. Human beings need the phantasms of pains since pains cause the desired reversal of perspective and point to the right path to follow. ${ }^{2}$ If life is the life of the senses, then death is the end of life, but if life is the life of the soul, then death is the end of the testing period. The time allotted to us is not for slumber but for an effort to understand God.

According to Malebranche, we can think of death in two ways. On one hand, we have the rational idea conceived with the intellect; it is a unique and true idea. On another hand, we have all the ideas born from the imagination, the infinity of ideas in the infinity of different modes in which we can represent the phantasm of our fears. With Malebranche, we must analyze the false ideas but, in order to understand his thought, we must previously consider his explanation of the intelligible extension and the "spiritual exercise" 3 or experiment of restrain that he suggests for its comprehension:

If we close our eyes, then the extended without limits would present itself to our mind. Within the immaterial extendedness that occupies no place except the mind that sees it, as I proved elsewhere, we can discover all sorts of figures and form a sphere or a cube like out of a block of matter. This extendedness and these figures are intelligible because it is impossible to sense them. When, however, we open our eyes, this same extendedness become sensible to our vision because it touches us more vividly and generate in our mind a multitude of different perceptions that we call colors. I am presenting what I feel without giving proofs, since this is not the proper place for them. It is sufficient to notice that in the sight that we have of the objects, for example, of this sheet of paper, we find only the extendedness and the whiteness, and once again, this would be enough for now. When we open our eyes in the midst of the countryside, all the variety of objects that our sight discovers derive from the distribution of the different colors that appear widespread on the different parts of the extendedness before our eyes. It is evident that we judge the difference of the bodily objects in relation to their colors. ${ }^{4}$

The experience to which Malebranche invited us constitutes a cognitive premise to the proof by way of a simple vision. When we close our eyes, we have immediately an extension without limits present in our mind. It is as if we had a switch with 
which to turn off the senses and bring darkness and silence to our soul. The effect of this action would produce a kind of mental void, an infinite extension (for no other reason except that it is without limits). If in the mind there was the notion of limit, then something would exist in it, but because of this slumber of all the senses, when we close our eyes, nothing in the mind can happen. If to our ideal and not-sensible vision of the mental infinitude we were to over impose any representation, this representation would become a limit, a veil between eternity and us. The representation would appear as a limitation and an extinction of reality, when on the contrary it is only hiding or covering the limitless substance on which it lays.

Malebranche stated that the representation in itself is not the essence of thought. Beyond the representation, underneath, we may say, the true essence of thought, the intelligible extension or extendedness exists. The representations do not dissolve the intelligible extendedness; they rather find their place inside of the extendedness. As we already observed, Descartes at the beginning of the third meditation took the shortcut of considering false all the representative thoughts instead of denying them in absolute. In reality, the course that Malebranche suggests we take is the same than that of the abstraction or what commonly is understood for reversed abstraction. We should not start from the representation and then try to cleanse it. On the contrary, we should begin from denying the abstraction with the result that from it we would abstract nothing.

Whichever the method suggested in order to deny mentally our representations, what we have to achieve is the silence of the body, an absolute absence of sensations, in the condition of the total feebleness of the senses. The only and uniquely possible example that Malebranche gave for achieving a negation of all the representative thoughts (those with a remarkable sensible component) was that of the rational thought of death. As death is the death of the body, and therefore its negation, so the thought of death is the negation of all corporeal thoughts. The human soul is a mind as long as it is united with the body; the body dies with death, but thought survives. All the thoughts that were the effect of the union of the mind with the body, that is, all the sensible thoughts representing corporeal entities, are also going to vanish with the death of the body. In the moral level, the idea of death invites us to understand that the sensible things, which are known to our souls as representations of sensible things, are not the limit of reality, they are not to be identified with reality, and they are only an apparent limitation.

With a mental experiment, Malebranche showed how to move from the total absence of representative thought to thought. Of what will we be conscious, when in the absence of all representative thoughts, we will think about the world? Obviously, we will obtain some sensible data. He said, "Mais lorsqu'on ouvre les yeux, cette meme étendue devient sensible à notre égard (When we open our eyes, this same extension becomes perceivable to our sight)..$^{5}$ We must remember that the location of this example in the original text is not casual; it is to be found after the exposi- 
tion of the difference between the true concept of death and the idea that of death we construct through the senses. A difference exists between the adequate idea of death, the total absence of sensitivity, and the fictitious idea of death rooted on nature, our human nature: death as the terrible thing that imagination portrays. This difference is equal to that between the adequate pure idea of the intelligible extension and the idea of the intelligible extension filled with the representations, which obfuscated it.

The passage, from an empty thought to one determined, happens necessarily through sensitivity. The passage from the adequate thought of death to the fictitious thought constructed on imagination follows the same procedures of the passage from the intelligible extentedness to determined thoughts. Both passages are from an idea that performs a complete and absolute abstraction from sensible data and an idea all dependent from sensitivity. Definitively, the passage from non-thought to thought will happen through sensitivity. The first thought will be a sensible thought.

The discourse we have developed hereherto has a particular goal. There exists a strong bond between the conception of the intelligible extension and the fantastic thought, though they are ontologically contrary. There also exists a strong bond between the rational idea of death and the fantastic and emotional idea of death. Naturally, and we underline this point, the rational idea of death can be acquired only when we are apt to be conscious of the intelligible extendedness.

It is easy to sense that the strongest imaginative thought is the fictitious thought of death. The fictitious thought of death can be characterized as universal because it polarizes the passions and combines in itself all the images. The fictitious thought of death takes its origin from sensitivity and from it proceeds abstracting from the emotions to aggregate progressively all fantasies, fears, and beliefs. If we consider thought from the psycho-anthropological perspective, we would understand that it proceeds from a matter extremely coarse and gross. Then, through the abstraction understood as contrary to the conscious abstraction of the intelligible extended, thought purifies and frees itself of the superfluous in order to arrive at the geometric image of the perceived object. In this work of conceptualization, the ideas lose content in direct proportion of what they gain in formal exactness.

Conscious thought or conscience necessarily starts from sensitivity and elevates itself from sensitivity, meaning that it will follow the path of the Aristotelian abstraction and oppose the method of the intelligible extended. If in metaphysics the priority of reason over sensitivity is not discussable, in psychology and anthropology things are otherwise. From the analysis of the false thought of death, in the contraposition with truth, the following conclusion derive: (1) the fear of death generates strong imaginations; (2) the conception of temporality connects strictly with the thought of death; (3) the variation of temporality is de- 
termined by the distinction between "a before" and "an after" and by the expectations about them.

When the human being thinks of death under the yoke of fantasy, its imagination becomes infuriated and expands the representations of reality projecting the passions, which for a Cartesian are passions of the soul as far as they are actions of the body, beyond the existence of the body. In this situation, the human being ends giving to its own thought of death a fantastic temporal perspective, at whose foundation a sensible component is always present. Eternity will be thought not with the pure mind, but as an infinite or indefinite expansion of a sensation. Eternity, then, will be an eternity of torments, or if the individual has a positive imagination, it will be an eternity of sensible pleasure, though this chance is mostly uncommon.

When the human being considers eternity rationally, it will know that with the death of the body there is the end of sensitivity. Eternity will be an eternity without sensitivity. ${ }^{6}$ The thought of death influences another aspect of our existence: our judgment on what is the good and the evil. Carnal human beings thinking of death will think of the goods they have to leave behind. The Christians thinking of death will think of the evils from which they will be free, though between the goods of the carnal human beings and the evils of the Christians no substantial difference may exist. The thought of death is indeed a criterion of evaluation. Death is for the Christians the end of all evils; for the atheists, it is the end of everything; and for the superstitious, generally, it is the protracted anguish that precedes the intake of the last gasp. To think of death as the end of everything is thinking of death as a privation and only the imagination can think this. With reason assisted by faith, death is not a privation but the disclosure of a superior reality infinitely better than the earthly one. As we saw previously with the experiment of restraining the senses, imagination imposes in the mind limits to the total vision of the intelligible extendedness. The imaginative thought of death is stronger than the rational thought, that is, it has the greatest weight in the conscience of the carnal human beings. In the pagan mind, sensation is stronger than ratiocination.

Human beings are living beings conscious of living. They are conscious of their existence because conscious of their mortality. The dominant thought in human minds is always the thought of death, though it is rarely rational and quite often fictitious. The thought of death accompanies us in all our projects and it is present with dreadful fears, sentiments, and frightful fantasies. With the thought of death, we touch the inner core of human nature. The thought of death is like the terminal of all other thoughts that will arrive at it either through the path of reason or that of the passions. The path of reason is like that of the intelligible extendedness; the path of passion in its way gathers in one special sentiment that comes with the fantastic thought of death: the essence of all sentiments. ${ }^{7}$ The thought of death changes all human ideas and at the psychological level it becomes the axle around which the ideas move. The thought of death is like the whirlwind 
that carries away everything in its path. Because of its power of judging all projects, the thought of death has both the psychological and the moral function of being the mental center.

In the sight of an enlightened spirit, in a psychological way, all goods and thoughts that occupy the human mind are merely phantasms. For this reason, Malebranche, analyzing the human psyche, considers its contents as spots on the mirror of reason that do not allow the perfect reflection of the ideas. For this same reason, the analysis of human knowledge that he developed in The Search after Truth is essentially a philosophy of the imagination, or, if we prefer, of fantasy because the dominant thoughts in the pagan mind are phantasms, and the most petrifying phantasm is that of death. ${ }^{8}$ The senses that die in us with the triumph of death are the source of fear itself. If we would reduce our being to sensation, by a reversal, we could apply the fear of the senses to the entirety of our being. In addition, if we have a frightful vision of death, even more terrifying must be for us the one who imposed death. If death is a merciless condemnation, then it must be the work of a vindictive god that intends punishing us for our lack of adoration and for our pretense to the goods that are of the divinity.

If we look at death from the tower of the imagination, death is seen as the punishment for infidelity to a vindictive god. The fictitious idea of death is the direct cause of idolatry. Given the importance of this statement, it is necessary to resume and summarize all that Malebranche has affirmed up to this point. (1) Imagination allows us to know things attributing a value to them. With the imagination, we believe all sensible things to be true goods. (2) When reality is thought with the imagination, death represents the worst evil because death deprives us of all goods. (3) Death, through the imagination, appears to us as a vindictive and cruel condemnation. (4) If death is a condemnation, then a judge exists. (5) God is the only judge who can impose death. (6) This god is pitiless, when we consider death and the consequences of death with the imagination. Death, understood in this way, is the definitive penalty for not having properly honored the divinity over all objects and, on the contrary, for having honored the objects of god over its divinity. This is the logic of imagination that Theodore turns upside down to show what must be the mental conduct of rational human beings. Humankind is only in a minimal part composed by rational beings. The greater part of humanity acts irrationally. The motivating and guiding logic of humankind is an erroneous logic: "The fear of death that you experience does not derive from what you know clearly but from what you sense confusedly that bodily objects are the best goods. If so, the fear is natural, and reason has no part in it" 9 The clarity of an idea is exhaustive after the mind has clarified every part of the object of which the subject has conscience. Automatic effects of this will be the disappearance of anxieties, fears, fantasies, and preoccupations of any kind. ${ }^{10}$ These things would have no hidden corner where to smuggle themselves; no fear can accompany the demonstrations of geometry. In evident ideas, the generating 
faculty, sensitivity, and the possibilities of satisfying needs, sentiments, and inclinations do not exist. The fear of dying is a greater fear than the one generated by the confused conception of reality; it is a natural fear because we are naturally united with a body whose knowledge is always confused. The fear of death is a fear we cannot expel from our inner consciousness. All that we can do is to reduce the sense of horror we experience when thinking of it and we can reach this goal by thinking of death with reason rather than with imagination. The words of Malebranche underline another important aspect of the question; they point to the fictitious idea of death as it is connected with the idea of an envious and vindictive god who will not forgive the insubordination of the transgressors. Given all that has been said, we may state that the first and most important effect on the human being for thinking with the imagination about death and dying is to make the human being an idolater. ${ }^{11}$ 



\section{TEN}

\section{THE ORIGIN OF IDOLATRY}

The idea of death is similar to a great container that when it is filled with reason, it will correspond, in the moral and religious fields, to the intelligible extended. If, on the contrary, it is filled with imagination, then it will be the most terrifying of phantasms, the fantastic universal of fear, as far as it gathers in itself all fears, worries, and passions that provoke panic. The Christian, who believes with the light of reason and the support of faith, will hold firmly on this distinction; the pagan will know no more than what the imagination will propose. ${ }^{1}$

For the pagans, the most horrific monster is death; this catalyst of all passions is a product in great part of the imagination. Malebranche reminds us that in his conception of natural causality one only cause exists and that this cause cannot be but the true god. The secondary causes are not true causes; they are the fruit of our imagination. Pagan divinities represent either the product of a theology of imagination and they are the religious correlatives of secondary causes (but believed to be primary causes by the pagans), or of imagined causes. Only the true religion can support reason and impede idolatry from penetrating into the human mind.

In the philosophy of Malebranche, reason and faith are allied in all battles of knowledge and religion. The fight of the true religion against idolatry and of the Roman Church against the heresies is reflected or is the reflection of what happens within the human spirit.

If religion teaches us that only one true God exists, this philosophy shows us that there is only one veritable cause. If religion convinces us that the divinities of paganism are merely lifeless and motionless stones and metals, this philosophy reveals that all the divinities of philosophy are matter and powerless wills. Finally, if religion teaches that we should not kneel before the gods who are not God, this philosophy explains that our imagination and our spirit should not be overcome by the imaginative greatness and power of causes that are not causes at all. We should neither love nor fear these causes. We should not care about them. We should think of God alone, see God in all things, fear and love God in all things. ${ }^{2}$ 
Malebranche says that true religion and true philosophy teach that our imagination and our mind should not feel discouraged before the imaginary magnitude and potency of causes that are not causes, though our very nature inclines us to think and act in that manner. Between the conception of idolatry and that of causality, a parallelism exists. The imagination allows us to connect the pagan divinities with a particular way of understanding the relationship of cause and effect. Malebranche points to Aristotelianism as the philosophy that constituted the forma mentis of paganism, which is the philosophy that constructed its foundations on the abnormal abstractions from the sensible representations. This vision of reality is conducive to our subordination to false idols that are the hypostasis of our passions, fantasies, and the feeble rationality of our thought that usually and easily is overcome by the power of sensitivity.

The thought of death that proceeds from the imagination becomes the filter of all the possible fears because it is the most horrifying of thoughts and is associated with the fear of a terrifying god that will torture in eternity. The thought of death has such a power that could at any time at its will annihilate us; it can bring to an impossible extreme the administration and tolerance of torment. Torments, however, must be tolerated so that this becomes part of our consciousness. Notice the gamble of the imagination: the soul is afraid of an intolerable suffering, but a truly intolerable suffering cannot be suffered. When a pain becomes intolerable, the human being loses consciousness and by losing consciousness, it no longer suffers.

Consciousness and suffering form an indissoluble binomial. To believe in an intolerable tremendous pain is contradictory, because it is equivalent to thinking a sentence that cannot be executed. This is the most important argument that Malebranche uses to sustain the thesis that the believer should not fear death. In reality, the believer understands very well that an intolerable pain like death is fantasized as if it were the acceptance of a tolerable one. Instead of reducing the fear of suffering to the real capacities of the conscience, the pagan extends or even better expands with the imagination its conscience to the point of provoking a terror of sufferance that is fantasized as infinite. Consciousness is proportioned to the fear of sufferance instead of being compared to the possibility of tolerance that consciousness has in relation to suffering. The source of uncontrollable fears is neither the reality of the divinity nor the possibility of the existence of such a divinity, but the possibility that a divinity could inflict great sufferings. If judgment is a rapport between two ideas or the rapport between rapports and ideas, we can then say that the possibility of a link between a divinity and the sufferance that this divinity eventually could inflict would indeed generate the greatest fear.

It does not matter if this idea of divinity and the idea of existence have any real link. It is indifferent, in terms of emotivity, if there is any relationship between our behavior and the effective damage that it may have inflicted on the presumed divinity. No tie exists between something real, nor between the possible realities or 
fantasies. It is not important whether some effective (rational) possibility exists or not. That some link between the possibilities (not realities) exists or not, it is not important. It is not even important if there is a reciprocal possibility between all the fantasies or that all fantasies would be tied together by an irrational logic that would create between them fictitious relationships. What is important and sufficient for giving birth to idolatry is the combination of two ideas alone between this presumed divinity and the fear of suffering.

Malebranche was amazed and annoyed by this erroneous logic, especially because it is not the exception but the ordinary one among human beings. Consider ratiocinations as the rapports between rapports of ideas, their validity in relation to the truth of ideas and the truth of the rapports that link them together, he was disturbed, because while examining the common human mentality, he was finding only false arguments and long series of fake beliefs linked together by fictitious rapports. He saw human beings acting according the impulse of sentiments that relied on the most absurd credences in such a way that often one single fundamental error could support an enormous number of other errors and prejudices, which in their totality constituted an insuperable wall for reason. He confessed, "Nothing more terrible or scaring for the spirit and that leaves an undeniable mark in the brain exists than the idea of an invisible power, which works solely to our detriment and to whom we cannot resist. All words that remind us of this idea are always heard with fear and curiosity. "We should reconsider the conclusions reached at the end of the previous chapter. First, it is with the imagination that we know things. Second, with the imagination we think of death as the worst of all evils because it deprives us of all the goods that the imagination represents before our own eyes. Third, death is considered the most terrifying experience because it is the effect of the condemnation pronounced by a pitiless god. Fear is the daughter of these tortuous and fantastic ideas of death and divinity.

\section{The Origin of Religions and Societies}

The pagan mind is afraid and kneels before its own ghosts, among which the first and the greatest is that of a god that can impute death at any instant and for no reason at all. This is the origin of idolatry; idolatry is the axis around which all the superstitions and the idolatric religions run. It is the point from which Vico begins his anthropological analysis: fear gives birth to religions. The fear of death and the imaginary conceptions of nature are found in every human conscience. Religions must necessarily originate with thought and human societies.

A society of atheists is not possible because the same laws that rule over the union of soul and body regulate societies. On this, both Malebranche and Vico agree. Since the Fall, the soul has become the slave of the body and has shown that it has a pagan mind, not an atheist mind. The human beings have experienced 
fear since birth because they had the sensible and confused cognition of their own fallibility in an unreflective, chaotic, and non-conceptualizing consciousness that, for this reason, felt its fallibility strongly, burningly, and vividly. Vico said, "These things give the right sense to the saying, 'Fear first created gods in the world' (Primos in orbe deos fecit timor) [Statius, Thebaid 3.661]: false religions were born not of imposture but of credulity." "4 Credulity is the principal effect of the fear of divinity; it does not originate from an external cause but from the interiority of the soul. If superstition could not count on precise needs of the spirit, if it were not the effect of fears or of the constitution of the human mind, if it were not a creation of the human beings who thereafter made themselves slaves of fears, then we would have never seen the origin and development of pagan religions. History would never have been traversed by ideologies on myth, ideological myths, idolatry, divinations, and slaveries that in different places, at different times, strategies, and ways determined the life of single human beings and entire nations.

Malebranche and Vico are aware that the pagan religious cults and rites are only one of the aspects of the question. In addition to religious superstition, a secular superstition exists that brings human beings to attribute honors, sacrifices, and obedience to other human beings and things that, in our corrupt imagination, are nothing else but the hypostases of our fears.

The secularization of superstition and idolatry is analyzed in The Search after Truth. Vico, in The New Science, penetrates the mind and analyzes the imaginative faculty of the first human beings. In his efforts, Vico reconstructs the genesis of the pagan mentality that, as we have already found, is the myth-thought of Jupiter. The terrifying religion of the lightning is frightening because the thunderbolt is the manifestation of homicidal potency. Religion is born from thought and thought is born as the religious thought that prostrates and kneels before the divinity that it has created while creating itself. On this, Vico commented: "The preceding remarks indicate that divine providence allowed humankind to be deceived into fearing Jupiter as a false deity who could strike them with lightning. (These crude, savage, and brutish people possessed enough human sense that in their despair of nature's aid they longed to be saved by a supernatural agent....). In this way, in the clouds of the first storms and the gleam of lightning, they beheld the great truth that divine providence watches over the well-being of the entire human race." 5 From which follows, "We must posit a hidden sense that nations have of God's omnipotence. This sense in turn engenders another by which all peoples are naturally led to offer infinite honors to divinity. This was the manner in which the poets founded religions among the pagans." We recall in these words the logicopsychological process that Malebranche previously described. The conscious sensation of fallibility, of a confused however strong fear, is the first sensation experienced by the theological poets, the cause that determines the first thought, Jupiter, and the first desire of being saved. The logical sequence runs in this way: the fear of death; the thought of the cause that is capable of inflicting death; the 
belief that what can kill can also save; the wish of preservation; finally, the veneration for this fantastic divine power. In this situation, everything is lived in an exasperating manner; every thought and every act are the fruit of this frightening superstition.

Without this psychological dynamism at the level of human sensations, societies would not have been possible. When nations are founded on human sensations and not on contractual agreements or by the manipulations of an enlightened or shrewd legislator, then the laws regulating them are the very same laws of the sentiments, which are the laws of relationship between mind and body. Vico taught that without the sentiments, without the bondage of idolatry and a sensible and superstitious thought, nations would neither originate nor persevere. ${ }^{7}$ He stated that the authority of the first family fathers of the world "was fortified by frightful religions and sanctioned by dreadful punishments." 8 Thought becomes automatically the constraint of human bestiality: the human beings no longer reacted simply and instinctively (as it happened before the enlightenment from Jupiter); the endless roaming stopped; the brutish being does not run to hide, but fearfully contemplates and reveres the heavens. The first exercise of conatus, the first actualization of a simple manifestation of will happens when facing the divinity. The first formal human act is the "coercion" of the divinity. The thought of the divinity imprisons itself with the chains of the sentiments caused by the fiction of the divinity that now fully constitutes thought. Instead of an instinctive search for cover, the brutish being remains at a standstill, overcome as it is by the terror experienced and the awareness of no other salvation than the clemency of the executioner. The constraint of the spirit is also the constraint of the body. Jupiter obtained the title of Stator, stayer, or settler, because he imposed an end to the brutish roaming, to the meaningless, instinctive, and bestial wandering, incapable of going against the purely biological dynamism. Thus, the age of the theological poets succeeded to that of the aimless wandering of the beasts. Explaining his new science, Vico narrated:

Moral virtue began, as it must, from a conscious effort (conatus). Chained under the mountains by their frightful religions of thunderbolts, the giants checked their bestial habit of wandering wild through the earth's great forest. Completely reversing their customs, they now settled down, hidden away in their land, so that they later became the founders of the nations and lords of the first commonwealths. According to popular tradition, this was the first great benefit, which Heaven bestowed on humankind during the age when He reined on earth through the religion of the auspices. In addition, it was the source of Jupiter's title of Stator, stayer or settler. With the conscious effort (conatus), the virtue of the spirit began to grow, and kept them from satisfying their bestial lust in the sight of Heaven, which now inspired their moral fear. Instead, each giant would drug a woman in- 
to his cave and keep her there as his lifelong mate. In this way, they practiced human intercourse secretly in private, which is to say, with modesty and shame. Hence, they began to feel a sense of shame, which Socrates called virtue's outward aspect. After religion, shame is the second bond that keeps nations united, just as shamelessness and impiety cause their ruin. ${ }^{9}$

The sentiment of fear has several prerogatives: it is also a sentiment of nothingness; self-awareness is at the level of nothingness; the only awareness is that of being afraid (this awareness comes through a sensible and unreflective conscience) and of the power of Jupiter. This confrontation between the human being and the opposing divinity produces the effect of a sensation of confusion as much as of danger. From this sensation, divination and auspices are born. Divination, the contributing cause of idolatry, is the salvation of humankind because humanity becomes capable of comprehending the messages of Jupiter.

\section{Divination and Auspices}

Divination, says Vico, is the science of the speech of the gods. It is necessary to comprehend the divine language (the language of nature) when reality is no longer lived biologically but has become a reality that is thought. A new world appears to the eyes of the theological poet, who does not know that this new world is his own creation. He experiences in his imagination a series of events that escape his control and seems instead to control him. For the first time, the theological poet is immersed into the living nature, his individual nature, and the one he faces through thought in his conscience, though not through awareness. Everything is then a mystery to be unveiled and divination constitutes the science of interpretation of the words of nature, which is to say, Jupiter. Until the human being moved by instinct, nature was static and its reality annihilated because of the absence of thought: the brutish being (the bestione of Vico) was only a biological machine. The machine moves while the reality in which it moves remains static.

With the myth of Jupiter, thought is born, and in the same instant, the machine bestione stops (Jupiter is indeed Stator!); what begins to move is the reality that flows vividly from the imagination. Divination is therefore the first human effort after the human being senses no guidance from the instinct and feels itself lost in the fictitious world that its mind has created. Divination is the first human attempt at an orientation in the labyrinth of the human fantasies and passions, which constitute the recently born thought. In every act and in every thought, the ampleness of the primitive mind cannot extend beyond the limits of sensitivity and imagination. The divination of which Vico speaks is not a speech in a symbolic language, in which the image of the divinity becomes the icon of itself without its 
full essence, or without fully incarnating into it; it is not an instrument for the orientation in a symbolic reality that spirits and gods animate from behind.

Jupiter does not pull the strings of the thunderbolt, the thunderclaps, the wind, and the heat of the sun; Neptune does not agitate the waters of the ocean; Neptune is the whirling itself. As the primitive mind has no abstractive ability to conceive the divinity, so it will not utilize strategies of control over the environmental factors that can be known only through the intellect and its abstracting faculty. Divination, before being a human activity, is a divine operation; it is the speech in natural signs of Jupiter, to whom the theological poet replies also with signs. In the gestures, however, no symbolic significance exists; the gestures are not signs that refer to an implicit signification; the significance of gesticulation remains unexpressed. The gesture is sign and signification because the signification is the action itself that the gesture performs. The immediacy with which the precariousness of the ambiance is experienced corresponds to the immediacy of the divinatory answer. All events tend to recuperate the stability that the birth of thought has shattered.

We may be able to imagine the situation of the first human beings if we think of the individual who comes out of a coma or a faintness, which can be assimilated to the psychological dynamism described by Malebranche where he speaks of the surfacing of thought in the newborn. The first perception of reality would be extremely confusing and things will have indefinite contours. The perception of oneself would be even more fragmented and frail. The recovering person would not think of itself, would not ask, "Who am I?" or "What is more advantageous to do?" The perception of things would be confused and the light would hurt our eyes while we would feel uneasiness and fastidiousness. The sounds of the words of the surrounding people would be felt enormously amplified and disturbing.

If we were to go through the experience of the above individual, we would find that the gestures and motions executed in that situation could not be the fruit of an intellective evaluation, but of a search for the equilibrium between sensations and for a reorganization of the imagination. The gestures and the motions will constitute the reaction of the imagination and the passions in view of defining with order what has happened. In such a situation, the environment would seem to move around us creating a dizziness that truly exists only within the head of the patient. This example, better than any other, shows the tie between the psychology of the theological poet and the famous principle of the Vichian anthropology: "People first feel things without noticing them, then notice them with inner distress and disturbance, and finally reflect on them with a clear mind." The present stage is that of the distressed and disturbed spirit. The primitive, who experiences the dizziness as he feels the world turning around, is similar to the patient coming out of coma. Divination remains the first reaction of the imagination for the con- 
trol of reality. To the sight of the gentile, Jupiter alone appears to be speaking and expressing a will. Vico narrates:

Moreover, since these early people communicated by signs, they naturally believed that lightning bolts and thunderclaps were signs made to them by Jupiter... They believed that Jupiter commanded by signs, that these signs were physical words, and that nature was Jupiter's language. The science of this language the pagans universally believed to be divination, which the Greeks called theology, meaning the science of god's speech. This is how Jupiter was assigned to the fearful kingdom of lightning, which made him the king of gods and men. He acquired two titles: optimus, the best, meaning fortissimus, the strongest, and maximus, the greatest, alluding to his body, which was as vast as the heavens. Because he did not destroy the human race with his bolts, he acquired the title Soter or Savior. And because he stayed the giants from their brutish wandering, so that they became the rulers of the nations, he acquired the title of Stator, or Stayer. ${ }^{11}$

The human beings live the situation in a spirit and sensation of danger, in a spirit and sensation of death, of returning to the condition of total anesthesia like that of the fetus as described by Malebranche. Reality continues to face and oppose the mind of the primitive, and begins to differentiate itself in that immense show of the universe that appears as Jupiter and overcomes the human being and its mind. Jupiter, fortunately, as long as he is not the homicidal personification with his destructive power, assumes now the persona of the Savior.

The human beings, no matter how much their intelligence is minimized or their humanity is rudimentary and brutish, when they find themselves in an extremely precarious situation, they wish necessarily for a divinity, a superior being able to save them. If the divinity saves them, it must be superior to them; if the divinity does not save them, then they could still save themselves, which means that they would be able to control nature and reality. ${ }^{12}$ Life, then, would depend from knowing how to interpret (with an interpretation that at the beginning is totally imaginative) the gestures of the savior so that he would continue to be the savior and would not change into being the executioner. According to Vico, the human science, by which I mean the science of nature, is born as the science of god's language because the divine word is nature itself: "Among the pagans, wisdom began with the Muse, whom Homer, in a golden passage of the Odyssey, defines as the knowledge of good and evil, or what was later called divination. By contrast, God founded the true religion of the Jew, from which Christianity arose, on the natural prohibition of divination, which is naturally denied to people. At first, the Muse must properly have been the science of divining by the auspices." The divination is also the science of good and evil, the science of what is forbidden and what is allowed. The pagan mind finds the motive for growth in the continuous and fan- 
tastic effort of interpreting the signs of Jupiter. Nature is the language that the divinity speaks; nature (experienced with sensitivity and fantasy) determines the good and the evil. The myth achieves the function of manifesting the divine laws. The efficiency of the myths consists in articulating the divine message, which would manifest itself always more complex and diverse through the phenomena of nature.

Divination is the complex of rules, the strategy with which the human being comes to confront nature. Human conduct will be stereotyped and rigidly ritualized because the voice of Jupiter ordering his will is strong and overbearing. Idolatry and divination, the pagan science of good and evil, have their roots in the same sentiment, as Vico demonstrated clearly: the terror of death, the sensation that reality escapes the control of the subject, and would suppress the individual. The fear of death is not an idea, as we understand ideas today. Malebranche and Vico have explained to us that the fear of death is due to the convergence of many different passions; it is the representative synthesis of many interacting psychological elements. Death itself appears as a pain through the eyes of the imagination, because, as the Dialogues on Death affirms, the senses and the imagination are the ones to die. If what follows death is the eternity of pains and torments as described in the Dantesque Hell, we would realize that the idea of the jealous and revengeful idol coalesces with the fantastic ideas of death and eternity, increasing significantly fears and superstitions.

\section{The Idea of Eternity}

The rational idea of eternity is always present to the mind, even to the pagan mind, but often the imagination modifies it (or presents to the conscience its confused representation of eternity) in a manner that makes eternity unrecognizable. ${ }^{14}$ What are the effects of the idea of eternity on our spirit or on the state of our conscience? If we think of death with the imagination, with imagination we will also think of eternity. If we imagine death as a horrifying end, then we will imagine eternity as an intolerable torturing condition. The question is, why are the human beings imagining death and eternity in this terrifying way? Human beings hate sufferance and love pleasure. Why cannot they fantasize about death and eternity as the perpetuity of gratification?

Malebranche's answer cannot be but as expected and it is irrefutable: human beings do not love pleasure as much as they hate suffering. This thought is subject to a further generalization because pleasure and sufferance are always connected with two other sentiments of the spirit: fear and hope. In the pagan mind, fear will dominate hope; the pagan mind will believe in a god for salvation, not for gratification. Malebranche says that salvation and gratification have not the same value; human beings' fears are greater than their hopes; pain and dolor are more 
intense and more severe than pleasures. In the dynamism that regulates the motions of the human spirit, whose effect are the representations (ideas produced by the imagination), fears have more definitive powers than wishes; wishes often are the hopes of avoiding pains. Malebranche remarks, "It must first be noted that the hope of an eternity of pleasure does not act as strongly upon minds as does the fear of an eternity of torments" 15 Though this statement could be only a psychological confirmation of what has been said, it has also a moral validity. The Christian does not reach salvation simply because he well behaved. His good behavior may be the fruit of specific calculations. If we are convinced that a God exists, then it is convenient for us to act accordingly, whether or not we adore the true God or an idol. Faith is the difference. The bigot and the superstitious pagan are similar because they think of their personal advantage, which is calculated with imagination and passion. To follow personal inclinations is always faulty because since the Fall, our nature is corrupt. The bigot acts wrongly because instead of with faith he adores God as an idol; he follows human nature's inclination to fear, showing the false authenticity of his devotion.

But because the true God threatens them in the secret recesses of their conscience with an eternity of torments to punish their excessive ingratitude, and because, in spite of this, they do not want to abandon their idolatry, they take it into their heads to perform some externally good works. They fast, as do others; they give alms; they say prayers. They continue such practices for a while, but because they are painful to those lacking in charity, they usually abandon them in order to embrace certain insignificant practices or easy devotions that accord with self-love and necessarily subvert the entire morality of Jesus Christ, but in a way that is imperceptible to them. They are faithful, ardent, and zealous defenders of these human traditions that unenlightened people persuade them are most useful, and that the idea of eternity, which frightens them, constantly represents to them as absolutely necessary for their salvation. ${ }^{16}$

Idolaters and zestful bigots are similar; their motives are identical. The object, god or idol, to which they refer has no importance; their particular psychological attitude shows that the idolatric rituals are in a direct proportion with the fear of an eternity of torments which is looked upon through self-love. This certainly supports what we said about the difference between idolatry and Christian charity, which consists not in the action itself but in the intentionality. If the motive of acting is self-love instead of faith, then the practices of the cult are always idolatric.

The practice of Christianity implies several acts that contradict self-love and this contradiction reveals the nature of the devotion of the believer. This gives extra value to Malebranche's saying, "Si le coeur est chrétiens, le fond de l'esprit est payen" (Though the heart is Christian, at its root the mind is pagan), because the nature of 
the spirit is the same in both the Christian and the pagan. At the bottom of the debauchery of customs and the falseness of conduct there is always a disorder of the spirit, of which the fantasized fear of an eternity of torments represents the extreme and final stage. Remorse speaks to the zestful bigot (at all effects, he is a pagan) but instead of refraining him, let him persevere in its idolatric practices. The fantasized eternity of sufferings as punishment for his ingratitude obliges the bigot in ceremonies and practices that are absurd to reason but perfectly congruent with his self-love that is the true motor of human actions. Paradoxically, these practices gradually would appear to become the opposite of what the Christian morality teaches, because self-love is exactly the contrary of Christian charity. For the idolater, all these ceremonies and practices would assume the character of necessity. It is necessary to execute these ceremonies and practices, if we want to curry favor with the divinity. The pagan thought, because it is a superstitious thought, is the product of a rigid mentality, all engrossed in itself, which fantasizes necessary relationships between objects that do not exist. The warning that the true God gives to the corrupt consciences is sensed and thought not as the admonition of the God infinitely good and just, but as the threat of a merciless authoritarian god whose intentions and actions are directly proportioned to the wretchedness and coarseness of the imagining spirit. The confusion of ideas that represents the most characteristic trait of the pagan mentality is the cause that obliges the human being to dedicate itself with firm conviction to idolatric practices, irrational devotions, which are nonetheless comprehensible to the philosopher because compatible with self-love and perfectly functional for the satisfaction of needs. The fear of suffering terrible pains caused by the threat of a fantasized overbearing divinity is the first motor of idolatry and the wretchedness of customs. Malebranche observed,

But what is especially noteworthy here, and which does not concern the disorder of morals as much as it does that of the mind, is that the fear of which we have just spoken often extends the faith as well as the zeal of those struck with it to include things that are false as well as unworthy of the holiness of our religion. There are many people who believe, but with an unflagging and obstinate faith, that the earth is immoble at the center of the universe; animals feel genuine pain; sensible qualities are spread over objects; there are forms or real accidents distinct from matter, and an infinity of such false or uncertain opinions, because they imagine that it would be contrary to the faith to deny them. ${ }^{17}$

The text of this citation is important because it shows how for Malebranche the fear of an eternity of pains is the presupposition of a series of errors similar to those we discussed in the first part. We want specifically to know what the meaning of the sentence is: "These peoples believe all these things because they 
imagined that to deny them will be against faith." These peoples had faith in their senses or exactly in the beliefs that they have formed starting from the mixture of their sensations and passions. The fear of the threats of an overbearing and jealous deity comes with a faith in the sensitivity. The kind of people mentioned think that by denying that matter can act means to deny faith because they imagine that the physical actions (phenomena) of nature are the threat itself of the deity. If this is true, the errors accumulate: to the error of believing that matter can act, we must add the error of attributing a divine nature to the actions of material agents. To deny what the senses, the fear, and, in brief, fantasy present to people as evident is to go against the command that the false god has given. At the origin of this, however, there is always the fear of the idea of an eternity of sufferings, an idea so intense that human beings come to approve, perhaps without absolute conviction, but at least with the example, most common human traditions. ${ }^{18}$

Customs, habits, and social conventionalities are strictly related to idolatry and the idolatric conceptions that a great part of humanity have of the true religion; their relationship embraces the fear that the idea of eternity (fictitious or imaginary) and death generate. The confused threat of a dreadful punishment, indefinite in time and in its results, influences the human spirit more than any other perspective. In human psychology, this perspective functions as the principal cause capable of determining an enormity of prejudices and attitudes; it imposes uniformity on the human mind. ${ }^{19}$ It becomes the supporting structure of the pagan mind, can support many correlated prejudices and also produce some even more dangerous ones. It gives shape to a kind of faith that is passionate and moves the human beings away from the light of reason with the consequence that they would believe in imaginary super-powers and fictitious entities that they should adore more than the true divinity. In the words of Malebranche,

This dreadful perspective generates the infinity of scruples in the mind and fortifies them in such a way that deliverance from them is nearly impossible. It extends faith, so to speak, to the boundaries of prejudice, and causes us to render to imaginary powers the worship due only unto God. It stubbornly entrenches the mind in vain or dangerous superstitions. It makes us ardently and zealously to embrace human traditions and practices useless for salvation, Jewish and Pharisaic devotions invented by servile fear. Finally, it sometimes casts men into a blindness of despair, with the result that, confusedly regarding death as nothingness, they brutally hurry toward their doom in order to be delivered from the mortal anxieties that agitate and frighten them. Women, young people, and feeble minds are the most subject to scruples and superstitions, and men are the most capable of despair. ${ }^{20}$ 
It is often believed that superstitions cause irrational fears, but Malebranche specifies by saying that fears that are not understood but only felt are the path to idolatry, superstitions, and subjection to ghosts. The fear of an eternal pain, infinite in time and intensity, gives origin to a fantastic idea of a divinity that like a universal can represent all particular fears and fictitious entities that the tainted mind is able to think. The sentiments that this mind provokes are not going to be temporary; on the contrary, these sentiments established themselves in the human spirit and condition emotively the entire life of the human beings, who will only be able to think through their emotive filter. Human beings would then not be able to think freely and independently because every one of their ideas would be under the dominion of an irrational fear.

It is easy to find an explanation of all these things; for it is obvious that the idea of eternity being the greatest, the most terrible and most frightening of all those that astonish the mind and strike the imagination, it is necessarily accompanied by a large following of ancillary ideas, which all have a considerable effect upon the mind because of their relation to this great and terrible idea of eternity. ${ }^{21}$

These words of Malebranche bring up a new point: the most terrible idea we can imagine (the idea of an eternity of torments) is a catalyst idea that carries a series of accessory ideas, as a great star that for its great mass has many minor planets gravitating around. The accessory ideas awake in the spirit some representations and beliefs that would increase the emotive power of the idea of eternity. In the pagan mind, the fear of a resentful god may associate with the fear of some phenomena presenting exceptional characters, or to the fear of particular animals, which human beings would see as new threats of the divinity. All these particular fears reinforce the general, fundamental fear of the eternity of pains that a vindictive god likes to inflict. The relationship between the principal idea and the accessory ideas form the biosphere of the pagan mind, the totality of those elements that permits its survival. It is as if the idea of eternity were to form a small mental biosphere, an agglomerate of ideas, or an idea that could be interpreted in different ways, and would perform various functions, even simultaneously. The multi-functionality of the idea of eternity is the cause of its survival and preservation in human consciences.

The pagan mental biosphere is comprehensive of the imaginative idea of death, the fictitious idea of eternity, the idea of the divine threat of the will of god or idol, the idea of suffering, the idea of the infinity of sufferings, and the idea of the idol. In the perspective of the analytical philosopher, the idea of eternity is the cause of human traditions and of the customs of social conventions. For Malebranche, the idea of eternity is the cause of all superstitions, all pagan rituals, and even of neurotic rituals, which he called rites of feeble, melancholic, hopeless spi- 
rits; it is the cause of all actions due to self-love, passions, and sentiments, instead of decisions based on reason or true faith.

\section{Human Sacrifices}

Sensitivity and imagination is the pivot of thinking and knowing in the pagan mind. The idea of death functions as a universal, a principal idea around which the accessory ideas run. In the psychology of the universal gravitation of the erroneous mind, the concept of force depends from the emotive intensity with which the sensible contents are presented, which is from the tension that the ghosts of the imagination produce. The life of the idolater is conditioned absolutely by the idea of death and an eternal suffering that, in the case of Vico's "first men," have a matrix exclusively sensitive. The pagan life exists in a reality that is the exasperation of the sentiment of precariousness. The interior instability of the pagan mind is qualified by the confusion, dangerousness, and un-foreseeability of the exterior world.

The remedy that the coarse and fluid pagan mind finds (and it is the only one available) is the idolatric superstition that regulates the poetic universe through a rigidly ritual order. The rigidity of the ordering is directly proportional to the chaos of the imagined reality. The fear of dying, the belief that life and death depend from Jupiter obliges the primitives to ritualize with superstitious rites all their actions. In this sense, Vico correlates idolatry, divination, fear of death, and ritualization of human conduct. The human sacrifice represents the extreme limit of the effects of the fear that controls divination and idolatry.

Divination is the science of good and evil, the science of human behavior. In the grade that the behavior is less conforming to the divine will, it will be seriously punished, which is the reason why human actions would be more rigidly ritualized. A life of fantasy alone is a life rigidly governed. Fear exaggerates rituals and their brutality, as in the example of the witches as killers of innocent children, 22 and brutality is proportional to the suffering that is imagined to be inflicted by the ferocious deity. The idea of the ferociousness of the deity is the direct psychological representation of the fear and sense of nullity of the human beings. The wildness of human sacrifices is the product of a distorted spirit, corrupted and incapable of overcoming individual nullity except by complying with the fantasies that are the effect of weakness.

Human sacrifices show that the fear of death is not the end but the bridge that allows a stronger fear to explicit itself: the fear of an eternal pain, the fear of a protracted death. For this reason, a life is sacrificed to the divinity with the hope that the divinity would be sated by human blood. The death of the sacrificial victim becomes a minor pain for the victim itself, which otherwise would experience the common fear of the infinite pains. If, in the light of what Malebranche said 
about the fear of death protracted to infinity, we consider this theoretical position of Vico, we would see that the human sacrifice is profoundly different from a proficuous exchange with the divinity, because the victim dies but not the idolatric executioner. The human sacrifice is part of the cosmic balance of the cosmology of the poetic metaphysics. The idolater notices fearfully that the cosmic balance is broken and devoutly assumes the responsibility for its restoration, no matter how high the price. The witch and the primitive are subjects unaware of their identity and try to acquire it through idolatric rituals. It is probable that as they do not recognize themselves for what they humanly are, so they would not recognize the humanness of other human beings.

In the pagan universe of the origins, the only being that has humanhood, provided with a soul, is the idol, not the human being. The rite, of which the human sacrifice represents the extreme limit, is an act of equalizing the human beings to the divinity. Through the ritual human beings acquire an extension to existence, approaching the divinity which is the exclusive possessor of will and life. The primitive idolater acknowledges neither will nor life; because he has no self-identity, he has neither will nor life of his own. Vico narrates, "The primitive morality of the savage and superstitious pagans gave rise to the custom of sacrificing human victims to the gods." 23 The example, in Malebranche, of witches and sorceresses underlines how the proper characteristic of Vico's primitive human beings is found also in the sorcerers and sorceresses of modern age. The same passions and imaginations guide sorceresses and wizards in the same way. The magic that still triumphed during the seventeenth century, some elements of the Renaissance astrology, some returned barbarism of the Middle Age, constitute the remains that from the antiquity or pre-history have reached us and these elements are not found among the ruins of ancient cities, but within us, in the most obscure corners of our modern conscience. As Malebranche and Vico like to repeat, ${ }^{24}$ the profound currents at the bottom of our conscience determine the volatile currents at the top of our spirit.

Malebranche observed that the men of the high society of the civilized France of the seventeenth century were not aware of how much their conduct was ritualized. In Vico's opinion, the origin of the ritualization of many of our actions (even language has a strong ritualistic component) is found in the idolatry of the origins. Malebranche sees the applicability of the theory, not about the first founders of nations, but to some particular psychological types that he described in The Search after Truth. As we will see, the most emblematic type is the sorcerer shepherd for the force of his imagination, who has many traits in common with Vico's theological poet.

For Vico, the religion of the thunder and the lightning made human beings naturally prudent. Their prudence was one thing with the ritualization because every action happened under the sight of Jupiter. The famous saying, "His are the auspices" (Auspicia esse sua), shows how much all conduct depended from Jupiter's 
will and how every error in the execution of a gesture or in the enunciation of the ritual phrase could cause divine anger.

Vico says, "In this manner, piety and religion made ... the first men naturally prudent because they consulted Jupiter's auspices. They became just both toward Jupiter ... and toward others, in whose affairs they did not meddle. The virtues of this primitive age ... were virtues of the senses which combined religion and cruel savagery, qualities which today we find in witches." 25 This text is important in various ways: it advanced again the similarity between the mentality of the wizards and that of the theological poets, because their senses combined religion and cruel savagery. Vico would affirm that the vestigia of the primitive mind are still present in the modern mind. In this affirmation, we find the significance of the extended analysis that Malebranche does on idolatry. Idolatry, for Malebranche, is the construction of the mentality according to the senses, abstracting from the senses, and becoming pagan. In Vico, the anthropological theory of Malebranche is re-proposed: the virtues of the senses, which combined religion and cruel savagery, form the pagan mind.

The Aristotelian philosophy contains the seed of the humanity's common sense that lies down and tunes knowledge to the senses. Modern mentality contains the traces of the dark and cruel past; these traces are found in the fools, the witches, and in some aspects of the character of the majority, from where they emerge with evidence. This is what Vico repeats in many passages, as in the one of the metaphor of the river maintaining its course for a long stretch within the sea. This is what Malebranche also repeats when constructing on the point of Archimedes the critique of the common mentality and of Aristotelianism, which is its most refined product. Another evident trace was the theological battle on the effects of the original sin that, because original, assumed a great importance for the beginning of human events on this planet.

\section{Religion, the Sense of Guilt, and Society}

In his own reflections, Malebranche places as central the thematic of the original sin, but this does not make him anti-Cartesian simply because Descartes avoided such thorny discussions. On the contrary, this assigns to his philosophy a diachronic dimension that the Cartesian philosophy does not enjoy. The Malebranchean anthropology would not be possible without the critique of "the religion of the senses" (idolatric), but neither it would have been constructed without the understanding of the meaning of the clarity of the sensitive contents and the acquisition by the sensitivity of an ontological state. All this was due to Descartes, affirmed Malebranche. In short, Malebranche's anthropology cannot be but Cartesian. On the other hand, Vico unequivocally begins from the claim that primitive religion and idolatric mentality are made of the virtues and faculties of the senses. Male- 
branche alone proposed a theoretical position of this kind. This is the Malebranchean matrix of a great part of Vico's anthropology.

Vico always stated that no nations could be without religion, because all knowledge begins from the fantastic imagination of sensitivity, of the sensible that pictures itself as divine. Fear is the catalyst of all thought and the twin of fantasy. Malebranche declared that there is no fear where fantasy is not there. Reality is then measured with the meter of sensitivity and the result is idolatry and superstition. "Tacitus notes one of the true properties of human nature when he writes that 'once struck with fear, minds are prone to superstition'. For when men are overcome by a fearful superstition, they associate it with all that they imagine, see, or even do." 26 We see here the moving force of the fantastic universal, the magnet that attracts the ideas and the sentiments.

The nations originated from fearful and superstitious men, consumed by an imaginary guilt. They did no wrong to the divinity, to Jupiter, who after all existed only in their fantasy. From birth, human beings acknowledge their own guilt, but they do not know what their faults actually are. Human beings come to know Jupiter as the one who charges them with faults. The religion of thunder and lightning becomes the religion of humankind. The sentiment of being powerless gives way to the sense of guilt and the sense of guilt opens the door to scruples; these scruples, by reaction, provoke thoughts and acts truly wicked. It is an old truth, but Vico applied it in a new way and used it in order to dismantle the thesis of those who looked at the state of nature as at the golden age of humankind, faultless and innocent. It was the thesis or the philosophical abstraction of conceited scholars. Vico wrote,

The only conclusion to draw from all this is the extreme vanity with which conceited scholars have previously affirmed the innocence of the Golden Age in the first pagan nations. In fact, their fanatical superstition held in moral check the savage, proud, and ferocious men of the early pagan world. Reflecting on such superstition, Plutarch poses this question: which is the lesser evil for men, to worship the gods in such an impious manner, or not to believe in them at all? But his antithesis is unfair. Even the most brilliant nations arose from such primitive worship, whereas no nation in the world has ever been founded on atheism. ${ }^{27}$

The sentiment of precariousness created the divinity in a reality that the human beings cannot control, and has caused the sense of guilt because if the divinity wishes to punish human beings, and the divinity can do what it will, then the human beings must have done something wicked.

Human societies, the pagan societies based on self-love, would not exist if the human beings were not living in a world of dangers, of phenomena that, like the thunderclaps and the thunderbolts, could hurt them. If the human sense of 
guilt and inferiority toward the nature within which we live did not exist, society would not exist. If the corruption of the human spirit were absolute, the primitives would not have had the possibility of changing their condition and history would not have had its course.

The history of nations and human beings that Vico narrates is a history that moves thanks to the capacity of the human mind, though without swiftness and with difficulties, to set humankind on the way of freedom from error, of growth, and of the dominion of the body. The consideration of human nature as either good or corrupt is for Malebranche and Vico a philosophical abstraction that does not explain rationally the reality or the motions of the soul.

Hercules is the character of the founders of nations, the first human beings with the strongest superstitions who began to construct society. In order to understand the figures of the many Hercules, we must ask the question: "In what sense the term 'society' should be taken when we speak of Vico?" What is the extension of this concept in Vico? Let us explain, beginning with the distinction between "nature" as the space afforded by the instinct of the brutish human being and "society" as the ambiance enjoyed by the theological poet, the reality created by the thinking being.

The "first society" is the direct product of the agreement-colloquy of the first human beings with their fantasies (Jupiter). Society is the effect of thought, the effect of a human action motivated by thought. Society, in this sense, is like a plowed field, the earth after the deforestation; society exists where human action operates; when there is an act of will, there is society. Society is the creation of a human thought, and wherever the human being can think and act, there is society. Hercules is the prototype of the idolater frightened by a fantastic deity, but incited to an action of courageous confrontation with nature. Hercules, under the yoke of fear, will face several challenges caused by fantastic dangers that existed only in his baffled imagination. Fear extends the limits of thought and of the thought reality. Jupiter is the cause of human arts and techniques because human beings, in the fear of the divinity, found the strength of overcoming the fear of the real dangers that they imagined inferior to the chastising of Jupiter. Societies were formed with idolatry and superstition, and through the societies, human beings came to know the world, progressively enlarging the sphere of their mental vision of reality. Vico, in The New Science, narrated:

The importance of the auspice taken from lightning has left traces in Greek myth. For example, Hercules, an archetype of the founders of nations, was born to Alcmena in a thunderclap. And another great Greek hero, Bacchus, was born when Semele was struck by lightning. This was the primary reason why heroes called themselves sons of Jupiter; indeed, they spoke with the truth of their senses because they were convinced that the gods determine everything. ... Urania, who was so called because she 
contemplated the heavens in order to take the auspices. Homer as the knowledge of good and evil defined Urania, the first-born of the Muses.... Earlier we saw the historical meaning of the poetic tag "Jupiter, the origin of the Muses." We may now add that Urania and all the other Muses were believed to be Jupiter's daughters, since all the civilized arts sprang from religion. The presiding deity of these arts was Apollo, who was chiefly worshipped as the god of divination. When the Muses are said to sing, it is in the sense of the Latin verb canere and cantare, which mean "to foretell." 28

The first society, the first created space that the pagan mind thought is therefore the sky, the heavens. To contemplate the heavens in order to take auspices is equivalent to create with the imagination the reality, which did not exist before having been thought. The human being can act only in a space that can be simultaneously physical and mental, but whose synthesis is found in the space of the imagination, that is, in a dimension of thought and not of matter. From this comes the conviction that the knowledge of the world begins from a subjective position because the subject thinks about reality even when perceiving it. The subject judges such a reality as objective, because the reality that has been thought is interchanged with effective physical reality.

Society and thought are born from the same illusion that stands at the center of the human common sense and of the pagan philosophies, which Cartesianism alone has discovered. Thanks to Descartes and Malebranche, Vico could identify and clarify the logic that produced both the thought of the origins and the pagan thought.

\section{The First Society}

The first society, the first human communication is with the divinity, and through this first communion of goods, human societies are formed. The first communion is the extension of space from the heavens to earth, from Jupiter to the other human beings. As the imagination conquers space within nature, becoming aware of it, the human beings create the arts that are the means of which the human mind has need in order to control its own products within the nature experienced with the imagination. The human beings can control nature only when they with the imagination become aware of the existence of nature and fantasize it as a danger. Human arts have a different nature than the techniques used by the brutish primitive (bestioni) because they represent strategies invented by the fantasy in order to face imaginary problems that, when proposed on a different scheme of action, influence physical reality with an exponential growth in contrast to the simple utilitarian techniques of the animals. 
The human authority over one's own bestiality logically precedes the human authority over the multitude and nature. Through the dominion over one's own superstitious fantasy, the human being acquires authority over nature. On one hand, human beings are slaves under the authority of Jupiter; on another hand, they own nature and are the authors of the arts: author and authority have the same etymological root. To be favored by the auspices of Jupiter means to have the force, in the imagination first and then in reality, of fighting and overcoming other human beings and nature itself. The fear determined by idolatry gives strength to the pagan. For this motive, the belief that "all things are full of Jupiter produced the human authority" determined that the first republics were formed by "those few and just individuals that Jupiter loved." 29 The presence of the divinity in the life of the theological poets is invasive and comprehensive because Jupiter is in everything or everything is full with Jupiter. Reality is known as far as it is identified with the divinity.

Jupiter speaks through the heavens and the heavens are his speech. Nature manifests itself as divine and reality is the place of the encounter between the human being and god. In the imagination, nature finds its space as divinity. Space, divinity, extension of thought (quantity and variety of the representations), and nature are fused together. In the divination, the mentioned archetypes give to the pagan mind a temporal and diachronic dimension. ${ }^{30}$ The birth of thought is the creation of the (represented) universe, the revelation of the world by the divinity that with the world is identified. The whole reality is the temple, the point of encounter between human beings and divinity. In the perspective of the primitive, the place where the temple is, is a real place as far as it is a place of the imagination, a place from where it is possible to observe. To observe what? The divinities, the product of one's own fantasy and the only thing visible with the sight of the mind. It is a real place from where it is possible, from our perspective, to see an unreal thing or, to the eyes of the primitive, something unusual and new. It is a real place that becomes a magic place, a fantastic place. A temple by extension is any place where the theological poet sees and thinks Jupiter. A temple is the physical reality experienced with the imagination. Vico observed, "The Romans called precincts of heaven templa coeli, those heavenly regions marked out by the augurs for taking auspices. Later templum came to mean any space that is open on all sides and has an unobstructed view." 31 He was trying to explain not a concept, but an experience. Seen from the interior of the perspective of the theological poet, reality presents itself as if the poet was initially in a rural environment, or in a natural setting never experienced before, open on all sides and with an unobstructed view or in a place completely dark (the night of bestiality, of the instinct) that he illumines with a torch (thought).

What we have considered parallels in psychological terms the dynamics that Malebranche analyzed in the chapter about the intelligible extension and the idea of death. Beginning with sensitivity in juxtaposition with pure reason, Male- 
branche explained how the images took possession of conscience. As the light increases, many more things can be distinguished; things further away can be seen, but always through the flame of the torch. All things will be illumined and thought with the light of Jupiter, though afterward with a multitude of divinities, the light will be reflected in many different ways. The form of the thought with which we begin to reflect beginning from sensitivity and imagination follows this path, this line of development. If we do not comprehend this dynamics, we will not comprehend the profound significance of the myth of Jupiter. We will not comprehend how all reality for the primitive was a temple, how every one of its actions was a ritual. We will have a superficial knowledge of something that is not difficult to understand but that eludes rigorous interpretations and does not endure conceptualizations.

Idolatry is the nature of the pagan thought that transforms reality into the temple of the false cult of the divinity and that with its dynamics diffuses itself through the environment making it knowable. With the myth of Jupiter, with idolatry, the poet becomes aware and knows reality; with divination, the poet comprehends reality and its significance. Idolatry and divination together and in unison advance by way of the dynamics of the pagan mind. Enlightened by religion, the human being deforests and cultivates the land. With thought, the human being creates physical space that is not considered physical but sacred. The physical reality when transformed by human power is no longer a physical place but a metaphysical-poetical one, the effect of the reality that is thought with the imagination. The human being transforms its own environment only as far as it knows it through the divinity. The reality of the heavens is reflected on earth through the human actions performed under the auspices of the gods. The proliferation of deities, which logically happens after the monism of Jupiter, is the indication and the cause of the differentiation of the human thought and actions. This event confirms the thesis that reality, being divine, is the temple or the physical and spiritual place for the meeting of divinity with humanity. ${ }^{33}$

The entire environment experienced by the theological poet is the physical and imagined point from which it is possible to contemplate the divinity and through the divinity to know the surrounding reality. The sphere or limit of the extension of the perceptions is amplified proportionally with the extension of the representations, which, at their own turn, follow the sphere or imaginative horizons of fantasy. The perception follows (logically because effectively the mental act is unique) the representation and the representation the fantasy. The pagan can perceive only what he can fantasize and because, at the beginning, he is able to fantasize only the divinity, everything he perceives will be a temple of divinity, a place where to know directly, without mediation, the divine, given that whatever is, is divine. If every place in which the human being will be found will be a temple, because Jupiter will be there also, then every act that the human being will perform will be a religious act of devotion. Veneration is the proper attitude of 
paganity. Veneration is passive subjection to what is superior, the divinity, and contemporaneously active subjection of what is inferior, the reality, in the name of what is superior. The divinity is an exceptional entity that can do whatever it wants because not tied by nature's rules, and because of its greatness and exceptionality, it demands veneration. For the same reasons, veneration may be due also to human beings. Vico wrote: "There is a golden passage in Lactantius, which describes the origins of idolatry: 'At first, primitive men called their kings gods, either for their miraculous valor, which these primitive and simple folk truly believed miraculous; or, as is customary, in wonder at their manifest power; or else for those benefits which had united them in civilization'." 34 Descartes reflected on this aspect of idolatry in the article 162 of The Passions of the Soul where he defined the pagan mentality in relation to the concept of causality, explaining more deeply, what he sustained in the letters to Princess Elizabeth:

Veneration or Respect is an inclination of the soul toward the esteem not only of the object venerated but also toward a subjection to it with some fear, in order to ingratiate its favor. We have veneration only for free causes that we judge to be capable of benefiting or hurting us, without our knowledge of which of the two actions they will take. The reason of this is that we have love and devotion, more than veneration, for those from which we expect only goodness. We have only hate for the things from which we expect only wickedness. If we think that the thing from which we expect some good or some evil is not free, then we do not submit ourselves to it in order to obtain its favors. In the same way, when the pagans had veneration for the woods, the fountain, and the mountains, it was not these dead things that they venerated but the divinities that they thought present in these things. The motions of the spirit that excites these passions are composed by the one that generates admiration and the other that generates fear. ${ }^{35}$

The concept of "free cause" is the one formed in the mind of the individual who commits the error described by Descartes in the letter to Princess Elizabeth. The human being imagined free causes in a context that in reality is ruled by a rigid determinism. The free cause has a will that is imagined by similitude to be like the will of the human beings. The free causes are not tied to a specific order of things in nature or society; they create a nature or a situation with the imperative order of their freedom. Furthermore, the free causes, because of their presumed freedom, are undetermined; they have the choice of doing or not doing what they wish or need. The indeterminacy of the free causes provokes in human beings the fear of the free cause, the terror of the divinity. The veneration, of which Descartes speaks, depends from the possibility of being. Malebranche observed that we do not venerate what necessarily is good or bad for us. If things cannot be different 
from what they already are, they cannot be object of veneration. A free cause, on the contrary, can bring us good or evil and because of this possibility, uncertainties and fears invade the human imagination.

\section{Marriage}

Human action and social activism began with the intention of captivating the free causality of the divinity: customs, conventions, usages, languages, juridical and moral rules are based on the fundament of the necessity of avoiding the evil and reaching the good that the imagination proposed. Vico, too, sustained the same when he affirmed that marriage was born as an idolatric practice. All the actions of the primitive human beings are a ritual because performed before god's countenance. Reality becomes extremely rigid as everything that happens, it happens under the auspices of Jupiter. A rigid imagination gives way to a rigid ritual. The rigidity of thought and action is a powerful weapon in the hands of the idolater poet, because nothing is more horrific than the direct punishment of the divinity, which is placated by the human manifestation of submission in the ritualism of the cult. 36 Inquiring on the origin of the social relationship between the sexes, particularly of marriage, Vico does not find the conjugal love but the fear of being destroyed by an inexistent divinity. Both Descartes and Vico speak of veneration as the means by which the idolater tries to control an evading reality, which instead controls him. Through the veneration, expressed in every gesture of the primitive human beings, from birth to burial, the human beings attempt to control the free causes by which they sensed to be controlled.

What, first Descartes, then Malebranche, and finally Vico want us to learn is that the human beings, in anthropological terms, can come to see the world and themselves either as the dominators or the dominated ones. We see in this the germs of the future dialectic of ownership and labor. Primitive human beings can understand reality mainly in antithetical terms: either we dominate nature and the other human beings, or the other human beings and nature dominate us. The practice of veneration is the way of reversing the rapport of power between the domineering inexistent authority (Jupiter) and the visionary subject (the theological poet). The daughter of veneration is shame. ${ }^{37}$ Shamelessness is fundamentally the sensation of being inferior before the superior, the sensation of being naked at the presence of Jupiter. In this situation, we find also the genesis of the mechanicalstructure of marriage: forbidden by his feelings and imagination to perform the coitus at the presence of the heavens and Jupiter, the hero pulls the woman by her hair into the dark cave. The primitive females were thus becoming part of the egoistic imagination of the theological poet, in a role much different from the one of the famuli or workers on the land. Juno, the goddess, forces on Hercules his fa- 
tigues, the fights against nature and the other males to assert his own identity, family, and imagined universe.

The goddess Juno imposed great labors on the Theban or Greek Hercules. ... Marriage, with its origin in piety, is the school in which we learn the rudiments of all the great virtues. With the favor of Jupiter, under whose auspices he had been conceived, Hercules accomplished all twelve labors; and so was called Heracles, meaning Hera's glory. If we adopt Cicero's apt definition of glory as "widespread fame for services to mankind," imagine how much glory is due to the Herculean figures who by their labors founded the various nations! 38

Idolatry, divination, veneration, and brazenness are, in different ways, the modes with which human beings can come to the dominion over nature and themselves. Uses and customs are the effects of this adaptation of the human mind to the representations of the imagination, as it grows and refines its cognitive capacities. 


\section{ELEVEN}

\section{PSYCHOLOGY AND PSYCHO-LINGUISTICS OF PAGANITY}

In The Search after Truth, Malebranche stated that the soul knows in three different ways: the senses, the imagination, and the pure intellect. ${ }^{1}$ By way of the senses, the soul apprehends sensible and coarse objects that may fall within the field of the action of the perception of the body. These perceived objects impress the organs of the senses so that their impressions will communicate with the brain. By way of the pure intellect, the soul will know spiritual and universal things, the idea of perfection, and in general, all the thoughts on which it will reflect. The knowledge of this special category of objects that the pure intellect acquired is called pure intellection or pure perception because the soul can think of them without forming any corporeal images. ${ }^{2}$ By way of the imagination, the soul forms the images of the material entities that are not perceived by the senses or the pure intellect. This is the imagination's narrowest definition, because the imagination still forms images of perceived entities and represents them to the mind's conscience. ${ }^{3}$

Imagination is the soul's faculty capable of representing corporeal objects that are thought as extended. The imagination cannot but represent and give form to concepts and ideas alone that have some connections with extended things. Imagination is a painter of limits. As we can imagine a circle and make a circle with a compass marking on paper its circumference, so the imagination equally impresses our conscience with different images.

The pure "acts of understanding" (concepts) of the intellect cannot be imagined naturally. We cannot represent the idea of infinity tracing a line with a compass and nevertheless our mind tries to trace and represent with images the spiritual and universal entities, falling into error. The imagination organizes into mental representations (images) all that the sensitivity gathers from the senses. Imagination and sensitivity are so strictly connected that Malebranche dares to affirm that between them the difference is purely quantitative and that, in reality, we should not separate them. ${ }^{4}$ In the first part of the second book of The Search after Truth a chapter exists that deals with the union of the soul with the body, in which 
Malebranche confirms the dualistic Cartesian position and the consequent Occasionalism. ${ }^{5}$

\section{The Natural Language: Traces and Ideas}

Malebranche's analysis considers the relationship between the traces in the brain, which are connected in correspondence with the motions of the animal spirits. ${ }^{6}$ The traces in the brain awake the ideas in the mind and the animal spirits provoke the passions. There is a natural bond between sensitivity, imagination, and passions, as well as between animal spirits and traces. ${ }^{7}$

Imaginative thoughts are perfectly suitable to the actual condition in which human nature exists. The representational contents of conscience are always of an imaginative character. Imagination and sensitivity are the window of the soul over the body and, given that the human life evolves between the circulation of blood and thought, as Malebranche says, by studying imagination, we study human nature. ${ }^{8}$ The natural correspondence between blood (brain) and thought is due to the laws that God has established. This correspondence consists in the fact that when the soul thinks new things, new traces are impressed in the brain; and vice versa when the objects produce new traces, the soul receives new ideas. ${ }^{9}$ There exists this correspondence or parallelism between what happens in the sphere of the real (the soul) and what happens in the sphere of the unreal (the body). The relationships or ties between ideas and traces would be able to unite something that pertains to two opposite realities, matter and mind, and is irreducible to any of the two.

We must keep in mind that when Malebranche speaks of these relationships and ties, in his discourse the acceptance of the Cartesian conception of the separation between thought and extended substance and the Occasionalist solution of the problem, are implicit. It is a union due to the laws of the Creator and not to a fusion or point of contact or real similarity between ideas and objects, as the major part of the pre-Cartesian philosophers thought. Before we analyze the connection between traces and ideas, let us distinguish the two kinds of traces: the natural and the acquired ones. Malebranche says, "Natural traces are profound and it is impossible to erase them completely; the acquired traces instead are not profoundly rooted and can be erased." 10 This distinction shows that there are in the human being ideas that are natural or are naturally present like the ideas of sensation, for instance. These kind of ideas produce traces that with the will alone cannot be easily cancelled because their tendency is that of continuously reproducing themselves. The acquired trace, on the contrary, as they are easily formed, so they are also easily erased from the brain. Their "second" cause is determined by the experiences that the individual goes through, mutable experiences that produce as many mutations. 
We should not confuse the nature of the traces with their intensity. There may be acquired traces that are more intense than the natural ones. The acquired traces are not substantially different from the natural ones: their nature and origin are the same; their durability is different. The natural traces accompany the human individuals during all their life. ${ }^{11}$ The acquired traces acquire more permanence in the brain with the representation of the cause that produced them in the first place, otherwise, little by little, they will lose their impact. The natural traces can be called hereditary, as something that in some manner gives to an individual the same inclination and disposition toward objects that the progenitors had. ${ }^{12}$ The usefulness of speaking about traces is purely expositive; what counts is to see how they connect with the ideas.

Malebranche has identified three causes of the connection between ideas and traces. The first cause is nature that is identified with the constant and immutable will of the Creator. If nature is the cause, also the effects that nature will produce (the connections between thought and traces) will be natural, and the natural connections will be independent from our will. For instance, there is a natural connection between the traces produced in our brain while our senses perceive a tree and the idea of the tree we form in our mind. ${ }^{13}$ A natural connection between traces and ideas is applicable also to the function of the sentiments. This natural connection will reach from the sphere of what is perceived to the dimension of the sentiments concerning the preservation of the human body: for instance, a sensible idea that stimulates in us fearful ideas and possibilities of threats. This is a fundamental point for Malebranche: he asserted that the ideas of piety, fear, and threat are naturally (that is, necessarily) connected with traces in the brain. A thought that like the pagan thought is born from sensitivity will have a natural penchant for tracing the idea of fear and threat to the natural entities and for the traces produced in the brain. ${ }^{14}$ The ties established between sensible ideas and traces during the perception are the strongest and to them are connected also the sentiments of compassion, fear, and danger. It is possible to sustain specific traces and, in determined cases, some specific sentiments are naturally tied to determined sensible ideas. These natural ties are identical in all human beings. ${ }^{15}$ Not all the ties between traces and ideas are natural; conventional ties also exist, such as the relationships between the ideas and the sound of the words, the written characters, and some other forms of language. ${ }^{16}$ All the ideas not derived from sensation have with the traces in the brain a conventional connection.

The human being places a connection where nature has none; he freely associates sign and significance, perceptions and ideas. In a branch of the olive tree or its representation nothing exists that will point naturally to what it symbolizes for a Christian. The language in our society is essentially composed of conventional ties. These ties are not established by nature because language is not necessary for living but only for living socially as human beings. Beside natural ties and natural connections, the conventional connections also exist. ${ }^{17}$ 
The will is the third cause of the link between traces and ideas. ${ }^{18}$ Malebranche says that the effectiveness of the will presupposes the other two kinds of causality. First, it is impossible for the will to go against nature; second, the conventional links that the will would establish would not be possible without the condition of the "identity of time." Concerning language learning, the will, the identity of time and nature perform at unison the task of constructing the words. In the imagination and sensitivity, the signs (words?) are linked in a conventional way to the things that they intend to signify. Different nations speak a different language because each nation agrees on different conventions that are determined by nature, such as environment, climate, and constitution of the subjects. In different times and places, given the interplay of the identity of time and space, societies would have some specific characteristics and not others. For these motives, the human will is always presupposing the coordination and cooperation of the other two causes of nature and time. Uncoordinated and unnatural ties are impossible. Language is the mutable product of a cultural, not a natural, convention between traces and ideas.

The cause of language is the human necessity of maintaining a society that finds the reason of its existence in the will of the human beings. As the human will is changeable, so the conditional conventions on which the human beings would agree will vary from commonwealth to commonwealth. Nature, at its own turn, acts on human wills bringing human beings to accept the indispensable accord for a life together. Without this propensity to associate not only tacitly and instinctively, but also with signs signifying ideas, societies would remain unstable and imperfect. ${ }^{19}$ The will to communicate is reinforced by the natural inclination to connecting the ideas to perceivable signs. Part of the nature of language is to connect ideas with the traces impressed in the brain through the perception of corporeal entities, linking the corporeal to the spiritual. The conventionality, which is at the root of this phenomenon, must be accepted consciously, because otherwise it would give origin to error.

Language in a way can be the source of error, but we cannot say that it is effectively the source of error. That language may deceive is well known to the mathematicians who with great care try to avoid all errors in their own discipline. ${ }^{20}$ They know that all conventionalities are arbitrary. The mathematicians do not link their ideas to traces of sensible entities. They move "contrary to nature," against the natural inclination of connecting the ideas of numbers to sensible traces. To do so, it would slow down mathematical ratiocinations and introduce confusion among ideas, which instead though with difficulty should be maintained at the level of conscientiousness. On the contrary, these mathematical abstract ideas would be more easily explained and remembered when tied with corporeal entities, but then they would be deficient in accuracy. This example shows the application of an important principle in the psychology of Malebranche. ${ }^{21}$ 
Language moves in two planes and consists greatly in explaining the rapports among spiritual things by way of the rapports between material things. We are mostly unaware of how many times our language is metaphorical and how frequently we mix the two planes. Our will prefers to give sensible form to abstract ideas, and language is its ground of battle: in other words, conventionality has the support of nature. If we link rapports between material things, but exclude every natural tie between ideas and traces, our comprehension and memorization of the material things would result quite arduous. ${ }^{22}$ The individuals who approach the studying of abstract objects like algebra and mathematical analysis experience how difficult it is to understand abstract demonstrations and to retain them. ${ }^{23}$ Usually geometric figures are represented with simple alphabetical letters, which have no natural connection with the representations of the different parallelograms and triangles. We can say that such linguistic expression as $a, b, a b, a b c$ used to identify geometric figures have no connection with the things they represent. For this reason, Malebranche suggests that the study of mathematics should begin with learning the basic elements of geometry. ${ }^{24}$

The usage of a mother language is the fruit of a convention accepted through the education, the culture of the society in which we had our birth and where we live. Other languages may be learned for an advantage or a tradition, as in the case of the languages of all the codified forms of knowledge. Many kinds of conventions exist and they mostly conform to nature. The conventional habit of considering geometric figures by means of alphabetic letters is less natural and more difficult to understand than the conception of the idea of anger of a jealous and vengeance prone god through the representation of a lightning and a thunder.

Human nature is endowed with precise dynamics that not even language can avoid. When writers manipulate literary expressions with the hope of communicating to the reader their own sentiments in a clearer or more remarkable fashion, they may produce a contrary effect. ${ }^{25}$ Malebranche takes position against those who support the theory of language as the product of a mere conventional or contractual action: language is not due to a mere formal agreement on the meaning to be attributed to words. In The Search after Truth, we read,

One might in passing recognize through what has just been said that these writers who coin a large number of words and new symbols to explain their opinions often write rather useless works. They think they are making themselves intelligible, when in fact they make themselves incomprehensible. We define all our terms and all our symbols, they say, and others should adapt to them. It is true, the others adapt to them voluntarily, but their nature repels them. Their ideas are not attached to these new terms, because that requires use and more use. The authors may have this practice, but their readers do not. When one claims to instruct the 
mind, it is necessary to understand it, because it is necessary to follow nature, and neither to irritate nor outrage it. ${ }^{26}$

In this context, to follow nature is not an irrational decision. It does not mean to abandon ourselves to our instincts and even less to modulate language on them. It is necessary to know the nature of our spirit in order to comprehend how conventions should be attuned to it. Though language is a fruit of the conventions produced by the will, in order to reach efficacy and usefulness, language must follow the specific inclination of human nature. Definitively language must follow human nature: it is conventional by right and fact, and natural by fact.

The art of formulating an efficacious language consists essentially in the ability of using terms whose new significance is not too far removed from the traditional significance assigned to them. ${ }^{27} \mathrm{It}$ is easy to see why it must be so. Nature, or the inclination of the will for connecting ideas to particular traces, has been abundantly influential in the formation of the language that modeled itself in time to the needs of a specific society. In the case of formal languages suitable for the communication of abstract truths, the only link that exists with the traces in the brain is the one introduced by the will; there is no connection with the "matter"; there is only an extremely weak connection without any sensible referent. ${ }^{28}$

Our mind has a natural inclination for forming links with things that follow under the imagination. The association of traces and ideas of material physical objects precedes the association of the ideas of abstract things with traces because in these associations the imagination is absent. The links between traces and abstract ideas are the most difficult to establish and maintain; they required a great effort and much experience. Natural and hybrid links (those that are conventionally imaginative) follow in the logical and chronological order and they are the more complex as they follow the more logically and chronologically. ${ }^{29}$ The maintenance of these last links needs a constant effort, which is not required for the other links: they demand a joint effort of reflection and memorization, abstraction and retention of the abstract concept. It is a difficult and laborious operation that the mind of a scholar can afford, though at times not even scholars are apt to perform as scholars. ${ }^{30}$ Our conclusion is that the links of the soul (the ideas) with the body (the traces), when they are not absolutely natural (established by the will of the creator) are certainly the products of the soul (of the human will), but they are also always in function of the body. In the pages of The Search after Truth, Malebranche listed the parameters of judgment applicable to the languages of the pagan peoples and valuable also for the classical languages, Latin and Greek. Though he does not build a philosophy of language nor found on language his anthropology, as Vico did, Malebranche keeps a historical-linguistic perspective for observing the human nature, to which he refers rather insistently. ${ }^{31}$ We have determined some of the theoretical elements that form the cardinal points of the linguistic theses of Vico's work. 


\section{Natural and Conventional Language}

In a summary, we may say that Malebranche has sustained the existence of two kinds of links between traces and thoughts: the natural and the artificial (conventional). Language is in part natural and in part conventional and between the two forms the difference is quantitative, not substantial. The more a language is natural, adapting itself greatly to sensitivity, the stronger it will be; more persistent in memory and more comprehensible, even though proportionally less definite. The natural language largely focuses on the stronger sentiments, which are those linked with the survival of the individual, and is particularly tied to fear. The conventional language is the one that the human beings build with their sentiments and has a "natural" origin: the human beings place linguistic ties between some things and ideas on which nature has placed none. The consequence is that the more pagan a mind is, using no part of its intellect, the more it would use the metaphorical property of language. Languages for Malebranche are essentially metaphorical. Exactness, as the language of mathematics shows, is indirectly proportional to metaphoricalness and symmetric with conventionality. Purely conventional languages are only formal; they convey abstract concepts but leave no sensible traces in the mind. They are not suitable as the means for public communication in society and for the ordinary communion among human beings.

Natural languages are called Italian, French, or other, accordingly to human nature, because they necessarily adjust to a specific human nature, that is, to the definite imagination of the people, who in Italy represent to themselves a world, an environment different from that of France. The more easily a single word would recall a sensible image, the more easily it would be comprehensible and retained. Vico thinks that all these characteristics are found in the language of the origin, of the myths. ${ }^{32}$ Myth must have natural relations with the things it intends to signify; in a myth there must be no symbolizing-abstracting difference between the word and its meaning. ${ }^{33}$ Language must come to life necessarily as an absolutely natural language; it cannot originate in function of a communication purely instrumental (without the psychological mediation of the myth, that is, of the metaphorical religious thought) in view of a material goal. Abstraction does not determine the difference between the brutish being (bestione) and the theological poet. Technology does not move from biology to psychology. The first thought of Gentilism was not an abstract thought and the first word's meaning was not due to conventionalities.

Thought was born as a natural thought in the human nature; it was born as sensible thought, imaginative and fantastic. Vico says that between the brute and the theological poet the difference is qualitative and that the quality that makes the difference is thought. Between sensible thought and abstract thought the difference is quantitative because otherwise the growth of language, mentality, 
and society would not be possible. The difference between pure ideas and simple abstractions is instead qualitative.

This ontological disposition of conceptual matter is found also in Malebranche: between the material and the mental the difference is qualitative and between sensitivity and abstraction it is quantitative. The ideas of the entities and the representations of the geometric entities, if we limit ourselves to psychology, are abstractions from the sensations, operations of the imagination that clear the subjective-sensible traits from the representations leaving only the geometric forms. Between the simplest sensation and the most abstract representation the difference is in grades. This difference becomes qualitative when we move from particular ideas (no matter how purified or abstract they may be) to absolute ideas, which are not properly ideas but the intelligible extended, that is, the possibility for the divine mind of thinking extended entities.

As we can easily comprehend, the agency of these evaluations is the imagination. The imagination and not the pure intellect determines the border line between the corporeal and the spiritual. The imagination is the active faculty, though in error, of the pagan mind; the imagination establishes the limit between the human and the divine mind. The human being has a double union: one with the bodies and one with the divinity. The perimeter of the soul is traced by the imagination. What differentiates one human being from other human beings is the imagination and is always the imagination that differentiates the human being from the Absolute Other. Beginning from the imagination's otherness of the pagan mind in relation to the universe, Vico constructs the analysis of the birth of thought and of myths among the gentiles:

In fact, the earliest speech, that of the theological poets, did not use words which suited the nature of the things they expressed. (This was the sacred language invented by Adam, on whom God bestowed divine onomatothesia, nomenclature, which is the art of assigning names to things according to their nature.) Rather, their first speech was a fantastic speech based on animate substances, most of which they imagined to be a divine nature. ${ }^{34}$

The quantitative difference between natural and conventional links that we found in Malebranche exists in the mythical language. The divine language (natural) and the language of the human beings (conventional) are quantitatively different. Vico says that this difference is the product of an impoverishment, a loss of religious significance. The naturalness of the language of the origins is recognizable, at this first stage, in its being essentially mute, that is by gestures. In it, a perfect imaginative identity between sign and significance seems to exist. 


\section{Metaphoric Language}

Language has a fantastic origin, but from a fantasy that is unstructured and simple. This language is mute, it is expressed with gestures that have natural relationships with the ideas that they intend to signify. In The New Science, Vico narrates,

The first pagan people conceived ideas of things using imaginative archetypes of animate beings, or personifications. In their mute condition, they expressed themselves by using gestures and object naturally related to their ideas, such as three ears of grain or three scythe strokes to mean three years. And they expressed themselves using language with natural meanings. The origins of languages and letters are inseparable. But philosophers and philologists treated them as separate, and so the inquiry proved too difficult. ${ }^{35}$

The imagination gives life to the things perceived and initiates a dialogue with nature believed to be divine. The speech of the dialogue would have the same character of the entity to which it is referred; it should be a corporeal speech with "divine" significance; as Malebranche insisted, it should explain the rapports between spiritual entities by means of rapports between corporeal entities. This speech will be necessarily metaphorical. But this metaphor of the first kind of speech will fuse together sensation and significance, a task impossible to the metaphor produced by an evolved mind. The three ears of grain, one for every harvest and therefore one for every year serve the purpose of explaining the passing of time. Even the modern mind can grasp the metaphor that makes easy the comprehension of an element in itself incorporeal, time.

The reasoning mind can think this concept independently from the metaphor, while the primitive mind could only grasp it through the experience of the succession of particular corporeal events, as the recurrence of harvesting. In the metaphor of the theological poet, the concept of time and the representation of the ears of grain are indissoluble. You can only think one in the other and vice versa. Only a learned mind can use the metaphor of the ears of grain in an abstract way, because the learned mind possesses already the concept of the passing of time independently from the example used for communicating it. Without the "natural" metaphor, the first hero would have no notion of the flux of time. The metaphor is a cognitive figure, ${ }^{36}$ before being a rhetorical one. The metaphor, as a cognitive figure, represents a way in which the mind figures out things for itself. Rhetoric is a valid form of knowledge because it adapts and uses the natural tendencies of language at the advantage of the rhetorician because language is born always as language of imagination. The strength and the efficacy of language is directly proportional to its minor or greater conformity with the nature of the human spirit. 
According to Vico, language for the theological poet is all his experience or, in other words, all what the theological poet experiences is linguistic, that is, with meaning. In Malebranche, language is "metaphysically" placed between mind and body. ${ }^{37}$ Between the natural and the conventional links that constitute language, Vico and Malebranche see a temporal continuity and a continuity of nature (in Malebranche's terminology, a continuity in the nature of the traces). The two philosophers agree on two fundamental points. First, language has a natural origin; the natural links that unite the sign and the meaning precedes and conditions also the conventional languages that are formed in a second moment. At the individual level, no child has ever learned mathematics before learning the language spoken by his parents, so mathematicians and philosophers have never preceded the poets. In the beginning, science and philosophy were by necessity poetical. Second, they place language as the intermediate link between the mind and the body. These two points constitute two fundamental theses of great importance. They imply another fundamental assumption that regarding Malebranche has been misunderstood: in the imagination, language has its origin; in the imagination, language takes shape; in the imagination, mind and body come together. The nature of language, in one word, is the imagination. The difference between natural, divine, and heroic language and the articulate language of human beings or, in the terms of the Malebranchean psycho-physics, between natural and conventional links, has been dictated by a different articulation of the fantasy, by the facility of combining the various images. The more the image exhausts itself in the sensation, the more natural will be the language; vice versa, the more the representation abstracts from the perception, the more effort the will makes to supply nature.

\section{The Identity of Time: Memory and History}

The second cause of the link between traces and ideas is timing, the identity of time, ${ }^{38}$ the concomitant presence in time of traces in the brain and of ideas in the soul. If at the same time that we perceive an atmospheric event of noticeable intensity we think of the divinity, then we have established a strong link between the traces produced in the brain during a storm and the idea of divinity. This is purely an extrinsic fact, extraneous to human nature and will, a pure causality for reason of casuality, because there is nothing more casual than when a thought comes to my mind, a physical fact comes to my conscience and a link is established between the two (psycho-physical?) events. The identity of time has no minor function than the other causes linking traces with traces. Malebranche says,

The cause of this connection among many traces is the identity of the times at which they were imprinted in the brain. For it is enough that many traces were produced at the same time for them all to rise again to- 
gether. This is because the animal spirits, finding the path of all the traces made at the same time half open, continue on them since it is easier for them to travel those paths than through other parts of the brain. This is the cause of memory and of the bodily habits we share with the beasts. ${ }^{39}$

This implicit simultaneity is the cause of our habits and memory. The brain and, in a parallel way, the conscience form a structure of traces and representations in such way that at the representation of one part all the other parts that composes the accumulated knowledge acquired previously would appear as well. Every trace that reappeared a second or third times required implicitly that the other traces that were form with it at the first instance, would also necessarily be re-awakened. As the animal spirits, so also thoughts find an easier going through an already known path.

Our habits of mind, which generate the usual ways of conduct, follow a special psycho-byological arrangement: we act and think as we are used to act and think, because this is the easier and most energy-saving way. Every time we change the habitualness of doing or thinking a thing we make an extra effort. As the river always follows the same course it took the first time, so the mind is inclined to follow the same traces. Vico uses the example of the river speaking of our habits that in a collective situation become respectively uses, customs, and languages; these habits, uses, customs, and languages maintain their effectiveness for a long time after their causes ceased. This happens for many reasons, which we would like to summarize with the formula, "for the force of inertia that they involve." Let us hear Vico: "Different climates clearly produce peoples with different natures and different customs, and these in turn produce different languages. Nations with different natures view what is necessary and useful to human life under different aspects. This produces different and even opposite customs, and at the same time different languages, which therefore vary according to their origins." 40

In this explanation, Vico combines the identity of time with the will: this combination determines the variety of the conventional-linguistic agreements among human beings. This is the classic example of how the will and the identity of time, producing the variety of costumes and tongues, interact. The production of different linguistic accords originated from the convergence, in every place where human beings are, of different events in which the will found itself. This is the psycho-anthropological activator of history. Human beings look at the same utilities in different moments and from diverse perspectives, with different willing and under the yoke of diverse passions. This causes the diversity of cultures, the birth, growth, and fall of nations.

Unintentionally, Malebranche offers the psycho-physiological justification that can introduce us to a historical dimension. History is the report on the events that human beings have created, made, but only of the results, the effects, their mentality, uses and customs that, at their turn, can be reduced to an organized sys- 
tem of habits. The habits and the consuetude are the social aspect of the parallelism we established between the traces in the brain and the ideas of the mind and the reciprocal links recognized and set between them. Therefore, because of the limited capability of the brain to receive an ample variety of traces, the traces that were formed simultaneously at the first time constitute a taut structure that tends at its own preservation. Consequently, at the time of the representation of one of these organized traces to the conscience, all the others as well will appear present to conscience, though indirectly through the ideas that in the mind represent them. The rapports between ideas will not be by chance; the ideas will reflect the structure of the traces that occasionally produced them. In The Search after Truth, Malebranche narrates, "If, for example, a man finds himself in some public ceremony, if he notes all the circumstances and all the principal persons assisting at it, the time, place, day, and all the other particulars, it would suffice for him to remember the place, or even some other less noteworthy circumstance of the ceremony, to have all the others recur to him." 41

This text evokes the story of Simonides, a famous lyric poet from Ceos, who at the banquet of a nobleman of Thessaly named Scopas, chanted a lyric poem in honor of his host, including also a passage in praise of Castor and Pollux. Scopas therefore decided to pay the poet only for the one half of the agreed upon sum. A little later, a messenger asked to see Simonides who left the room of the banquet. As he was outside the building, the roof of the banquet hall fell, crashing Scopas and all the guests to death. The corpses were so mangled that the relatives who came for them were unable to identify them. But Simonides remembered where everyone was sitting and indicated each corpse to the perspective relatives. Based on this simple story and its reconstruction and analysis in Cicero and Quintilian, Simonides has been considered the inventor of artificial memory. What could have been the mechanism of Simonides for remembering peoples and places is explained in Cicero's De Oratore (bk. 2, ch. 86) and Quintilian's Institutio Oratoria (bk. 9, ch. 2). Malebranche suggested the same mechanism for the explanation of the functioning of the reciprocal links between the traces in the brain. We must point out that the reciprocal links between traces, which is a fact in itself natural and with a representative configuration, is applicable also to the linguistic conventional sphere. For this reason, a speech that has conventional links with the traces, will be always more "naturalized" because the links with the traces will be natural or inclined by nature to be what they are.

Though the link that connects a word to a trace is conventional, the link that connects such a specific trace to another trace is natural or determined by the identity or simultaneity in time of the natural event. Then, the words will be indirectly united by natural links through their traces. ${ }^{42}$ The relationship between things re-awakens the relationship between words in the memory. Now, the pagan mentality rests on this kind of mechanism. To this regard, Lamy suggested that all poetry per se upsets the spirits of readers or listeners because a vivid poetry leaves 
"firm vestiges" in their brains after the poems ended. "The works of the poets upset the spirit of those who read them not only when they read them but also after they abandon that reading. All the excellent truths of whose knowledge we need for the acquisition of virtues and sciences find no place in their head because it is full already of all these great and rare happenings that are the ordinary topic of poetry." 43 Lamy applies to poetry the same psychological principles of Malebranche. The images and the connections that the images have among themselves find in poetry a synthesis of such a force that can upset the consciences. The images suggested by poetry are in the mind of the poet more real than the world that surrounds him. A word is linked to another by a conventional link chosen according the grammatical rules of the natural language of which the words are participant. These words are linked together also through the links that tie together the traces to which they are linked. The word "church" is linked to the word "bill" because of a convention internal to the grammar: "It is the church on the bill." The words "church" and "bill" are linked also with the traces in the brain that allow conscience to represent to itself the church on the hill. When we perceive "the church on the hill," the links between these traces are certainly natural. The word "church" is conventionally tied to the word "bill" by the grammar, but it is also, indirectly, tied to "bill" by nature; this natural link is indirect because directly only the traces are naturally connected among themselves, but not to the words.

The insistence on this point allows us to clarify in what sense we can speak of nature and convention in regard to language. For Malebranche, language is conventional, but in this convention nature plays an important role. The role of nature shines in the memory, the comprehension, and the mnemonic techniques of rhetoric, which would be the maximum of artifice and is the persuasive force that inclines toward a general agreement or consent. Rhetoric is artifice, but an artifice that conforms to nature, complies with it, and when possible uses it for its own goals. The identity of time is an important principle that regulates the functioning of our mind and helps to comprehend how our habits are formed and preserved. Given that our life is always the full sum of our habits of mind and conduct, it is important to understand the connectivity and the reciprocal correlativity of thoughts and perceptions. ${ }^{44}$

\section{The Art of Rhetoric}

Rhetoric, for Malebranche, is not merely a forensic art; rhetoric is a branch of psychology because following the nature of human thought, the art of rhetoric demonstrates its full awareness of the nature of the human mind and provides efficacious knowledge. If the rhetoric's principles were false, if they based themselves on an erroneous nature of the human mind, then rhetoric would be useless. The supposition of the similarity of the previous example with the story of 
Simonides was not due to haste..$^{45}$ Malebranche explicitly refers to rhetoric as the evident example of the links between traces. Society itself relies on the communion of minds, which naturally relies on the communion of links between traces in the brain and ideas in the mind. For this reason, Malebranche reminds, "It is very useful to seek with care for the different effects that these various connections are capable of producing, because these effects are very numerous and of great importance for the knowledge of the human nature." 46 Besides nature, will, and the identity of time, another element exists that is influential on the links between traces and ideas: the emotions. We all know that passions and sentiments affect thought. Not one human being can dominate fully its own emotions. The sentiments have a strong power over our spirit because they can insinuate themselves into the center of our thoughts, among the links between traces and ideas, reinforcing or undermining them, ascertaining or defiling them. The intensity of sensations and passions decrees the profundity of the traces. It is necessary to repeat in time the meeting of ideas and traces in order to reinforce their connections. Human will must practice the exercise of reinforcing the connections or of providing an identity of time when in nature the conditions are recreated for maintaining what in the first time was produced in the traces.

This would not be possible if the human beings were not equally inclined to provide the same kinds of links between traces and ideas, if God were not to have given to all human beings the same disposition for uniting ideas to certain sensible signs, which are naturally connected with the traces. ${ }^{47}$ The passions agitate the spirits because without sentiments the communication would be impossible. An emotive charge exists in every word and it permits the fruition of the word in the hearer. An absolutely apathetic language is a contradiction. Even the mathematical language is not completely apathetic. In the case of math and the sciences, the effort in favor of an apathetic and aseptic language is indispensable in order to eliminate any trait that could undermine the objectivity of the ratiocination proper to that specific discipline. What Malebranche says concerning the emotive intensity of language as being indirectly proportional to the precision and the exactness of what is affirmed, finds a supporting agreement in Vico's On the Most Ancient Wisdom of the Italians, as we mentioned it in a previous chapter. Even in this work, the argumentation is uninterested in the rhetorical tradition; it starts from a psychological reflection on language, philosophy, and science. In On the Most Ancient Wisdom, Vico expressly deals with geometry, mathematics, and physics.

Malebranche, in The Search after Truth, discusses rhetoric not in order to theorize on rhetoric but to prove that rhetoric adapt itself to language and the pagan thought. Rhetoric is the logical form of the thought common to peoples and of ordinary speech. The rhetorical art, as we read in the works of Cicero and Quintilian, must try to adequate itself to human mentality and modify it only in the measure in which it can comprehend it (in its etymological sense). The structure of ordinary speech and of the nature itself of the pagan thought reflects itself in the 
rhetorical art. The rhetorical art takes the same paths of the natural traces, advantages itself of the same rapports of the sensible thought, and affects the consciences relying on the help of rationality and nature. When desiring to influence the intellect and introducing truths of reason, the rhetorical art must go through the certainties of opinion. With the same intent, Vico speaks about a topics of the senses: "The first founders of civilization strove to devise an art of sensory topics. This allowed them to combine what might be termed the concrete properties, qualities, and relations of individual objects and their species. These combinations in turn created their poetic genres." 48 Thought establishes itself as the metaphorical reflection of the perceived worlds; the first logic is a sensory topics. In the classic art of rhetoric, topics was the art of finding loci (topics), the "dwelling places" from which arguments are derived. Vico goes beyond the search for the loci, in the direction of Malebranche. Topics is the art of finding the loci that are common because they are the fruit of habits of thought, mental habits, and therefore it is a branch of psychology and the object of philosophical reflection and speculation. As the art of Cicero is an intellectualized rhetoric, speculative, flamboyant, and founded on principles quite clear to the mind, so the topics of the primitives, the thought of the origins, is the rhetoric of the senses, ingenuous, natural, and unconscious.

The relationships that the pagan thought institutes among the ideas are the same that exist in its imagination among the corporeal beings. Poetry launches a logic based on the qualitative order in which reality is represented by the imagination to the poet. The sensory topic of the theological poet is the "geography" of the imagination, in its constitutive ultimate elements. The poetical genres are the expression of the structuring of the relationships among ideas, of the hierarchy that between traces and ideas and between ideas and ideas come to form in those first moments of forming and reinforcing themselves in the process. Topics teaches to dash through the loci, the "dwelling places" of memory, and this sensible memory will teach parallelly how to know the things that perception presents to the attention of the individual. Topic, in paradoxical terms, is a cognitive rhetoric.

Classic rhetoric is built at the image and similarity of the natural "physiology" of the poetic thought of the heroes and the art of the orator is the more effective the more its efforts press on the mental mechanisms that are at the basis of conscience and represent its genesis. Rhetoric is the activity of the conscience of the theological poet when his conscience places itself in confrontation with itself and the known world. He who knows the principles of the rhetorical art possesses the principles that regulate thought: "The world's first age people ... created a crude form of topics. For this art regulates our mind's primary function by showing us all the commonplaces which we must review in order to know a subject well and completely." 49 Rhetoric is connected to mnemotechniques and the rhetorical topics. The loci of topics are not real "dwelling places," but places of the imagination because in our thought we can go "through them as swiftly as we 
would go through all the letters of the alphabet when we read." When we associate a temple or a field, which are due to the human work of the fantasy before being the effect of the plow, to a physical place, we are building mental places out of physical places..$^{50}$ We construct mentally some places in our mind, in our imagination, to which some physical places correspond, whose physicalness is merely the result of something of which we become aware only after we thought of them and with imagination created them.

The pagan mind considers these places real, but not physical. The pagan thinking mind considers these places as concrete entities that exist in the same way in which fantasy presents them to conscience. Physical reality, separated from what the pagan mind imagines, does not exist for the primitive because the primitives perceptively but also and particularly passionately intuit reality. Passions and phantasies construct reality. Illusions assume objectivity, whereas physicalness does not exist for the primitive mind. The physical place does not exist for the theological poet. It exists for the instinct of the animals and, in an opposite way, for the modern humankind. The physical place for the instinct is materiality and, Malebranche would say, it is part of the dynamics of reaction of the machine, the body. The fully displayed thought of modern humankind is abstract; it acknowledges a clear separation between physicalness and spiritualness. In the theological poet, physicalness and spiritualness are melted together and he experienced them without being conscious that his life is physicalness and spiritualness fused together. The loci or places of rhetoric or poetic of the pagan mind are at a different level than the loci of the instinct and of the fully displayed reason. The loci of the pagan mind are the loci of the all-pervasive imagination, of the fantasy that fills up the mind and allows no confrontation between individual illusions and the concepts of the intellect. The loci of the pagan mind suffocate reason under the representations and break the direct, biological link between perception and the particular environment of the instinct. ${ }^{51}$

Rhetoric considered as the mirror of the pagan mind is the thesis that Vico will present and develop in an innovative original way. The study of the primitive conscience brings together rhetoric, pagan mentality, imagination, and persuasion. Only Malebranche studied the primitive conscience in the same way Vico did after him. In relation to this point, Vichian remarks exist that have been universally accepted as anti-Cartesian, but that the new analyses of The Search after Truth have shown them in a less contrastive tone, at least for what concerns Malebranche's Cartesianism. In The New Science, Vico wrote:

Providence directed human affairs wisely by causing the human mind to conceive the art of topics before that of criticism, for we must be familiars with things before we can judge of them. Topics make the mind more inventive, just as criticism makes it more exact. In that early age, the institutions necessary to human life had to be invented, and invention is 
the proper task of ingenuity. In fact, on closer consideration, we find that, even before philosophers existed, the Greeks had invented not only the things necessary to life, but also many useful, comfortable, and pleasant things, including non-essential luxuries, as we shall see later in discussing Homer's age. As Axiom 52 states: "Children excel in imitation; poetry is simply imitation; and the arts are simply imitations of nature and are, in a certain sense, concrete poetry." In other words, the first peoples were the children of the human race, and founded the world of the arts. Coming much later, the philosophers were the old men of the nations and founded the world of the sciences, by which civilization was completed. ${ }^{52}$

The mentioned imitation is the imitation of the imagination and of the imagined as they are believed to be. Poetry is a creative imitation; it is not a simple copy of what is imitated. The rhetoric of the primitive is a poetic psychology, a construction in fantastic loci of a personal environment, in which everything is a fantasy of absolute concreteness. With these statements, is Vico opposing the Cartesianism that preferred the criticism to the topics? If so, these affirmations must be redimensioned. Topics viewed as the natural mode of thinking of the theological poet, for Vico, carries no truth. As a good philosopher, Vico opposes the heroic metaphysics to Christian metaphysics. But this is what Malebranche does, opposing pagan Aristotelian metaphysics to the Cartesian Platonic philosophy, the true Christian philosophy. Furthermore, Malebranche opposes Christian morality to the Stoic morality that proposes the heroism of egotism that is identical to the heroism of Vico's first human beings. Topics do not oppose criticism because they possess truth. Vico insistently repeats that the first theological poets were all sensation and imagination and that they were erring because of the psychological and evolving priority that "the places of the fantasy" had in the economy of the human mind. These statements do not contradict Cartesianism, but comply with it. In this work, hundred of citations are given that under many aspects show Malebranche sustaining that psychologically and anthropologically the senses (and therefore the topics) precede the intellect (and therefore criticism). Moreover, in the first part of this work, we have exposed the theological and metaphysical reasons of this thesis. It cannot be otherwise, because the Cartesian metaphysics opposes ontologically the common sense, which is all made of prejudices.

Criticism has no other function than that of recognizing and purging error. God has no need of the Cartesian method in order to purge prejudices from its mind. Only in God, criticism does not chase error because no error exists in God. In his meditations, Descartes begins by considering error, not the clarity and distinction of ideas. The encounter with truth follows the doubts on acquired credences. Descartes would have agreed with Vico in affirming that human beings think by following sensible topics; Vico agreed with Descartes in stating that all knowledge acquired through the sensible topics is false and that a critical know- 
ledge must be built on the psychological mechanisms (credences) that created the false knowledge. Neither Descartes nor Malebranche have asserted that criticism precedes topics in the evolving of conscience; they insisted that criticism ought to revise and cleanse the mind from the errors that the sensible topics has originated. Criticism is needed because the quotidian life is subject to the topics of sensation, error, and prejudices. The two philosophers can share the profound significance of Vico's thesis. In nouvelles réflexions sur l'art poétique, Bernard Lamy demonstrates that it is erroneous to oppose conceptually the Cartesian and Malebranchean anthropology to the Vichian conception of the pagan mind. Vico's topical-rhetorical opposition to Cartesianism was developed at a different level and for an end essentially pedagogical. It was an opposition to Descartes and Malebranche, but especially to those worsened forms of Cartesianism of the first half of the eighteenth century. As we saw, Malebranche understood perfectly the cognitive value of the rhetorical art, which he used in the religious works like the Christian Conversations and Dialogues on Metaphysics and on Religion recognizing that the human mind thinks in a rhetorical manner and follows the same principles that this art has developed at its own advantage. As the good orator appeals more to the sentiments of the audience than to reason, so the pagan mind constructs its sensible topics on passions. The human thought (and the relationships that it creates with the objects of its representations) possesses always an emotive intensity.

The links between traces and ideas are always rich with passions. Without emotions, it is impossible to understand others; communication would be impossible when the relationships between traces and ideas are not activated. "Imagination, imitation, and society," as we will see, will be impossible without the existence of passions in human beings. No form of society or complex culture would be possible, if passions are not moving the human beings. Without the forcing motion of the animal spirits, without an emotive tension, the links between traces and ideas will not be unwavering. When emotivity is absent, communication fails and thought looses its brilliancy. What would happen to the human being who cannot understand others and is unable to web intricate links sufficiently stable for the construction of an argumentation? The problem presents two sides: as the strong emotions may determine the strength of the links, so the weak ones let the links dissolve. Malebranche asserted, "Thus, the spirits being agitated only by passions, if men did not have them for communicating their feelings and sharing in those of others, the precise connection of their ideas to certain traces clearly would be very weak, since they only submit themselves to these precise and regular connections in order to communicate their thoughts." 53

Strong connections between traces and ideas or among ideas are fixed at the time of their first inter-action under an emotional pressure. As the force of the sentiments increases, so the connections grow in stability and reliability. ${ }^{54}$ It is obvious that if there was no criterion (determined by nature, will, identity of time, and passionateness) suitable for the establishment of a consequentiality apt to 
providing coherence and consistency to the connections and links of thought, it would be impossible to explain the existence of any structured meaningful form of reasoning. It would be like affirming that a canto of Dante's The Divine Comedy was composed by the disposition of a series of shells on an ocean beach. As Malebranche stated, this would be the strangest case, if the oceanic tides could have written in hendecasyllables.

The harmony of wills is the indispensable condition for communication; without a consonance of minds and hearts, a society would not be possible. Every individual would live in isolation, in an exclusive linguistic and sentimental world that would exclude the possibility of interpersonal relationships. In the writings of a more definite theological character, Vico underlines how charity and compassion (clemency) have a fundamental social function. We may declare as one of his axiom the indirect proportionality between compassion (clemency) and social tensions: as the sentiment of compassion grows, the relationships among human beings improve. God has provided the human being with the possibility of an identical passional physicalness and an identical linkage between traces and ideas. .55 We see in this what we have previously said. Though our will is free, since we can unite conventionally abstract ideas to the traces that we prefer, it is nevertheless inclined in a definite direction that, more than being due to an autonomous choice, has been willed by God to dispose us to live in society.

The will undulates between sentiments and ideas, fantasies and sensations, representations and abstract ideas, and chooses following the specific connections and links formed gradually and successively between traces and ideas, like a river, free but running on a preestablished bed. Notice that the links between abstract ideas are the most difficult to establish and uphold because they are the ones deprived of emotionality. All the links between traces and ideas exist in a moral polarity of good and evil. With the greater goodness or evilness of the links goes the higher degree of intensity of the traces and the ideas that can retrieve them in the conscience. The strength of the links between traces and ideas is in proportion to their ability of helping or hurting us. Every link between traces and ideas is emotively connotative; it always implies the search for a real or imagined good and the avoidance of evil. At the root of this reasoning there is always the goal of the preservation of life. ${ }^{56}$ The preservation of life is the cause of the distinction in our mind between the good/useful things and the evil/useless ones. This distinction produces the emotional intensity of the links and the ideas, which, at its turn, determines the consistency of thought and the possibility of communication. Communication is the fundamental pivot of the human society. We have thus arrived at the conclusion that, beside the links that relate to perception (I perceive and think the square as square, without any alternative), the strongest links are those that generate in the spirits the emotions relating to the preservation of life. ${ }^{57}$ 


\section{Communication for Preservation}

The greatest emotions are those tied to life-preservation. It sounds simple and clear, but we do not realize that the first and most durable thoughts formed, and on the model of which all the other thoughts are formed, are those that relate to life-preservation, which means also the fear of death. What Malebranche sustains, though it appears going against the stereotyped Cartesianism of analysis, method, clarity, and distinction, and though the center of his philosophy is the evidence of reason, is that the human mind is pagan at all effects and acts diametrically in opposition to what Cartesianism suggests. The human thinking being does not follow the Cartesian method when thinking, but its human nature, and its nature since the Fall is less inclined to reason than the Cartesian meditations. We have come by a different path to assert the centrality of the thought of death and dying. All sentiments directly or indirectly deal with the preservation of life and determine thought from within, determining the links. ${ }^{58}$

In general, we may say that the reciprocal links between traces, ideas, ideas and traces are natural. The conventional links, too, are due to a deficit of nature. The conventional links are always consecutive and posterior logically and chronologically to the natural links in the same way that "natural" thought is logically and chronologically prior to the merely conventional thought. For Malebranche, reasoning is constituted of the links of several judgments; a judgment is formed by the link of several ideas; the ideas are linked to traces. In the conscience, the traces are always connoting sensations, and thus thought is always imaginative and emotive. The fervent activity of the animal spirits has a fundamental importance especially at the first moment when a link is formed between traces and ideas. As it was mentioned previously, "If the first link between a trace and an idea is not happening with a virulent motion of the animal spirits, the link will not be firm, strong, and durable."

The emotive component always refers to the fear of death which points to the natural tendency for the preservation of life. The fear of death indicates also that the cause of the links between traces and ideas are all present in the considerations that Malebranche expressed about the birth of the link between the idea of god (manifestly a false god) and the traces in the brain. Let us bring up a citation that enlightens and should be carefully analyzed:

If the idea of God is presented to my mind at the same time that my brain has been struck by the sight of the three characters $i a h$, or by the sound of this same word, the recurrence of the traces these characters, or their sound, will have produced, will suffice for me to think of God. And I could not think of God without the occurrence in my brain of some confused traces of the characters or sound that accompanied the thought I had of God, because since the brain is never 
without traces or impressions, it always has those which have some relation to what we are thinking at any given moment, though these traces are often very imperfect and very confused. 59

This passage shows an extraordinary similarity with the Vichian theory of the birth of thought. The passage encloses all the characteristic elements that Malebranche attributed to the links between traces and ideas, which actually are summarized in the idea of divinity, which we wish to analyze. The imaginative thoughts present in conscience represent the condition in which the human spirit at different times adapts itself. The fictitious idea of divinity is the pivotal idea of the pagan mind. It will necessarily be the idea that is most loaded with emotivity and determine the mood of the individual and the flowing of images in its conscience.

The pagan mind elevates itself over all confuse thoughts with the greatest possible emotive capacity, with the imaginative ideas of divinity and death. For the pagan mind, the idea of a god of vengeance, jealous, menacing, and tyrannical, who mercilessly inflicts death on victims, is the most fearful idea that carries to an extreme the sentiments of fearlessness, terror, and dreadfulness. How can this idea of divinity be linked to traces produced in the brain at the time of the perception of a specific physical event? Malebranche believed that this linkage effectively happens in virtue of the three causes that generally link traces in the brain with ideas in the mind.

First, through the natural link between traces, the idea of divinity is referred to a series of perceivable representations like a lightning, a thunder, anything the senses may perceive, phenomena intensively and exceptionally striking, capable of generating in the human spirit the idea of an overpowering magnitude and fearlessness of being annihilated by such gigantic power. The depth of the traces is connected naturally with the passions that connote lifepreservation and the strength of the emotions.

Second, there is no temporal sequence between the idea of divinity and the linguistic elements with which we associate it. The identity of time exists between the perception of thunder and the emotional imaginative creation of the divinity. If at the moment I think of God I perceive a definite sound like the Jähveh of the example of Malebranche or the sizzle of the lightning in that of Vico, I certainly will afterward link the two events, that of my mind (the thought of divinity) and the physical phenomenon (the character Jãhveh impressed on a sheet of paper or the lightning). In short, I will associate the two events and assimilate them in such a way that I will confuse them. I will think of the lightning as I perceive Jähveh as a manifestation of divinity. The association becomes indissoluble, but it is an association produced not in the intellect but in the imagination. Traces and ideas, though they are extremely vivid and profoundly impressed, are also confused and incline the mind to confuse what is thought with what is perceived, what is sensation with what is reflection. The pagan is unable to distinguish be- 
tween the representation of the physical phenomenon and the idea of divinity. For the pagan, Jähveh and god are one and the same thing. The pagan has formed a confused idea of the divinity: the sign and the signified, Jäbveh and god are mixed together; when one of the two elements is represented in the mind, the other follows. This confused superimposition of the sign (Jâhveb) on the signified (the idea of divinity) is made possible by the imperfection and confusion of the first element and the obscurity of the second one. The emotional intensity involved is so great that it mixes the elements in such a way that even a total fusion becomes possible.

Third, the link between the fictitious idea of god and the sign Jãhveb is made possible by the human will. This link is arbitrary and conventional, even though the conventionality and the will that determines it is partially directed by the first two presupposed causes. As we already explained, the convention is possible only when it is compatible with nature and it is more easily acceptable to human beings if it follows human inclinations. The conventionality that links the mathematical signs to their meanings encompasses little imagination and rarely follows natural human inclinations. The signs used in mathematics are intended for exactness, conciseness, and everything that would favor a rapid flow of reasoning. The mathematicians avoid the natural inclinations of a corrupted soul. If they were to represent the numbers with signs and symbols that please the imagination more than the Arabic numbers, the Latin alphabet, and all the other signs of the formal language, the result would produce a slowing down and a toll in the processing of operation, demonstrations, and theorization.

Independently from the validity of the mathematical sciences, the mathematical language is the fruit of a rational convention that intended the achievement of rational goals (exactness, velocity, simplicity, clarity, evidence), a convention that intended to exclude the necessity of representing entities by means of images proper to the corrupt pagan mind. From the text of The Search after Truth, we may conclude that the links that unite the traces in the brain relative to the sign Jaahveh and the idea of a god are also of the conventional nature but not of the same kind as that of mathematics. These traces are in step with the nature of the corrupt mind, its rigidity and confusion. The pagan mind is a mind with reduced powers of reflection, with little propensity for abstraction and analysis. It thinks always the same things and hardly changes its interest from one thing to another, unless the most recent is present to the senses. Malebranche advises that we exercise with as many objects of thought as possible, that we reflect on a greater variety of scientific, literary, and philosophical questions in order to achieve a progressive greater mental elasticity. ${ }^{60}$ 


\section{Onomatopoeia and Language}

Malebranche offers a theory of onomatopoeia, of a word made at the sensible imitation of a sound perceived by a subject, in which the word does not signifies the sound but the idea of god. The theory of onomatopoeia is useful in the demonstration of the theory of the links between traces and ideas, that is to say of occasionalism. We already discussed the passage in which Malebranche theorizes on this topic. The squeal of the newborn baby is interpreted as the prayer addressed to the surrounding giants (the parents and the obstetrician). Further down these pages, Malebranche will consider the ululation of a werewolf to the moon, an ululating that is not a simple reproduction of the animal agitation, but the result of the aberration of the imagination, that is, of a form of thought. In the writings of Malebranche, psychological and cognitive situations are recalled that are similar or even identical to those of the theological poet of Vico.

The onomatopoeia represents the linguistic product of the most natural link between traces and ideas. The sign (the word) is the perfect imitation of what has been heard (the sound). The conventional choice of the word and what it signifies seems to coincide, if we stay on the ground of pure sensitivity. The onomatopoeic expression coincides with the reproduction of the sound heard, but it is not reduced to that. The meaning of the onomatopoeia, though it is locked in the sensitivity and is fully comprehensible with the imagination, goes beyond the simple mechanical reproduction of the sound: the idea of divinity. The onomatopoeia is the most natural word (in the sense clarified in the above pages) we can hypothesize and includes a conventional component dictated by the imagination, the idea of god and the fantastic universal of Jupiter. The origin of thought is the origin of language and, in their coming to be, their nature is revealed. In The New Science it is written: "Just as the divine character of Jupiter was taking shape as the first human thought of the pagan world, articulate language began to take shape in onomatopoeia, which children still happily use to express themselves. In Latin, Jupiter was initially called Ious after the sound of crashing thunder; and in Greek, he was called Zeus after the whistling sound of lightning. In the Near East, he was called Ur, after the sound of burning fire." 61

The onomatopoeia is the children language, but paradoxically is pregnant more than any other language with meanings. In the ululation of the theological poet who seems to ululate to the storm, as the newborn baby prays with his crying, the word hide in itself a complexity of meanings: the sense of fear, the answer to a whole world through the madly manifestation of bestial passions in a disgusting howling (werewolf?), the consciousness of otherness, of the divinity, of an imperfect conatus.

These meanings are the different elements in the mind of the historian, the critic, the philosopher, but all together are found in the pagan mind, "in the mind of the historical infant," all condensed, synthesized with the most unrefined 
fantasy and expressed in a monosyllabic canto. The onomatopoeia is the poorest of all expressing words because it is the first linguistic form. ${ }^{62}$ Onomatopoeia semantically possesses potentially all the possible meanings of which languages and human minds are capable, but syntactically in the moment when the primitive arrive at thought, it is only a simple imitation of a crash. It may not be evident why to speak of onomatopoeia as the product of imagination, given that it is a word prevalently acoustic. A double explanation exists. Malebranche could answer that though the imagination seems to touch only one aspect of sensitivity, because of the imagination's essentially visual nature, nonetheless it has factors that can be reduced to or derived from other senses.

In Vico's theory, onomatopoeia is the reproduction of the sound made by Jupiter, and Jupiter is essentially an enormous animate body, is an image absolutely of visive nature. Jupiter manifests itself in the imagination as a body, an ensemble of clouds; the trees, the river will become Jupiter. He manifests himself as animate partially in the visive imagination and partially in the acoustic one with the clap of the thunder and the whistling of the wind. For both Malebranche and Vico, the onomatopoeia often possesses a visual-imaginative component, though it manifests itself as sound. The (visual) image is the visual equivalency of onomatopoeia.

The expansion of human passions in the created world is actualized in sounds. The human being with the sound of its voice expands itself in the universe and implicitly and metaphorically becomes the lord of creation. The theological poet with the onomatopoeia attempts at a communion with the divinity. The names themselves (terms) of Zeus and Jupiter have a matrix exclusively onomatopoeic; in their origin, they have an element absolutely representative and imaginative. The same should be said for the definitions of these names; they are definitions of the image, of the characters (signs) that identify them. ${ }^{63}$ Language or speech stands between mind and body, places always itself at the level of imagination. Words are created by fantasy and they at their turn shape fantasy and fit it within their structure. In language, imagination manifests its "dialectic" nature.

In the linguistic transformations, Vico saw the evolving growth and the continuous broadening of the metamorphosizing of the human mind. Linguistic innovations assume the correspondent articulations of the imagination. As long as the representative faculty is occupied in a single idea, only one word is necessary: Jupiter. When other ideas by way of cytodieresis are coming to join the first one, then new relationships are created among the new ideas that, in order to be expressed, need new linguistic forms. For instance, we sense the necessity of introducing articles and pronouns into the language. If interjections, articles, pronouns, and adverbs, under many aspects, indicate the links between ideas, then words (names) represent ideas and, for this reason, there is no sentence or discourse that does not show one word (name) functioning as subject. ${ }^{64}$ Vico's philology shows the dialectic component of the functionality of the imagination in language. It shows how, from an image to which a word is connected, we move, 
through the transformation of the image or images that with it have links, to a transformation of the word or of the syntax of the language.

The structural modifications happening in the imagination manifest themselves in language. In the imagination of the first human thinking the first idea in time some fractures formed that cause the progressive fractioning of the divine omnipresence of Jupiter into a plurality of divinities acting on nature. The idea of Jupiter, after its explosion in the mental nullity, expanded its fantastic universe, creating a new dimension and a new planet: an individual human being capable of thinking. This expansion brought up also a dissociation: galaxies, solar systems, and planet were formed. Vico said that not by chance these new entities came to have the names of pagan divinities. The universe is the metaphor of the mind, which is the metaphor of itself, of its imagination. We may notice the cognitive transformations that have their genesis at the level of the imagination in the language itself. ${ }^{65}$ The phenomenon of dissociation of the ideas became the point of departure of abstraction. As we saw in Malebranche, the abstraction consists essentially of the links between ideas.

An idea may be considered as abstract not only in itself (in itself all ideas are formally identical for being "portions" of the mental extension) but for the abstractness of the relationships held with other ideas. Clarity and distinction are not abstract "characters" of the ideas, but their concrete propriety. A clear and distinct idea per se is not abstract; it is not the fruit of the process of abstraction from the imagination or, in the rationalistic perspective, from sensation. Abstraction finds its way in the relationships among ideas and between traces and ideas. Abstractions are formulated when and where conventionalities exist. However, an objection is possible. If the union of soul and body is the product of a convention, why is the human being not conventional and abstract at the same time?

This understanding of the Occasionalism of Malebranche is nonsense, because it is not aware of two fundamental elements. First, convention in the human language is abstract because it establishes between ideas links that are situated at the level of imagination or from the imagination derives an intellectual abstraction. Second, in the creation of god no abstraction from a corporeal image exists. The human being, therefore, is not the fruit of an abstraction but of a universal law ordered by a rational divine verdict. The divine law exists at a different metaphysical level than the human abstraction.

We have already stated with Vico that abstraction comes to exist automatically when the dissociation of images finds its way to the human mind. This abstraction consists in part of the links present between traces and ideas and among ideas. The image in itself can never be said abstract; its definition is always in relation to another image and the relationships existing between the two images. We may say that we abstract the figure of the cube from a block of ice, but in reality we only have obtain the result of the comparison between two images: the image of a block of ice, and the image of the cube that I represent mentally only 
for its geometric shape. If we were to analyze every representation in itself, we would easily realize that no minor or greater abstractness exists anywhere. Only in a comparison and through a comparison between two things, we are able to state that one thing is the abstraction of the other. This is as much as we can say of Malebranche's theory of imagination and of the links between ideas. The same can be said of Vico's theory of the articulation of language and the evolving of thought. The idea of Jupiter is not an abstract idea and will never be an abstract idea because, being the only sensible representation present in the mind, it cannot be the abstraction of a previous perception. The myth of Jupiter is contemporaneously the only sensation and representation: if it were an abstract idea, it would be a contradiction by being the abstractness of itself. The concept of metamorphosis will clarify in a conceptual way what we have been saying.

Metamorphosis means a transformation of form or representation. The poet grasped in his thought an image, Jupiter; Jupiter represents the poet's full mental content. The passage from one single idea to a plurality of ideas happens through the endogenous transformation of the single idea and not through an imposition of many posterior ideas upon the prior one. The image is transformed by acquiring new characteristics and the sum of these qualities will affect gradually a true and suitable scission of the representations. The metamorphosis is an obligatory step in the path toward the human thought: it accompanies the actualization of distinctions between ideas. The metamorphosis is the fundamental aspect of the differentiation of ideas; it is what Vico proves philologically with the example of the mythological monsters, which are the product of the distinguishing. Concerning this matter, Bernard Lamy wrote:

As we have seen, for the poet it is an easy thing to extract from the inside of the earth all the gold there hidden, of making it as common as the iron. We can think and say all that we want. These imaginary treasure please every body and a miser when he hears of them feeds himself joyfully with these imaginations. In poetic stories there are always scepter and crowns. In these works, all the personages introduced by the poets are famous and admired for their birth or for the great and rare favors the have obtained from fortune. ${ }^{66}$

\section{Again in Nouvelle Reflexions sur l'Art Poetique:}

Nothing is more diversified than the writings of the poets: they continuously change their stories, their words and expressions, and their rhythm. All that is in the heavens and on earth is suitable matter for their verses: the movement of the planets, rain, hail, lightning, thunder, mountains, planes, forests, crops, and fountains appear in their descriptions. The poets open the womb of the earth to discover what goes on in it. 
They show us the lives of men, the wars of kings, and the combats, the sieges of cities, the customs and inclinations of different nations in an extraordinary and new fashion. Besides enjoying their power by transforming everything that the universe contains in itself, the poets use their imagination in order to create chimeras, centaurs, and other monsters that are not in nature. With these portentous figures, they surprise even more humankind. ${ }^{67}$

Vico approved these statements of Lamy, and what he said can be derived from the reading of The Search after Truth. In The New Science, we read, "Metamorphoses in turn sprang from distinctions between ideas...." 68 For Vico, the pagan mind cannot distinguish with language because it does not discern with reflection. To know how to make the description of a phenomenon is in direct proportion with the knowledge of it. The greater knowledge we have of a phenomenon, the better description we can give of it. Speaking is the manifestation of thinking. The mind is reflected in its language. An undifferentiated language signifies a thought that is coacted, indistinct, and compact in its opacity. The intellect's abstraction transforms things, though perhaps this transformation is a kind of "depuration" or "distillation." The true transformations, the metamorphoses, are performed by the primitive mind that has not yet learned how to link and relate abstractly the ideas with the intellect. We have the mythological monsters, in which the images are not in relation with each other but altogether fused.

The primitive mind does not know how to think characteristic traits separate from the images and cannot even imagine different things simultaneously. For example, it cannot imagine the wings separated from the animals which use them; it cannot comprehend contemporaneously a bird and a horse. Hence, the Pegasus: the chaotic synthesis of what the pagan mind cannot do. It cannot discern the animal present in the human being without transforming the human being into an animal, at least for what must be expressed, in one representation, of so much that there is in the little of humanity present in the Minotaur. The monster is an image perceived, transformed, and used in substitution of another image that could be thought in its place or at its side. In Vico's science, Vico explains: "Poetic monsters and metamorphoses were necessary products of early human nature, since people were incapable of abstracting forms and properties from objects, as Axiom 49 states. Using poetic logic, they had either (1) to combine objects in order to combine their underlying forms, or (2) to destroy an object in order to distinguish its proper form from any contrary forms imposed on it. Poetic monsters sprang from combinations of forms and ideas." 69 The imagination models thought and language on the frequency of its own tune; thought articulates in relation to the articulation of the imagination. This is the dialectics of imagination within the myth: from one image, different ones and often opposite ones are born. Because of the incapacity of creating abstract links between the representations, the mind 
of the theological poet uses the imagination. In so doing, the imagination becomes more malleable and ready to create conventional (abstract) links between its "natural" icons, as soon as the social conditions would be favorable, as for example, the establishment of the famuli within the heroic families. Language develops following the development of imagination. Vico narrates, "Finally, the authors of languages formed verbs. In just this way, we observe that children often express nouns and particles, but leave the verbs to be understood. For nouns awake ideas and images which leave clear mental imprints, and particles do the same by signifying modifications of these ideas. But verbs signify motions, which imply past and future moments measured against an indivisible present, a concept which even the philosophers find difficult to grasp." 70 The ideas that leave firm imprints and the images and the nouns that refer to them are easily and efficaciously preserved in the mind. Nouns are easily learned because they firmly represent the things in the mind.

Different is the discourse concerning verbs. Verbs do not connote things or images, but "movement." In order to be represented, verbs need more than one simple image; they need a series of images linked together. Verbs presuppose in the speaker a mind already in possession of a series of ideas and capable of connecting these ideas by means of specific relationships. These relationships and links are not natural, but conventional. Why? Because the verbs, in contrast with nouns, do not connote the ideas of things, but the relations between the ideas (for this reason, verbs may be considered as complex ideas). Verbs are the indisputable sign of the presence of abstractness in thinking. Let us, for instance, think of the words "apple" and "eating." In the case of the noun "apple," only one link ties the word to the representation of the object, and the mind receives a clear and firm imprint. In the case of the verb "eating," the possibility of asking "eating what?" and the fact of having no determined object, manifests the first element of a cognitive complexity of the term. If we say, "eating an apple," the mind of the speaker must represent to itself "an apple," "a person," and the act of "eating," which can be represented only with a sequence of representations.

In order to represent a verb, many images are indispensable and a complex net of relations that connect them together. The selection of the verb "to eat" was intentional because it requires an easy network of relations, just the opposite of verbs like "to will," "to verify," "to realize," "to be sorry," and "to sin." The apprehension of verbs is a complex operation that is possible only when the mind has become expert in representing images and connecting them. ${ }^{71}$ The birth of thought happened with the birth of one noun, of an idea of simple comprehension. This notion is implicit in Vico's theory of historical and cognitive precedence of poetry over prose. The theory confutes the opposite "instrumental" theory that declared thought to have been born from the specialization of techniques, from the abstraction that human beings progressively practiced. They started from the progressive specialization and complexity in the usage of the instruments con- 
structed to the advantage of their survival. The classic conceptions, theorized and become common during the eighteenth century, were teaching that human beings became intelligent because when their hands were no longer used for moving from place to place, they constructed tools and in order to plan for tools they had to think. This theory saw also that because of the ten fingers, human beings used the decimal system; because of the free thumb that facilitated the handling of objects, human beings advanced advantageously in their effort for survival. Vico implicitly intended to confute these ideas, not in their plausibility, but in their pretense of identifying the origin of thought.

If thought would have originated from the technical specialization of the tools used, language would not have been born with onomatopoeia but with verbs. If the origin of thought were from "doing," then words would have been originated that express action and actions are in the Vichian theory connoted by verbs. If born as a "verb," thought would have been already complex, because the comprehension of the verb demands multiplicity of ideas and relations. For these same reasons, modern psychology, as in Malebranche, and the new historical and philological science, as in Vico, deny the allegorical explanation of myths and the explanation of the progressive potentiality of abstraction of the faculties (as in Aristotelianism) or representations (as in the theory of nature of the ideas in Empiricism) of the birth of thought.

Malebranche has not considered in historical terms the problem of whether human thought was born from one idea alone or from an agglomeration of ideas. As we read in The Search after Truth about the thought in the newborn and will consider again in details, Malebranche faced the problem in psychological terms, and came to formulate a complex and complete theory concerning the fantastic universals. He has resolved at a psychological level an historical problem that he was not considering. The pagan thought is the complex of the representations and of the possible ways of connecting them of a mind whose center of gravitation is located in the imagination. This is the way in which Vico intends the problem:

All these observations prove that human nature determined the creation of poetic style before prose style, just as human nature determined the creation of mythical and imaginative universal before rational and philosophical universals, which were the product of discourse in prose. For after the poets had formed poetic speech by way of the composition of particular ideas ... the nations formed prose speech by contracting these poetic combinations into single words, as if into general categories. Take for example the poetic sentence "My blood boils in my heart," which expresses a natural, eternal, and universal property of humankind. They took the notions of blood, boiling, and heart, and formed them into a single word, or general cat- 
egory: anger, which is called stomachos in Greek, ira in Latin, and collera in Italian. ${ }^{72}$

In this passage, Vico shows the dialectics of imagination through the linguistic mutations. First, there is the fantastic universal, a unique idea that fills up the mind and is expressed with one onomatopoeic word. Second, we have the dissociation of the idea into different representations, and an increasing number of ideas is formed due to the enrichment of the mythical experience of the theological poet. Words are multiplied and the syntax or faculty of creating new relations between the images originates. Then, prose comes to follow poetry. Third, the linguistic phenomenon of the compression of a phrase into one single word, like in the above example of collera, happens. This movement goes from a single concrete idea that, from the point of view of the pagan mind, is Jupiter, to a plurality of ideas (other gods) and words. With the human language of the famuli who ignored the existence of the divinity and of the magical world that the heroes represented, the preference for a concise concept and a single word expressing a plurality of ideas and complete phrases becomes manifest.

In these linguistic modifications, the metaphor goes through various transformations. It is at first a real metaphor, in the sense specified in the chapter on the birth of thought. Then, with the articulation of the linguistic imagination, the dissociation begins between sign and significance. Finally, when the pagan conscience learned to comprehend with greater facility and rapidity what it thinks, the imaginative mind will be able to formulate one single word that contains the entire metaphor. This last word will be also a concept derived from a complex process of abstraction, made possible by the variety and quality of the relations that the mind established among its representations and ideas.

In short, thought originates in poverty, in the sense that it is born from a single idea, without any relation or link with others. This first idea has in itself the seed of the future. Though alone in the beginning, this idea makes human experience significant. This new experience will enrich progressively itself, thought, and the primitive language, because these three elements are indissoluble. Other ideas are created and with them relations are made that link them. The language and the links that determine the language have always a double side: on one side, the merely representative component; on the other, the passionful one. The example of collera in Vico gives the idea. In reality, every human thought is connoted sentimentally and possesses a link to goodness or wickedness. Book four of The Search after Truth deals with this matter. Vico, in harmony with Malebranche, assigns to the first thought the double valence of fear and joy. ${ }^{73}$ According to Vico, to these two natural elements or modifiers of language we should add the one of the conventionality, which is the social modifier originating from living in society.

Life in society with other human beings, especially with the famuli, will provoke an increase of the conventional links among ideas. These conventional 
ties are the cause of abstraction. The greater capacity of a language for creating conventional links among ideas gives way to a greater capacity of thought for abstractions. Examples can be derived from mathematics. In the prospective from which we initiated the study of fantasy, the difference between the divine, heroic, and human languages, in the philosophy of Vico, is due to the diverse competencies of the mind in every one of its phases of development and to the capacities that the mind acquires of articulating (representing ideas and linking them among themselves) its own thoughts. ${ }^{74}$ 



\section{TWELVE}

\section{SENSITIVITY AND INTELLECT}

In the comments on the analysis of the pagan mind that Malebranche makes, we will find how its principles are compatible with the psychological and anthropological principles with which Vico constructed and structured his new science. The analysis of the mind of the theological poet was performed by means of the conception of the fantastic thought that could not be but modern and, in a specific way, Malebranchean. This would become apparent when we will compare the functions carried out independently by the intellect and the senses. Both imagination and memory proceed in their construction of thought in a manner similar to the one of the intellect. Imagination and memory apply to thought, however in an extrinsic manner, those procedures of the intellect that, among other philosophers, even Leibniz used. ${ }^{1}$ In this chapter, we will not introduce other theories in addition to the ones already presented. Of these theories, we would comprehend in detail how they became possible and why Malebranche and Vico used them in the effort to reconstruct the theoretical genesis of the fantastic universal.

\section{Analysis of the Pagan Mind}

The study of philosophical anthropology begins from the knowledge of the individual human being, from ontogenesis, from the senses. For Vico, the human beings first feel things without noticing them, then notice them with inner distress and disturbance, and finally reflect on them with a clear mind. ${ }^{2}$ Given the actual human condition, Vico states that this is the justifiable truth of the description of the steps of growth of the pagan mind. At the psychological level, the priorities are a reverse of those of metaphysics: at the cognitive level, the precedence is due to the senses. We must initiate from the prejudices of the senses and the imagination, if we wish to penetrate the imaginative faculty of those first human beings who founded the gentile nations. As much as their intellect was inconsistent, so much more was the power of their imagination. Vico suggests that we start with the analysis of sensitivity and imagination and thereafter advance with a careful analysis of our passions because of their weighty incidence in the formation of 
mentality. We find the same course in The Search after Truth. It is an anthropological course, though it obviously has its metaphysical and, given our goals, theological presuppositions. The imagination is placed between sensitivity and intellection and determines prevalently the dynamics that regulate the "natural" thought of the human beings.

Only with a great effort and always reluctantly, the human soul studies the intelligible things, promptly diverting their interests whenever possible. The kind of union we have with god does not generate love for him. ${ }^{3}$ It is a union less pressing than the one that links us to corporeal things. The connection with corporeal things stirs up a physical love that makes us slaves of the material beings in many different ways. The sensitivity and the intellect do not possess the same intensity and the same role within the dynamics of our conscience. We may confess that sensitivity clearly weights more on the scale. In all human beings, the body enjoys a kingly presentiality that the spirit may experience only in a few holy or heroic individuals. This invasive presence in our conscience has caused the general opinion that the body is the better part, or the most important, of the human being. This natural connection, extremely reinforced by the Fall, with our body has generated an unyielding love for the body and through the body for all the sensible objects in which we suspect the possibility of pleasures. Thus, we become slaves of corporeal goods. This slavery reinforces the unitive dependence of the soul from the body. As it is actualized, this slavery reinforces the cause that produced it. The misfit that we accomplished at our own expenses does not stop at the pathetical play of psychological compensations, but invests the complete cognitive area.

The human being, the more he thinks in function of the body, following its own passions and inclinations, the more he increases and reinforces the tie and the dependence of its soul from the body. To establish the body as the goal of our existence is to become blind to the simplest truths. In reality, this would be possible only by degrading the spirit without glorifying the body. ${ }^{4}$ To change the status and the finality of matter is up to the agency that created matter. Sensual pleasures anesthetize the mind. When sensitivity comes to be excited beyond reason, reason falls into a deep sleep and the reaching of intelligible truths becomes difficult. If perchance some truth reaches the mindless pagan soul, it means that the soul has assumed sensible habits and has become acknowledgeable to the senses.

Combining his theology with the Cartesian philosophy, Malebranche arrives at a significant conclusion concerning imagination: what the human being truly wants is the goodness that exists in God. ${ }^{5}$ Given its actual situation, the soul continues wanting the goodness of God, but it represents to itself only bodies, and it is in them that it presumes to find happiness. The imagination does not show to the individual its authentic wishes. The imagination is the field of battle in which self-love, sensitivity, and passions set their tents. What the imagination represents are essentially the compensations between frustrations, inferiority sentiments, in- 
security, and all the complexes of the most disparate nature. The imagination does not indicate what the individual wants; it shows only the algebraic sum of its internal tensions. In poverty, the poor individual would fantasize about wealth, not because he wishes to be rich but because he senses the precariousness of his actual situation. His fantasy makes him to believe that his secure condition is attached to the economical situation that is opposite to his own. He would dream of riches, while simply wishing for a safe economic stability. Where would any human being find a safe and true stability? Certainly, not in the wealth that imagination prospectively offers but in the absolute Goodness of God. The true contradiction of the human soul is found between what it desires (Goodness) and what it believes that it desires (the material goods). Even in the most miser and luxurious human beings, Malebranche declares, the rational wish for the absolute Good always persists, though it remains under the ashes of the fire of the passions, at the bottom of their spirit.

The deception of the imagination consists in bringing the human being to desire things that, if it used reason, it would wish to avoid. The imagination is the receptacle of all passions, fears, egoism, and destructive sentiments that hang on the pagan mind. The representations that the pagan mind will make will be the effect of these sentiments. The human being wants the objects that the imagination will present and that in reality are the compensations of its own fears and of its lowest sentiments. Does the human being really want this? Certainly not. Humankind wants the happiness that it knows to exist in the divinity. The human being deceives itself when it wishes for what it wants to reject. The good is what the human being wants, but it ends with the possession of what will constitute its ruin. The true realization of the individual and of humankind comes from the happy possession of the true good, but its damnation emerges from its submission to the representations of the imagination. The imagination does not represent the Goodness of God, but the effects of the passions and of egoism. The imagination does not represent what we need to have, but what we need to avoid. If we follow our fantasies, we will end inevitably into the arms of the monsters from which we have tried to escape. A theological opposition exists between the imagined goodness and the Good truly wanted. The theological poet of Vico is the historical example of this case: he objectified his own fears into an image of a false divinity, and in the unconscious effort to liberate himself from fears he made himself even more a slave of fears. The knowledge of the dynamics that regulate the functioning of the imagination makes us gradually always more conscious of ourselves. We come to learn how to distinguish between what we represent to ourselves because of our passions and what we really want. We should steam away from the pagan mentality, whose exponent is the theological poet, and join the divine mind.

The imagination elevates the lowest passions to acceptable levels of representation, at the same time lowering the highest ideas to images. In this, we have the best precept for the teaching of the pure sciences: to remediate the defect of 
application of the mind to truths that shun the senses by expressing the same ideas with sensible means that court them. ${ }^{7}$ It is the way of giving examples. In the philosophical field, we use a complex of images to express by analogy in an illustrative manner what in itself is not directly representable. The attention of the learner is strongly conditioned by the sensible force with which the images are represented to the soul. The conscience cannot be attentive to what is unconnected with the soul. Malebranche remarked, "Since images of spiritual things cannot be formed, it follows that the soul cannot imagine them; and this should be noted well." 8 The soul then cannot imagine spiritual entities or think them, and will try the possibility of imagining them by analogy. Analogy, however, also is subject to fantasizing because a pure idea is not analogous to any other idea. Between a pure idea and another, there is an irreducible ontological difference. Only the ideas of corporeal things represent similarities, the proportions of compatible forms. A man may resemble another because of some specific traits that recall to the imagination the traits of the second man. Pure ideas have no traits or parts similar to other ideas. All the different metaphors that start from abstract ideas in order to arrive at images contain the seeds of error, even if they are not erroneous in themselves.

The reduction to images of abstract ideas is the fundamental characteristic of the pagan mentality, the fountainhead of all its errors and failures. Conscious life is a process of sensations, remembrances, wishes, and hopes for the future, but these things are nothing but images as in our perceptions, or fantasies as in our memories and hopes. Our conscience is like a filmic sequence reflected on the screen of the soul, a series of images from birth to death. This dynamism moves in a double direction. We may imagine things that are not imaginable, or we assign corporeal life to entities that have an eternal and immaterial life, like in god; on the other hand, we attribute life to entities that have none. We lessen spiritual entities to the level of material entities and raise inanimate bodies to the sphere of incorporeal beings.

This characteristic that in The Search after Truth has prevalently a psychological and scientific propaedeutical value, in The New Science becomes the pivot for the understanding of the imaginative reserve of the gentiles and for constructing an interpretive canon of pagan poetry. Thought itself, born as the awareness of what is exterior to the thinker, the corporeal world, is the act of giving sense and emotions to insensate things. This is a principle of greater value in the psychological system of Malebranche and that Vico applied to his conception of the poetic mind. "The most sublime task of poetry is to attribute sense and emotion to insensate objects. It is characteristic of children to pick up inanimate objects and to talk to them in their play as if they were living persons." What in theological terms is the effect of the Fall, in anthropological terms represent the "earthly" birth of humanity. Human history is born from and with the Fall. An animal makes no error or sin; it follows its instinct. In the animal nature fulfills its proper course. The animal is an entity totally determined. Only an entity capable of over- 
coming nature may fall into error and sin. The illusion, contrary to the instinct, is a revolutionary event; with the illusion, a conscience is born that did not exist previously. The work of poetry in all this is sublime because it invents a world that does not exist, the world of fantasy, brings light with the senses to the darkness of the conscience. By attributing sense and emotions to things, the human being has created myth and has thought reality.

From our point of view, the poetic character is a particular fantastic thought of the first human beings and this thought has created mythology. People, says Vico, has the habit of fabulating, of believing fables as true, enjoying their embellishment with decorations. Ornamentations in the fable are not a frame; they are part of the essence of the fable. The pagan mind specializes its competencies and enriches its thought in the operation of ornamenting and decorating. What in a fable may be just ornamental, in the myth may become the nucleus of the narration. The function of the ornaments is that of making the fable credible. The more particular and better descriptions exist in a fable, the greater the credibility and the concreteness of the fable would be.

These three axioms show us the origin of the poetic archetypes which constitute the essence of the myths. The first axiom describes the natural inclination of the masses to invent myths, and to invent them with the propriety of poetic decorum. The second axiom proves that the earliest men, as the children of the human race, were unable to conceive rational categories of things, and thus felt a natural need to invent poetic archetypes. These archetype were imaginative categories of universals, to which (like ideal models, or portraits) men could assign all the particular species that resembled them, And by virtue of this resemblance, ancient myths were invented with propriety. ${ }^{10}$

The mind needs the fantastic or imaginative universals in order to think the particularities of things. If the mind possesses an intellect covered with layers of sensations and passions, it certainly will not be able to build on rational supporting thrusts. The imaginative universals are the product of pagan architecture, the iconic surrogate of the categories of the intellect. The imaginative universal may represent the determined particular through some relations of resemblance to sensitive nature. For Vico, "The imagination is more robust in proportion as reasoning power is weak." 11 Fantasy is what controls our existence for the most part of our life; only a minimal part is concerned with the meditation on immaterial entities, and even less is turned to the consideration of ideas thought in their pure essence. Human beings have formed the habit of believing real what is familiar to them (their fantasies). This has meaning only if considered in an analogical and metaphorical sense. In this case, human beings should be truly conscious that 
what they believe are analogies and metaphors, maintaining the planes of the intelligibles and of the fantasies constantly distinct.

The senses are equally deceitful in regard of corporeal and incorporeal things, the reason being that they are habitually thinking incorporeal entities with corporeal images. Thus, human beings come to believe that spiritual entities effectively possess a bodily structure. ${ }^{12}$ The pagan mind cannot think the divine attributes or the divinity itself in their purity, in their full abstraction from sensible contents and enjoys instead to figure them out representatively through the power of the imagination. The same destiny is reserved for our soul, whose images is rarely possible to represent, whereas for "god" the humans can forge an infinity of imaginative representations..$^{13}$ Our mind is an object of difficult metaphorical representation. For this reason, the first human beings, who thought only in metaphorical formulations, had no self-awareness. A metaphor can always be found; it is, after all, the conventional product of a link between ideas and traces or ideas and ideas. This metaphor, unfortunately, would be a forced metaphor, the product of an extraordinary effort of the imagination; it would not be the operation of the imagination in accordance with the nature of the soul. Malebranche recognizes the difficulty when he said that if we wanted to figure out the soul's possible representation, we would have to form a corporeal image of it. ${ }^{14}$ Sensitivity puts our conscience in a state of submission toward the external world. Using a metaphor, we may say that the senses pour our conscience into the world external to the soul. Human attention is tending always toward the contents of sensitivity and what sensitivity presents to us is always external to the soul. In this way, conscience is predominantly conscience of what is corporeal; it is not conscience of itself. ${ }^{15}$ Human beings sense with facileness and almost by necessity, but comprehend with difficulty, because nothing forces them to rational reflections.

\section{The Human Nature}

Human nature prefers sensible links to the conventional ones. Sensitivity makes the soul self-conscious of what exists outside in the world, though it does it in an erroneous manner when it is not supported by the intellect. Through the operation of knowing, conscience pours itself in the known, not thinking of itself but of what is present and external to itself. The imagination has precedence over the intellect and the sensitivity has precedence over the imagination. The soul unites itself more strongly with the objects whose images can be formed than with the incorporeal ones (like god and the soul). The soul unites even more with the objects that it has already perceived than with those only imagined or of which it received notice from others. Of these last objects, the soul can make only a fantasized image; not a reconstruction of something it had previously sensed. 
These dynamics are not the same in all human beings or, to be more exact, the power of sensitivity over the intellect is not the same. He who applies himself to his studies willing to use reason, he who looks after the good of the spirit, will always be less slave of the imagination than those who let passions and inclinations dominate them. ${ }^{16}$ The majority of the human beings does not oppose their corporeity and even in those who make the most use of reason, the natural ties with the senses are not rescindable. Nature's forces in human beings are stronger than any opposition of the intellect, even if some of them can be modulated and reduced in their intensity. The natural forces are the cause that induces conscience to think interiority in function of exteriority or to represent before anything else one's own body and the bodies that gravitate around one's own body. In this way conscience fills itself up with the representations of its own body and of the bodies existing in the surrounding space. ${ }^{17}$ This thought is central in Vico's conception of the nature of the thought of the origins. It constitutes our inheritance from the dawn of humankind, the part that we have not yet dilapidated. The patrimony of errors is found also in the mind of modern human beings. Vico affirmed, "When people cannot know the true things, they strive to follow what is certain and defined. In this way, even if their intellect cannot be satisfied by abstract knowledge (science), at least their will may rest on practical knowledge (conscience)." 18 Conscience outstretches itself to the outside of itself. Conscience is like a clouded up mirror and the little it reflects is the reflection of what stands in front of it (the external world) and not of what stands behind (the soul). With greater light on the mirror, greater will be the distortion of the image, if we take the reflection for what is the reflected. With the greater intensity of the sensations, the more attention the conscience will give to what in a confused manner will be represented of the corporeal world, the less capable it will become of comprehending those truths that to a conscience enlightened by reason will seem the simplest truths. ${ }^{19}$ The bewilderment of the soul, which the intensity of sensations produced, renders the mind unable to comprehend even what is most simple, unless it is connected directly to the sensations that in that instant affect it.

The qualitative universe that faces conscience is due to a thought situated at a different abstractive level than that of the intellect. With the intellect the human being analyzes and interprets the fantastic thought, but the two forms of thought remain situated at two different conceptual planes. It is erroneous to use the same kind of logic for both planes. Imaginative thought has a logic that at the light of the intellect is found erroneous, and nonetheless cannot be reduced to the logic of the intellect. The pagan mind is the mind whose fulcrum of thought is the imagination and cannot use the logic of rational thought. The principles on which the pagan mind relies are not rational but sensible. When Malebranche repeatedly observes that the soul is absorbed more by the exterior sensible cover of things than by their substance (the extension), he intends to affirm the principle according to which the pagan mind thinks a qualitative, animated world that is 
impregnated with emotivity. He does not assert that the mind is grasped first by the truth and then is deceived by corporeity, but that truth is hidden to the pagan mind, when the conscience lives in an entourage of passions.

Fantasy depicts to conscience a world with the colors of glaring sensations. The pagan mind is inclined to become absorbed in this world and, from this world that the imagination has presented, it will receive the rules for its way of thinking. ${ }^{20}$ Fantasy then constructs a universe that is parallel to the real one. As God by knowing everything, can create everything, so the pagans by ignoring everything to everything could attribute their nature, into everything they could pour their sensitivity, passions, and fears. Vico, with these presuppositions, interpreted the motions of the poetic spirit.

In this manner, the earliest people of the pagan nations created things according to their own ideas: for they were the children of the nascent human race .... Yet their act of creation was infinitely removed from the creation of god, who by his perfect understanding knows things and creates them in this knowledge. In their robust ignorance, the earliest people could create only by using their imagination, which was grossly physical. Yet this very physicality made their creation wonderfully sublime, and this sublimity was so great and powerful that it excited their imagination to ecstasy. By virtue of this imaginative creation, they were called poets, which in Greek means creators. ${ }^{21}$

In the anthropological analyses and in the criticism of the pagan mentality, Vico assumes that thought is rotating around the pivot of sensitivity; thought is not the spiral staircase to abstract ideas. This is the manifest characteristic of his anthropology, but its evidence escapes those who are simply dealing with his metaphysics. For Malebranche, the pagan thought is a thought in whose logic none of the structures that characterize intellectual thought is present. Sensitivity and imagination should be considered for themselves independently from intellectual thought, from which they differentiate deeply. No person, however, can doubt that the analysis of sensitivity and imagination has to be handled at the shining of the intellect. The logic that Malebranche derives from the analysis of fantastic thought is not the same logic that regulates intelligible thought. Human conscience is permeated by sensible thought, images, and fantasies that put it faraway from verity. Human language, for example, makes clear that the human spirit prefers to use the senses as the movers of thought. ${ }^{22}$ Words are the servant of human nature; they excite the senses, awake the mind; but bring the spirit away from truth. Truth is virgin; it possesses no sensible qualities; it has no need of ornaments; it is frame and portrait together.

The thought generated by a colorful, rotund, emotional language and by a false eloquence that dazzles instead of enlightening, is a thought that fantasy and 
imagination dominate. This kind of thought generates a pagan mentality, in which the intellect is atrophied and nullified by the quagmire of the imaginary and the senses. Vico says that the imagination is capable of using the impossible as the unique believable interpretation of reality, thanks to the psychological primacy of sensitivity.

We find confirmation of this origin of poetry in this invariable property: the proper subject of poetry is a believable impossibility. Thus, while it is impossible that physical object have intelligence, people believed that the thundering heavens were Jupiter. This is why poets are so fond of singing the wonders created by the spells of sorceresses. To explain this, we must posit a hidden sense that nations have of God's omnipotence. This sense in turn engenders another by which all peoples are naturally led to offer infinite honors to divinity. This was the manner in which the poets founded religions among the pagans. ${ }^{23}$

Language, Malebranche observes, runs on the channel of sensitivity. The communication between human individuals can run only on the channel of sensitivity. On this earth, the souls, deprived as they are of telepathy, must communicate by way of the bodies and language becomes conditioned in all its aspects by the vector that carries it. In this point of view, rhetoric becomes the strainer of falseness. To develop oratorical skills for the sole purpose of persuading means to deploy the intelligence for an absurd goal. It means to speak imaginatively to the imagination of the people. In this way, the rationality of reasoning and the force of the argumentations are washed away, submerged by the flood of strong images and dreadful or alluring fantasies. The imagination of the audience goes through the fantastic places where the eloquence of the speaker brings them, and the unaware speaker is dragged by the ghosts in his conscience. ${ }^{24}$ The faculty of self-criticism dissolves as sensitivity steps on the cathedra. Thought stops at the hall of the imagination and imagination no longer being servant to the intellect enjoys its new self-centered purpose. Language, at this point, becomes the vehicle of a persuasion emptied of realities. This language convinces through sensitivity, but the hearer is the one who persuades himself.

Corrupt rhetoric can continue its work of perdition because the yoke of imagination and the captivity of the senses are not difficulties easily surmountable by a fallen human nature. Human nature's links with corporeal objects are natural and human beings cannot reach the goal of an absolute ascetism, of a complete alienation from corporeity. The sensible data per se are not false; perhaps my reasoning based on them may be false; I should have based it on reason. The sensible data, however, make it easy for human beings to fall into error; under this aspect, life is a continuous easing toward error. 
Speaking about the renunciation of corporeal goods as the way of salvation, Malebranche is nonetheless conscious that the perfect control over the individual corporeity is out of the question. In the Traite de Morale, he gives us this insight: "Death is the shortest way to the freedom from the desires of our body" (La mort est une voie abrégé de se délivrer de la concupiscence). ${ }^{25}$ It means that the only way to avoid the fascinating charm of the senses and the imagination is that of freeing completely the soul from the body. In their union, the soul cannot disregard the natural love for the pleasures that come from the bodily activities. While soul and body are united, with its own forces, the soul neither can separate itself from the body nor free itself from the incantations and illusions of the senses and the imagination. ${ }^{26}$ It is impossible to free completely ourselves from the nets of sensitivity, unless we end our life. The reason is that "all the thoughts that happen to come to the soul originate or depend from the body and are in function of the body and particularly of the imagination. ${ }^{27}$ The soul's perspective on the world is that of the body to which it is united. With greater human sensitivity, goes a greater inclination of the soul for externalizing itself. The human being will gradually lose conscious lordship of itself, at the mercy of corporeity.28

We may argue that every vision of the universe is in a relationship with the human nature and not with the nature of the universe. To this end, Malebranche cites a sentence of Francis Bacon that can be interpreted as taking a position in favor of the thesis of the subjectivity of the sensible qualities. Bacon's sentence reflects perfectly the idea of the principle that Malebranche wishes to establish: "The vision of the world that human beings construct with the senses is not connected with the real structure of the world, but only with the cognitive structure of the human beings." Unique is the world, but numerous are the conceptions of the world that the human beings have formulated. If we were to check the particularities of these human conceptions, we would say that there are as many wordly visions as there are thinkers. Verity has one form, but errancy has infinite forms, as many as the passions, the fantasies, the inclinations, and the sensations of the human beings. Error is omnipresent. It appears in human customs, ways of life, traditions, practices, and rites. Errableness is what human beings have inherited. Vico agrees with Bacon and Malebranche. He wrote: "People naturally interpret doubtful or obscure matters affecting them according to their own nature, with its passions and customs." 29 This principle functions as the interpretive key of the mythology and poetical metaphysics with which the gentiles applied their own customs to the gods. Vico continues,

This axiom offers an important standard for our study of mythology. It means that all the myths invented by the first savage and crude people were interpreted severely, as befitted nations emerging from fierce and bestial freedom. Later, with the passage of many years and changes in customs, the myths lost their proper meaning, and were altered and obscured 
in the dissolute and corrupt age that preceded Homer. Yet religion still mattered to the Greeks, and they feared that the gods would prove contrary to their prayers if divine morals were contrary to their own. So the Greeks imputed their own customs to the gods, and thus gave foul, filthy, and obscene meanings to their myths. ${ }^{30}$

This text shows that for our two philosophers all the erroneous conceptions of reality depend from our human nature and the guises, times, and places in which the human nature finds itself. Because of the inconstancy and the feebleness of our will, our intellect cannot reach the truth of the things that daily and immediately present themselves to us. To a greater extent, because of our errableness, we cannot pronounce ourselves on things removed from our senses, on abstract things that have no ties with our body or the bodies of other peoples. ${ }^{31}$

Our knowledge of everything corporeal may be false, but it is of easily access. No effort is required to sense and imagine in relation to our own passions and inclinations. It happens fully automatically. The things that have the stricter rapport with us are the ones we know more easily and intensively, but also less clearly. Truly, the more the sensible objects approach us, the more we move away from our principle. ${ }^{32}$ The boundary between the exploitation of the imaginative aspects of an object of study for the purpose of a scientific knowledge and the seizing of conscience by the fantasy and the passions is always dictated by the determination of the will.

The will must oppose the inclinations of our nature to debasing and muddling in corporeity our conscience by moving our intellect away from the quagmire of sensitivity. If our quotidian activities do not allow an absolute ascetism, we must anyway, in our studies, to achieve a kind of partial ascetism. We should concentrate on the clear and distinct contents of our mind, proceed according to logic in our ratiocinations, and only reach evident conclusions. In one word, we should act the exact contrary to the acting of almost the totality of the human beings. The weakness of the will and the strength of passions and sensations slacken and derailed the progress of the sciences. ${ }^{33}$ The difference between the modern human being and the primitive, in the positions of Malebranche and Vico, is essentially a difference in the quality, quantity, and intensity of the prejudices of the false credences that they create.

The dynamics of the human spirit and of the pagan mind develop in conformity with the emotive balance, the rapports of force between the domineering passion, the present sensations, the habits, the prejudices, and everything involving inclinations and imagination. Reason is thus suffocated by the sand storm caused by the clash between all these forces for the dominion of conscience. To this regard, in The Search after Truth, we read, "The passions, then, act on the imagination, and the imagination thus corrupted combats reason by continually representing things to it not as they are in themselves, so that the mind might issue a true 
judgment, but as they are in relation to the present passion, so that the mind might be led into a favorable judgment of it." 34 The majority of the human judgments is fashioned according to the dominant passions of the moment and contrary to truth, which is stable, human judgments are as variable as the changing moods of the human spirit. Malebranche uses the term "confused reasons" to define the totality of the drives that determine conscious thought, and insists that they are the effect of the corruption of the human spirit and the cause of its concupiscence and errancy. The corporeal human drives are "confused reasons" and precisely for this motive they are compelling. ${ }^{35}$ The center of Malebranche's reasoning is always the question of the original myth of the Fall, after which the connections of human beings with their Creator lost pre-eminence in favor of the inclinations for corporeal things. Human paganism is the result of the human Fall from Heaven.

The drives of corporeal origin determine the thought of the individual human being and the mentality of the mass. Human instincts cause the human mind to conform to the conventional links between ideas and traces and between ideas (and of this conformation the judgment consists), on the model of the natural links between traces and sensible ideas. This compliance and yielding of the "reason" of the intellect to the "reasons" of the senses is due to the debility of the human will in relation to the vigor of the body.

The pagan mind does not think the ideas in God like the pure mind. The pagan mind is in the condition of psychological solipsism because it does not express judgments on things but on the representations (always confused) that it forms of the things. The pagan mind believes to be the center of the world and centers on itself. While becoming unaware of its own essence and invading the world not knowing its own limits, the pagan mind expands throughout the world of which it made for itself a representation. Things are known to the pagan mind only through the defective reproduction that sensitivity presents of them. ${ }^{36}$ The human beings are not aware that they are judging only subjective representations of things; they believe to be dealing with the things themselves. On this false credence, others are based, which are even more damaging.

Idolatry, superstition, and all forms of irrationality have at their origin this error: they base free judgments on the natural judgments that means that they misinterpret what is subjective for what is real. If human beings could omit this error, they could be free from many others. What is evidently false or impossible present no problem. On the contrary, the verisimilar that represents some of the conspicuous, extrinsic, of easy comprehension and retention characters of things, constitutes the greatest danger of falling into error. ${ }^{37}$

Deceit and error could not be possible, if there were no confusion between verity and verisimilarity. What presents itself evidently as false cannot obtain assent. The false to be deceitful must be first believable, must concentrate the mind on what fills up conscience and simultaneously occupy conscience with free judgments conformed to natural judgments. The verisimilar instead is more easily 
interpreted as true than the true itself because it shows the same exterior characters than the true (to the consideration of which the majority of humankind stops), but the verisimilar shows the characters of the true in a more accentuated manner. If we were to have known the truth beforehand, there would be no obstacle in the judging an object. In the pagan mind, the verisimilar precedes the true because if it were to come afterward it could not be verisimilar, but true.

The verisimilar is what the conscience recognizes as true, relying on the imagination to form suitable judgments. It happens to all human beings in many daily situations, in regular studies and in all manners of living, where the possibility of falling into error exists. ${ }^{38}$ The theorization of the similar as the source of error and as a mediate concept between truth and falseness must assume in the pagan mind the prerequisite assumption of the idea of truth. If the mind were to have no conception of truth, it would not misinterpret truth for falseness, it would not believe in anything because one believes in what he thinks true.

The pagan mind, at the origin, is without cognition, intuition, and contradiction; it can think simultaneously opposite things as true. Aristotle had clarified that if there are contraries in nature, this fact would not undermine the principle of non-contradiction, because it is necessary to keep separate the two levels of reflection. According to Malebranche, Aristotle on this point has not been coherent. Aristotle has constructed a correct logic, but he has not observed it in his physics. Though Aristotle was the greatest pagan philosopher, on this matter he represented an extreme level of pagan mentality in contrast with the common position held by the majority of people at the origins of the pagan societies. Malebranche with the theorization of the verisimilar affirmed that, before thinking the true and the false, and how they are distinct, the first men thought only the true, what they believed to be the true, and all what they thought, they thought it as true, as the theological poets, who thought Jupiter. The material ubiquity of being was not a contradiction for the primitive beings.

The human beings are not good at breaking with an entrenched habit of mind when logically they should be able to see that this habit ought not to be binding. 



\section{THIRTEEN}

\section{THE FAMILIAR IDEAS AND MENTALITY}

Malebranche often discusses the problem of attention. His principal interest to this regard is the focusing of the mind on the clear and distinct ideas, on analysis, on the acknowledgment and critique of all the false creeds, and on the organization of knowledge on the model of the pure sciences. This argument is treated under many aspects in different parts of The Search after Truth. ${ }^{1}$ We would like to express this Malebranchean position in synthesis with the affirmation that human beings detain in their mind only a minimal part of all the objects that come within their perceptive field.

\section{The Problem of Attention}

Conscience has knowledge only of what captures its attention. The human beings and the pagans cannot think what does not attract their attention. Therefore, what is present in the conscience exists; what is not present, is not existent. For the pagan mind, these equations are valid: what is present in the conscience is true; what is true exists in the conscience. Even though we cannot say that for the pagan what is absent is false or inexistent, we can affirm that the pagan can think neither the false nor the inexistent. In this sense must be interpreted the term "true" as used by Vico in regard to the poetic logic. What the pagan poet, the primitive, will consider present is what will greatly impress the senses, everything with the character of greatness. This is the mechanism at the root of all the oddities and manifest absurdities that can be found in the ancient poetry and myths.

The poet narrates what hits his imagination; everything he thinks is believed to be true. The poet does not discern the true from the false, or himself from what surrounds him. All the images going through the poet's mind have the same value; they may differentiate only because of their perceptive intensity. A student supporting an allegorical conception of myth will find it impossible to comprehend how in the myth an eagle could transform itself into a human being, unless he uses a symbolic explanation. On the contrary, a Malebranchean disciple will have no difficulty since the image of the eagle will be follow by that of the 
human being, as in his experience the drawing on the curtains, when pulled over the window, substitutes the panorama that could be seen from the window. The principle of all this is to consider every thought as true. Malebranche's psychological analysis was embraced by Vico in his interpretation of myth, of the passage from one myth to another, of the mythological monsters, and, in synthesis, of the primitive mentality. In this case, too, Lamy places himself between Malebranche and Vico in regard to the problems of the general explication of the mental structures and formulation of the psychological principles that underline the poetic mentality. In Novelles Reflexions sur l'art poetique, Lamy wrote:

The freedom that the poets reserved for themselves has given them license of deceiving and abusing the strong inclination that we have for everything truly great, providing us with some vain appearance of it. As they are great teachers of their subject matter, they choose for topic of their discourses everything that is extraordinarily grand and considerable in the world. Without respect for the laws of history or of truth, they change, add, or cut as best as they like. In addition, if the nutshell of what they narrate is true, they give a certain twist to things in such a way that all what they say would seem prodigious. And all things true change into something astounding. ${ }^{2}$

Vico goes far beyond Lamy but in the same direction. He understands the historical cognitive movement that justifies this continuous change, modification, transformation, cutting, and joining that characterizes ancient poems and myths. Through also these operations of poetical fictions, the human beings acquire the elasticity of thought, which is an ability that develops gradually. It is certainly impossible to retain the knowledge of everything that we have perceived. The mind could become overburden with uselessly superfluous information. As evident as this principle may be, it is not at all banal and its evidence is Cartesian warranty of its importance.

No knowledge is possible without focusing the mind's attention on what we intend to know. No attention can be given to any object without bringing a representation of that object to the vision of the mind, which is an automatic operation. The pure ideas, which cannot be represented, are known with great difficulty, because they are lacking the sensible support on which our attention can focus. ${ }^{3}$ Though having all the ontological possibilities of thinking intelligible entities, the mind experiences the psychological difficulty of concentrating on anything with the necessary and suitably extended attention. In the pagan mind, the attention is the capacity of imagining what is of our own interest. We could say that the attention is the imagination attending to its activity. How can we explain the mechanism of attention in psycho-physical terms? Let us assume an object of thought that is imaginable. Paying attention to this imaginable object means to 
maintain its image present to the conscience. To do this means to use a part of our brain or impress the animal spirits with a motion (if the motion we had previously was contrary to the necessary motion) in a way of making possible the formation of the traces to which the ideas that represent the imaginable object are linked. ${ }^{4} \mathrm{At}$ the psychological level, paying attention to something means to converge toward that something all the thoughts and change the representations of what the mind was previously considering. From what we just said, it may appear that the human being can easily control his own cerebral motions through the dominion over the proper "fluxes" of thought in the conscience. It is not as it appears. As the human soul has its habits and customs, so the brain has its "hardened" fibers that, using the technical Malebranchean language, channeled the course of the animal spirits and incline the individual human being to the thinking of the same kinds of entities. The fibers of the brain, even if they are "malleable," may harden to the effect that after they have acquired a determined "fold" it would be difficult to change their structure. The human being in this condition will be liable to think always the same things or of thinking of them always in the same fashion, with the same logical perspective.

\section{The Problem of the Familiarity of Ideas}

A clay slate not yet hardened is easily incised meanwhile it is pliable, but as it hardens or dries the incisions become more difficult and always more superficial. As the clay slate, so the traces, previously made when the material was malleable, by drying up become more hard and less modifiable. The fibers are capable only of the inclinations that they took when they were malleable (when the human being was still young), and as the human being becomes older, the fibers of his brain become furtherly inflexible. Malebranche specifies that even in a young person, the hardening of the fibers in the brain is verifiable in the sense that the first experience is the one that determines the successive ones. Even an adolescent mentality can be already recognized as rigid. Because of this psycho-physical process, some ideas become more familiar than others. It may happen that "The soul would not be able to imagine nor consequently bring its attention to what it wants but to the ideas alone which are familiar with it." The familiarity with certain ideas and things is determined by the hardening of the cerebral structures. The rigidity of thought is due to a stiffening of the body. Things, however, are not as static as we have said. The rigidity of the cerebral fibers, beyond the metaphor of the clay, is not absolute and does not bring to immobility; it only reduces the number and speed of the movement of the traces. Vico has insisted on the topic of the familiarity of the ideas and has formulated two important axioms: "Property of the human mind is that, when people form no idea of distant and unfamiliar things, they judge them by what is present and familiar. This axiom indicates the 
inexhaustible source of all the erroneous views which entire nations and all scholars have entertained concerning the beginning of civilization." 5 Obviously the human beings would not always think the same things they have learned at an earlier age, but they will reason always, or almost always, in function and in relation to those ideas with which our mind has become familiar and that constitute, we may say, our mentality. Malebranche affirmed that "human beings reason about things in relation to the ideas with which they have the greater familiarity." ${ }^{\text {In }}$ all their reflections (discourses, reasoning, judgments) human beings have guiding ideas that represent the established center around which all the other ideas rotate, the axis of the planet of mentality, around which the trajectory is developed of the orbit of the ratiocinations formulated in different times. On familiarity, structured on the perceived and perceptible similarity, Vico will found the fundamental character of the fantastic or imaginative universal, the pivot of the poetic thought: "Jupiter was born naturally in poetry as a divine archetype or imaginative universal, to which the ancient pagans with their poetic nature referred every aspect of divination." The imaginative universal is the universal suitable to a limited mentality that searches within itself a point of steady reference around which to construct a proper language and an organized system of beliefs. ${ }^{8}$ The most familiar ideas, and among them the idea of Jupiter, are the sustaining columns of mentality and the other ideas are thought in function of them. The question might be raised: why is it that some ideas are more familiar than others? Education and experience may not be an adequate explanation because in each one of us (in the patrimony of our memory) many ideas exist that have been encouraged by parents, teachers, the society but that we refute totally or that have, in the life of our thought, a negligible influence.

Malebranche recognized the weight of education and other variable social agencies on the formation of individual character, but he sustained that they are only the cooperating causes. He individuated another major cause that allowed the selection among the multitude of sensations, thoughts, and images that succeed each other in the mind in time. This cause must explain why some ideas come to be lost or forgotten while others remain vibrant in the conscience. This true cause should be searched in psycho-physics more than in sociology: the most familiar ideas are the ideas of the things that in the brain impressed the most energetic traces. ${ }^{9}$ Some ideas preserve the most impressive traces because the nervous system comes to be excited more vigorously by them. In an Occasionalist sense, we may explain that with a greater excitement of the animal spirits, there will be a stronger sensation. The familiar ideas are those that reappear most easily and successfully to the human conscience. Human memory recalls better the things of which the human soul can form images from the keenest sensations. At the same time, the keenest sensations are those that, at a physical level, determine a major agitation among the animal spirits, which consequently produce more profound traces among the fibers of the brain. ${ }^{10}$ The most imposing images in the con- 
science are those relating to the most intense perceptions. At the two extremes on the scale of intensity of the images we have the strongest sensations that give the representations most confused, and the most abstract ideas that offer no representation at all. Intense sensations are the primary element for the formation of the familiar ideas that come to constitute the individual mentality of the human beings. An intense sensation, a "colorful" image, becomes a familiar idea and creates a specific mentality if it is forcefully vibrant and many times repeated. An image accrues its importance within the structure of thought if it is reproduced many times and every time it appears very bright. In this way, some ideas become more familiar than others that perhaps are similar but, because they evade the same deep traces, remain unrepresented and the imagination disregard them. For Malebranche, this is the most common psycho-physical cause of our prejudices. If the most familiar ideas, if the thought that constitutes the mentality are truly the sensations and the strong passions that accompany them and not the clear and distinct ideas, then they will be the basis of an erroneous thinking. ${ }^{11}$ For Malebranche, madness is the imagination taking over the control of the soul. In every time and place, mentalities will be always "compositions of prejudices," uses and customs of socially organized madness. Mentality forms itself out of a complex of ideas, whose origin is sensible, that became the nucleus of our thought, the pivot of all our reasoning, judging, and believing. The most profound traces that produce the more intimate ideas are the psycho- physical cause of mentality.

When a mentality is established, the acceptable and most remembered ideas will be those coherent with the familiar ideas. Naturally, this coherence is not rationally logical; it is the coherence of sensitivity. We will accept beliefs and opinions only if they would be compatible with those that dominate our conscience and constitute our mentality. In terms of the Malebranchean psycho-physics, we will accept only the ideas produced by the animals spirits that go through the most profound traces. ${ }^{12}$ To think in conformity with our mentality and prejudices means to reinforce both of them. When the mentality has been constituted in the mind, thinking itself will become an operation that reinforces that mentality. The rigidity of the mentality will be given by the force and magnitude of the familiar ideas that constitute it. The thinking in a superstitious person will be in function of its superstitions which he or she will confirm and reinforce by simply thinking. The origin of the mentality is neither merely mental nor physical. The reinforcement of mentality always is a psycho-physical question: at the corporeal level, it is a passage of the animal spirits through the usual traces; at the "mental" level, it is the habit of thinking in function of specific ideas that we consider so personal that often we are not even conscious of their importance. We believe then that it is impossible to think in any other way. All reasoning will represent always the association of ideas that Malebranche called familiar ideas. ${ }^{13}$ 


\section{The Body, Corporeity, and Common Sense}

The body in itself is only extension, but corporeity, the force that the body exercises on the soul, is something profoundly different. To affirm that the cause of prejudices is psycho-physical is something different from saying that it derives from either a simple biological or philosophical dynamics. In the Malebranchean Occasionalist conception, nature and culture come together to produce effects that cannot be reduced or comprehended in any one of the two argumentative levels, nor to their alchemical combination. The effects must be seen in the optics of the consideration of the status of the human soul after the Fall contemporaneously with the dualistic Cartesian conception and Occasionalist derivation.

The human being, though having a will that warrants its freedom, possesses also a body that actually imprisons its liberty. The result is that human beings form for themselves a mentality, a structure of beliefs not freely associated (which would be possible only with reason) but produced by the capacity of thinking mediated through the actual nature of the links between ideas and traces. With this, mentality becomes a natural thought in the sense that human beings tend to conform their free judgments to the natural judgments of their senses. This is the origin of the human common sense, which is the combination of the judgments acritically accepted by people, who are without doubt whether these judgments could be false and often are not even aware of having them. Vico said, "Common sense is an unreflecting judgment shared by an entire social order, people, nation, or even all humankind." 14 The common sense is one of the strongest social bonds; it is the mentality of a nation that, at its turn, is the grouping of the judgments conforming with the natural judgments of the senses. The Search after Truth speaks of the importance of the common sense, analyses its structure, and is the study on the topic that has no equivalent in the literature of the same historical period. Malebranche, on the footsteps of his teacher Descartes, has treated the common sense with all the due attention and succeeding in showing the social victory of imagination over the intellect. To narrate the history of humankind in philosophical and philological terms means to narrate the history of common sense. Vico again explained, "When uniform ideas arise in entire nations which are unknown to each other, they must have a common ground of truth. This axiom is an important principle. For it establishes that mankind's common sense is a criterion which divine providence teaches peoples to aid them in defining what is certain in the natural law of nations. They arrive at this certainty by looking beyond local variations of this law to recognize its essential unities, on which they all agree. From these unities, we may derive a conceptual dictionary which traces the origins of all the various articulate languages." 15 The common sense of a specific nation in a certain epoch is the most important element for the comprehension of the human mind in its historical becoming. Human beings organize themselves always in relation to ideas that they consciously and, at times, unconsciously, share. 
Malebranche and Vico speak of an unawareness that human beings may have about some ideas radically rooted in their conscience, in their manner of reasoning, so that they never doubt of the validity of such ideas. Their mentality often conform to such ideas to the point that they are not even aware of the role of these ideas and of the importance they have in the formulation of the most different and controversial judgments. These "uniform ideas" function as if they were a mental dictionary that all the members of a community, commonwealth, or humankind use in the construction of their thought, credences, and laws.

The agreement at the root of the common sense, which we may define also as the unit of measurement of the pagan mentality, is not conventional but, on the contrary, natural and originates the "familiar" credences that are often, for both Malebranche and Vico, false. The mental dictionary thus constituted is an instrument for attributing judgments on reality; it is a prejudice on reality, an alphabet already per se significant. The rigidity increases with the age of the human being and, in the adults, it is impossible to change mentality. In this context, age plays the most important role: in childhood, mentality is beginning to form; in adolescence, mentality establishes its whole structure; in adulthood, mentality becomes inflexible. The process of the stiffening of the traces in the brain corresponds to the processes uniquely cultural, such as the production of mentality.

The education received can condition notably the formation of the mentality in an individual person, but must deal with the dynamics of human nature. An education would be contrary to nature, limited and limiting, if not coherent with the needed production of traces in the brain and the motions of the animal spirits. Education is a powerful means in the hand of reason in the battle against prejudices, but in the majority human beings do not use reason, so that education, in all its forms, ends in reinforcing erroneous credences and perpetuating the superstitious mentality. ${ }^{16}$ Once the nucleus of familiar ideas has formed, thinking will be a permanent confirmation of the prejudices that the ideas convey, because thinking will happen in their function. Passions represents the centripetal force of the common sense. Vico observed, "Tacitus notes one of the true properties of human nature when he writes 'once struck with fear, minds are prone to superstition' (mobiles ad superstitionem perculsae semel mentes). For once men are overcome a fearful superstition, they associate it with all that they imagine, see, or even do." 17 The idolater, the more he thinks and acts, the more his idolatry is reinforced and divulged. The peoples who do not attend at making their mind flexible, their brain capable of always new traces, would see their critical and reflective capacity compromised in a manner almost definitive. With the corporeal inflexibility comes the mental inflexibility. ${ }^{18}$ The kind of mentality we are presenting is an erroneous mentality that in the terminology of Malebranche is a pagan thought. The peculiarity here evinced is that rigidity or inflexibility implies also the superficiality of thought. Meditation, reflection, and research of truth demand a thought free from 
the burdening bundle of prejudices and of everything that with the power of images captures the conscience.

Sensations and images are the surface of conscience; they fill up easily conscience merely with appearances. A conscience formed in this fashion would not penetrate the truth of things beyond their outward show. The pagan mind would fail in the task of reaching truth because it limits itself to the consideration of the sensible shell that things assume and to their compatibility with the familiar ideas.

The first impressions, the first ideas that human beings receive are often those that impose themselves with ease to the mind and forcefully resist the mind. The first ideas are those that leave greater and deeper traces, and doubtlessly become familiar ideas and form inflexible patterns of thoughts and reasoning. 


\section{FOURTEEN}

\section{VERISIMILARITY AND IMAGINATION}

The superimposition of personal thought on top of reality exists in the pagan mind. In the pagan mind, a cognitive egocentrism, which is also egoism, exists and by reason of it everything this mind thinks exists and, if it exists, is because this mind thinks it and it is its own property. There is the solipsism of the imagination. If the pagan thinks something, it must exist and, if it exists, it is as the pagan mind thought it.

The pagan mind cannot detach itself from itself; it has no sense of distance. The pagan mind does not know how to take itself as the object of its thinking and thus makes real in its imagination whatever it thinks. Believing that what comes to be thought exists and it exists as it comes to be thought, the pagan mind limits the extension of its action to its own (imaginative) thought and cannot go beyond. The pagan mind does not comprehend that reality is beyond its fantasy, and is independent from its passions. When the limit of the action of the mind is established by personal thoughts, or their representative content, then every rational form of awareness would be missing. The mind would not recognize the fantasies as its own imaginations and would not be able to distinguish between thought and the reality that thought represents to the mind. ${ }^{1}$

Our mind is easily captured and guided by the sentiments and its expressed judgments are always impulsive and inexact, so that their results and credences are assumed in a compulsory and a-critical manner. Because of a paradoxical reversal of the imagination, the mind attributes reality to things that do not exist, confuses the objective (in a Cartesian sense) reality of the idea with its own presence before the conscience. Unwittingly, the mind interprets the sensible vivaciousness of the representation as the cause of the reality of the represented thing. ${ }^{2}$ In order for us to become conscious of an object it is necessary that the idea of the object be actually presented to us. In order to perceive something, it is not indispensable that the thing would exist truly outside of us in the moment we perceive it; it is enough for us to be able to represent it to ourselves.

The idea of the object must be present continuously to the spirit. The possibility of perceiving an object is subject to the possibility of the actual presence of the object to the mind. ${ }^{3}$ This principle is at the root of the phenomenon of hallu- 
cination. The visionaries perceive inexistent things. Hallucination is the extreme limit case of a mechanism that is not exceptional but ordinary in the economy of the human mind. For Malebranche, all of us are visionary, and called visionary only those that are visionary beyond the normal fashion.

In order to have an actual perception, the presence of the idea of the thing perceived is required beforehand in the conscience, because we cannot perceive what we cannot think. ${ }^{4}$ We must possess the idea of what we perceive in order to be conscious of our own perceptions at the physical level but also to interpret the perception and thus obtain knowledge of it. Descartes and Malebranche said that we are conscious only of our own ideas. That of which we have no idea cannot be present in our conscience. Under this aspect, knowledge is reduced to an interpretive process that happens first at the perceptive level and thereafter at the theoretical one. In this way, we come to attribute our sensations to objects. ${ }^{5}$

The ideas of which we speak are not the Platonic ideas, but those sensible ideas that are the product of the link of the soul with the body and not with God. This means that we can think an object only by way of representing it to ourselves. If an object cannot be represented, even if it were to exist, it cannot be thought. For the pagan mind, which is at the level of imagination, what exists is only what with its representation can fill up conscience. The more an idea is sensibly vivacious, the more passions it would generate and more of reality it would believe to possess. Definitively, the new principle will state that we are more inclined to consider as existent the things that we can with easiness imagine for ourselves. ${ }^{6}$ For the pagan mind, the ability of representing to itself an object is like the unit of measurement for the judgment of the reality of the object. The idea of the object, the stronger of a sensible strength it is, the more the object will be believed real. Gold and lead are very heavy and hard, and are perceived straightforwardly, whereas water and air, which are tenuous and vague, are generally barely perceived. Sliding pleasurably into the unawareness of its sensations, the human being becomes also increasingly forgetful of and foreign to its soul. ${ }^{7}$ The errors perpetrated by human beings when judging bodies extend themselves beyond the bodies. When a human being judges erroneously two corporeal things, the same human being would also misjudge their relationships. ${ }^{8}$ In this case, it is dangerous to explain one thing in function of another. Where reason has not constructed with order, the ideas come to be placed in the order of fantasy. ${ }^{9}$

\section{The Representation of Images}

As the mind's ability of representation of objects is not perfect, so the brain's capability of reception of traces is not endless. In an Occasionalist conception, a parallelism would be necessary between an infinite imagination and a brain infinitely disposed to receive traces. This is not the case, and thus the traces are many 
but easily confusion rules among them. Many are the traces and often similar, so that they become entangled with the inevitable result of affecting the conscience with a confusion of ideas. In fact, the persons who enjoy a good memory are instead incapable of judging exactly the things for which a ponderous use of attention is required. ${ }^{10}$ Memory, as we saw previously, is based on the association between ideas and traces. The more spontaneous the human capacity is for connecting the ideas produced by superficial traces with the ideas produced by profound traces, the greater the ability of recollection will be.

The similarity among the representations and the proximity among the traces contribute simultaneously and equally to the obscurity and confusion of ideas. A "narrow" intellect, entirely dominated by what has been perceived, is not in the position of ordering its own ideas. ${ }^{11}$ The painters suggest to exercise the imagination by fantasizing animals, faces, and other things while looking at irregular walls, but Malebranche discourages such an exercise, precisely because it develops imagination. For Malebranche, similarity brings the overlapping of the ideas of different things and become the cause of errors. For the artists, similarity is the foundation of artistic creation.

The imagination is a creative faculty, and Malebranche recognizes that the imagination has its part in the artistic production, as it does in geometry. Imagination can be seen as the only human faculty with some creative effectiveness, while the senses are passive and the intellect thinks the ideas in God. Of what is imagination creative? The imagination creatively represents images, confused representations, and confused ideas. The brain lacks the infinite capability of producing traces, and the imagination lacks the infinite capability of forming representations. The imagination perhaps has the ability of producing an infinity of combinations between the representations, of assimilating things whose differences are in part hidden or if noticeable they could demand an effort of the attention of the unprepared will. ${ }^{12}$ If the deep traces of a face exist in the brain, it is sufficient for conscience to form some similar representations and the idea of that face would be re-awakened. As we demonstrated in the previous chapter, the obscure and indistinct idea of divinity is connected to specific objects or words, so that at the reappearance of the representation of that object or a similar one, the idea of divinity will be immediately renewed. If the (pagan) mind is vividly impressed by the letters $i a h-w e h$ (or by the sound of thunder), the traces connected to the idea of idol, which at their own turn are linked with the traces of iah-weh, will be awakened together with the thought of God.

The imagination creates links between things that at first sight the intellect of a critical spirit would not understand. What link can be established between the sound of thunder, the sparks of lightnings, and the idea of divinity? Nothing will be able to connect them, but Malebranche observes that the imagination creates connections between disparate things and even without any apparent causal relation. We should recall that the human spirit forms images of spiritual entities 
through sensitivity and the identity of time plays a role in the process of creating bonds between things and ideas. It is possible to comprehend how a human being would see a face in the moon, a lion in a cloud, and God in lightning and thunder. ${ }^{13}$ An imagined similarity brings close to each other what is known and what is very approximately known. The human habit of paying attention to faces inclines us to see faces where there are no faces. In a visage, furthermore, many small different features can be noticed that, if present in other objects, they will remain absolutely unobserved.

If we reflect on the difference between two human faces, we would say that the differences are variations of little value. The difference and variations in shape and color between one mouth and another, one nose and another, should be measured in millimeters. If the same differences and measurements were found on other objects, for instance on two vases of little value, they probably would not be noticed, but in the face they are enough for distinguishing immediately between one person and another. The reason of all this is that we are accustomed to look at human faces more than at any other thing. Our habits of thinking determinate things, inclines us to see these things where they are not. All events are subject to the power or the lack of power of the senses and the sensations. A man with short sight may see in the moon a completely different thing than the person with good sight. ${ }^{14}$

No psychological necessity dictates that we must have a univocal interpretation of an image. No law exists that establishes how the individual imagination should shape its own material. Imagination does not follow reason, but the shocks of the passions. If it were to follow reason, imagination had to follow logic in ordering the representations and not the whim of the sentiments. What could be done is to establish some laws about why things happen the way they do in regard to imagination; to analyze how imagination, as a faculty of the entire humankind functions; and to comprehend the structures that constitutes and regulates it. Not everybody sees a face in the moon; peoples may see other things and certainly someone may see the moon just as moon. If in the moon we see something that is not of the moon, this happens because of imagination: we imagine things in function of the ideas that we represent to ourselves most frequently. ${ }^{15}$ As the affluents, the torrents that have little depth, flow into the river, so the ideas with an emotive charge not too intense, unable to trace an image in profundity in the mind, flow, assimilate, and conform to ideas emotionally more relevant for the soul.

The limits of our mind determine the capacity of comprehension; and the limits of our body (of the brain in its suitability to receiving traces) determine the limits of our imagination. These two entities condition markedly the capacity of thinking objects that differ from those to which we have been familiarized and they make us fall into error as we assimilate into one image alone many diverse things. ${ }^{16}$ This is the inclination that characterizes the pagan mind, a narrow intellect, and a powerful imagination, so much more powerful as it finds dissimilar 
things to be similar, different things to be identical. The mind that thinks with the eyes of the imagination judges only what it sees and it often sees poorly unless the intellect glows its light in the mind. The mind believes that what it reproduces in itself is what really exists; it judges existence from the presence in the mind. If in an object the mind does not see motion or corruption, it does not mean that neither exists in the object, but that the mind believes that what it imagines also exists. In a "transitory" reality, in a phenomenal world where all things wax and wane, the imagination deceives the pagan mind in presuming stability where instead because of rigidity the mind is fixed on one representation. Things (phenomenally) are never similar to themselves; even more mutable is the conscience that perceives them. As the world changes, so the human beings do. The conception, which the human being has of the world, finds itself between the world and the human being and it is the point of friction between the two. Thus, the human conceptions of the world change. The human conceptions of the world are the repository of all the drives, the most turbid and confusing sentiments, the terminus (in the opposite side) of the nervous system, and the point where all burdens are released. The conscience, which is essentially imagination, is at the center of the dimension that, like the chaotic synthesis of a double universe (of the two res), spins around it, knocking it from one side to another, turning it in continuity so that it looses all sense of orientation. In this situation, the conscience has only one possible reaction and searches for equilibrium in the static consideration of the representations. Conscience creates a fictitious stability for itself while facing the universal chaos.

The imagination constructs dense networks with the lines of illusion wherever the mind sees the edge of the precipice from the abysmal side. The mind rejects everything it cannot control or, even more frequently, the mind rejects what cannot control the mind. What the mind cannot report to itself does not exist. This is the principle at the root of the pagan mentality. The things whose representations the pagan mentality reports to itself are as they are represented to the mind. Malebranche, in The Search after Truth, says, "The spirit should not assume a kind of immutability in the things simply because it does not see in them any evident corruption or mutation. Because the spirit does not notice any difference in things, it does not mean that they are always identical to themselves. Because the spirit has no idea or knowledge of certain things, it does not mean that they do not exist."17 The fixation of the mind on specific iconic contents is born out of a necessity of orientation, but it is due to the weakness of its intellect in contrast to the overbearingness of its passions. The fixation on one idea brings the mind into the error of considering identical things that are different, because the mind will have both ideas reported in one single representation. Such idea will become the star around which will gravitate various planets and at different distances a fictitious solar system, confuse gravitations, assimilated orbits, or will dissolve in a nebulous and compact whole. This mental galaxy will be something 
homogeneous although in reality things will be different. The mind is more limited than a galaxy. The galaxy of the pagan mind can be reduced to one single solar system in which the planets, the ideas, are closer to each other in a manner that their orbits will be confused. The resulting thought will be monochromatic and indistinct. "The mind is extremely limited and thus is incapable of distinguishing the differences among the subjects it considers, which are infinite or almost infinite. The mind therefore supposes imaginary resemblances, or fails to notice real and positive differences, since ideas of resemblance are simpler, more familiar, and more present to it than others." 18

\section{Assimilation and Resemblance}

A mind with limited capacities tends to agglomerate different ideas; it reduces everything to what is familiar and easy to understand. Distinction and negation are two operations that a weak mind cannot accomplish or, at least, accomplish correctly. These two operations are complex and require a capacity of abstraction and concentration that the pagan mind cannot afford. On the contrary, the pagan mind prefers to assimilate, homologate, and accept a-critically all the false credences that it formulate for itself. The pagan mind proceeds always through the easier paths, even though they may be inexact; it proceeds slowly when it has to create new links or recognize the true links between things and ideas. The assimilation of ideas of different things under one idea is the short-way to error, the end that we never failed to reach. "For clearly resemblance includes only one relation, and a single idea is needed to judge that a thousand things are similar, whereas to judge without fear of error that a thousand objects are all different from one another, a thousand different ideas absolutely must be present to the mind." 19 One idea is enough for a limited mind, all closed in itself, to comprehend a myriad of different things, of which it will be incapable of specifying any characteristic. Malebranche offers numerous examples both at the logical and moral level showing the principle that with the assimilation with and in one idea, thousand different things can be known, while with the distinction thousand ideas are needed for thousand things. In his anthropology, Malebranche underlines this principle as the origin of racial prejudices. ${ }^{20}$ If a French person dealt for whatever reasons with an Italian or English person, it will thereafter from this experience formulate a judgment about the people of which the Italian or the English are the connationals. This French national would be inclined to the praising or criticizing of all the Italians or the English, without consideration of what of admirable or regrettable there may have been in the individual character of the persons they dealt with, and that is not truly the specific trait of their people and nation. Here below, an example of Malebranche is given. It will be a remarkable example also for another 
argument that will be discussed in the next chapter and of which it can be a partial premise. $^{21}$

A member of some religious order falls into error and this is enough for most of those who know about it to condemn indifferently all the individuals of the same order. They all wear the same habit and have the same name, and as they are alike in these things it is enough for ordinary men to fancy them alike in everything. They suppose them alike because they do not penetrate to the bottom of the hearts of these individuals to see positively whether they differ. Slanderers who seek means of besmirching their enemies' reputation commonly employ this technique, and experience informs us of their almost universal success. Indeed, it is well suited to the standard of ordinary men, and there is no difficulty in finding in large communities, however holy they might be, somebody who fails to keep the rule or is of improper persuasion, since in company of apostles, of which Jesus Christ Himself was the head, there was a robber, a trator, a hypocrite, in a word, a Judas. ${ }^{22}$

The vision presented by Malebranche invites us to think about how true it is, even in our present society, what he said. Our society, too, moves always in between the ridicule and the tragic, the stupidity and the evilness of human beings, who when they can choose between the bad and the very bad, they chose the very bad. Human beings, because of their limited intelligence and great egoism, are inclined to accept falseness both at the scientific and moral levels. The calumniators, the slanderers who propagate false beliefs with the goal of destroying others and advancing advantageously themselves, unwittingly abuse one of the most important principles of the human mind. As wicked rhetors, they exploit the wrinkles of the mind and the sores of the conscience for their shameful aims. In this way, the prejudice and the stiffness of the imagination find their baleful application to the contrasts of forces among human beings.

\section{Images and Uniformity}

The narration of Malebranche shows how important is the place of imagination in all the human activities of personal and collective life. We will pick up this thread again. At the present, let us conclude by remarking how what Malebranche called the rigidity of imagination intervenes in favor of the assimilation that the mind accomplishes considering similar the ideas of things that are different and, often, extremely different.

The tendency of the images is that of becoming stable and stiff. We think of things as if they were fixed and immobile. Whenever needed, reason suggests 
revision of our credences, but our passions and the imagination make us to build novel beliefs on the old ones, reinforcing and strengthening the representations that we already possess and have constructed in an erroneous mental architecture. Whenever we have formulated the idea of a thing, it is with great difficulty that we will change it even if the thing mutates. Often, if we change the preconceived idea, following the mutation of the thing, we fall into an even more erroneous idea about the thing. If sensible experience does not guarantee forcefully the evolution of the situation, we are predisposed to represent it as static, and even when we have realized the change, we ascertain it starting from the static and preconceived image we already possessed. "The mind also assumes uniformity in the duration of things, and when it is not forced, as it were, by the reports of the senses to judge otherwise, it imagines that things are not subject to change and instability." 23 The stiffening of the mind on some ideas is considered by Malebranche a sickness of the mind; for him, the fixation on some ideas prior of being a pathology is an innate defect of the soul. Human beings may try to control this deficiency by reducing its obnoxious effects, but it will remain an enduring characteristic. What we called a mental malady would be in effect the extreme result of a process that the mind normally performs. The pagan mind uniforms things to its ideas, which have an iconographic character.

Descartes uses the chiliagon as an example in his Sixth Meditation. He, too, wanted to demonstrate the difference between pure intellection and imagination. It is easy to fall into the error of confusing the intellectual idea of a triangle with the image that we reproduce and represent in our mind. An error of this kind is easy because we can easily imagine a triangle. If instead of a triangle, we would try to think of a chiliagon or myriagon, we will find that their concepts can simply be understood as that of the triangle, but they would not be imagined by us as easy as the representation of the triangle. Our imagination cannot "design" chiliagon, even less a myriagon, on our mind; the imagination cannot reproduce all the characteristics of the chiliagon, though its concept is clear and distinct. The imagination resolves the problem by assimilating the chiliagon to the figure of the circle, though the two concepts are different. Truly, the chiliagon and the myriagon are more like the triangle than the circle, but the imagination will picture them as the circle. We comprehend, with this Cartesian example, how the imagination by its nature reduces the differences of the things that the intellect can easily conceive as completely different (chiliagon and circle, myriagon and circle) to the unique image of the circle. It is an example applicable to everything that the imagination reproduces in the mind. ${ }^{24}$ The process of the uniformity of ideas, which consists in reducing the diversity or variation of the ideas of multiple things to the idea or image of one thing, happens naturally, often without human awareness. We come to know about uniformity with philosophical practice, as Descartes did with his narration of the problem presented in imagining the chiliagon. We become aware of the difference between fantasy and intellect, icon and idea. 


\section{Uniformity and Universality in Vico}

It is because of Cartesianism and particularly of Malebranche that modern philosophy has constructed a theory of the proceeding of the imagination in relation with that of the intellect. While "the uniform" of the intellect is the divine thought, the intelligible extended, "the uniform" of the pagan thought is the representation, the image in which all passions and sentiments of the human conscience are condensed. In both cases, the mind must assign to itself a universalistic order, a search for universality. Vico was well aware of this and one most known of his axioms says, "The human mind naturally tends to take delight in what is uniform." 25

Without this tendency, the human mind would not have formed. Without the ability of uniforming (of condensing all the most intimate instincts, fears, passions, and bestial reactions) to a unique image, human thought would not have been created. The first thought is also the first universal that gathers in itself all the instances, disparate and contrary, that make up the human being. Everything the human being does, everything it thinks, everything it senses or is afraid of sensing, the possible and the impossible, the true and the false converge into the opaque representation of the infinite being (an infinity represented and representative) that is Jupiter. Vico wrote, "Jupiter, the king and father of gods and men, in the act of hurling a thunderbolt ... [The early people who founded pagan antiquity] believed that everything they saw, imagined, or even did themselves was Jupiter ... and they endowed all the universe and its parts with the being of an animate substance. This is the civil and historical meaning of the poetic tag 'all things are full of Jupiter'." 26 Jupiter represents the artifice of the imagination for knowing things, for amplifying the faculty of the mind. Jupiter is the way of the human ability of delighting in uniformity. To uniform means to confer a unique form, to carry different things back to the same principle, to the same form. This form, this universal genus is the myth. This explains how it is possible for the primitive mind to place on a unique plane things that exist at different planes. In reality, the imagination, in the case of the theological poet, makes the same error that it made in the case of the chiliagon and of the fixed stars. Sensible experience may take us to doubt about the duration and uniformity of things. Only when sensitivity convinces us, we agree to change our beliefs. The example of Descartes had this purpose. Malebranche extends the same principle to all the cognitive human sphere. Only when touched by experiential data, we change the ideas that were based on images. This is fully understandable if we focus on the fact that imagination is the second side of the medal of sensitivity. Consequently, the imagination will change its own ideas only when sensitivity with its actions will influence imagination.

Human beings believe in what they see; however, they do not see what is, but what they imagine to see. The myth of the primitive is a crude image, the only 
one that the primitive mind could produce. The real difference between the things that the primitive mind reproduces for itself and the manner in which it represents them is not important for the pagan mind. The real or possible similarity between Jupiter and the thunderstorm is not important.

The mediation between the image and the thing is not established on the base of their effective congruency, but only in relation to the cognitive capability of the thinker. No matter how different and incompatible the idea and the reality may be, the myopia of the human mind acknowledges very different entities at the same level. It is said that by night all cows are black; things that at the sunlight are seen as opposed, at night seem uniform, because of the specific defect of our sight that in order to function has need of a definite luminous intensity. Myth is the thought of the twilight. Full darkness is beginning to disappear from the pagan mind, but the light is still too feeble in order to judge the real differences among things. It is already a lot to comprehend that in the darkness a reality exists, Jupiter.

The theological poet presupposes identity, similarity, and proportion in nature, but these qualities are not likened to nature. Identity, similarity, and proportion are likened to the imagination of the theological poet. In this way, the theological poet judges everything he knows by uniforming it to what he already know, the myth of Jupiter. What Malebranche states in The Search after Truth, can be easily interpreted as one of Vico's axiom in The New Science: "Human beings not only suppose identity, likeness, or proportion in the nature, number, and essential differences of substances, but they make the same suppositions about everything they perceive." 27 Human thought reduces the complexity of reality to the capacity of the mind. Human thought models reality in the imagination. This principle has a universal value because it refers to a modality of thought with universal character.

Imaginative thought grants privileges universally. To all objects that the imaginative thought can comprehend, it grants identity, similarity, and proportion of substances, but it cannot provide a perspective and logically differentiated vision of things dissimilar. The universe is not like the vault of a ceiling; the stars are far removed from each other and their distance from the earth varies greatly for each one of them. Nevertheless, until technology furnished the human beings with the instruments to become aware "sensibly" of such differences (obvious reference to Galileo), for millennia the imagination kept in its hand the credences of humankind. Before having knowledge of the real distances of the stars, no logical need existed for preferring another theory rather than the one that wanted the stars equidistant. Furthermore, because the imagination was representing the stars as similar and on the same plane, human beings preferred to follow the natural judgment of the senses instead of that of reason, which would have required a suspension of judgment. 
The imagination reduces thought to the iconographic level; it renders as similar substances that are heterogeneous; it represents in the same manner spiritual and corporeal entities; because it cannot represent spiritual entities per se, it always assign to them form and figure. The imagination lacks a perspective; it produces figures but has one plane alone on which to dispose them. The homologation performed by the imagination begins from the reduction of the different planes of reality, but extends itself to variety. The imagination performs a substitution of the variety of reality with a fictitious reality produced by the sensitivity. The simplification actualized by the pagan mind begins from sensitivity and hypostatizes itself in the imaginary, being disposed to the change of the imaginary only in function of the hypostatized sensible object: "When the mind finds itself forced to admit differences between bodies by the different sensastions it has of them, and for other reasons as well, it always does so to the least extent that it can. This is why it easily convinces itself that the essences of things are indivisible and that they are like numbers, as we have just said, because it then needs but one idea to represent all the bodies it terms of the same kind." 28

\section{Distinction and Imagination. Identity and Difference}

Distinguishing is an operation of the mind that demands attention and concentration; it goes against the nature of the imagination. Distinction is thus an operation that the pagan mind reluctantly affords, and when it is obliged to it, it is compelled to it not by the intellect (as in the Cartesian method) but by a sensible evidence. Human beings believe with no trouble that the essence of things is indivisible, because then it is enough to have one specific idea with which to think a multitude of objects, which are considered incorrectly to be of the same species. No matter from where we approach the question, the conclusion is always the same: human beings judge according to their sensations, and particularly according to what they see. It is impossible to have an adequate vision of all the differences and particularities of things, because the power of our spirit is limited, but even more limited is the capability of our force of representation, which depends from the ability of the brain to form images.

For the pagan mind, the easiness of representing the ideas through images, of simplifying and transfiguring ideas, is a snare into which the will of the weak will falls, because it is always ready to judge with haste and superficiality. Up to this point, we have faced the question in the logical line with Malebranche in terms of "identity" and "difference." The imagination is inclined to reduce the differences to identity, through the category of similarity or resemblance. Many real differences escape the imagination, because where it does not notice fictitious diversities, the imagination assumes uniformity. The opposite error is of easy making: we cannot assume a substantial difference simply because the imagination 
cannot represent perfect identity. The imagination as a faculty gives always a partial representation of the thing, that is, from a specific point of view of the subject. The judgment that the individual formulates beginning from the representation does not stop at the representation but refers to the thing. If the sensitivity is showing to the subject the differences more than the similarity, then we would suppose a substantial difference; in the contrary and most frequent case, we will believe equal in substance things that apparently are similar. "For just as we need not hastily suppose an essential identity between things between which we see no differences, so we need not posit essential differences where we do not find perfect identity. For these are mistakes we usually make." ${ }^{29}$ Human beings begin always from a preconceived conception; they judge the reality of things starting from the senses, and from what they see on the outside (the appearances) they judge what is inside (the substance of things). The imagination moves from one side to the opposite, from perfect identity to total difference. In the things that imagination represents, it transforms quantitative differences (in the order of more and less) into qualitative ones (in the order of substance).

The soul possesses a limited representation of the world. The representation is not proportioned to the capability of the soul's intellect, but to that of the senses. The soul finds itself, with its finitude, immersed in a reality in which the differences are infinite because infinite is the universe that surrounds it. For Malebranche, human beings know reality through their thought, but they do not know everything they can think or, at least, they do not possess an adequate knowledge. Thought goes far beyond the light of the intellect, and farther the thought goes less illumination covers the things, which with less light suffer of obscuration and confusion:

What we immediately find in man's thought, then, is that it is very limited, from which two very important consequences follow. The first is that the soul cannot perfectly know the infinite. The second is that it cannot even know distinctly several things simultaneously. Just as a piece of wax is incapable of having the infinity of different figures simultaneously, so the soul is incapable of knowing the infinity of objects simultaneously. Further, just as a piece of wax cannot be both square and round at the same time, but only half round and half square, and as the more different figures it has, the less perfect and distinct it will be, so the soul cannot perceive several things at the same time, and its thoughts are the more confused as they are the more numerous. ${ }^{30}$

The imagination assumes the function of regulator, reduces tension, congregate all reality to its funnel and lets it to fall into the urn of the human conscience. In a manner contrary to that of the alembic of reason that distillates only pure ideas, the funnel of the imagination allows the passage to dense and turbid liquids. 
Though the imagination produces representations misrepresenting reality, it tries nonetheless to structure in some ways the knowledge it achieved. With the process of agglomeration by resemblance or similarity, imagination puts in order the ideas, although in a fictitious order, and organizes a whole (that to the mind appears chaotic) into a few images. The imagination constructs a finite representation (like all figures, the representation has limits, borders that defined it) of what is infinite. It is obliged to represent together and indistinctly things that should be thought distinctly and one at the time, but that the senses impress on it in a confused and coercive manner. The imagination is the organizer of sensations, sentiments, and inclinations, but the result produced is directly proportional to the method used: error. The organization given to the pagan mind by the imagination can only give a partial vision, albeit distorted, of the real. When producing knowledge, the conscience falls always into error about everything and even itself. To be ignorant of the role and the functioning of sensitivity implies being ignorant in everything. On these principles, Vico builds the bases of his historical inquiry. He begins with the consideration of a being that is ignorant about everything and, because of ignorance, this being is ignorant also of what it senses. An erroneous conscience, the more it is ignorant of its sensitivity, the more the sensitivity establishes its tyranny. The more the human being is ignorant, the more the sensitivity extends its dominion. To ignore the causes of what happens does not free the ignorant from avoiding the effects of the causes. When a rational criterion for evaluating sensitivity is missing, sensitivity itself becomes the judge and the evaluator of what happens. When sensitivity is the barycenter of thought, it ousts all adequate criteria of reason for its interpretation and makes itself the criterion. Sensitivity as the window of the soul on the world turns itself into the organizer of the panorama (in the sense that sensitivity cognitively structures the panorama).

\section{Anthropomorphism}

For Vico, unlikewise for Descartes and partially for Malebranche, the functions of regulations, homologation, and transformation of ideas that the imagination holds in the pagan mind have a positive quality because they made possible the rising of the human being from the post-diluvian bestiality. For Malebranche, the imagination is a powerful social bonding agent and an indispensable element for the maintenance of human relations. The analysis of the imagination in its rapport with the intellect has brought our authors to conclude that sensitivity completes a fantastic fusion between the physical world and the intimate passions of the soul. The logic of the imagination, based on iconic similarities and the familiarity of ideas, becomes the interpretive canon of the pagan universe. The conclusion is the anthropomorphism. 
What our three authors intend to say is that every time the human production (intellectual or material) is noticed having anthropomorphic characters, it signals to the presence of the imagination. Although abstract, sophisticated, and at the appearance rational the results achieved in these works may be, if a hint to anthropomorphism may be found in them, it means that imagination was acting from within them. The evidence of the action of the imagination may be even imperceptible, hidden to the eyes, but certainly worked in profundity in a determined manner. The imagination acts freely, without restrictions, when the intellect is dormant, when it does not bring light to the mind, itself, and the universe. A principle known to philosophers synthesizes what we said: "When the mind lacks an internal criterion of truth, it attributes to the body what instead should be attributed to the mind." Vico appears to place this principle as one fundamental of his new science and reformulates it in this way: "By its own nature, the human mind is indeterminate. When the human beings are sunk in ignorance, they make themselves the measure of the universe." 31 The primitive mind is deprived of the clarity that would allow it to see its own internal light and through it conceive what is its and what instead is of the universe. The theological poet makes himself (and its particular way of sensing) the criterion of judgment of the world. When we use reason, we unfold our mind, extending its limits and explicating all its potentialities. Reality is comprehended in proportion to the clarification of the mind. We know who we are and we do not create an image of ourselves in the proportion and the form of the sentiments and the passions that reason has swept up. When the intellect is buried under the thick blanket of sensations, emotions, passions, and foolishness (the actual condition of the pagan mind), fantasy creates a whole universe in which it places the human individual as the unconscious center emanating life and energy. 32

Human beings through the imagination transform themselves into what they fantasize. Truly, they do not transform into the object of their imagining but into what in real life will be the result of the actions that they performed with the beliefs of being what they have fantasized. The Vichian hero imagined that he was the son of Jupiter. This belief did not cause the hero to become son of Jupiter (a deity existing in his fantasy), but to become what his actions (made so far as he believes to be the son of a divinity) made him to become. Thus, the hero became hunter, warrior, and farmer as long as he believed in being the son of Jupiter. The hero did not transform really himself into what he fantasized (of being the son of Jupiter), and became in effect what the imaginary cause of his actions produced.

The analysis developed by Malebranche and the principles that he deducted from it coincide with the principles that Vico adopted for the construction of his anthropology and science of poetry. Lamy, building a bridge between Malebranche and Vico, beginning from Malebranchean psychological principles and applying them to pagan poetry, formulated theories very close to those of the Neapolitan, for conceptual affinities and for the perspective used in approaching 
the pagan production in poetry. Myths do not possess those meanings that euhemerists, Neo-Platonists, and literati have attributed to them. Myths find their reason of being in the mentality that generated them, in a crude mind that began from the senses and ended in the imagination, endowed with little abstractive capacities, and that founded a morality, a vision of the world, a religion and some customs in what was perceived. 

PART THREE

THE SOCIAL FUNCTIONS OF IMAGINATION 



\section{FIFTEEN}

\section{THE FUNCTION OF IMAGINATION AND IMITATION IN SOCIETY}

The birth of thought is for Vico contemporaneous and parallel to the constitution of society. Jupiter, as "the first thought," represents the awakening of the mind of the brute (bestione); as the "divinity," Jupiter is the bond among the first human beings, the catalyst of their passions and of their common feeling. As at the individual level, the myth represented the constraint of the ferine roving, and it was a coercive deterrent directly proportional to the brutish sentiments to be controlled, so at the social level myth represented the law. The law that the myth represents is not a law that can be either applied or neglected, as it happens in the evolved human societies. It is an inflexible law that has no category of the permitted beside those of the forbidden and the enforced. It is a law binding every action and gesture to the divinity: everything that the human beings do are in function of and under the scrutiny of the divinity. Law is strictly correlated to idolatry and superstition.

\section{The Birth of Thought and Authority}

Imagination is the ground on which rights are born, and the first law is a divine law. The first law produces a ritual that does not represent a specific moment or an aspect of a well defined social life, but the totality of the human experience. Fantasy establishes the quotidianness because it legislates regarding every human action. The passions are modeled according to the representation of reality and bind human action and the will to the fear of the divinity. Through the law, the myth of Jupiter becomes the objective nutshell of social living. Through the law, human beings move from fantasy to reality. The false thoughts of the primitive superstition bring human beings to effectively accomplished behaviors and repeated ritualistic actions that constitute the supporting structure of social relationships.

Fantasy is the subjective window of the soul from which to look at the world; it represents the corporeal perspective of the soul. Even though fantasy is 
intimate and private to each human being, it conditions action, which is always real and public when performed within the community. Fantasy binds human thought to the corporeal reality through action and the sensitivity's passions that agitate it. The imagination makes visible the objects of the mind; without the imagination, without fears, human beings would have remained a brute. The imagination is the fire that illumines the reality within and around the spirit of the primitive human being in the sylvan night of the bestial solitude, but illumines reality with the falsifying light of fear. The relationships between human beings and things that fear creates have by nature a coercive quality because fear is a sentiment that admits only a flight from what inspires fears toward what can save. Neutrality is impossible because freedom is not allowed within the dominion of terror. The truth tells us that what we wish to avoid and what we hope would save us have the same origin in Jupiter. We can understand how the society born from the myth would produce a coercive law, a way of living completely ritualized. The law of Jupiter must counterbalance the force of the instinct in the animal and must formulate a legislation that wraps up the whole conscience and locks it with the poetic chains of myth.

The human action is born as the answer to the law of thunder lights and claps; it is the necessary answer of the being that bows completely before the entity to which it answers. At its origin, law is veneration, the total ritualization of every motion and thought. Law is the force of the self-imposed religious illusion, unconscious but strong enough, to get the human being to perform the leap from nature to culture. Law, therefore, is religion and religion, at its turn, is superstition and self-deceit. The "guardianship of the laws," the "inalterable formulas of consecrated words," and everything that appear as stupid credences to modern people, represent a fundamental step in the history of humankind, creating a world that before did not exist. This new world was the world of the first aristocratic republics. Vico wrote, "In the divine age, the guarding of the laws was scrupulously observed; and this observance of divine laws was simply called religion. This was perpetuated by all later governments, under which the divine laws had to be observed with certain inalterable formulas of consecrated words and solemn ceremonies. There is nothing so essential to aristocracies as the guarding of the laws." 1 The aristocratic republics are the social product of the myth-making power of the theological poets. In essence, all societies are the production of human fantasy; law is a form of fake religion. ${ }^{2}$ The philosophy of imagination is a philosophy of law and an historical anthropology. The concept itself of authority possesses, in this perspective, a gnoseological origin in the imagination, which represents to the human beings only what captivates their attention. An object, in order to be relevant to our consideration, must possess characteristics that differentiate it from the rest of the things that lie on the background of the representation. In other words, the object to be considered must have the authority (intensity of percep- 
tion) of placing itself manifestly in the imagination. With the idea of the thing, we can appropriate the thing. ${ }^{3}$ Vico explains:

Originally, authority was divine. By it, the deity appropriated those few giants mentioned above, by properly casting them down into cavernous depths and recesses beneath the mountains. In myth, this is represented by the iron links which chained these giants to the earth. Scattered on the mountains, these giants were transfixed by their fear of heaven and of Jupiter when the heavens first thundered. Thus, Tityus and Prometheus were chained to a high cliff and had their hearts devoured by an eagle, which symbolizes the religion of Jupiter's auspices. In a heroic phrase, the Romans said they were transfixed by terror, terrore defixi, which is how painters depict them, with such links chaining their hands and feet to the mountains. ${ }^{4}$

The human being founds society in the precise moment when he became properly human. The divine law essentially demands the control of the bestial instincts, the end of the wild roaming, and the transformation into something entirely different, something yet unknown. Ignorant as they were, the theological poets imprisoned themselves in the cell of their imagination with the chains of the religion of Jupiter. This confinement was representing to them their horizon of reality, the limit of their action, and the stage of the divine demeanor.

The divine laws are written in the heavens, they are the heavens, and the divinity in person vigilantes, watching that human beings thoroughly observe its decrees. Societies are the product of the poetic capability of these first heroes who believed to have been chosen by the divinity. Divinity indeed elected the heroes and for this reason they are not observers but observed. The first word was proffered by Jupiter with the lightning and the thunderbolt; the ceremonies (the actualization of the divine will) are only the answer due to the tyrannical presence of the god. The human beings kneel before the divinity that they believe would destroy them, but at the same time they are pleased of having been chosen. ${ }^{5} \mathrm{Hu}-$ man primitive action becomes social action because of the primitive presumption of being among the few ones loved by Jupiter. Primitive human beings impose themselves to nature through their submission to divinity. Society is born poetical$\mathrm{ly}$, as the imaginative solution of the problem of mind and body. The law is a form of reasoning, the only one possible to the narrow and crude primitive mind. For the widely open mind of the active intellect, an idea can be considered as true or false, good or bad, or morally indifferent. For the primitive mind, every idea is true in the sense that it is certain, believed true because of the sensible certainty presented to the imagination. As Malebranche stated, the intellect is passive in relation to truth. Human beings are not free when they think a theorem of geometry in a manner different from the way we think it or when they think that two and three is not five. The will of primitive people finds itself in a coercive condition in 
relation to the content of their imagination. This condition is similar to the one that the intellectualized mind experiences in relation to the truths of reason: it must think what it thinks as true. ${ }^{6}$ The Vichian theory recalls the theory of Malebranche according to which the will is not free to consent to a truth of reason once it has perceived it with clarity; it is free only from not presenting the truth to conscience. When the will has considered an idea as true, the intellect is no longer free of thinking it as false. The pagan mind is disposed to the retention of what it thinks or represents to itself as true. The theological poet thinks only of Jupiter and thinks of him as real. Jupiter is the new authority that reconsiders the directing biological forces of the brute and establishes the foundation for a new organization of the human material. Idolatry and divination constitute the first civil code. Vico wrote, "As our principles of poetry tells us, idolatry and divination were the twin daughters born of that first civil metaphor in which Jupiter, identified with the Sky, would write his laws in lightning and promulgate them in thunder." $\mathrm{Vi}$ co's conception of society is relying on the psychology of the pagan mind. In the human being, mind and body are united; society follows the dynamism and the structure of the mind of the theological poet, of the hero-founder of society. The event in the psychology of an individual human being has a correspondence in the community to whose foundation and organization this being contributes. This shows how the subjective products of the mind objectify themselves in the laws of a (poetic) nation. Idolatry and divination are two events contemporaneously individual and social, and have specific functions in the constitution of the gentile nations of heroes.

\section{Divination and Idolatry}

Divination is the technique for the discovery of future events or present unknown events through the examination of signs that express the will of the gods. In Vico, the prediction refers directly to the will of the gods that is one thing with the signs that it manifests. In the beginning, the present, the future, the divine signs, and the divine essence are all fused together into a unique image that reproduces itself changing physiognomy, and these sensible changes activate the mental faculties. The interpretation of the divine signs is the first true language that will come to articulate and gradually specialize as the signs would multiply in quantity and variety. The conception itself of time will come to form in the conscience in different ways as the prediction is of something of the present referring to something of the future. Prediction introduces anticipation and assigns a diachronic perspective to a monolithic mind whose rock is one myth, one only image.

With divination, a series of alternatives opens for human thought and action, but one must keep in mind that divination is the comprehension of the divine law. Divination is a "juridical" practice. Matrimonies, funerals, uses and cus- 
toms, work in the fields, the deforestation of woods, the appropriation of the land, and the war against rivals are all executions of the divine will, practices performed under the auspices of Jupiter, actions conforming to the law. Jupiter does not exist; it is only a function of the imagination and of the sentiments. Jupiter is the self-deception of the human being. The laws and society are the products of this original deception. Humanity is constituted by many single human beings who in identical and different moments have suffered the same hallucination of the fantastic thought. What is thought in a being that up to a certain point was without thought, if not a hallucination that opposes the corporeal instincts? The societies constituted on an unreal thought, the myth of Jupiter, have a fantastic origin and their structure will always be constructed and reproduced in consideration of the imagination.

Divination is one of the two causes of the poetic world, idolatry is the other. As divination is the first exercise of mental gymnastics, so idolatry is the first manifestation of the human will. Religions, said Vico, should be venerated rather than reflected upon: veneration, faith in the idol, reverence are exercises of the will. Idolatry and divination, mind and will, are directed toward and attracted by a unique image: the fantastic universal of Jupiter. Through idolatry and divination, humankind becomes the slave of itself. The idolatry provides the brutish being with the ropes of thought with which to tie the animal body to submission, transforming the brute into the theological poet. In its primitive form, law is ceremonial and the ceremony is not something isolated from the daily actions, it is instead an integrated and collective activity. Law is not a ritual to be performed at specific times and places mentally different, but something inherent in the human beings acting in society and at all times permeating them. Every action that human beings do is ceremonial; all the human life is ceremonious because Jupiter observes the hero at every moment. In addition, at this stage, every place is a temple because it is the milieu that the human beings know through the revelation of the divinity. The divinity reveals itself in the natural phenomena as divine events and makes them known as divine, not as simple inert things, or as portions of extension.

\section{The Dominion of the Land}

All human reality is a temple and every action of human beings is an effect of the divine law. The dominion over the land is an effect of having ended the bestial roaming, and it was possible only because the human being feels itself as the one chosen by the divinity. The land is of the hero because Jupiter stopped the hero on that land. Revealing himself, Jupiter has created the milieu (so the primitive believes), the reality for the first time seen by human eyes through the imagination. Before transforming reality, the human beings must make it their own, and in or- 
der to make it their own, they must transform it in their imagination, otherwise they would not recognize it. ${ }^{8}$

Society could be established only after the heroes appropriated the physical place. The human beings would possess the land for reason of the cult due to the divinity. Without the fantastic appropriation at first and the effective appropriation thereafter, the heroes would not be truly heroes and society would not actualize because of the lack of a place. The law consists in the fixation of the subjective fears of the individual on something objective like the divine will. The law is thus the effect of human feebleness. At the same time, law represents the creative power of a being that, for reason of the greater threat of the divine vengeance, would face what are believed the minor threats from nature.

The law is the will of a divinity with the greatest strength, capable of mercilessly killing. The hero is hero because he is conscious of being the survivor from the vengeance of the gods and imagined himself a privileged chosen under the auspices of Jupiter. No incentive to action is more powerful than the combination of the fear of a greater danger with the belief of having destiny on one's own side. ${ }^{9}$ Jurisprudence is born as a theological science, as an interpretation of nature believed to be divine, as an organization of real interventions on nature and in nature, in view of an adaptation to an imagined reality. Being everywhere in the same kind of situation, the human mind has found salvation in the idea of a divinity. ${ }^{10}$ The law that this first idea produced for itself is a canon of behavior that allows the subject to structure and organize its life. Though the causes of the law exist in the imagination, the effects of the law exist in the reality. For us modern, the two planes of reality and illusion are distinct, but for the primitive mind they were one thing. For the primitive mind, the causes of the law were as real as the effects of the law. The law is an idea and a word, and as a word (ius) has the same onomatopoeic origin.

The illusion of the divinity produces fear, and fear generates a conduct conforming both to the belief and to the natural reality. The reality is not lived as a physical reality but as a divine reality, and its results and actions accomplished under the divine imperative become words, integral part of the law. Jupiter reveals himself in the actions that human beings do; he is neither the cause nor the effects of what human beings do; he is present through the total chain of the events. Jupiter exists in the cause of the actions, in the effects as much as in the cause itself. The pervasiveness of the divine presence determines the legislative absolute and the extreme compulsion in the application of the decree. ${ }^{12}$

Law and usage, imposition and social action had the same origin. Unwittingly about this, the human beings organized themselves in society in every part of the world in the same earthly manner, though with a thousand difficulties dictated by the specific ambient contexts. Unconsciously, all human beings manifest the same humanity. Unconscious of their own illusions of having founded a society, established some rights, and subjected themselves to laws in every part of the 
globe, the primitives gave life to societies identical in their structure, in the logic and mentality that made them according to what they were. Vico said, "The natural law of nations arose together with the customs of the nations. Such customs conform to a human common sense, which occurs without any reflection and without any imitation between nations." 13 The human beings know nature through the myth and through myth fantasy takes possession of nature and believes to own what it can think. This is an extremely important thought of Vico. It is in this way that the slave of Jupiter obtains the dominion over nature. The slaves of Jupiter make their actions dependent from fantasy and fantasy is the owner of nature. The entire poetical life extends itself through the fantasy and the balance of values. Through the fantasy, the primitive beings know the ambient and construct thought on it. Jupiter reaches as far as where our sight arrives; Jupiter exists in everything that moves, that makes a sound, and that attracts the attention. The universe begins from the ego itself, and from the love of itself reaches out to anywhere the senses receive stimulations. Between the center, the body, and the periphery, the horizon of sensitivity, the sentiments unfold, the visions are knitted, the ordinances of the law form the tapestry of jurisprudence, and the rapport of forces are established. Vico narrates,

In the myths, Plato observed that the gods' customs were entirely inappropriate to their divinity, but quite appropriate to his own ideas. Take, for example, the poetic dictum "All things are full of Jupiter." Plato imposed on the mythical Jupiter his own idea of ether, which pervades and penetrates everything. But in fact the Jupiter of the theological poets was no higher than the mountain tops and the region of the atmosphere which generates lightning. And Plato imposed the idea of breathable air, a $\varepsilon$ in Greek, on the mythical Juno, since her Greek name is Hera. But in fact Juno has no offspring by Jupiter, whereas air and ether produce everything. By this poetic tag, the theological poets intended neither the truth of physics that ether fills the universe, not that truth of metaphysics which demonstrates what natural theologians call god's omnipresence! On the basis of poetic heroism, Plato constructed his philosophical heroism, which places the hero above both man and beast. For Plato, the beast is a slave to its passions; man places in the middle, struggles with his passions, but the hero commands his passions as he chooses. In this way, the heroic nature lies midway between human and divine nature. ${ }^{14}$

The hero stands above the slave and the slave is a beast among the beasts that populated the forests of the earth. The hero is above the beast because he possesses the imagination. From its beginning, society is a hierarchical organization controlled by the force of the imagination. The Fathers, the Heroes, the first human beings who moved from the brutish to the idolatric life, with their strong religious 
fantasy, dictated the laws according to which the civil life within the families was supposed to evolve. Their authority, their power stood on fear and terror, and they stood as the link between the divine reality and the families.

The Hero communicated imagination and passions to the famuli or family servants, who were essentially slaves; the Father, Lord of the family, communicated them to his wife and children. They created a network of emotive ties that tended to become rigid and fixed in precise rules for a life in common, rules centered on the rapports between human beings through the mediation of the divinity. The subordination of the famulus to the hero was not a direct submission as the one between two animals that have established who is the leader of the pack. It was from the object, Jupiter, of the thought of the hero that the hero derived the strength, which was all in the imagination, for the domination over the famulus, which was blind to the vision of the divine reality. From the hero's submission to the divinity derives the superiority over nature so that the hero imposes himself to the famulus.

The famulus in the eyes of the imagination of the hero is a part of the nature that the hero must subdue and come to its possession. ${ }^{15}$ From his part, the famulus tries to satisfy the primary need of safety from the dangers of the wild beasts of the forests. The famulus attributes no religious significance to his actions, sees no manifestation of the divine in nature, wishes no dominion over the land because only the instinct dominates him and all beings have only a biological inclination. The famulus has a biological relationship with the hero, but such relationship, under the will of the hero, is transformed into a social relationship. As the hero is related to everything through the divinity, so through the divinity he relates to the famulus. The relationship between hero and ambient is a relationship mediated by the imagination, whereas in the modern man between man and nature reason, abstraction, conscious discernment exist, between what is due to things per se and what is due to the human individual emotivity. For the hero, everything exists in the imagination. The heroes are the sons of the earth, the earth on which they stand is the ambient that the imagination has brought them to know.

Imagination keeps human beings together. The powerful imagination of the heroes makes the heroes strong. The weak imagination of the famuli makes the famuli subdue. The double character of imagination is found also in the evolved mind. The weak becomes slave to the strong through the imagination, as the powerful are such because they have an imagination overpowering that of the weak. Societies are not made through either deceitfulness or treachery or the military or physical power of kings, but by the imagination of the theological poets. At its origin, imagination may be strong as well as weak. With the first aggregations of families and the introduction of the famuli, thought presents itself as twofold, because the path through which human beings arrive at thinking is double. ${ }^{16}$ The imagination of the theological poet creates a strong reality (Jupiter), and the thought diffuses itself in the world through the representations of the mind as a 
weak thought dominated and conditioned by the divinity, which at its turn is the strong product of the weak imagination of the theological poet.

Unwittingly, the human beings with myth organize a strategy of survival opposite to the one they followed during the period of their beastly roaming. Idolatry and veneration have produced a behavior linked to a precise ritual codex, whose rigidity is inversely proportional to the instability, opacity, and indistinction of the representation of the ambient (Jupiter). The progressive focusing of conscience on the image determines a progressive articulation of conduct and, therefore, of law. We may sustain that religion was the law of the heroic families, and idolatry and divination are in effect social facts and religious experiences at the same time. In their causes, idolatry and divination are laws of thought, both psychological and juridical. All this is the effect of the credo in Jupiter, which is simultaneously religion, jurisprudence, and language. In all its aspects it is effect and cause of thought, and it is thanks to this thought that human society were born, maintained, and transformed themselves. ${ }^{17}$

Societies are a network of communication of strong imaginations; a network with channels that are the narrower as the imagination gets the stronger and more confused, while the intellect is weakening and the precariousness of existence pressing. ${ }^{18}$ The pagan mind trained itself to think with religion and transforms itself in the measure in which it transforms its fantastic representations of reality. In the beginnings, the image of the world is altered because in the narrow primitive spirit thought has exploded giving way to the outburst of the myth of Jupiter and the image that the primitive has of itself is nonexistent. In the course of time, with the articulation of the myths, the mutation of the ceremonial actions, and the increase of the social relationships, a more adequate conception of reality appeared in the pagan mind. The representations assumed increasingly more definable and defined connotations. The vision of the perceived becomes clearer and nature is gradually distinguished from the subject that perceived it, and the subject becomes more realistically conscious of itself. Vico, in Poetic Economics, or Household Management section of The New Science, narrates,

With their merely human senses, the heroes sensed two truths which constitute the whole science of household management. These truths are preserved in the two Latin verbs educere, to bring forth, and educare, to bring up. With supreme elegance, educere refers to the education of the mind, while educare refers to the education of the body. Later, by a learned metaphor, physicists transferred educere the bringing forth the forms from matter. For heroic education had begun in a way to bring forth the form of the human soul, which had lain buried by matter in the giants' huge bodies. And it likewise began to bring forth the form of the human body in its just dimensions from the disproportionate bodies of the giants. ${ }^{19}$ 
The human beings become civil through thought and thought is brought out through religion and its rites. The perception of the world in due course becomes more definite, leaving behind vagueness, confusion, and the incapacity of giving an exact form to things. All things and particularly the individual body evolve in a shape gradually more proportioned. The modulation of the perception goes hand in hand with the definition of the image and the individual conscience. For the primitive, reality is as wide as "the sight of the imagination"; it extends to the top of the mountain where Jupiter is and stops at the profundity of the burial chamber. These are the extremes of reality as it is dictated by fantasy. Within this mechanism in continuous evolution, the communication of strong imaginations plays a fundamental role.

What makes a hero out of the theological poet is his interaction with the ambient. The society that the theological poet created enmeshes him in a web of shared and thus social individual passions that oblige him to act as the agent and beneficiary of strong fantasies. The sharing of the illusion is for Vico what characterized the human society. Thank to the imagination, the human primitives have domesticated. ${ }^{20}$ The beast has become a civil animal and society is the effect and the reason of its domestication. Societies originated with the sharing of specific credences by some groups of human beings. Society is the collective participation of a multitude in fantasies, myths, and passions.

\section{The Heroic Mentality}

At this point, we will consider Malebranche in The Search after Truth who describes how the communication of strong imaginations in pagan societies happened, and how they produced the heroic mentality. Then, we will discuss how Vico in his anthropology adopted these principles and vision.

Malebranche speaks of the contagious influence of the strong imaginations. The imagination crosses metaphorically the space that separates a mind from another, penetrates the second mind with the fantasies and the passions of the first, and encloses it within its own dimension. The more the second mind struggles to free itself like a prey in the net, the more it entraps itself and becomes slave of the icons of fears and sentiments of the first mind. The imagination provides the diffuse and penetrating contagiousness on which civil societies erect and maintain themselves. Society is not due to reason, or a just and natural law, or the decree of a demiurge, or a social contract. Society is born as a community of passions and fantasies. The human being unites to others and to things through the body and through their bodies, human beings constitute the society.

The dynamism of society is that of the imagination; in the Malebranchean optics, the political science is the science of the allocation of imagination. Society, in Vico, is the community of those few human beings chosen by Jupiter, those few 
human beings sharing the same fantasy of the divinity, the same fear of death, filtered and transformed by a fantastic conception of reality. In Vico's Poetic Politics, politics is the science of the communication of imagination. The deeds of the human beings, the relationships that run among them and rule society are motivated by the myths of the community. The myths are the poetic product of the pagan mind; they are fantasy and imagination. For Malebranche, we are connected with other human beings and things by way of our body, not directly through the body, but through the representations that we have of our body, of that of others, of our and their possessions, and of the cities where we live. We value the things that can, or we imagine they can, satisfy out needs and wishes, which are never rational, based as they are on the subordination of the soul to the body. The value we give to things and persons is not a real value, but the product of our imagination. Malebranche often speaks of the value of all sensible goods, real value and imaginary one. ${ }^{21}$ The value that represents the value of all sensible goods is the value of money. From the rational perspective, with evident ideas, the value of a gold coin is the same than that of a copper coin. They have the same geometric shape, and are a portion of extension, and their difference is in their sensible non-objective qualities. What makes them different in value is the conventional value that the society has attributed to each one of them. The value that Malebranche attributed to money is like the one he attributed to language. Books would have no meaning if there were no agreement among human beings of attributing to the same signs the same significance. Notes and bills would have no more value than a piece of paper if human beings did not ascribe to them an extrinsic imaginary worth. Without the law of the union between soul and body, our libraries would contain collections of black and white sheets of paper. ${ }^{22}$ The life in society has determined as one of its most evident effects the production of a variety of objects or utensils, instruments fabricated in view of a goal or usage. Things have significance in relation to the human intelligence that has planned them. Things are extended objects that have a function in the material reality and possess a spiritual finality in relation to the human mind that ideated them. Malebranche observes that all the objects that characterized our society, of which the books constitute the clearest example, without the law of the union of mind and brain would be insignificant. Truly, all sensible goods are the intermediaries of our fantasies. In this sense, our societies are communities of imagination inside which the human beings with the most powerful imagination are the rulers. It is with imagination that an individual or a narrow minority may impose themselves on a multitude of peoples. ${ }^{23}$

Societies are guided, ruled by the powerful imaginations that succeed at imposing themselves over the powerless, dominate, and lead them. Societies float on the irrationality of fantasy and the powerful imaginations, and keep the common human beings in a common bondage. This thesis of Malebranche permeates every one of his political and anthropological judgments. 
Society is the battlefield of imaginations. The real wars, the supremacy among nations and every kind of community are the effect of the wars that the imaginations of human leaders fight. Fighters fight for a flag, and a flag, even money, is a symbol. Vico's heroes used to fight for land, but what did the land represent for the Vichian Hercules? The fight for land was a fight against nature under the auspices of Jupiter. The heroes did not think that their deeds were of an agricultural or hydro-geological order. The engagement in the war was caused by strong passions and mythological fantasies. Nature was not nature but hydra, monster, a product, believed real, of the fantasy. The message of Idanthyrsus is symbolic, but he had no consciousness of the symbolism of the words expressed, because all reality is the symbol of the imagination and the mind is the symbol of the body not as corporeal but as fantastic.

The pagan mind lives at the level of the imagination. Primitive societies are functioning and governed at the level of the imagination and are maintained with symbols and signs. Without a continued reflection on this point, a foundational concept will escape the comprehension of the social analyst. Our two authors, in different languages and with various proposals, sustained that human industriousness is the flower of the imagination, the dynamics of society are the dynamics of the imagination, and the stronger the symbolic function of the imagination is, and the weaker in awareness is the symbolic nature of its reality. The country of Idanthyrsus is not a real country, but the symbol of his fantasies. The overturn is total: the real country is used conceptually by Idanthyrsus as the symbol of the land of his imagination, cultivated and made his own under the auspices of Jupiter. The more the symbol and its significance are identifiable, the less the subject is conscious of the fantastic, symbolic nature of his objects of thought. The stronger the imagination, the more the dynamics of the individuals and the society is determined. The more the passions are unaware in their genesis and in their consequences, the more they condition existence. When reason does not guide the actions and the representations of the imagination, the actions guide the mind to rotate around the fantasies and the imagination. A pagan society, like every single pagan mind, does not know any other reality beside the one lived in the imagination. The strong imaginations dominate the weak ones. Society will be always the result of the fight between strong and weak imaginations, between strong and strong ones, between the conditions of the strong and those of the weak, and vice versa, between the fantasy of the single against that of the multitude. This is the common point of the Vichian and Malebranchean anthropologies: the communicative diffusion of the strong imaginations. The imagination has created the earliest pagan version of the world. 


\section{SIXTEEN}

\section{THE ORGANICISTIC CONCEPTION OF SOCIETY}

In Malebranche, we find two reciprocally exclusive concepts of society. ${ }^{1}$ For him, the true society is the society based on the love of your neighbor as preached in the Gospels, whereas all other societies have as a foundational principle that of self-loving. In the Malebranchean assumption, the human society is the one that favors the communicative expansion and the participation in the strong imaginations, and we will deal with it, after merely mentioning the perfect society of the Kingdom of Heaven, in which heart and mind are harmoniously united. The diversity of opinions has obfuscated the minds, and has been the obstacle for a society that elected to be Christian.

\section{The Malebranchean Societies}

Opinions come from an inner selfish love. An opinion is a personal judgment that reveals the perspective from which an individual looks at the world. ${ }^{2}$ An opinion is always a partial knowledge, a limited vision that generates a judgment on an object that remains for the most out of the individual's horizon. Finitude is the true cause of error. A communion of hearts is the requirement for the perfect society. As the minds must contemplate an immutable unique truth, the hearts should be fond of a unique goodness. A unique goodness loved by everyone without jealousy and rivalry is an infinite goodness.

The corporeal reality on which human societies are founded is a finite reality, with a limited amount of resources that are never enough for all societies. This consideration explains the possible conflicts that will emerge between communities, countries, and nations. The only universal society capable of overextending itself to embrace all societies in a communion of equal sentiments and material goods sharing, for Malebranche, is the Church of Jesus Christ. ${ }^{3}$ All the other human societies are imperfect commonwealths, each of which aims at a national welfare that may be conflictual with that of the other societies. Like the single human beings, the societies fall into errors because of their collective fears and passions. Psychology exists at the core of politics. A specific kind of mind when 
extended to a community becomes a mentality and may cause a society with that specific Weltanschauung. Malebranche said, "God unites us together by the laws of the union of the soul and the body, not only people with people, but every creature with all those which are useful to it, each one in its own way." 4 What form the society are not only the human beings, but also what the human beings have constructed in order to live together. Houses, cities, harbors, ships, and cars are the instruments that unite us because we use them at our individual advantage. Our societies are controlled and guided by the concupiscence that ties our bodies to other bodies, the objects, which we use with our individual body. Psychology teaches us how societies are structured and Malebranche dedicates to this issue the twelfth discourse of the Dialogues on Metaphysics and on Religion. He underlines again the subjectivity of the sensible qualities of things and their dangerousness for the mind when taken as real qualities. Definitively, there are "the laws of the union of the soul and the body and the laws of the union of the spirit with reason. Societies are formed according to these two kinds of laws." 5 All the connections of the human beings with other human beings constitute the cause of society; human beings build societies at their own image and similitude. The human being is for Malebranche the intermediate being between God and things. For Descartes, the human being intermediates between being and no-being. The laws of the union of mind and body regulate the society that, at its turn, would repropose to human consciousness the internal dynamics, the same impulses, and the same irrationality. The society structured and intended for pure capitalism (material possessions) is a mad society. ${ }^{6}$ The premise to an organicistic conception of society is viewing society as the extension of the human being. Society is a complex organism dominated by the passions of human beings, and sustained by the primary law of selfishness. ${ }^{7}$ Removed from the Divine Word societies suffer for the confusion of the laws and the instability of the institutions, though Malebranche assures that self-centeredness will move individuals and nations toward new horizons.

Here, Malebranche appears to appropriate some theories of Hobbes. To submit to laws by necessity, to respect them only in appearance, and to cohabit with others purely for advantage are positions of Hobbesian tenor. In Malebranche, the necessity of obedience to the law is the necessity internal to the imagination; the Hobbesian advantage concerns the primary goods for survival (protection against natural disasters, wars, hunger) and essentially is what the imagination previews for the individual. The false formal respect for the law does not exclude the looking at reality with the fantasy. In many parts of his works, Malebranche does not shun from a criticism of Hobbes, ${ }^{8}$ and the organicistic conception of society is confirmed. The formation of prejudices, by analogy, can be compared to historical events. Thoughts and beliefs of the individuals are those of the society, in a reduced format; the imagination plays a central part in this contagious relation: "To understand what this contagion is, and how it is transmitted from one person to another, it is necessary to know that men need one another, 
and that they were created that they might form several bodies, all of whose parts have a mutual correspondence." Survival requires that human beings aggregate in families, tribes, communities, casts, and nations in order to constitute a unique body. Society will remain intact if all the parts are compatible. If a single human being or a group of human beings cannot harmonize with the whole, they must be expelled in order to avoid lacerations and dangerous tensions. As an example, heresies, apart the theological disputes, constitute bodies internal to the Body of the Church. Like the animal body will survive only if all the principal organs will function in the proper harmony and cooperation, the social-political body will survive only if the individuals come to harmonize themselves with the whole. Within certain limits, the alterity or otherness of some individuals will not compromise the functioning of the whole society, but the extreme point of toleration may be reached and the expulsion or suppression of renegades will become necessary.

Our understanding of the life in society begins with the analysis of the single person, trying to find out what is its perspective on the other members of society, what conflicts are felt by its conscience, and whether its internal conflicts are the same external conflicts of the society. The laws that order society are the same that determine the essence of the human being. If our union with the Supreme Principle, the Creator, were stronger than the one that we have with corporeities, we will live in a perfect society ruled by an eternal and immutable Reason and in view of a true Goodness. Unfortunately, the weight of our body determines for the most the economy of our conscience and it is through the body that we are linked to other bodies and through them to the souls of other human beings. It is through the body that we are tied to the life in society. ${ }^{10}$ For this fundamental reason, the laws that regulate the rapport soul-body regulate also the relationships between the individuals and the society.

\section{The Vichian Society}

It is difficult to establish whether Vico ever reflected on these Malebranchean theories. It was known from the most popular theory of Descartes that the general laws that govern the relationships between the soul and the body are the same than those that govern society. In On The Most Ancient Wisdom of the Italians, Vico had examined such laws, from which he derived a complex theorization of imagination in relation to the origin of thought. In language, Vico sees the metaphysical center of the human being, the phenomenon in which the rapports of body and mind are manifesting themselves. Malebranche had reached the same conclusion. Language is the expression and the function of the representative world of the human being. The language of imagination lives at the center of the human being. Vico concluded, "To sum up, a human being properly consists only of mind, body, and speech, with the last as a sort of intermediate between mind and 
body."11 Earlier in the Inaugural Orations, Vico spoke more in a Malebranchean fashion, addressing himself to university students, "And if I say that each of you must search within himself in order to consider carefully his human nature, he will in truth see himself to be nothing but mind, spirit, and the capacity for language. Indeed, when he analyzes his body and its functions he will judge it to be either that of a brute or in common with the brutish. From this, he will note that man is thoroughly corrupted, first by the inadequacy of language, then by a mind cluttered with opinions, and finally a spirit polluted by vice."12

Vico, believing that societies are born by way of poetical means and poetry is regulated by the relationships of mind and body, sustained that societies follow the same laws of the union of mind and body. ${ }^{13}$ Furthermore, in his philosophy the subdivision of time goes parallel to that of language, thought, law, and forms of state. To every mentality corresponds a particular society: a heroic mentality flourishes a heroic society, and vice versa. Beside these considerations, there are unequivocal statements of Vico supporting and confirming the case:

All of this was possible only because these institutions had already belonged to the family fathers when they were monarchs in the state of nature. So, when they now united in a social order, they created a sovereign civil power, formed of those sovereign families power which in the state of nature had been subject to none but God. This sovereign civil power was a sort of person formed of mind and body. Its mind was an order of sages, who were as wise as was possible in that extremely crude and simple age. This established the first invariable property of commonwealths: that without an order of wise men, a state may outwardly appear to be a commonwealth, but is in fact a dead and soulless body. Its body in turn was formed of the head and lesser members. This established the second invariable property of commonwealths: that some citizen must apply their mind to the task of civil wisdom, while others must employ their bodies in the useful arts and crafts of peace and war. And the distinction between the two established a third invariable property of commonwealths: that the mind must always command and the body always obey. ${ }^{14}$

For Malebranche as for Vico, society obeys the same divine laws (in history, providential laws) of the union of mind and brain, soul and body, because in society as in the person between mind and body there is language, fault, and the providence that will determine the actions for the salvation of humankind. In this metaphor, Vico surprisingly considers mind and brain two distinct and opposed substances as Descartes did. In the human being, mind and brain are separate and separate must be the mind and the body of the society. Nations without an order of wise men may appear functioning commonwealths, but in reality are dead bodies, collective mindless automatons. 
Vico says that the mind of society is involved in the logic that supports the political action, in the legislating, in the goal of the political action, and in the common mentality of the people of the nation, rather than in the political action itself. The mind must command, overview the politics, but leave the action to the social body. In other terms, the society must have the same anatomical structure (physiological, mental, and moral) than the people who form the society: "Governments must conform to the nature of the people governed. This axiom indicates that, by the nature of human civil institutions, the public school of rulers is the morality of the people." $15 \mathrm{He}$ has affirmed that the human being is made of soul and body, the body is inert matter (extension), and societies are composed like human beings of a soul and a body. Then he ended proposing another parallelism: the relations between the mind and the body of society must be of the same nature of those between the mind and the body of the human beings that compose the society. This means that in a society composed of human beings slave of their passions no wise government can exist. The same nature exists in the human beings governed as in those who govern. The same laws are valid for the soul of those governed as for the forms of human communities, so that the development of society proceeds parallelly to that of the needs of its people. ${ }^{16}$

Vico's analysis of human nature is essentially anthropological; it is not political, not even when the object of his discourse is political or juridical. "The nature of peoples is first crude, then severe, next generous, later delicate, and finally dissolute."17 Human nature is at first brutish, then with myth becomes severe (extremely rigid in observance to the divine imperative, characterized by rituals), next benign when the conditions ameliorate (greater control of nature and reliability), later delicate as wealth and power increase, and finally dissolute as justice and morality alter. The cause of these social changes have to be found in the character of the human beings, in the analysis of their passions: "The weak want laws; the powerful reject them. The ambitious promote laws to gain adherents. Rulers protect the laws in order to make the powerful equal to the weak."18 The weak live with the fear of being wronged and want the protection of the law. The powerful do not suffer limitations to their authority because they have the mentality of the heroes, the chosen by Jupiter, who battled and overcame labors, the believers in the law of force. The wise prince should transform the weakness of the multitude into a political force by way of the law. The princes holding the power by force and by law must be the mediators between the multitude of the weak and the small number of heroes.

Human passions are the true motor of politics. The true law that regulates social dynamism is not the possession of land or wealth, but the will to prevail, the fear of failing, the wish to succeed, gain, overcome, and the dread of disappointments. Material goods and economics, for Vico, are only partial elements for the comprehension of political phenomena, but they do not explain it. In The New Science, the changing of epochs and societies is depending on the mutation of the 
characters of the powerful who controlled them: Polyphemi, Achilleses, Aristideses, Scipiones Africani, Alexandri, Caesares, Tiberii, Caliguli, Nerones, and Domitiani. These are personal names in the plural, a kind of synecdoche in order to explain that each of these individuals represented the mentality of their epoch, and that every epoch is characterized for particular passions, sentiments, in short, particular psychological aspects.

In the human race there first arise monstrous and grotesque beings, like Polyphemus and the Cyclopes, then great-spirited and proud heroes, like Achilles; next, courageous and just men, like Aristides and Scipio Africanus; closer to us, imposing figures in whom images of great virtues are linked to great vices, and whom the masses hail as men of true glory, like Alexander and Caesar; still later, wicked and brooding men, like Tiberius; and finally dissolute and shameless madmen, like Caligula, Nero, and Domitian. As this axiom states, the first kind of people were needed to make individuals obey each other in the family state, and to prepare them to obey law in the coming state of the city. The second kind, who by nature would not yield to their peers, were needed to establish aristocracies on the basis of the families. The third kind were needed to open the way towards popular liberty; the fourth, to introduce monarchies; the fifth, to consolidate them; and the sixth, to topple them. ${ }^{19}$

This paragraph like the previous ones shows the mutation of the character of the powerful in society in relation to the transformation of the material conditions, which are the effect of a mentality produced by the imagination. The mutation in the imagination creates a mutation in the material conditions of society, which in its turn change the mentality and the character of the rulers of society. ${ }^{20}$ If indeed the anthropological characters of nations change in consideration of the change of their political institutions and of the psychological stance of the single citizens, then it is true that the laws determining the rapports body-soul determine also society. The timing of the changes in society is proportioned to the changes in the life of the individuals. "Native customs, especially natural liberty, do not change at once, but only gradually and over a long time." 21 The imagination exists at the center of this vitality. Imagination is the ground on which the weak are weak and the powerful are powerful. At the root of every historical dialectic exists a political dialectic, in which we find a juridical dialectic, and as the substrate of everything the dialectic of imagination and of the rapport body-soul.

Society is part of the representation of the world that each human being constructs. Vico suggests that having specific conceptions of the place we occupy within society or the nation, will generate corresponding specific wishes. The poor will wish for riches, the rich will wish to maintain the acquired privileges, the uncertain will hope for guidance, and the domineering will look for the possibility of conquest. Every human being has its own fantastic cosmology. The psychology of 
each human being is a mixture of fantasies and passions. The individual psyches come to constitute the collective psyche, the mentality, which at its turn would influence, by reaction, the fantastic personal universe.

At first, people desire to throw off oppression and seek equality: witness the plebeians living in aristocracies, which eventually become democracies. Next, they strive to surpass their peers: witness the plebeians in democracies, which are corrupted and become oligarchies. Finally, they seek to place themselves above the laws: witness the anarchy of uncontrolled democracies. These are in fact the worst form of tyranny, since there are as many tyrants as there are bold and dissolute persons in the cities. At this point, the plebeians become aware of their ills and as remedy seek to have themselves under a monarchy. ${ }^{22}$

Human conduct is the result of reciprocal competitions between subjective desires, all and always inspired by self-love, and the real situation. The individual desires modify the real situation that, at its turn, would modify the desires. Selflove brings the inferior to ask for equality before the law. Men in the position of inferiority demand the law, because equality, under the hypocritical shield of justice, can turn to personal advantage. The law that protects the inferior in relation to the superior diminishes the level of inferiority, bringing the individual to the level of parity. From the level of equality, the individual wishes to escalate the social pyramid. Then, law becomes an obstacle for those who want to impose their will on others. The ambitious hypocrite turns liberty to personal advantage. With the victory of selfishness, we return to the dominion of the imagination over reasonableness. We recall that imagination means the appropriation of reality with thought by the pagan mind. When the human beings are blinded by fantasies, oppressed by passions, slaves to selfishness, they believe to own the world and to have right to its possession. Vico said, "We defend our natural liberty most fiercely to preserve the goods most essential to our survival. By contrast, we submit to the chains of civil servitude to obtain external goods which are most necessary to life. The first part of this axiom is a principle basic to the natural heroism of the earliest peoples. The second part is a natural principle of monarchies." 23

Every human being is free to do what it wants in its world: this we think and the pagan heroes thought. It is up to the modern heroes to conquer, dominate, and control. The pagan mind is always the mixture of selfishness and fantasy that dictates the rhythm of thought. Uncontrolled liberty, either in the society or the single person, always produces anarchy, which is never an absence of power, but the appropriation of power by that part of society that extended its liberty on the cadavers of those who opposed it. From the desire of a just law, we arrived at the uncontrolled freedom that ended necessarily in anarchy.

What must be underlined in all this is that the motor of this historicalpolitical process is self-love. Self-love, by contrast, makes human beings return to 
wisdom as they realize the total chaos created by general anarchy and the madness of tyranny that followed. The hypocritical illusions of equality and liberty are pretenses for personal special status. It is always for selfishness that the plebeians seek refuge in monarchies, and the condition of nationality exists in monarchies, with peoples united in fraternity. At the same time that the Transalpine Illuminists were proclaiming liberty, equality, and fraternity, Vico was reversing the motto they formulated in a political vein reconsidering it with the instruments of morality and psychology. Returning to the anthropology of the second half of the seventeenth century, Vico deduced conclusions that were more pessimistic than those of the Illuminists, who began their reflections from that same anthropology. 


\section{SEVENTEEN}

\section{THE NATURE OF SOCIAL INTERRELATIONS}

The human beings in communion with the universe of corporeal things gradually and unconsciously accrued their need of them, and when they united in society they became equally dependent from the social universe. The human beings became slaves of society in the same manner that their souls became slaves and dependent from their bodies after the Fall from Eden. In The Search after Truth, Malebranche illustrates how society models and conditions humankind. ${ }^{1}$ The process begins from the fetal stage when the fetus absorbs passively from the mother not only her individual corrupted and erroneous tendencies but also those of the entire humankind. Then, in infancy, the conditioning and the fixation of social prejudices in the mind reach their high point: nurses, parents, and teachers complete the damage that nature, in the interaction of the maternal body with the fetus, had begun.

\section{The Corporeity of the Universe of Corporeal Things}

The union with the rest of humankind is noxious and, though useful for survival, is not necessary. Nonetheless, humankind prefers wickedness, slavery, errors and offenses to a safe and complacent solitude. Malebranche underlines that he is not referring to a hermitic life as to the perfect life. The hermit and the good savage are far from his point of view. The commerce with other human beings can be of great value and comfort. He knows that the human being cannot become civilized in solitude; it needs the community of civilized beings. If the body is the vehicle through which spirits interact among themselves, transmitting evident knowledge, right moral teachings, and adequate ways of thinking and speaking, then the commerce with the neighbors will be proficuous. Life in society is certainly not a life in a community of pure minds, but of passions, confused sentiments, hate, jealousies, competition, and manifest or repressed fears. From this are born the obsequy for opinionatedness, the esteem for what the majority appreciate, though perhaps un- 
worthy. From this come the hypocrisy, the falseness, and the disharmony between action and intention.

Malebranche does not speak of the community of minds, but of the community based on the sensible union between our imagination and the exterior manners of those who are in contact with us. A society relating at the level of the corporeal reality cannot be but hypocritical: conduct and opinions will be in function of appearances, because human beings will know society with the senses and think of it with the imagination. Individually or communally, a life lived at the level of imagination is a life of appearances with an unreliable frail conscience. A psychology controlled by biology conduces to a false morality. A universe of corporeity unfolds the seed of conflict because the lies forged by the imagination find a solid foundation on it. Truth is one, but falsehood has infinite faces. The interest that truth announces is always one and equal to itself: Goodness. The illusory interests about which the pagan mind, entrapped in corporeity, fantasizes, are multiple and mutable; they are not shared equally, but are contested and pretended by all as their own. The illusory reality proposed by the imagination gives way to real conflicts, and fantasized goods provoke wickedness. ${ }^{2} \mathrm{~A}$ thought, the more it is dependent from corporeity, the more it is false and noxious. Through its appurtenance to the body, the soul becomes dependent also from the corporeal entities that are in contact with the body or relate to the body. In this way, the stronger these relations are, the greater the appurtenance and the slavery of the individual within the society or universe of corporeity will be.

From the perspective of their body, the human beings look at the world, the universe of corporeity, and everything assumes a values for them that is proportional to the position that everything has in regard to the human body. The value is expressible and is expressed in the emotive intensity generated in the human soul. ${ }^{3}$ The individual human being is the center of a circle whose circumference is the limit of the horizon of its senses. The more a thing moves far from the center, the less relevance it has; the more it approaches the center, the more emotively relevant it becomes. Individual bodies create particularly strong ties with parents, relatives, and friends; these ties are resilient. This is the reason why Descartes, Malebranche, and Vico consider the family as the foundational nucleus of society. The family must precede logically any other kind of institution because parents, relatives, and friends have the most intimate connections among them in conscience, sentiments, and passions. It is in these relationships of fantasies that Vico found the origin of society, starting his considerations from the psychological subjective assumption that the family is the first social layer forming itself around the human consciousness. These emotive ties and relationships are regulated by the same laws that regulate the union of the soul with the body and, through the body, the soul is united to the sensible universe of corporeal things. Like the Stoics, those who want to be indifferent to the universe of corporeity are wrong, ${ }^{4}$ because it is impossible to free oneself from this corporeal universe ex- 
cept by suicide. ${ }^{5}$ The ties and connections that bind human beings are invisible and determined by the laws of the union of the soul with the body. A consciously preventive action to avoid the predominance of these ontological ties is possible only with a philosophical preparation, which for Malebranche consists in the reading of Descartes and St. Augustine. ${ }^{6}$ The conservation of society is correlated to the conservation of the human body. Consciously and more often unconsciously, human beings act in favor of the maintenance of society because this maintenance is equivalent to the maintenance of the individual human body. The same tension that inclines the human beings to act in favor of the preservation of the social body inclines human beings to appreciate those false goods and opinions that the multitude of people appreciates, instead of inclining to the search after truth.

\section{Imitation, Imagination, and Freedom}

Imitation is a function of the imagination for the maintenance of the social body, which relies on the closeness and communality of the component individual bodies. Mentality is the imitation of the manner of thinking diffused among the peoples of one or more countries. What can be imitated are the exterior aspects, visible and reproducible in the imagination. Intentions and the pure ideas of the intellect are difficult to communicate and impossible to imitate. Living at the level of imagination, human beings have society as the stage. Human dependency from the body determines human beings and the corporeal society of which they are part. Assuming human liberty, human beings could refute to conform to the public mentality of the social body; human beings could decide otherwise than what everyone else would decide. This is as much as Malebranche believes: the human being enjoys a certain measure of freedom of the will. It is difficult, however, clearly to distinguish inclination from coercion. The human will is theoretically free, but practically is like a ship at the mercy of the gales of errors and opinions. It is hard to accept that the Stoic believe that human beings have enough power to contrast and win the needs of the body. ${ }^{7}$ What has a sensible origin cannot be judged for what it really is. It is erroneous to affirm that a cake does not please the palate as much as the cake is good in itself because it pleases the palate. Erroneous is also the judgment of goodness of material goods on the base of the natural ties human beings have with them. Human beings are not free from natural ties because they are independent from the human will. The ties that human beings have with parents, relatives, and friends are not conventional. To parents and relatives, human beings are tied by blood, but also by all the other ties that customarily they have with the persons they frequent and are part of their life. All these ties are invisible, but determined by the laws that govern the union of the soul with the body, and thus natural. The ties do not possess the same strength, because they observe the hierarchy of the social and emotive relationships that can arrive to be 
conventional. Between the traces produced in the brain by natural and conventional ties there exists a difference of intensity, not of nature. An evident different articulation of the imagination in different human beings confirms that not all human beings are tied to the same things in the same manner. The human relations with things show their effects at the level of the imagination when they influence the human conscience with images and sentiments; human beings live almost exclusively in this fantastic world of corporeity. Human alienation is due to this: human beings loose themselves running after things corporeal, and their conscience is more interested in corporeity than in its own immateriality. Thus, human beings become dependent from the things with which they relate, are more interested in them than in their own reason, often squandering the light of their intellect in the shallow puddle of the senses, in confused images and turbid sentiments.

\section{Human Alienation}

Human alienation in material goods is the stronger as the relationships with things are the more numerous and vincolating. ${ }^{8}$ The maximal intensity of relationships with the corporeal things is felt within the human body; the minimal intensity or no intensity exists with the relationships with things of which we ignore the existence. All the known things at the emotive level lay on this ideal line between these two extremes. Human beings establish and maintain relationships with an enormous and complex amount of corporeal entities (human and not human) that come to constitute their individual consciences. The human beings the more they know things the more they will be in a stage of dependency. The individual human being becomes annihilated in society by holding a multiplicity of ties that imprison it: every new relation is like a cord that ties it to its ambiance.

From the imaginary extension of the individual human knowledge depends the breadth of the human dependency from the corporeal objects. ${ }^{9}$ The more they have rapports with things, the more the human beings will be slave to those things; the more intense those rapports are, the more controlled the human beings will become. The laborious farmer, whose horizon of knowledge (rational and imaginary) reaches the borders of the village nearer to the field he cultivates, has no ties with any other part of the universe of material entities (human or not human). On the contrary, the powerful king has a complete interaction with the entire universe of things, because all relationships of his subjects and those of foreign peoples also relate to him. The dependence of the individual from the universe of things reaches in the figure of the king, or of the powerful in general, its maximal intensity. The king of the kingdom is in reality its first slave. A common belief is reversed: the material universe is the dungeon of humankind instead of being its splendid palace. Every human being has a certain amount of relation- 
ships with things and persons. These relations are obliging and demanding, whether they are public or private. The complexity of the relations gives life to the spectrum of emotions and sentiments with which the imagination will reduce the clarity of the mind that will lose the power of distinguishing the truth of reason from that of the senses. In the dungeon of their emotivity, human beings live at the edges of a universe that they can rarely control. For Vico, who sees things in a perspective of emancipation from the brutish life, the alienation with the imagination from the ferine condition is something positive. Under this aspect, the myth is a priceless illusion. For Malebranche, on the contrary, the imagination removes the attention of the conscience from the thought about God and it is a dangerous notion. Vico's and Malebranche's point of departure is different: the bestioni in one and the eternal verities in the other. Anyway, the imagination itself has its own "dimension": it is not merely physicalness, nor it is merely reasonableness. Thus, we may assert that imagination may well produce human madness and alienation.

Imagination as the principal factor of alienation represents the tie between the individual and the surrounding things. The stronger and more pressing chains correspond to the greater intensity and wideness of the relationships that tie the human beings to their fantasies and to the harder slavery that they have accepted at their own expense. The more the human beings have enslaved themselves, the more they will be apt to dominate their reality, things, and human beings that are part of it. Heroism is the posture taken in reaction to the pressure dictated by passions and fantasies on conscience. Heroism, on one hand, is a kind of selfimposed slavery, a neurosis. On the other hand, heroism is the mean of imposition, an instrument of dominion. The imagination and the fantasies that heroism produces in combination with passions form the compound foundational elements of society and of the interplay of forces that operate within it.

Heroic honor and fame are for Vico the manifest example of the self-love that, particularly during the periods of barbarism and returned barbarism, constituted the supporting column of all social relations. Military valor, the center of many disputes, was based on honor. ${ }^{10}$ War is the result of collective fears, of desires of prevalence, of subjugating in order not to be subjugated, of conquering in order not to be conquered. For Vico, honor has the same origin and evolution than the liberty born from self-love. The more the imaginary goods refer to the body and influence sensitivity, the more the honor will bring human beings to act mercilessly with cruelty and savagery. ${ }^{11}$ In a text, exemplary for conciseness and intellectual clearness, Vico referred to the topics relative to self-love that characterized the larger part of the moral reflection of the seventeenth century:

Because of their corrupt nature, people are tyrannized by self-love, and so pursue their own advantage above all else. Seeking everything that is useful for themselves and nothing for their companion, they cannot subject their passions to the conscious impulse that directs them to just ends. This 
leads us to establish the following principle. In his bestial state, a man loves only his own well-being, After he takes a wife and has children, he continues to love his own well-being and comes to love the well-being of his family as well. After he enters civil life, he comes to love the well-being of his city. After his city extends its rules over other peoples, he comes to love the well-being of his nation. And after such nations are united through war, peace, alliances, and trade, he comes to love the well-being of the entire human race. In these contests, the individual continues to love his own advantage above all else. Hence, it is by divine providence alone that the individual remains within these social orders, observing justice in the society of the family, of the city, and finally of humankind. Within these orders, when an individual cannot obtain the advantages he wants, he will seek instead the advantages which are his dues: this we call his just portion. In this way, all human justice is governed by the divine justice which divine providence administers to preserve human society. ${ }^{12}$

The text certainly alludes to what Malebranche said about the correlation of selflove and society and the question of social obligations. Vico once more will apply Malebranchean theories inherent in the relations between subject-environment to mythology and historical anthropology. We must remember that the human beings always consider other human beings as things, and when they consider their humanness, they consider it quite often for the satisfaction of their own passions. Pride, exasperated egoism, presumption, the desire to excel, envy, jealousy, hate, and, in one word, the will to power and the feeling of inferiority produce the emotive mixture that constitutes the amalgam, the metal of the chains of humankind. The army general through these passions becomes the prisoner of war (the war of recognition) of his own soldiers, subordinate to his troops. In them, he must maintain the sense of respect; he must act in order to inspire or generate sentiments in others; he must learn to exist for others; and he must be as the slave of the sentiments of others. Glory, success, and wishes for greatness are the domineering lords; the passions are the dungeon of the soul. The passions imprison those who believe themselves to be the owners of the world, those who can have anything they wish, albeit end as the ones owned by what they imagined to own. ${ }^{13}$ To act is the fruit of a fictitious virtue that is apt to masquerade real passions: the love of fame and glory. The human beings act under the compelling of a passion activated by a burning emotion, a sensitivity roused by the force of a frantic motion of the animal spirits. Malebranche often demonstrates, with psychophysiological arguments, that human actions are the disguised result of our brutish part, even when they appear to come from the rational activity or from the inner surge of the soul toward Goodness and a meditated morality.

The contextual condition determines the particular emotivity of an individual human being, while passionfulness determines the relations that tie the 
individual human being to every surrounding thing. The relation that ties a human being to an object is the emotive tension created between the human being and the thing. The judgment of a human being from an anthropological-philosophical perspective will require the consideration of a certain quantity of variables that is impossible to enumerate. As we mentioned in the introduction, three are the different orders of discourse from which the variables originate: from the physical level (the physical relations between the object, the body, the internal parts of the body, the functioning of the nervous system, the animal spirits, and the traces in the brain); from the mental level (for which the objects are merely extension); and from the psycho-physical level (where the laws of the union of soul and body are applicable).

The individual differences are also variables that cannot be determine in a psychologically generalizing map: they interact among themselves and follow forcible relations that change from person to person, moment to moment, and place to place. One can speak in general about the diverse conditions of the human beings, but the things to which they apply themselves cannot be explained in any detail. ${ }^{14}$ Human passions are the product of all the mentioned variables and differ from person to person. The differentiation is found only in the particulars because for Malebranche the nature of the soul is the same in every human being. The way of thinking, the mentality, changes with the changing of the physical and psychological conditions of the individuals, or, in a more ample terms, of the people of which the individuals are participants. The context (the term must be considered as the sum of the psychological and material content that constitutes the lived part of each individual) determines every specific emotivity. ${ }^{15}$ The existential and experiential condition of the individual is determined by the nature of the relations that connect the individual to the surrounding universe of things, by how it lives its own individual reality.

\section{Stoicism and Spirituality}

All relations are ineliminable. The human beings must always relate to their environment. The physical world in which the human beings are cannot be discarded or denied. The pride of the Stoics of rejecting corporeity turns them even more into being slave of corporeity. Like kings and generals, the Stoics aim at greatness. While kings and generals increased their superior power over material goods, that is, inclined to a tangible superiority, the Stoics instead concentrated their fantasies of predominance over spiritual goods. The superiority of the wise consists in the fact that he is richer than the richest human being, because he can do without such wealth. In reality, no human being will be able to stockpile a wealth greater than the one the Stoics will be glad to give up. 
The secret pride and the self-love that sustain the Stoics in their impassiveness are the considerations of the mind as superior to the body and of the will as superior to everything else. But human beings should not love spirituality because they believe to find in it the key for imposing themselves on others. They must love reason, goodness, and proceed in the way of spirituality, disregarding concupiscence, for the salvation of their soul. To become an ascetic because of the fanaticism for a mystical spirituality is for Malebranche a form of prejudice that hides a fermentation of self-love. The slavery of those who want to achieve the superiority in spirituality is a heavier and more disgraceful yoke than the one of those who assumes the task of accumulating wealth. To the misery of the soul, they will add the deprivations of the body. ${ }^{16}$ It is said that the Stoics attempt at the superiority in spirit because of passions that originate in the body. One of the foundational principles that regulate the human being says that the force of the passions increases as it is directed toward the interiority of the human being. As the human being searches for his superiority over others, he falls further down into slavery to others. Probably who wants to become rich through commerce, would not suffer for money all that the Stoic suffers in order to achieve the esteem and the admiration of others. For the purpose of achieving a superior goal the Stoics place themselves below those who want material riches, because they sell their efforts at a price lower than that of those applied to commerce. With wealth, one can buy anything and at times even more than what the seller believes to be selling. Admiration is not negotiable and often to be admired by one person means to be despised by ten others, because admiration is said to be the antechamber of envy.

If society is the community of individual bodies and the community of spirits by means of the bodies, then the will of affirming oneself within society through an imaginary superiority of the spirit brings to a slavery that is worse than that of those who seek superiority in material wealth. For sure, the material wealth like money, land, horses, cars, and jewelry for the pagan mind is a kind of wealth inferior to the spiritual one, but it is believed to be the sign of the spiritual superiority, which is imagined and fantasized. The slavery of the spirit is harder than the slavery of imagination to material goods. With the arrogance of elevating imagination to a place that it does not deserve, human beings make themselves slaves of passions that diminish rather than aggrandize them.

Ordinarily, the human beings with imagination take on the path of spirituality when they observe within themselves and in the surrounding neighbors misery, despair, desolation, uncertainty, and instability. Then, in their spiritual superiority, they fantasize stability, certainty, true self-reliance, and a wealth that no contrary event will be able to take away. But these are fantasies. The real mover is self-love, which transforms fear into courage, the feeling of inferiority into that of prideful superiority, and the immense ignorance into the persuasive certainty of imagination. Self-love creates in the pagan mind a heroic mentality, whose philo- 
sophical sublimation is the moral heroism of Stoicism. Malebranche has described with efficacy the upturning that self-love accomplishes through the senses and the imagination, which he finalized at the level of pertinence due to them as human faculties. The spiritual superiority is pursued only in the measure in which it can be manifest, imposing itself to the conscience of the individual person and of the people close to him. ${ }^{17}$

Those who assume the attitude of the hero, the great man, transforms fear into pride, pride into courage, and courage into power because, at the end, who takes the greatest risks would have more possibilities of outclassing the human multitude. This, too, is a false power. At the light of reason, it is a total and oppressing slavery, but at the eyes of the pagan mind, fooled by the senses, it is a tangible power. In a society founded on sensitivity and corporeity, this elite of slaves of the senses would be able to control all those less gifted in imagination and deprived of strong sensations and passions. The heroic mentality is represented by The Search after Truth with the figure of Cato, the Stoic hero described by Seneca. The heroic mentality is opposed to the Christian mentality as the pagan mind is opposed to the Christian "heart," self-love to reason, and imagination to the intellect. Studying Montaigne, Tertullian, and Seneca on the topic of this triadic opposition, Malebranche manages an analysis of the heroic mentality in the evolved or civil (in Vico's sense) nations.

\section{Christian and Pagan Mentality}

The developments analyzed by Malebranche and the psychological portraits of the "heroes of the imagination" that are found in The Search after Truth have numerous characteristics in common with the anthropological conceptions of Vico. The theoretical contexts, in which the philosophers theorize on the imagination, are different and equally different is the accentuation made for the products of the heroic mind. For both, the discourse develops between the contrary poles of the pagan heroism nourished by self-love and Christian reasonableness founded on reason and faith. Societies are constructed with the bricks of the senses and the imagination, and with the cement of self-love, though, according to Malebranche, things have not always gone that way. In the beginnings, God impressed the noble sentiment of love (charity) in the human spirits, as the bonding force in the human society. Love alone could build a perfect society. Charity, this love for the others, because of the experience of the Fall, soon changed into the love for one-self. Both extremes could serve divinely for the maintenance and preservation of society. The failure of one love gave way to the success of another kind of love. ${ }^{18}$ In Vico, the two opposite extremes for the preservation of society are piety and selfishness and with the lack of piety or love for God, self-love as pagan piety excelled: 
Poetic morality originated in the piety which divine providence ordained as the foundation of the nations. Indeed, among all nations, piety is popularly called the mother of all the moral virtues: personal, domestic, and civil. And if philosophy is useful in discussing virtuous behavior, religion alone is capable of inspiring it. And piety originated in religion, which properly consists in the fear of divinity. The heroic origin of the word "religion" was preserved among the Romans, according to the scholars who derive it from religare, to bind. For this verb refers to the chains which bound Tityus and Prometheus to mountain cliffs, where their heart and organs were devoured by an eagle, the symbol of the frightful religion of Jupiter's auspices. This was the source of that invariable property of all nations, that piety is instilled in children by their fear of some divinity. ${ }^{19}$

Malebranche's and Vico's conceptions are classically Christian. You can hear in them Neo-Platonic and Augustinian trends in every analysis that places ideas between the human mind and society. Providence has made the hearts resounding with the sentiment of piety because nations are to be founded on justice. In the Gentilized nations, piety, the mother of morality, has assumed the color of the paganism that has selfishness for god. ${ }^{20}$ Fearing God glue people together as for a protection. In Vichian philology, piety appears like the bad conscience that ties human beings together with the chains of Jupiter's auspices. These bonding sentiments are incubated in the minds from infancy, when a pliable mentality can be created, manipulated, and influenced. Human beings respect what they have been habituated to respect. Habits are an effect of imitation, and they go hand in hand with self-love. ${ }^{21}$

The implication of this axiom decides the great debate "whether law exists in nature or in human opinion," which is the same question ... "whether human nature is sociable." The natural law of nations was established by custom, which Dio compares to a king commanding by pleasure rather than by law, which Dio compares to a tyrant commanding by force. This natural law was born of human customs which sprang from the common nature of nations, and this natural law preserves human society: for there is nothing more natural, because more pleasing, than observing natural customs. Consequently human nature, which is the source of human customs, is sociable. 22

These Vichian texts are coherent with the Malebranchean principles that societies are governed by the same principles that regulate the relationships between soul and body. If speaking of the law as a custom, a habit, and an imitation is equivalent to speaking of the human nature (because union of soul and body), then 
speaking of the sociable nature is equivalent to speaking of society as regulated by the same principles of the union soul-body, self-love, and imagination. In the society, the consuetude is similar to the king and the law is similar to the tyrant, so in the individual, the habit (custom) is a king that rules over us with the consent of our will, while the moral obligation tyrannizes obligingly. The parallelism returns between "society and individual" and "mind and body".

Habits are individual uses and customs, and uses and customs are collective habits. We can also say that uses and customs are the individual imitations of collective conduct. In this case, law is the obligation for the individual of imitating the general rules of public behavior. Malebranche examined this question from the psycho-physiological and moral points of view. Under the first aspect, the ties between traces and firm ideas are greatly responsible for the individual and the collective habits. Given our actual existential condition, the ties that deal with selflove possess a component of naturalness that makes them particularly strong and resistant to the wear of times and to superficial mutations. These natural ties become the principal collaborators of self-love because together they are functionally for the body rather than the mind: their effect is the imitation.

\section{Imitation and Imagination. Rationality and Irrationality}

Imitation is essentially an irrational activity, because it runs through sensitivity and stops at imagination. Imitation, for Malebranche, is merely a mechanic operation, of which even animals are capable. Imitation in the hands of a thinking being, especially one with an illusive selfishness, is an instrument or field of action proper to the imagination. ${ }^{23}$ In order to survive, human beings need each other. This statement implicitly sustains a utilitarian conception of society. Society exists because for the individual human being life in society is safer and more advantageous than a life in the wilderness. Malebranche believes that what keeps human beings in the arms of society is self-love and self-love originates the contagiousness of strong imaginations. Failing to found on earth a society inspired by reason and governed by charity, providence provided self-love and imitation as the substitutes for reason and charity. Unfortunately, selfishness and imitation have the tendency of homologating human beings, creating the conformity of sentiments and passions. In order to unite, human beings must have a common feeling. To have a similar mentality is the prerequisite that people must possess for being part of society. To live together and to communicate reciprocally, human beings must enjoy some similarities. The more the imagination acts on people, the more it will make them similar in irrationality. The more a group (city, sect, tribe, nation, party) of human beings is connected among themselves, the more it will far remove itself from the rest of peoples who do not share the same fantasies. The inferior subject imitates the superior to be like the superior. The individuals will accept the preju- 
dices that are shared by the majority rather than search for truths, unknown, hidden, or accepted by a few individuals. The instinct of nature itself inclines human beings to imitation and conformity, for which a cerebral disposition already exists. ${ }^{24}$

Imitation is not the natural propensity to what in the human nature is properly humane, but to what in the human nature is brutish. Vico pointed at this animal part of the human beings when speaking of the famuli who integrated themselves into the society of the heroes by imitating the heroic language that they truly could not comprehend in its original significance but only in its instrumental usage. Imitation is the one virtue of the animal that is preserved in the human being. This animal inheritance is the necessary component for being assimilated into the human society. Imitation inclines to compassion, to feeling the same things in the same way: judgments, sentiments, passions, attitudes, and life styles. A different case is that of the individual with a different sensitivity and imagination who has hard time integrating into society: the emarginated. Madness is an alienation of sensitivity and imagination that gradually reduces the right use of reason. The true fool is doubly fooled because society is essentially based on madness.

The natural disposition to imitation preserves human beings from alienation and irrationality. The human beings with originality, who in a well-regulated society stand out for their creative ability of being different, may appear irrational. The irrationality of originality may be due to some human ingeniousness, or some uncontrolled ego-centrism expressed in some kind of exhibitionism, or some forms of mental disorders. In every case, the fool, the genius, and the sick are like a piece of wood that does not fit in the mortise. ${ }^{25}$

Imitation trains human beings for the life in society. Who does not imitate does not integrate, and who does not integrate becomes a stranger, not conforming, unstable, and unacceptable. The maladjusted in an organicistic society cannot imitate and cannot sympathize. Contemporary societies, unfortunately, are based on the human ability of feeling like the neighbor, on associating images and ideas like the majority of other peoples do. No society survives without the sharing of the same sentiments and passions. The communication of imaginations runs on the lines of imitation: imitation is the best conductor without which the energy of the imagination would not run through from the imitated to the imitator. The imagination through the imitation tends to unite the human beings on the level of irrationality. Society is possible only through the anthropological category of similarity. ${ }^{26}$ Those who are similar to us, are closer to us. Self-love is a magnet that attracts us to those who physically and emotively are closer to us. Imitation and similarity are the invisible ropes that tie us to the immediately surrounding world: they give us a sense of security.

Imitation is often present in the relationships between persons, superior and inferior, parents and children, and it is in function of what we expect from them. What is indifferent attracts no imitation. What we love or fear often de- 
mands our imitation. The fear of being hurt by a force that is beyond our will, as in the case of the theological poet, or the need of being accepted and integrated in a community, as in the case of the famuli in the primitive nations, or the ambition of emerging, the opportunism of alliances and assimilation with the strongest, bring human beings to the acceptance of attitudes and credences conditioned by imagination and self-love. If imagination and self-love on one hand drive human beings to imitation, on another hand, they drive the subject also to an affirmation of differentiation from the others. The two inclinations seem to be contradictory, albeit only in appearance.

Human beings imitate others or try to distinguish themselves in consideration of what the imagination and self-love, never the reason, sparkles as the best way to reach an imagined goal. Often, the two inclinations appear in the same circumstance. Someone may imitate another person whom he judges as original so that he would distinguish himself, too, from the mass. Human beings may imitate for irrational finalities, but never indiscriminately. The human being imitates and imagines always for a specific end: life style, selected consciously or unconsciously, is always in view of a particular goal. ${ }^{28}$ Each person judges things according to its situation, and the moral causes of errors will be as many as the situations in which human beings will find themselves acting in relation to them. Imitation and fantastic contagiousness will follow a multiplicity of always changing ways according to the mutations of internal and external events. The principal lines of the cultural dynamics are the imitation and the epidemic of the strong imaginations, and they are intended for the preservation of the individual life and of the entire society. Human beings have common and equal communion of feelings with their surrounding things and neighbors. Those who know more will have more personal interrelationships and a communion of sensitivity with a wider social circle. Consequently, these individuals will have a more developed and pliable imagination. On the contrary, those who have minimal cultural exchanges and a limited knowledge of the world will have a narrower social circle with which to communicate and be part of. Their imagination will be rooted on a confined and rigid imagination and passionateness. In conclusion, these are the two extremes of humanness: on one hand, we have the individuals who could commit a large spectrum of errors, given the pliability of their imagination and the loftiness of their mind; on another hand, the individuals who could commit few, but repeatedly the same, errors, given the rigidness of their imagination and the obtuseness of their mind. ${ }^{29}$

The imitation, as a form of communication, and the communication, though they are the sources of all errors because connected with the imagination, make society possible through their thick network of contacts. The human beings who possess a strong imagination normally possess also the great persuasiveness that makes easy the passage of errors from one person to many others who passively become inspired to imitate..$^{30}$ The inclination toward the imitation of those who have inspired us has profound roots, of which the most important is the con- 
venience of some comfort or opportunity. Convenience, in one word, expresses all the motivations that can convince human beings to imitate others instead of facing attritions and fastidious choices, or instead of directly opposing the errors and prejudices shared by the society. Malebranche said, "For even the wisest of men guide themselves by the imagination of others, i. e., by opinion and custom rather than by the rules of reason." 31

How could the wise fall in the same ensnare than the masses of peoples who lay themselves comfortably in the sea of anonymity and uniformity? For Malebranche, natural law or right is not perfectly rational because based on the human nature of the mythical Fall..$^{32}$ Malebranche may be either lax or rationalist (in contrast to Calvinists and Jansenists), but the fact remains that to found rights and laws on nature means to found a jurisprudence basically on the triumph of self-love. Furthermore, if jurisprudence concerns society and not the individual person, and if there is a possibility of a naturally rational jurisprudence, then there should be a society based on reason. For Malebranche, a rational society is impossible. How does society manifest itself? Society manifests itself in corporeal things like houses, books, schools, prisons, roads, hospitals, army bases, cultivated fields, and churches or in conventional things like laws, uses, and customs. What is preeminent is always the corporeal entity because laws are always referring to corporeal actions and physical objects and communication is always physical. Human beings always live in bodily vessels.

Human minds are always at a distance among themselves; human souls approach each other as much as the bodies come nearer to each other. Mentality, credences, and prejudices are not corporeal, but because of the laws of the union of the soul and the body, they have an occasional cause in the body. Human beings come closer with their bodies and if they had no soul they would not form a society but an aggregation like among animals. Human society is the product of human nature or, rather, the product of what is corporeal in the human nature. Malebranche repeated that all that comes from the body is for the good of the body; society and human communication through the body are for the good of the body. Society finds its balance not so much in reason, but in the passions, the imagination, self-love, and the wish to shine or stand out. Passions and fantasies, when balanced, are the cement of society and providentially succeed with selfishness in preserving social life, supporting human interaction. ${ }^{33}$ The relations that connect us with the objects that constitute our environment are regulated by the relations that they have with the sentiments and the mechanisms of our conscience and they adapt to the variety of subjective changes. Imitation is one of these mechanisms, indispensable for the harmonization of the passions in order to achieve, beyond all selfishness and dividing particularism, order and tranquility. ${ }^{34}$ The animal in us helps the human part in accepting the other individuals of the same species; imitation and compassion have a physical cause. Human beings are in- 
clined by a biological force to imitate those who are closer to them and to share their identical passions.

What are the causes of this biological, cerebral instance or pressure for imitation? Malebranche recognizes two causes: one physical and one mental. The mental factor consists in the inclination of humankind for fame and prestige. Human beings want to acquire a prestigious and relevant position in relation to other human beings, though many times they will never exteriorize such an interest. Often pride may masquerade with a veil of false modesty the desire for a "dreamlike" greatness that will remain senseless and unreachable.

\section{Society and the Wish for Fame}

The wish for glory or fame, for elevating oneself at a loftier level than others incites many human beings to copy blue-blood personalities, celebrities, and most famous athletes. ${ }^{35}$ Malebranche adds that this sentiment pushes people to follow fashions, styles, and the attitudes of men and women of success. More strangely, he speaks of "the volubility of living languages," claiming that the wish for greatness is their cause. The imitation of those who appear superior to us will introduce new preferable attitudes that include speech among them. If language is a social product, it is a product of imitation, which, with the succession of generations, will change the characteristics of the human community. Language (idioms) as an object of imitation continuously changes with the change of new personalities, new times, and new places. In the existential equilibrium between inclinations and conservation of society, language plays an important role. The knowledge of how to harmonize all the components of society is the indispensable tool for the comprehension of the human nature.

What today we will call the proper area of the social sciences, the study of how the individual drives and the structures of society intersect and interact, is considered by Malebranche a work more profitable to be undertaken than the science of physics and the study of the relationship of mind and body. ${ }^{36}$ In this kind of research we could see the manifestation of the compromised internal equilibrium of the human being in the sense that the inclinations that apparently seem to be the most contrary to the conservation of society in reality can become, in a moderate measure, the discreet gluing element of society in substitution of the loss of the spirit of love. ${ }^{37}$ Moderation should be considered as a requirement. Given that human beings are spirit united with body, they have natural passions and inclinations that in order to have a balance must be kept under control. An excess of passions and fantasy in an individual is its ruin in the same way than an excess of passional sensibility in a society constitutes its dissolution. ${ }^{38}$ As a poison, when taken in small doses, transforms itself in a useful medicine, the wish for greatness, when dominated and properly channeled, results advantageous to social living. 
Though springing from self-love, the wish for greatness manifests itself in actions that benefit the community and that in the eyes of the people are judged worthwhile and honest altruistic deeds. Often these deeds appear as good even to the conscience of their perpetrator. When the wish for glory is immoderate, the individual no longer looks for endorsement and acceptance, no longer conquers the favor of the mass with its own accomplishments, but tries to impose itself on them, who become the victims that "the great" must sacrifice to the gods. The wish for greatness, if moderately proposed would elevate the lucky wisher over the multitude, but if exasperated would force the multitude to subjection for its own glory. In the first case, the commonwealth would find an advantage; in the second, it may perish.

The wish for greatness is a powerful sentiment that, if not controlled by other sentiments and social conventions, would cause damage to society. Human will exercises some power over this wish and may channel it into a beneficial reservoir of energy in favor of society. Society is possible because of the enforced control of the great passions, which remain available for the moment, physical or social or political, of deployment. All passions based on self-love, like the wish for greatness or glorification, are of such power that they can keep conscience itself in check. Only the human will, often helped by opposite passions, can moderate and control these incentive passions. The moderate sense of greatness aims at conviction rather than repression and is the cause of oratory and political strategy. This sentiment must be moderated and camouflaged, so that it will not cause the emergence in others of the same wish and sentiment but with an opposite connotation: envy. ${ }^{39}$ Life in society is the performance on the stage of the imagination where everything is the opposite of what it seems. The great human beings act humbly so that their subalterns will not plot behind them. The depleted, the superficial, the human beings of little significance put on airs. Human beings are inclined to imitate their opposites. Imitation tends to reduce the differences among human beings, to round off edges and corners, to create similarities, and to make possible communal living. The powerful plays humility not to be similar to its servants, but for egoistic goals: he is afraid of generating excessive envy that will upset public order and harmony; he intends to tranquilize those he wishes to swindle. At the end, his actions help to preserve the stability of society; the powerful acts for himself, but actually helps everybody.

The morality of hypocrisy governs society. The lack of charity and love for order dictate fraudulent attitudes. The dissimulation of real intentions is necessary in communal living. What will happen if everyone would show the true intents of their actions? Human relationships will be impossible. In touch with social reality, the individual human being must mediate and moderate its own desires with the effective possibilities of realization of the same desires. Human beings must muffle and dissimulate their wish of greatness, and predominance. In order to achieve its goals, the human being must feign to be what it is not, and it can do this only 
by imitating those it wishes to swindle. Here is the message that the politician portrayed by Malebranche (on the model of Macchiavelli) wishes to communicate, imitating the manners of the meek: do not fear me; I am not dangerous; do not envy me because I have nothing that could interest you. ${ }^{40}$ The arrogant politician would instead offer a vulnerable side uselessly to a great number of dangers. It is the necessary play of passions: he who has much has the envy of those who have little; those who have little have contempt for those who have much. With the lack of order in the pagan mind, passions substitute the frail hierarchy of their intensity to the cold and cutting edge of reasonableness. The structure of society is not made up with consciously established decisions in the light of the intellect, but with precarious balances determined by the joined action of some passions in contrast to others, with confused sentiments connected with pretences and deviations of confused inclinations. The conflicts, once interpreted in this way, are the effects of the imbalance of the collective passionateness. The wish for greatness like all other passions displays its strength at the level of the imagination. It is within the parameters of the imagination that a human being senses its being to be less or more than that of another human being. It is at the level of imagination that the connectivity with oneself and the collectivity is felt. Sensible goods are imaginary goods and their values for the conscience are fictitious, but they are also the vehicles for other goods, other credences that apparently have no relation to them. Malebranche says that normally it is believed that people fear their sovereign because he possesses an enormous political, economic, and military power, but in reality things are not so. The idea of greatness that the sovereign incarnates is the greatest motive for the subjection of his subjects, greater than the powers he actually possesses. We may even claim that because of the idea of greatness he has these powers, not vice versa. The power of the king over his people is the power he has on their imagination. When they revolt against him, he automatically loses all powers, which he will lose even when they would decide to ignore him. The obedience that is due to him in reality is the tribute paid by the community to a collective prejudice. Thus, the people will believe his words even in questions in which he has no authority and could be believed at times in preference to those who have competency in those matters. He would be believed not just superficially or for a convenience, as we say, but because the idea of greatness he inspires in the mind of his subjects is strong though indeterminate. ${ }^{41}$ The king is believed great not only in politics, but also in science, philosophy, and theology. The great majority of all credences are founded on superstitions and fantasies. We always believe in what we imagine convenient or threatening. Nothing is easier for the people than accepting the opinions of the sovereign. The more he will speak to their passions and imaginations, the more they will respect him. The more he will speak to their lower passions, the more they will elevate him, and their imaginary slavery will effectively contribute to the stabilization of the society. The subjects, imitating their sovereign, become according to the modalities of the imagination 
similar to their sovereign and are likely to form a unique body of their nation. For Malebranche, this tendency for its regularity is a law comparable to the physical ones of nature. The achievement of a national life depends on the achievement of similarity among its citizens: a great discrepancy of interpersonal relationships within families, social classes, and institutions will ruin the commonwealth. Society is more a community of bodies than of spirits, but its compactness is valued from the physical actions that are determined by the intentions of the mentality of the spirits. We should be aware of the homogeneity of mentality and of the uniformity of behavior, because they are both needed for the preservation of society. ${ }^{42}$ The stronger the ties are between imitator and imitated, the greater is the dependency of the one from the other. Malebranche observed that mothers are the true depositary of the culture of a nation; they are the ring of conjunction between one generation and another. No human being is so inferior as a child in relation to the mother who has given life, and in the first years has cared for all needs. No other human being is as great an imitator as a son, and no one is more imitated than a mother. Every generation is shaped essentially by the women of the previous generation. The relations mother-son or daughter constitute the prototype of the relations with which the credences, the mentality, the attitudes are transmitted. The role of imitation within the dynamics of these relationships is absolute and unmistakable. ${ }^{43}$

The mechanism of imitation is also the key in the formation of the various social groups, with the difference that in the case of mother-daughter the experience is we may say "concentrated." In the formation of society, a certain level of uniformity between the component members is required. This uniformity entails a certain kind of emotive tonality, an almost identical ability of feeling, a capability of suffering together, of living and experiencing in the same manner, of perceiving and conceiving the world with the same passions. The human beings' diversity of feeling, perceiving, and conceiving gives way to the different social groups; the human emotive diversity will materialize in a complete new mannerism in the individual members of the group. All these elements will also constitute barriers that separate one group from another and with difficulty could be overcome. ${ }^{44}$ Society is formed when persons with the same passions find a univocal manner for their expression. When a contrast exists between the domineering passion and the imagination, between perceiving and representing the one to the other, then the conflict will be almost inevitable. Passions are communicated through the imagination, and when the passions are shared and fixed in the same representations, a new community is born. This is true for Malebranche, but it works also for Vico, for whom myth is precisely a series of beliefs at the imaginative level, established by strong passions within rigid representations. At the birth of nations, we find the happening of an indispensable uniformity of senses of all participants and the participation in identical passions. 


\section{EIGHTEEN}

\section{THE COMMUNICATIVE POWER OF THE STRONG IMAGES}

Imitation, among the human activities, is the most effective for the communication of strong images. This means that we should identify those human individuals who are endowed with a remarkable imagination. In The Search after Truth, Malebranche defines this kind of strong and vigorous imagination as "the first such characteristic is that these persons are incapable of making sound judgments about even slightly difficult and intricate things, because their mind's capacity is occupied with ideas tied by nature to these very deep traces in the brain, and therefore they are not free to think of many things at once." 1 Those who possess this kind of imagination are at the same time shy in reasoning, unable to apply themselves to anything other than to what their imagination puts forward. The corporeity of sensations and passions imprisons the conscience of the natural human beings in such way that they cannot obey but the dictates of their gross imagination.

\section{The Corporeity of the Universe of Things}

The pagan mind is completely overcharged with the fantastic representations founded on sensations and intense images. It cannot even consider what is not from the senses. Strongly imaginative individuals can still consider things that are beyond experience, but would remain ignorant of what they are. The experience of nature that these individuals have is an imagined experience. Unbridled fantasy reigns in their minds. Fantasy is the process of abstraction of the imagination from the representative contents presented to conscience by sensitivity. This is an abstraction far different than that of reason; its tortuousness and erroneousness produce a fictitious universality of ideas. Malebranche underlines the intensity of the inclination in these individuals toward an imaginative universality, whose contents fill up the mind and induce the individuals to value only what regards them directly. What their mind can think will be nothing but an appalling imaginative construction. It may seem that the psycho-physical cause of the mechanism above described is related to the sharp depth of the traces in the brain, to the whirling of 
the animal spirits, and to events merely physical. It is not so. It is true that the traces and the animal spirits in themselves are part of the physical reality, but they are phenomena regulated by the same laws that rule the unity of body and soul. The path from the nervous system to the imagination is a two-lane path: the perception does not reflect a static perceptive system, but varies according to the ways the individual "experiences" its own sensations. In different subjects, different representations of the same perceptions can be found. The same corporeal thing can be perceived and represented and, therefore, imagined in a variety of ways that can be as numerous as the perceiving subjects. In the pages of the second book of The Search after Truth, Malebranche compares two categories of peoples: the reasonable and the unreasonable, who are provided with an overpowering or irrational imagination. Within this last category, he distinguishes the insane and the visionary. ${ }^{2}$ Even in this case, the reason of the classification springs from a psycho-physical cause.

\section{The Insane, the Madman, and the Visionary}

The insane persons, as the ones who are under the frenetic agitations of the animal spirits, configure the rapports of their body and soul in a manner that the will is completely underrated by a sensitivity that is as oppressive as confused. The visionary ones are influenced by traces profoundly settled in the brain by the structure itself of their brain and not by the activity of the animal spirits. This means that the insane are distressed by the unbalance of their perceptions and the instability of their intellections. The visionary, on the contrary, are mad in the measure in which they follow an erroneous mentality, founded on sensitivity and imagination.

Unreasonableness is not always pathological. Unreasonableness in the visionary is the source of serious errors, but it is in conformity with the human nature of the individual and its path is different from the unreasonableness of the insane. The insane is insane because it stands in opposition to its environment. The insane perceives what does not exist at that present moment in time and is without the needed uniformity of perception, so that its errors are numerous and of different nature. The visionary fantasizes its own reality, and represents it to itself always in the same way. In all its errors, the visionary follows a specific mentality and its vision of the world is articulated according to representations that are coherent, though their coherence is also erroneous. The visionary proceeds according to principles, albeit fantastic. The insane is untied to principles. The visionary possesses the logic of erroneousness, while the insane possesses the erroneousness of logic and mindlessness.

The visionary's mentality does not oppose reality and makes the effort to be adequate to it. The insane opposes reality and enters on the stage of reality armed with conflicts. The speech of the insane does not refer to what is discussed 
by the actual conversers, but touches on things beyond. The errors of the insane generate a conflict with reality and the maladjustment. The errors of the visionary generate a (fictitious) conciliation with reality. The dynamics of the imagination in the visionary constitute a process of adjustment.

The study of the visionaries appears to Malebranche as a study more interesting than the study of the insane. Madmen and madwomen do not represent a danger for society, because they go contrary to the way of the common human beings, but cannot communicate their madness or their fantasies to them, and are known as insane by all. An insane orator is a contradiction, since the orator must be persuasive. ${ }^{3}$ The visionary orator is a tautology, since the orator must persuade others, not himself. The insane inspires no sentiments of respects, no emulation, nor any other sentiment indispensable for the communication of strong imaginations. On the contrary, the insane is the object of contempt, distrust, and fear because his actions are unreliable and unforeseeable. The insane individual provokes sentiments of rejection.

The communication of strong imaginations requires the conformity between the minds of the speaker and the listener: an identical mentality is required between the two. This characteristic makes the errors of the visionaries shareable, while those of the insane remain unshared. The insane peoples enjoy no conformity among themselves, because madness represents a world apart. The visionary, on the other hand, projects always a world acceptable and accessible to anybody, comprehensible to the majority, uniform and coherent, albeit at the level of fantasy, not of reason. A madman always strikes the imagination of those who observe and listen to him, but the impressions he generates are always momentary and vanish as soon as he quiets and reenters his interior solitary world. It is not enough to strike the imagination; what is needed is to focus and fix the images in the mind with the nails of passions and sentiments. ${ }^{4}$

\section{The Pagan Mind is an Imaginative Visionary Mind}

Malebranche wanted to scrutinize the strong imaginations that are susceptible to the strong impressions of even weak and less efficacious objects. ${ }^{5}$ The pagan mind, in other words, is not like that of the insane, but like the one of the imaginative visionary. The fervent imagination is not a defective imagination. The imagination is not a faculty that can cause negative excesses. Malebranche is not a degrader of the imagination; he does not retain it as dangerous. The person with a powerful imagination would not be irrational. All great scientists, particularly mathematicians and geometricians, are individuals with a great imagination, and the same can be said for poets, artists, and orators. The strong imagination is indeed required in many specific human activities. The defective side could be found in the frailty of the human being who would be lead by the passions into concupis- 
cence. ${ }^{6}$ The faculty of comprehension of the human spirit is very limited and often the passions, the gross part of the imagination, are sufficient to use it up. For this reason, the spirits endowed with a strong imagination are in the majority of cases also not gifted with a strong will and an enlightened mind.

Erroneousness depends from judgment, and judgment comes from the will. Imagination in itself is a nonaligned faculty. The weak will lets imagination fall into the abyss of concupiscence. When in The Search after Truth one speaks of spirits with strong imagination one intends always to refer to the human being of nature, the pagan, and not to the mathematician, the rationalist philosopher, the enlightened theologian, or Descartes, Augustine, and Malebranche. The defects of those who possess a strong imagination in conjunction with a weak will are, first, the inability of judging wisely things that are somewhat difficult and complex; second, the inability of considering a variety of things at the same time, because their ideas are attached to traces too deeply rooted by nature in the brain; third, the inability of responding to complex questions, because for the same reason given previously, their spirit is not free nor swift enough to gather the rapports and the relationship necessary for the resolution of the question. ${ }^{7}$

The first defect of the human being of nature, the pagan, is to have a mind limited in the quantity and quality of the things it can comprehend. ${ }^{8}$ When we are taken by a strong passion, we cannot consider things with clarity of mind or analyze relationships between our mind and other things. Within an altered state, complex and emotive, we cannot embrace with the eye of our mind the horizon of the objects within our perceptive sphere. Even the most enlightened spirit, when pressed by a strong sensation like a penetrating pain would not be able to reflect with a firm mind. Nonetheless, such a spirit cannot be labeled as a narrow spirit.

The paganish mind is the one impressed in the imagination by feeble perceptions and is restricted in proportion to the greater number of images and perceptions in it. The difference between the pagan or man of nature and the rationalist Christian is not given by the strong sensation of perceptive character, but by the sensations felt with a strong passional intensity unmotivated by a real cause. The fear of the lion does not change a mind into a pagan mind, if the lion is truly there. The fear of something merely imagined is the typical characteristic of the pagan mind. The fears of the idolater and the superstitious are disproportioned to the causes that produced them. The fear of an overbearing and vindictive deity that threatens with thunder and lightning is not proportional to the real danger of a lightning, unless the lightning happens to descend on us. The interpretation of this fact is not proportional to the reality of the event, but to the limits of the mind and the configuration of the imagination.

The insane can be easily identified, but the imaginative visionary can be recognized as such only by the rationalist philosopher and the Christian. ${ }^{9}$ Reflecting the mentality of the majority of humankind (paganism), though in a more vivid tonality, the visionary is rarely immediately recognized as one. There is a difference 
between the visionary of the senses and the visionary of the imagination. The visionary of the senses are the insane, who do not see things as they are and see often things that do not exist. The visionary of the imagination imagine things in a total different way than what they are and imagine them as what they are not. ${ }^{10} \mathrm{All}$ human beings with a strong imagination are visionary and the difference between those with insanity and those with visionariness is merely quantitative. What makes the difference is the intensity of the fantasies and the effects they produced.

The pagan, who believed that the thunder and the lightning were manifestations of Jupiter, was an imaginative visionary because he was fantasticating on a perception that in itself was coherent with reality. The insane sees a lightning even when there is no storm. The imaginative visionary distorts the reality through his fantastic interpretations, but it is a distortion that does not misrepresent completely the reality. The insane substitutes his fantasies to the perceptions, and he ends with perceiving only his own fantasies. The world of the insane person does not constitute a mentality and madness does not constitute the mentality of the insane. Contrariwise, the imaginative visionary is the vehicle of error within society. Malebranche describes the visionary human being as the one whose spirit is ebullient in excess at all occasions. The visionary lifts what is in a low place, aggrandizes what is small, and draws near what is far. Nothing appears to the visionary as it is. The visionary admires everything without judgment, without discernment. ${ }^{11}$ This Malebranchean description of the human being of nature is a valid description for the Vichian first men of gentility. It is evident that Malebranche has no intention of providing the principles of a science of the common nature of nations, though implicitly he affirms that the laws of the union of mind and body are the same laws of societies. The object of study of the two philosophers remains the human being of nature, whose mentality is pagan.

What in these pages Malebranche affirms of the human beings, contextualizing them in a situation and a theoretical perspective other than the Vichian, can nevertheless be said about the heroes of The New Science. The pagan mind extends and misinterprets reality in relation to its own passions and fantasies; it represents as big what it barely perceives, inflating it with its various sentiments. Its emotivity is exceptional and wonders about all things, painting them with the colors of its own passions. If the pagan minds are constitutionally disposed to fear, they will fear at any moment, trembling at the fall of a leaf. If they are rich in blood and spirits, they live with vain hopes, abandon themselves to an imagination fertile in ideas, and with great satisfaction and pleasure build castles in the air. ${ }^{12}$ The human being of nature shows two opposed characteristics: fear and boastfulness.

The pagan is afraid of the smallest things and, simultaneously, constructs for itself those castles in the air, in which it lives a reality that the imagination has constructed and that sensitivity has not offered. Human sensitivity is an alive perception, which the human being interprets, far from being the biological machine of the animal. From this point of view, what differentiates the human being from 
the animal is the human possibility of erring, of interpreting in a distorted way what the senses bring to conscience. Character determines the conception of the world: fear shows danger everywhere; pride makes one to believe in itself in a disproportional way from what are the real individual capacities; the world is a fantasy built on imaginary ideas that melt the one into the others, making the mind confused and blind to truth. ${ }^{13}$ The wealth of passions inflates the human spirit that becomes stubborn in its own opinions and believes itself strong in its weaknesses. The attitudes of the visionary are incoherent with reality because the visionary imagines as real the icons of its own fantasies. The visionaries, among whom the theological poet is the first, cannot follow nature because they have substituted it with the artificial nature of their pride, of their perturbed spirit. Their mentality is in an antithesis with nature and also a reaction to it.

Nature makes the visionaries weak and vain. Nature makes the visionaries to become bodies among bodies. Fantasy, instead, with the force of passions, makes them haughty. To their natural weakness, fantasy substitutes an artificial power; to their natural precariousness, fantasy substitutes a fictitious security. The result is a character built in an unnatural way that answers to a fantastic world represented to a confused conscience, whose will is also the weak prey of the sentiments born out of pride and self-love. ${ }^{14}$ The visionaries then live a life of appearances, and what they are is conforming to these appearances according to a conscience modeled on the representations of things and itself, as an entity merely imaginary and imagined.

The visionary personality is reduced to a harangue of the jury of the spectators, of all those who are present at the show of its life. Thought is reduced to imagination and the language that reflects it is a figurative language, metaphorical, all rhetorical metaphors and tropes. Psychology will display itself as rhetoric, and religion will be trapped in the net of falseness. It would not be a religion founded on reason, but on weakness, concupiscence, idolatry, and superstition. It would be a rhetorical religion; it will be paganism. The lovers of this divinity would be the lovers of an anthropomorphized image, an idol: Jupiter.

\section{Strong Imagination and Persuasion}

Self-love and a few other fundamental sentiments induce the human being to construct a fictitious nature by way of imagining oneself capable of counter-opposing both the true reality that it has no strength to face and the personal sentiments. This human being, then, is obliged to imagine itself stronger than it actually is in order not to succumb to itself. The more it senses itself weak, the more it imagines itself stronger. From this point of view, mentality is a complex operation of autoconvincing. What we call mentality is the sum of all the credences that we have made our own and that we convey and share with those who live with us, the 
community of which we are a part. It is an individual and collective phenomenon that develops in the garden of the imagination. The reaction to the fear of losing our most important good, life, is the first generating spring of the formation of a mentality. The possessors of a strong imagination have an easy access to its persuasive powers. ${ }^{15}$ The persuasion of persons other than ourselves is thought also as auto-persuasion since no one can convince others about something of which he or she is not convinced. Only when we are convinced of something, we would activate those passions that constitute the tools for the communication of personal convictions to others. When we are not convinced of what we say, the passions with which we communicate will be false, unsupportive, and rarely effective. Communication is emotive and, in a minimal part, verbal. Strong imaginative individuals convince with easiness because they act on the imagination of their listeners. The orator is the slave of his imagination and transfers his slavery to others. By believing in our own fantasies, we make them believable to others: persuasion acts through imagination. ${ }^{16}$ Malebranche underlines the unnaturalness of the effects of imagination, because with the imaginative power we cut the ties with the immediate ordinary naturalness and in its place we have a fictitious, fantasized nature more consonant with the needs of inclinations and passions in the specific situation. To arrive at the heart of the others, persuasion must follow the best of all channels, the senses and every thing else in their sphere should become the means of the persuasive language. Not only words, but also mime and infinite other components become part of the persuasive operation. The rhetor with his imagination makes others to participate in his visions. The intervention that reason exercises only on a narrow number of persons is an essential part of persuasion. The imagination and the senses are the best instruments that the visionaries gifted with particular oratorical faculties can use. With the imagination, the visionaries succeed to attract common human beings in a multitude more numerous than the rationalists would attract trusting on a geometric methodology of propaganda. As Malebranche says that the first thing to do in order to convince a friend is to capture his attention by means of sensitive things. ${ }^{17}$ Thought is easily communicable when the speaker makes it pleasing to the listener, making the ideas comprehensible through perceptible and vivid images. The visionary easily communicates his own ideas because they are visions, fantastic representations that with easiness can be decanted in a colorful language understandable by most human beings. ${ }^{18}$ The second thing in persuading is the use of simple arguments that are also straightforwardly shared. The emotive charge must remedy to the absence of valid reasons. Valid reasons, everybody knows, can never substitute the lack of emotivity. The appeal to the senses is the most convincing appeal, because sensitivity is the human faculty most removed from the critical attitude and most erratic. ${ }^{19}$ To speak in the most common fashion and with the most of zest is the most reliable path for convincing listeners. The visionary normally affords speeches acceptable by the whole audience. In this way, he will not challenge the credences already es- 
tablished in the mind of his listeners or assert things that contradict their prejudices and universally shared errors. The visionary rhetorician speaks in generic terms, avoiding the public susceptibility, never compromising the possibility of convincing, and he does this unaware, while the professional rhetorician will have to use these ways of the visionary with a voluntary and conscious choice. The visionary does not know the psychological and psycho-physical laws that are behind his conduct and his thought. The truth is that the less he will know about these laws, the more and better he will utilize them. If he truly could know how and why he thinks the way he does, then the causes of his fantasizing will gradually cease functioning.

There is a hidden antithesis between being a visionary and the correct manager of the personal intelligence, with the exception exemplified in Malebranche himself in whom a grand orator and an imaginative visionary existed. In the large majority of humanity, the capacity of persuasiveness and of reasonableness are in a contrasting rapport. ${ }^{20}$ The obtuseness of the visionaries marries with the obtuseness of the auditors, who let themselves be convinced. Moving within the vagueness of ideas and the fogginess of fantasies, the visionary grabs the attention of his listeners and communicates to them his visionary epidemic, errors and exclusive visions, making them as visionary as he is. Imitation, persuasion, communication of strong imaginations, and attentiveness are the elements of capital importance in the Malebranchean analyses of society. In his analyses, imagination will come to be the true cementing element of corrupt human societies.

\section{The Anthropology of Persuasion}

The power that superiors in authority have over their inferiors is the power of the superior imagination over the inferior one. Without the subsidy of imagination, the superiors could not be superior and have control over inferiors and subalterns. ${ }^{21}$ The imagination is an important instrument of social control, maintains the rapports within society, and is a political means. In the vicissitudes that link superiors and inferiors, the category of imagination is the determining factor in the structuring of the juridical, political, and moral relationships. Those in authority would maintain their superiority as long as they have an imagination superior to that of their subjects and subalterns.

We know that owners and leaders with a weak imagination are often dependent from their employees much rich in fantasy. ${ }^{22}$ It is proven that what determines the true relationships of power among peoples is not their material riches, or social position, which are often instead the effects and the results of a strong communicative imagination. In the dynamics between individuals of equal imagination, authority and personal wealth play no role, but persuasion will. The individual pagan finds itself always in a situation definable as psychological solips- 
ism: he is always at the center of his world, and his world never extends beyond the ray of perception of his senses.

The child, as long as he is an infant, can only be influenced by his parents, because it spends its total time at home with their exclusive company. The world of an infant stops at the house's door. The human beings who have never visited outside their own village or town are in a situation similar to that of young children. They are "social infants." The prejudices, the mentality of their fellowcitizens, the superstitions and the gossips of the village or town will represent the credences according to which the social infants will judge about everything. The socially infants lack the terms of comparison for they lack the screen on which to make their credences visible and compare them with those of others. This is the cause and the effect at the same time of prejudice, because the mind would know only one way of thinking, according to which it would judge everything else. Things from abroad would be looked upon with diffidence and incomprehension. ${ }^{23}$ With the lack of variety, the individuals learn to imitate those closest to them. It is easier to condition someone inferior to us and whose mind is only pervaded by our presence. If the subject, as in the case of the child, is absolutely inferior, then its thought and being will be at the similitude of the superior. The imitation is carried out by the imagination and will extend itself to cover thought, mentality, attitudes, and everything that regards the sphere of corporeity. ${ }^{24}$ This is the psychological reason for the rites or the ritualization of the quotidian life, which attributes to our countenance and gestures the significance of what surrounds us. The human being is inclined to judge what is hidden from what appears. This is the origin of the power of kings over peoples, a power that is created at the moment that it manifests itself.

There are men who judge of what is not apparent by what is, of the grandeur, strength, and capacity of mind hidden from them, through the gallantry, titles, and riches known to them. They often measure the one by the other. And the dependence men have on the great, the desire to share in their greatness, and the perceptible glamour surrounding them, often causes men to render divine honors to mere mortals, if I might so speak. For if God gives authority to princes, men give them infallibility, but an infallibility not limited to certain subjects, nor to certain occasions, and not attached to certain ceremonies. The great know everything by nature; they are always right, even if they decide questions about which they know nothing. 25

These human inclinations bring human beings to judge of one thing in relation to similar things. What is seen serves for judging what is hidden. The wealth of thought construed in the imagination is the measure of the spiritual wealth, because the universality of the imagination reaches only so far as sight goes. To the 
imagination of the human beings of nature the Prince appears as the divinity, because to their fantasies the Prince can do anything within the universe of imagination.

A fundamentally different discourse is that about courtiers or individuals with a wider vision of the world. ${ }^{26}$ Subjection becomes veneration. To move astray from the path decided by the Prince is like to oppose the will of the Prince. The imagination becomes the tool of coercion that obliges the subject to think in function of the superior, to act and behave in a stereotyped fashion, and to obey to the fantasies of the Prince. To do otherwise will be rebellion, disobedience to a deity that maintains the subjects in life and protected. "This is why courtiers, and as a necessary consequence nearly all people, subscribe without thought to all the opinions of their ruler, even to the point of frequently yielding to their caprices and whims concerning the truths of religion." 27

The people and the courtiers are under the spell that their Kings exercise on their imaginations. They identify the King with the idea itself of greatness, of absolute authority. What the King thinks is true and automatically becomes law, for the sole reason that it is believed. Religion itself is His decree. Malebranche, at this point, shows the strict correlation between idolatric religions and the forms of government. Princes and Kings decreed with their imagination the validity of the dogmas of faith, the way religion must be interpreted and practiced, the nature of the divinity and of the cult to be given. Through religion, the powerful noble structures, modifies, and decides about society, because religion is the foundation of jurisprudence and a vision of the world. In this, the strength of the Prince has to be found. Human beings may rebel to a law, but not to a vision of the world; after this vision has been appropriated, the soul has found its prison. Courtiers and citizens blindly follow their Lord Leader, not for advantage or fear, but because their imagination has absorbed a vision of the world, within which they think, judge, and act. In his mind, Malebranche, is describing the religious-political events that characterized his time. ${ }^{28}$

In the way that religion is received and interpreted by the fantasies of the people, religion is reduced to a mere instrument of politics. Politics, at its turn, is the outcome of the conflicts or/and rapports of force of the imaginations. ${ }^{29}$ The command, or the exercise of the power of imagination, is essentially directed toward collective action. Ceremonies and activities increase in number, rigidity, and ritualism in the direct proportion with the increase in power of the individual who controls the community or the commonwealth. The Princes decide the religious and secular ceremonies that support the civil living, and these ceremonies act on the imagination of the people, maintaining and reinforcing the constituted authority. If the Prince were not the owner of the collective imagination, he would not have the absolute power of decisions, and even less of the ritualization of the behavior of those subject to him. The index of an absolute mental slavery is given by those Princes who would act as deities, having the power of decision about every- 
thing. The human beings who are the victims of their corrupted imagination form a superstitious population that depend in spirit from their impious rulers who are helped by the self-love of their subjects, self-love that functions as wise mediator between religious prejudices and personal material advantages. ${ }^{30}$

The power of imagination is superior to the power over things and without the power of imagination, the power over things would be difficult to acquire and even more difficult to preserve. Social changes, generally, follow mental changes which are nothing else than mutation in the imagination of the population. ${ }^{31}$ Certainly there are other different causes of social changes, but if the objective to be reached in persuading and ruling is the imagination, then the error that in such operation is conveyed by the imagination diffuses itself throughout all the mentality of the population.

"If the religion of the Prince is the religion of his subjects, the reason of the Prince will also be the reason of his subjects." 32 A few powerful individuals may decide the mentality of the multitude. The story narrated by Plutarch and cited by Malebranche in relation to the tyrant Dyonisius is emblematic. ${ }^{33}$ An object of study like geometry, an undoubtable example of rationality, can become a fashionable thing, and at the end an irrationality. But at the wink of the tyrant in contrast with Plato, everything returns to the old traditional custom of the tyrant's court.

It seems, continues this author, that they are enchanted, and that Circe transforms them into different men. They pass from an inclination toward philosophy to one for debauchery, and from a horror of debauchery to one of philosophy. Thus can princes change vices into virtues, and virtues into vices, and a single word from them is capable of completely changing their ideas. A single word, a gesture, or a movement of his eyes or his lips is all is needed to construe science and wisdom as base pedantry, or temerity, brutality, and cruelty as great courage, or impiety and free thought as strength and freedom of mind. ${ }^{34}$

A wince of the sovereign can become the cause of great changes within a nation. A grimace of the sovereign can decide the end of human lives. A word can create new attitudes and habits. Social causality and occasions are represented by the imagination. The imagination amplifies and upturns reality. The imagination produces effects so catastrophic and at the same time unnoticeable that only scholars succeed in becoming aware of them.

We have spoken as if imagination per se would sustain only irrational credences. At times, imagination goes with rational motivations or irreproachable morality, increasing their power of persuasion. ${ }^{35}$ The imagination in conjunction with verisimilarity and a thinking that, though erroneous, does not contradict manifestly the elementary moral rules, is a powerful reinforcement of mentality. 



\section{NINETEEN}

\section{THE HEROIC MENTALITY}

Vico said that primitive humanity communicated through the passions. It is sharing their passions that human beings can share and communicate their ideas to the members of the family. The passions are the social vehicle of the imagination. The heroes are the persons with strong imaginations and passions, capable of dominating the individuals with a weaker imagination. They dominate nature and family with physical force, but especially with the imagination.

\section{The Hero}

The hero is a visionary; his thoughts are linked to a few images of a religious character, the myths, which overtake and inflame the mind. The hero thinks always thoughts of facile comprehension, for which reason, he generally possesses a great persuasive ability. The persuasion of the hero originates always from the understanding that the hero has of himself, because there is no persuasion of others without the conviction of oneself. This may be the most important philosophical and anthropological point of the Vichian reflection. The theological poet is the first historical example of self-persuasion, and the families are the first social vehicle of passions. Given that the images are communicated through the passions, without compassions, there will be no contagiousness, no persuasion. Consequently, no families or nations will exist. Another theoretical element emerging from The New Science is that persuasion is essentially explicated in the imitation of a behavior that implies also an imitation of perception, a sharing of the same passions, myths, and ideas.

The heroic society diffuses the passions within its body in order to support the structure that binds and keeps it together, but, on another hand, with the conatus, is inclined to limit the intensity of the passions. An incontrollable passionfulness dissolves any possible social and emotive connection, while some passions like military valor, pride, shame, admiration, and fear contribute to the preservation of society. Language is the element in which imitation, communication, and emotivity join together and become the most important social binding 
factor. The imagination is the producer of natural languages and language is the tool with which an infective imagination passes from one patient to another. The world of the imagination penetrates the pagan mind and moulds it to its semblance.

In Malebranche, we find a conception of the heroic mentality that is similar to that of Vico. Our analysis will continue with the Malebranchean theses, and we will end with the exposition of the theory of the imaginative universals found in The Search after Truth. As in Vico so in Malebranche the psychological precedence of sensitivity and imagination over reason in the constitution of the mentality will exist in a temporal course, and with a succession of experiences. It is not necessary to speak of historicity for reason; but in regard to errors, prejudices, and wicked conduct, for the pagan mind, it is indispensable to introduce in our analysis a diachronic optic. Once we entered in the order of ideas of the human mind with a pagan mentality, we will comprehend more easily how the pagan mentality will assume the traits of a fantasy marked by heroism. A logical tread is common to the analyses of Lamy, Malebranche, and Vico. Their analyses will originate from different perspectives but the three of them show the unique structure of the pagan mind.

\section{The Pedagogic Value of Pagan Poetry and Heroism in Bernard Lamy's View}

It is commonly believed that Cartesianism has refused to attribute value to poetry and history. If correctly interpreted, this assumption is true. First of all, Descartes and the major exponents of the movement were the ones who took this position, which they justified as the strongest mean for freeing science from the atavism of the tradition and the unwanted influence of preconceived conceptions. On the contrary, we find in Malebranche an alert interest for history and for the chronicles that narrate the uses and the costumes of peoples. The work of Descartes consisted in eradicating the prejudices from the old principles of science in order to apply the new principles of science to the prejudices. When in the library, Malebranche used to say that it was good to have the science of the Scholastics tight inside the dusty volumes and not in his head. The basic question was always "what is science?" Malebranche cited the classics, even those he opposed, the like of Seneca and Tertullian, and in their analyzes he put all interest and energy.

Bernard Lamy, in Les Nouvelles Reflexions, considered the Vichian question on the usefulness of reading the classic (pagan) poets for the education of the youth, and the conclusion he reached was Vichian. Considering epic poetry, we may state that epics is a poetry essentially natural because it shides from the reflective and conceptual knowledge of the sentiments. The pagan mind is less capable of symbolizing than the modern mind because its products do not offer an ab- 
stract and reflective knowledge, but represent only the manifesting of the capricious and momentary passion. Modern poetry, instead, knowing human fragility, focuses on the lowest inclinations in order to cause the most efficacious form of conditioning. "The modern poets know better the web of passions of the human beings of their time. They know what is in conformity with the human debasing inclinations and what is capable of stimulating them (Les poetes modernes connoissent mieux le ressort des passions des hommes de leur temps: ils savent ce qui est conforme à leurs inclinations corrompues, \& ce qui est capable de le toucher)"1 Epic poetry offers a direct insight of the human spirit. It does not provide a description with conceits of what human beings are. It expresses directly the passions of the pagan conscience and some basic, elementary moral principles. It does not act from outside on the frailties of the spirit, but manifests its intimate instance. It is not a corrupting poetry, but it may be the expression of a corrupted conscience. Modern poetry intends to cause specific passions in the poet and the reader; epic poetry, on the contrary, is the effect of the passions. Modern poetry has a goal beyond itself: at the origin, in the poet; at the end, in the reader or listener.

The epic poet does not generate epic poetry for his own satisfaction or for stimulating his own passions in other human beings. Epic poetry has no goal or scope because it is not causative. Though it produces some effects, it is not a cause when it is generated. Epic poetry is simply the expression, neither reflective nor introspective, of the sentiments that nestle in the conscience of the human beings who perceive, although without clear conception, the precariousness of their existence. In a different way than that of the pagan classics, the modern poets have a clear conscience of themselves; they know which passions agitate human breasts, and can manipulate them for definite purposes.

The modern poets intend to gratify the sensations with pleasure, flater la cupidite; whereas the pagans produced a natural poetry, ingenuous, capable of creating in the spirit loftier emotions and passions like heroism, courage, and pride. ${ }^{2}$ The simplicity in thought always matches the simplicity in life. The life of the pagans was simple, dominated by a few but powerful passions serving the purpose of survival rather than immediate self-satisfaction, though always conceived by the alliance of need with pleasure. In the epic poetry, self-love and primary goods are combined. Under divine instigation, the Vichian heroes construct a shelter, take a companion, and plow the earth. They act in accordance to what they think, and think what self-love dictates. The heroic mentality is in function of survival. Where there is opposition between survival and self-love, credence takes over like in military courage, when the disregard for individual life becomes the strategic psychological pivot of action. In the heroic age, only the famuli (at the moment, a metaphysically irrelevant grafting of humanity) subordinate the poetic world of imagination to self-preservation.

In the modern poets, we see a contrary process. The lowest passions serve self-love rather than self-preservation. Modern times allowed an easier life and 
fantasies feel the attraction of what foments self-love, producing the lowest passions of vanity, envy, superiority, greediness, affectation, and ego-cult. Epic poetry, because naturally instinctive, neither felt the need nor could touch the inferior cords of the soul, and had, on the contrary, work for the preservation of the subject generating the loftiest cords of courage, audacity, altruism, and honesty.

Poetry, though the effect of human feebleness, is not to be devalued, if, on the contrary of the cause that produced it, gives way to healthy sentiments that give vigor to the spirit. Lamy recognizes that his own age was a decadent age because controlled by insignificant passions. To it, he opposed the morality of the Gentleman, the Knight, the Greek Hero, or the Roman Centurion. Though a Christian, Lamy admires in the pagans the limpidity of sentiments that moves them, while lamenting the corporeal origin of these sentiments. In his contemporaries, he derides the morality of commodities embraced by many Christians, who condemn violence when they are in the situation of suffering it and use violence, when the situation takes a reversed direction. These Christians profess obsequiousness to the laws, even when they are laws at the advantage of the despot, because they have not the courage of redeeming themselves from their slavery under the tyranny. These Christians follow goodness when wickedness is hardly available to them, and sustain the ideal of wishing goodness to those whom they are wickedly hurting. To the poetry that expresses in verses this kind of soul, corrupted by corporeity and modernity, Lamy opposes the purity of the pagan epic poetry, a purity derived from the direct and natural expression of some passions, not from a clear and rational vision of what is good and just. The pagan poet has no definite concept of his personality like the modern poet, and though unconsciously acting according to his self-love, his mentality is not false or fulsome. There is another reason why Lamy and even Malebranche prefer the poetry and the morality of the pagan to the pseudo-Christian one, degraded by material incentives that make it ostentatious in corporeity.

The epic hero is courageous and indifferent to death and dolor; the modern poet fears death and even the dolor from a rose's thorn. The epic hero, in the light of the Christian Gospel or laws, is guilty of murder like when killing in a duel, but his intent is not as wicked as that of many peoples who do not the evil for fear alone of suffering the consequences of the law. The modern poet, with sickness in his soul, plots even against those who love him. Christ's attitude toward death was more epic like than modern. The heroic attitude faces dangerousness without hesitation and fearfulness, in opposition to the modern one that fails even in the face of the smallest obstacle. This is not a digression, because morality, poetry, and pagan imagination constitute the elements of the heroic mentality that Vico described in The New Science. Vico, Malebranche, and Lamy value pagan poetry because the denial of the value of the body and of corporeity is the first step toward the acknowledgement of the human bond with divinity. Modern poetry, on the contrary, concentrates on corporeity: the lowest passions, the sentiments, the 
fears, the pains (even those of the heart, due to love and hate) whose origin is always in the union the mind has with the body.

The theoretical status of poetry is situated at the level of discussion on representativeness. Beginning from the conception of the intelligible extended, we have seen how Malebranche intended the rapport between the absolute rational thought and the representative pagan thought, limited and limiting the correct vision of our essence. In order to complete the picture, we must consider the application of the Malebranchean psychology to poetry and the direct connection between its metaphysical instances and poetry. This step was accomplished by Lamy. In Les Nowvelles Reflexions, Lamy applies to poetry the exercise of the intelligible extended, diverting our attention from all the representative contents of our thought so to be able to comprehend ourselves. Poetry does exactly the contrary: it presents to our attention only fantastic images and deviant illusions.

Poetry nourishes the fantasy with unreal images and by proposing a lot of them at the same time stuns the reader who is carried into an enchanted world existent only in his head. ${ }^{3}$ Poetry deters the sight from the present miseries toward inexistent riches, deludes all spirits, which lose their splendor and straightforwardness. In its essence, modern poetry is a moral insufficiency. Ancient, pagan poetry is rich with beautiful moral reflections, from which antiquity is known. ${ }^{4}$ The knowledge of antiquity for the Cartesian Malebranchean Lamy is a necessity. The knowledge of epic poetry provides valid moral teachings. Poetic morality and history are condemned only when they are misused. Lamy sees the link between philology and philosophy and like Vico uses etymology to clarify concepts. He said: "The subject matter of epic poems is a shocking action of great importance, like a war or the establishment of an empire. The style used in narrating must be elevated, so that the words would correspond to the greatness of the things treated. It is for this reason that these poems are called Epic par excellence because the word epic comes from the Greek word epos, which precisely means word." 5 From a poem it is possible to deduce all the aspects of the civil life proper to the society in which the poet who wrote it lived.

Poetry is a fundamental source of information for the anthropologist. In the stories that poetry narrates, we can find the origins of our civilization, the evolution of uses and costumes. In the Aeneid, for instance, the epic vision of reality of our ancestors and the poetic nature of their society are manifest. Lamy stated, "The goal of an epic poem is that of portraying what of the most importance is happening in the world, like great discoveries, travels, great building and renowned palaces, a famous city, wars, battles, sieges, and other similar events. The poets pretend to create kings, captains and write down lessons for the best conduct in grand happenings, in war as in peace. It is what we can find in the Aeneid, which is the work of this kind the most complete and perfect that ever existed." And again, "In the Aeneid, we can find the full Roman history. From it, we can learn the antiquities of Italy and of all the world, the birth of cities and nations, and all 
fables exist in it. In it, we can see the different ways of battling and making sieges; all ceremonies are explained in their proper terms, as Macrobe shows. In it, there is philosophy, astronomy, geography so that a young Roman adult who studies this poet carefully would learn in an agreeable manner all that a young man of quality was obliged to know in those times. And this is the motive of confusion for the majority of our modern poets, whose poetical verses contain nothing but nice words that mean nothing." 7 Modernity offers a symbolic abstract poetry, while ancient epic poetry is like a code of life, a canon of behavior, with an immediate significance that coincided with the deeds that the words narrated. Epic poetry was a life manual, an essay of practical anthropology, the explanation of uses and costumes that the reader had to acquire. The reader, by reading the Aene$i d$, was supposed to become what the book was narrating, a hero. "The fables were part of the beliefs and of the religion the pagans had. It was therefore necessary for Virgil to find occasions in his works for instructing the youth. He did not invent the fables; he spoke what was the common opinion. He always instructed his readers about everything that could be learned on the matter of that precise moment in the narration. He wrote to make known the antiquity of the city, the origin of a feast, a sacrifice, according to how it was believed and to how the historians gave account of these things." 8 The epic classic poetry is a multidisciplinary manual for the use of the youths who want to become valid citizens and a mine of resources for the studies in anthropology, philosophy, and philology. "The Great St. Basil, in one of his homilies, explained the manner in which the books of the Gentiles should be read. He recognized their usefulness and suggested that in the same way that before being tinted in purple the tissues must be colored in other less brilliant colors, so the classic studies should dispose the youth to doctrines even more solid." "The reference to Basil shows the desire of Lamy for the support of the Roman Church for his theories. In Les Nouvelles Reflexions, he explained the right manner of studying the literature of the classics and combined his thoughts with those that Malebranche had already exposed in The Search after Truth.

The correct method of studying the classics is found in the combination of Descartes's reasonableness with what St. Augustine absorbed from the writings of St. Basil. Basil told this metaphor, "What the leaves are for the tree, the knowledge acquired from the books of the pagans is for the soul. If we would consider knowledge like a tree, then verity is like its fruits and it is agreeable to see the tree with the fruits, and not without its leaves, which are like its ornaments. For this reason, we may let the Christian youth read the ancient poets. All the evil we have shown to be found in poetry, does not exist in their works. The ancient poets are less dangerous than those who write in our time because their writings leave little impressions on the spirits." 10 We notice again the contrasts between the ancients and the moderns. Ancient poetry had the pedagogical goal of forming the civil human being, while modern poetry introduces alienation, cowardliness, and laggardness. An epic morality provides the motives for action, while a modern poetry 
dazzles the mind in fruitless shades, in passivity. If the mind is inactive, the body is active and passive is the conscience. Virgil shows a spirit fundamentally Christian. ${ }^{11}$ His words convey knowledge, not concupiscence. Mythology and poetry are not historical rejects; the specific poetry discussed in these pages has functions at the scientific and pedagogical levels. In The Search after Truth, the anthropological analyses about the primitive mentality occupy the prominent part.

\section{The Malebranchean Myth of the Good Savage}

The thinkers of the seventeenth century had a scientific interest in the mentality of the African peoples and of other Western countries, like shepherds and slaves, for the most uncultivated. In the second part of this work, Malebranche rewrites a story from Diodorus Siculus, a Greek historian of the first century. This is the way Malebranche's narration goes,

An ancient author reports that in Ethiopia the courtiers crippled and deforme themselves, amputated limbs, and even killed themselves to make themselves like their princes. It was as shameful to appear with two eyes and to walk erect in the train of a blind and crippled king as it would be now if one dared to present himself at court in ruffles and a cap, or with white leggins and golden spurs. This fashion of the Ethiopians was extremely bizarre and disagreable, but nonetheless it was the fashion. They followed it with joy, and did not think as much about the pain that the fashion made it necessary to suffer as about the honor they brought on themselves by appearing to be full of generosity and affection for their king. ${ }^{12}$

The customs of the primitive people allows the identification of some inclination of the human spirit in a manner more direct, more natural and thus less complicated than if we were to examine modern customs. In the narration, two kinds of customs are counter opposed, the ancient and the modern. In the ancient custom, the courtiers manifest an impressive and rare devotion and affection for their sovereigns, to the point of self-imposing corporeal mutilations. Their imitation was not for personal gains, they imitate the sovereigns in their feebleness, not in their greatness. The social law that convinces a courtier to mutilate himself is the centripetal force that maintains in a suspension the society. The act of the courtier reinforces the cohesion of the community. The Ethiopian custom invested the sphere of inner and outer existence. This was not the custom at the Court of Louis XIV. The French nobility dressed in order to impress. At the French Court, we had mutations without mutilations. Mutilations are irreversible and prove that the Ethiopians could not have believed that amputations were 
making them happier, better, and more beautiful or elegant in the eyes of their kings. The Ethiopians believed that only with a personal sacrifice they could demonstrate their devotion to the sovereigns. The French nobles made no sacrifice in their ostentatious camouflages trying to attract the attention of the Sun King. The individual motivations of the Ethiopian and French courtiers may have been selfcentered, but when the relations between superiors and inferiors are involved, then rituals from fashionable change into customs and from customs into laws. ${ }^{13}$ In the case of courtiers, their friendship with the sovereign is always motivated by self-interest. Human beings, particularly the courtiers are naturally and ceremoniously inclined to adulation, in order to become trustworthy and well accepted. ${ }^{14}$ The passage from fashion to law is not automatic, it must pass through the stage of being a custom widely diffused and accepted. The custom is a fashion that persists and cannot be nulled by a more impressive or incoming fashion. Human laws are constituted through the process of customs, and customs often are contrary to reason and right judgment. "The story of travelers in the Levant teaches us that this custom, as well as others contrary to common sense and reason, is observed in many countries. But it is not necessary to cross two borders to see unreasonable laws and customs religiously observed, or to find men who follow disagreable and bizarre fashions; one need not leave France for that."15

With this remark, Malebranche shows two aspects of his theory. First, he attacks ethnocentrism against all those who judge other cultures as inferior to theirs. Second, he underlines the fact that the moderns are no different from the ancients: nonsense and irrationality exist at home. The same laws operate in all humankind; error has the same causes at the tropics as at the poles. ${ }^{16}$

Returning to the preceding observations, we may say that fashions and customs are rooted in social behavior in a manner of becoming an unwritten law rigidly observed and more efficacious than the laws of God written on the Tables of Moses. ${ }^{17}$ Fashions and customs become laws religiously observed because written on the shield of self-love. Uses and customs are established fashions able to survive the epoch in which they originated and to determine laws of life in common in successive epochs. Fashions are manifestations of the work of the imagination that develops and changes as it transforms differently from one epoch to another. "In truth," says Malebranche, "I do not know whether the French are completely right to mock the Ethiopians and the savages. It is true that upon first seeing a blind and crippled king with only blind and crippled people in his train, one would have trouble preventing oneself from laughing. But in time, one would no longer laugh; one might have more admiration for the magnitude of their courage and friendship and not ridicule the weakness of their mind. It is not the same with fashions in France. Their extravagance is not supported by any apparent reason, and if they have the advantage of not being as distressing, they do not always have the advantage of being as reasonable. In brief, they bear the character of an 
age still more corrupted, in which nothing is strong enough to control the disorder of the imagination."'18

The reasonableness of the customs and fashions of the ancients or primitive human beings like the Ethiopians consists in promoting courage and many other sentiments that have the double scope of keeping self-love and imagination under control and cement society. On the contrary, modern fashions and customs, French and Not-French, give free hand to flirtatiousness, narcissism, arrogance, and a vanity that extends itself to all aspects of life.

The scope of all fashions is always the same: sensitive pleasures; to please oneself, for the purpose of pleasing those who are superior. The typical wish of self-love is that of being recognized and of surpassing others. It finds in our evolved societies the fertile ground in which to grow the false sentiment of superiority, vain and apparent, which, compared to the Ethiopic customs presents no real value, but only an ephemeral appearance.

Fashions and customs are a modality of politics, means for the establishment of the rapports of forces in society. Fashions and customs constitute the rapports that tie the inferiors to their superiors and through them social tensions are fuelled. Malebranche affirmed, "What I have just said of courtiers should also be understood of most servants with regard to their masters, maids with regard to their mistresses, and (in order to avoid useless enumeration) all inferiors with regard to their superiors." 19

As we have seen, fashions and customs dictate the conditions of living in society. Why some people find themselves in the position of having authority, superiority, or power may be due to birth, inheritance, personal achievement, merit and conquest, or simply fortune. Malebranche, Lamy, and Vico insist that all these desirable goods are also the fruits of a great imaginative power. 



\section{TWENTY}

\section{THE HEROES OF THE IMAGINATION}

We have shown how the greatness and deepness of the traces in the brain allow us to sense things in our soul. We have also narrated how some human beings, with an imagination highly developed because of their traces more deeply pressed, perceive the same things we perceive in a different way than we do. These special individuals float in a sea of great passions. It is through ebullient passions that the imagination suffers contagiousness. Contagious images and fantasies corrode equally thought as well as the conduct and the attitudes of the individuals.

\section{The Heroes}

Persons of great imagination control people with less imaginative potential and gradually bring them to adopt their attitudes, characteristics, and ways. With the special gift of imaginativeness, some individuals can move the heart, persuade the mind, and convince the spirit of other to imitate them. These imaginative individuals easily translate their thoughts into perceivable vivid images. ${ }^{1}$ Having an extraordinary imagination, an individual is a visionary. His thoughts are always linked to imaginations that shock and move, but these thoughts are of no difficult comprehension and with great force of persuasiveness. Persuasiveness, Malebranche reminds us, is self-persuasion before becoming forceful in persuading others. The same opinion is in Vico, whose poetic theologians become capable of thought through a mental operation of self-persuasion, because by illuding themselves that the sky was Jupiter came to comprehend reality as being animate. This act of self-persuasion is a semantic act that attributes meanings to things. The art of rhetoric has taught Vico that no communication exists without passion and no conviction without an emotional impact. Vico's brutish being (bestione) is guided by forceful passions and through passions and imagination it convinces itself, illudes itself, and starts to think. ${ }^{2}$ In The Search after Truth, the process of the selfpersuasive persuasion and of the contagious persuasive persuasion of others is 
analyzed. What is the connection between "interpersonal persuasion" and "selfconvincing"? We have seen that persuasion is operative between superiors and inferiors. If this were to be the only possibility, then society would have had a different solidly hierarchical structure, more than we imagine. Many things would not be possible and we would have to live in an absolute submission to those who are extraordinarily imaginative and contemporaneously in an authoritative or preeminent social position. Dialectics would not be permissible and the critical art would be expiring. Finally, if we were to convince ourselves only of those things of which we were told by the people in higher positions, we would become unable to have personal ideas and self-convincing would be inexistent.

For Malebranche, human beings have some autonomy; they can be convinced by peers, inferiors or superiors, and by themselves. In the case of persuasion among peers, Malebranche explains, "In order to act on the imagination of others, it is not absolutely necessary that we have authority over them, or that they be in some way dependent upon us. Often force of imagination alone is sufficient for this. It sometimes happens that unknown people, who have no reputation, and for whom we were not biased by any esteem, have such strength of imagination and as a result such vivid and affective expressions that they persuade us withou our knowing either why or even precisely of what we are persuaded. It is true that this seems quite extraordinary, but nonetheless there is nothing more common." 3 The force itself of the imagination is sufficient for the activation of the mechanism of persuasion and imitation. To become convinced is like a primitive need of the spirit that we cannot avoid. As an end in itself, persuasion is the unnoticed most common phenomenon and experience. Malebranche adds, "Now, this imaginary persuasion can come only from the force of a visionary mind that speaks vividly without understanding what it says, thereby causing the minds of those who hear what it says to believe strongly without understanding what they believe. For most men allow themselves to be led by the force of sensible impression, which distracts and confuses them and impels them to judge what they conceive only confusedly through passion." 4 Within this kind of dynamism, the "content" is irrelevant, what counts are the "means" that transfer it. Conscience is seduced by the senses and the first to be convinced are the sentiments that are like confused reasons. Thought is the pretest for the actualization of the passions. Human beings are convinced for reason of how things are said more than for what the things are. An air of piety and seriousness conveys a sense of reliability to what is said, and we will believe a message for the ability of recitation of the orator more than for the truth of his words. The more easily a thought is communicated, the more imaginary it must be considered, with the characteristics of sensitivity and passionfulness. Visionary spirits are controlled by their passions. The communication of ideas is a pretest for the communication of sentiments. ${ }^{5}$ The expression of a thought is always something sensible. Communication goes through the senses. Truth does not go through the senses; everyone perceives 
truth in the intelligible extension. Truth resides in our mind. Communication is useful in order to bring conscience to focus on itself, to recognize prejudices and errors. The speaker should be free from prejudices and the listeners must have sufficient good will to start on the path of knowledge. These requirements are rarely followed; human beings prefer the teachings of the senses ending into the grip of imagination and of the leaders who will organize them at their advantage. Those who impose themselves on others are visionaries: they use imagination and are used by it. For this motive, those who stand on the superior platform are also unlucky slaves of imagination. Descartes said that all human beings have the same kind of capable intellect; what is different in the human beings is the kind of imagination and the passions which they possess. Fantasies and prejudices are responsible for the limitations of our intellective capacities. Human defects make human beings different: we vary in errors and conform in truth. The Search after Truth says that the regularities of errors are not regularities of reason. Error is the source of differentiation among human beings; social, political, and cultural inequalities have their origin in error. In this sense, the studying of uses and customs, anthropology and folklore are studies of how the imagination brings us into the abysmal forest of errors. The visionaries of imagination are the pipeline of erroneousness and inequalities in society and at the same time the maintainers of contemporary advanced societies. Without the visionary of imagination establishing hierarchies in the human minds, self-love could bring to self-destruction. Controlled passions contribute to the welfare of the commonwealth. The indispensable equilibrium in society is coming from the presentiality of forceful and forceless, superior and inferior imaginations. Vico agrees that to study the society is to study the human passions. He counterbalances the emotivity of kings and nations with the actual political structures. Society itself, for Vico, is the effect of conatus. Human societies are possible because human beings can control their most destructive passions. If human beings were not capable of restraining their passions and from becoming their slaves, they would not have created culture and would still live like the bestioni described in the chapter of the "universal deluge and giants." Forceful imagination is necessary psychologically for the control of strong passions.

\section{Tertullian}

Persons of strong imagination exist in every century, at all levels of society, and in all branches of human activities. Malebranche selects Tertullian, Seneca, and Montaigne as significant exemplar personalities having forceful imagination and as representatives of the typical characteristics of visionaries. ${ }^{6}$ The imagination of these writers is so powerful that they merely with words can rouse firing passions in their readers. Words are extremely persuasive means in the hands of imagina- 
tion. Words can convey imagination through the centuries. The words of these authors "penetrate the soul and control it to absolute obedience without understanding them; they obey to their orders without knowing them. People want to believe without knowing what to believe because, when they want to know with precision what must be believed or is believed, they approach those phantasms trying to know them, but the phantasmagoria of words vanishes in thin air with all their rhetorical monsters and their splendor."' The soul is dominated by words, words that are carved into images and sentiments, words of passions, without abstractions, words of the senses finding their path to the depth of the soul, words rulers over the imagination and, thus, the comprehension. The pagan mind is enslaved by the power of this language of imagination, absorbed in fantasy, imprisoned and wholly captured. The substance of the thought of Malebranche is that of Vico's anthropology of the heroes, whose minds are modeled by the myth. The language of myth is representative, a synthesis of phantasma in a phantasmagoria that dissolves at the rays of reason. Imagination, society, language, credences, and structures of the mind are elements present in this analysis of Malebranche.

A psychological necessity ties genetically language to imagination. The totality of humankind uses the language of imagination and submits to fantasy. The social function of language is performed universally by the language of the visionaries, the language of imagination. No natural language is born on the frequencies of reasonableness. Visionary spirits present the most characteristic traits of the pagan mind. ${ }^{8}$ Tertullian, representing the pagan mind, is more memory than judgment, is amplitude of imagination and obtuseness of intellect, forceful imagination and feeble reasonableness, sensible thought more than capable and reflective. His language is the result of the melting of ideas and things in the burning kiln of imagination, which shapes it naturally and kaleidoscopically. In the mentality and conduct of Tertullian, the changes of nature bring no changes. We may say that he is convinced that natural phenomena are the sufficient causes of the disturbances and changes in his conscience. In a manner analogous to that of the astrologers, Tertullian sees in the changes of nature the forces that brought the human being to change his fashion of dressing, thinking, and living. ${ }^{9}$ A clear mind could thrust aside the false causality of these events, but not that of Tertullian at this period in his life. The analysis of Tertullian's mentality shows the same characteristics of the heroic mind of Vico. In a manner more radical than that of Tertullian, the brutish human being of Vico changed his ways of dressing, thinking, and living in relation to atmospheric phenomena. In a more profound way than Tertullian, the primitive human beings of Vico interpret nature, attributing to it an arbitrary significance capable of disrupting their spirits and conduct.

The passions of the soul alter in relation to the great, visible, and magnificent phenomena of nature. The pagan mind interprets the analogy between the earthquake and the trembling of the spirit for fear or love as a correspondence of 
causality. The mutations in nature have created the mutations in the human nature. The analogy that imagination constructed on two facts is judged as being a real causality. If we go beyond the evident oratorical abilities of Tertullian, we will find that his reasons are inexistent. The language of imagination possesses one main goal: the dazing of the intellect, the puzzlement of the spirit, and the welcoming of all passions. ${ }^{10}$ Tertullian has been the champion among the visionaries: a puzzled mind that expressed confused ideas in a ebullient, captivating, and impressionable kind of writing. Certainly, the contingent historical moment, the individual character, and the common customs may have challenged Tertullian, but the cause of his obscurity must be found in his effervescent passions. Ambiguity, for the natural human being, for Tertullian and the theological poet, is a sign of mental depth. The Cartesian mind instead saw truth in clarity. In Tertullian, imagination triumphs; in Malebranche, reason reigns.

\section{Seneca}

The heroes of the imagination have other characteristics that, as in Tertullian, also can be recognized in Seneca. A peculiarity of the pagan mind is that of meaninglessly rotating around itself, while convinced of reaching the winning post. The mind of Seneca travels and speedily advances in the direction opposite to truth and itself. Seneca leaves the moorage and moves into the open sea of the fantasy, a sea whose waves takes him far away and in all directions, without any wish for returning to the mooring. His home is the horizon of the imagination, a sea with numerous enchanting islands that made useless the attempts at a return. Why should we feel the need of returning to the place from where we never departed? Malebranche wrote, "Seneca's imagination is sometimes no better controlled than Tertullian's. His impetuous impulses often carry him into unknown territory where he nevertheless walks with the same assurance as if he knew where he was and where he was going. As long as he makes great strides, designed strides, in a precise cadence, he imagines he has made great progress, but in truth he is like a dancer who always ends up where he begins." 11 The power of the imagination is one whole with an impulsive sensitivity. The words born and originated from a mind in a sea of imagination are words that attract, enchant, and mesmerize the audiences, mixing in metaphors and analogies things that in the reality are different. The language of Seneca confuses beauty with reason, rotund and touching expressions as evident reasons; it brings people on the path of error, but with the pleasure of melodious words and fantastic images. With the imagination, he travels faraway, but remains always at the same distance from truth. Malebranche explains, 
It is necessary to distinguish the power and beauty of words from the power and evidence of arguments. There is doubtless great power and some beauty in the words of Seneca, but there is very little power or evidence in his arguments. He gives a certain turn to his words through the force of his imagination that affects, agitates, and persuades through impression, but he does not give them that clarity and pure light that illuminates and persuades through evidence. He convinces because he arouses the emotions and because he pleases, but I do not believe he can persuade those who can read him calmly, who are prepared against surprise, and who are accustomed to yield only to the clarity and evidence of arguments. In a word, although he speaks and speaks well, he is careless about what he says, as if one could speak well without knowing what one says, and hence he often persuades without our knowing either what we are persuaded of or how we are persuaded, as if one should ever permit oneself to be persuaded of something without conceiving it distinctly, and examining the proofs that demonstrate it. ${ }^{12}$

\section{The Language of Imagination: Sign and Meaning}

The language of the imagination finds essentially its meaning in the expression. The meaning is not something alien and detached from the expression with which the language expressed itself. The language of fantasy persuades without knowledge of what it persuades, because the meaning that it conveyed is found in the means themselves used for convincing. The sign is one thing with the signification; sign and meaning are the same thing; the meaning identifies with the sign. We are persuaded by the sign: the word, the sentence-expression, the beauty characterizing the expression, the power of imagination transpiring through the expression. When we search for the meaning (conceptual or abstract) the sign represents, we find no meaning. Reason cannot find a meaning, because for reason there is an ontological distinction between sign and meaning. For the pagan mind, the meaning is the sign itself.

The mind of Malebranche, gifted with abstractiveness and reasonableness, would find no conventional link between the oratory of a visionary and the meanings that his harangue would communicate. The visionary rhetor does not speak to the reason of his listeners, but to their sentiments, passions, and fantasies. Malebranche says that in order to communicate in the visionary mode, no need exists of conventional links between the traces and the ideas; it is enough "to follow nature," giving free vent to the imagination that will follow the natural link among the traces. For this reason, "one of the greatest and most remarkable proofs of the power that some imaginations have over others is the power some authors have of persuading without arguments." 13 The force of the imagination is proportional to 
the force of vanity. What counts is to fire the senses and to be what one wants to be. Language on the lips of visionaries has only this function: to impress and convince, to persuade other of one's superiority, to impose oneself and be recognized. About the visionaries, Malebranche remarks, "In view of this they treat only rare and extraordinary subjects, and this is also why they couch all their explanations in rare and extraordinary terms, and quote only rare and extraordinary authors. They hardly ever write in their own language because it is too common; nor in simple, clear, and easy Latin; it is not for the purpose of being understood that they speak, but simply for speaking itself, in order to be admired." 14 The validity of the content of their discourse is not important; what is important is to stimulate admiration, wonder, mystery, secrecy, and magnificence. In other terms, the meaning is null, the efficacy of the sign on the imagination is what is desirable. The only real meaning in the language of the visionary is the efficacy of the sign on the passions and fantasies that are generated in the spirits with feebleness. To this end, it is possible to speak an unknown language. ${ }^{15}$ To speak a language unknown to the audience excludes a priori the possibility of conveying conventional meanings between speaker and listeners. The only meaning verified in this kind of communication is the communication of sentiments, images originated from the sensible impressions that the speaker performed on the listeners.

The language of the visionaries is a primordial language, simpler and more immediate than the conventional language. The language spoken by a visionary may be one of the many conventional languages, French, Italian or German, but in reality the language is conventional only for the form not for the content. The content of the language of the visionary is unconventional, natural, and the words are not conventionally tied to abstract concepts, but to sentiments. If we were to consider the language of the visionaries as a symbolic language, the link between the word (symbol) and the meaning would not be a symbolic link, because there is no abstraction in the natural language. A word in the visionary language has a charge of passions that represent its meaning and, if it were a symbol, it would be a symbol in unison with the meaning. The Stoics are visionary thinkers, who through a conventional language convey the content of a primitive natural language in which the words and their meanings, the sign and the passion, the symbol and the image are one identical thing. They are fused and confused together, and thrown by the catapult of sensitivity over the spirit of those feeble minds that become deeply changed by them. ${ }^{16}$ The vanity and the desire of being known, appreciated, and esteemed as superior produce the dynamic of the visionary language, as in the case of the Stoics. Under some aspects, the superiority of the Stoics is real, but the Stoic remains primarily a visionary. The Stoic suffers of autoillusion, which in practice is a delusion. Self-love, vanity, and fear are the propellers of this self-illuding, of this primordial language constructed on primordial passions. An impostor, a liar, is a case of self-persuasion. The liar is certain of himself; he is certain of what he says and cannot be a liar without believing what 
he says. ${ }^{17}$ All the proofs that the liar brings up in his argumentation refer to the imagination; they are sensible proofs that to those who listen appear as proving the thesis sustained, whereas they only witness to the impetuosity and conviction of the speaker.

\section{Cato}

The visionary is a good rhetor and a perfect liar, but an arrogant and vain human being. He pictures himself as a hero, a hero of the imagination, so to hide himself behind a mask in order to achieve his goals of pride and vanity, which pour out from his self-love. The fantasy of Seneca describes a hero, a wise man with unbelievable physical, mental, and moral faculties, in the person of Cato. It is an unrealistic portrait, but it represents faithfully the passions that move the soul of the Stoic: pride, vanity, and arrogance. The hero of Seneca is described as a superhuman being, with the abilities of making himself insensitive by mere force of the will. What makes Seneca fantasizing the huge power, the immeasurable resistance to pain of Cato is truly the hypostatization of his own pride, and it is the implicit acknowledgment of his own frailty. Unable to face real problems, Seneca denies them. It is the same with the offences. The wise Cato cannot be offended by anyone, neither physically or morally. His virtue takes him infinitely above all those who intend to strike him, insult him. In reality, he does not reply when offended because either he does not have the force or is short of courage. His ostentatious quietness in front of danger is in reality a fear that manifests itself in immobility. ${ }^{18}$

Malebranche observed that those who know nature will not be deceived by this kind of visionaries. They force reality in a way that it will coincide with their fantasy. ${ }^{19}$ The nature of Seneca's hero is a fantasized nature: the more the present situation is pitiful, miserable, and difficult, the more the man is inept, feeble, offended, the more strongly he would fantasize, insensitive to the blows of destiny and of other men. The hero of the Stoics is the fantasy as the counterpart, the rival, in the spirit of the visionary, to the continuous frustrations that are felt about the precariousness of life. With the example of Cato, Malebranche shows one of the most characteristic traits of the visionary spirits: to know how to face present miseries, real difficulties, burning insults with fantastic virtues, with courageous qualities, force, and will, which they do not possess and could never have. When in a hopeless condition of miseries, the human beings do not react by thinking of satisfying the real primary necessities, but by constructing a fictitious world for themselves in which they act in the exact contrary way to what they act in the real world. The visionary reacts to the difficulties of present life by moving from the realm of this world to that of the imagination, where he will construct a new and better reality. Malebranche illustrates this point comparing the false wise Cato with Christ, the true wise. 
When Cato was struck in the face, he was not angered; he did not avenge himself, neither did he pardon the offense, but he proudly denied that anyone had done him injury. He wanted everyone to consider him infinitely above those who had struck him. His patience was only blindness and pride. It was shocking and insulting to those who had mistreated him, and Cato signified, by this Stoical patience, that he regarded his enemies as beasts against whom it was shameful to be angry. It is this contempt for his enemies and great esteem for himself that Seneca call the greatnes of courage. ... How extravagant it is to confuse the greatness of courage with pride, and to separate patience from humility to join it with insufferable pride. But how agreably these excesses flatter the vanity of man, who never wishes to lower himself, and how dangerous it is, especially to Christians, to instruct themselves in morality from an author so injudicious as Seneca, whose imagination is so strong, so lively, and so imperious that it dazzles, distracts, and carries away those with but little firmness of mind and much sensibility for all that flatters the concupiscence of pride. ${ }^{20}$

Pride prods the imagination when sensibility is acute, reason lethargic, and the situation difficult. The visionary in such situation of precariousness and misery will repatriate as a king, a hero, or even a god in the fictitious realm. He is no Christ. ${ }^{21}$

On the contrary, unable or not daring to exact a real vengeance against the wrong he had received, Cato tries to exact an imaginary one, which flatters his vanity and conceit. In spirit he exalts himself to the clouds; from there he sees men here below as small as flies, and holds them in contempt, as thought they were insects incapable of having offended him and deserved his anger. This vision is a thought worthy of the wise Cato. This gives him the greatness of soul and this firmess of courage that make him like the gods. This makes him invulnerable, because it is this vision that places him above all the influence, power, and malignity of other men. Poor Cato! You imagine your virtue raises you above all things; your wisdom is but folly and your grandeur but an abomination before God, whatever the wise men of the world think of them. ${ }^{22}$

The psychological principle of the fantasies of Cato, the visionary hero of Seneca, is the principle of compensation: the more the reality would present precariousness, dangers, and indigence, the greater the pride and the vanity, and many more the fantasies that pictures security, safety, courage, force, and riches would be. "But there is nothing new about men believing they can become gods, they have always believed it and perhaps more than they do now. Vanity has always made 
this thought rather propable to them. They get it from their first parents, who doutbless share this view when they obeyed the demon, who tempted them with the promise that they would become like God." 23 The doubt exists why we do not consider these fantasies as follies instead of being accepted by the common majority of the peoples. The visionary is not considered a visionary by other visionaries, or by the impotent spirits. In a society composed by transgressors and feeble spirits guided by physical motives, the visionaries look like the best people, attractive and charming, honored for their peculiarities. Other people will willingly share the fantasies of those at the top. ${ }^{24}$ The credences that constitute the mentality of a nation are the trees grown from the sprout of some visionary of the imagination.

Bayle said that the credences are created by a few peoples, and all the people accept them without any critical analysis. The visionaries of the imagination constitute the real danger for the truth of the conditions of a society because the visionary spirits are for the most part the ones who created the society. Those with a visionary fantasy would never be considered foolish or mad, because substantially they are not different from the rest of the members of society, who quite often would consider the visionary to be "a great person." In a society of sages, a visionary would be immediately identified and would not constitute a danger, no more than the visionaries of the senses, the insane individuals. Nobody would believe an insane who would insist on being a rooster, because his folly is manifest not only to the sages but also to the visionaries of the imagination. Among common peoples, the visionaries with a strong imagination converse with other visionaries and, in this way, errors proliferate. Idolatry originates from this practice. Visionaries who believe being like gods create practices that place them at the level of the divinities. When these visionaries ritualized submission to the gods, they do it in a mental context in which they are in touch with the deity, interpret the divine will and its temper and wishes. From this came the pagan sacrifices and ceremonies. The pagans are never conscious of their arrogance, and do not understand the role that pride played in religion.

Idolatric practices, beyond their appearances, are a way of approaching the divinity, in order to become equal if not superior to the divinity. The sacrifices are offerings in exchange for favors from destiny, favor always greater than the offerings given. Idolatry and auspices are a kind of barter of fantasy with the deity, an activity in which the human being unconsciously plays the part of the shrewd merchant. In idolatry, we find that the human vanity gambles for the communion with the divinity, a fantastic direct contact, in view of the goodness no less imaginary. Paganism is an existential perspective totally fictitious and the more dominated the more ignorant the pagans are of their dependency from the reality of nature, however perceived with the imagination. 25

Pride and arrogance are defective sentiments; they indirectly proclaim the awareness of the precariousness of existence; they are the reactions of the imagination and self-love to the fear that human beings feel when facing reality. In the 
attempt at suppressing these negative sentiments, the human being aggrandizes itself, as its original first parents did in Eden. ${ }^{26}$ These sentiments are the tangible sign of the fact that human beings are conscious of their feebleness, but intend to ignore this frailty by removing its idea and the sentiment of fear that accompanies it. Without the confused awareness of personal frailty no pride or arrogance would exist. The Stoic in this view is the prideful person par excellence, but his virtue, as Malebranche discovers, is pure fiction and a shield against fear with the exhibition of force. Nonetheless, the Stoics, when there is an audience, perform heroic actions, but they are no heroes of virtue albeit only of imagination. The visionary of the senses is essentially a pagan aware of his feebleness, which he hides within himself with the cloak of pride and arrogance. ${ }^{27}$ This effort for a cover up has two effects: first, it hides the personal shortcomings of the hero; second, it convinces the feeble minds about the greatness of the hero. The mechanism resolving the passions and fantasies of the Stoic works in the manner that with the greater sense of inferiority, the Stoic would search for a greater emotive impact on the imagination of his audience. The show activated by the Stoic appears to the sight of Malebranche as the comedy of art, a tragic-comic exhibition that roots its efficacy in desperation. ${ }^{28}$ The intensity of the produced sensations determines the level of communication of the strong imaginations, which with their impetuosity blind the individual, who in blindness still sees even better as he imagines being in front of God. The visionary who believes himself god will find always a band of persons ready to believe him and share his passions and follies.

Imitation and the spirit of emulation incline the audience of a visionary to a careful listening and identification in order to share his power, which stands in the imagination, not in the reality of things. The desire of superiority and fitness force the visionary to look for superiority in the only one place where it can be found, in the imagination. Feeble spirits, believing that the loftiness of the visionary is within real experience rather than merely in the imagination, illude themselves in the effort of gaining some of it with their emulation of the visionary's conduct. Malebranche stated, "When one is struck by this proud blindness, one places oneself among the noble and powerful minds. Even others include us in this class and admire us. Thus, nothing is more contagious than this blindness, because the vanity and the sensibility of men, the corruption of our senses and passions, dispose them to search after it, to be struck by it, and excite them to impress others with it." 29 All humankind, even those who do not possess a strong imagination to be counted among visionary spirits, aspire at being superior to others and accept everything capable of providing it. The Stoic virtue is only a form of hypocrisy, because human beings would be reaching higher in nature only through grace. No Stoic, with the sole power of his spirit, has despised the glory and the esteem of other men..$^{30}$ Though it is done in a tortuous way, the dynamics that brings human mind to behave as a visionary mind have the effect of reinforcing the human character. The human being learns to feign virtue even if he will 
never achieve it. In the psychological perspective, Malebranche observes that the human conduct receives from this feigned virtue a linearity, and a coherence, which, even though founded on imagination, still are of use and benefit. ${ }^{31}$ 


\section{TWENTY-ONE}

\section{THE POWER OF IMAGINATION AND OF SUPERSTITION}

Malebranche said, "The most extreme effect of the force of the imagination is the unreasonable fear of the apparition of ghosts, spells, characters, charms, lycanthropes, or werewolves, and generally of everything we imagine to depend upon the power of the devil."' The sentiment of inadequacy and inferiority in nature and in general in an environment that seems to crush us, before which we are helpless, if in one way takes in us the form of arrogance and pride, in another way it assumes the aspect of superstition. This new element definitively underlines the great fear that human beings experience feeling themselves naked and abandoned in a world that they cannot control.

\section{Nature, Demons, and Fear}

Nature is overwhelming, threatening, and challenging. Nature can suppress an individual human being in an instant: nothing scares human beings more than the potency of nature, but "nature" is not the physical world, as the modern mentality understands it. Nature is effective; it acts and has a will. Nothing is more frightening than an invisible power that acts in nature and can injure or destroy us, against which there is no defense. "All the talks that can refer to this idea of nature are heard with fear and curiosity. Human beings are highly interested in everything that is extraordinary. They enjoy narrating these surprising and prodigious stories about the power and the malice of sorcerers, with the intention of bizarrely scaring other persons and themselves." 2 The narrations the wizards present have the social function of amalgamating the people; they scared narrator and listeners and teach them to act on the self-love of the collectivity. Images are communicated through language and form the web that bonds firmly the community. In other words, fear creates aggregation. We narrate what scares the others and ourselves in order to share fear and, by so doing, exorcize it. This, too, is a form of compassion. Self-love acts here in an indirect way, but in a visible manner: we come to 
know that the others share our fears and are subject to the same fate. By so doing, we come to accept fate.

The fear of nature is the fear of a hidden agency within nature that acts through nature. It is a distressing emotion aroused by impending danger, evil, pain, whether the threat is real or imagined. People can reduce and attenuate the personal fears of sorcerers and werewolves by verbalizing to others the events that they feel to have experienced. A shared fear is no longer a true fear. Fear and curiosity are fused together in fantastic stories. Curiosity embraces everything that is extraordinary, exceptional, and yet unknown. Exceptional facts stimulate curiosity for many reasons, but if they generate fear it is because in exceptionality human beings see what is beyond there complete control or management. All that escape the human control or foresight has sensible characters of exceptionality, mysteriousness, and power that inculcate fright. Apprehensions and fright give way to a chain of behaviors that would reinforce the same fears and the stories that generated them. A society based on anxieties and fears is a society of superstitions within which peace and justice will not find an abode. ${ }^{3}$ In a society or community within which fear is strongly rooted, or is the cause of the aggregation into a communal living, wizards and sorcerers, the fantastic representatives of the materialization of the collective fears, are widely present. The feeling of being afraid creates these representative personalities. The passions regarding fear need the representational presence on which to establish. In a society of anxious and fearful people, some wizards and astrologers will necessarily appear, who will direct and converge the flow of the collective angst on them.

In a community, so imbued with fears and related fantasies, the first victims will be the persons with weak minds. It will be easy, almost natural, to identify the wizard in a fool with an uncommon behavior, incomprehensible to others as incomprehensible are the magic rituals to those who have not been initiated to them. This fool may believe himself to be the wizard. He will not clearly perceive the difference between himself and the others, but will share the same fears and the credences in regard to their collective representations in such way of sensing the responsibility for them. The fool will be the first to believe the fantastic interpretations of the sorcerers and accept them to the point of identifying himself as one of the sorcerers. A madman is a visionary of the senses, a mind fully confused, capable of receiving from the surroundings only the passions and the sentiments that are directly coming from sensitivity and receive them in a distorted manner. The fool, a visionary of imagination, on the other hand, will perceive in all its intensity the "vibrant mood of the community," the fear that like fog expands itself over the surrounding reality. In that fog, the fool will believe all the fantasies that, by receiving them from the ambiance, he has promptly assimilated and transformed. No madman or fool will truly be a wizard. "And so in places where sorcerers are burned, we find many of them, because in these places it is truly believed that they are burned for what they are, and this belief is strengthened by 
discussions of them. If they were to cease punishing them and treat them as mad people, in a little while they would no longer be sorcerers, because those who are sorcerers only because of imagination, which certainly constitutes the greatest number of them, would revert to the normal state of men."4

We can underline again that at the root of these dynamics within society there is the epiphany of language. Language is the vehicle of beliefs, especially the false ones. The capital sentence of witches and wizards is a form of language in which the fear of sortileges and magic is communicated. The pyre or the burning at the stake is the word that gives meaning to magic; the power of the fire is proportional to that of the sorcerers, wizard or witch. The sign and the meaning of the power of wickedness are centered on the fire that is supposed to eliminate them. The imagination of the people imagines a direct connection between the gravity of the sentence with the effectiveness of magic: there is a heavier sentence for the stronger magic. For the pagan mind, truly, the reverse should be correct: there is the stronger magic for the heavier sentence. In this way, the fear for sorcery and witchcraft expands: by criminalizing sorcery, we make it stronger and efficacious. The impression we have before a pyre is proportioned to the strength of the condemned to the stake. Why to cure with fire a disease of the soul and of society, if this disease is not dangerous and contagious? If we kill a man or a woman for sorcery or witchcraft, it means that their power is real and their magic powerful. The hunting for witches and wizards gives way to these thoughts in the mind of the common folks. In all of this, we must make the distinction between the true sorcerers, who truly exist according to Malebranche, and the visionaries of the senses (madmen) and those of the imagination (fools).

True sorcerers are persons in which self-love has reached an exaggerated hopelessness, and hate, envy, wickedness have triumphed in them, so that they are ready to truly procure evil to others. ${ }^{5}$ A society where no rational distinction is made between the human crimes is a society in the hands of wicked people. Thus, paradoxically, the more the authority will persecute the false sorcerers as the true ones, the more the true sorcerers will expand their influence and power. Madmen will become tools in the hand of true sorcerers and magicians in order to divulged superstition and fear within the community. Malebranche sustains implicitly that judges, because of their role, should be the first to fight sorcery, but it appears that they end with favoring sorcery with their sentences, in which rather than reason, pride in office rules, so that without any distinction among the accused, they sentence equally madmen, fools, and true sorcerers.

In The Search after Truth, Malebranche performs as a scientist, and in the second book, he acts as the psychologist of imagination. He avoids speaking about the false questions of a confused theology applied to anthropology. In many passages of his works, he states the principle that we must give to faith what is its own: there should be no intrusion of faith into the vicissitudes of miserable human beings. He knows that precisely those authorities who are supposed to 
eliminate sorcery share the mentality of the sorcerers. He knows that is almost impossible to convince these authorities that they are condemning indiscriminately fools, madmen, and true sorcerers. Visionary judges and sorcerers of the imagination end by supporting the true sorcerers who are malign and wickedly disposed toward other human beings. The positions of Malebranche, beyond the theological perspective, will always be valuable and actual. Imagination moves in the darkness of confusion and does not allow seeing wickedness where truly it is. The judges with imagination become unconscious accomplices and victims of the sorcerers. The truth remains that the sorcerers of imagination do not possess a wicked heart as the true sorcerers; they simply have a feeble ability of ratiocination that permits the presence in them of all the infantile characteristics and the foolishness of the pagan spirit. "I well know that certain persons will criticize me for attributing most tales of witchcraft to the strength of the imagination, because I understand that men love what frightens them, that they are angered by those who wish to disillusion them, that they are like those hypochondriacs who listen with respect, and faithfully execute the orders of doctors who make dire prognostications for them. Superstitions are not easily destroyed, and one does not attack them without encountering many of their defenders; and this inclination to believe all the dreams of demonographers is blindly produced and upheld by the same cause that makes the superstitious stubborn, as is easy to prove."' The imaginary sick individual will believe the doctor whose prognosis agree with his own fantasized sickness. A menacing deity will be believed and its orders followed by a superstitious mind, in the same way than the hypochondriac follows to the letter the prescriptions for curing a sickness present only in his fantasies. The pagan, by definition a superstitious being, will scrupulously believe all the physical events and interprets them as auspices because they correspond perfectly with his sentiments and fantasies. "If I am afraid, there is a reason for my fear; my fantasies tell me there is a reason and this reason exists in an invisible power that can destroy me or in a malefice that will ruin me." This, in synthesis, is the tortuous and often unconscious reasoning of the visionary, the sorcerers with power of imagination, the superstitious person, or, in one word, the pagan. Pagan thought is a visionary thought, superstitious, that expresses itself and is based on a natural language, sensible, without the abstractive character of the scientific language and of all those who reflect and use reasonableness. Malebranche, in the following paragraph, narrates how superstitions are perfectly integrated within the structures of society, within language; how the mechanisms with which society strives are effectively functional for the divulgation of superstitions. It tells what a shepherd returning home, after his imaginary participation in the witches' Sabbath, told his wife and sons.

A shepherd in his hut after supper tells his wife and children the adventures of witches' sabbath. As his imagination is moderately heated by the vapors of wine, and as he believes that he has attended several times this 
imaginary assembly, he is sure to speak in a strong and lively manner. His natural eloquence, joined to the disposition of his family to listen attentively to a subject so novel and terrible, doubtless produces strange impressions in weak imaginations, and it is naturally impossible that his wife and children should not be quite frightened, impressed, and convinced by what he has told them. He is after all a husband, he is a father talking about what he has seen, of what he has done; they love and respect him; why would they not believe him? This shepherd repeats his tale on different days. The imagination of the mother and children gradually receive more profound impressions of it; they become accustomed to it; fears pass, and conviction remains; and finally curiosity brings them to the witches' sabbath. They annoint themselves with the particular drug prescribed in the story; they go to bed. This disposition of their hearts warms their imaginations still more, and the traces the shepherd has formed in their brains open sufficiently for them to judge in their sleep that all the movements of the ceremony whose description has been given to them are present. They wake up, they speak with one another and tell what they have seen. In this way they fortify the traces of their visions in themselves, and the one who has the strongest imagination, being more persuasive than the rest, is sure to take charge of the imaginary history of the witches' sabbath in a few nights time. Here then are the accomplished sorcerers the shepherd has produced, and they themselves will one day make many others if, having strong and vivid imaginations, fear does not prevent them from recounting such stories. ${ }^{7}$

All the elements that according to Malebranche characterize the pagan mind are present in this narration. In the shepherd sorcerer are also found all the psychoanthropological elements that Vico attributed to the heroes founders of the first families. The same mental structures and the same social dynamics emerge from the analyses of the shepherd of Malebranche and the heroes of Vico.

\section{Dreams and Daydreaming}

The example is about a family situation, which is the foundational nucleus of every society. The story is about an event that is of an imaginative and implausible nature. The shepherd is an illiterate, solitary individual that spends most of his time in isolation in touch with nature, in situations favorable to the activism of the fantasy. Because of the wine, an external cause, the fantasy is excited and the desire to share is overpowering. His way of speaking hits his intimate audience with the force of the sensitivity and vivacity of his mimics. Malebranche underlines that the shepherd's eloquence is natural, born from his sentiments and directed to the sen- 
timents of his familiar listeners, who are attentive and well-disposed toward him. In addition, the shepherd plays the natural function of authority within the family, inculcating both fear and love. What he says carries an absolute validity. His wife and children are gradually familiarizing with the new thoughts and the new images, as he returns at different times to this story of the witches' Sabbath. Moved by curiosity, the family inclines to the idea of the participation to the strange meeting, meanwhile they simply enjoy dreaming about it. In time, it appears that the children cannot distinguish the difference between reality and imaginations, dreaming day and night. The fear is gone; their vision of the Sabbath is familiar and constant. The internal fire will continue to burn.

The idea of the Sabbath represents a cognitive stumble. An imaginary reality is created that is alternative to the phenomenal reality in which we all live. This alternative reality is all shadows with a few lights, which are not enough in order to recognize definitively the different objects, their precise nature, and what actually happened. The idea of the Sabbath, from being a fantastic tale narrated by an intoxicated father, has finally become a true story. The shepherd has truly formed real and perfect sorcerers with the force of his imagination. At this point, Malebranche focuses on the future of these children and sees the propagation of the horrors of superstition once more through the families that they, growing up, will form. Superstitions or false credences like that of the Sabbath are many within society. They are common and contagious. Only the new superstitions will require a powerfully imaginative and domineering mind. To absorb a superstition is facile, but in order to create one is needed an extraordinary faculty. This is manifest, when we think of the tales of the big bad wolf (Lupo Mannaro). ${ }^{8}$

The belief of being a werewolf originates from a more terrific and horrible imagination than that of thinking of having participated to a witches' sabat. This psychic phenomenon will be rarer than the Sabbath. However, when someone will be so mad to believe himself a lycanthrope (a werewolf or alien spirit in the physical form of a bloodthirsty wolf or a monster able to change appearance from human to wolf and back again), there will be a large number of people well disposed to accept that he actually is a lycanthrope. The anthropological principle of this phenomenon tells us that in order to create a superstition is enough to have an altered and strong imagination, but for its reception and acceptance the usually common human imagination is sufficient. A second principle regulating this behavior is that an objective ambient situation, joined with a subjective altered mental condition, determines absurd superstition. These two principles of Malebranchean psychology indirectly confirm the particular reconstructions of myths and primitive societies formulated in Vico's works: human beings began thinking when they imagined the sky a greatly animated body. It was not a farfetched theory, since in those first and primitive poets a concomitance existed between the ambient situation and the altered human emotivity. Fantasies are like dreams, daydreams, and follow their own developmental logic. The confused representations of passions 
follow a different logic than the intellect; fantastic or oneiric thought run on paths alien to the reasonableness. All human beings experience that as the night comes infinite sentiments spring up in the mind and force it to formulate a multitude of symbolisms. The night means a break from the reality of the day, but not for the

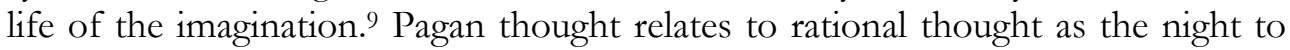
the day; thus, a visionary, a superstitious person confuses his life with his dreams; for him, in a certain way, the day is in the darkness.

The visionary is a person capable of impressing in the brain the deep traces of the fantastic representations that he imagines. For this reason, he can have a clear memory of the dreams that, in his brain, according to the scientific terminology of Malebranche, have left their signs. ${ }^{10}$ The ambient itself contributes to the growth of the imagination: the night does not allow the clear delineation of things; the effect of the ceremony confuses totally the mind; the belief of having a lycanthropic nature. Under this aspect, no continuity between the shepherd in the day and the sorcerer at night, between the normal human being during the day and the lupo mannaro at night, exists. The example of the lycanthrope indicates clearly that folly, uncontrolled imagination, may change the nature of the human being: the madman as the pray of his own fantasy would see his hair grow, feel his premolar teeth change into canine, desire to howl to the moon, slobber and perceive sounds and odors of which before he had no sensations. All reality would change about him. Abnormal passions and fantastic representations will torment the feeble mind of the unfortunate man-wolf, and the ambient situation of the night would be propitious.

One preferred tool of the Cartesians is the distinction. Sorcerers and lycanthropes are very little Cartesians; they do not know how to distinguish the night from the day, sleeping from waking; their life is a continuous dreaming. "The chief cause that prevents us from taking our dreams for reality is that we cannot connect our dreams with the things we have done while awake, for this is how we recognize that they are only dreams." 11 Descartes and Leibniz remarked that the unique difference between sleeping and waking is of a logical gnoseological order: a lack of connection exists between daily and nightly representations. In general, this has been the thesis that all Post-Cartesian philosophers have accepted. Kant adopted it. Malebranche used it.

For an individual in full possession of his mental capacities this system is functional, even though, as Descartes advised in the First Meditation, it may happen to anyone to get confused. Things move in a different direction for sorcerers, wizards, witches, and lycanthropes. They have no need of an evident connection or distinction between daily and oneiric representations. The last representation of the day connects with the first representation of the night in a manner similar to that uniting the representations of the preceding day. The waking of the madman is an illogical representation similar to the representation of his dreaming. He lacks a point of reference. He cannot distinguish between waking and dreaming because 
he is dreaming even when awakened. ${ }^{12}$ The sorcerers described by Malebranche have no points of reference like those of normal human beings. They cannot be convinced by us, when they cannot accept the presuppositions on which our ratiocinations stand. Sabbath represents an alternative way of communication with nature and the individual self. The world that opens itself at night in the Sabbath celebration is a reality different from the one we usually perceive; it is a dimension disconnected from the logical, conventional, and rational ties that gives some coherence to reality. Malebranche's paradox states, "In the mind of the visionary wizards, the more the representations are puzzled and bizarre, the more they will seem real." The more the imagined reality is removed from the one effectively experienced, the more it will seems true. We must immerge ourselves for an instant into the reality of these sorcerers and lycanthropes of the society in the seventeenth century: they are avoided by all, when not openly persecuted, abandoned by relatives and friends, because of their mental disorders unsuitable for any minimal kind of work, and without any material goods or support.

Logically, we could think that these special individuals would be concerned primarily on how to provide the goods for their own survival. On the contrary, they would believe to be exceptional creatures, capable of changing into different beings or of participating in special ceremonies or of thinking out fantastic entities that for us still may be abstract conceptions like demons, deities, werewolves, and witches, while for them they are what there can be of most concrete and effectively real. 


\section{TWENTY-TWO}

\section{THE CONCEIT OF THE LEARNED AND THE PROBLEM OF KNOWLEDGE}

Malebranche stated, "Scholars often do not pay attention to what they are told because the vanity of their erudition inclines them to judge things before formulating a clear opinion of them. The learned fall in those gross errors, from which the common people are preserved." Knowledge can function as an obstacle in the acquisition of new knowledge when, because of emotive falseness and pervasiveness, it occupies fully the mind of the learned person. The pagan mind is not typical of the analphabets or of the less learned part of society, but also of those "learned" individuals who approach knowledge with knowledge already acquired by memory and under the impulse of vanity. The obtuseness of these so-called learned persons is as perseverant as that of the shepherds by force of imagination sorcerers, or as the lupi mannari who, howling to the moon of their false wisdom, believe in being some special critters, superior to others. These scholars do not search truth but the affirmation of themselves. Their presumptions make them aloof to the calls of reason: they hear only what they themselves say and do not accept the interruptions of their soliloquy. At times, they ask for explanations more convincing than the ones they appreciate for their arrogance. Many times, they ignore fully any appeal to reality, because reality is too far removed from the idea they have constructed.

\section{The Boasting of Scholars and New Learning}

Within the real world presented by reason, they occupy a minimal part of the place that instead their intellectual megalomania has in the world of fantasy. For the learned persons (who for Malebranche are the majority of the intellectuals) learning and knowledge represent only a way for personal affirmation, as it is for money, position, and political power. For them, studying and learning is secondary to the goals they wish to achieve. Knowledge (the false one pretending to be true) is a means that self-love uses for satisfying their boria or conceit, arrogance and presumption of superiority. People who search for knowledge with this kind of 
dispositions will not advance their learning but stand tenaciously on their positions. Their conscience will be one with their ideas, with the force of their boasting and selfishness. ${ }^{1}$ The stubbornness of ideas, the tenacity of prejudices are determined by the same passions that have brought them to the search for knowledge. These scholars, with their attitude and unknowingly evince a typical characteristic of the pagan mentality that in peoples of lower culture will remain latent. It consists in the obsessive attachment to personal intellectual credences that are retained without any critical analysis, the most recent ones piled up on the previous, forming piles of cognitive structures based on prejudices that they have never doubted or discussed. The tendency of the primitive or contemporary pagan is that of accumulating, adding knowledge to knowledge without questioning the real consistency of the presumed reasons that are the foundations of the castle that the mind is in the process of constructing. The tenaciousness of beliefs is always the product, proportional in its strength, to the intensity of the passions that brought the spirit to thinking. Anyone who wants to know anything in relation to a desire, inclination, or passion must form a knowledge that is suitably favorable to such desire, inclination, or passion. The greater the force of the passion (cause), the stronger the tenaciousness (effect) with which the new belief would attach itself to conscience.

The knowledge obtained through these passions will be a tenacious knowledge with essentially mnemonic characteristics. A learning as a mere fruit of reflection would automatically avoid the prejudice; false credences are prejudices that are rooted on a mentality that is the combination of other previous prejudices. The only activity (an inappropriate term in Cartesianism) in the pagan mind is that of the imagination, and it is essentially mnemonic. When this activity invents, it invents so to confirm the credences to which it is connected. This activity consists in a process of coercive confirmations of previous credences, which, if unsuccessful, will be followed by a secondary ones intended to support the primary, and so on. Passions are the connectedness of the prejudices, but also the causal force for creating new prejudices proving the previous ones. These scholars "are afraid of not being superior to their auditors, become angry even when the students follow them, frighten when students ask questions, and shield themselves with pride when the students contradict them. Finally, they bubble over things so novel and extraordinary ... that their listeners remain like stunned."2 Speech is turned into the show of a juggler. The goal of communication is not the search for truth, but the compensation of passions, the search for a fictitious equilibrium resting on the establishment and reinforcement of credences that are false but useful to the economy of self-love. Scholars inclined to boastfulness shide from being understood and their speeches do not communicate knowledge, but the personal affirmation of the speaker. These learned persons want to change their auditors into followers of their vanity: their speech merely proclaims their superiority over the common mass of people. 
The boastfulness of the learned is similar to that of the Stoics, whose language is for its end and content identical to that of Seneca and Cato. The paradox that produces their conduct is such only in appearance: "They always look for some argument by which to defend themselves; they never speak with more ardor and conviction than when they have nothing to say; with each argument that is brought against them, they imagine that they have been insulted and that someone is trying to belittle them; and the stronger and more judicious these arguments are, the more it irritates their aversion and pride."3

The boasting of the learned is the same boasting of the Stoics and of the sorcerers of imagination. Boastfulness is vanity in the pagan mind. In all their life, when they should have been silent, they spoke in order to be admired, congratulated, and for conquering the souls of others, glorifying themselves. Their thoughts are all focused on that. These scholars think of themselves as of exceptional persons, chosen, in which passion is what speaks and to passions this passion speaks. They convince others only in so far as the listeners are disposed to the reception of sensible solicitations and of the phantasms of the imaginations. These passions construct the fantastic superiority of the individual on the quagmire of their frailties; they convince by filling up the imagination and emptying the intellect. When the end of knowledge is not the truth, language, studying, and credences automatically clear their content, which become one thing with the expression, the rhetorical figures, the images that these tropes generate. It is for pure vanity that the boastful learned loads himself with the hardship of studying, reducing thought to something futile. Again, we have a narration from Malebranche:

In our unhappy state, it often happens that the least rational passions encourage us more to seek the truth and offer greater consolation in the difficulties involved therein than the more proper and more rational passions. Vanity, for example, agitates us a great deal more than love for truth, and we daily see people constantly studying when they know there are others to whom they can relate what they have learned, but who give up their studies altogether when there is no one to listen to them. The confused perception of the glory they will receive when they announce their views sustains their courage even during the driest and most uninteresting studies. But if, through circumstances dictated either by chance or by necessities of life, they find themselves separated from their little flock of admirers, their ardor immediately cools; even the most worthwhile studies no longer have an attraction for them; disgust, boredom, and vexation overtake them, and they give up everything. Vanity triumphs over their natural sloth, but sloth, in turn, triumphs over their love for truth; for vanity sometimes stands up against sloth, but sloth is nearly always victorious over love of truth. ${ }^{4}$ 
With the example of the boastful scholar, who through his studies runs away from the dangerous world for which he feels inadequate, Malebranche intends to sustain that the pagan kind of thought is born from the feebleness of the human nature.

\section{The Power of Vanity}

Pagan thought is the psychological answer to the team of passions that opens the way to the sense of inferiority and produces vanity and pride. Human thought then will channel itself through the only path in which self-love will have some chance (though imaginary) for a self-satisfaction: the path to wisdom. These boastful students, who embrace a life of studying in order to avoid a competitive world, become brave and volatile in the hope of attracting some attention from the world that they have repudiated, no matter how complex the difficulties and the problems they will encounter. All of this, for a secret sense of individual vanity. A passion like vanity succeeds in winning fear, in transforming the practical coward into the imaginary hero capable of facing tasks superior to his capacities and mediocrity. Those who are physically frail (or believes so) and live with their frailty in relation to their ambient, find an escape and a refuge in their imaginary spiritual or intellective superiority. "In order to recognize that we are vain we must test, examine, and scrutinize ourselves. We do not know enough that vanity is the motor of the majority of all our actions and though our self-love knows it, it knows it for no other purpose than camouflaging vanity to the rest of ourselves." 5 What the human being does, it does it in order to comply with the imaginary goals that selflove planned in its confused conscience. Another important characteristic of the pagan mind is that it knows no art of management; its only leverage is the imagination. The only true point of support for thought is reason, but when reason is gone astray, no compass and no polar star will be available.

Vanity is the "hidden" cause determining the greater part of the activity. No one is conscious of it, because to admit to ourselves that we do what we do for vanity is equivalent to recognizing that we would like to be tall and strong because we are small; that we want to be sturdy precisely because frail; that we aspire to a spiritual loftiness because we are lacking the prerequisites to a superiority in the normal active life. To recognize personal vanity would mean recognizing personal inferiority, except in the case of Montaigne. ${ }^{6}$ In Montaigne's age, the recognition of personal vanity became a fashionable thing, in which case vanity, because of the paradoxical play of self-love, is not denied but affirmed twice. As Malebranche says, quoting Montaigne (but for darting against him his own words), the praising and despising of oneself originate from the same spirit of arrogance. For Malebranche, this is a serious indication of the corruption in our modern age, his and ours. 
The admission of personal deficiencies and faults for proving personal superiority even in weakness instead of for redemption is purely absolute vanity. Vanity is the heat that activates the bundle of human corporeal actions. Vanity is the force of gravity of the soul that continuously acts with the same intensity and whose awareness appears when challenged. As we do not notice the temperature of the body, so we do not notice the emotional heat produced by vanity, which can continue its work of conditioning because hardly we can achieve consciousness of it. ${ }^{7}$ Vanity is likely so combined in our conscience that rarely we sense its control over us. Vanity drives us into action in order to gather the goods the imagination presents and itself obliged imagination to present. In this way, self-love assigns a value to all things, to the experiential and thinkable world that provides a conception of reality. Everything has the value that vanity assigned. For a businessman, to whose mind vanity has imposed the value of money, money will be the worthiest thing, while for a Stoic whose mind's vanity and imagination have presented an invisible superiority in the riches of thought, money will be nothing. Verisimilarly, in two men moved by the same vanity, may prospect to one the value of wealth, to the other the absolute detachment from wealth. The value that vanity attributes is the measure of the distortion that will occur between the representation of the imagination and the clear and distinct idea of the thing.

Returning to the consideration of the learned, Malebranche asks,

And what can support them in their thankless, disagreable, difficult, and useless work if it is not the hope of some elevation and the sight of some vain grandeur? Indeed, We look at them as rare men; we compliment them on their profound erudition; we listen to them more willingly than to others; and although it can be said that they are usually the least judicious of men (as would be the case if only because they spend their entire lives in such a useless task, which can make them neither wiser nor happier), nevertheless they are imagined to be more intelligent and judicious than other people. Because they are more knowledgeable about the origin of words, we let ourselves be persuaded that they are learned in the nature of things. ${ }^{8}$

We can apply to these individuals the things said about the Stoics. They spend their years in a demanding and painful task for the approval of a superficial and uninterested public that will soon forget them and support instead those who affirmed the contrary of what they previously approved. Vanity makes us to believe that things are as desired. The darkness that vanity brings to the mind cannot be removed because it is the effect of all the prejudices accumulated and fixed firmly in the mind. 
We have dealt with the passions that brought to human beings the desire of being better or superior to others. We should now analyze a passion that is equally shared by the active and passive agents in this relationship: wonder. 


\section{TWENTY-THREE}

\section{PASSIONS AND IMAGINATION: THE POWER OF WONDER}

The anxiety of knowledge is not the desire of achieving the loftiness of truth, but the need of calming the passions that upset a delicate and sensitive spirit. At this point, the ideas of grandioseness and rareness begin their way within the human conscience. The spirit tends toward those goods that appear with rareness and grandioseness. The enchantment of such objects provokes in the fantasy what suits perfectly the passions for knowledge. The attention is absorbed into the orb of imaginary goods and sensible satisfaction. ${ }^{1}$ The anxiety of knowledge is tied with the double knot of fear and insecurity. In all uncertainties, the anxiety of knowing is stimulated, and the greater uncertainty will kindle the greater anxiety for the knowledge of the causes of precariousness and insecurity. Conscience will begin to search for the solution and will slide into the easy trap of the false judgments of imagination and passions, which at their turn will propose in grandioseness, splendor, and magnificence, everything that may cause wonder.

\section{The Dynamism of Passions}

Knowledge becomes the pretext for satisfying anxiety, which is the apparent concern for knowledge. The search for verities comes to be replaced with curiosity for everything that charms sensitivity. "Some people are taken by almost every trifle, and their occupation is always justified by the false judgments their vain curiosity leads them to make"2 Thought is almost fully dedicated to the operation of justifying the duping judgments that curiosity and the passions have formed in the mind of human beings. Personal credences are formed within this dynamics. Primitive passions, like fear, wonder, and various other appetites, incline human subjects to scrutinize the surrounding world, with curiosity, not directly like an animal would do. In the world, they will search for an outlet to the anxiety accumulated in their spirit and that they cannot abort with an instinctive action.

Judgment is born in the pagan mind in this way. The natural phenomenon is interpreted by a thought confused under the oppression of tortuous passions 
and sentiments, and the judgment that follows the interpretation will need its justification. Credences and superstitions formed themselves in this sequel, and a chain of justification will follow them by natural necessity, without ever providing a true justification. Psychologically, thought is born as a justification of experienced passions; the natural tensions of our spirit for the preservation of the equilibrium use credences for opposing each passion. Like in a puzzle, prejudices and credences of any kind connect together in the mosaic of the imagination. The mind remains as prisoner of the alliance between desires and ideas, so that the vision of verities is completely buried under the fantastical layers of verisimilar representations. "For, in short, in order to infer immediately which judgments are those that the passions make us form, it is enough for us to suppose that all the passions seek their own justification and that they distract the imagination and then the mind in such a way as to preserve their own emotion." 3 The passions can control the mind through the imagination, because the imagination is the "abstractive part" of sensitivity. Sensitivity is the door of access to the soul through the passions, because the passions of the soul are the actions of the body. The passions can direct the mind through the imagination, and those with a strong imagination are more vulnerable to the actions of the passions. This individual person will be the better instrument than others in the hand of the passions for the purpose of conveying images and passions to other individuals. Malebranche says,

Those of an active and vivid imagination and those extremely sensitive and liable to the impulse of the passions can see these things for themselves perfectly well from their sensation of what takes place in them; and they even speak of them in a way that is more pleasant and sometimes more instructive than do those who have more reason than imagination. For it should not be thought that those who best examine self-love and whose penetration into the inner recesses of the human heart is deepest are always the most enlightened. Often this is only a sign that they are livelier, more imaginative, and sometimes more malicious and corrupt than others. ${ }^{4}$

This paragraph shows the motive why he who is provided with most imagination transfers his visions to others. This mechanism appears to be avoiding the consciousness of the person and it happens unconsciously because as motivation it represents the cause of the action by referring to sensation. We know that the more knowledge is of a perceptive character, the more the subject, referring only to sensitivity, is unconscious of the real causes that produced it. The example for this was given above when speaking of the vanity. As heat makes possible the physiology of the body without our conscious involvement, so vanity influence the human being though it is not aware or pays attention to it. The visionary of imagination can influence others, in the sense of inducing the same psychological 
processes that determine him. The visionary is a person who can convince himself and the others with an extreme facility that what he thinks is true; he can find with extreme facility justifications to his own superstitious credences. ${ }^{5}$ Passions and superstition reinforce each other reciprocally. After the credence is formed, to preserve itself, it should find a passion from which it could receive conviction and force. If passion and credence come together properly, if one finds in the other an ally, then they reinforce themselves equally. If the passion is sufficiently strong and the credence enough verisimilar (that is plausible to the imagination), reasonableness will hardly be capable of rescinding their association.

The conditioning to erring does not end here. The passions, says Malebranche, never travel alone. The human spirit is the perfect place where the associations among the passions happen. A passion is often the spring of another one; a passion can give birth to another and make it grow. The pagan mind acts in this way: it unravels itself among the thread of passions, sentiments, visions, fantasies, and the setting up of images. All of this comes together into a whole and then sets itself up into a structure that the more it grows and diffuses in the mind, the more rigid it becomes. This structure is the mentality, by definition rigid and certain but not to the point of becoming immobile, like death. On the contrary, passion and imagination would start a noticeable dynamism that is not like the one that reasonableness would provide. We should keep in mind, "For the passions are in no way indifferent to one another. All those that can exist together faithfully contribute to each other's preservation. Thus, the judgments that justify one's thirst for language, or for whatever else you may wish, are always cared for and reinforced by all the passions that are not contrary to this desire." 6 Passions do not present themselves to the soul in a parade, or in an Indian line, but all together in a coalition. Passions alone cannot survive, because they will be like a faint flame that will never develop into a roaring fire. An isolated passion does not exist. Human beings are slaves of none or a multitude of passions, because of the power of vanity.

If each passion acted only in its own behalf without caring about any others, they would all disappear soon after their birth. They could not form enough false judgments in order to subsists, nor could they long support the imagination against the light of reason. But everything about the passions is arranged in the most appropriate way possible for their mutual preservation. They strengthen one another, and even the most remote are of help; and they need only fall short of being open enemies to cooperate in following the rules of a well-ordered society. ${ }^{7}$

The "logic" of passions exists; an order, within which they organize themselves, unless a "contradiction" between them will not allow coexistence, exists. Passions have their regulated society; each assumes a natural position in respect to all the 
others, according to a specific hierarchy. For their survival within the human spirit, passions need to respect a second condition: they must be with a mental perspective. $^{8}$ In order to remain active and for a long time in the conscience, passions must refer to an idea or a credence (an unchanging series of representative ideas), in which case they will have a steady "referent." It is believed that the strongest and longest-surviving passions are the passions that come with the most vivid sensations, like suffering, bereavement, and offenses. Malebranche denies this. The passion of fear that comes with pain is combined with pain and vanishes as pain subsides. Even animals seem to be afraid of pain (but not so for Cartesians). The fear of suffering when suffering is present is substituted by the suffering. A strong and long-persevering fear of suffering exists when suffering is not yet present but there are "reasons" or verisimilar motives (verisimilar is what appears true to the imagination) for believing that it is incumbent.

A similar discourse is done for the event of death. It is in doubt accompanied by probability that fear fires. Passions needs to plant themselves on the "ground" of sensitivity, but without a mental perspective they will not grow and survive. This is true particularly for the "social" fears, like hate, envy, and jealousy, interwoven with false representations of the individual conscience by self-love. To understand this is to understand the nucleus of the mental gentility, the center around which all superstitions, false credences, uses and customs, and the majority of the rules that societies dictate, move. If a passion joins a representation, or better, if a number of passions link themselves to a sequence of representations (that is the credence, the cognition of ourselves or of others), then they become stable and they steady also others. A passion can continue for a long time, meanwhile the representation of the thing is gaudy. The life of a passion at its birth is due to the sensation, but its survival to the representation. For this reason, at times, we attribute our own passions to animals and even inanimate things. "Thus, we attribute to the objects of our passions the emotions they produce in us, and we believe all other men, and sometimes even beasts, to be moved by them as we are. But besides this, we even more rashly judge that the cause of our passions, which is often only something imaginary, is really in some object." 9 This is a trick that the imagination and the passions throw at us. This is the unhealthy principle assumed by the pagan reasonableness, the upturning of reality; what scares us is our fear and not the thing in itself; the passion grows itself from within itself. The lightning and the thunderclap with their exceptionality become the cause of the fear in all those who have not the clear knowledge of their own spirit and nature. The gentile truly believes that they are the intimidations of an arrogant god, the true causes of his fears. Fear is not coming from us, but from thunder and lightning, the true cause of a sentiment of which we know not the origin and is confused and chaotic in a more troubled spirit. If we attribute to the objects of our passions the emotions that they stimulate in us, given that we feel ourselves alive, then alive must be nature. This Malebranchean principle finds its correspondence in some Vichian axioms (pars. 120, 180), 
of which the first says, "By its nature, the human mind is indeterminate; hence, when man is sunk in ignorance, he makes himself the measure of the universe" and the thirty-second, "When people are ignorant of the natural causes that produce things, and cannot even explain them in terms of similar things, they attribute their own nature to them. For example, the masses say that a magnet loves iron." Almost all the philosophers of the seventeenth century agree with Vico, but Malebranche is the only one who studied and deepened the knowledge of the emotive-cognitive structure of passions. One passion "typically Vichian," more than in any other work of the Grand Siècle, has been amply and carefully studied in The Search after Truth: wonder.

\section{Marvel and Wonder}

[Wonder: the emotion aroused by something awe-inspiring or astounding.

Marvel: one that evokes great surprise and admiration]

The human beings pay attention to what stimulates the imagination, to what marveled them. The passions determine the object of knowledge. Humans are not interested in what failed to stimulate in them some sentiments. If something does not touch us in the interiority of our soul, if something does not give way to a motion of attraction or repulsion, then we will feel nothing, even if that something is within the field of our perception. As our perception moves away from that something, it will be forgotten; nothing remains of it in us. A certain dosage of passionateness, given our actual conditions, therefore, is indispensable to our knowledge and consciousness. Actually, the dosage (the measure of force of the passions) itself has the power of differentiation. Malebranche has told us,

Each of the passions has two notable effects: it applies the mind, and wins over the heart. Insofar as they apply the mind, the passions can be very helpful in knowing the truth provided we know how to use them; for applying the mind produces light, and light reveals the truth. But insofar as they win the heart, the passions always have a bad effect because they win over the heart only by corrupting reason and representing things to it not as they are in themselves or according to the truth but according to their relation to us. ${ }^{10}$

In moderate doses, the passions drive to knowledge, but when they addressed themselves to the heart, they may poison it. To be of usefulness to knowledge, passions must relate to the spirit in the right proportion, and avoid the concerns of the heart. 
Of all the passions, wonder least affects the heart. For we are agitated by seeing things as good or evil, whereas seeing things as new, great, or extraordinary, with no other relation to us, hardly affects us. Thus, the wonder that arises when we realize the greatness or excellence of something we have just begun to consider corrupts reason a great deal less than any of the other passions, and it might even be put to great use toward knowing the truth, provided that great care is taken to prevent it from being followed by other passions, as it almost always is. ${ }^{11}$

Wonder is the passion that comes with things new, astounding, greatly impressive and rare. We can say that wonder is "neutral" because we do not marvel directly at the consideration of good and bad things, useful or useless, safe or dangerous. Wonder and marvel corrupt the mind less than any other passion, and more than any other passion can help in the search for truth. Generally, wonder is not alone when traveling through the traces of the brain; with other passions, wonder grows and survives. But how enduring can wonderment be?

The passion of wonder has a great import among all passions. Wonder is connected with the new ideas and makes possible the progress of thought. Without wondering, we will not think about new things, we will think always the same things, and perhaps we will not think at all. At the psychological level, in our existence there must be the first moment when we will think the first idea, which as the first will be new in the absolute sense. Wonder is the passion that surges when we think a new idea or a new connection between ideas. It is an imperfect passion nevertheless because wonder does not originate in the body or is not completely determined by corporeity. Among all passions, wonder is the most frail and most "intellectual" because it deals with the novelty of an idea or judgment (a link between ideas), never before thought. The scientist, discovering something, will marvel at what he found. ${ }^{12}$ Wonder determines the development of the thought that accompanies the new links between the old ideas and the new ones, and among the new ones. The person overcome by wonder is a person overcome by turmoil, a sensitive jolting, and a natural event may arouse in him the sense and idea of a grandeur and magnificence that act on his nervous system causing an agitation that cannot be discharged in an instinctive action. The physical and mental agitation will incline the person in question to apply himself considerately to the represented object and attribute to it the proper characters of the passions that overcame him. A feeble sensation, unexpected and out of the normal routine, can so impress human sensation that it will concentrate on the object that has provoked it. This represents the psycho-physical substratum of wonderment. ${ }^{13}$

Novelty often contributes and sustains the feebleness of a sensation, thus provoking a considerable motion in the body and in the soul. Wonder and, in general, the attention to something new, introduces a new element that, in part, is hardly classifiable within the Malebranchean psycho-physics. If the movements of 
the body through the laws that regulate the union of body and soul are "parallel"- -they are linked in an occasionalistic way with the movements of the soul (thoughts, passions, sensations, images)— then some specific ideas will correspond to specifically determined traces. This statement represents what happens, but in Malebranche's theory of wonder an asymmetry is noticeable that has to be necessarily explored in the relationships of body-soul. The general perspective must be extended and a new analysis is needed. The asymmetry is not between traces and sensitivity but between the physical perception, the trace, the sensation, the emotion, and the ideas. How can a feebler perception provoke a greater commotion of animal spirits and rouse more intense sentiments than a stronger perception? If the rigid determinism of the laws of nature and of human nature is real, how is it that the stronger perception did not necessarily provoke more emotions and passions than the feebler one? Someone may object that the pain felt after a serious injury provokes the most intense sensations beside which all the rest pale; no novelty can stand the comparison. But this is not the point of our discussion. How can novelty, which is not a physical phenomenon but a psychological event, supplement the intensity of a perception? In other words, how can wonder, a frail and imperfect passion, reinforce a feeble sensation in relation to a stronger one?

Once more, the solution is found in the idea of imagination that Malebranche elaborated in the second book of The Search after Truth. ${ }^{14}$ Our perception can give rise to images in our mind. Our imagination can provoke strong perceptions or, at least, amplify them. The lane that goes from the body to the soul, from pure perception (not the sensation, which is a psychological phenomenon, but the physical event as it is understood in the seventeenth century, from the motion of the animal spirits and traces) to thought, is a double way street. In this way, the will, too, will perform its role. On a one-way street, the will could be unable to oppose; the will will be annulled not in the psycho-physical determinism, but only in the physical one. On the contrary, the will could oppose the intensity of the sensations exercised on the attention, or suspend judgment. We must keep this context present, if we want to penetrate the meaning of the analysis done by Malebranche in his work.

We know that to be known, something must be emotively relevant. For Malebranche, as for Vico and many other thinkers, knowledge emotively relevant is the product or, at times, the associate cause of the exceptional agitation of the animal spirits. Every new knowledge implies a break from ordinariness (from the ordinary motions of the animal spirits), a change and, consequently, a revolution in the cognitive individual system. Wonder can bring us closer to truth if it breaks the structure of our prejudices, if it will serve reasonableness. Wonder, unfortunately, can also make us unaware subject to the worst credences, if guided by the lower kind of curiosity, by turbid passions and the self-love that blinds the intellect. 
It is not enough that wonder should arouse our attention, it must also make us inquisitive; it is not enough that we should have considered one aspect of an object, to know it fully we must be inquisitive enough to examine all its aspects; otherwise we have no basis for a solid judgment. Thus, when wonder does not lead us to conduct a complete examination of things, or when it prevents us from doing so, it is altogether useless in knowing the truth. In these cases, it stocks the mind only with probabilities and leads us into rash jugments about everything. It is not enough to wonder simply for the sake of wondering; we must wonder in order to examine more easily. ${ }^{15}$

In a rationalist, wonder originates from an invention of the intellect; the cause of wonder is a truth of reason. In a pagan, wonder is generated by the presentation of a new image in the conscience. The pagan mind makes no efforts for the search of truth, but rest content lying on the comfortable positions of the verisimilarities. Then, it will judge temerariously about all things that will make it marveling. It is important to notice that wonder is the spring that moves us to examine the nature of things, no matter if afterward it will form either false or true ideas. Wonder establishes the break in the conception that the subject has about reality; wonder forces the individual to change perspective or to acquire one, if it had none. As we know, children wonder and marvel at everything. Vico and Malebranche considered this fact marvelous! With wonder, the child approaches reality, and comes to know it. Though his knowledge is marvelous, non conducive to truth, it is still important because before this moment the child had no vision of the world, or had it in a less structured fashion. Wonder has a foundational importance in the formation of thought: in goodness or wickedness, wonder accrues knowledge. In this case, the difference between the good or bad effect that may come from it is determined by its emotive intensity. Within limits, wonder is useful for the acquisition of truth; beyond those limits, wonder may become counterproductive.

But when we are aroused by an impulse of wonder, the animal spirits naturally flow into the traces made by the object exciting it. They clearly represent this object to the mind, and they perform whatever is required in the brain in order to produce light and certainty without the will exhausting itself in controlling the unruly spirits. Thus, those capable of wonder are better suited for study than those who are not; they are nimble-minded whereas the others are dense. Nonetheless, when wonder becomes excessive to the point of stupefaction, or when it no longer involves a rational curiosity, it produces a very bad effect. The animal spirits are then entirely occupied in representing the object according to its aspect we are wondering at. We do not think about its other facets that might also be considered. ${ }^{16}$ 
The last consideration of wonderment assumes in the pagan mind a relevant importance. Excessive wonderment becomes bewilderment. The pagan mind, marveled by some phenomenon that is extraordinary, becomes dismayed and frightened. The pagan will consider the phenomenon as it presents itself, through sensible characteristics, always changed by the commuting spirit, and judged it accordingly forming a fantastic idea of it. A reality seen with an attitude of wonderment is a marvelous magic reality that is born and ends with the marvelous aspects that made it relevant in the imagination. To consider an object through the sensible aspects that can dismay and bewilder the mind and excite wonder, means to think it in an irrational manner. Every object is supposed to be considered for its clear and distinct idea, and a sensible wonderment cannot be part of this process of rationalization of cognitions. Wonder, per se, will not become an "escamotage," a side-stepping away from the achievement of truth, unless we make of it an end in itself, then it will tend to the formation and reinforcement of paganism. Wonder has the power of maintaining interest and attention on the representation of a thing so it could be studied. ${ }^{17}$ Abstract things (ideas) are kept in the mind with difficulty, because they are deprived of the sensible traits of magnitude, magnificence, and novelty on which wonder browses and grazes.

From this, we may deduce the principle that the human mind has the propensity to represent things that stirs up wonder, things out of the ordinary normality. The first thought that the pagan mind thinks is provoked by the passion of wonderment. Strange things, things out of the ordinary, unfamiliar, and unprecedented draw attention, excite the sentiments of apprehension, fear, and wonder. Persons without the capacity of reflection are victims to the forces of wonderment and marvel. Wonder is the psychological premise to the advancement and triumph of superstition, idolatry, and a myriad of other false judgments in the pagan mind. ${ }^{18}$ In this, we see the return of the principle that rareness and novelty constitute the propulsion of the motions of the nervous system and of the dilatation of sensitivity. In addition, rareness and novelty warp reason in such manner that thought succumbs to imagination and sensitivity.

The veneration for extraordinariness implies the nullification of oneself in relation to it; the individual subject places his knowledge above himself, becoming its slave. The mind, says Malebranche, does not dare to judge or to stand above what it respects. What the mind reveres in reality is only the fruit of its imagination, a prestidigitation of nature in complicity with the human nature. Furthermore, by becoming subject to what marvels us means to become ourselves marvelous, coming to the possession of those characteristics of exceptionality and magnificence that we revere in the things that marvel us.

Wonderment, then, fuses itself with selfishness (self-love). Great men are the men who admire great things. Great men are those who subjugate themselves to what towers over them, and this is the imagination alone, but at the same time, 
imagination makes them superior to everything else that does not share their wonderment. At the root of this reasoning is a psychological principle: through wonder, the value of things is judged according to their greater or minor sensible magnitude and magnificence, their influential impact on fantasies and self-love. ${ }^{19}$ Things that appear captivating and magnificent are also capable of making us known and magnificent, participants, through wonderment, of their appeal and magnificence. In wonderment, human beings wonder truly only about themselves. Astonished and in fear, human beings bend over before the imagination. Human beings through pagan thought become slaves of their sentiments and concupiscence or violent desires. The sneaky trick that the imagination performed on the soul has another side. If, for an eccentric reversal of reality, fantasy invites human beings to genuflect before the null, then because of a paradoxical somersault fantasy will illude them about the possibility of sharing the power of the universe, ${ }^{20}$ that is, the power of the imagined divinity that wonder has presented to the mind and that, truly, exists only in the imagination. With these assumptions, many social rapports have been delineated: the greatness of a king depends from the wonder that he has excited in the spirits of his subjects, ${ }^{21}$ the same wonder as the stars marveled humankind. These assumptions constitute the elements of idolatry, sorcery, and superstition.

Those great bodies, for example, that revolve above our heads have always greatly impressed men. At first they were adored on account of their size and brilliance. Other, bolder minds examined their motion, with the result that stars have been the object either of study or of veneration of many people down through the centuries. It might even be said that the fear of those imaginary influences that still affect astrologers and weaker minds is a kind of adoration that a humbled imagination pays to the idea of greatness representing the celestial bodies. ${ }^{22}$

The more courageous and ingenious spirit is not the Cartesian spirit, but rather the mad poet, the astrologer that offers horoscopes, the visionary of imagination, the human being with the mind with a feeble intellect, prey of imagination and passion for power. The feebleness of the mind bows to the fascination of the magnitude and magnificence of the heavenly luminaries, to the marvel they generate. Respect, veneration, and adoration come with wonder; they are the elements on which the social hierarchies also are established. Superstition and idolatry are the contributing causes of this madness. "The things that marvel us appear always attractive and magnificent; wonder generates appreciation, respect, and veneration." 23 Wonder is a passion that is greater than others and is capable of universalizing its own representations. The novelty, greatness, and magnificence that provoke wonderment incite the imagination to think about what comes to be present to it as sensibly great, strong, and universal. What is more than what we are, who towers over us, 
excites us to subjection and veneration and this is a form of the superstition. According to Malebranche, the true God asks not for veneration but for love. In the processes of universalization through the imagination, the passion of wonderment constitutes the first step of the process.

The Vichian theory on wonder smacks of the Malebranchean theories. The Vichian description of the wonder that the theological poets experienced when observing the changes in the sky parallels the Malebranchean one. What Vico adds to the Malebranchean theory is the affirmation that wonder is born at the birth of the child. The poetry of the origins is the expression of wonderment for a universe that unveils itself to the human being.

As the first wisdom of the pagan world, poetic wisdom must have begun with a metaphysics which, unlike the rational and abstract metaphysics of today's scholars, sprang from the senses and imagination of the first people. For they lacked the power of reason, and were entirely guided by their vigorous sensations and vivid imagination. This metaphysics was their own poetry, which sprang from an innate poetic faculty: for they were naturally endowed with sense and imagination. Their poetry also sprang naturally from their ignorance of causes. For ... ignorance is the mother of wonder; and being ignorant of all things, the first people were amazed by everything. In them, poetry began as literally divine. For whenever something aroused their feelings of wonder, they imagined its cause as a god. And at the same time, whatever aroused their wonder they endowed with a substantial being based on their own ideas. ${ }^{24}$

The psychological aspect presented by Vico is relative to the greatness and magnificence of the object perceived directly proportional to the ignorance of the perceiving subject. Wonder is the passion that springs from new ideas; it is the passion that makes possible the progress of thought, and, in Vico, also the birth of thought. Nothing newer than myth for the bestione; nothing newer than the first idea in absolute: the first thought of paganism. The thunderstorm is the manifestation of something novel, Jupiter, whom men have never experienced before. Wonder in this case is also the dilatation of the intensity of the imagination. Novelty often can increase the intensity of a sensation to the point of sublimating it into a new thought. 



\section{TWENTY-FOUR}

\section{THE UNIVERSALS OF THE IMAGINATION}

In Malebranche, we have found a theory on the fantastic universals that is even more developed in its structure than the one in The New Science. The universality of the imagination in these two philosophers concerns the same humanity, but different is in them the valence, the applications, and the presuppositions of the theory. Vico narrates about the first human beings in their becoming "modern" (rational through the imagination) whereas Malebranche considers the "modern" human beings (rational through the imagination) in their becoming "post-modern" (irrational through the imagination). If Vico searches for the modern or the birth of civilization in the primitive mind, Malebranche searches for the primitiveness of imagination and passions in the modern mind. ${ }^{1}$

Vico constitutes the positive pole, while Malebranche the negative, but it is Vico's theory of "corsi e ricorsi" that bridges the two poles. Vico's narration is about a natural religion, Malebranche's affirmations are about a positive religion. Vico uses mythological representations, Malebranche instead contemporary stories.

\section{The Fantastic Universals of Vico}

The universality of the imagination is the point on which Vico and Malebranche show analyses that in part are identical and in part complementary. Their metaphysical perspectives are also in part different. For both men, the human beings they describe do not have a mind with the capability of universalizing through reason, but only through the imagination. For Malebranche, the human being lives all his life with and through thought, but his thought is almost totally imaginative. Rational universality, so much important in philosophy and sciences, in the mind of people is lurking, and has no real weight. On the contrary, the universality of the imagination determines the life of all individuals and society. It is not the negative copy of the universality of rationality; it stands at a different dimension of thought; it follows a different logic. 
The universality of imagination functions like the similarity of ideas and their reciprocal familiarity. In previous chapters, we saw how the individual human beings (anthropologically) reason through the familiarity of ideas or think always referring to few ideas that, in addition, are similar. The other ideas that these individual human beings would think will be thought in function of their familiar ideas and for the similarity they may have to the most familiar ones. It is easy to notice that this is a form of universalization because the familiar ideas function as universals, in the sense that all other recently acquired or formed thoughts must be referred to them. The familiar ideas are not pure ideas, but representations, products of the imagination. The human soul always looks for things that have or it imagines they have rapports with itself or the ideas that are most familiar. ${ }^{2}$ The ideas more familiar to individual persons are those that more easily can attract their attention. It is almost impossible to think things whose ideas do not stimulate our interest.

The universality of the imagination is a universality believed to be universal, but in reality it is impossible for the imagination to embrace any universality, in so far that the imagination produces representations (figures) in the mind, and these figures have always some limits. Representations and figures can never be true universals as the example of the chiliagon in Decartes's first meditation showed. The motor that moves the spirit and makes some ideas, images, more familiar than others is the imagination with the passions. ${ }^{3}$ Often things and ideas come to be connected that are familiar to us, that we think as ours, but with which the things do not have any real affinity or rapport. In these circumstances, we interpret some objects with unsuitable ideas, with the secret tendency of finding in all these various things our familiar ideas.

In new things, with which we are not yet familiar, we hope to find something that will make them less unknown for the purpose of driving out the fear we always feel for the unknown. Passions tend toward the homologation of the ideas that occupy the greater space in the pagan mind. The preconceptions, in this view, are the progressive adjustment of judgments to the familiar ideas. The pagan "cannot judge in a wise way those things which have some relationship with what is the subject of his previous adhesion, nor he can apply himself to things totally extraneous to the objects of his previous preferences." 4

The universality provided with the familiar ideas is an operation of exclusion of everything that cannot present, not even superficially, the characters of similarity. It is a process of inclusion and, contemporaneously, exclusion. The sifting is obviously performed by the imagination that will compare the similar traits that a thing may have with the familiar ideas. The familiar ideas are true and proper universals of the imagination, but the passions are the powerful magnet that attracts toward the most familiar ideas the less familiar ones. ${ }^{5}$

The principal object of thought is the idea that more than others we feel it as ours. But this idea will be the first victim of the distortion operated by passions 
and sensations. The ideas that for similarity will be categorized by the pagan mind as internal to the universal idea will also become distorted. These ideas will also become distorted in equal or greater measure, because they previously suffered the distortion of having being assimilated to the familiar idea that functions as their universal. The more an individual will be passionful and imaginative, the more this process of distortion will be exaggerated. ${ }^{6}$

These mental processes are permeated by consuetude in the mental life so much that we often do not pay any attention to them. When we speak about them, we feel the temptation of speaking hurriedly as if we were saying well-known things. Nonetheless, nothing is more obscure to conscience than these modes of thoughts.

We must remember that the processes simplest for description and comprehension are also the same ones that we mostly use and that distinguished the paganism of mind. The processes of ideas that because of their obviousness we use with an absolute unawareness are so much ours that they are one thing with our individual nature. We must keep in mind the effects that these characteristics of the natural man acquire in the formation of the universals of the imagination. These effects are practically infinite for their variety and disposition; they start from the personal mental sphere and reach the social one. The conclusion of Malebranche says,

The things I have just discussed are such widespread and fertile sources of error, prejudice, and injustice, that it is impossible to take note of all their consequences. Most of the truths, or rather the errors restricted to certain places, times, communities, and families, are its consequences. What is true in Spain is false in France; what is true in Paris is false in Rome; what is certain among the Franciscans seems to be in error among the Dominicans. The Dominicans feel themselves obliged to follow Saint Thomas, and why? Often it is because the holy doctor was a member of their order. The Franciscans, on the other hand, stand by the opinions of Scotus, because Scotus was a Franciscan. Such is the case with truths and errors limited to certain times. ${ }^{7}$

From one single idea, too many conclusions derive. One single idea is used for judging the most disparate things. The experiences we have of reality come to be interpreted always in consideration of the usual images, as if a scientist would obtain many conclusions from one single experiment, trying to prove too much. ${ }^{8}$ Truly, the demonstrations that prove too much, prove nothing. Human disposition invites attention to those aspects of reality that can confirm what human beings wish to sustain, that is, can back up their erroneous mental mechanisms. The method is simple and disconcerting: these human beings retain everything useful to the confirmation of credences, everything that comes under the sphere of 
the universal of imagination; then, they eliminate everything that present characters divergent from the characters of what they have retained. ${ }^{9}$

The familiar ideas are those to which the mind is tenaciously attached and function as the universals or principles for the explanation of everything that will fall within the perceptive sphere of the individual. This phenomenon is not limited to a limited category of persons; all human beings experience this and those who do science should be capable of avoiding its snares. Every human being refers all the knowledge that he acquires to a few ideas that he uses as the principles and the crux of his thought. ${ }^{10}$

The familiar ideas shape the mind at their own image and through it all the surrounding reality. The smaller the number of the ideas that function as universals, the greater the homologation of things would be. The dedication to a kind of studies, as the living in a continuous similar way, confines an individual in a conceptual cage, from which he will not escape. "There was one scholar, for example, who had written many volumes on the Cross; that made him see crosses in everything, and it is with reason that Père Morin [Ratio Studiorum a Magistris et Professoribus (Paris, 1645)] takes him to task for believing that a medal represented a cross, when it represented something quite different."11

The example is significant for two aspects. First, there is no real corresponding link between the idea of the cross and the medal; second, the fantasy of the scholar has created the connection. He has created a fictitious link between things in which there was no similarity.

At this point we have a new phenomenon. The imagination is a master of confusion in regard to similar ideas, but in the case of the medal and the cross the similarity, even the sensible one, is absent. The scholar has first created an imaginary similarity and then with his fantasy has united things that should have remained distinct. Père Morin narrated and made fun of a case of an extreme fixation of a single idea (cross) in the human mind: an imaginative universal. The phenomenon of assimilation becomes a univocal perceptive projection as the number of familiar ideas decreases. If the mind has only one idea and it uses it as a universal, then the process of homologation will reach its greatest application. Fantasy becomes interpretation and overlooks the explanation of all the natural phenomena with a single idea. ${ }^{12}$ At the root of the process a principle exists according to which our paying attention automatically brings nearly together the ideas of the things to which we are paying attention. Unawaringly, when we draw nearly together the things we give attention to, we reinforce the conventional and the natural ties of these things, because we are thinking in sequence or at the same time about them. ${ }^{13}$

Similarity (affinity, alikeness, analogy, comparison, correspondence, parallelism, resemblance, similitude, uniformity, uniformness) is a category, the only one with which an obtuse mind reasons, with little autonomy of thinking. The homologation (interoperability: the 3-steps approach: aggregation, rationalization, harmonization) process of 
many particular ideas (which have little in common) under a familiar idea (an idea with which the mind has confidence, knows well through passions, sensations; an idea of which the mind is not conscious of its falseness) is a psychological process through which the pagan mind exercises its imagination to proceed by way of universals.

It is the universality that is felt, imagined, on which one has reflected very little. It is the universality out of the reach of the criticism of the intellect. It is generally in those minds in which the light of reason is drowsy, if not fully buried under layers of prejudices, passions, sensations, and fantasies. It is a universality of the body: it began from the senses and on them it constructs its false certainty. "The errors of our senses are useful to us as general principles from which we derive erroneous conclusions, which at their turn will be useful as principles." 14 Malebranche has affirmed that the senses are not the ones that deceive us, but precipitations are. With precipitation, we judge relying on the witness of the senses instead than relying on the evidence of ideas. In this situation, the errors of the senses are those due to precipitous judgments, with which pagan thought builds its world. The form of these errors is the one characteristic of the classic philosophy, particularly of the Aristotelian. The erroneousness of paganism is that of assigning to things the sensible qualities which are instead proper to the mode of perceiving of the perceiver.

\section{The Structure of the Universals of the Imagination and of Pagan Religions}

The conception of reality deduced from this kind of thinking is that of a grand animate body, because attributing to things what is instead of the soul is like attributing a form of life to reality. This complex interpretation is the actual perspective from which to look at the world; it functions as the general principle with which to explain all the numerous phenomena. This synthetic but precise explanation of what Malebranche intends for the universals of sensitivity and imagination, (for the general principles that are also the universals of superstition, idolatry, and all the false sciences) originated from the confusion of the pagan mind.

These general errors are used as indubitable premises in the explanation of everything. An infinite number of false conclusions are drawn from them that are then used as premises from which other conclusions are drawn. Finally, these fictitious sciences have been built up gradually without substance or reality and ultimately lead only to blind groping. They are sciences that are like ghosts and only yield their supporters either confu- 
sion and shame for letting themselves be seduced, or the insanity which enjoys feasting on illusions and chimeras. ${ }^{15}$

These errors are true and proper universals because they are used for the explanation of everything; they are valid for any application; they are indeed universals. They are principles of irrationality because they substitute for the rules of reason. The unique universal that a Cartesian like Malebranche would accept is the idea of extension, the idea of thought and intelligible extension, though the last universal differs in application and status from all the others. The universals of the imagination substitute those of reason, but they do not follow the same strategies and the same logic. The two modes of thinking do not proceed parallelly. To the linearity of reason, no parallel linearity of imagination corresponds. The imagination proceeds by fits and starts, follows irregular parables, and changes direction suddenly. The logic of the imagination is the logic of the pagan mind, of the science of nature of the Aristotelians, who, with all their conceits of doing philosophy, still adopt a magic perspective in their observation of nature.

But though I do not think it right to judge hastily that every being is either a mind or a body, yet I feel that it is completely contrary to reason that philosophers, in order to explain natural effects, employ ideas other than those depending on thought and extension, since these are indeed the only ideas we have that are distinct or particular. There is nothing so unreasonable as to imagine an infinity of beings based on the simple ideas of logic, to attribute to them an infinity of properties, and to wish thus to explain things we do not understand through things we not only do not conceive but even cannot conceive. This is to act like blindmen, who, wishing to converse about colors and to have opinions about them, would use definitions philosophers give them to draw conclusions. For as these blindmen could produce only comical and ridiculous arguments about color (because they would have no distinct ideas of them, and because they would reason on the basis of general ideas and ideas of logic), so philosophers cannot reason solidly on the effects of nature when to this end they employ only general ideas and ideas of logic, i.e., act, potency, being, cause, form, quality, and other such ideas. ${ }^{16}$

The above paragraph aims at Aristotle or at the mentality of which he represents the philosophical sublimation. The Aristotelian philosophy is like the grappa distilled from the vines of the pagan mentality. The mentality that the Aristotelian philosophy implies is certainly grosser, its errors are more evident and obvious, but the logic is identical. Aristotle and an analphabet pagan, who believe the lightning and the thunderclap to be the manifestations and the body of Jupiter, are certainly two persons with the most contrasting intellectual capacities, and diverse cre- 
dences. The viewpoints from which they look at the world are not so different from the genius of Aristotle and his encyclopedic culture would make us to believe. Aristotle and the pagan, relying on simple ideas of logic (pagan or poetical), imagine an infinity of beings. To what they imagined, they attribute an infinity of qualities, which are really the qualities of their souls; properties that form things falsely, and inflate them exaggeratedly to the point of being incomprehensible.

The imagination does not parallel reality or over impose itself on it: for the pagan, the imagined is the reality. With the generalization accomplished with the imagination, we have the explanation of incomprehensible things with things that are inconceivable and that it is impossible to conceive. The pagan logic that generalizes the judgments beginning from the erroneous perspective of looking at the world as it proceeds exactly in this way. Given that the true nature of things is not available to the pagan mind, the pagan logic interprets it under the influence of passions and fantasies. The credences with which the pagan explains the world are also inexplicable. How can one explain that thunderclap and lightning are truly a divinity, that the substance of the divinity is infused in the message (thunder and lightning) that the divinity sent to the first men in the way of imagined "transubstantiation"?

The pagan mind will never see the end of these irrational credences. The pagan is like the blind man who does not see the real nature of things and construes a series of fantasies. The pagan philosophers are blind intellectually because they want to explain logically all natural phenomena, constructing instead a distorted and fantastic vision of reality. They fill nature with entities having life, intelligence and will, that is spirit, whereas in nature there is only extension and motion. The tension of imagination for universalizing comes with another typical tension of the pagan mind: to make inferences through natural and real causes. When a new phenomenon happens, a new cause must exist inside the phenomenon produced. "They see a new phenomenon and imagine immediately that a new entity has produced it. The fire warms us up. There is then an entity in the fire that produces heat. This entity is not of the same matter of which fire is made." 17 Of the entity that produces the fire, the pagan in reality sees only the effect, the fire that produces itself. It seems a word play, but it is the way that unawarely the pagan thinks, or he thinks consciously, but the erroneous logic of his thinking is hidden from him; he is not conscious of the contradiction into which he falls. The entity that causes the effect is something different from the effect, from the fire, but the pagan mind infers the cause from the effect and he knows only the visible effect; the cause is imagined in the effect. The critique of Malebranche is against a form of philosophical thought that is the model of all pagan thoughts; it is their sublimation. This thought is structured with a strong capacity for abstraction. It is a thought more structured than the one in possession of the majority of people, with which it has in common the origin and the logic but not the extension, the abstractive capacity, the quantity of knowledge and, lastly, a coherence that the 
popular credences, produced by people who spend their time in activities other than thinking. Notice that the pagan thought distinguishes artificially with the Aristotelian philosophy what before it had united imaginatively. The pagan thought imagines first that the cause of the fire is within the fire, one thing with it, then, with a reflection, that the pagan who is not a philosopher does not possess, differentiates between the manifestation of the cause, the fire, and the substance of the cause. At the philosophical level, this differentiation or distinction assumes that, in a previous moment, things were thought as united, as one thing. The abstraction will follow, at the anthropological level, but not regularly. The fire is the symbol of the cause that produced it; the cause manifests itself through the fire, and it is one thing with the fire. Symbol and referent, sign and significance, for the pagan, in nature are one thing; they compenetrate and confound each other, though, in a second time, they are abstractly distinguishable. "Given that the fire is capable of many different effects-separating bodies, reducing them to ashes or glass, drying, hardening, melting, expanding, purifying, warming, and making light-we generously assign to fire many faculties and real qualities as many as the different effects that the fire is capable of producing." 18 The example of the fire is valid for our understanding of how the association of ideas illustrates the heart of the process of the universalization through imagination. From the idea of the fire, we obtained a fully imaginary cause of the fire; from the idea of this cause we have deduced a wide number of different and even contrary effects. From one idea, we have obtained many others: the cause is the universal of the effects and, thus, the idea of the cause is the universal of the ideas of the effects.

\section{Causality: Jupiter and God}

At this point, the erroneous logic falls, victim of another psychological dynamism. The idea of cause will never be the idea of a normal thing, but of a thing that presents the characteristics of greatness, magnitude, and magnificence, capable of re-awakening the sentiment of wonderment. To judge fire, in the way the pagan would do, is to judge it with passion and sentimentality. To imagine a cause means to imagine it with the sensible traits of power, magnitude, magnificence, and everything else that inspires the idea of an entity with the power of action, a divine entity. "Thus is that men permit themselves to be dazzled by a false idea of grandeur that flatters and excites them. As soon as their imagination is struck by it, it bows down before this phantom; it reveres this phantom while overthrowing and blinding reason, which ought to judge such matters. It seems that men are in a dream when they judge the object of their passion, and that they are lacking in common sense." 19 The cause the pagan will find will be a sensible and passionate cause. The universal cause produced by the imagination in an instant will transforms itself into a ghost. 
Judging from the outside, the psychological situation of the pagan is easily identifiable as the condition of the visionary. From his point of view reality is truly as he imagined it. Reality's deities, the acting forces in nature, are truly present in the phenomena; they are the phenomena; the spirit is in corporeity and it gives life to matter. The spirit is the matter. No distinction (except a posteriori, in the reflection of the pagan philosophers, who represent the elite cream of the crop among the pagans, whose thought has an abstractive ability that the sorcerers and the lycanthropes do not have) exists between the substance and the modalities with which the substance manifests itself. In this way an unknown reality comes to be interpreted with the fictions of entities that neither are known nor can be known, because no spirit exists in the lightning or the thunderclap, in the wind or the spring. ${ }^{20}$

The pagan person explains nature to himself with the idea of an object that in reality does not exist. His ideas are consequently confused, not corresponding to a precise thing but only to perplexed sensations and blinding passions. Because his idea does not correspond to anything in particular, it can be utilized for the explanation of anything, if it is a thing that appears confused to the pagan eyes. This eventuality is the most common one in paganism. This idea becomes a universal of the imagination in a confused and chaotic imagination, because it has no direct reference to a specific object, it can be applied to everything else. The human being, imagining an acting entity in the natural phenomena and having no clear cognition of that entity, will accept the entity as the cause of everything that is happening. The inadequacy of the idea of cause is tied with the imagination to the confused cognition of the effect. ${ }^{21}$ In general, the causal entity should be distinct from its manifestation (the effect), but the idea of its substance is not a distinct idea from the representation of the event. What in the philosophical speculation of the Aristotelians is given as distinct, in reality it is thought as confused, "con-fused" fused together, in a dense mixture with a hybrid color, refractory to abstraction.

If the human being has no distinct or evident idea of the causal entity (presumed distinct from matter, but imagined with it in reality) that is in the matter, then the idea would be confused with the matter, from which the philosopher has tried to extract it by abstraction. For example, the divinity of Jupiter is imagined by the Vichian brute (bestione) as one thing with the lightning and the thunderclap. The Vichian brute has a confused idea of the divinity and does not have the abstractive faculty of the Aristotelian philosopher. The Vichian brute is coarser than the Aristotelian thinker; his mind is infinitely more obtuse, limited in its extension, and in the ability of mental operations he is inferior to the most mediocre Aristotelian. In time, listening to the theological poet, the Aristotelian philosopher will germinate from the ferine roaming throughout the grand forest of the earth. With Malebranche, we bounced from the universals of imagination to the consideration of religion and mythology. Here is how he explains the connec- 
tions between the concepts of cause, the universal of imagination, and the idea of divinity.

If we next consider attentively our idea of cause or of power to act, we cannot doubt that this idea represents something divine. For the idea of sovereign power is the idea of sovereign divinity, and the idea of a subordinate power is the idea of a lower divinity, but a genuine one, at least according to the pagans, assuming that it is the idea of a genuine power or cause. We therefore admit something divine in all the bodies around us when we posit forms, faculties, quality, virtues, or real being capable of producing certain effects through the force of their nature; and thus we insensibly adopt the opinion of the pagans because of our respect for their philosophy. It is true that faith corrects us; but perhaps it can be said in this connection that if the heart is Christian, the mind is basically pagan. ${ }^{22}$

The critique of the Christian theologian is here confused and joined with the analysis of the Cartesian psychologist: to think through natural causes is equivalent to thinking that the reality that surrounds us is something divine. For Malebranche, the rationalist thinker adopts as a scientific principle the occasional causality, while the idolatric pagan is naturally brought to think through natural causes. Occasional causality is from reason; natural causality is from imagination. The criticism of the pagan deities has no pre-eminent moral character. The critic does not try to condemn or justify, but, on the contrary, to acknowledge in idolatry and superstition a typical characteristic of human thought: the inclination to explain through natural causes.

The incoherent amalgam of the passions pours itself into a thought not fully formed, because the pagan thought is an incomplete thought that cannot reflect upon itself. It is too ingenuous before the influence of the sensible ideas; it can construct on sensitivity the ideas of God, cause, and infinity, which represent the maximum of abstraction. The parallelism that we cannot construct between the pagan logic and the rational logic, can instead be built between the pagan (natural) divinity and the rational God of positive religions, in the sense that the idea of Jupiter in the pagan mind performs the same role than the idea of God in the rational mind, maintaining all the ontological and logical differences mentioned. These are ideas that in the pagan have nothing of speculative, since they are immersed in the matter to which they give form and life. When the mind (pagan) is buried in sensitivity, the natural world will assume intelligence. The pagans will think that forms, faculties, and virtues are acting within nature as entities that animate nature, and reveal the intentionality existing in it.

Natural causality, real qualities, criticism of Aristotelianism, animism, the bonding agent of thinking by way of familiar ideas, are all elements that fuse together in the critical analyses of Malebranche. Natural causality is definitively the 
logical principle that is at the bottom of every idolatry and Pre-Christian philosophy that distinguish erroneously the attributes of matter from those of the spirit. The connection between natural causality and the idea of idol is identifiable in the power of things to act; in the intentionality attributed to the events that induce the pagans to believe that one or more deities manifest themselves in nature and through nature. There is something more to it. The idea of idolatry is connatural to the human mind and it is the first idea that human beings have of the divinity. If the mind is pagan, the first representative idea of god that the mind will produce, will be the idea of a pagan god. At the psychological level, the idea of a pagan god is antecedent to the idea of a true god and to any other idea. The reason for this is that the human being thinks always in reference to the familiar ideas that constitute the ground on which the universals of the imagination are formed. The familiar ideas per se are not the universals, but furnish the possibility of formation of the universals of the imagination. The inference by way of natural causes constitutes the second element for the composition of the universals of the imagination. First, there are the familiar ideas that are a mode for considering the events (natural causality). Second, the human being considers the world through the events applying the familiar ideas to all the phenomena that will fall within his perceptive horizon. Third, the universals of imagination come to be born from the representative ideas, imagined and imaginary, utilized through the logic of natural causality for explaining all the phenomena. These universals will be confused ideas identified as universal causes and as the divinity. This, in synthesis, is the process that brings to idolatry, but that summarizes the evolution of the human mind and its logic. The process does not stop here: the idea of universal cause comes to be identified in the pagan mind as a particular being: Jupiter. ${ }^{23}$ Jupiter, the first pagan divinity, is the general cause, the general term, and a particular being.

The first representation the thinker will infer by means of natural causes will be that of an absolute cause capable of explaining all possible phenomena. The first thought forming in the mind, in a logical order, will be the thought of a divinity, which will be the universal absolute cause. The Malebranchean argument develops in this way: the first thought will be the representation of an event; the first reflection will be on the cause of this event; the first cause will be perceived by means of nature. The first conclusion will be the thought of a cause as an active entity, a divinity. Malebranche's logic is that of connecting the idea of the power of action with the idea of the divine and of identifying the concept of cause with that of universal cause. For a pagan, the cause of everything is one and unique is the divinity that incarnates that cause.

In this perspective, Malebranche seems inclined to consider the pagan religion as a polytheism "derivative" from an original monotheism. He does not connect, like many other philosophers do, idolatry to a plurality of gods. The pagan fantasy, before creating the infinity of false idols, produces only one divinity that is present in everything that happens. In The Search after Truth, Malebranche 
says, "If we consider carefully the idea we have of cause or of the power of acting, we cannot doubt that this idea represents something divine, because the idea of a sovereign power is the idea of a sovereign divinity. The idea of a subaltern power is the idea of an inferior deity, but a veritable deity, nonetheless, at least according to the thought of the pagans." 24 All the aspects of this question are centered on what Malebranche just said. Malebranche and Vico have taken the task of organizing all the elements of this issue in order to construct a complex theory of the universals of the imagination. The primary monotheism began from a logical necessity all internal to the pagan mentality and it is something that all the majority of the philosophers contemporary to Malebranche, including Spinoza, have not recognized. On the other hand, it is what brings Malebranche closer, in a clear and unequivocal way, to Vico.

In a secondary perspective, and in a successive moment, paganism is absolutely polytheism. The particular causes, as causes of circumstantial events and subaltern divinities, join the universal cause, the divinity that permeates everything, produces everything. If we think in the manner that the pagans think, says Malebranche, we must admit something divine in all bodies. The divinity permeates all things, is present in all things. Saying that all things are divine is not the same as saying that all things have something of divinity in themselves. Christian religion and reason oppose necessarily this vision of things. Criticizing paganism and judging human irrationalism, Malebranche evinces the typical characters of the pagan mind:

For if religion teaches us that there is only one God, this philosophy shows us that there is only one true cause. If religion teaches us that all the divinities of paganism are merely stones and metals without life or motion, this philosophy also reveals to us that all secondary causes, or all the divinities of philosophy, are merely matter and inefficacious wills. Finally, if religion teaches us that we must not genuflect before false gods, this philosophy also teaches us that our imaginations and minds must not bow before the imaginary greatness and power of causes that are not causes at all; that we must neither love nor fear them; that we must not be concerned with them; that we must think only of God alone, see God in all things, fear and love God in all things. ${ }^{25}$

The contrast Christianity-Paganism, Reason-Idolatry is enlightening. Malebranche has affirmed that we should see God in all things, love and fear God in all things, but this seeing, loving and fearing have a motive totally different from the one that move the pagan to adore Jupiter. The comparison Christianity-Paganism, combined with the criticism of the universal natural causality, demonstrates paganism as the monotheism of imagination against the monotheism of reason. The true cause for a Christian Occasionalist (Malebranche) is God; the true cause for a pa- 
gan who reasons by way of natural causes is Jupiter. The derivation of polytheism from an initial original monotheism is evident. In the same way that particular causes derive and depend from the universal cause, so all the other gods derive and depend from the god Jupiter, because for the pagan the material causes, universal and divine, are the same identical thing. The thought that proceeds by way of natural causality tends for its internal dynamism to represent first what it perceives as universal cause and thereafter what it perceives as cooperative causes in all that happens. Before Vico, Malebranche identifies the universal cause that the pagan imagined and thought with the myth of Jupiter. At any rate, the pagan idolatry, under the Occasionalist analysis of the natural causes and of the familiar ideas, reveals in its psychological origin the nature of monotheism logically preceding the polytheism of all pagan religions. There is another reason in part metaphysical and in part anthropological, which drives Malebranche to connect the three notions of God, natural causes, and first thought.

The idea of God, either true God or idol, cannot be consider the same than any other idea. According to the teachings of the Malebranchean NeoPlatonism, we see all things in God. In God are all the ideas, not the representations, but the forms of things, the ideas in the Platonic sense. Among all the ideas, the idea of God plays a particular, unique, and irreplaceable role as their universal. Of God, however, we cannot form a representation and of his idea, Malebranche says, that it is not an idea like the idea of the circle or the horse. The idea of God is an idea completely different from all other possible ideas. This issue cannot be part of the present analysis. We want to underline that for Malebranche the same rapport of dependency that exists on the metaphysical level between the idea of God and the ideas of all other things, exists also on the psychological level between the idea of Jupiter and the ideas of the other idols. In both cases, from the first ideas derive and depend all the successive ones. The logic and the ground on which this dependency is actualized make the difference. The comparison is possible only by way of analogy. The psychological priority of the idea of idol in relation to the idea of God shows how a corrupted nature will always forms prejudices before reason can dissipate them. The metaphysical priority of the idea of God has been already proved. In addition, we can represent God only anthropomorphically; we create a false idol with the imagination but with the intentionality of thinking, through such fiction, the true God. We produce these fantastic representations because of our own natural inclination to assign to every idea an image that will represent it.

Though on two different levels and with diverse logics, the intellect and the imagination proceed at the sound of the same drum. The relationships between representations must exist also between the corresponding ideas, otherwise human thought would not be possible. According to the metaphysical theocentrism of Malebranche, all the ideas depend necessarily from the idea of God, and the same necessity must be imposed to the images of idols: "The idea of a supreme power is the idea of a supreme divinity and the idea of a subordinate power 
is the idea of an inferior divinity." 26 The illusion of the pagans is that of holding as adequate (in reality) the inadequate representations of God. Once more, it is important to understand that the "reconstruction of a theory of the universals of imagination" in the Malebranchean system is not to be found in the analysis of contingent questions, but in the heart itself of his philosophical meditations.

Paganism is the agent of a universal subversion of customs that seems to possess some verisimilar motives. ${ }^{27}$ Only a universal cause can provoke a universal corruption of customs. Only the idea of an idol whose power can subvert the minds of pagan people, who then will follow a poisonous thought, will make them embrace a conduct intimately dominated by unreasonableness. Knowing already about the relation between idolatry and fear, between the formation of beliefs and the idea of goodness, we must consider the logical side of the question from the point of view of the paganish logic.

It is true that reason does not teach that it is necessary to adore onions and leeks, for example, as the sovereign divinity, because they cannot make us completely happy when we have them, nor entirely unhappy when we do not. Also the pagans never gave them as much honor as they gave to the great Jupiter, on whom all their divinities depended, or as they gave to the sun, which our senses represent to us as the universal cause that gives life and motion to all things, and that we cannot help regarding as a divinity if we assume with the pagan philosophers that it encompasses in its being the true causes of everything it seems to produce, not only in our bodies and minds, but also in all the beings that surround us. ${ }^{28}$

Human beings imagine themselves as part of this universal show as the protagonists at the side of God. They are not passive spectators, but participants of the divine potency, of the creative activity present in their nature and in the nature that opens before their eyes. "This share in God's power that men boast of for representing objects to themselves and for several other particular actions is a share that seems to involve a certain independence. But it is also an illusory share, which men's ignorance and vanity makes them imagine." 29 Malebranche says that in all kinds of idolatry and superstition, one element is constantly present: in the fiction and illusion that the human beings make within their conscience, the imagination creates the sensible representation of the particular object on which the attention focuses at a specific moment.

Human beings believe to see in what they perceived what they imagined. This means that what is imagined is confused with what is perceived, so that we form a distorted representation of reality that is coherent with the credences dominating the conscience. Though the pagan thought is a consequence of the Fall, it is a creative process of the human mind. Pagans, through their altered imagination, believe to participate in the divine potence. They are so fully participant in the po- 
tence of the gods because they have created these gods through their tendency to imagine universal causes. The speculative difference between "intelligible universal" and "imaginative universal" is found in their contrasting logic. The fantastic universal is inclined to uniformity: it aggregates everything that the mind knows to itself; it nulls all differences and creates similarities that are improbable or even inconceivable to a clear mind.

Jupiter encloses in himself many elements, but what he presents to the rude mind cannot be but Jupiter himself. Jupiter is the proper name of the divinity, and to this name is connected everything that concern the auspices. Auspices are the thunderclap, the lightning, and any occasional event that hits powerfully the senses and the imagination, such as to provoke wonderment. In this manner, a multitude of elements becomes Jupiter, which from being a proper name becomes a generic name apt to point at a totality. This tendency to think in reference to the universals gestated by the imagination and nursed by obtuseness is analyzed from many points of view in The Search after Truth. Malebranche, explaining the passage from "proper" to "generic" name, wrote:

A disease is new: it causes ravages that astonish the world. This imprints such profound traces in the brain that this disease is always before the mind. If this disease is called scurvy, for example, then all diseases will be scurvy. Scurvy has a dozen symptoms, of which many are common to other maladies; this means nothing. If it happens that a sick man has some one of these symptoms, it will be scurvy, and no one will even think of the other diseases having the same symptoms. One will expect that all the accidents that have happened to those observed ill with scurvy will also happen to him. The same medicines will be given, and everyone will be surprised when they do not have the same effect observed in others. ${ }^{30}$

The scorbute, which is the name of a precise pathology, is used for other diseases that may have some symptoms in common with it. It is used as a generic name. There is a new element in this quotation: the prevision, or a concept of the future.

The universals of the imagination explain the new things that we have come to know, but it also disposes us while waiting for those that will be known sometime in the future. The waiting for something in the future is satisfied by way of the previsions that confirm our familiar ideas and that allow categorizing the new unknown thing within what is ancient and already known. The pagan follows the principle that reality must adequate itself to thought in order to become known. When a thing cannot be referred and presented to a familiar idea, a universal, it will evade the fact of becoming known by the pagan. This unfamiliar representation of the things will pass unnoticed until gradually becoming more similar to the familiar ideas. In the visionary, it is reality that must adequate to thought. In the contrary case, damned is reality! 
The visionaries of the senses, those afflicted by madness, can be identified when reality contradicts manifestly their credences. In a lunatic asylum, when all the patients believe to be some kind of horses, not the one who neighs is taken as a madman, but the one who barks, while the others neigh. ${ }^{31}$ They will all be called crazy by the one who speaks meanwhile they neigh or bark. In human societies the measure of judgment is not based on reason but on opinion and the opinion is sustained always by the verisimilar. Thus, we have errors and prejudices.

\section{Has the Shadow of Malebranche Shadowed Vico?}

In the third part of the book, we have seen how the Malebranchean anthropology is similar to the questions in a large part of the Vichian philosophy: the genesis of authority found in the dynamics of the imagination, the link with the idolatric conception of the divinity, the conception of the "paganish" society, the nature and the social rapports, the communication of strong imaginations, persuasion, analysis of the heroic mentality, and the theory of the universals through the imagination. These are topics in the philosophy of Malebranche that have not been considered in relation to Vico, in most past studies. The social anthropology and the dynamism of the imagination that have been dealt in this last part, together with the linguistics and the psychological principles, made clear the possibility of an approach of the two strong points of the Vichian reflection (poetic logic and poetic truth) with the Malebranchean theorizations.

Through the fusion of Cartesian principles with the theoretical foundations of the Christian theology (the concept of "carnal man"), Malebranche has proposed a new anthropology and an original psychology. In Malebranche, Cartesianism creates a tension between psychological problems and religious goals, and successfully provides some direction for the development of his own metaphysical system. As in Vico, so in Malebranche the distinction between Paganish, Jewish, and Christian people exists. In Vico, a line of demarcation is clearly traced between anthropology and history, at one side, and theology, on the opposite side. In Malebranche, instead, the principal interest remains the religious one. In the critique of Pagandom, Vico's anthropology intertwines with history, while that of Malebranche is glued with theology. For this reason, Vico can say of having created a "new science" and Malebranche only a new psychology and perhaps a new conception of theology. The Malebranchean anthropology moves synchronically, while the Vichian one runs diachronically. The reason may be that the Malebranchean anthropology is Cartesian, has a preeminent religious goal, and goes in the direction of theology. The factual evidence is that the Vichian anthropology intends to constitute itself as an autonomous science, which wants to know beginning from what man does and not from the consideration of how God created. And this gave way to the Vichian new conception of history. 
Though Malebranche started from freeing anthropology from theology, he has not gone to the bottom of it; in him, in the background, the metaphysical principles of the Christian Platonic medieval philosophy are still domineering. But the psycho-social theses developed in The Search after Truth have no need of a theological "support." In Vico, pagan thought has a component exclusively anthropological. In Vico, the pagan thought is not seen as the thought of the "carnal man" but as that of the primitive human that lives in a brutish stage of existence. Vico's theory is a stronger affirmation of the independence of anthropology from theology in favor of history, and this renders the Vichian psychology, whose matrix is nevertheless Malebranchean, really new and innovative. 



\section{NOTES}

\section{Introduction}

1. Giambattista Vico, The New Science of Giambattista Vico: Unabridged Translation of the Third Edition (1744), translated by Thomas Goddard Bergin and Max Harold Fisch (Ithaca, NY: Cornell University Press, 1976), par. 330.

2. Giambattista Vico, The Autobiography of Giambattista Vico, translated by Max Harold Fisch and Thomas Goddard Bergin (Ithaca, NY: Cornell University Press, 1975), p. 134.

3. Paolo Rossi, Le Sterminate Antichità e nuovi saggi vichiani (Florence: La Nuova Italia, 1999), p. 44.

4. Isaiah Berlin, Vico and Herder: Two Studies in the History of Ideas (New York: Viking Press, 1976), p. 3.

5. Giambattista Vico, On the Most Ancient Wisdom of the Italians Unearthed from the Origins of the Latin Language trans. L. M. Palmer (Ithaca, NY: Cornell Univ. Press, 1988), pp. 53-57.

6. The New Science, par. 122-123.

7. Autobiography, p. 154.

8. Paolo Rossi, "Chi sono I contemporanei di Vico" in Le Sterminate Antichità e nuovi saggi vichiani (Florence: La Nuova Italia, 1999), pp. 275-304.

9. Autobiography, pp. 165-166.

10. Gustavo Costa, "Vico e l'inquisitione" in Novelles de la Republiques des Lettres 2 (1999), pp. 93-124.

11. Max Harold Fisch, "The Academy of the Investigators," in Science, Medicine, and History: Essays in Honor of Charles Singer, Volume 1, ed. E. A. Underwood (London: Oxford University Press, 1953), pp. 521-563.

12. Antonio Borrelli, "Vico e gli atomisti napoletani" in Vico Nel Mondo/Il Mondo de Vico: in ricordo di Giorgio Tagliacozzo (Perugia: Guerra, 2000), pp. 151-165.

13. Giambattista Vico, On the Most Ancient Wisdom of the Italians, p. 74.

14. Giambattista Vico, On the Study Methods of Our Time, trans. Elio Gianturco (Ithaca, NY: Cornell University Press, 1990), p. 6.

15. On the Study Methods, p. 41.

16. Joseph M. Levine, "Giambattista Vico and the Quarrel between the Ancients and the Moderns" Journal of the History of Ideas 52, 1 (1991): pp. 55-79.

17. Harold Samuel Stone, Vico's Cultural History: The Production and Transmission of Ideas in Naples 1685-1750, New York: Brill, 1997, p. 93.

18. Giambattista Vico "On the Sumptuous Dinners of the Romans," trans. George Trone in New Vico Studies 20 (2002), pp. 79-89.

19. Stone, pp. 39-41.

20. Levine, p. 62.

21. The New Science, par. 696 
22. René Descartes, On the Passions of the Soul in The Philosophical Writings of Descartes vol. 1, trans. John Cottingham, Robert Stoothoff and Dugald Murdoch (Cambridge: Cambridge University Press, 1985), pp. 335-6. Alberto Mario Damiani examines Vico's early use of the concept of animus and relates it to his later political ideas of human being constructing the civil world. Alberto Mario Damiani, "Le Idea de Animus en las Primeras Obras de Giambattista Vico" Revista Latinoamericana de Filosofia 26, 1 (2000), pp. 85-109.

23. The New Science, par. 706.

24. Silvia Contarini, "Descartes in Naples: The Reception of the Passions de l'ame" trans. Stephen P. McCormick in Reason and Its Others: Italy, Spain and the New World. Ed. David Castillo and Massimo Lollini (Nashville: Vanderbilt Univ. Press, 2006), pp. 39-60.

25. John Robertson, The Case for Enlightenment: Scotland and Naples 1680-1760 (Cambridge: Cambridge Univ. Press, 2005), p. 193.

26. Pietro Giannone, Istoria Civile del Regno di Napoli, vol. 1-4, edited by Antonio Marongiu (Milan: Marzorati Editore, 1970), pp. 25-27.

27. Girolamo Imbruglia, "Enlightenment in Eighteenth-Century Naples" in Naples in the Eighteenth Century: The Birth and Death of a Nation State ed. Girolamo Imbruglia (Cambridge: Cambride Univ. Press, 2002), pp. 70-94.

28. Ibid, p. 82.

29. Marcel Danesi, Vico, Metaphor, and the Origin of Language (Bloomington: Indiana Univ. Press, 1993). Trabant, Jürgen, Vico's New Science of Ancient Signs: A Study of Sematology (New York: Routledge, 2003).

30. Catherine L. Hobbs, Rhetoric on the Margins of Modernity: Vico, Condillac, Monbodo. (Carbondale: Southern Illinois University Press, 2002), pp. 75-79.

31. Ibid., pp. 100-101.

32. On the Study Methods, p. 77.

33. Ibid., p. 47.

34. Giuseppe Mazzotta, The New Map of the World: The Poetic Philosophy of Giambattista Vico (Princeton: Princeton Univ. Press, 1999), p. 10.

35. Ibid., p. 8.

36. The New Science, par. 34.

37. Andrea Battistini, Vico tra antichi e moderni (Bologna: Società Editrice il Mulino, 2004), p. 180.

38. Ibid., pp. 184-185.

\section{Proemium}

1. Malebranche, Traité de Morale, bk. 2, ch. 10, \$S 13-14. Concerning many questions agitated in this book, see Beatrice K. Rome, The Philosophy of Malebranche: A Study of His Integration of Faith, Reason, and Experimental Observation (Chicago: H. Regnery Co., 1963); Andrew Pyle, Malebranche: Arguments of the Philosophers (London: Routlege, 2003).

2. Malebranche considers the study of the exact sciences as an activity propedeutic to meditation in order to free the mind from prejudices and reach a contact with God, trying to open the mind to the infinite intelligible extension: "Il faut être homme, chrétien, français, avant que d'être grammairien, poète, historien, étranger. Il ne faut pas même être géomètre pour se remplir la tête des propriétés des lignes: mais pour donner à son esprit la force, l'étendue, la perfection dont il est capable," in Malebranche, Traité de Morale, bk. 2, ch.10, \14. See Stanclene Dalla Marija, "The Theory of Powers in Malebranche" in Logos (41/2005), pp. 71-79.

3. A. Del Noce, Riforma cattolica e filosofia moderna (Bologna: Il Mulino, 1965), p. 694.

4. M. Agrimi, Vico e Malebranche (Napoli: Cuen, 1999), p. 10. 


\section{Ibid., p. 19}

6. F. Botturi, La sapienza della storia (Milano: Vita e Pensiero, 1991), p. 241.

7. Paolo Fabiani, "Fantasia e immaginazione in Malebranche e Vico" in Giambattista Vico nel suo tempo e nel nostro (Napoli: Cuen, 1999). Manuela Sanna, La fantasia che è l'occhio dell'ingegno. La questione della verita e della sua rappresentazione in Vico (Napoli: Alfredo Guida, 2001) is not the last product of her reflections. She has produced multiple essays on the different aspects of the image and the imagination in Vico's theory of knowledge. Her final work on the imagination is Immaginazione (Napoli: Alfredo Guida, 2007).

\section{PART ONE \\ The Frst Kind of Imagination \\ From Error to the Birth of Thought}

\section{Chapter One}

(The Rules for the Avoidance of Error)

1. Malebranche's De la Recherche de la Vérité is available in English as The Search after Trutb: Wherein Are Treated the Nature of Man's Mind and the Use He Must Make of It to Avoid Error in the Sciences, ed. by Thomas M. Lennon and Paul J. Olscamp, Cambridge Texts in the History of Philosophy (Cambridge: Cambridge Universithy Press, 1997). This book is composed of six sections and seventeen elucidations. The six sections are: The Senses; The Imagination (Imaginations and The Contagious Communications of Strong Imaginations); The Understanding, or Pure Mind (with The Pure Understanding and The Nature of Ideas); The Inclinations or the Mind's Natural Impulses; The Passions; and Method. In our opinion, this Malebranchean work can be read as an articulate critique of Aristotelianism. About Aristotle, Malebranche said, "Truths are for all time. If Aristotle discovered any truths, they can be discovered as well today. The views of this author must be proved as they may, for if his views were sound in his own time, they are still so now. To attempt to prove truths of nature through human authority is mere illusion. You might perhaps prove that Aristotle had certain thoughts on certain subjects, but it is not very reasonable to read Aristotle or any other author with a great deal of care and trouble only to learn historical views and to teach them to others" The Search after Truth, bk. 5, ch. 7, pp. 382-383.

2. For a Cartesian, confused and sensible ideas are the same. A science beginning from sensible data cannot be but a confused science: "Aristotle, who justly deserved the title of Prince of these Philosophers, because he is the father of this philosophy which they have cultivated with great care and effort, reasons almost always with confused ideas that are obtained from the senses and other vague, general, and indeterminate ideas that represent to the spirit nothing particular" in The Search after Truth, bk. 4, ch. 3, p. 281

3. The Search after Truth, bk. 2.

4. See Leibniz, Discourse on Metaphysics, \27: “Aristotle preferred to compare our souls to blank tablets prepared for writing, and he maintained that nothing is in the understanding which does not come through the senses. This position is in accord with the popular conceptions as Aristotle's positions usually are. Plato thinks more profoundly. Such tenets or practicologies are nevertheless allowable in ordinary use somewhat in the same way as those who accept the Copernican theory still continue to speak of the rising and setting of the sun. I find indeed that these usages can be given a real meaning containing no error, quite in the same way as I have already pointed out that we may truly say particular substances act upon one another. In this same sense we may say that knowledge is received from without through the medium of the senses because certain exterior things contain or express more particularly the 
causes which determine us to certain thoughts. Because in the ordinary uses of life we attribute to the soul only that which belongs to it most manifestly and particularly, and there is no advantage in going further. When, however, we are dealing with the exactness of metaphysical truths, it is important to recognize the powers and independence of the soul which extend infinitely further than is commonly supposed. In order, therefore, to avoid misunderstandings it would be well to choose separate terms for the two. These expressions which are in the soul whether one is conceiving of them or not may be called ideas, while those which one conceives of or constructs may be called conceptions, conceptus. But whatever terms are used, it is always false to say that all our conceptions come from the so-called external senses, because those conceptions which I have of myself and of my thoughts, and consequently of being, of substance, of action, of identity, and of many others came from an inner experience." (Translation of Dr. George R. Montgomery (1902); revised by Dr. Albert R. Chandler (1924).

5. Descartes, Oeuvres (Adam-Tannery, Paris: 1964-1976), bk. 3, pp. 663-668, 690-695.

6. Ibid., p. 691: “....apres avoir distingué trois genres d'idées ou de notions primitives qui se connoissent chacune d'une façon particuliere \& non par la comparaison de l'une à l'autre, à savoir la notion que nous avons de l'âme, celle du corps, \& celle de l'union qui est entre l'âme \& le corps....".

7. Ibid., p. 665.

8. Ibid., pp. 665-666.

9. Ibid., p. 666: "Et d'autant que l'usage des sens nous a rendu les notions de l'extension, des figures \& des mouvemens, beaucoup plus familieres que les autres, la principale cause de nos erreurs est en ce que nous voulons ordinairement nous servir de ces notions, pour expliquer les choses à qui elles n'appartiennent pas, comme lorsqu'on se veut servir de l'imagination pour concevoir la nature de l'âme, ou bien lorsqu'on veut concevoir la façon dont l'âme meut le corps, par celle dont un cors est mû par un autre cors."

10. Ibid., p. 667.

11. Descartes, Diottrica (Adam-Tannery), pp. 112-113.

12. Idem, Oeuvres (Adam-Tannery), p. 667.

13. Ibid., pp. 667-668.

14. Malebranche, The Search after Truth, bk. 6, pt. 3, p. 448.

15. Idem, bk. 3, pt. 2, p. 253.

16. Ibid., p. 253.

17. For a complete treatment of these topics, see Malebranche, Dialogues on Metaphysics and Religion, ed. by Nicholas Jolley and David Scott, Cambridge Texts in the History of Philosophy (Cambridge: Cambridge university Press, 1997), dialogues 6 and 7.

\section{Chapter Two}

(The Third Primitive Notion and the Human Fall)

1. Henri Gouhier, La pensée métaphisique de Descartes (Paris: Vrin, 1962) agrees on this point, affirming that the difficulty Descartes faced was more psychological than philosophical ( $\mathrm{p}$. 237).

2. Descartes, writing to Arnauld, underlines this concept, stating that Aristotelian philosophers have also made the error of considering weight as a force, a quality in itself, elevating to a scientific law a prejudice merely acceptable in ordinary life of common people.

3. This condition is presented by Descartes in the letter of 28 June 1643 to Princess Elizabeth: “...et enfin, c'est en vsant seulement de la vie \& des conuersations ordinaires, \& en s'abstenant de mediter \& d'etudier aux choses qui exercent l'imagination, qu'on apprend à conceuoir l'vnion de l'ame \& du corps (...) ie n'ay iamais employé que fort peu d'heures, par iour, 
aux pensées qui occupent l'imagination, \& fort peu d'heures, par an, à celles qui occupent l'entendement seul, \& que i'ay donné tout le reste de mon temps au relasche des sens \& au repos de l'esprit; mesmeie conte, entre les exercices de l'imagination, toutes les conuersations seriuses, \& tout ce à quoy il faut auoir de l'attention." Descartes, Oenvres, bk. 3, pp. 692-693. Elizabeth of Bohemia (1618-1680), after reading Descartes's Meditations on First Philosophy in 1642 , began challenging the philosopher. She became known as "the woman who took on Descartes."

4. The logical process with which Malebranche sustains that of the soul we can have consciousness but not knowledge is complex and needs a survey on Malebranchean metaphysics. Reducing the explanation to the minimum, we may say, “... There is no other pure intelligible substance than that of God without whose light there is nothing we can discover with evidence" in The Search after Truth, bk. 3, pt. 3, ch. 7, p. 237. The interior sentiment lacks the unique means (God) capable of making conscience intelligible to it: "Though we are united with ourselves, we are and will be intelligible to ourselves, so long as we see ourselves in God and that He Himself will present the perfectly intelligible ideas that He possesses of our existence enclosed in His." We know the soul through the interior sentiment by way of sensations: "It is the same about our soul; we do not know it through its idea; we do not see it in God. We know it only through consciousness, and for that reason our knowledge of it is imperfect. Of our soul, we know only what we sense to go on within us. If we have not experienced pain, heat, light, we will not be able to know if we could experience these things, because we do not know our soul through its own idea," in ibid., p. 237.

5. The use of the Cartesian theory of the primitive notions by Malebranche in the psychophysical field is an established point in the Malebranchean studies. See Ferdinand Alquiér: "Aux deux notions primitives qui nous font connaitre l'ame et le corps, Descartes ajoute une troisiéme notion, qui nous révèle l'union. Il découvre ici un domaine nouveau, qui a sa vérité propre, et insiste sur le caractére irremplaçable des leçons que nous donne l'affectivité. (...) Or malgré le rejet, par Malebranche, de l'idée d'union comme notion primitive, tout cela se retrouve dans The Search after Truth" in Alquié, Le cartésianisme de Malebranche (Paris: Vrin, 1974), p. 47. See also Martial Gueroult, Malebranche (Aubier/Montaigne: 1955-1959), 3 vols., bk. 3, p. 50. In Malebranche, see the confirming texts: "Now, these natural judgments, although quite useful, often involve us in error of some sort, by making us form free judgments in perfect agreement with them" in The Search after Truth, bk. 1, ch. 7, pp. 35-36; "What leads the soul even more into wanting a fanciful view of its sensations is that it judges them to be in objects and even to be modifications of objects, and consequently that they are corporeal and can be imagined " in ibid., bk. 1, ch. 13, pp. 62-63; “... we feel ourselves strongly inclined by an entrenched habit toward judging that our sensations are in objects " in ibid., p. 70. The rooted habit mentioned by Malebranche is in other terms the same habit that Descartes identified as the cause of our erroneous conception of force: "The errors of our senses provide us with general premises conducive to false conclusions, which themselves provide further premises" in ibid., bk. 1, ch. 16, p. 73 .

6. It is useful to consider here some concepts of Alquié on which we will insists later: "Les sens ne nous représentent pas les choses, selon ce qu'elles sont en elles-mêmes; les connaissances sensibles sont toutes fausses et confuses par rapport aux objets qu'elles représentent. Mais elles sont très utiles à la conservation du corps, et des biens qui ont rapport aux corps, c'est-à-dire à la vie. Car si nous voulions connaître par raison l'utilité ou la nocivité des objets qui nous entrourent, nous devrions posséder une science que nous n'avons pas, et du reste, en chaque cas, user d'analyses et d'examens qui demanderaient un temps incompatible avec l'urgence de l'action quotidienne" in Alquié, Le cartesianisme de Malebranche, p. 47. 
7. Alquié explains the question: "Et, à cet égard, les Jugements sensibles sont si bien proportionnés avec la fin pour laquelle ils nous sont donnés qu'on ne peut entrer dans la pensée de ceux qui dissent qu'ils sont entièrement corrompus par le péché originel. Bien au contraire, les sens s'aquittent admirablement de leur devoir. Cette profession de foi, visiblement antijanséniste, est fidèle à Descartes" in ibid., p. 47

8. Descartes never mentions the sin of Adam as a justification for the errors of the senses, but only for an individual and personal story of acquired prejudices. This is essentially the position of Alquié. However, we should distinguish between the prejudices and the other errors of the senses. In the meditations, Descartes gives the example of the hydropic who arrives to the point of death in the satisfaction of drinking liquids of which he cannot adequately free himself through the normal discharges of the body's organs. We could challenge Malebranche, more than Descartes, saying that the senses are not fulfilling their duty. Descartes seems to suggest that the hydropic body is not sick, but that like all bodies is following the laws of nature. It can be said that the hydropic can be diagnosed as sick only by an extrinsic judgment because a union of soul and body, in which sensations are no longer suitable to survival. The Cartesian solution is explicitly an anti-finality in physics, without denying that the mechanicism at the physical level will exclude finality at the anthropological level. These argumentations are limited to the physical mechanicism and exclude the possible argumentations at a theological level: "Descartes, cependant, s'en tient là. Refusant toute interrogation d'ordre finaliste, il ne se domande jamais pourquoi notre ame a été unie à un corps, pas plus, du reste, qu'il ne pose la question de savoir pourquoi il existe des ames et des corps. Le caractère insondable des desseins de Dieu rend, d'emblée, ces problèmes insolubles. Voulant, au contraire, tout expliquer à partir de tels desseins, Malebranche doit résoudre ces problèmes, et, selon les expressions de M. Gueroult, découvrir la raison de l'union psychophysique et une fin éthico-religieuse. En d'autres termes, l'union de l'ame avec le corps doit apparaitre comme un moyen de son union avec Dieu, unique but de sa creation" in ibid., pp. 47-48.

9. "Or, un telle subordination est d'autant plus difficile à decouvrir que, précisement, l'union de l'ame et du corps nous fait oublier Dieu: la Préface de La Recherche oppose l'union avec le corps e l'union avec Dieu, et etablit entre elles, non la possibilité d'un équilibre, mais la nécessité d'un conflit. Car notre union avec Dieu diminue et s'affaiblit à mesure que celle que nous avons avec les choses sensibles augmente et se fortifie, et d'autre part, l'union de notre esprit avec notre corps... diminue à proportion que celle que nous avons avec Dieu s'augmente. Et cela ne peut etre considéré comme une cosequence du péché: déjà, chez Adam, l'attrait du plaisir a contribué à la chute. En remplissant ou partageant la capacité qu'il avait de penser, le plaisir a effacé ou diminué dans son esprit la présence de son vrai bien et de son devoir. Dieu ayant créé notre ame pour etre aimé, on ne voit donc plus pourquoi il l'a unie à un corps. Contredisant la fin meme de la création de l'ame, la fin biologique de l'union cesse d'etre, à elle seule, explicative, et l'on ne peut plus rendre compte des sentiments relatifs à cette union en invoquant la seule utilitè du corps. Si, en effet, l'ame était unie au corps dans l'unique fin de la conserver, elle se trouverait subordonnée à lui, ce qui serait contraire à l'ordre. Au reste, le seul jeu du mécanisme suffisant à sauvegarder le corps des animaux, il pourrait tout aussi bien suffire pour celui des hommes. Considérée dans le seul plan de la vie, l'union à la fois comme scandaleuse et inutile"'in ibid., p. 48.

10. Ibid., p. 48: "Il faut donc lui découvrir d'autres raisons, et justifier les sentiments et les passions autrement que par la seule nécessité de conserver le corps lui-meme. C'est pourquoi on peut trouver, chez Malebranche, bien de motivations non biologiques de l'union. Il établit que la sensibilité sert, en définitive, la fin supreme de l'ame, qui est la connaissance de Dieu: en effet, nous renseignant, par voie brève, sur ce qui nous est utile ou nuisible, elle dispense l'ame de s'attacher au détail des actions exigées pour la protection du corps, et lui permet de ne pas 
perdre son temps dans l'acquisition d'une science inaccessible. Dieu a du se charger de nous avertir en temps et lieu par des sentiments prévenants de ce qui ragarde le bien du corps pour nous laisser tout entiers occupés à la recherche des vrais biens."

11. In the third letter of 28 June 1643 to Princess Elizabeth in order to describe the area of application of the third notion, Descartes wrote, "Et enfin, c'est en usant seulement de la vie \& des conversations ordinaires, \& en s'abstenant de mediter \& d'etudier aux choses qui exercent l'imagination, qu'on apprend à concevoir l'union de l'ame \& du corps."

12. Alquié, Le cartesianisme de Malebranche, pp. 48-49. See Malebranche, Meditations chrétiennes, bk.. 6, in Oewvres, bk. 10, ch. 63; Dialogues on Metaphysics and Religion, ed. by Nicholas Jolly and David Scott (Cambridge: Cambridge University Press, 1997), dialogues. 3 and 4. Also M. Gueroult, Malebranche, bk. 3, p. 50 and pp. $138 \mathrm{ff}$.

13. Descartes supports these ideas in the letter of 21 May 1643 to Princess Elizabeth.

14. In the letters to Princess Elizabeth, Descartes says that we can know our soul and the nature of bodies, extension, with our intellect, thus making impossible the way to erring. The following dedicatory letter to Elizabeth of the Principia Philosophiae of 1644 is part of the correspondence between the two: "To The Most Serene Princess, Elizabeth, Eldest Daughter Of Frederick, King Of Bohemia, Count Palatine, And Elector Of The Sacred Roman Empire. Madam,the greatest advantage I have derived from the writings which I have already published, has arisen from my having, through means of them, become known to your Highness, and thus been privileged to hold occasional converse with one in whom so many rare and estimable qualities are united, as to lead me to believe I should do service to the public by proposing them as an example to posterity. It would ill become me to flatter, or to give expression to anything of which I had no certain knowledge, especially in the first pages of a work in which I aim at laying down the principles of truth. And the generous modesty that is conspicuous in all your actions, assures me that the frank and simple judgment of a man who only writes what he believes will be more agreeable to you than the ornate laudations of those who have studied the art of compliment. For this reason, I will give insertion to nothing in this letter for which I have not the certainty both of experience and reason; and in the exordium, as in the rest of the work, I will write only as becomes a philosopher. There is a vast difference between real and apparent virtues; and there is also a great discrepancy between those real virtues that proceed from an accurate knowledge of the truth, and such as are accompanied with ignorance or error. The virtues I call apparent are only, properly speaking, vices, which, as they are less frequent than the vices that are opposed to them, and are farther removed from them than the intermediate virtues, are usually held in higher esteem than those virtues. Thus, because those who fear dangers too much are more numerous than they who fear them too little, temerity is frequently opposed to the vice of timidity, and taken for a virtue, and is commonly more highly esteemed than true fortitude. Thus, also, the prodigal are in ordinary more praised than the liberal; and none more easily acquire a great reputation for piety than the superstitious and hypocritical. With regard to true virtues, these do not all proceed from true knowledge, for there are some that likewise spring from defect or error; thus, simplicity is frequently the source of goodness, fear of devotion, and despair of courage. The virtues that are thus accompanied with some imperfections differ from each other, and have received diverse appellations. But those pure and perfect virtues that arise from the knowledge of good alone are all of the same nature, and may be comprised under the single term wisdom. For, whoever owns the firm and constant resolution of always using his reason as well as lies in his power, and in all his actions of doing what he judges to be best, is truly wise, as far as his nature permits; and by this alone he is just, courageous, temperate, and possesses all the other virtues, but so well balanced as that none of them appears more prominent than another: and for this reason, although they are much more perfect than the virtues that blaze forth through the mixture of some defect, yet, because the 
crowd thus observes them less, they are not usually extolled so highly. Besides, of the two things that are requisite for the wisdom thus described, namely, the perception of the understanding and the disposition of the will, it is only that which lies in the will which all men can possess equally, inasmuch as the understanding of some is inferior to that of others. But although those who have only an inferior understanding may be as perfectly wise as their nature permits, and may render themselves highly acceptable to God by their virtue, provided they preserve always a firm and constant resolution to do all that they shall judge to be right, and to omit nothing that may lead them to the knowledge of the duties of which they are ignorant; nevertheless, those who preserve a constant resolution of performing the right, and are especially careful in instructing themselves, and who possess also a highly perspicacious intellect, arrive doubtless at a higher degree of wisdom than others; and I see that these three particulars are found in great perfection in your Highness. For, in the first place, your desire of selfinstruction is manifest, from the circumstance that neither the amusements of the court, nor the accustomed mode of educating ladies, which ordinarily condemns them to ignorance, have been sufficient to prevent you from studying with much care all that is best in the arts and sciences; and the incomparable perspicacity of your intellect is evinced by this, that you penetrated the secrets of the sciences and acquired an accurate knowledge of them in a very short period. But of the vigour of your intellect I have a still stronger proof, and one peculiar to myself, in that I have never yet met any one who understood so generally and so well as yourself all that is contained in my writings. For there are several, even among men of the highest intellect and learning, who find them very obscure. And I remark, in almost all those who are versant in Metaphysics, that they are wholly disinclined from Geometry; and, on the other hand, that the cultivators of Geometry have no ability for the investigations of the First Philosophy: insomuch that I can say with truth I know but one mind, and that is your own, to which both studies are alike congenial, and which I therefore, with propriety, designate incomparable. But what most of all enhances my admiration is, that so accurate and varied an acquaintance with the whole circle of the sciences is not found in some aged doctor who has employed many years in contemplation, but in a Princess still young, and whose countenance and years would more fitly represent one of the Graces than a Muse or the sage Minerva. In conclusion, I not only remark in your Highness all that is requisite on the part of the mind to perfect and sublime wisdom, but also all that can be required on the part of the will or the manners, in which benignity and gentleness are so conjoined with majesty that, though fortune has attacked you with continued injustice, it has failed either to irritate or crush you. And this constrains me to such veneration that I not only think this work due to you, since it treats of philosophy which is the study of wisdom, but likewise feel not more zeal for my reputation as a philosopher than pleasure in subscribing myself, Of your most Serene Highness, The most devoted servant, Descartes." The translation is of John Veitch and more information can be found at <http://home.infionline.net/ ddisse/elisabet.html $>$.

\section{Chapter Three}

(The Human Fall and the Pagan Mentality)

1. The Search after Truth, bk. 1, ch. 1, p. 1: "Error is the cause of men's misery; it is the sinister principle that has produced the evil in the world; it generates and maintains in our soul all the evils that afflict us, and we may hope for sound and genuine happiness only by seriously laboring to avoid it." Error is the wok of the will, of the tendency of humankind to precipitous judgments or judgments on things of which one has no knowledge: "All our ways of perceiving are to us so many occasions of error, for since our false judgement include two things, the consent of the will and the perception of the understanding, it is quite clear that each of the 
ways in which we perceivecan provide us with an occasion for error, since they can lead us to precipitous consent," ibid., bk. 1, ch. 4, p. 16.

2. About the rapports error-union of body-soul we have information in the letters of Descartes to Princess Elizabeth; Malebranche, however, sees in these rapports the vehicle through which sin passes from generation to generation: "God has foreseen that in certain circumstances men would sin and that their sin be communicated to all their posterity because of the laws of the union of body and soul." in Dialogues on Metaphysics and on Religion, dialogue 12, pp. 316ff. Also, "Our first parents, after their sin, received in their brain great vestiges and traces so profound that they could very well have been transmitted to their children. ... Thus, we must have been born with concupiscence and the original sin," The Search after Truth, bk. 2, pt. 1, ch.7, p. 120. On this topic Malebranche speaks in the $8^{\text {th }}$ Elucidation dedicated to the original sin: for Malebranche sin is situated in the parallelism between brain traces and sensible ideas. "And so we are bound to be born with concupiscence and Original Sin, with concupiscence, if it is nothing other than a natural effort by the brain traces to attach the mind to sensible things, and with Original Sin, if Original Sin is nothing but the reign of concupiscence grown victorious, and master of the mind," ibid., p. 120.

3. God is not the author of sin. The human being is the one who will abandon God, not vice versa. God is omniscient, foresees sin but continues to assist the human being throughout. Malebranche is guided by theological motivations. Those who challenge divine goodness by saying that God is authoring sin are actually witness of their own psychological and moral disposition. By feeling as the victims of God's actions, these human beings proclaim the truth of the existence of some original sin.

4. "The first man's sin has so weakened our mind's union with God that it can be felt only by those whose heart is purified and whose mind is enlightened, for this union appears imaginary to all those who blindly follow the judgments of the senses and the impulses of the passions," The Search after Truth, Preface, p. xxxiv; "On the contrary, Original Sin has so strengthened our soul's union with our body that it seems to us that these two parts of us are but one and the same substance; or, rather, it has subjected us to our senses and passions in such a way that we are led to believe that our body is the more important of the two parts of which we are composed," in ibid., p. xxxiv.

5. Because of the Fall in Eden, the relationship of the soul with the body has prospered at the disadvantage of the relationship of the soul with God. The knowledge of one-self will depend only from the senses and from conscience, no longer from reason. Sin has insinuated itself within the mechanism of universal legislation of the rapports sould-body. "Original Sin not only makes man the slave of his body and subject to the impulses of concupiscence, it also fills him with entirely spiritual vices," Elucidaton 8, p. 596.

6. See Descartes, Les passions de l'ame, the article 162 on veneration, where there is a brief mention of idolatry and the pagan mentality. It is not a treatise on the topic, as we have in Malebranche.

7. Malebranche, in reference to the heresies of those who wanted to deny the truth of the dogma of the trinity in the divinity, whether Unitarians or Socinians: "If Jesus Christ did not watch over His church, the number of Unitarians would soon surpass the number of true Catholics. I understand that. For there is nothing in the opinions of these heretics which does not naturally occur to the mind. I can well conceive how opinions commensurate to our intellect can be established over time. I can even conceive how the most bizarre opinions can predominate among certain peoples of an entirely singular turn of imagination," Dialogues on Metaphysics and on Religion, dialogue 14, p. $266 .$.

8. "God has predestined that after the sin, the union of the mind and the body would have change into the dependence of the mind from the body," Dialogues on Death, dialogue 13; "Af- 
ter the sin, the union of mind and body changed to a subjection of the mind to the body, though this is not an entire subjection" in Dialogues on Metaphysics and on Religion, dialogue 12.

9. See Dialogues on Metaphysics and on Religion, dialogue 13, p. 249: “... everyone is not always in a position to savor this truth ... Carnal people, those who still have the Jewish spirit, understand nothing of it."

10. Ibid., p. 248: "If we were Jews, I mean carnal Jews, we will have here on earth a recompense in proportion to our merits; I repeat, if we were carnal Jews. The Christian Jews, instead, who had part with the cross of Jesus Christ, will be sharing His glory."

11. The study of man for Malebranche has a finality that is religious and gnoseological; his analysis centers on a definition of man as the carnal man, a definition borrowed from St. Bernard: "It was necessary that the Word will become flesh, and that the Wisdom, hidden and inaccessible to carnal human beings will instruct them in a carnal way, carnaliter, as St. Bernard said," The Search after Truth, bk. 4, ch. 2, p. 272; the reference is not to Serm. 39, but to Serm. 3 of In Nativitate Domini in Patrologie Latine, tome 183, p. 124. Mentions of the carnal man and of St. Bernard are found also in Malebranche's Dialogues (Italian edition, p. 408). The discussion on the carnal nature of man takes its beginning from St. John Evangelist and Paul, and it is to these two sources that Malebranche appeals in his conception of the pagan mentality as the mentality of the carnal man. "Saint Paul in many places calls wisdom the law, while he calls the desires and the works of the flesh what is contrary to the law of the spirit. (...) Among the works of the flesh he includes idolatry, heresies, dissensions, and many other vices that people would call spiritual," Elucidation 8, p. 598. B. Lamy also speaks of the carnal nature of the pagan poets, but relying only on Malebranche: "The poets writes for those whose life is totally pagan. Poets never refer to Christian virtues," Nowvelle Reflexions sur l'Art Poetique, p. 38 and "Carnal men cannot comprehend these truths; their view is all for the creatures," ibid., p. 5.

12. The rapport between sin and the errors due to sensible judgments, that is, the common errors of the unlearned and of the Aristotelians, is proven by a long series of citations from Descartes and Malebranche, whose point of view is that of the need of fighting the human tendency of judging according to the data of the senses and not those of reason. Of these citations we will give a sample: "But to account entirely for the strangeness of our judgments about sensible qualities, it should be considered that the soul is so closely joined to its body and has become even so carnal since the Fall and consequently so incapable of concentration that it attributes to the body many things that belong only to itself, and hardly distinguishes itself from the body anymore," The Search after Truth, bk. 1, ch. 12, p. 57. "But since the sin, since the advent of the deranged love of prevenient, dominant, and victorious pleasures, the mind has become so feeble that it can penetrate nothing, and so material and dependent upon its senses that it cannot take hold of anything without a body, or pay attention to aabstract truths that do not affect it," ibid., bk. 4, ch. 11, p. 314. "The spirit, after the fall, has become almost material and terrestrial," in ibid., bk. 5, ch. 1, p. 339. "After the original sin, the pleasure of the senses has brought the soul at the level of sensible things," ibid., bk. 4, ch. 10, p. 307. "Given the sin, man has been reduced merely to flesh and blood" in ibid., bk. 3, pt. 2, ch. 9, p. 249.

13. The Search after Truth, bk. 4, pp. 312-336. For a general conception of the human spirit: "The blindness of the spirit and the irresponsability of the heart are the sources of all our imperfections. They are the consequence of the union of the spirit with the body, as I have often proven," ibid., bk. 5 , ch. 4 , p. 358.

14. Ibid., bk. 6, pt. 2, ch. 3, p. 451.

15. Ibid., Elucidation 15, p. 684.

16. The Search after Truth, Preface, p. xxxiv: “... but it is morally impossible that minds of flesh and blood, which are capable of knowing only what can be sensed, should ever be con- 
vinced by such reasoning. For these sorts of people, gross sensible proofs are required, because to them nothing appears solid unless it makes some impression on their senses"; "But because their body is related to all sensible objects, their soul not only is the slave of the body but is, moreover, the slave of all sensible things through or because of the body," ibid., p. xxxv. As the human bond with the body grows stronger, the bond with God gets weaker: "It is true that our union with God is diminished and weakened to the extent that our union with sensible things is increased and strengthened: but it is impossible that this union should be entirely broken without the destruction of our being," ibid., p. xxxvi; "Without doubt, the nature of man is presently corrupted ... the spirit has become material and terrestrial because of sin," ibid., bk. 5, ch. 1 , p. 339 , bk. 5 , ch. 4 , p. 358 ).

\section{Chapter Four}

(Aristotelianism: The Logical Sublimation of the Pagan Mentality)

1. The Search after Truth, Elucidation 15, p. 657. This passage expresses clearly the conceptual horizon of the pagan mind: "I grant that there are many people who through a principle different from that of the pagan philosophers follow their opinion on nature and secondary causes," ibid., p. 657.

2. The philosophy of the Stoics has merely extrinsic affinities with Christianity. It expresses a pagan mind because it does not justify the rapport of dependence between soul and body. In other words, Stoic philosophy does not recognize the Fall and sin as factors that determine human conduct. The pride of the Stoics is an effect of selfishness, the presumption of being capable of creating personal destiny or commanding the events; this in the Christian eyes is pure paganism, alienation from the given grace of the divinity. See The Search after Truth: "Epicurus was right in saying that offenses were bearable by a wise man. But Seneca is wrong to say that wise men cannot even be offended. The virtue of the Stoics could not render them invulnerable, since true virtue does not prevent one from being miserable and worthy of compassion when one suffers some evil. Saint Paul and the first Christians had more virtue than Cato and the Stoics. They nevertheless admit that they were wretched because of the pain they endured, although they were made happy by the hope of eternal reward," bk. 2, pt. 3, ch. 4, p. 178. And the final arguments of negation of the great Stoic virtue: "To destroy the Stoic wisdom completely, one need know but one thing, which is sufficiently proved through experience and by what has already been said, that we are tied to our body, to our parents, to our friends, to our prince, to our country, by bonds we cannot break, and would even be ashamed to try to break. Our soul is joined to our body, and through our body to all visible things. ... One is never above nature, unless through grace, and a Stoic will never hold the glory and esteem of men in contempt simply through the strength of his mind," ibid., pp. 182-183.

3. The Search after Truth: "It is certainly true that without the grace of Jesus Christ, the sweetness tasted by the soul that abandoned itself to passions is more acceptable than the sweetness obtained in following the rules of reason. This sweet pleasure is the origin of all the disorder that was caused by the original sin. It would have made us slaves of our passions, if the Son of God did not free us from that slavery by means of His Grace. The things I am saying about the joy of the spirit contrary to the joy of the senses are true only for the Christians. They are false when they come from the mouth of Seneca, even of Epicurus and of all the Philosophers who seem to speak most reasonably," bk. 2, pt. 3, ch. 4, pp. 178-183.

4. Malebranche considers at the same level the mentality of the common folks and that expressed in the pagan philosophies. There is no difference between the mentality of the common man and that of the pagan philosophers: "I am not surprised that ordinary men or pagan philosophers consider only the soul's relation and union with the body, without recogni- 
zing the relation and union it has with God. But I am surprised that Christian philosophers, who ought to prefer the mind of God to the mind of man, Moses to Aristotle, and Saint Augustine to some worthless commentator on a pagan philosopher, should regard the soul more as the form of the body than as being made in the image and for the image of God," The Search after Truth, Preface, p. xxxiii. See also: “... it would be necessary to overthrow the fundamental principles of pagan philosophy, to explicate the disorders of sin, to combat what is falsely called experience, and to argue against the prejudices and illusions of the senses," ibid., p. xxxiv.

5. The Search after Truth, bk. 1, ch. 12, p. 57. God, absolute substance and absolutely spiritual, has some corporeity; this was the prejudice of Tertullian, which was embraced by a large part of the pagans. The consideration of God as something corporeal: "If you carefully read Tertullian ... he has fallen into the utter folly of fancying that God Himself is corporeal."

6. "For in the end, given that every natural impulse is an impression by the Author of nature, who acts only for Himself, and who can turn us only toward Himself, the true impulse of the soul is always essentially the love of good and only accidentally flight from evil. ....all the objects of our senses are incapable by themsemselves to make themselves sensed by us; it was God who taught us that they are present by way of the sentiments that He donated us. This is what the pagan philosophers have never understood," ibid., bk. 5, ch. 3, p. 348.

7. The Search after Truth, bk. 1, ch. 14, pp. 67-70: “... we are strongly inclined to judge that our sensations are in the objects";. Also, bk. 1, ch. 13, p. 63: "What leads the soul even more into wanting a fanciful view of its sensations is that it judges them to be in objects and even to be modifications of objects, and consequently that they are corporeal and can be imagined." For Malebranche, only God is the true cause.

8. Ibid., bk. 6, pt. 2, ch. 3, p. 448 "A natural cause is therefore not a real and true but only an occasional cause, which determines the Author of nature to act in such and such a manner in such and such a situation." This statement is repeated many times and it can be found in the work of Malebranche that is essential for this research, see ibid., "The most dangerour error of the philosophy of the ancients."

9. The Search after Truth, bk. 6, pt. 2, ch. 2, p. 444.

10. Ibid., pp. 443-444: "There are still those who believe that within the fire are a substantial form and faculties for producing heat, rarefaction, fluidity, and so on, would be useless to me in discovering whether fire would be capable ofhardening mud and softening wax, there being no connection whatsoever between the ideas of the hardness of mud and the softness of wax and the idea of the substantial form of fire, and of the qualities of producingrarefaction, fluidity, and so on."

\section{Chapter Five \\ (The Scientific Foundations of Vico's Psychology)}

1. See The New Science (1730), par. 180: "When people are ignorant of the natural causes that produce things, and cannot even explain them in terms of similar things, they attribute their own nature to them. For example, the masses say that a magnet loves iron"; again par. 182: "The natural science of the ignorant is a sort of popular metaphysics, which explains the unknown...." Vico presents a principle which is expressed equally by Malebranche saying that the Aristotelian physics is a kind of logic. Spinoza, in the Ethics, believes the same.

2. Ibid., par. 363: "Throughout this work, I shall show that everything that the poets sensed in their popular wisdom was later understood by the philosophers in their esoteric wisdom. We may say then that the poets were the sense of mankind, and the philosophers its intellect. Thus, what Aristotle said in particular about the individual is also true in general about humankind: 'Nothing is found in the intellectwhich was not found first in the senses', Nibil est 
in intellectu quin prius fuerit in sensu. This means that the human mind can only understand a thing after the senses have furnished an impression of it, which is what today's metaphysicians (Malebranche) call an occasion. For the mind uses the intellect whenever it 'gathers' something insensible from a sense impression, and this act of gathering is the proper meaning of the Latin verb intelligere, to understand." dicono occasione da sensi, la quale allora usa l'intelletto quando, da cosa che sente, raccoglie cosa che non cade sotto de sensi; lo che propriamente a' latini vuol dire intelligere." Vico refers to Leibniz in speaking of Aristotle in order to explain the way of thinking of the human mind: an abstraction from what is perceived. Both Vico and Leibniz, by affirming that the human mind behaves in the same way than the Aristotelian physics, do not intend to support the philosophy of the school of the Stagyrite. On the contrary, they see Aristotelianism as the forma mentis of the common sense, that is, of the pagan mind. The relationship between the poetic theologian as an Aristotelian ingenuous philosopher and the Aristotelian philosopher as a pagan who has reached the loftiest abstractive capacity and widest use of his intellect, is presented by Vico in pars. 498, 499, and 500.

3. To understand how popular Cartesianism and Malebrancheanism were in the cultural ambiance of Naples among the literati, see N. Badaloni, Introduzione a Vico (Milano, 1961); M. Torrini, "Il problema del rapporto scienza filosofia nel pensiero del primo Vico", in "Physis" num. 20 ; E. Garin, Storia della filosofia italiana, (Torino, 1966), bk. 2, English trans. History of Italian Philosophy (Amsterdam-New York: Rodopi, 2008); M.T. Marcialis, La disputa sei-settecentesca sugli antichi e sui moderni (Milano, 1960); M. Agrimi, "Descartes nella Napoli di fine Seicento" in Atti del convegno Descartes il metodo e i saggi (Roma, 1990); L.B. de Besaucèdes, Le cartésiens d'Italie (Paris, 1920); G. Maugain, Etude sur l'évolution intellectuelle de l'Italie de 1657 à 1750 environ (Paris, 1909), and Fr. Boullier, Histoire de la philosophie cartésienne (Paris, 1868).

4. See Vico, On the Most Ancient Wisdom of the Italians unearthed from the origins of the Latin language, trans. L. Palmer (Ithaca: Cornell University Press, 1988): ch. 4, sect. 6: "Motion is not Communicated"; and sect. 3: "There is no Conatus in Extended Things."

5. Ibid., ch. 4, sect. 3 .

6. Ibid., ch. 4 , sect. 3 .

7. "One term from metaphysics still survives, the word conatus. So that physicists could advance further in their studies of physical things, this concept as well should be given up by the physicists and returned to metaphysics" (Superest adhuc ex metaphysica id conatus vocabulum. Quare quo disserendi genus de rebus physicis omnino perficiatur, e physicorum scholis est ad metaphysicos amandandum), ibid., ch. 4 , sect. 3 .

8. Ibid., ch. 4, sect. 6 .

9. See Vico, On the Study Methods of Our Time, trans. Elio Gianturco (Ithaca: Conell University Press, 2000), ch. 7: "It is an error to apply to the prudent conduct of life the abstract criterion of reasoning that obtains in the domain of science. A correct judgment deems that men-who are, for the most part, but fools-are ruled, not by forethought, but by whim or chance." (Non recte igitur, per haec, quae diximus, ii faciunt, qui iudicandi rationem, qua utitur scientia, in prudentiae usum transferunt: nam ii res recta ratione aestimant, et homines, cum bona ex parte stulti sint, non consilio, sed libidine vel fortuna reguntur: ipsi de rebus iudicant, quales esse oportuerit, et res, ut plurimum, temere gestae sunt).

10. Ibid., ch. 7. The discussion moves on the incommensurability of the general principles in relation to the particular intentions and goals: "Abstract or general truths are eternal; concrete or specific ones change momentarily from truths to untruths. Eternal truths stand above nature; in nature, instead, everything is unstable, mutable" (At ex genere vera aeterna sunt, particularia autem quoque temporis momento in falsa mutantur; aeterna supra naturam extant; in natura enim nibil, nisi mobile, nisi mutabile continentur).

11. Ibid., ch. 1. 
12. Vico, First New Science, ed. and trans. Leon Pompa (Cambridge: Cambridge University Press, 2002), bk. 1, sect. 5, par. 16.

13. Id., On the Study Methods of Our Time, ch. 4, sect. 3, p. 24.

14. This distinction (subtlety-acuteness) comes from the study of rhetoric, for which consult Vico, The Art of Rhetoric, Giorgio Pinton trans. (New York-Amsterdam: Rodopi, 1996) and does concern all questions, including the scientific. The same can be said for Malebranche who insists on the equivocity of language as being the source of errors and also for him the critique is not limited to the sciences alone but also to pseudo-sciences, Galenic medicine and Aristotelian physics included, with their connection with the preconceived common sense. See for this The Search after Truth, book 6, pt. 2, ch. 1: Rule to be observed in the search after truth.

15. Vico, On the Most Ancient Wisdom of the Italians, ch. 2: Genera or Ideas, p. 62.

16. Ibid., ch. 2: Genera or Ideas, p. 60.

17. Ibid., ch. 2: Genera or Ideas, p. 62.

18. Many critics have considered Leibniz's approach superficial or of convenience. We must be aware of the perspective from which the rationalists of the grand siècle considered the rapports between common sense, Aristotelianism, and abstraction from the sensible, as we presented them in these pages, then their approach with the empiricism has its own profound reason. Vico will propose the same parallelism of common-sense, Aristotelianism, and Empiricism. He can do it, because he takes the opposed rationalistic perspective.

19. Ibid., ch. 2: Genera or Ideas, p. 62: "All philosophical errors arise from homonyms, which are commonly called equivocations. Yet equivocations are nothing but words that signify more than one thing. For without genera equivocations will not exist, since men are naturally averse to homonyms. ... This is the case in physics because the nouns matter and forms are generic; in jurisprudence because the term just ranges far and wide; in medicine because the words bealthy and sick are far too broad; and in practical life because the expression useful has not been defined" (Et vero omnes sectae in philosophia, medicina, iurisprudentia, omnes in vita agenda controversiae et iurgia sunt a generibus; quia a generibus sunt homonymiae, seu aequivocationes, quae ab errore esse dicuntur. In physica, quia generica materiae et formae nomina; in iurisprudentia, quia longe lateque patet appellatio iusti; in medicina, quia sanum et corruptum sunt nimis ampla vocabula; in vita agenda, quia vox utile definita non est.)

20. Ibid., ch. 2, p. 61.

21. Ibid., ch. 7, p. 100.

22. Ibid., ch. 2, p. 61.

23. Ibid:: "This is the difference between physical and metaphysical matter. Physical matter evolves the best form for itself, no matter how peculiar that form may be, since the way it evolved was the only possible way. Because all peculiar forms are imperfect, however, so metaphysical matter contains the best form in the kind itself or in the idea" (Atque hoc differt inter materiam physicam et metaphysicam. Physica materia ideo quamlibet formam peculiarem educat, educit optimam; quia qua via educit, ea ex omnibus una erat. Materia autem metaphysica, quia peculiares formae omnes sunt imperfectae, genere ipso, sive idea, continet optimam).

24. Vico, On Humanistic Education (Six Inaugural Orations, 1699-1707) Giorgio Pinton trans. (Ithaca: Cornell University Press, 1993), Oration VI, par. 9, p. 132.

25. Ibid., Oration 3, par. 6, p. 80.

26. Ibid., Oration 6, par. 3, p. 127.

27. Vico, On the Most Ancient Wisdom of the Italians, ch. 4, sect. 6, pp. 82-83.

28. Ibid., ch. 4 , sect. 6 .

29. Ibid., ch. 4, sect. 5, p. 82: "Therefore, nothing in nature holds on to the same place and bodily environment, even for an instant. The opinion that things steadily pursue the form with which they have once and for all been endowed befits the scholastics, who regard these prin- 
ciples of self-conservation as belonging among the causes of natural things" (Quare nibil in natura hanc corporum viciniam, seu eundem situm, vel momento quidem temporis obtinet. Et illud placitum: quod res pergant obtinere formam, qua semel praeditae sunt, Scholas decet, quae ista tutoria naturae consilia in rerum naturalium caussis habent).

30. Ibid., ch. 4, sect. 6, p. 83.

31. Ibid., ch. 7, sect. 1, pp. 93-94.

32. Ibid., ch. 7, sect. 1, p. 93.

33. Ibid., Vico's First Response, pp. 126-127.

34. Ibid., ch. 7, sect. 2, pp. 94-95.

35. Ibid., ch. 2, sect. 5, p. 62. Among the various meanings in which the term "genus" is used in the Aristotelian philosophy, the one that interests us is that of the subject to which are attributed the oppositions or the specific differences. "Genus" is the first constituent of the definition. Aristotle, Metaphysics, V, 28, 1024. In order to understand the bond between genus and universal, we must refer to the concept of substance. See Aristotle, Metaphysics, VIII, 1, 1042: "We have said that the causes, principles, and elements of substances are the object of our search. And some substances are recognized by every one, but some have been advocated by particular schools. Those generally recognized are the natural substances, i.e. fire, earth, water, air, \&c., the simple bodies; second plants and their parts, and animals and the parts of animals; and finally the physical universe and its parts; while some particular schools say that Forms and theobjects of mathematics are substances. But there are arguments which lead to the conclusion that there are other substances, the essence and the substratum. Again, in another way the genus seems more substantial than the various species, and the universal than the particulars. And with the universal and the genus the Ideas are connected; it is in virtue of the same argument that they are thought to be substances. And since the essence is substance, and the definition is a formula of the essence, for this reason we have discussed definition and essential predication. Since the definition is a formula, and a formula has parts, we had to consider also with respect to the notion of 'part', what are parts of the substance and what are not, and whether the parts of the substance are also parts of the definition." Translated by W. D. Ross. Fabiani's rendition follows: "Poiché la sostanza è l'essenza necessaria e l'espressione di questa è la definizione (...) e poiché, d'altronde, la definizione è un discorso ed un discorso ha parti, fu necessario distinguere quali sono le parti della sostanza e quali no e se queste sono anche parte della definizione e così vedemmo che né l'universale né il genere è sostanza." The genus is not a substance but the component of the necessary essence that is the substance. From this came the medieval discussion on the universals, that is, of genus and species as universals.

36. On the Most Ancient Wisdom of the Italians, ch. 2, sect. 5, p. 62.

37. Vico's First Response, ibid., sect. 3, p. 132.

\section{Chapter Six}

(The Most Dangerous Error of the Ancients)

1. The Search after Truth, bk. 6, pt. 2, ch. 2, p. 440: "Nearly all his works [of Aristotle], but mainly his eight books abou physics, of which there are as many different commentators as there are teachers of philosophy, are only pure logic." On this topic, Malebranche continues in several chapters: ibid., bk. 2, pt. 2, ch. 6 and Elucidations 1 and 3. He opposes the logic of the mathematicians and geometricians in ibid., Elucidations 1, 3, and 4. Ibid., bk. 3, pt. 1, ch. 3, p. 209: "The method of geometers increases the mind's capacity, whereas Aristotle's diminishes it. ... This alone shows that the ordinary sorts of logic are more suited for diminishing rather than increasing the mind's capacity, because clearly, if in the search after a given truth, one wishes to use the rules these logics give us, the mind's capacity will be so divided up that it will 
have less capacity for carefully understanding the full extent of the subject under examination." Ibid., p. 210. Malebranche tries to identify the logic of the Aristotelian physics with the logic of the common sense: "It happens regularly that philosophers as they see a new effect, they imagine that there is a new cause capable of producing that effect." Imagination establishes a rapport of cause and effect, founding its judgment on a logical principle abstracted from sensible experience: "The fire heats: there is therefore an entity within the fire producing that effect [here is the logical deduction], and this entity must be different than the components of fire. And because the fire can produce different effects, they assign to fire many faculties and qualities capable of producing so many different effects," ibid., bk. 3, pt. 2, ch. 8, p. 242. It is easy to identify in all this the same elements that characterize the interpretation of reality that is performed by the Vichian theological poets. See Elucidation 16, p. 694: "The generation of fire."

2. The Search after Truth, bk. 3, pt. 2, ch. 8, p. 243. In ibid., bk. 3, pt. 1, ch. 2, p. 209, Malebranche refers to the Aristotelian logic in negative terms not only in regard to the logic of syllogisms (to which he prefers the Regulae of Descartes) but also to the erroneous logic that is at base of the gnoseology of the natural causes and of the substantial forms: "Experience shows us that the ogic of Aristotle is of no great use. The reason is that it occupies too much the spirit and the attention turns away from what it is considering." In ibid., bk. 6, pt. 1, ch. 5, pp. 431-436, Malebranche explains that he is referring not so much to the logic formalized in the Organon as much as to the logic that constitutes the structure of the false knowledge of the Peripatetics and, in another sense, of the superstitious: "I have made it clear enough ... that his manner of philosophizing is completely useless for discovering truth," p. 210; also: "Aristotle reasons only by way of ideas that are confused and other ideas vagues, general, and indetermined, which represent nothing particular to the spirit. ... The other kind of equivocation used by the philosophers comprehends general terms of logic by means of which it is easy to explain all things without having any knowledge of them." It is evident that Malebranche refers to the formal logic but also to the logic of deduction in the judgments on physical phenomena. "Aristotle himself is the one who used mostly this method and all his books are full of it and some of them are merely of pure logic. He proposes and resolves all things using the charming words of genus, space, act, potency, nature, form faculty, quality, cause in itself and accidental cause," bk. 6, pt. 2, ch. 2, p. 443; the chapter constitutes a complete criticism of Aristotle's physical theories. Malebranche repeats, "We intend to show into which kind of errors one may fall by reasoning with the confused and false ideas of the senses and with the vague and indetermined ideas of a pure logic." The Aristotelian philosophy shares with the pagan mentality not only a vision of the world but also an erroneous logic, a logic that Vico will call poetical and that Malebranche only defines as pagan. Thus, he speaks: "Behold the reasoning of the prince of philosophers and the genius of nature, who, instead of making the true cause of natural effects known by clear and distinct ideas, establishes a pagan philosophy on the false and confused ideas of the senses, or on ideas too general to be useful in the search for truth," p. 471

3. Some citations to serve as examples, from The Search after Truth, Preface, p. xxxix: "Most of those whom everyone regards as competent see in only very confused fashion the essential difference between the mind and the body. Saint Augustine himself, who distinguished these two things so well, confesses that for a long while he was unable to see the difference. And although it must be agreed that he explained the properties of the soul and the body better than all those who preceeded him and who have followed him until our own time, nonetheless, he would have done better not to attribute to the bodies sorrounding us all the sensible qualities we perceive by means of them, for in the final analysis these qualities are not clearly contained in the idea that he had of matter. As a result, it can be said with some assurance that the differences between the mind and the body has been known with sufficient clarityfor only a few years." See also the chapters on the ignorance of humankind: ibid., bk. 3, pt. 1, ch. 4, pp. 211- 
214; bk., p. 441: "Only since Descartes do we respond to these confused and indeterminate questions, whether fire is hot, grass green, sugar sweet, and so on, by distinguishing the equivocation of the sensible terms that express them." And finally, the consideration on the compatibility between the Christian religion and the Cartesian philosophy, in bk. 6, pt. 2, ch. 4, pp. 453-466.

4. Ibid., bk. 6, pt. 2, ch. 3, pp. 446-452.

5. Many of the Malebranchean conceptions expressed in the pages of these chapters will return in many other parts of his work. In them, the foundations on which this work is constructed should be found.

6. Ibid., bk. 6, pt. 2, ch. 3, p. 446: "Not only do philosophers say what they do not conceive when they explain natural effects through certain beings of which they have not one single particular idea, they even furnish a principle from which one can directly infer very false and very dangerous conclusions."

7. Ibid., p. 446: "For if we assume, in accordance with their opinion, that bodies have certain entities distinct from matter in them, then, having no distinct idea of these entities, we can easily imagine that they are the true or major causes of the effects we see. That is even the general opinion of ordinary philosophers; for it is mainly to explain these effects that they think there are substantial form, real qualities, and other similar entities."

8. The argument developed in The Search after Truth, bk. 6, pt. 2, ch. 3 develops one of the principal themes of this book. The argumentation will be developed in the next chapters in which we must pay attention to the relationship of natural causality, substantial forms, and the idolatric pagan conceptions of divinity. The above mentioned chapter intends to show the interconnection of the three elements.

9. The connection between idolatry and the conception of causality is for Malebranche a psychological necessity, in the sense that the creative productive action is an attribute of the divinity alone. If the principle of this creative action were to be posited within nature, than this principle would be the divinity. God, in this case, could not communicate to critters its own power not even if it would, because such an action would mean to make the critters gods. This is an ontological contradiction, before being a logical one; a contradiction that would bring to an idolatric reality made of semi-divinities, with limited power of action, but still capable of acting in a kind of cosmic anarchy. Within this cosmic situation, hierarchies will be soon created according to the individual power of these natural causes. It would be a pagan universe made of confusion, removed from divine reasonableness. If the world were governed by pure natural causality, if critters had true power of action, we would have a pagan universe as it is imagined by idolaters and mapped in the Aristotelian physics. "God cannot even communicate His power to creatures, if we follow the lights of reason; He cannot make true causes of them, He cannot make them gods," The Search after Truth, bk. 6, pt. 2, ch. 3, p. 451.

10. The Search after Truth, bk. 6, pt. 2, ch. 3, pp. 446-447. The discourse goes on with the observation: "It is true that faith corrects us; but perhaps it can be said in this connection that if the heart is Christian, the mind is basically pagan." The substantial forms as schematism, as an interpretive screen of reality bring us necessarily to a pagan conception of the divinity, an idolatric vision of nature, because we cannot consider as intelligent a cause that produces something that to the mind appears complex: "Perhaps it would be said that substantial forms, those plastic forms, for example, that produce animals and plants, do not know what they are doing and that, thus, lacking intelligence, they have no relation to the divinities of the pagans. But who will be able to believe that what produces works that manifest a wisdom that surpasses all philosophers produces them without intelligence?”

11. We will speak of Vico in a short while and remind the reader that the conception of the universality of the imagination in Malebranche will be treated diffusely later on. The inten- 
tion of this paragraph is to show how the conception of divinity that the pagans form is strictly connected with the theories of the substantial forms and natural causality.

12. The universality of the imagination is at the root of this discussion under development. On the relations of the universality of imagination with the idea of Jupiter, universal cause (in the perspective of natural causality), there is this enlightening passage in Malebranche: "It is true that reason does not teach that it is necessary to adore onions and leeks, for example, as the sovereign divinity, because they cannot make us completely happy when we have them, nor entirely unhappy when we do not. Also the pagans never gave them much honor as they gave to the great Jupiter, on whom all their divinities depended, or as they gave to the sun, which our senses represent to us as the universal cause that gives life and motion to all things, and that we cannot help regarding as a divinity if we assume with the pagan philosophers that it encopasses in its being the true causes of everything it seems to produce, not only in our bodies and minds, but also in all the beings that surround us," The Search after Truth, bk. 6, pt. 2, ch. 3, p. 447. As we notice, in all this there is also an emotive component. A mind that thinks through substantial forms and by way of natural causality, besides having a qualitative conception must also have an emotive knowledge of reality. All these elements are anthropological conceptions inherent in this discussion.

13. Ibid., p. 450: "A true cause as I understand it is one such that the mind perceives a necessary connection between it and its effects"

14. Ibid., p. 454: "They have, on the contrary, and for the same reason, great respect and eagernessfor great things that concern the infinite, and even for those that are obscure and mysterious. It is not basically that they love darkness; it is just that they hope to find there the good that they desire, and that in broad daylight they realize that it is not to be found here below."

15. Ibid., p. 444-445: "So their idea of this faculty is no different from the general idea of cause and the confused idea of the effect they see. They therefore have no clear idea of what they are saying when they allow for these particular things. Thus, they say what they do not even conceive, and even what is impossible to conceive."

16. Vico, The New Science, par. 374: "And to the extent that human nature coincides with that of animals, it must rely on the senses as the sole means of knowing things."

17. Ibid., par. 182.

18. Vico's position is more articulate than it may seem. His position regarding the Aristotelian physics and the critique of the subjective qualities, in addition to the statement that there is no conatus (force, power, willingness) in physical natural bodies, has been discussed. Though this aspect of the Vichian thought is well known, much less known are the effects of its application to anthropology.

19. Vico, The New Science, par. 191.

20. Ibid., par. 495: "The first founders of civilization strove to devise an art of sensory topics. This allowed them to combine what might be termed the concrete properties, qualities, and relations of individual objects and their species. These combinations in turn created their poetic genres."

21. Ibid., par. 490: "This is why the poets said 'All things are full of Jupiter' Iovis omnia plena. Although this was misinterpreted as a statement of poetic metaphysics, it was in fact a truth of rational metaphysics, which conferred human authority (in the sense of domain or ownership) on the giants who had occupied the world's first vacant lands."

22. Ibid., par. 402: "Today we reverse this mental process when we deal with intellectual notions, such as the faculties of the human mind, the emotions, virtues, vices, sciences, and arts. For we generally imagine them as femini ne personifications, to which we refer their various properties, causes, and effects. And when we wish to express our understanding of 
intellectual notions, our imagination must assist us in explaining them and in giving them human form, as painters of allegories do. By contrast, the theological poets could not use their understanding, and so performed the contrary operation, which is far more sublime. They attributed senses and emotions to physical bodies, even bodies as vast as the sky, earth and sea, as we have just seen. Later, as their vast imagination diminished and their powers of abstraction increased, these deities shrank to diminutive symbols of themselves." Joseph Mali, The Rebabilitation of Myth (Cambridge: Cambridge University Press, 1992) says, "The man who elucidates animate behaviour out of inanimate objects performs a peculiar act of unconscious selfrecognition: by reading into the object the very qualities which it in turn re-presents to him, he becomes aware of these-his own-qualities. The fallacy of anthropomorphism, then, turns out to be crucial and beneficial to man once we realize its constructive functions in the psychological-historical process" (p. 187).

23. Ibid., par. 379.

24. Ibid., par. 383: "We find confirmation of this origin of poetry in the invariable property: the proper subject of poetry is a believable impossibility. Thus, while it is impossible that physical objects have intelligence, people believed that the thundering heavens were Jupiter."

25. Ibid., par. 400: "Hence, now that we have considered poetry as a poetic metaphysics, by which the theological poets imagined most physical objects to be divine substances, we may consider it as a poetic logic, by which it signifies those substances."

26. Ibid., par. 404: "The first poets attributed to physical bodies the being of animate substances, endowed with limited powers of sense and emotion like their own. In this way, they created myths about them; and every such metaphor is a miniature myth."

27. Ibid., par. 405.

28. It is the example of the false savants. See The Search after Truth, bk. 6, pt. 2, ch. 4, p. 454: "Thus, false scholars do not find it to their advantage and are not admired as they wish when they use intelligible principles, because we clearly recognize that they are saying nothing true." Malebranche shows here the elements of the success of idolatry: human beings have always a religious respect for what they believe erroneously to be superior to their intelligence. Pride would do the rest. If someone or something overcomes my intelligence, it must be something divine. The false savants like the pagan priests, the false prophets, and sourcerers and witches, try to cover themselves with an aureola of sanctity, of divinity.

29. The Search after Truth, bk. 6, pt. 2, ch. 4, p. 454.

30. Ibid., p. 452: "But that is not the inclination of some philosophers. They do not want to see God, they do not want to think about God; for since sin there is a secret opposition between man and God. They take pleasure in fabrikating gods at their whim, and they willingly love and fear the figments of their imagination." Pagan mentality and infantile mind are similar: they create the objects of their fears, the desires of their passions. The divinity is the hypostasizing of the infantile impressions dominating conscience.

31. Ibid., bk. 5, ch. 5, p. 363: "The false zealots imagine to render a service to God ... an insurmountable opinion."

32. Ibid., bk. 2, pt. 3, ch. 6, pp. 191-194: "Superstitions are not easily destroyed, and one does not attack them without encountering many of their defenders. This inclination to believe all the dreams of the demographers is blindly produced and upheld by the same cause that makes the superstitious stubborn, as is easy to prove."

33. Ibid., bk. 3, pt. 1, ch. 2, p. 205.

34. Ibid., p. 205.

35. Ibid., p. 205.

36. Ibid., p. 205: “... all these subtle, human arguments can rouse in them their secret pride; they lead them to misuse their mind by framing a religion suitable to its capability." This criti- 
cism is against the false savants, but it can be directed also against all those who think in function of their passions and on these passions build their mentality, vision of the world, and philosophy.

37. Quoting Bacon, Malebranche affirms, "Ex divinorum \& bumanorum malesana admixtione, continuet-il, non solum educitur Philosophia phantastica, sed etiam Religio haeretica," (From the improper mixing of things divine and human, not only a fantastic philosophy derives but also a heretic religion), The Search after Truth, bk. 1, pt. 2, ch. 7, pp. 157-158.

38. Vico, The New Science, par. 515: "Plato imposed on the mythical Jupiter his own idea of ether, which pervades and penetrates everything. But in fact the Jupiter of the theological poets was no higher than the mountain tops and the region of the atmosphere which generates lightning"

39. Ibid., par. 180: "When people are ignorant of the natural causes that produce things, and cannot even explain them in terms of similar things, they attribute their own nature to them."

40. Ibid., par. 120: "By its nature, the human mind is indeterminate; hence, when man is sunk in ignorancre, he makes himself the measure of the universe."

41. Malebranche, .Entretiens sur la mort, Dialogue 12.

42. Id., Dialogues on Metaphysics and on Religion, Dialogue 9, p. 148.

43. Ibid., Dialogue 9, pp. 138-139: “Human beings are always imbued with the inner feeling they have of wwhat is transpiring in their minds and hearts. They can only sense confusedly what they are and hope to be. Thus, they quite naturally project themselves onto the object of their knowledge, and by their humanity measure not only everything surrounding them, but even the infinite substance of the divinity. It is true that the notion of the infinitely perfect Being is deeply engraved in our mind. We never exist without thinking of Being. But far from employing this vast and immense notion of Being without restriction to measure thereby the divinity which is continually represented to us, we consider this immense notion as a pure fiction of our mind. This is because, Aristes, Being in general does not strike our senses and we judge the reality and solidity of objects by the force by which they affect us."

44. Ibid., Dialogue 7, p. 111.

\section{Chapter Seven}

(The Birth of Thought)

1. Vico, First New Science, bk. 1, ch. 13: "For we need to measure the life of mankind, which is that of men who grow old with the passage of years, so that it is we who are the old while the founders of nations were the young. But it has been found that, by the age of seven at most, children born in nations where language has already developed, have already acquired a large vocabulary...." Vico's interest is not the psychological developement of the child, but the historical-metaphysical process of the pagan mind.

2. The Search after Truth, bk. 2, pt. 1, ch. 8, pp. 125-129.

3. Ibid., p. 125.

4. This is the principal argument of bk. 4: "The inclinations, or, the mind's natural impulses," pp. 265ff. The human being is confused about its inclination toward the absolute good. Because of this unconscious sentiment, human beings search for goodness in corporeity rather than in divinity.

5. The sentiment of solitude assigns a different and superior value to the search for goodness, because physical reality is beyond that search, while the true goodness can be found by moving inwardly, in the mind, and find God in it.

6. Vico, The New Science, par. 236. 
7. Lamy, Nouvelle Reflexions sur l'Art Poetique (Paris 1668), p. 23: “The poets cover all creatures with a false splendor that shines and blind $s$ them in their spirit, so that they cannot reflect upon themselves or realize the nothingness of reality" (Les poetes couvrent toutes les creatures d'un faux éclat: ils occupent tellement l'esprit (avec le vers), qu'ils ne peuvent faire aucune reflexion sur euxmêmes, et sur le neant des creatures).

8. The Search after Truth, bk. 2, pt. 1, ch. 8, p. 125.

9. Malebranche is speaking of infants, but his discourse is generalized at a theoretical level, in a theory on the origin of thought. He is interested not in the thought of the infants but on thought per se.

10. The Search after Truth, bk. 2, pt. 1, ch. 8, p. 125.

11. In this case it is useless to ask if for Malebranche the ontogenesis traces the path of phylogenesis. This is not the present perspective. Malebranche is only interested in freeing the mind from error. He does not care about how humankind has moved from one level of civilization to another, whether the Etiopians would organize their society like the French. As long as societies make errors, they are pagan. The meaning is that a perfect rationalism triumphs only in a parallel line with Christianity, as France and its history seems to prove. Erroneousness is implicit in human nature and is equivalent to irrationality. But there is more to this in the chapters to come.

12. The Search after Truth, bk. 2, pt. 1, ch. 8, p. 126.

13. Ibid., p. 126.

14. Ibid., p. 126.

15. Ibid., p. 126.

16. Bernard Lamy (1640-1715) was a dear friend of Malebranche and a peer in the same religious order. Lamy exposed his Malebrancheanism in Entretiens sur les sciences, Morale Chrétienne and in the last editions of La Rhétorique ou art de parler. Lamy's work under consideration was published by the same printer of The Search after Truth at the moment when Malebranche was beginning to write it, when there was no Malebranchean philosophy yet. Nonetheless the work of Lamy should be qualified as being a Malebranchean text. The philosophical system of Malebranche took its shape in the period 1664, the year of discovery of Descartes, to 1668, the year of the writing the first version of La Recherche. We have to assume a verisimilar exchange between the two friends. A second explanation is that the majority of the members of the Religious Society of the Oratory were Augustinian and Cartesian. In all of them the goal was of finding the mediation between the two philosophies. Malebranche was the one who succeeded in mediating between the two philosophies and also of formulating a synthesis of the two that will offer an overcoming of Cartesianism. In a sense, Malebranche represented the vertix of a cultural movement, substantially homogeneous at the inside of the same religious order in which both he and Lamy lived. These motivations are proved by all the studies done on the cultural ambiance of Malebranche.

17. In Nouvelles Reflexions sur l'art poetique (Paris 1668), Lamy begins with the most classic statement: "Poetry is a picture speaking about what there is of most beautiful among the creatures" (La poesie est une peinture parlante de ce qu'ily a de plus beau dans les Creatures) but immediately adds, "which make us forget about God." Lamy proclaims of making new considerations about old questions that need to be re-examined: "To say that poetry is a speaking picture is not new" (Dire que la Poesie est une peinture parlante, ce n'est pas une nouvelle remarque). What Lamy intends to evince is the gnoseological and cognitive aspect, specifically, of understanding poetry as a speaking painting. Poetry is capable of inserting in the mind the stable vestigia of the ideas. It is the cognitive aspect and the perceptive capacity of painting, that is, the representations that determine the value of poetry. 
18. There is no doubt that Lamy shares the Malebranchean division of pagan mind-Christian mind, and that the imagination hides the true knowledge of God. We may say that the work of Lamy is an application of the Malebranchean psychology and morality to literary criticism and poetry as the molders of mentality.

19. Nouvelle Reflexions sur l'Art Poetique, p. 3: “The matter of the poet's verses is ordinarily about great things and they employ rich colors to paint what is excellent. The eyes do not see anything beautiful neither in heaven nor on earth. The imagination cannot represent marvellous things when among men the description of things is exact. All that could be said of excellent about poetry has been already said and it is known by everybody. Everybody, however, does not remark that the things of the world make us forget about the vivid painting that the poets ordinarily trace of the great wordly things. Those who read their verses are not aware that the great attractive things they represent are images that exist in God, about Whom they never think. They do not see that they attach themselves to these images that are no less senseless than the man, who, having lost his wife, has become so extravagant to reach the point of loving her finely painted picture. It is a suprising truth that the admirers of the profane poets, which I am criticizing, cannot be easily persuaded that their error is great and dangeorus" ( $\mathrm{La}$ matiere de leurs vers est ordinairement grande, \& ils n'employent de si riches couleurs que pour peindre ce qu'il ya de plus excellent. Les yeux ne voyent rien de beau ny dans le ciel ny sur la terre, \& l'imagination ne se peut rien representer de grand, dont l'on ne trouve chez eux des descriptions exactes. Tout ce que l'on peut dire de l'excellence de la poësie a êté dit, \& n'est ignoré de personne: mais tout le monde ne remarque pas quelles sont les choses que nous fait oublier cette peinture si vive que les poëtes font ordinairement des grandeurs d'ici-bas; ceux qui les lisent ne s'apperçoivent pas que ces grandeurs qu'on leur represente, ne sont que des images de celles qui sont en Dieu, auquel ils ne pensent jamais; \& ils ne voyent pas lors qu'ils s'attachent à ces images, qu'ils ne sont pas moins insensez que le seroit un homme que la mort de sa famme auroit rendu si extravagant, qu'il prendtroit pour elle même un portrait bien fait. Cependant c'est une verité, mais comme elle est surprenante, \& que les admirateurs des poëtes prophanes que j'attaque icy, ne se persuadent pas facilement que leur erreur soit si grande \& si dangereuse).

20. Ibid., pp. 1-2: "Ordinary paintings show gross and material coulours; they express some frail impressions. On the contrary, poetry with its harmony and the cadence of its verses produces in the soul such vivid and agreable impressions that we shall not marvel that one of the Masters of this Art had said that the Poets, by enclosing their thoughts in the rythm of their verses and by putting their words in a narrow prison, have learned to chain reason with the rhyme" (Les peintures ordinaires ne s'exprimant que par des couleurs grossieres \& materielles; they give faint expressions ne sont que de foibles impressions: au lieu que la poësie par l'armonie \& la cadence de ses vers, en fait dans l'Ame de si vives \& de si agrables, que l'on ne se doit pas étonner si un des Maitres de l'Art a pûu dire que les Poëtes renfermant leur pensées dans les bornes d'un Vers, \& donnant une prison étroite à leurs mots, sçavent par là enchaîner la raison avec la rime).

21. It seems that each chapter of this work begins with the description of a theory of Malebranche: the vision of God or the ideas in God, the problem of grace or of the nature of representations.

22. Lamy faces the argument of abstraction in relation to the pagan mind by comparing the pagan epic poetry with modern poetry. Modern poetry has the knowledge of the human spirit and acts on it from the exterior. Epic poetry instead has no knowledge of the reflexive physiology of the soul expressing itself in the conscience and expresses only what the pagan conscience is: "Modern poets know very well the spring of passions of the people of their time. They know what conforms to their corrupted inclinations and what is capable of influencing them" (Les poëtes modernes connoissent mieux le ressort des passions des hommes de leur temps: ils sçavent ce qui est conforme à leurs inclinations corrompuës, \& ce qui est capable de le toucher), Nouvelle Re- 
flexions sur l'Art Poetique, p. 220. In other words, epic poetry represents directly what the human spirt is, it portrays human spirit as it is without ornaments and corrections.

23. Ibid., p. 2.

24. Ibid., pp. 2-3.

25. Vico, On Humanistic Education, Oratio 6, par. 6: "Three are the very duties of wisdom-with eloquence to tame the impetuousness of the fools, with prudence to lead them out of error, with virtue toward them to earn their goodwill, and in these ways, each according to his ability, to foster with zeal the society of men. Those who do these things are indeed men much above the rest of mankind, and, if I may say, only a little less than the gods."

26. Nouvelle Reflexions sur l'Art Poetique, p. 3.

27. Ibid., p. 16.

28. Ibid., p. 15: "The poets have the freedom of deceiving and abusing the strong inclination that we feel for greatness and they show us its vain appearance" (La libertè que les Poëtes prennent, leur donne le moyen de tromper \& d'abuser cette forte inclination que nous avons pour la grandeur, nous en presentant une vaine apparence).

29. Ibid., p. 12: "The poets manipulate this illusion of mankind. They do not tell mankind the imperfections of the creatures, and amuse men with a senseless appearance of greatness" (Les poëtes entretiennent cette illusion des hommes: ils derobent a leur connoissance les imperfections des creatures, et les amusent par une vaine apparence de grandeur).

30. Ibid., p. 34: "A capable poet can modify the thoughts that men may have about their miseries and make them to consider other things in their mind, things that the poets themselves suggest to them so that they cannot apply themselves to something else or see any other thing" (Un poëte habile détourne toutes les pensées que les hommes peuvent avoir de leurs miseres, empêchant qu'ils ne leur considerent: \& pour cela occupant leur esprit ailleurs, il attaque si fortement ses lecturs à ce qu'il leur propose, qu'ils peuvent pas porter la veue d'un autre côté, \& voir autre choses).

31. Ibid., p. 25: "The poets have the freedom of deceiving and abusing the strong inclination that we feel for greatness and they show us its vain appearance " (La libertè que les Poëtes prennent, leur donne le moyen de tromper \& d'abuser cette forte inclinationque nous avons pour la grandeur, nous en presentant une vaine apparence); again ibid., p. 15: "In one word, let me say that all the things that the poets describe are capable of impressing our spirit and turn it toward them because of their npovelty, rarity, and greatness"(En un mot, toutes les choses que rapportent les poëtes, sont capables d'arréter l'esprit, \& de le tourner vers elles par leur nouveauté, par leur rareté, ¿ par leur grandeur).

32. Ibid., pp. 37-38.

33. Ibid., p. 23.

34. Ibid., p. 73: "Comme l'esprit ne se porte à connoître que la verité, ou ce qui en a l'apparence; les poëtes aussi tâchent de rendre vray-semblable tout ce qu'ils proposent."

35. The Search after Truth, bk. 1, ch. 3, pp. 14f.: "Undeniably, there are other truths, besides those of faith, concerning which it would be wrong to ask for incontrovertible demonstrations, such as those regarding the facts of history, and other matters that depend on the will of men. For there are two kinds of truths, those that are necessary and those that are contingent."

36. Ibid., p. 15: “... but in history, which covers contingent matters, we must be satisfied with the greatest probability. For the term history can be applied generally to knowledge of languages, customs, and even the different opinions of philosophers, when they have been learned only by memory, and without any evidence or certitude for them."

37. Ibid., p. 15.

38. Nouvelle Reflexions sur l'Art Poetique, p. 73: "In the same way that our mind is inclined to know nothing else but the truth or what appears as true, so the poets assume the task of making verisimilar everything they propose " (Comme l'esprit ne se porte à connoitre que la verité, ou ce qui en a l'apparence; les poëtes aussi tâchent de rendre vray-semblable tout ce qu'ils proposent.). 
39. Ibid., pp. 73-74.

40. The New Science, par. 167: "The true God founded Judaism on the prohibition of divination. By contrast, all the pagan nations sprang from the practice of divination."

41. Ibid., par. 193: "Every pagan nation had a Jupiter, who hurled his lightning bolts and laid low the giants"; par. 585: "The nature of the world's first kings is shown by the poets' image of Jupiter as king of the gods and men." These two paragraphs make explicit two principal functions of myth: creator of thought and founder of nations. Malebranche, too, saw the correlation of imaginative thought and the constitution of society.

42. Vico, without using very often the term, has made instinct the point of constant reference in his philosophy; instinct is in opposition to thought, both rational and fantastic. The human mind is born as a contradiction of instinct, negation of pure bestiality. Emblematic is the attempt at the description (between the scientific and the poetic fashion that smacks of its baroque matrix) of the ferine condition of the first men in the chapter of Poetic Wisdom of The New Science, par. 340: "Now, before they became the founders of the pagan nations, the earliest men must have thought in powerful surges of violent passion, which is how beasts think. So we must begin with the popular metaphysics mentioned in Axiom 33, which proves to be the theology of the poets"; par. 369: "The founders of pagan antiquity must have ... renounced the true religion of their common father Noah. This religion was the only bond which kept them within human society, both in the union of marriage and hence in their family groups. When they renounced it and began to couple promiscuosly, they dissolved their marriages and dispersed their families. In this way they began to wander like brutes through the earth's great forest. ... Since mothers abandoned their children, they grew up without hearing any human speech, or learning any human behaviour, and sank to an utterly bestial and brutish state. ... these children lacked that fear of gods, fathers, and teachers which tempers the most exuberant phase of childhood"; par. 374: "And to the extent that human nature coincides with that of animals, it must rely on the senses as the sole means of knowing things." Vico is not taking position in favor of empiricism or Aristotelianism in par. 363, but intends to underline the real condition of communality between beasts and human beings in their perceptive faculties; no consciousness or awareness is involved, but the simple mechanicism of stimulusresponse, the instinct. In par. 363, in order to introduce the sensation, as modification of the soul, in relation to the perception, corporeal phenomenon, Vico speaks explicitly of the occasion (adding, "as it is called nowday by the metaphysicians") which is a reference to Malebranche. Here are some definitions among the many that can be found in The New Science of the gentile as a simple animal, as an entity simply controlled by instinct, par. 518: “... conceited scholars have previously affirmed the innocence of the Golden Age in the first pagan nations. In fact, it was their fanatical superstition which, by means of the powerful teror their imagined deity inspired, held in moral check the savage, proud, and ferocious men of the early pagan world"; par. 523: "... developing from a state of bestial native freedom through a long period" (que' tempi tutti orgoglio e fierezza per la fresca origine della libertà bestial); par. 531: "These aborigines were called giants, a term which properly means sons of the Earth."

43. The New Science, par. 120.

44. Ibid., pars. 236 and 237: "Because of the senses, the human mind naturally tends to view itself externally in the body, and it is only with great difficulty that it can understand itself by means of reflection" and "This axiom offers us this universal principle of etymology in all languages: words are transferred from physical objects and their properties to signify what is conceptual and spiritual." Vico sees this principle as the fundational one for the comprehension of languages, that is myth, and by extension, of the imaginative thought.

45. Ibid., par. 431.

46. Ibid., par. 496. 
47. Ibid., par. 554: "When the first, pious giants entered the first stage of society, which is marriage, it was the keen stimulus of bestial lust that urged them, and the powerful restraint of fearful religions that kept them within its bounds"; par. 504: "Moral virtue began, as it must, from a conscious effort (conatus). Chained under the mountains by their frightful religion of thunderbolts, the giants checked their bestial habit of wandering wild through the earth's great forest. Completely reversing their customs, they now settled down, hidden away in their lands, so that they later became the founders of the nations and lords of their first commonwealths. According to popular tradition, this was the first great benefit which heaven bestowed on human kind during the age when he reigned on earth through the religion of the auspices. And it was the source of Jupiter's title of Stator, stayer or settler; par. 379: "The science of this language the pagans universally believed to be divination, which the Greeks called theology, meaning the science of god's speech. This is how Jupiter was assigned to the fearful kingdom of lightning, which made him king of gods and men." Also ibid., pars. 387-389.

48. Ibid., bk. 2, sect. 1, ch. 1, par. 377.

49. Ibid., par. 177: "Once warfare has made a people so fierce that human laws no longer have a place among them, religion is the only means powerful enough to subdue them"; par. 178: "This axiom establishes that divine providence initiated the process by which fierce and violent men were led from their lawless condition to enter civilization and create nations. Providence did this by awakening in them a confused idea of divinity, which in their ignorance they ascribed to objects incomaptible with the divine. Still, in their fear of this imaginary divinity, they began to create some order in their lives."

50. Ibid., par. 379: "And since these early people communicated by signs, they naturally believed that lightning bolts and thundercaps were signs made to them by Jupiter. ... The science of this language the pagans universally believed to be divination. ... This is how Jupiter ... acquired two titles: optimus, best, meaning fortissimus, strongest, and maximus, greatest, alluding to his body, which was as vast as the heavens."

\section{Chapter Eight}

(The Metaphysical Nature of Thought)

1. The New Science, par. 224: "Among the Near Eastern peoples, Egyptians, Greeks, and Romans, we find that the first authors were poets, as were the first writers of the new European languages during the medieval return of barbarism."

2. The nobles as "sons of the earth" as it is affirmed in many parts of The New Science. There is a bond between man and its land and environment, which are products of the imagination. Societies like thought had hard and coarse origins that must be understood as sensible, founded on perceptions and some elementary passions like fear, wonder, desire of excelling. See ibid., par. 361: "In the axioms, we established that all the histories of the pagan nations had mythical origins; that among the Greeks, who are the source of all our knowledge of pagan antiquity, the first wise men were theological poets; and that all temporal institutions by nature have crude origins. When we turn to poetic wisdom, we must regard its origins in the same light."

3. Ibid., par. 404.

4. Ibid., par. 209: "Axioms $47 \& 49$ show us the origin of the poetic archetypes which constiotute the essence of the myths. Axion 47 describes the natural inclination of the masses to invent myths, and to invent them with the propriety of poetic decorum. Axiom 48 proves that the earliest men, as the children of the human race, were unable to conceive rational categories of things, and thus felt a natural need to invent poetic archetypes. These archetypes were imaginative categories or universals, to which (like ideal models or portraits) men could assign all 
the particular species that resembled them. And by virtue of this resemblance, ancient myths were invented with propriety"; par. 448: "It seems likely that, when the first lightning bolts had awakenbed the wonder of human kind, Jupiter's exclamation called forth the first human exclamation, the syllable $p a$. Later, the syllable was doubled and became the exclamation of astonishment pape, from which was derived Jupiter's title of father, pater, of gods and men"; par. 202: "All the histories of barbarous peoples have mythical origins."

5. Ibid., par. 402: "For example, the theological poets understood Jupiter, Cybele or Berecynthia, Neptune in this way. At first, pointing mutely they interpreted them as the substances of the sky, earth, and sea, which they imagined to be animate deities; and trusting the truth of their senses, they believed they were gods. In this way, they used these three deities to explain everything related to the sky, earth, and sea, which is the function of poetic archetypes...."

6. Ibid., par. 400: “... the theological poets imagined most physical objects to be divine substances"; and again the par. 402.

7. Ibid., par. 402.

8. Ibid., par. 340: "Now, before they became the founders of the pagan nations, the earliest men must have thought in powerful surges of violent passion, which is how beasts think. So we must begin with the mentioned popular metaphysics, which proves to be the theology of the poets. From this, we must seek that terrifying thought of a deity which imposed form and measure on the bestial passions of these lost men and made them human passions. Such a thought must have given rise to the moral effort, or conatus, which is proper to the human will and which restrains the impulses that the body urges on the mind."

9. Ibid., par. 362: "The first reason was their reverence for religion, for it was by their myths that the pagan nations were everywhere founded on the basis of religion. The second was the great effect of their religion, namely the civil world, which is so wisely ordered that it can only be the result of superhuman wisdom. The third reason was the opportunity which their myths, bolstered by a religious veneration and believed to contain great wisdom, offered the philosophers for investigating and pondering lofty philosophical topics."

10. Ibid., par. 366: "In fact, divine providence directed human institutions so that poetic and natural theology prepared the nations for revealed theology. For poetic theology governed them through certain sensible signs, which they believed to be divine counsels sent by the gods to humankind; while natural theology demonstrates providence by eternal and insensible arguments"; par. 367: "And by nature all things must have crude origins .. that leads us to trace the beginning of poetic wisdom to a crude metaphysics. ...I shall trace clearly and distinctly how the founders of pagan civilization used thei poetic wisdom. We shall see how they used their natural theology or metaphysics to imagine the gods; their logic to invent language; their ethics to create heroes; their household economy to found families; and their politics to found cities."

11. Ibid., par. 213: "In every endeavour but poetry, people with no natural gift can still succeed by diligent study of an art; but in poetry, no one who lacks the natural gift can possibly succeed through art"; par. 214: "This axiom proves that the first poets were natural poets, for poetry laid the foundation of pagan civilization, which in turn was the sole source of all the arts." In other words, human beings have arrived at the intelligence not through technology but by nature; it was a providential occasion when mind originated as fantasticating or fabulating mind. It was not born through a complete action of abstraction. The mind is not a "refinement" of perception, it is not the fruit of corporeity, it is not and cannot be like the Aristotelians think of it, or the empirist or the materialists. The first poets were naturally poets, their capacities were from nature, not from having developed intellective faculties beginning from specializations of active methods, nor because of an abstraction from sensation. 
12. Ibid., par. 333: "We observe that the barbarous and civilized nations of the world, despite their great separation in space and time and their separate foundations, all share these three human customs: all have some religion, all contract solemn marriages, and all bury their dead. And in every nation, no matter how savage and crude, no rites are celebrated with more elaborate ceremonies or more sacred solemnities than those of religion, marriage, and burial." At the original roots of all pagan nations there is the same mentality that produced all over the same effects in isolation, that is, without the different populations coming I n touch with each other. Imagination has acted everywhere in the same way, though the material conditions had provoked those notable differences from one place to another that determine a direct ambiental adaptation. The diversity among the different cultures was not due to the material conditions that determine the ambiental adaptation, but to the fact that these diverse material physical conditions were lived or experienced with imagination, that is, were represented differently from place to place. Much before the scientific anthropologists, Vico determined the proper characteristics of humankind: burials, matrimonies, religious ritualization; what differentiates the human being from the beast or animal is religion, not directly the greater specialization of techniques.

13. Ibid., par. 34 .

14. Malebranche objects, "We have given some idea of the physical causes of disorder of men's imagination in other parts. In this part, we shall try to apply these causes to the most general errors, and we shall speak again of those causes of errors called moral causes. ... the delicacy of the brain's fibers is one of the principal causes impeding our efforts to apply ourselves to discovering truths that are slightly hidden." The Search after Truth, bk. 2, pt. 2, ch. 1, pp. 130ff., where the imagination of women, men, and the aged is considered and differentiated.

15. This example is also used by Vico. See The New Science, par. 423: "The name Draco means dragon, and so Draco must represent one of the Gorgon's serpents that were nailed to the shield of Perseus, a symbol of the authority of the laws. Indeed, by its frightful penalties, this shield petrified all who beheld it; and its laws, like those mentioned in the Bible, were called laws of blood, leges sanguinis, because of their exemplary punishments. Minerva, who armed herself with such a shield, was called Athena ... Today, the dragon is likewise the emblem of civil rule among the Chinese, who still write in hieroglyphics"; par. 542: "The Chinese charge their royal arms with a dragon, and they carry a dragon as an emblem of their civil authority."

16. First New Science, bk. 3, ch. 1.

17. The New Science, par. 338: "Furthermore, we must begin our discussion at the point when these creatures began to think humanly. ... Yet as I sought to discover the manner in which the first human thought arose in the pagan world, I met with arduous difficulties which have cost me a full twenty years of research to overcome. For I had to descend from today's civilized human nature to the savage and monstrous nature of these early people, which we can by no means imagine and can conceive only with great effort."

18. Ibid., par. 377.

19. Ibid., par. 379.

20. First New Science, bk. 3, ch. 4.

21. The New Science, par. 402.

22. First New Science, bk. 1, ch. 13: "Hence we can scarcely understand, and are quite unable to imagine, how those first men of the impious races must have thought, or the crude manner in which they formed their thoughts, or the confused way in which they connected them, in that state in which they had never heard yet a single human word."

23 The New Science, par. 376. 


\author{
PART TWO \\ The First and Second Kind of Imagination \\ The Senses and the Intellect
}

Chapter Nine

(The Intelligible Extension, the Idea of Death and of Idolatry)

1. Dialogues on Metaphysics and on Religion, Dialogue 7, par. 7: "The moment of creation has passed! But if this moment does not pass, then you are in a spot, and will have to yield. Therefore, take note. God wills that a certain kind of world exist. His will is omnipotent, and this world is thus created. Let God no longer will there to be a world, and it is thereby annihilated. For the world assuredly depends on the will of the creator. If the world subsists, it is because God continues to will its existence. Thus, the conservation of creatures is, on the part of God, nothing but their continued creation. I say on the part of God who acts. For on the part of creatures there appears to be a difference, since by the act of creation they pass from nothingness to being, whereas by the act of conservation they continue to be. But in essence the at of creation does not cease, because in God creation and conservation are but a single volition which, consequently, is necessarily followed by the same effects."

2. Ibid., Dialogue 7, par. 8: "The foundation of your being depends essentially from your creator."

3. Descartes, Oeuvres, A. T. edition, bk. 7, p. 34. The reference is to the Third Cartesian Meditation: "Claudam (...) redere conabor."

4. Dialogues on Metaphysics and on Religion, Dialogue 1, p. 17. See also Entretiens sur la Mort, Oeuvres, Tome 13, pp. 407-408: "When we think of the extension ... such is its idea" (Lorsqu'on pense à l'étendue (...) telle est son idée).

5. Entretiens sur la Mort., Tome 13, p. 408: "When we open ... because we cannot see the bodies in them" (Mais lorsqu'on ouvre ... car on ne voit point les corps en eux-mêmes).

6. Ibid., pp. 359-360: "Death is the end of everything; after death, we will find happiness and joy"(C'est la fin de tous (...) nous trouverons la félicité et la joïe).

7. Ibid., p. 360: "Ultimately, the thought about death modifies all our ideas and condemns all our plans. For time compared to eternity becomes so near to nothing that all the goods and the evils during such a short space vanish like shadows in a spirit well convinced of its immortality" (En effet la pensée de la mort change toutes nos idées et condamne tous nos desseins. Car le temps comparé à l'èternitè s'approche si fort du néant, que les biens et les maux d'une si courte durée ne possent que pour des fantomes dans un esprit bien convaincu de son immortalité).

8. Ibid., p. 360: "Ariste, if you pay attention ... substances exist that are subject to you" (Si vous regardiez, Ariste ... substances qui vous sont assujetties).

9. Ibid., p. 523.

10. For Malebranche some truths have only a rational component (in mathematics, for example), while other truths implie the rapport with goodness, and with them we have a different discourse. The (rational) idea of death is part of the second group. It is important to point out that the false idea of death will lose the affective component once it is analyzed under the light of reason. Now, this does not mean that we stop fearing death, but only that no longer we fear the false death that the pagan mind will represent to us.

11. Entretiens sur la Mort, pp. 371-372: “Ariste, man humanizes all things, even the divinity. To God, man attributes human plans, human goals and sometimes even his own passions, an example of which, is the adultery of Jupiter, the rage of Juno, the larceny of Mercury. ... It is easy to judge. We should pay attention and work hard before giving any judgment on things; 
we should become used to seriously meditate. ... In one word, man attributes to all causes, no matter what their nature is, characteristics and properties strongly similar to our own."

\section{Chapter 10}

(The Origin of Idolatry)

1. Entretiens sur la Mort, in Oeuvres, Tome 13, p. 363: "The pagans, Ariste, fear death. They are sinners of a kind who don't even know that the Son of Mary was called Jesus, because he was destined to deliver his people from sin. There is no more terrible monster for them" (Que le païens, Ariste, craignent la mort, ces pécheurs qui ne savent pas que le Fils de Marie a été nommé Jésus, parce qu'il devait délivrer son peuple de leurs péchés. Il n'y a point pour eux de monster plus terrible).

2. The Search after Truth, bk. 6, pt. 2, ch. 3, p. 452.

3. Ibid., bk. 2, pt. 3, ch. 6, p. 191

4. The New Science, par. 191.

5. Ibid., par. 385.

6. Ibid., par. 383 .

7. Ibid., par. 554: "What caused these fierce and untamed people, living in brutish state ... the powerful restraint of fearful religion ... kept them within ... bounds."

8. Ibid., par. 522.

9. Ibid., par. 504 .

10. Ibid., par. 218.

11. Ibid., par. 379; see also pars. 333-335.

12. Ibid., par. 339: "For all these reasons, we must begin with some notion of God that is found in even the most wild, savage and monstrous people. We may show that this notion is the following. When people fall into despairing of any natural assistance, they desire something higher to save them. But only God is higher than nature, and this is the light which God has shed on all people."

13. Ibid., par. 365.

14. The Search after Truth, bk. 4, ch. 12, p. 326: "If it often happens that the slight pleasures and pains we actually feel, or even expect to feel, greatly upset our imagination and prevent us from judging things according to their true ideas, we must not imagine that the expectation of eternity does not act upon our minds. But it is appropriate to consider what that expectation is capable of producing in them."

15. Ibid., p. 326.

16. Ibid., p. 328.

17. Ibid., p. 328.

18. Ibid., p. 328: "Nevertheless, it can be said that this fear that the idea of eternity causes in their minds sometimes produces such a great disturbance in their imaginations that they dare not condemn these human traditions outright, and they often approve them by their example, because they have some appearance of wisdom in their superstition and in their false humility, as do these Pharisaic traditions of which Saint Paul speaks."

19. Ibid., p. 326: "Thus, even the just fear an eternity of torments more vividly than they hope for an eternity of pleasure. Therefore, the vision of pain is more effective than that of reward; and the following is roughly what is capable of producing, not by itself but as principal cause" (La vî̈e de la peine agit donc davantage que la vîë de la récompense; \&o voici à peu près ce qu'elle est capable de produire, non pas toute seule, mais comme cause principale).

20. Ibid., p. 326.

21. Ibid., p. 327. 
22. The New Science, par. 190: "Witches, who are full of fearful superstitions, are also extremely savage and monstrous. When the solemn rites of their witchcraft reaquires it, they will heartlessly kill and dismember even darling and innocent babies."

23. Ibid., par. 517.

24. Ibid., pars. 412, 629. The beautiful metaphor about the river that flowing into the ocean keeps for a while its own course and the sweetness of the water was first in The New Science, pars. 249, 412, 629.

25. The New Science, par. 516.

26. Ibid., par. 183 .

27. Ibid., par. 518 .

28. Ibid., par. 508.

29. Ibid., par. 490: "It was in fact a truth of rational metaphysics, which conferred human authority (in the sense of domain or ownership) on the giants who had occupied the world's first vacant lands." It was indeed the truth of reasoned metaphysic about the ubiquity of God, learned with the false sense of poetic metaphysics (Jovis omnia plena) that produced human authority (auspicia esse sua)." See also par. 491: "Now, with his lightning bolts, which were the source of the greater auspices, Jupiter had laid low the giants, driving them underground to live in mountain caves. By laying them low, he brought them good fortune: for they became the lord of the ground in which they dwelt hidden, and so emerged as the lords of the first commonwealth."

30. Ibid., par. 476: "For the Egyptians as well, Jupiter was the heavens, which they thought influenced sublunar affairs and presaged the future. Hence they believed they could arness the influence of the heavens by casting statues of their gods at prescribed times. Even today, the Egyptians, or gypsies, practise a popular form of divination."

31. Ibid., par. 478.

32. Ibid., par. 479: "As for the ancient Germans, Tacitus relates that they worshipped their gods in holy places which he calls sacred groves and woods, luci et nemona, meaning areas cleared in the thick of the forest."

33. Ibid., par. 391: "For ... Jupiter's lightning bolts were the origin of the Muse, which Homer calls the knowledge of good and evil. Later philosophers found it all too easy to impose their interpretation of the phrase as the biblical maxim, "The beginning of wisdom is piety."

34. Ibid., par. 188.

35. Descartes, On the Passions of the Soul, bk. 11, pp. 454-455.

36. The New Science, par. 505: "In this manner, marriage was introduced, which we may define as a carnal union modestly consummated in fear of some divinity. Marriage is the second principle basic to my New Science, and derives from the first principle, which is divine providence. From its origin, marriage involved three solemn rites"; also, par. 506: "The first marriage rite was the auspices of Jupiter, which were taken from the lightning bolts which had led the giants to celebrate marriages. ... These were the praises which people could rightly offer to the gods."

37. Shame (pudor) will follow the same path than all the other primitive sentiments. As societies and mentalities change, so the objects that provoke them will also change. Many of the primitive customs described in the myths were promoted by shame. In time, the descendants of the theological poets felt shame if they had to continue with the customs of their forefathers and things began to change. Thus, myth was born because of shame and shame continue to be experienced when the traditional customs could no longer be understood. no longer. See The New Science, par. 222: "There is a golden passage in Eusebius, whose description of the Egyptians' wisdom may be generalized to apply to all pagan nations: 'The Egyptians's first theology 
was merely a history with interpolated myths. When later generations felt ashamed of these myths, they began gradually to supply them with invented mystical meanings. This was also done by the Egyptian high priest manetho, who converted all of Egyptian history into a sublime natural theology." [The original theology of the Egyptians was a history mixed with fables, but because in time they were shameful of them, they began to assign to their stories a mystical meaning].

38. The New Science, par. 514.

\section{Chapter Eleven}

(Psychology and Psycho-Linguistics of Paganity)

1. The Search after Truth, bk. 1, ch. 4, p. 17: "Thus our souls perceive things in only three ways, by the pure understanding, by the imagination, and by the senses" (L'ame peut appercevoir les choses en trois maniéres, par l'entendement pur, par l'imagination, par le sens).

2. Ibid., pp. 16-17.

3. Ibid., pp. 17: "Through the imagination the soul perceives only material things, making them present when in fact they are absent, by forming images of them, as it were, in the brain. It is in this way that we imagine all sorts of figures, a circle, a triangle, a face, a horse, cities, and the countryside, whether we have already seen them or not. This sort of perceptions might be called imaginations, because the soul represents these objects to itself by forming images of them in the brain; and, since images of spiritual things csannot be formed, it follows that the soul cannot imagine them (and this should be noted well)."

4. Ibid., bk. 2 , pt. 1 , ch. 1 , p. 87 : “... there is such a closep relationship between the senses and the imagination that they should not be separated"; p. 88 : "... the senses and the imagination differ only in degree ...."

5. Ibid., p. 89.

6. Ibid., bk. 2, pt. 2, ch. 2, p. 134: "I think I have sufficiently explained ... the various changes encountered in the animal spirits, and in the constitution of the brain fibers, according to the different ages. Thus, provided one meditates a little on what I have said of them. one will soon have a rather distinct knowledge of the imagination and of the most ordinary physical causes of the differences among minds, since all the changes occurring in the imagination and the mind are only the consequences of those encountered in the animal spirits and the fibers of which the brain is composed."

7. Ibid., bk. 2, pt. 1, ch. 1, p. 101: "It is not enough merely to feel, or to have a vague understanding, that the brain traces are linked to each other, and are followed by movements of the animal spirits, that the traces aroused in the brain arouse ideas in the mind, and that the movements excited in the animal spirits excite passions in the will. it is necessary, as far as possible, to understand distinctly the cause of all these different connections, and especially the effects they are capable of producing."

8. Ibid., p. 102: "The only alliance of mind and body known to us consists in a natural and mutual correspondence of the soul's thoughts with the brain traces, and of the soul's emotions with the movements of the animal spirits" (Toute l'alliance de l'esprit \& du corps qui nous est commuë, consiste dans une correspondence naturelle \& mutuelle des pensées de l'ame avec le traces du cerveau, \& des émotion de l'ame avec les mouvemens des esprits animaux).

9. Ibid., p. 102: "As soon as the soul receives some new ideas, new traces are imprinted in the brain; and as soon as objects produce new traces, the soul receives new ideas" (Dés que l'ame reçoit quelques nouvelles idées, il s'imprime dans le cerveau de nouvelles traces, \& dés que les objets produisent de nouvelles traces, l'ame reçoit de nouvelles idées). 
10. Ibid., p. 106: "But there are traces in our brains that are naturally tied to one another, and even to certain emotions of the spirit, because that is necessary to preservation of life; and their connection cannot be broken, or at least cannot easily be broken, because it is good that it be always the same."

11. Ibid., p. 106: "Thus, it is necessary, for the conservation of all animals that there be certain connections of traces that can easily be formed and destroyed, and that there be others that can be broken only with difficulty, and finally, still others that can never be broken."

12. Ibid., p. 120: "Having traces in our brains similar to those of the persons who brought us into being, we necessarily also have the same thoughts and inclinations with respect to sensible objects. And so we are bound to be born with concupiscence and Original Sin, if Original Sin is nothing but the reign of concupiscence grown victorious, and master of the mind and heart of the child. Now, there is much to suggest that the reign or victory of concupiscence is what we call Original Sin in infants, and actual sin in free men." The influence of the Fall from Eden insinuates itself in the rapport between traces and thoughts, between mind and body.

13. Ibid., p. 102: "There are three very important causes of the connection of ideas and traces, The first, and the one the others presuppose, is nature, or the constant and immutable will of the Creator. There is, for example, a natural connection, independent of our will, between the traces producing a tree or a mountain we see and the ideas of tree or mountain, between the traces that produce in our brain the cry of a suffering man or animal and our understanding him to complain, between the expression of a man who threaten or fears us and the ideas of pain, strength, weakness, and even among the feeling of compassion, fear, and courage arising in us."

14. Ibid., p. 102: "When I come to speak of the passions, I shall talk about the connections between the brain traces and the movements of the spirits, and that between the ideas and the emotions of the soul, for all the passions depend on them."

15. Ibid., p. 102: "These natural connections are the strongest of all. They are generally similar in all men, and they are absolutely necessary for the preservation of life. This is why they do not depend at all upon our wills."

16. Ibid., p. 103: "It must be carefully noted here that the connection of ideas that represent spiritual things distinct from us by means of brain traces is not and cannot be natural, and as a result it is or can be different in all men, since it has no other cause than their will and the identity of time."

17. Ibid., p. 102-103: "For, if the connection of ideas with sounds and certain characters is weak, and quite different in different countries, it is because it depends upon the weak and changeable will of men. And the reason why this connection depends upon it is that this connection is not absolutely necessary for living, but only for living as men, who should form a rational society among themselves."

18. Ibid., p. 103: "The third cause of the connection of ideas and traces, which always assumes the two others, is the will of men. This will is necessary so that the connection of ideas with traces be regulated and accommodated to practice."

19. Ibid., p. 103: "For if men did not naturally have the inclination to agree among themselves to attach their ideas to sensible signs, not only would this connection of ideas be completely useless for society, it would also be very irregular and very imperfect."

20. Ibid., p. 104: "Because the words are connected to the ideas only by an arbitrary convention, they do not arouse these ideas with enough speed and clarity for easy recognition of the relations, and this is the principle cause of difficulty in learning the sciences."

21. Ibid., p. 104: "It is so true that all of the difficulty in understanding and retaining spiritual and abstract things comes from the difficulty we have in strengthening the connection 
between their ideas and the brain traces, that when one finds a way to explain them through their relations with material things, one makes them easily understandable."

22. Ibid., p. 104: "On the other hand, when we express the relations found among material things in such a way that there is no nevcessary link between these things and the traces of their expressions, it is much more difficult to understand them, and one easily forgets them."

23. Ibid., p. 104: "For example, those who begin the study of algebra or analysis can understand algebraic demonstrations only with great difficulty, and once they have understood them, they do not long remember them."

24. Ibid., p. 104: "But those who begin the study of common geometry conceive very clearly and quickly the little demonstrations one explains to them, provided they very clearly understand the terms used, because the ideas of square, circle, and so forth, are tied naturally to the traces of the figures they see before their eyes."

25. Ibid., p. 104: "This is because, for example, squares, parallelograms, cubes, solids, and so on, being expressed by aa, ab, $\mathrm{a}^{3}$, abc, and so on, since these traces have no natural connection with their ideas, the mind can find no grip by which it can fasten onto them and examine their relations."

26. Ibid., p. 104-105.

27. Ibid., p. 105: "However, one need not condemn the care mathematicians take in defining their terms, because obviously they must define them to avoid equivocations. But as far as possible, one must use accepted terms or terms whose ordinary signification is not so far removed from what one is claiming to introduce, and this is not always observed in mathematics."

28. Ibid., p. 104: "But because the traces with a natural connection to ideas affect and engage the mind, and consequently render it attentive, most men rather easily understand and retain sensible and palpable truths, that is to say, relations among bodies. And on the other hand, because traces with no other connection to the ideas than those the will places there do not strike the mind vividly, all men have difficulty understanding, and even more in retaining, abstract truths, i. e., relations among things that do not come under the imagination."

29. Ibid., p. 104: "But since these relations are slightly complicated, they seem absolutely incomprehensible, especially to those not accustomed to them, because they have not strenghthened the connection of these abstract ideas with their traces through continual meditation."

30. Ibid., p. 104: "And although others have perfectly understood them, they forget them in a short time, because this connection is almost never as strong as natural ones."

31. Malebranche, though a non specialist, had profound knowledge and acquaintance with the classical literature, including the oratorical science. In addition, something not often recognized by scholars, in many of his argumentation of religious and theological character, he referred implicitly to the Patristics and through some of the Fathers to his Neo-Platonic authors. In other words, he had always presented the fact that between the Christian and the pagan visions of the world, there was always the presence of Platonism. Thus, without having theorized about the linguistics of Paganity, nevertheless he constructed a linguistics in relation to error, keeping present the historical context to which it referred.

32. The New Science, par. 410: "Poetic monsters and metamorphoses were necessary products of early human nature, since people were incapable of abstracting forms and properties from objects. ... Poetic monsters sprang from combinations of forms and ideas."

33. Ibid., par. 434: “... three indisputable truths. (1) Since all the first pagan nations were at first mute, they must have expressed themselves by gestures or objects naturally related to their ideas. (2) They must have used signs to secure the boundaries of their estates and to provide lasting witness of their rights. (3) They all used some form of money." 
34. Ibid., par. 401.

35. Ibid., par. 431.

36. Ibid., par. 225: "Mute people express themselves by using gestures or objects which bear a natural relation to the ideas they wish to signify." What Vico said about metaphor, he extends it to other rhetorical tropes, synecdoche and metonimia. See ibid., par. 406: "Using their poetic logic, which was a product of poetic metaphysics, the early poetic peoples named things in two ways: (1) by using sensible ideas, which are the source of metonymy; and (2) by using particular ideas, which are the source of synecdoche."

37. See G. Cantelli, Mente, corpo, linguaggio (Firenze: Florence University Press: 1986), p. 38: "The second cause of the connection of ideas with traces is the identity of the times. Our having had certain thoughts at a time when there were some new traces on our brain often suffices to make it impossible for these traces to recur without our having these same thoughts again" (La seconde cause de la liaison des idées avec les traces, c'est l'identité du temps. Car il suffit souvent que nous ayons ê̂u certaines pensées dans le temps qu'ily avoit dans nôtre cerveau quelques nouvelles traces, afin que ces traces ne puissent plus se produire sans que nous ayïons de nouveau ces mêmes pensées) Also The Search after Truth, bk. 2, pt. 1, ch. 5, p. 102. Malebranche speaks of the identity of time in order to understand simultaneity. The formula of identity of time is used in order to accentuate the psychological "fusion" of the events in the same time and therefore the reduction of different times in the identity of psychological events.

39. The Search after Truth, bk. 2, pt. 1, ch. 5, p. 106.

40. The New Science, par. 445.

41. The Search after Truth, bk. 2, pt. 1, ch. 5, p. 105.

42. Idem., p. 105: "This is why, when we do not recall the principal name of a thing, we designate it sufficiently by using a name that signifies some property or circumstance of that thing. For example, if we cannot remember the proper name of a church, we can use another name that signifies something related to it in some way. We could say, it is that church where there was such a crowd, where Father so-and-so preached, where we went on Sunday. And being unable to remember a person's name, or where it is more appropriate to identify him in another way, we can single him out by his pocked face, or as this tall, handsome man, this little hunchback, according to one's inclinations toward him, although of course it is wrong to use words of scorn."

43. B. Lamy, Nouvelle reflexions sur l'art poetique, p. 26.

44. The Search after Truth, bk. 2, pt. 1, ch. 5, pp. 105-106: "Now the mutual connection of the traces and consequently of the ideas with one another is not only the basis for all rhetorical figures but also for an infinity of other things of greater importance in morality, politics, and generally in all the sciences having some relation to man, and consequently to many things of which I shall speak in the sequel."

45. There is no doub about Malebranche's knowledge of the oratorical art. It is evident that a careful study of his theological works would prove how well he could handle that art. After 14 September 1644, the date of his sacerdotal ordination, Malebranche studied Greek and Latin historians, the texts of the fathers of the Church, the grammars of Oriental languages, and different manuals of rhetorics.

46. The Search after Truth, bk. 2, pt. 1, ch. 5, p. 106.

47. Ibid., p. 103: "First, because the ideas are not strongly connected to the traces, when the spirits are agitated, they render these traces deep and lasting."

48. The New Science, par. 495.

49. Ibid., par. 497.

50. Ibid., pars. 478-479. 
51. The relations between the instinct (in the figure of the brutish being, the bestione) and the fantasy and the abstract reason, are not formulated by Vico in relation to the various faculties of the spirit (sensitivity, imagination, intellect) that produce them but to the mentality that they formed. If we interpret carefully the classifications of the philosophical currents that Vico formulates in The New Science, we would notice that he does not discuss the metaphysical principles thet they profess but the mental attitude they have toward reality and in connection with the theological poets. In The New Science, par. 499: "This historical development of human ideas finds wonderful confirmation in the history of philosophy. When men first began philosophize crudely, they used the evidence of the senses, which the Greeks call autopsía, seeing for oneself. (Later this was used by Epicurus who, being a philosopher of the senses, was content to base his judgments on sensory evidence.) Indeed my 'Origins of Poetry' has shown that the first poetic nations possessed the most vigorous senses. Next came Aesop, symbol of the socalled popular moralists, who preceded the Seven Sages of Greece. Aesop reasoned by example; and since he lived in an age of poetry, he created his examples by inventing similes. (One of these, the fable of the belly and the limbs, was used by the worthy Menenius Agrippa to reduce the rebellious Roman plebeians to obedience.) Even today an example of this sort, especially a true one convinces the ignorant masses more effectively than the irrefutable logic of maxims. Then came Socrates, who introduced dialectic, which resolves doubtful questions by induction from what is more certain. Even before Socrates, medicine had used induction from observations. And it has produced Hippocrates, the prince of physicians both for his achievements and for his antiquity...." We should here notice that the example given is real; it is an example that even the mind of the ignorant people can easily picture, represent, and thus can persuade better than any sentence that abstracts from the particular, and accentuates a concept in an abstract universal. Persuasion, in Vico's mind, in a Platonic sense, is to convince oneself of the opinion that, contrary to truth, lacks a true real foundation. This foundation that opinion cannot provide is surreptitiously provided by the imagination. One can convince the people as much as these peoples would be able to convince themselves. With abstract maxims, the plebs would not receive the message; with a real example (real of the reality of the imagination, not of the reality of reason or perception). It is the certainty in what one believes that becomes reality in our mind.

52. The New Science, par. 498.

53. The Search after Truth, bk. 2, pt. 1, ch. 5, p. 103.

54. Ibid., p. 103: "Second, since repetition of the encounter of the same ideas with the same traces is necessary to form a durable connection, because a first encounter, unaccompanied by a violent movement of the animal spirits, cannot make strong connections, it is clear that if men did not want to agree, the occurrence of these encounters of the same traces would be the greatest coincidence in the world."

55. Ibid., p. 103: "So the will of men is necessary in order to regulate the connection of the same ideas with the same traces, although this will to agree is not so much an affect of their choice and reason as it is an impression of the Author of nature who made us all for each other, and with very strong inclination to unite spiritually as much as we are in body."

56. Ibid., p. 106: "These connections of the traces are not always joined with the emotions of the spirits, because all the things we see do not always seem good or bad. These connections can also change, and break, because not always being necessary for the preservation of life, they need not always be the same."

57. Ibid., p. 106: "But there are traces in our brains that are naturally tied to one another, and even to certain emotions of the spirits, because that is necessary to preservation of life, and their connections cannot be broken, or at least cannot easily be broken, because it is good that it be always the same." 
58. Ibid., p. 106: "For example, the trace of a great elevation one sees below oneself, and from which one is in danger of falling, or that of a large body, about to fall on us and crush us, is naturally tied to the one that represents death to us, and to an emotions of the spirit that disposes us to flight and to the desire to flee."

59. Ibid., pp. 103.

60. Ibid., p. 132: "From this it must be concluded that it is very advantageous to be practiced in meditating on all kinds of subjects to acquire a certain facility in thinking about whatever one wishes. For just as we acquire a facility for moving the fingers of our hands in all kinds of ways and with great speed by the frequent use we make of them in playing instruments, so too the parts of our brain whose movement is necessary for imagining whatever we wish acquire through use of certain facility for being bent that enables one to imagine what one wishes with great ease, promptness, and even clarity."

61. The New Science, par. 447.

62. Ibid., par. 456: "In this manner the nations formed poetic language, which was first composed of divine and heroic symbols, then expressed in vernacular languages, and finally written in vernacular characters. It arose entirely from the first peoples' poverty of language and their need for expression, as the basic ornaments of poetic style indicate. These include vivid depictions, images, similes, comparisons, metaphors, and periphrases; as well as phrases explaining things by their natural properties, descriptions of things drawn from their most particular and inmportant effects; and, finally, emphatic and even redundant pleonasm."

63. Ibid., par. 433: 'In Greek, the nouns 'name' and 'character' were synonymous. ... In Latin, the nouns 'name' and 'definition' are likewise synonymous. Hence, in rhetoric, the definition of the fact is called the question of name, quaestio nominis."

64. Ibid., par. 450-452: "Next, people proceeded to form pronouns. Exclamations give vent to personal emotions, which can be expressed in solitude. By contrast, pronouns serve to signify things whose proper names we do not know or others cannot understand. Like exclamations, nearly all pronouns are monosylabic in every language. ... This is why the articles from the beginning have had the invariable property of preceding the nouns and verbs which they modify. ... Nouns began to be formed gradually. ... And that nouns originated before verbs is shown by the invariable property that there can be no sentence without a noun as its subject, whether expressed or understood."

65. Ibid., par. 438: "The Egyptians said that the second kind of speech, which corresponds to the age of heroes, was spoken by using symbols. These must have included heroic emblems like those mute similes which Homer call semata, the signs written by the heroes." The mute similarities are the initial phase of the progressive dissociation between the name and the image, between the sign and the signification: abstraction consists properly in the dissociation from name to image, that is, from sign to signification.

66. B. Lamy, Nouvelle reflexions sur l'art poetique, pp. 36-37.

67. Ibid., pp. 20-21.

68. The New Science, par. 411.

69. Ibid., par. 410.

70. Ibid., par. 453.

71. Ibid., par. 458: "Inversions in word order arose from the difficulty of completing sentences with verbs, which were the last words to be invented."

72. Ibid., par. 460.

73. Ibid., par. 463: "The first verse must have originated in a form appropriate to the age and language of heroes, that is, as heroic verse. Born of violent emotions of fear and joy, this grandiose verse is proper to heroic poetry, which deals only with the most turbulent passions." 
74. Ibid., par. 432: “The Egyptians related that the entire history of the world was divided into three ages: the ages of gods, heroes, and men. And people in these ages spoke three languages: first, the hieroglyphic, or sacred and divine language; second, the symbolic language, which used signs and heroic emblems; and third, the epistolary language, by which people at a distance communicated their current needs."

\section{Chapter Twelve}

(Sensitivity and Intellect)

1. See Leibniz, Monadology, part 1, par. 26: "Memoria species consecutionis suppeditat animabus, quae rationem imitatur, sed ab ea distingui debet."

2. The New Science, par. 218: "People first feel things without noticing them, then notice them with inner distress and disturbance, and finally reflect on them with a clear mind" par. 219: "This axiom is the first principle of poetic statements, which are formed by feelings of passions and emotions. By contrast, philosophical statements are formed by reflection and reasoning. Philosophical statements approach the truth as they ascend to universality. Poetic statements gain certainty as they descend to particulars."

3. The Search after Truth, bk. 5, ch. 2, p. 368: "Our natural union with God, therefore, does not excite our love for Him. But such is not the case with the union we have with sensible things. All our sensations reaffirm this union, for bodies are visible when they act in us; Their action is in no way hidden. Our own body is even more present to us than our mind, and we consider it the best part of ourselves. Hence, the union we have with our body, and through it with all sensible objects, excite a fervent love in us that increases this union and makes us depend on things infinitely below us."

4. Ibid., bk. 4, ch. 11, p. 314: "When our pleasures are great, when our sensations are lively, we are incapable of grasping the simplest truths, and we do not even agree with common notions unless they include some sensible material."

5. This important argument dealing with natural inclinations is found in the bk. 4 of The Search after Truth: "The Inclinations, or, the Mind's Natural Impulses."

6. In Dialogues on Metaphysics and on Religion as well as in Dialogues on Death, Malebranche describes how a man became more peaceful with himself and the world around him, after he lost his finances in an economic disaster, because he at last found his real self.

7. The Search after Truth, bk. 5. ch. 8, p. 385: "Each of the passions has two notable effects: it applies the mind, and wins over the heart. Insofar as they apply the mind, the passions can be very helpful in knowing the truth provided we know how to use them; for applying the mind produces light, and light reveals the truth. But insofar as they win the heart, the passions always have a bad effect because they win over the heart not only by corrupting reason and representing things to it not as they are in themselves or according to the truth but according to their relationt o us. .

8. Ibid., bk. 1, ch. 4, p. 17.

9. The New Science, par. 186.

10. Ibid., par. 209.

11. Ibid., par. 185.

12. The Search after Truth, bk. 1, ch. 18, p. 79: "That our senses lead us into error even about things that are not sensible."

13. Ibid., bk.1, ch. 13, p. 62: "Nevertheless, there are some things, such as our soul with all its modifications, that, not being corporeal, cannot be represented to he mind by corporeal images." 
14. Ibid., p. 62: "When, therefore, our soul wishes to represent to itself its own nature and its own sensations, it tries to form a corporeal image of them."

15. Ibid., bk. 4, ch. 11, p. 316: "Their eyes govern their decisions. They judge according to what they sense and not according to what they conceive, for they sense with pleasure and conceive with pain."

16. Ibid., bk. 5, ch. 2, p. 343: "The soul's union with the sensible objects we have seen and tasted is much stronger than its union with those it has only imagined or heard about. We are more closely tied to sensible things by sensation, because sensation almost always produces much greater traces in the brain and excites more violent motion in the spirits than does the imagination alone."

17. Ibid., bk. 3, pt. 2, ch. 10, p. 253: "Moreover, given that men sense pleasure, pain, odors, tastes, and so on, and that their body is more present to them than their very soul, i.e., that they easily imagine their body and cannot imagine their soul, they have attributed to the body the faculties of sensing, imagining, and sometimes even of conceiving, all of which can belong only to the soul."

18. The New Science, par. 137.

19. The Search after Truth, bk. 4. ch. 11, p. 314: "When our pleasures or other sensations are moderate, we can understand some simple and easy truths; but if we were entirely free from pleasure and sensations, we could easily discover the most abstract and difficult truths known. For to the extent that we remove ourselves from what is not God, we bring ourselves nearer to God Himself; we avoid error and discover truth."

20. Vico assumes a Malebranchean perspective on this point, not only because he takes as his own the principle "Because of the senses, the human mind naturally tends to view itself external to the body, and it is only with great difficulty that it can understand itself by means of reflection" (in The New Science, par. 236), but especially because his analysis of the pagan primitive mind follows through the same steps than the ones covered by Malebranche.

21. The New Science, par. 376. We see returning the parallelism-counteropposition of the Malebranchean philosophy with the primacy of the intelligible, poetic metaphysics, structured on a fantastic universality.

22. The Search after Truth, bk. 6, pt. 1, ch. 3, p. 417: "We see people everyday who apply themselves only to what affect the senses and who express themselves in a way so sensible that the truth is, as it were, stifled under the weight of the vain ornamentation of their false eloquence." The consideration of the same concept as a law of human nature, is found in ibid., bk. 1, ch. 3, p. 15: "An infinity of people will prefer never to reason than to reason under these conditions" [those of reason].

23. The New Science, par. 383.

24. The Search after Truth, bk. 6, pt. 1, ch. 3, pp. 417: "Consequently, since those who listen to themare more affected by the cadence of their speech and by their facial expression than by the arguments they hear, they let themselves be persuaded without knowing why or even of what they are persuaded."

25. Traitè de Morale, bk. 11, ch. 1.

26. The Search after Truth, bk. 3, pt. 1, ch. 4, p. 214: "It should be clear from what has been said above, that the capacity and scope of man's mind is very much taken up with the passions and sensations (agreable or vexing) it always has, and that when man wishes to use the rest of his capacity to examine some truth, he is often distracted from doing so by new sensations, by the distatefulness of this enterprise, and by the inconstancy of the will, which disturbs the mind and unceasingly leads it from one object to another. As a result of this, if the habit of conquering these obstacles is not acquired at an early age, you will find yourself incapable of understanding anything at all difficult or requiring any attention.” 
27. Ibid., bk. 2, pt. 3, ch. 6, p. 195: "It is time to complete this second book and to take note of the fact, through the things that have been said in this and the preceding book, that all the thoughts the soul has through the body, are all for the sake of the body; that they are false and obscure; that they serve only to unite us to sensible goods and to everything that can procure them for us; and that this union involves us in infinite errors and very great miseries, although we do not always feel these miseries, just as we are not aware of the errors that cause them."

28. Ibid., bk. 2, pt. 2, ch. 2, p. 136: “Thus, men's different passions, their inclinations, conditions, employments, qualities, studies, in short, all the different ways of living, causing very great differences in their ideas, make them fall into an infinite number of errors we shall explain in the sequel. And it is this which made Chancellor Bacon utter these very judicious words: 'All perceptions, as well of the sense as of the mind, are according to the measure of the individual, and not according to the measure of the universe. And the human understanding is like a false mirror, which receiving rays irregularly, distorts, and disorders the nature of things by mingling its own nature with it'." New Organon, 2, 84.

29. The New Science, par. 220.

30. Ibid., par. 221.

31. The Search after Truth, bk. 4, ch. 2, p. 275: "If the inconstancy and weakness of our will does not permit our understanding to penetrate to the bottom of things immediately present to it and of the utmost importance for us to know, it is easy to judge that it will permit us even less to meditate upon those things removed from us, having no relation to us."

32. Ibid., p. 275: "When things are closely related to us, when they are sensible and fall under our imagination easily, the mind can be said to apply itself to them and to be able to have some knowledge of them. For when we know that things are related to us, we are inclined to think about them; and when we sense that they affect us, we apply ourselves to them with pleasure."

33. Ibid., p. 275: "Therefore, we should be wiser than we are with regard to a great many things, where it not for restleness and agitation of our will, which ceaselessly troubles and tires our attention."

34. Ibid., bk. 5, ch. 11, pp. 402-403.

35. Ibid., bk. 1, ch. 12, p. 59: "Now the reason why the soul does not avail itself of reason, i.e., of pure intellection, when it considers an object perceptible to the senses is that the soul is not affected by things it perceives through pure intellection, and that, on the other hand, it is very much affected by sensible things; for the soul attends closely to things that greatly affect it and ignore thing that do not. Thus, it almost always accords its free judgments to the natural judgments of the senses."

36. Ibid., bk. 1, ch. 2, p. 9: "Now if we consider these things closely, we will clearly recognize that it is always the will that assents, not only to things agreable to it, but to the representation of things."

37. Ibid., bk. 2, pt. 2, ch. 8, p. 157: "When error wears the livery of truth, it is often more respected than truth itself and this false respect has very dangerous consequences.'The worst thing is to glorify error, which has to be taken as the plague of the intellect, if it begins to receive a vain estimation'."

38. Ibid. Preface, p. xxxix-xli; bk. 1, ch. 2, p. 11: "Now, while we might feel strongly inclined to consent to probability, yet if we are careful to note whether we clearly see that we are obliged to consent to it, we shall undoubtedly find that the answer is not. For if probability is based on our sense-impression, probability or verisimilitude is really a misnomer, we shall then be very much inclined to yield to it; but no other cause of this inclination will be discovered than some passion or general affection we have for what affects the senses. 


\section{Chapter Thirteen}

(The Familiar Ideas and Mentality)

1. The reference is to The Search after Truth, bk. 1, ch. 18; bk. 2, pt. 2, ch. 2; bk. 3, pt. 1, ch. 4; bk. 4, ch. 2; bk. 5, chs. 9, 11; bk. 6, chs. 1, 2 .

2. B. Lamy, Nouvelle reflexions sur l'art poetique, p. 15.

3. The Search after Truth, bk. 2, pt. 2, ch. 1, p. 132: "To clarify these things, it must be realized that we cannot learn anything if we do not give it our attention, and that we can hardly be attentive to something if we do not imagine it and do not represent it vividly in our brain."

4. Ibid., p. 132: "Now in order to be able to imagine certain objects, we must make some part of our brain submit, or imprint some other motion upon it, to be able to form the traces to which ideas are attached, which represent these objects to us. So that if the brain fibers are slightly hardened, they will only be capable of the disposition and motion they formerly had. Thus, the soul would be unable to imagine, and consequently unable to attend to, whaterver it wishes, but only to the things familiar to it."

5. The New Science, par. 122-123.

6. The Search after Truth, bk. 2, pt. 2, ch. 1, p. 132.

7. The New Science, par. 381.

8. Ibid., par. 456: "In this manner the nations formed poetic language, which was first composed of divine and heroic symbols, then expressed in vernacular languages, and finally written in vernacular characters. It arose entirely from the first peoples' poverty of language and their need for expression, as the basic ornaments of poetic style indicate. These include vivid depictions, images, similes, comparisons, metaphors, and periphrases; as well as phrases explaining things by their natural properties, descriptions of things drawn from their most particular and inmportant effects; and, finally, emphatic and even redundant pleonasm."

9. The Search after Truth, bk. 2, pt. 2, ch. 2, p. 134: “... we imagine things more strongly in proportion as these traces are deeper and better engraved."

10. Ibid., p. 134: "In order to understand completely all the changes the different conditions produce in the imagination, it is aabsolutely necessary to be reminded that we imagined objects only by forming images of them, and that these images are nothing other than the traces the animal spirits make in the brain ; that we imagine things more strongly in proportion as these traces are deeper and better engraved, and as the animal spirits have passed through these traces more often and more violently; and that when the spirits have passed through these traces many times, they enter there more easily than other places nearby, through which thwy have never passed, or have not passed as often. This is the most ordinary cause of the confusion and falsity of our ideas."

11. Ibid., bk. 2, pt. 3, ch. 1, p. 165: "Those who imagine things strongly express them strongly, and all those whom they persuade are convinced by their air and through sensible impression, rather than by the strength of arguments."

12. Ibid., bk. 2, pt. 2, ch. 2, p. 134: "For the animal spirits that were directed by the action of external objects, or even by orders of the soul, to produce certain traces in the brain often produce others that truly resemble them in some things, but are not quite the traces of these same objects, nor those the soul desired to be represented, because the animal spirits, finding some resistance in the parts of the brain whence they should pass, and being easily detoured crowd into the deep traces of the ideas that are more familiar to us."

13. Ibid., bk. 2, pt. 2, ch. 1, p. 131: "I say then that the solidity and consistency found with maturity in the fibers of the brains of men, makes their errors solid and consistent, if one may 
so speak. It is the seal that confirms their prejudices and their false opinions, and that hides them from the force of their reason."

14. The New Science, par. 142.

15. Ibid., par. 144-145. Also ibid., par. 150: "Another great task of my New Science is to discover these grounds of truth, even when the passage of time and the subsequent changes in languages and custom have enveloped the truth in falsehood."

16. The Search after Truth, bk. 2, pt. 2, ch. 1, p. 131: "In brief, however advantageous this constitution of the brain fibers may be to well-bred persons, it is just as harmful to most men, since it confirms them in the thoughts they already have."

17. The New Science, par. 183.

18. The Search after Truth, bk. 2, pt. 2, ch. 1, p. 132: "This consistency of the brain fibers has another very bad effect, principally in the older persons, which is to render them incapable of meditation. They cannot bring their attention to bear on most of the things they want to know, and thus they cannot penetrate slighly hidden truths. They cannot consider the most reasonable opinions when they are founded upon principles that seem novel to them, though they are otherwise very intelligent concerning things of which age has given them much experience. But everything I say here is intended to be true only of those who have spent their youth without using their mind, without applying it."

\section{Chapter Fourteen}

(Verisimilarity and Imagination)

1. The Search after Truth, bk. 1, ch. 6, p: 29: "From the fact that we have an idea of a thing, it does not follow that the thing exists and still less that it is entirely like our idea of it."

2. Ibid., p. 29: "It is true that God never deceives us, but we often deceive ourselves by judging things too hastily. For we often judge that the objects of which we have ideas exists, and even that they are altogether like these ideas. But it often turns out that these objects are not at all like our ideas, and even that they do not exist."

3. Ibid., bk. 3, pt. 2, ch. 1, p. 217: "It should be carefully noted that for the mind to perceive an object, it is absolutely necessary for the idea of that object to be actually present to it, and about this there can be no doubt; but there need not be any external thing like that which affects and modifies the mind with the perception it has of an object."

4. Ibid., p. 217: "When, for example, a man imagines a golden mountain, it is absolutely necessary that the idea of this mountain really to be present to his mind. When a madman or someone asleep or in a high fever sees some animal before his eyes, it is certain that what he sees is not nothing, and that therefore the idea of this animal really does exist, though the golden mountain and the animal have never existed."

5. Ibid., bk. 1, ch. 11, p. 54: "As a result, it is generally the case that we attribute our sensations to objects when the causes of these sensations are unknown."

6. Ibid., bk. 1, ch. 19, p. 82: "One of the many errors we fall into in physics is to imagine that there is more substance in bodies that are more perceptible than in those that are hardly perceptible at all. Most people believe that there is more matter in gold or lead than in air or water, and children, who have not noticed its effects through their senses, generally even think that air is not something real."

7. Ibid., p. 84: "But they are too fond of the illusion of their senses, they have yielded for too long to their prejudices, and their soul has been too much ignored for them to realize that all the perfections their soul fancies it sees in bodies in fact belong to itself."

8. Ibid., bk. 1, ch. 6, p. 32: "Our eyes, therefore, deceive us not only with regard to the size of bodies in themselves but also with regard to the relation bodies have among themselves." 
9. Ibid., bk. 2, pt. 2, ch. 4, p. 141: "The reason is that their brain traces are confused with each other, because there are so many of them, and reason has not arranged them in order. This prevents the mind from imagining and from representing clearly to itself the things it needs. When the mind wants to open certain traces but encounters other more familiar ones crossing them, it is misled."

10. Ibid., p. 141: “The brain's capacity not being infinite, it is nearly impossible for so many traces, formed without order, to avoid becoming mixed up and bringing confusion into the ideas. It is for this same reason that persons of great memory are not normally capable of judging things well where it is necessary to bring much attention to bear."

11. Ibid., bk. 2, pt. 2, ch. 2, p. 135: "It is also for this same reason that we imagine ourselves to see chariots, men, lions, or other animals in the clouds, when there is any slight relationship between their shapes and these animals; and this is why everyone, especially those accustomed to drawing, sometimes see men's heads on walls with many irregular patches."

12. Ibid., p. 135: "Besides, the apparent size of the moon is not very different from that of an ordinary head at a certain distance. Hence the moon forms traces through her impressions that are very much linked to those representing a nose, a mouth, and eyes, thereby determining the spirits to follow the traces of a face. There are those who see a man on horseback in the moon or something other than a face, because, their imagination having been vividly struck by certain objects, the traces of these objects are reopened by the least thing relating to them."

13. Ibid., p. 135: "Now, the reason we normally see a face in the moon, and not the irregular blotches that are there, is that our brain traces of a face are very deep, because we often look at faces, and with much attention."

14. Ibid., p. 135: "When those who are slightly nearsighted look at the moon, they ordinarily see two eyes, a nose, a mouth, in a word, they seem to see a face. However, there is nothing on the moon corresponding to what they think they see there. Many persons see something else there."

15. Ibid., p. 134-135: "For the animal spirits that were directed by the action of external objects, or even by orders of the soul, to produce certain traces in the brain often produce others that truly resemble them in some things, but that are not quite the traces of these same objects, nor those the soul desired to be represented, because the animal spirits, finding some resistance in the parts of the brain whence they should pass, and being easily detoured crowd into the deep traces of ideas that are more familiar to us."

16. Ibid., bk. 3, pt. 2, ch. 10, p. 253: "Men imagine, then, that things of a different nature are of the same nature, and that all things of the same species hardly differ from one another. They judge that unequal things are equal, that uncertain things are certain, and that things without order or proportion are well-ordered and proportioned. In a word, they often believe that things different in nature, quality, extension, duration, and proportion are alike in all these things. But this deserves to be explained at greater length with several examples, because it is the cause of an infinite number of errors."

17. Ibid., p. 253: "Mind, the substance that thinks, and body, the substance that is extended, are two entirely different and completely contrary kinds of beings; what belongs to the one cannot belong to the other. Yet since they pay so little attention to the properties of thought, and since they are continually affected by the body, most men have viewed the soul and the body as one and the same thing; they have fancied a resemblance between two so different things. They have made the soul out to be material, i. e., extended throughout the entire body and figured like the body. They have attributed to the mind what can belong only to the body."

18. Ibid., p. 253: "The mind is extremely limited and thus is incapable of distinguishing the differences among the subjects it considers, which are infinite or almost infinite. The mind 
therefore supposes imaginary resemblances, or fails to notice real and positive differences, since ideas of resemblance are simpler, more familiar, and more present to it than others."

19. Ibid., p. 253.

20. This example is found in The Search after Truth, bk. 3, pt. 2, ch. 11, p. 258.

21. The theorization of the universals of the imagination begins.

22. The Search after Truth, bk. 3, pt. 2, ch. 11, p. 258.

23. Ibid., bk. 3, pt. 2, ch. 10, p. 255.

24. Ibid., p. 253: "Men not only suppose identity, likeness, or proportion in the nature, number, and essential differences of substances, but they make the same suppositions about everything they perceive. Practically all men judge that the fixed stars are all at an equal distance from the earth and are attached to the sky as to a vault."

25. The New Science, par. 204.

26. Ibid., par. 379.

27. The Search after Truth, bk. 3, pt. 2, ch. 10, p. 255.

28. Ibid., p. 254.

29. Ibid., bk. 2, pt. 2, ch. 1, p. 131.

30. Ibid., bk. 3, pt. 1, ch. 2, p. 203.

31. The New Science, par. 120.

32. Ibid., par. 405: "All this follows from axiom 1: 'In his ignorance, man makes himself the measure of the universe.' And in the example cited, man has reduced the entire world to his own body. Now, rational metaphysics teaches us that man becomes all things through understanding, homo intelligendo fit omnia. But with perhaps greater truth, this imaginative metaphysics shows that man becomes all things by not understanding, homo non intelligendo fit omnia. For when man understands, he entends his mind to comprehend things; but when he does not understand, he makes them out of himself and, by transforming himself, becomes them."

\section{PART THREE \\ The Social Functions of Imagination}

\section{Chapter Fifteen}

(Society, Imagination, and Imitation)

1. The New Science, par. 1000.

2. Ibid., par. 919: "The first customs were imbued with religion and piety, like those of Deucalion and Pyrrha just after the flood" and par. 922: "The first natural law was divine, by which people believed that their lives and affairs depended on the gods, whom they regarded as respondible for all things."

3. Ibid., par. 198: "They prove that these nations could neither be founded without religion, nor grow without virtue. ... that the earliest myths must have contained civil truths, and therefore must have been the histories of the earliest peoples" and par. 386: "Here begins the philosophy of authority, which is the second aspect of my Science. I take the word authority in its primary sense of property."

4. Ibid., par. 387.

5. Ibid., par. 196: "Every pagan nation had its own Hercules, the son of Jupiter"and par. 197: "This axiom refers to the beginning of heroism among the first peoples, which was born of the false opinion that heroes were of divine origin."

6. Ibid., par. 388: "This divine authority led to human authority. In the purest philosophical sense, this authority is the essential property of human nature which not even God can take 
from man without destroying him. ... Now, human authority lies in the free use of the will, for the intellecyt is merely a passive power subject to truth. Hence, the starting-point of all human affairs dates from the time when people began to exercize the freedom of their human will and so to control their bodily impulses, either by suppressing them altogether or by directing them to better ends. (This is the conscious effort, or conatus, which is proper to free agents, as we saw.) By such an effort, the giants gave up their bestial custom of wandering through the earth's great forest. Instead, they grew accustomed to remaining hidden and settled in their caves for a long time."

7. Ibid., par. 411.

8. The New Science, par. 389: "The authority of human nature was followed by the authority of natural law. Now, the giants had occupied the lands where they chanced to be at the time of the first thunder, and became lords of these lands after a long period of settlement. For occupation and longstanding possession are the source of all ownership in the world."

9. Ibid., par. 414: “... the universal pattern which is described in my Science. The heroes, meaning the nobles, claimed to have a nature of divine origin, by virtue of which they said that the gods, and hence the divine auspices, belonged to them."

10. Ibid., par. 482: "From this survey of nations, we gather that the first laws everywhere were the divine laws of Jupiter, god of the heavens. This ancient origin must account for the use of 'heaven' for 'god' in the language of many Christian nations."

11. Ibid. par. 489: "The Latin name of Jupiter was Ious. Contracted to ius, it must have meant the fat of the victims sacrificed as his due. We find a similar combination of ideal and real in the medieval return of barbarism, when the term canon meant both an ecclesiastical law and the payment which a fief holder made directly to his lord"; par. 389: "The authority of human nature was followed by the authority of natural law. Now, the giants had occupied the lands where they chanced to be at the time of the first thunder, and became lords of these lands after a long period of settlement. For occupation and longstanding possession are the source of all ownership in the world."

12. Ibid., par. 490: "It was in fact a truth of rational metaphysics, which conferred human authority (in the sense of domain or ownership) on the giants who had occupied the world's first vacant lands. It was indeed the truth of reasoned metaphysic about the ubiquity of God, learned with the false sense of poetic metaphysics (Jovis omnia plena) that produced human authority (auspicia esse sua)."

13. Ibid., par. 311.

14. Ibid., par. 515.

15. Ibid., pars. 530 and 597: "We must conclude that, since the tribes were at first made up of nobles, the first cities were composed of nobles alone"; also: par. 531: "By the burial sites of their dead, the giants indicated their dominion over their lands; and under Roman law burying the dead in the proper place made it hallowed ground. The gianst spoke truly when they uttered heroic sentences such as 'We are sons of this earth' or 'We were born of these oaks'.... The aborigines were called giants, a term which properly means sons of Earth. This is why the ancient myths faithfully relate that Earth was the mother of the gods and the giants."

16. See ibid., par. 589: "At this point, the Greek nations imagined the tenth deity of the major clans, Minerva, whose birth they imagined in a savage and grotesque fashion. Vulcan splits Jupiter's head with an axe, and Minerva springs forth. The myth signified that the masses of family servants, whose servile arts belonged to the poetic category of plebeian Vulcan, broke Jupiter's reign, that is, weakened or diminished it." The poetic characteristic of the famuli represent the weak mind, in imagination, in opposition to the strong mind and domineering of the heroe. 
17. The New Science, par. 551: "It was thus by religion that the family fathers supported their heroic families, whose structure was likewise preserved by religion. Hence, it was invariably the custom for the nobles to be religious. And when the nobility scorn their native religion, it is clear indication that their nation is in decline."

18. Ibid., par. 522: "And they possessed an authority which was enforced by terrifying religion and sanctioned by brutal punishments, like that of the Cyclopes, whom Plato regards as the world's first family fathers. But since this popular tradition was later misunderstood, it gave rise to the serious misconception, later shared by political thinkers, that the world's first form of civil government was monarchy. And this in turn gave rise to those unjust principles of bad politics which say that civil governments were created either by open violence or by deceit which erupted into violence. But let us consider that early age, when proud and fierce people, having just abandoned their bestial wanderings, led a crudely simple life, eating nature's freely offered fruits, drinking water from springs, and sleeping in caves. in the natural equality of this state, all the father were sovereign in their own faamilies, which makes it inconceivable that one father could, by fraud or violence, have subjected the others to a monarchical state." On this argument about the imagination as an instrument of power, see the other paragraphs 523 and 555 .

19. Ibid., par. 520 .

20. Education is the exercise of authority toward oneself, but believing that it is an exercise of obsequiousness toward the divinity, education is the discipline that gave form to one own soul. See The New Science, par. 523: "At this point, we may contemplate the long time which must have passed before the pagan peoples, developing from a state of bestial native freedom through a long periodof Cyclopean family discipline, were civilized enough to obey naturally the laws of their emerging civil states. From this, we may deduce the invariable property that a commonwealth will be happier than Plato's ideal republic, if its fathers teach their children religious piety, and if its children admire their fathers as sages, revere them as priests, and fear them as kings. Such great divine force was necessary to reduce these grotesque and savage giants to civilized behaviour!"

21. See chs. 6 and 10 of the second part of the Traite de Morale; bks. 4 and 5 of The Search after truth; and the Dialogues on Death.

22. Dialogues on Metaphysics and on Religion, Dialogue 12, p. 225: "In your .books you have the opinions of the philosophers and the history of the ages. But without the laws of the union of the soul and the body, your entire library would be no more than black and white paper."

23. The Search after Truth, bk. 2, pt. 3, ch. 1, p. 161: "Strong imaginations are extremely contagious; they dominate weaker ones, gradually giving them their own orientation, and imprinting their own characteristics on them."

24. The New Science, par. 435: "In Northern Asia, we have already seen how the Scythian king Idanthyrsus used five physical objects as words to reply to Darius the Great, who had declared war on him. ... The five objects were a frog, a mouse, a bird, a plough, and a bow. The frog meant that Idanthyrsus had been born of the Scythian earth, just as frogs are born of the earth after sumnmer rainstorms. The mouse meant that he had made his home where he was born, that is, had founded a nation. The bird meant that the auspices were his, and hence that he was subject only to God. The plough meant that he had placed his lands under cultivation, that is, conquered and claimed by force. And finally the bow meant that he was supreme commander of the arms of Scythia, and thus was bound and able to defend his country." 


\author{
Chapter Sixteen \\ (The Organicistic Conception of Society)
}

1. The term organicistic is used because Vico and Malebranche refer to the metaphor of the body in order to explain and conceive society. The fact remains that their usage of the term is tied with the dualistic conception of the human nature and of society. This makes their organicism differs from the theories normally defined as organicistic.

2. Dialogues on Death, Dialogue 13, p. 419: "Ariste, I call society the agreement of minds and hearts. The agreement of minds is certainly derived from the clear view of the immutable Truth. The agreement of hearts depends from the rejoicement of the inextinguishable happiness. Nothing is more evidently alien to the mind more than the diversity of sentiments and the diversity of corruptible goods that excite and divide our hearts. No perfect and pleasurable society would be possible in this world, although it is true that the Church of Jesus Christ is a veritable society."

3. Ibid., p. 420.

4. Dialogues on Metaphysics and on Religion, Dialogue 12, p. 224.

5. Ibid., Dialogue 12, p. 222.

6. Dialogues on Death, Dialogue 13, p. 417.

7. Ibid., Dialogue 13, p. 422: "The diversity of nations, the inequality of conditions, the multiplicity of laws and customs derive certainly from human self-love, sin, and concupiscence. Having abandoned God, their natural and legitime King, and Reason, their common law, men have formed for their preservation an infinity of particular societies, in which they love their associates for interest, obey the laws for necessity, and respect their souverain for fear .... The wicked are prosperous. The force, which is the law of the brutes, assigns power and authority to the strongest men. Grand crimes make men great and form great nations."(Le diversité des états, l'inégalité des conditions, la multiplicité des loix \& des coûtumes ne tirent, ce me semble, leur origine que de l'amour propre, du peché \& de la concupiscence. Les hommes ä̈ant abandonné Dieu leur Roi naturel \& legitime, \& la Raison leur commune loi, ils ont formé pour leur mutuelle conservation une infinité de socitez. particulieres, où l'on n'aime son associé que par intérêt, où l'on ne se soumet aux loix que par nécessité, où l'on ne respecte son souverain que par grimaces .... Les méchants prosperent. La force, la loi des brutes défere l'empire aux plus forts. Les grands crimes font les grands hommes \& les grands états).

8. Dialogues on Metaphysics and on Religion, Dialogue 8, p. 144.

9. The Search after Truth, bk. 2, pt. 3, ch. 1, p. 161.

10. Ibid., bk. 5, ch. 2, p. 341: "But God has given us a body, and by this body has joined us to all sensible things."

11. The New Science, par. 1045.

12. Vico, On Humanistic Education, Oratio VI, par. 3.

13. The New Science, par. 199: "The first wise men of the Greek world were theological poets, who clearly flourished before the heroic poets, just as the divine Jupiter was the father of heroic Hercules"; par. 200: “... all the pagan nations were poetic in their origins since each had its own Jupiter and its own Hercules. Among them, divine poetry arose first, and later heroic poetry." Two problems must be kept in mind: language stands between mind and body, and through language is explicated the unity of the opposed substances in man. Societies were born poetic that is as a linguistic community. The second problem is that language is at the root of society for Vico. Societies were born as a linguistic community. The conclusion is that language stand between mind and body of the individual and between men and men in their community. One entity (poetry) is at the fulcrum between the two different kinds of union, between mind and body, on one side, and between the various individuals and the community, 
on another side. The implicit presupposition is that the metaphysical locus of meeting and attraction between body and mind, individuals and society is the language.

14. Ibid., par. 630.

15. Ibid., par. 246-247.

16. Ibid., par. 239: "Here is the order of human institutions: first forests, then huts, next villages, later cities, and finally academies." The development of society follows the developments of the needs and the human necessities, as narrated in ibid., par. 241: "People first sense what is necessary, then consider what is useful, next attend to comfort, later delight in pleasures, soon grow dissolute in luxury, and finally go mad squandering their estates."

17. Ibid., par. 242: "The nature of peoples is first crude, then severe, next generous, later delicate, and finally dissolute."

18. The New Science, par. 283.

19. Ibid., par. 243-244.

20. Ibid., par. 241: "People first sense what is necessary, then consider what is useful, next attend to comfort, later delight in pleasures, soon grow dissolute in luxury, and finally go mad squandering their estates." The following paragraph extends the concept from the individual person to the all people: "The nature of peoples is first crude, then severe, next generous, later delicate, and finally dissolute"; ibid., par. 242. For a wider consideration of the topic, see paragraphs 916, 917, and 918.

21. Ibid., par. 249: "Native customs, especially natural liberty, do not change all at once, but only gradually and over a long time."

22. Ibid., par. 292.

23. Ibid., par. 291.

\section{Chapter Seventeen}

(The Nature of Social Relationships)

1. See The Search after Truth, bks. 2, 3, 6.

2. Ibid., bk. 5, ch. 2, p. 341: "Sin has subjugated us to this body and by it has made us dependent on all sensible things. It is the order of nature and the will of the Creator that all the beings He has created should depend on one another. We are to some extent joined to the entire universe, and it is the first man's sin that has made us dependent on all those beings to which God had but joined us."

3. Ibid., p. 342: "Thus, there is now no one who is not both joined and subjugated to his body and through his body to his relatives, friends, city, prince, country, clothes, house, land, horse, dog, to the entire earth, the sun, the stars, to all the heavens."

4. Ibid., bk. 2, pt. 3, ch. 4, pp. 176-183.

5. See ch. 11 of the first part of Traité de Morale where the themes relative to the sensitive links, concupiscence and death are dealt.

6. Dialogues on Metaphysics and on Religion, p. 287: "Consider rather the consequences of these laws [of the union of mind and body] in the establishment of societies, in the education of children, in the advance of the sciences, in the formation of the church. How do you know me? You see only my face, simply a certain arrangement of matter visible through color alone. I move the air by my words. That air strikes your ear, and you know what I am thinking. Follow these laws in religion. How are you a Christian? It is because you are not deaf. It is through our ears that faith is spread into our hearts."

7. The Search after Truth, bk. 5, ch. 2, p. 342: "It is therefore ridiculous to tell men that it is up to them to be happy, wise, and free, and to advise them seriously not to be upset at the loss of their friends or goods is to mock them. For just as it is ridiculous to advise men not to feel 
pain when they are struck or not to take pleasure in eating while hungry, so the Stoics are wrong; or perhaps they are joking with us, when they exhort us not to be afflicted at the death of a father, the loss of our goods, exile, prison, and other such things, nor to be delighted with good success in our business, for we are tied to our country, our goods, our parents, and so on, by natural union that does not now depend on our will."

8. Ibid., p. 343: "This union, which is common to all men, is not of equal extent or strength in all men. For as the union depends on the mind's knowledge, it might be said that we are not tied to objects we have no knowledge of."

9. Ibid., p. 136: "A peasant in his cottage takes no part in the glory of his prince and country, but only in the glory of his own and neighboring villages, because his knowledge extends no further."

10. The New Science, par. 277.

11. The most efficacious description of this psycho-social dynamic is found in The New Science, par. 290: "We defend our natural liberty most fiercely to preserve the goods most essential to our survival. By contrast, we submit to the chains of civil servitude to obtain external goods which are not necessary to life."; par. 291: "The first part of this axiom is a principle basic to the natural heroism of the earliest peoples. The second part is a natural principle of monarchies."

12. The New Science, par. 341.

13. The Search after Truth, bk. 5, ch. 2, pp. 343-344: "Often their vanity spurs their virtue, because the love of glory is generally stronger than the love of truth and justice. I am speaking here of the love of glory, not as a simple inclination, but as a passion, because this love can indeed be sensible and because it is often accompanied by very strong and violent disturbances in the animal spirits."

14. Ibid., p. 344: "It is evident, then, that this sensible union between the mind of men and whatever is related to the preservation of their life or of the society of which they are considered members is different in different people, since it is of greater extent in those of greater knowledge, better circumstances, higher station and whose imagination is of a wider scope, and is limited but stronger in those who are more involved with the senses, who have a livelier imagination and who more blindly follow the impulses of their passions."

15. Ibid., bk. 3, pt. 2, ch. 8, p. 246-247: "Also, obscure and tenuous explanations of the faith, which we are not obliged to believe, should not serve as rules and principles in philosophical reasoning, were only evidence should convince us. The clear and distinct ideas of extension, figure, and locomotion must not be exchanged for the general and confused ideas of principle or subject of extension, form, quiddities, real qualities, or motion other than locomotion such as generation, corruption, alteration and the like. Real ideas produce real science, but general or logical ideas never produce anything, but a science that is vague, superficial, and sterile. We must, then, carefully consider the distinct, particular ideas of things in order to discover the properties they contain, and study nature in this way rather than losing ourselves in chimeras that exist only in certain philosophers' minds."

16. Ibid., p. 343: "Their pride sustains their courage, but it does not prevent them from actually suffering pain with uneasiness, and from being miserable. Thus, the union they have with their body is not destroyed, nor does their pain vanish; rather it is a matter of the union they have with other men (strengthened by the desire for their esteem) undermining to a certain extent the union they have with their own bodies. The sight of their associates looking at them arrests the flow of the spirits accompanying pain and erases the appearance that pain imprints on their face; for if no one were looking at them, this look of determination and freedom of mind would soon vanish. Thus, the Stoics to a certain extent undo the union they have with their body only by making themselves greater slaves to other men, to whom they are tied by 
the passion for glory. It is a certain truth, then, that all men are tied by nature to every sensible thing, and that through sin they are dependent on them.".

17. Ibid., bk. 5, ch. 7, p. 378: "Now this high esteem in which people of strong and lively imagination hold themselves and their qualities swells their courage and causes them to assume a dominant and decisive bearing. They listen to others only with scorn, they answer them only by jeering, they think only in relation to themselves. As they regard the mind's attention, so necessary for the discovery of truth, as a kind of slavery, they are altogether undisciplined. Pride, ignorance, and blindness will always go hand in hand. Strong minds, or rather proud and haughty minds, do not wish to be disciples of truth; they enter into themselves only to contemplate and admire themselves. Thus, he who resits the proud shines in the midst of their shadows without enlightening them."

18. Ibid., bk. 1, p. 161: "To maintain this union God has commanded us to have charity for one another. But because self-love can gradually destroy charity, and break the bond of civil society, it was appropriate for God to preserve it by also uniting men through natural ties, which subsisted without charity and appealed to self-love."

19. The New Science, par. 503.

20. Also for Vico piety, self-love, and pagan piety are strongly related with what happened in Eden. See The New Science, par. 310: “... humankind is not unjust by its absolute nature, but only by its fallen and weak nature."

21. Ibid., par. 201: "People tend naturally to preserve the memory of the laws and social orders that keep them within society."

22. Ibid., par. 309.

23. The Search after Truth, bk. 2, pt. 3, ch. 1, p. 161-162: "These natural ties we share with the beasts consist in a certain disposition of the brain all men have to imitate those with whom they converse, to form the same judgments they make, and to share the same passions by which they are moved. And this disposition normally ties men to one another much more closely than charity founded upon reason, because such charity is very rare."

24. Ibid., p. 162: "All men then have the same disposition of the brain that naturally inclines them to behave in the same way as some of those with whom they live."

25. Ibid., p. 162: "When a man does not have this disposition of the brain enabling him to enter into our sensations and passions, he is by his nature incapable of binding himself to us, and of making up the same body with us. He resembles those irregular stones for which there is no place in a building because they cannot be joined to the others."

26. Ibid., bk. 2, pt. 1, ch. 7, p. 113: "For in order for men to be bound to one another, they must resemble one another in body and spirit. This is the principle of infinitely many things of which we shall speak in what follows."

27. Ibid., p. 112: "It is, it seems to me, evident that we are connected to all things and that we have natural relations to all things around us that are very useful for the preservation and convenience of life. But these relations are not all equal. We are much more closely attached to France than to China, to the sun than to some star, to our own house than to our neighbor's. There are invisible ties that bind us much more closely to men than to beasts, to our parents and friends than to strangers, to those upon whom we depend for the preservation of our being than to those from whom we neither fear nor hope for anything."

28. Ibid., bk. 2, pt. 2, ch. 3, p. 137: “The differences in men's ways of life are almost infinite. There are a very great number of different conditions, employment, responsabilities, and communities. These differences make nearly all men act for quite different ends, and reason according to different principles. It would be rather difficult to find several residents with identical views in the same community, where they should have a united mind, and the same pattern. Their different jobs and relationships necessarily posit some difference in the course 
and manner they wish to take in accomplishing things, even those things on which they agree. This shows it would be an impossible undertaking to explain in detail the moral causes of error, and it would be uselfess to do so here. I wish only to speak of ways of living that sustain more errors, and more important errors."

29. Ibid., bk. 5, ch. 2, p. 344: "It is evident, then, that this sensible union between the mind of men and whatever is related to the preservation of their life or of the society of which they are considered members is different in different people, since it is of greater extent in those of greater knowledge, better circumstances, higher station and whose imagination is of a wider scope, and is limited but stronger in those who are more involved with the senses, who have a livelier imagination and who more blindly follow the impulses of their passions."

30. Ibid., bk. 2, pt. 3, ch. 1, p. 162: "The other cause that strengthens our disposition for imitating others, of which we must especially speak here, consists in certain impression made by persons of strong imagination upon weak minds, and upon tender and delicate brains."

31. Ibid., bk. 2, pt. 3, ch. 6, p. 193.

32. The Traité de Morale, speaks of the natural right of Princes to govern. But such a right does not derive from the human nature as it is after the Fall, but from the coincidence between the conduct of the sovereign and Reason. Natural right comes to be defined in that chapter as the hypocrital acceptance and submission to the laws of the nation for convenience. This discourse would need more time and space, but our objectives aim at the imagination and not at jurisprudence and laws.

33. The Search after Truth, bk. 5, ch. 7, p. 377: "Nothing is more marvelous than this arrangement of our passions and this disposition of our bodies with regard to objects surrounding us. All that mechanically takes place in us is worthy of the wisdom of Him who has created us. And, as God has made us capable of all the passions that move us mainly in order to link us to all sensible things for the preservation of society and of our sensible being. His plan is so faithfully carried out in the construction of his work that we cannot fail to wonder at its construction and design" (Il n'y a rien de plus merveilleux que cette economie de nos passions, \& que cette disposition de nôtre corps par rapport aux objets qui nous environnent. (...) Et comme Dieu nous a rendus capables de toutes les passions qui nous agitent, afin principalement de nous lier avec toutes les choses sensibles, pour la conservation de la societé \& de nôtre être sensible, son dessein s'execute si fidellement par la construction de son ouvrage, qu'on ne peut s'empêcher d'en admirer l'artifice \& les resorts).

34. Ibid., bk. 2, pt. 1, ch. 7, p. 113: "Of course, there are powers in our brain that naturally incline us toward imitation, for this is necessary to civil society. Not only is it necessary that children believe their parents, pupils their teachers, and inferiors those above them, but also that all men have some some disposition to adopt the same manners and perform the same actions as those with whom they wish to live."

35. Ibid., bk. 2, pt. 3, ch. 1, p. 162: "Now, this disposition has two principal causes that support and strengthen it. One is in the soul, the other in the body. The first consists principally in the inclination all men have for grandeur and high position, and for obtaining an honorable place in others' minds. For it is this inclination that secretly excites us to speak, walk, dress, and comport ourselves with the air of people of quality. This is the source of new styles, the instability of living languages, and even of certain general corruptions of mores. In short, this is the principal source of all the extravagant and bizarre novelties founded not upon reason, but only upon men's fantasies."

36. Ibid., bk. 4, ch. 13, p. 333: "The relations that the Author of nature had placed among our natural inclinations in order to unite us with one another seem still more worthy of our study and inquiries than those among bodies, or among minds in relation to bodies."

37. Ibid., p. 333. 
38. Ibid., p. 333: "For example, the desire all men have for grandeur tends by itself toward the dissolution of all societies. Nevertheless this desire is tempered by the order of nature in such a way that it works to the good of the state much more than other weak and languid inclinations. For it gives rise to emulation, excise to virtue, sustains courage in the service of our country, and we will not win so many victories if soldiers and especially officers did not aspire to glory and command. Thus, all those composing armies, working only for their particular interests, nevertheless procure the good of the entire country. This demonstraates that it is most advantageous for the public good that all men have a secret desire for greatness, provided it be moderated."

39. Ibid., p. 333: "Finally, in default of charity and love of order, it has been necessary for those who command others to have the art of deceiving them by an imaginary abasement that consists only in civilities and speech, in order that they might enjoy without being envied, that preeminence which is necessary in all bodies. For in this way all men possess in some way the greatness they desire, the great really possess it, and the insignificant and weak possess it only through the imagination, being persuaded to some extent by the compliments of others that they are not regarded as what they are, namely the least among men."

40. The Search after Truth, bk. 2, pt. 2, ch. 8; bk. 2, pt. 3, ch. 2; and Entretiens sur la mort, Dialogues 2 and 3.

41. The Search after Truth, bk. 2, pt. 3, ch. 2, p. 168: "This is why courtiers, and as a necessary consequence nearly all people, subscribe without thought to the opinion of their ruler, even to the point of frequently yielding to their caprices and whims concerning the truth of religion."

42. Ibid., bk. 2, pt. 1, ch. 7, p. 113: "Not only is it necessary that children believe their parents, pupils their teachers, and inferiors those above them, but also that all men have some disposition to adopt the same manners and perform the same actions as those with whom they wish to live."

43. Ibid., bk. 2, pt. 1, ch. 7, section 1: The communication between the brain of the mother and that of her child.

44. Ibid., bk. 2, pt. 3, ch. 7, p. 162: "More virtue than might be thought is necessary to maintain relation with those who have no regard for our passions and who have feelings contrary to ours. And this is not completely without reason; for when a man has reason to be in a state of sadness or joy, it is to a certain extent an insult to him not to share his feelings. If he is sad, we should not present ourselves before him with a gay and mindful air, which signifies joy and forcefully impresses the impulses thereof in his imagination. For this is to wish to drive him from the state must suitable and agreable to him, sadness itself being the most agreable of all passions to a man suffering from some misery."

\section{Chapter Eighteen \\ (The Communication of Strong Images)}

1. The Search after Truth, bk. 2, pt. 3, ch. 1, p. 164.

2. Ibid., p. 162-163: "There are two kinds of people who have a strong imagination in this sense. The first receive these deep traces from an involuntary and disordered impression of the animal spirits. And the others, of which I principally wish to speak, receive them from the disposition found in their brain substance. It is clear that the first sort are completely insane, since they are forced by the natural union between their ideas and these brain traces to think of things not thought of by others with whom they converse. This makes them incapable of speaking to the point and correctly answering questions put to them." 
3. Ibid., p. 163: "But it should be noted that all these kinds of people are incapable of corrupting the imagination of even the feeblest minds, or of the softest and most tender brains, for two main reasons. First, being unable to conform their answers to the ideas of others, they cannot persuade them of anything. Second, the disorder of their mind is so obvious that everyone holds their opinions in contempt."

4. Ibid., p. 163: "It is true, however, that impassioned people raise passion in us, and that they cause impressions in our imagination that resemble those by which they are affected. But because their distraction is so obvious, we resist these impressions and usually rid ourselves of them within a short time. They fade away by themselves when no longer maintained by the cause that produced them, that is, when these deranged people are no longer in our presence, and when our visible impression of the characteristic passion formed in their faces no longer produces any change in our brain fibers or any agitation in our animal spirits."

5. Ibid., p. 163: "Here I wish to examine only that kind of strong and vigorous imagination consisting in a disposition of the brain for receiving very deep traces from the weakest and least active objects."

6. Ibid., p. 163: "It is not a defect to have a brain that can imagine things strongly, and that receives very distinct and vivid images from the least important objects, provided that the soul always remains the master of the imagination and that these images are imprinted at the direction of the soul and erased when it wishes. On the contrary, this is the origin of subtlety and strength of mind. But when the imagination dominates the soul, and when without attention to the the direction of will these traces are formed because of the disposition of the brain and by the action of objects and the animal spirits, it is clear that this is a very bad quality and a sort of madness.".

7. Ibid., p. 164: "Hence, since those of who we are speaking have deeper traces of the same objects than others, as we suppose, they cannot have as much scope of mind or comprehend as many things as they do. Thus, the first defect of these people is that they have a small mind, and it is smaller to the extent that their brain receives deeper traces from the least important objects."

8. Ibid., p. 164.

9. Ibid., p. 164: "The second defect is that they are visionaries, but in a delicate way that is rather difficult to recognize. Ordinary men do not think of them as visionaries, and only men of enlightened and accurate mind are aware of their visions and the derangement of their imagination."

10. Ibid., p. 164: "The visionaries of whom I speak are not so insane as to believe that they see absent objects before their eyes. Their brain traces are not yet that deep, they are only half mad. And if they were completely insane we should not have to speak of them here, because everyone would perceive their derangement, and we could not be lead into error by it. They are not visionaries of the senses but only of the imagination. Madmen are visionaries of the senses, because they do not see things as they are, and because often they see things that are not. But those of whom I speak here are visionaries of the imagination, because they imagine things that are quite different than they are, and because they even imagine some things that do not exist."

11. Ibid., p. 164.

12. Ibid., p. 165.

13. Ibid., p. 165: "They are vehement in their passions, biased in their opinions, and always conceited and very self-satisfied. When they get into their head to pass for fine wits and set themselves up as authors (for there are authors of all kinds, visionaries and others), then what extravagances, wanderings, and irregular movements we see! They never imitate nature; everything is affected, forced, and exaggerated." 
14. Ibid. p. 165: "They do not walk, they bound; they walk only in cadence, and everything is in metaphors and hyperbole. When they wish to become pious, and to arrive there by their fantasies, they enter completely into the spirit of the Jew and Pharisee. They ordinarily stop at the surface of things, and are completely occupied with visible ceremonies and rituals of little importance. They become scrupulous, timid, and superstitious. Everything becomes a matter of faith, everything is essential to them, except what is truly a matter of faith and what is really essential."

15. Ibid., p. 166: "For, in short, a man penetrated by what he says usually impresses others, as an impassioned man always arouses the emotions of others. Eventhough his rhetoric is often irregular, it is nonetheless persuasive, because his presence and manner make themselves felt, and thus act upon the imagination of men more vividly than the strongest discourses coldy delivered, because these discourses do not flatter their senses and do not strike their imagination."

16. Ibid., p. 166: "This advantage consists in the facility for expressing themselves in a strong and vivid, though unnatural, manner. Those who imagine things strongly express them strongly, and all those whom they persuade are convinced by their air and through sensible impression, rather than by the strength of arguments."

17. Ibid., p. 165.

18. Ibid., p. 166: "Persons of imagination therefore have the advantage of being able to please, affect, and persuade, because they form very vivid and sensible images of their thoughts. But there are still other causes that contribute to their facility in winning over minds. For they usually speak only about simple subjects within the capacity of ordinary minds. They use only expressions and terms that arouse the confused notions of sense, always very strong and affective."

19. Ibid., p. 166: "They treat of great and difficult matters only in a vague way and in commonplaces, without taking the risk of entering into detail and without committing themselves to principles, either because they do not understand these matters or because they fear that being at a loss for words they will become confusing and tire the minds of those not capable of close attention."

20. Ibid., p. 166: "It is not easy to judge from what has just been said that disorders of the imagination are extremely contagious, and that they insinuate and spread themselves in the majority of minds with great ease. But because those who have a strong imagination are usually the enemies of reason and common sense, because of the pettiness of their minds and the visions to which they are subject, we can also recognize that there are very few more general causes of their errors than the contagious communication of the disorders and ills of the imagination."

21. Ibid. bk. 2, pt. 3, ch. 2, p. 167: "Very common examples of this communication of the imagination are found in children with regard to their fathers (and still more in daughters with regard to their mothers), servants to their masters, maids to their mistresses, students to their teachers, courtiers to kings, and generally all inferiors with regard to their superiors, provided, however, that the fathers, masters, and other superiors have some strength of imagination. For without it, the children and servants might receive no significant impression from the weak imagination of their fathers or masters."

22. Ibid., p. 167: "Finally, we even find these defects created in superior people by their inferiors, for the latter sometimes have such a vivid and dominating imagination that they twist the minds of their masters and superiors as they please."

23. Ibid., p. 168: “... normally children have very little to do with the rest of men, who might sometimes trace different impressions in their brain and to some extent disrupt the constant force of the paternal impression. For just as a man has never left his country usually 
imagines that the mores and customs of foreigners are completely contrary to reason because they are contrary to the customs of his city, by which he allows himself to be guided, so a child who has never left the paternal house imagines that the feelings and manners of his parents are the universal rule: or rather it never occurs to him that there could be other principles of reason or virtue besides the imitation of them. He therefore believes everything he hears them say, and he does everything he sees them do."

24. Ibid., p. 168: "But this paternal impression is so strong that it acts not only on the imagination of children but even on the other parts of their body. A young boy walks, talks and makes the same gestures as his father. A little girl dresses like her mother, walks like her, and speaks as she does; if the mothers lisps, so does the daughter, if the mother has some unusual motion of the head, the daughter adopts it. In short, children imitate their parents in everything, in their defects and their affectations as well as in their errors and vices."

25. Ibid.,p. 168.

26. Ibid., p. 168: "To examine what they propose is not to know how to live, to doubt them is to lack respect, to condem them is to rebel, or at least to exhibit oneself as foolish, extravagant, and ridiculous. But when the great do us the honor of liking us, it is no longer simply obstinacy, conceit, or rebellion; it is now ingratitude and perfidy not to surrender blindly to all their opinions. It is an irreparable fault that makes us forever unworthy of being in their good graces."

27. Ibid., p. 168.

28. Ibid., p. 168: "England and Germany furnish us with only too many examples of these inordinate submissions of peoples to the impious wills of their princes. The histories of recent times are full of them; and we have sometimes seen even aged person change religion four or five times because of the various changes of their princes."

29. Ibid., p. 169: "The kings and even the queens of England have "the right of governing over all the states of their realms, whether ecclesiastical or civil, in all causes'."

30. Ibid., p. 169: "Finally, it can be said that the kings of England have even more power over the spiritual than the temporal lives of their subjects, because these miserable peoples, these children of the earth, are concerned less with preserving the faith than with the preservation of their own goods, and therefore they easily adopt all the opinions of their princes provided their temporal and material interests are not contrary to them."

31. Ibid., p. 169: "The religious revolutions that have occurred in Sweden and Denmark could again serve to prove to us the power some minds have over others, but all these revolutions have also had many other quite significant causes. These surprising changes are indeed proof of the contagious communication of the imagination, but they are proofs too vast and sweeping. They astonish and confuse the mind more than enlighten it, because there are too many causes that concur in the production of these great events."

32. Ibid., p. 169.

33. Ibid., p. 169.

34. Ibid., p. 169-170.

35. Ibid., p. 336: "If the strength of the imagination alone and without any help from reason can produce such surprising effects, there is nothing so bizarre and extravagant of which it cannot persuade people when supported by some probable arguments."

\section{Chapter Nineteen}

(The Heroic Mentality)

1. B. Lamy, Nouvelle reflexions sur l'art poetique, p. 220.

2. Ibid., p. 221. 
3. Ibid., p. 25: "To understand the love for the created beings, it is necessary to forget them and not to think about them; for recognizing their nothingness, we must penetrate within ourselves, and consider that they cannot give us the happiness that we desire. Modern poets with all their art try to divert us from this indispensable duty both of religion and of reason. They propose so many things that they present to their readers at the same time, anticipating their desires. They do not forget to present all that could be useful for the achievement of greatness. They know how to stimulate the imagination with rare happenings, moving words, bloody wars, sieges of cities, battles, the fall of nations or establishments and the rise of some new empire. In one word, the poets narrate all things capable of attracting and capturing the mind and turning it toward new, rare, great things."

4. Ibid., p. 221.

5. Ibid., p. 211.

6. Ibid., p. 213.

7. Ibid., pp. 214-215.

8. Ibid., p. 215.

9. Ibid., p. 219.

10. Ibid., p. 220.

11. Ibid., p. 216: "Virgil is a poet admirable in his expressions as well as for the things he presents. No one of his time has spoken a better Latin, or in a more wise way. His words are most proper, natural, clear. Though he is strong, in a few words he says an infinity of things."

12. The Search after Truth, bk. 2, pt. 3, ch. 2, p. 170.

13. Ibid., p. 170.

14. Ibid., bk. 4, ch. 13, p. 335-336: "We should also bear in mind that most men are inclined toward flattery, or toward paying us compliments, because of a sort of natural inclination to appear witty, to draw the good will of others toward themselves, and because they hope for some reward in return, or finally, because of a kind of malice and mockery."

15. Ibid., bk. 2, pt. 3. ch. 2, p. 170.

16. Ibid., p. 171: "Wherever there are men susceptible to the passions, and wherever the imagination is mistress of reason, there we shall find the bizarre, indeed, the incomprehensible bizarre. If one suffers less pain from baring one's breast during the rude chill winter, and from lacing up the body during the excessive heat of summer, than from plucking out an eye or cutting off an arm, one should suffer more shame. The pain is not so great, but the reason for enduring it is less clear, so they are at least equally bizarre."

17. Ibid., p. 171: "An Ethiopian can say it is because of generosity that he plucks out an eye, but what can a Christian lady say who exposes what natural prudence and religion oblige her to conceal? That it is the fashion, and nothing more. But this fashion is bizarre, disagreable, unseemly, and unworthy in every way. It has no other source than a manifest corruption of the heart; one cannot follow it without scandal and without overtly taking the side of the imagination's disorders against reason, of impurity against purity, of the mind of the world against the mind of God. In a word, to follow this fashion is to violate the cause of reason and the Gospel. But that does not matter; it is the fashion, i.e., a law more holy and more inviolable than that God wrote with His hands on the tablet of Moses, and engraved with His spirit in the heart of Christians."

18. Ibid., p. 171.

19. Ibid., p. 171. 


\section{Chapter Twenty}

(The Heroes of the Imagination)

1. The Search after Truth, bk. 2, pt. 3, ch. 1, p. 166: "For a man penetrated by what he says usually impresses others, as an impassioned man always arouses the emotions of others."

2. Ibid., p. 166: "Persons of imagination therefore have the advantage of being able to please, affect, persuade, because they form very vivid and sensible images of their thoughts."

3. Ibid., bk. 2, pt. 3, ch. 2, p. 171.

4. Ibid., p. 171.

5. Ibid., p. 172: “These petty minds usually have a great deal of fire, and a certan free and proud air that dominates and disposes weak imaginations so that they become susceptible to lively and specious words, which signify nothing to attentive minds. They are completely at home in expression, but very ill at ease with argument. But because men. however reasonable they may be, much prefer to be affected by the sensible pleasure of manner and expression than to be fatigued in the examination of arguments, it is clear that these minds must triumph over others, and hence communicate their errors and their malignity through their power over the imagination of other men."

6. Ibid., bk. 2, pt. 3, ch. 3, p. 173: "For example, the turn that Tertullian, Seneca, Montaigne, and certain others give to their words has so much charm and flair that it dazzles the minds of most people, though their speech is but a weak picture, a shadow, as it were, of the imaginations of these authors. Their words, dead though they be, have more vigor than the arguments of certain other people."

7. Ibid., p. 173: "They enter, they penetrate, they dominate the soul in a manner so imperious that they are obeyed without being understood, and we yield to their orders without knowing them."

8. Ibid., p. 173-174: "Tertullian was in truth a man of profound erudition, but he had more memory than judgment, more penetration and scope of imagination than penetration and scope of mind. Finally one cannot doubt that he was a visionary in the sense I have explained, and that he had nearly all the qualities I have attributed to visionary minds."

9. Ibid., p. 174: "What can he conclude from these pompous and magnificent descriptions of changes that occur in the world? And what can they contribute to his justification? The moon is different in its phases, the year in its seasons, the countryside changes its face from winter to summer. Floods occur that drown entire provinces, and earthquakes that swallow them up. New cities are built, new colonies established, we have seen inundations of peoples who have ravished entire countries; in short, all of nature is subject to change. Therefore, he had reason to doff the robe in order to take up the mantle! What relation is there between what he must prove on the one hand and all these changes and many more on the other, which he researches with great care, describing them with forced, obscure, and strained expression?"

10. Ibid., pp. 174-175: "But even if the genius of the nation, the whim of the fashion which reigned at that time, and finally the nature of satire or humor were capable to justify to some degree this remarkable plan of making himself obscure and incomporehensible, it could not excuse the worthless arguments and ramblings of an author who, in many other works besides those considered here, says anything that comes into mind, provided it be some extraordinary thought and that he have some bold expression through which he might hope to parade the strength, or better the derangement, of his imagination."

11. Ibid., bk. 2, pt. 3, ch. 4, p. 176.

12. Ibid., p. 176.

13. Ibid., bk. 2, pt. 3, ch. 3, p. 173.

14. Ibid., bk. 4, ch. 8 , p. 302 . 
15. Ibid., bk. 2. pt. 2, ch. 6, p. 150: “There are many men whom vanity prompts to speak in Greek, and even sometimes in a language they do not understand."

16. Ibid., bk. 4, ch. 10, p. 307: "These philosophers are quite moving and very imaginative, they immediately arouse weak minds and those who allow themselves to be impressed by what they hear; for Stoics are rather visionary, and visionaries are passionate. Hence they easily impress upon others by the false view with which they themselves are prejudiced."

17. Ibid., bk 2, pt. 3, ch. 4, p. 181: "Hence, when a bold liar lies with great assurance, he often causes the most unbelievable things to be believed, for the assurance with which he speaks is a proof that affects the senses, and consequently is exceedingly strong and quite persuasive to most men. Thus, few people regard the Stoics as visionaries or bold liars, for we have no sensible proof of what happens in the depth of their hearts, and because their facial expression is a sensible proof that easily convince. Besides, their vanity incline them to believe that man's mind is capable of that greatness and independence of which he boasts."

18. Ibid., bk. 2, pt. 3, ch. 4, p. 176: "The portrait he draws of Cato is too noble to be natural; it is but varnish and plaster, meaning nothing except in the view of those who neither study nor know anything of nature. Cato was a man subject to the misery of men, he was not at all invulnerable, this is but a myth; those who struck him, hurt him. He had neither the hardness of a diamond unbreakable by iron nor the solidity of rocks immovable by floods, as Seneca pretends."

19. Ibid., p. 178: “This is the extent to which Seneca's feeble reason is carried away by his vigorous imagination. But can he cause men who continually feel their miseries and weaknesses to fall under the spell of such proud and vain opinions? Can a reasonable man ever be persuaded that his pain does not affect and hurt him? And as wise and as strong as he was, could Cato suffer without some uneasines or at least some distraction, I do not say the atrocious injuries of an enraged people who dragged him, stripped him, and beat him, but even the strings of a simple fly? What is more feeble against the strong and convincing proofs of our own experience than this pretty argument of Seneca's, which is nonetheless one of his principal proofs?"

20. Ibid., p. 179.

21. Ibid., p. 179.

22. Ibid., p. 179-180.

23. Ibid., p. 180.

24. Ibid., p. 180: "But if men always regard those who are sure they have become cocks and hens as fools, they do not always think those who say that their virtue renders them independent and equal to God are truly visionaries. The reason for this is that to be judged a fool it is not sufficient to have foolish thoughts. Beside this, other men must take the thoughts you have as visionary and foolish. For fools do not pass for what they are among fools like themselves but only among resonable men, just as wise men do not pass for what they are among fools. Therefore men recognize as fools those who imagine they have become cocks or kings, because everyone has reason for not believing that one can so easily become a cock or a king."

25. Ibid., p. 180: "Even the purest and most enlightened intelligences were so completely blinded by their own pride that they desired and perhaps believed themselves capable of becoming independent, and they even planned to assume the throne of God. Consequently, we need not be surprised if men who have neither the purity nor the light of the angels abandon themselves to the impulses of their vanity, which blind and seduce them. If the temptation to grandeur and independence is the strongest of all, this is because it appears to us, as to our first parents, to conform to our reason as well as our inclination, because we are not always aware of all our dependence."

26. Ibid., bk. 2, pt. 1, ch. 8, p. 125-126. 
27. Ibid., bk. 2, pt. 3, ch. 4, p. 181: "But when Cato asserts that those who struck him did not hurt him at all, and that he is above all injuries that anyone could cause him, he asserts it, or may assert it, with such pride and gravity that we cannot tell if inside he really is as he appears to be. One is even led to believe that his soul is not shaken since his body remains immobile, because the outward appearance of our body is a natural sign of what takes place in the innermost recesses of our soul."

28. Ibid., p. 181: "All this shows that few errors are more dangerous, or more easily communicable, than those which Seneca's books are filled. For these errors are refined, suited to man's nature, and similar to that in which the demon engaged our first parents. They are clad in these books with pompous and splendid ornaments, which gain entry for them into most minds. They enter, grasp, stun, and blind them. But they blind them with a proud blindness, a dazzling blindness, a blindness accompanied by glimmering lights, not a humiliating blindness full of shadows that make one aware that one is blind and force one to admit it to others. When one is struck by this proud blindness, one places oneself among the noble and powerful minds. Even others include us in this class and admire us. Thus, nothing is more contagious than this blindness, because the vanity and the sensibility of men, the corruption of our senses and passions, dispose them to search after it, to be struck by it, and excite them to impress others with it."

29. Ibid., p. 181.

30. Ibid., p. 183: “... a Stoic will never hold the glory and esteem of men in contempt simply through the strength of his mind."

31. Ibid. bk. 1, p. 357: "Men can indeed overcome their passions through contrary passions; they can conquer fear or pain through vanity; I mean merely that they can choose not to flee or complain when, feeling themselves under the gaze of the mob, the desire for glory sustains them and stops the movement in their bodies that urges them toward flight. They can conquer their passions in this way, but this is not really to conquer them, this is not really to be delivered from their servitude."

\section{Chapter Twenty-One}

(The Power of Imagination and Superstition)

1. The Search after Truth, bk. 2, pt. 3, ch. 6, p. 191.

2. Ibid., p. 191: "Men, attached to everything extraordinary, take bizarre pleasure in recounting these astonishing and prodigious stories about the power and malice of sorcerers to frighten themselves and others."

3. Ibid., p. 191: "Hence, we should not be surprised that sorcerers are so common in certain countries where the belief in the witches' sabbath is so deeply rooted, where all the most extravagant tales of witchcraft are taken as authentic histories, and where fools and visionaries whose imagination has been deranged at least as much by listening to these tales as by the corruption of their hearts are burned as true witches."

4. Ibid., p. 193.

5. Ibid., p. 193: "It is indubitable that true sorcerers deserve death, and that even those who are sorcerers only through imagination should not be considered completely innocent, because normally they have convinced themselves that they are sorcerers only because they have a dispositon to go to the witches' sabbath, and because they have annointed themselves with some drug in order to bring about their evil designs. But by punishing all these criminals indifferently, the common persuasion is strengthened, imaginary sorcerers are multiplied, and thus an infinity of people are lost and damned. Thus, it is with reason that many courts do not 
punish sorcerers, for fewer of them are found in their jurisdictions, and the envy, the hatred, and the malice of the wicked cannot use this pretext in order to destroy the innocent."

6. Ibid., p. 191.

7. Ibid., p. 192.

8. Ibid., p. 194: "Although I am persuaded that true sorcerers are very rare, that the witches' sabbath is nothing but a dream, and that courts that overturn accusations of witchcraft are the most equitable, nevertheless, I do not doubt that there can be sorcerers, charms, spells, and so on, and that the devil sometimes exercises his malice on men with the special permission of a superior power."

9. Ibid., p. 193: "But the conviction that one has been transformed into a wolf supposes an upsetting of the brain much more difficult to produce than that of a man who merely believes that he goes to the witches' sabbath, i.e., a man who thinks he sees things in the night that are not there and who, upon awakening, cannot distinguish these dreams from the thoughts he had during the day."

10. Ibid., p. 193: "It is fairly common for certain people to have dreams at night vivid enough to be exactly recalled when they awake, even though the subject of their dream is not in itself very terrible. And so it is not difficult for people to persuade themselves that they have been to the witches' sabbath, for it is sufficient for this that their brain preserve the traces caused there during their sleep."

11. Ibid., p. 194.

12. Ibid., p. 194: "Now imaginary witches cannot recognize by this means that their witches' sabbath is a dream, for they go to the witches' sabbath only during the night, and what happens at the sabbath cannot be connected to other actions during the daytime. Hence, it is morally impossible to disabuse them in this way. Nor need the things these pretended witches think they have seen at the sabbath have a natural order among them, for they appear to be more real to the degree that their sequence is more extravagant and confused. It is therefore sufficient to deceive them that the ideas of the sabbath rites be vivid and frightening, which they cannot fail to be, if one considers that they represent novel and extraordinary things."

\section{Chapter Twenty-Two}

(The Conceit of the Learned and Knowledge)

1. The Search after Truth, bk. 2, pt. 2, ch. 1, pp. 132-133.

2. Ibid., bk. 4, ch. 8, p. 299: "If the ordinary desire to become learned often makes men more ignorant, the desire to appear learned not only makes them more ignorant but seems to subvert their reason. For there are an infinity of people who lose their common sense because they wish to surpass it, and who utter nothing but stupidities because they wish to speak only in paradoxes. They deviate so far from all common thinking in their plan for acquiring the quality of a rare and extraordinary mind that indeed they succeed, and are no longer noticed, or are regarded either with admiration or with very much contempt."

3. Ibid., p. 300: "They always look for some argument by which to defend themselves; they never speak with more ardor and conviction than when they have nothing to say; with each argument that is brought against them, they imagine that they have been insulted and that someone is trying to belittle them; and the stronger and more judicious these arguments are, the more it irritates their aversion and pride."

4. The Search after Truth, bk. 6, pt. 1, ch. 3, p. 414. Vico sustains an identical thesis: all intellects are the same, whereas the imaginations are different. Rationality is the same in all human beings, while the imagination, depending from the union mind-body, vary from one individual to another, vary because different are the bodies, their collocation in the environment, in the 
world. In The New Science, par. 415: "This is the civil and historical sense of the Virgilian tag Jupiter omnibus aequus, Jupiter is equal for all. (Later, scholars imposed on this verse the doctrine that all mind are initially equal, but that differences in their physical constitution and civil education make them different). Reflecting on this equality, the plebeians began to seek equality with the patricians in civil liberty, and eventually changed the Roman state from an aristocracy to a democracy." This is an example of how Vico borrows from Malebranche in the conception of soul-body applied to society. It is evident from this paragraph how also for Vico Cartesianally the intellect does not change from man to man, but the conscience, the variation of mentality, that is of uses and customs of culture, do change. Prejudices, passions, affections, in one word, corporeity, change. This passage confirms also that Vico applies the terms mindbody, in a manner evidently dualistic, in reference to society, through the concept of the civil education.

5. The Search after Truth, bk. 1, p. 296.

6. Malebranche develops a careful psychological analysis of Montaigne in The Search after Truth, bk. 2, pt. 3, ch. 5, pp. 184-190; bk. 2, pt. 3, ch. 3, pp. 173-174; Elucidation 9.

7. Ibid., bk. 2, pt. 2, ch. 6, p. 147: "Men do not feel the heat in their heart, although it gives life and movement to all the other parts of their body. They must touch and feel themselves to be convinced of it, because this heat is natural. The same is true of vanity; it is so natural to men that he does not feel it, and although it gives, so to speak, life and movement to most of his thoughts and plans, it often does so in a way imperceptible to him."

8. Ibid., bk. 4, ch. 7, p. 295.

\section{Chapter Twenty-Three}

(Passions and Imagination: The Marvelous Power of Wonder)

1. The Search after Truth, bk. 5, ch. 11, p. 400: "All men naturally desire to know, for all minds are created for the truth; but the desire to know, as perfectly correct and rational as it is in itself, often becomes a very dangerous vice through the false judgments that accompany it. Curiosity often tempts the mind with vain objects for its meditation and often attaches to these ideas false ideas of greatness; it enhances them with the deceptive luster of rarity and represents them so attractively that we have difficulty contemplating them without excessive pleasure and attachment."

2. Ibid., p. 400.

3. Ibid., bk. 5, ch. 10, p. 397.

4. Ibid, p. 397.

5. Ibid., p. 397: "The passions all seek their own justification; they unceasingly represent to the soul the object agitating it in the way most likely to maintain and increase its agitation. The judgment or the perception causing the agitation is strengthened to the extent that the passion increases, and the passion increases to the extent that the judgment producing it is in turn strengthened. False judgments and the passions unceasingly contribute to each other's preservation."

6. Ibid., bk. 5, ch. 11, pp. 401-402.

7. Ibid., p. 402.

8. Ibid., bk. 5, ch. 12, p. 406: "It should be noted that some passions appear but once, and that there are other persistent ones that subsist for a long while. Those do not last that are not sustained by the mind's perception or by some plausible reason, but that are only produced and strengthened by the sensible perception of some object and the fermentation of the blood; they generally die immediately after their birth. But those accompanied by the mind's perception are constant; for the principle that produces them is not liable to change as are the blood 
and humors. As a result, hatred, dread, and the other passions that are excited or preserved in us by the mind's knowledge, and not by the sensible perception of some evil, must subsist for a long while. These passions, therefore, are the most lasting, the most violent and the most unjust. But they are not the most vivid and the most sensible."

9. Ibid., bk. 5, ch. 6, p. 370 .

10. Ibid., bk. 5, ch. 8, p. 385 .

11. Ibid., p. 385.

12. Ibid., bk. 5, ch. 7, p. 375: "Thus, a new idea or a new connection of old ideas causes an imperfect passion in us that precedes all the others and is termed wonder. I call this passion imperfect because it is no way excited by either the idea or the sensation of good."

13. Ibid., p. 375: "When the brain is struck in places in which it has never been struck before, or when it is struck in an entirely new way, the soul is sensibly affected by it and therefore closely attends to whatever is novel in its object; because of this, merely by tickling the soles of the feet, a very intense sensation is excited in the soul, more through its novelty than through the strength of the impression. There are still other reasons for the soul's attention to novelties, but I have accounted for them while discussing the natural inclinations; here the soul has been considered only in relation to the body, and in this context, extraordinary agitation of the animal spirits is the cause of its attention to novelties, for the ordinary agitation of the animal spirits arouses our attention but very little."

14. Ibid., bk. 2, pt. 1, ch. 1, pp. 87-90.

15. Ibid., bk. 5 , ch. 8 , p. 386 .

16. Ibid., p. 386.

17. Ibid., p. 385: "Nothing is more difficult than applying oneself for any length of time to something that fails to excite our wonder, since then the animal spirits are not so easily led into those parts of the brain necessary to represent it."

18. Ibid., bk. 5, ch. 7, p. 382: "Rare and extraordinary things produce greater and more perceptible motion in the spirits than things seen everyday; we wonder at them, and consequently we assign an idea of greatness to them, and hence they excite passions of esteem and respect in the spirits. Here we have the source of the confusion in many people's reason: many of them are so taken with what remains to us of antiquity, with what comes from far off, or with what is rare and out of the ordinary that their mind is like a slave to these things, for the mind dares not judge or place itself above what it reveres."

19. Ibid., p. 381.

20. Ibid., bk. 3, pt. 2, ch. 3, p. 222: "According to them, it is in this that man is made after the image of God and shares in His power. Further, just as God created all things from nothing, and can annihilate them and create new things in their place, so man can create and annihilate ideas of anything he pleases. But there is good reason to distrust all these views that elevate man. These are generally thoughts that come from his pride and vanity, and not from the Father of lights. This share in God's power that men boast of for representing objects to themselves and for several other particular actions is a share that seems to involve a certain independence. But it is also an illusory share, which men's ignorance and vanity makes them imagine."

21. Ibid., bk 5, ch. 7, p. 382: "There have been princes and kings who have boasted of being astronomers. The greatness of the stars seemed to agree with the greatness of their dignity; but I do not think that any of them have so honored the knowledge of anatomy, or the dissection of a heart or brain. The same thing is true of many other sciences."

22. Ibid., p. 382.

23. Ibid., p. 381. Vico had knowledge of the fact that wonder is always combined with other passions as curiosity and fear, as when he said, "Wonder is the daughter of ignorance. The 
greater the cause inspiring it, the greater the wonder" in The New Science, par. 184. Also "Curiosity is an inborn human trait which is the daughter of ignorance and the mother of knowledge. Once wonder has opened our minds, curiosity has this habit: observing an extraordinary natural phenomenon—such as a comet, a parhelion, or a star at noon-our curiosity asks at once what it can mean or signify."

24. The New Science, par. 375.

\section{Chapter Twenty-Four}

(The Universals of the Imagination)

1. The Search after Truth, bk. 6, pt.1, ch. 3, p. 415: "But most men are not in this state; they have neither the taste, nor intelligence, nor fastidiousness for anything but what affects the senses. Their imagination is corrupted by an almost infinite number of deep traces, which arouse only false ideas, for they depend on everything falling under the senses and imagination, and always judge them according to the impression they receive from them, i.e., in relation to themselves. Pride, debauchery, plots, driving desire to make money, all so common among men of the world, obscure their perception of truth as well as stifle their sense of piety, because they separate them from God, who alone can enlighten us and govern us."

2. Ibid., bk. 3, pt. 2, ch. 10, p. 252: "It is certain that the mind of man seeks out only the relations of things; first those objects it is considering might have with it, and then the relations they have among themselves. For the mind of man seeks out only two things, its own good and truth.".

3. Ibid., bk. 2, pt. 2, ch. 7, p. 153: "Passions confuse all its ideas in a thousand ways and nearly always cause us to see in an object what we desire to find there."

4. Ibid., bk. 2, pt. 2, ch. 6, p. 150-151.

5. Ibid., bk. 5, ch. 6, p. 371: "Our passions conceal not only their main object from us but also everything to which they have any relation."

6. Ibid., p. 371: "They hold even greater sway among those whose imagination is stronger and of greater scope, for their passions' hold on their mind is so vast and of such great scope that their limits cannot be determined."

7. Ibid., p. 371.

8. Ibid., bk. 2, pt. 2, ch. 8, p. 159: "The fifth defect is that from a single experiment they draw too many conclusions. On the contrary, many experiments are nearly always necessary to draw a single conclusion, even though a single experiment can help in deriving many conclusions."

9. Ibid., bk. 2, pt. 2, ch. 7, p. 152: "These sort of people usually have a very strong imagination. Their brain fibers are such that they can preserve the traces imprinted on them for a long time. Thus, when they have once imagined a system with a certain probability [vraisemblance], one cannot disabuse them of it. They jealously retain and preserve everything that can serve in any way to confirm the system; and on the contrary, they can hardly perceive any objections brought against it, or else they overcome them with some frivolous distinction.".

10. Ibid., bk. 2, pt. 2. ch. 1, p. 132: "When a chemist wants to reason about some natural body, his three principles immediately come to mind; a Peripatetic thinks first of the four elements and the four primary qualities; and another philosopher relates everything to other principles."

11. Ibid., bk. 2, pt. 2, ch. 2, p. 136.

12. Ibid., p. 136: "It is by a similar turn of the imagination that Gilbert and many others, after having studied the magnet and admired its properties, wanted to relate a large number of natural effects to these magnetic qualities, which had not the least relation to them." 
13. Ibid., bk. 3, pt.1, ch. 4, p. 213: "One of the main causes of our mind's lack of application to abstract truths is that we view item as remote, whereas things much closer to the mind are constantly being presented to it. The mind's close attention, as it were, brings the ideas of objects it is attending to much closer, but it often happens that when one is intent upon metaphysical speculations, one is distracted from them because some sensation crops up in the soul that is, as it were, still closer to it than its ideas. All that is needed for this is a bit of pain or pleasure, since pleasure and pain, and generally all sensations, are within the soul itself, they modify and affect it more than do the simple ideas of pure intellection, which, though present to the mind, do not modify or affect it sensibly."

14. Ibid., bk. 1, ch. 16 , p. 73

15. Ibid., p. 73.

16. Ibid., bk. 1, p. 250.

17. Ibid., bk. 3, pt 2, ch. 8, p. 242.

18. Ibid., p. 242.

19. Ibid., bk. 4, ch. 7, p. 296.

20. This is an important point useful for the understanding of how from a confused idea of causality is originated the universality of the imagination. See ibid., bk. 6, pt. 2, ch. 3, p. 446: "Not only the philosophers say what they do not conceive when they explain natural effects through certain beings of which they have not one single particular idea, they even furnish a principle from which one can directly infer very false and very dangerous conclusions."

21. Ibid., p. 446: "For if we assume, in accordance with their opinion, that bodies have certain entities distinct from matter in them, then, having no distinct idea of these entities, we can easily imagine that they are the true or major causes of the effects we see."

22. Ibid., p. 446.

23. Ibid., bk 6, pt. 2, ch. 2, p. 444: "For philosophers are not content to use general terms and vague ideas that correspond to them; in addition they would have these terms signify certain particular beings."

24. This principle possesses two aspects that in the mind of the analyst are distinct but that in the pagan mind are fused together: the confused idea of cause makes the subject believes that nature is animated and therefore divine; this makes possible the fictitious hierarchy of causes. The more the idea of cause has sensible characters of greatness, the more it will be believed to be active and effective.

25. Ibid., bk. 6, pt. 2, ch. 3, p. 452.

26. Ibid., bk. 6, pt. 2, ch. 2, p. 446.

27. Ibid., p. 447: "If we assume this false opinion of the philosophers, which we are here trying to destroy, that the bodies that surround us are the true causes of the pleasure and ills we feel, reason seems to some degree to justify a religion similar to that of the pagans, and to approve the universal disorder of morals."

28. Ibid., p. 447.

29. Ibid., bk. 3, pt. 2, ch. 3, p. 222.

30. Ibid., bk. 2, pt. 2, p. 135.

31. Ibid., bk. 3 , pt. 2, ch. 6, pp. 230f.; bk. 4, chs. 2-3, pp. 269f.; bk. 5, chs. 4-6. 



\section{BIBLIOGRAPHY}

\section{Primary Sources}

Bayle, Pierre, Pensèes diverses (Rotterdam: Leers, 1680)

-Dictionnaire historique et critique (Rotterdam: Leers, 1697)

Descartes, René, Oeuvres de Descartes, eds. C Adam, P. Tannery (Paris: Vrin, 1964-1976)

-The Philosophical Writings of Descartes, trans. J. Cottingham (Cambridge: Cambridge U.P., 1999)

The Passions of the Soul, trans. S. H. Voss (Indianapolis: Hackett Publishing Co., 1989)

Meditations on First Philosophy, trans. J. Cottingham (Cambridge: Cambridge U. P., 1996)

Lamy, Bernard, 1668, Nouvelles reflexions sur l'art poëtique (Paris: Prailard, 1668)

Malebranche, Nicolas, Oeuvres complétes de Malebranche, ed. André Robinet (Paris: Vrin, 1958-1968)

The Search after Truth: Wherein Are Treated the Nature of Man's Mind and the Use He Must

Make of It to Avoid Error in the Sciences, ed. by Thomas M. Lennon and Paul J.

Olscamp, Cambridge Texts in the History of Philosophy (Cambridge: Cambridge Universithy Press, 1997)

_Dialogues on Metaphysics and Religion, eds. N. Jolley, D. Scott (Cambridge: Cambridge U. P., 1997)

Vico, Giambattista, Opere di Giambattista Vico, eds. Benedetto Croce, Fausto Nicolini

(Bari: Laterza, 1914-1941).

-Opere filosofiche, ed. P. Cristofolini (Firenze: Sansoni, 1971)

Opere giuridiche, ed. P. Cristofolini (Firenze: Sansoni, 1974)

The First New Science, ed. Leon Pompa (Cambridge: Cambridge U. P., 2002)

The New Science, ed. and trans. T. G. Bergin, M. H. Fisch (Ithaca: Cornell U. P., 1968)

New Science, trans. David Marsh (London: Penguin Books, 1999)

The Art of Rhetoric (Institutiones Oratoriae, 1711-1741), eds. trans. G. A. Pinton,

A. W. Shippee (Amsterdam-Atlanta: Rodopi, 1996)

On the Most Ancient Wisdom of the Italians, trans. \& introd. L. Palmer (Ithaca: Cornell U. P., 1988)

On the Study Methods of Our Time, trans. \& introd. Elio Gianturco (New York: Library of Liberal Arts, 1965)

On Humanistic Education (Six Inaugural Orations, 1699-1707), trans. G. A. Pinton,

A. W. Shippee (Ithaca: Cornell U. P., 1993)

Universal Right, trans. \& eds. G. Pinton, M. Diehl (Amsterdam-Atlanta:

Rodopi, 2000) 


\section{Studies on Descartes}

Alquié, Ferdinand, La découverte métaphisique de l'homme chez. Descartes (Paris: P.U.F., 1950) Clarke, Desmond, Descartes: A Biography (Cambridge: Cambridge University Press, 2006) Cottingham, John, Cartesio (Bologna: Il Mulino, 1991)

Cottingham, John, The Cambridge Companion to Descartes (Cambridge: Cambridge U.P., 1992) Garber, Daniel, Descartes’ Metaphysical Physics (Chicago: Chicago U.P., 1992)

Garin, Eugenio, Vita ed opere di Cartesio (Bari: Laterza, 1984)

Gouhier, Henri, La pensée métaphisique de Descartes (Paris: Vrin, 1962)

Gueroult, Martial, Descartes selon l'ordre des raisons (Paris: Aubier, 1952)

\section{Studies on Malebranche}

Alquié, Ferdinand, Le Cartésianisme de Malebranche (Paris: Vrin, 1974)

Banchetti, Silvestro, Il pensiero e l'opera di N. Malebranche (Milano: Marzorati, 1963)

Del Noce, Augusto, Il problema dell'ateismo (Bologna: Il Mulino, 1964)

_-Riforma Cattolica e filosofia moderna, Cartesio (Bologna: Il Mulino, 1965)

Gouhier, Henri, La vocation de Malebranche (Paris: Vrin, 1926)

-La philosophie de Malebranche et son experience religieuse (Paris: Vrin, 1948)

-Etendue et psiycologie chez. Malebranche (Paris: Vrin, 1987)

Geroult, Martial, Malebranche (Paris: Aubier, 1955-1959)

Nadler, Steve, Causation in Early Modern Philosophy (University Park, PA: Pennsylvania U.P., 1993)

Pyle, Andrew, Malebranche (Taylor \& Francis, Inc., 2003)

Rome, Beatrice K., The Philosophy of Malebrance (Chicago: Henry Regnery Co., 1963)

Schmaltz, Tad M. Malebranche's Theory of the Soul (New York Oxford: Oxford U.P., 1996)

\section{Studies on Vico}

Agrimi, Mario, Descartes nella Napoli di fine Seicento; Retorica e filosofia in G.B. Vico (Napoli: Guida, 1990-1994)

Vico e Malebranche, in G.B. Vico nel suo tempo e nel nostro (Napoli: Cuen, 1999)

Auxier, Randall E., "Imagination and Historical Knowledge in Vico: A Critique of

Leon Pompa's Recent Work" in Humanitas X, 1 (1997)

Badaloni, Nicola, Introduzione a G.B. Vico (Milano: Feltrinelli, 1961)

Botturi, Francesco, La Sapienza della storia, G.B. Vico e la filosofia pratica (Milano:

Vita e pensiero, 1990)

Tempo, linguaggio e azione (Napoli: Alfredo Guida Editore., 1996)

Poetica e pragmatica, in G.B. Vico nel suo tempo e nel nostro (Napoli: Cuen, 1999)

Cantelli, Gianfranco, Mente, corpo, linguaggio, Saggio sull'interpretąione vichiana del mito (Firenze:

Sansoni, 1986)

"Reflections on the Vichian Thesis that the Original Language of Humanity Was a

Language Spoken by the Gods" in New Vico Studies 11 (1993), pp. 112

Chambliss, J.J., "Giambattista Vico's Imaginative Universals and Plato's Quest for the

Good" in Educational Theory 38: 3 (2005), pp. 311320

Connelly, Frances S.,"Embodied Meaning: Giambattista Vico's Theory of Images" in 
New Vico Studies 17 (1999), pp. 6784

Costa, Gustavo, "Genesi del concetto vichiano di fantasia" in VV. AA., Phantasia-Imaginatio (Roma: E.d.A., 1988)

"Malebranche y Vico" in Cuadernos sobre Vico (Sivilla, Spain)

"Cecilia Miller. Giambattista Vico: Imagination and Historical Knowledge"

Reviewed in New Vico Studies 13 (1995), pp. 6770

Cottingham, John \& V. Gessa Kurotschka, "Ragione e passioni/passioni e ragione. Note su metafisica, antropologia, ed etica in Descartes and Vico" in Bollettino del Centro Studi Vichiani XXXIII, 301305 (2003)

Danesi, Marcel, "Language and the Origin of the Human Imagination: A Vichian Perspective" in New Vico Studies 4 (1986), pp. 45-56

Fabiani, Paolo, "La persuasion desde la Institutiones Oratoriae a la Scienza Nuova" in Cuadernos sobre Vico (Sivilla, Spain)

"Fantasia ed immaginazione in Malebranche e Vico" in Giambattista Vico nel suo tempo e nel nostro $v v$. eds. (Napoli: Cuen, 1999)

Garin, Eugenio, Dal Rinascimento all'Illuminismo (Pisa: Nistri-Lischi, 1970)

Haskell, Robert E., "Vico and Jaynes: Neurocultural and Cognitive Operations in the Origin of Consciousness" in New Vico Studies 11 (1993), pp. 2452

Horkheimer, Max, "Vico and Mythology" in New Vico Studies 5 (1987), pp. 6378

Ingegno, A., "Da Malebranche a Vico" in AA. VV., Filosofia e cultura (Roma: Editori Riuniti, 1991)

Lovekin, David, "Giambattista Vico and Jacques Ellul: The intelligible universals and the technical phenomenon" in Man and World 15407416 (1982)

MacIntyre, Alasdair, "Imaginative Universals and Historical Falsification: A Rejoinder to Professor Verene" in New Vico Studies 6 (1988), pp. 2130

Miller, Cecilia, Giambattista Vico: Imagination and Historical Knowledge (New York: St Martin Press, 1993)

Paparella, Emanuel L., "Vico’s Poetic Philosophy within Europe’s Cultural Identity" (at http://www.ovimagazine.com/art/1776)

Pompa, Leon, Vico: A Study of the New Science (Oxford: Oxford U.P., 1975)

Rossi, Paolo, Le sterminate Antichità. Studi vichiani (Pisa: Nistri-Lischi, 1969)

Verene, Phillip Donald, Vico's Science of Imagination (Ithaca: Cornell U.P., 1981, 1991)

-Vico: La scienza della fantasia (Roma: Armando, 1984)

"Imaginative Universals and Narrative Truth" in New Vico Studies 6 (1988), pp. 120

Woolhouse, R. S. Ed., Metaphysics and Philosophy of Science in the 17th and 18th Centuries (Kluwer, 1988) 

1. Brunetto Chiarelli, Renzo Bigazzi, Luca Sineo (a cura di), Alia: Antropologia di una comunità dell'entroterra siciliano

2. Vincenzo Cavaliere, Dario Rosini, Da amministratore a manager. Il dirigente pubblico nella gestione del personale: esperienze a confronto

3. Carlo Biagini, Information technology ed automazione del progetto

4. Cosimo Chiarelli, Walter Pasini (a cura di), Paolo Mantegazza. Medico, antropologo, viaggiatore

5. Luca Solari, Topics in Fluvial and Lagoon Morphodynamics

6. Salvatore Cesario, Chiara Fredianelli, Alessandro Remorini, Un pacchetto evidence based di tecniche cognitivo-comportamentali sui generis

7. Marco Masseti, Uomini e (non solo) topi. Gli animali domestici e la fauna antropocora

8. Simone Margherini (a cura di), BIL Bibliografia Informatizzata Leopardiana 1815-1999: manuale d'uso ver. 1.0

9. Paolo Puma, Disegno dell'architettura. Appunti per la didattica

10. Antonio Calvani (a cura di), Innovazione tecnologica e cambiamento dell'università. Verso l'università virtuale

11. Leonardo Casini, Enrico Marone, Silvio Menghini, La riforma della Politica Agricola Comunitaria e la filiera olivicolo-olearia italiana

12. Salvatore Cesario, L'ultima a dover morire è la speranza. Tentativi di narrativa autobiografica e di "autobiografia assistita"

13. Alessandro Bertirotti, L'uomo, il suono e la musica

14. Maria Antonietta Rovida, Palazzi senesi tra '600 e '700. Modelli abitativi e architettura tra tradizione e innovazione

15. Simone Guercini, Roberto Piovan, Schemi di negoziato e tecniche di comunicazione per il tessile e abbigliamento
16. Antonio Calvani, Technological innovation and change in the university. Moving towards the Virtual University

17. Paolo Emilio Pecorella, Tell Barri/Kahat: la campagna del 2000. Relazione preliminare

18. Marta Chevanne, Appunti di Patologia Generale. Corso di laurea in Tecniche di Radiologia Medica per Immagini e Radioterapia

19. Paolo Ventura, Città e stazione ferroviaria

20. Nicola Spinosi, Critica sociale e individuazione

21. Roberto Ventura (a cura di), Dalla misurazione dei servizi alla customer satisfaction

22. Dimitra Babalis (a cura di), Ecological Design for an Effective Urban Regeneration

23. Massimo Papini, Debora Tringali (a cura di), Il pupazzo di garza. L'esperienza della malattia potenzialmente mortale nei bambini e negli adolescenti

24. Manlio Marchetta, La progettazione della città portuale. Sperimentazioni didattiche per una nuova Livorno

25. Fabrizio F.V. Arrigoni, Note su progetto e metropoli

26. Leonardo Casini, Enrico Marone, Silvio Menghini, OCM seminativi: tendenze evolutive e assetto territoriale

27. Pecorella Paolo Emilio, Raffaella Pierobon Benoit, Tell Barri/Kahat: la campagna del 2001. Relazione preliminare

28. Nicola Spinosi, Wir Kinder. La questione del potere delle relazione adultil bambini

29. Stefano Cordero di Montezemolo, I profili finanziari delle società vinicole

30. Luca Bagnoli, Maurizio Catalano, Il bilancio sociale degli enti non profit: esperienze toscane

31. Elena Rotelli, Il capitolo della cattedrale di Firenze dalle origini al XV secolo 
32. Leonardo Trisciuzzi, Barbara Sandrucci, Tamara Zappaterra, Il recupero del sé attraverso l'autobiografia

33. Nicola Spinosi, Invito alla psicologia sociale

34. Raffaele Moschillo, Laboratorio di disegno. Esercitazioni guidate al disegno di arredo

35. Niccolò Bellanca, Le emergenze umanitarie complesse. Un'introduzione

36. Giovanni Allegretti, Porto Alegre una biografia territoriale. Ricercando la qualità urbana a partire dal patrimonio sociale

37. Riccardo Passeri, Leonardo Quagliotti, Christian Simoni, Procedure concorsuali e governo dell'impresa artigiana in Toscana

38. Nicola Spinosi, Un soffitto viola. Psicoterapia, formazione, autobiografia

39. Tommaso Urso, Una biblioteca in divenire. La biblioteca della Facoltà di Lettere dalla penna all'elaboratore. Seconda edizione rivista e accresciuta

40. Paolo Emilio Pecorella, Raffaella Pierobon Benoit, Tell Barri/Kahat: la campagna del 2002. Relazione preliminare

41. Antonio Pellicanò, Da Galileo Galilei a Cosimo Noferi: verso una nuova scien$z a$. Un inedito trattato galileiano di architettura nella Firenze del 1650

42. Aldo Burresi (a cura di), Il marketing della moda. Temi emergenti nel tessile-abbigliamento

43. Curzio Cipriani, Appunti di museologia naturalistica

44. Fabrizio F.V. Arrigoni, Incipit. Esercizi di composizione architettonica

45. Roberta Gentile, Stefano Mancuso, Silvia Martelli, Simona Rizzitelli, Il Giardino di Villa Corsini a Mezzomonte. Descrizione dello stato di fatto e proposta di restauro conservativo

46. Arnaldo Nesti, Alba Scarpellini (a cura di), Mondo democristiano, mondo cattolico nel secondo Novecento italiano

47. Stefano Alessandri, Sintesi e discussioni su temi di chimica generale

48. Gianni Galeota (a cura di), Traslocare, riaggregare, rifondare. Il caso della Bi- blioteca di Scienze Sociali dell'Università di Firenze

49. Gianni Cavallina, Nuove città antichi segni. Tre esperienze didattiche

50. Bruno Zanoni, Tecnologia alimentare 1. La classe delle operazioni unitarie di disidratazione per la conservazione dei prodotti alimentari

51. Gianfranco Martiello, La tutela penale del capitale sociale nelle società per azioni

52. Salvatore Cingari (a cura di), Cultura democratica e istituzioni rappresentative. Due esempi a confronto: Italia e Romania

53. Laura Leonardi (a cura di), Il distretto delle donne

54. Cristina Delogu (a cura di), Tecnologia per il web learning. Realtà e scenari

55. Luca Bagnoli (a cura di), La lettura dei bilanci delle Organizzazioni di Volontariato toscane nel biennio 2004-2005

56. Lorenzo Grifone Baglioni (a cura di), Una generazione che cambia. Civismo, solidarietà e nuove incertezze dei giovani della provincia di Firenze

57. Monica Bolognesi, Laura Donati, Gabriella Granatiero, Acque e territorio. Progetti e regole per la qualità dell'abitare

58. Carlo Natali, Daniela Poli (a cura di), Città e territori da vivere oggi e domani. Il contributo scientifico delle tesi di laurea

59. Riccardo Passeri, Valutazioni imprenditoriali per la successione nell'impresa familiare

60. Brunetto Chiarelli, Alberto Simonetta, Storia dei musei naturalistici fiorentini

61. Gianfranco Bettin Lattes, Marco Bontempi (a cura di), Generazione Erasmus? L'identità europea tra vissuto e istituzioni

62. Paolo Emilio Pecorella, Raffaella Pierobon Benoit, Tell Barri / Kahat. La campagna del 2003

63. Fabrizio F.V. Arrigoni, Il cervello delle passioni. Dieci tesi di Adolfo Natalini

64. Saverio Pisaniello, Esistenza minima. Stanze, spazî della mente, reliquiario 
65. Maria Antonietta Rovida (a cura di), Fonti per la storia dell'architettura, della città, del territorio

66. Ornella De Zordo, Saggi di anglistica e americanistica. Temi e prospettive di ricerca

67. Chiara Favilli, Maria Paola Monaco, Materiali per lo studio del diritto antidiscriminatorio

68. Paolo Emilio Pecorella, Raffaella Pierobon Benoit, Tell Barri / Kahat. La campagna del 2004

69. Emanuela Caldognetto Magno, Federica Cavicchio, Aspetti emotivi e relazionali nell'e-learning

70. Marco Masseti, Uomini e (non solo) topi ( $2^{\mathrm{a}}$ edizione)

71. Giovanni Nerli, Marco Pierini, Costruzione di macchine

72. Lorenzo Viviani, L'Europa dei partiti. Per una sociologia dei partiti politici nel processo di integrazione europea

73 Teresa Crespellani, Terremoto e ricerca. Un percorso scientifico condiviso per la caratterizzazione del comportamento sismico di alcuni depositi italiani

74 Fabrizio F.V. Arrigoni, Cava. Architettura in "ars marmoris"

75. Ernesto Tavoletti, Higher Education and Local Economic Development

76. Carmelo Calabrò, Liberalismo, democrazia, socialismo. L'itinerario di Carlo Rosselli (1917-1930)
77. Luca Bagnoli, Massimo Cini (a cura di), La cooperazione sociale nell'area metropolitana fiorentina. Una lettura dei bilanci d'esercizio delle cooperative sociali di Firenze, Pistoia e Prato nel quadriennio 2004-2007

78. Lamberto Ippolito, La villa del Novecento

79. Cosimo Di Bari, A passo di critica. Il modello di Media Education nell'opera di Umberto Eco

80. Leonardo Chiesi, Identità sociale e territorio. Il Montalbano

81. Piero Degl'Innocenti, Cinquant'anni, cento chiese. L'edilizia di culto nelle diocesi di Firenze, Prato e Fiesole (1946-2000)

82. Giancarlo Paba, Camilla Perrone, Partecipazione in Toscana: interpretazioni e racconti

83. Alberto Magnaghi, Sara Giacomozzi (a cura di), Un fiume per il territorio. Indirizzi progettuali per il parco fluviale del Valdarno empolese

84. Dino Costantini (a cura di), Multiculturalismo alla francese?

85. Alessandro Viviani (a cura di), Firms and System Competitiveness in Italy

86. Paolo Fabiani, The Philosophy of the Imagination in Vico and Malebranche 